\title{
ANÁLISE DO COMPORTAMENTO ESTRUTURAL DE LIGAÇÕES PARAFUSADAS VIGA-PILAR COM CHAPA DE TOPO ESTENDIDA
}

\author{
YURI IVAN MAGGI
}

Tese apresentada à Escola de Engenharia de São Carlos da Universidade de São Paulo, como parte dos requisitos para obtenção do título de Doutor em Engenharia de Estruturas.

Orientador:

Prof. Associado Roberto Martins Gonçalves 
À minha querida esposa, Patrícia, companheira para toda a vida. 


\section{AGRADECIMENTOS}

Ao Professor Roberto Martins Gonçalves pela confiança, pela amizade e pela dedicação com a qual sempre pude contar nas discussões não só para o desenvolvimento deste trabalho, mas também para o meu amadurecimento pessoal e profissional, como engenheiro e pesquisador.

À FAPESP, pelo auxílio financeiro ao desenvolvimento deste trabalho de pesquisa.

Ao Professor Luiz Fernando Loureiro Ribeiro, um amigo e constante contribuinte deste trabalho.

Ao Professor Luís Calado, pela atenção, pelo empenho em contribuir com seus materiais bibliográficos e pela disponibilidade com que sempre auxiliou nas discussões deste trabalho.

Em especial, ao Professor Roberto Leon, cuja competência, receptividade e generosidade tornaram o Doutorado Sanduíche uma experiência excelente em termos profissionais e pessoais, além do empenho em contribuir para a divulgação internacional deste trabalho.

A todos os professores do Departamento de Estruturas que, de uma forma ou outra, contribuíram para o desenvolvimento desta pesquisa, em especial aos Professores Walter Savassi, Maximiliano Malite e Jorge Munaiar Neto.

A todos os funcionários da Secretaria do Departamento de Estruturas, pela amizade e por facilitarem o dia-a-dia do nosso trabalho. 
A todos os funcionários do Laboratório de Estruturas.

Aos amigos Raïssa, Rodrigo, Kênia, Alio, Suzana e Walter, pelo companheirismo, pelas conversas, por todos os momentos que passamos juntos.

Aos amigos Luciana, Gustavo e Alex, companheiros também naquelas discussões infindáveis sobre "Estruturas" e "Ligações".

Aos colegas que, enfim, fizeram de todo esse processo de doutoramento uma lição muito além dos "assuntos técnicos".

Aos meus pais, Hilda e Carlos, e aos meus irmãos, Gustavo e Cibele, que sempre me incentivaram em tudo que fiz. Vocês são especiais e minhas conquistas são também suas.

E finalmente, um agradecimento muito especial a minha esposa, Patrícia, que passou esse processo junto comigo não só como companheira, mas também como colega de trabalho. Pelo apoio, pelo incentivo, pelo carinho, por tudo, muito obrigado !!! 
"Meu maior orgulho aos 80 anos é saber metade do que pensava saber aos 20..."

\section{Pablo Picasso}




\section{RESUMO}

MAGGI, Y. I. (2004). Análise do Comportamento Estrutural de Ligações Parafusadas Viga-Pilar com Chapa de Topo Estendida. São Carlos. Tese (Doutorado). Escola de Engenharia de São Carlos, Universidade de São Paulo.

Este trabalho apresenta uma análise numérica e experimental sobre o comportamento estrutural de ligações parafusadas viga-pilar com chapa de topo estendida. Discute-se, em particular, o comportamento da chapa de topo e dos parafusos na determinação da capacidade resistente dessas ligações. A análise de resultados numéricos é utilizada como base para as discussões neste trabalho e a modelagem numérica, realizada em elementos finitos com o software ANSYS ${ }^{\circledR}$, incluiu modelos tridimensionais de ligações com chapa de topo estendida e de ligações duplo "T". Com os resultados numéricos e experimentais, os mecanismos de transferência dos esforços entre viga e pilar e os mecanismos de plastificação da chapa de topo e dos parafusos são observados, avaliando-se as linhas de plastificação na chapa de topo em confronto com a metodologia proposta pelo Eurocode 3 na determinação dos perfis " $T$ " equivalentes. Para esses fatores, observou-se que os modos de falha indicados pelo Eurocode 3 não representam satisfatoriamente 0 comportamento das ligações analisadas. A modelagem numérica, por sua vez, mostrou-se generalista e representativa como ferramenta para análises paramétricas e como complemento de análises experimentais.

Palavras-chave: Estruturas, aço, ligações, semi-rígidas, viga-pilar 


\section{ABSTRACT}

MAGGI, Y. I. (2004). Analysis of the Structural Behavior of Bolted BeamColumn Extended End Plate Connections. São Carlos. Thesis (Doctorate). São Carlos School of Engineering, University of São Paulo, Brazil.

This work presents a numerical and experimental analysis on the structural behavior of bolted beam-column extended end plate connections. The behavior of the end plate and bolts used in the calculations of the end plate strength is specially discussed. Numerical results are used as basis to the discussions presented in this work and the modeling methodology, with FE models built with the ANSYS ${ }^{\circledR}$ code, included 3D models of extended end plate and T-stub connections. The beam-to-column load transfer mechanisms and the yielding mechanisms at end plates and bolts are observed using numerical and experimental results. The yielding lines at the end plate are evaluated against the methodology proposed by Eurocode 3 for the calculations on the equivalent T-stub. Regarding the aforementioned factors, it is shown that the collapse modes indicated by Eurocode 3 do not represent satisfactorily the behavior of the analyzed connections. The numerical modeling was found to be general in application and reliable as a tool for parametric analyses and as a complement to experiments.

Keywords: Structures, steel, connections, semi-rigid, beam-column 


\section{SUMÁRIO}

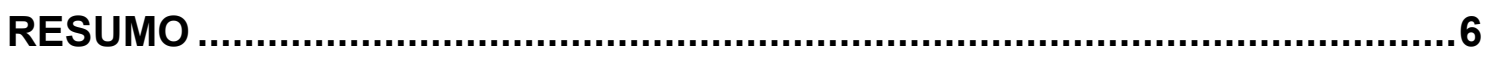

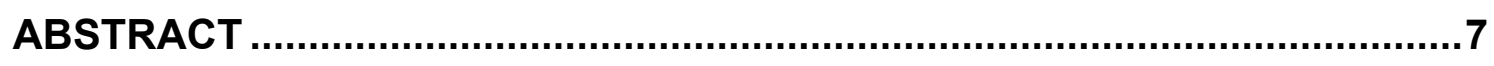

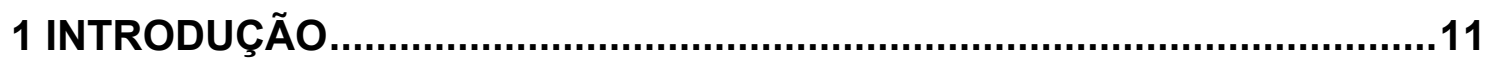

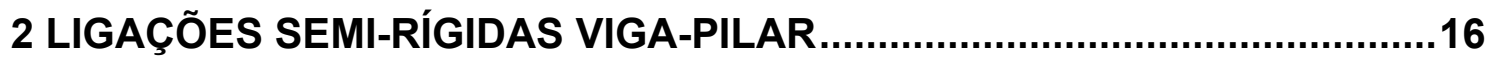

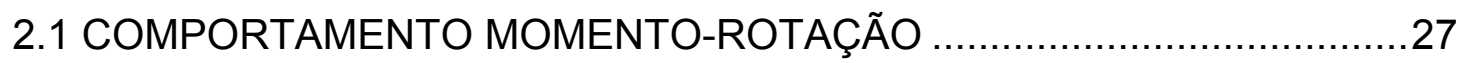

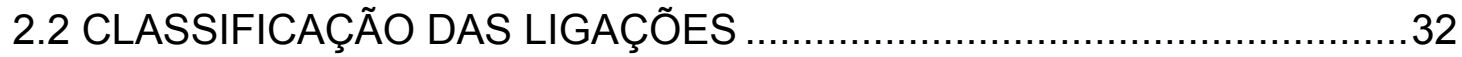

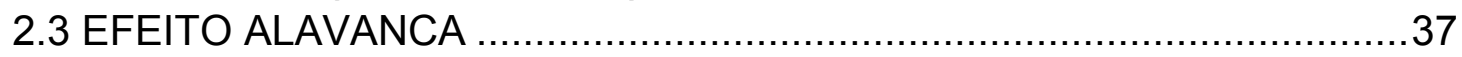

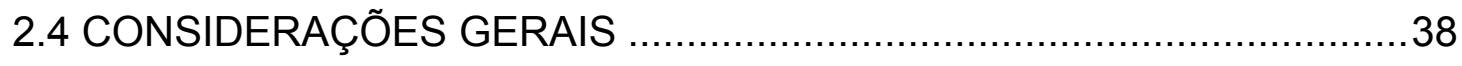

3 LIGAÇÕES PARAFUSADAS VIGA-PILAR COM CHAPA DE TOPO ............39

3.1 FUNDAMENTOS DO EUROCODE 3: O MÉTODO DOS COMPONENTES

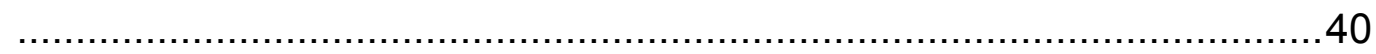

3.2 CAPACIDADE RESISTENTE DE PERFIS “T” ....................................45

3.2.1 Modo 1: formação da rótula plástica na linha de parafusos .................46

3.2.2 Modo 2: formação de rótula plástica na intersecção mesa/alma com

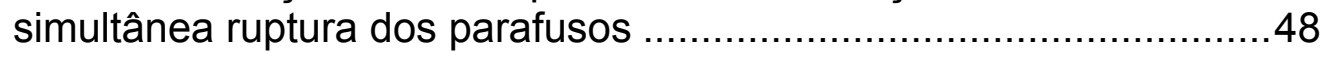

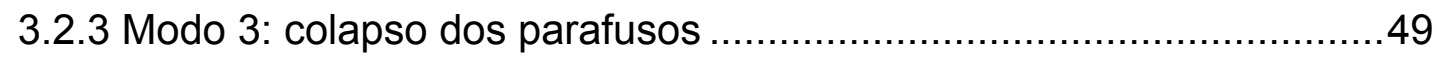

3.2.4 Modelos analíticos para a determinação da resistência de perfis " $T$ " . 50

3.2.4.1 Modelo de Kulak et al. (1987) ...................................................51

3.2.4.2 Modelo de Swanson (1999) - Kulak et al. Modificado ....................54

3.2.4.3 Eurocode 3 (1993)............................................................... 54

3.3 APLICAÇÃO DOS MODELOS DE PERFIS "T" PARA A VERIFICAÇÃO

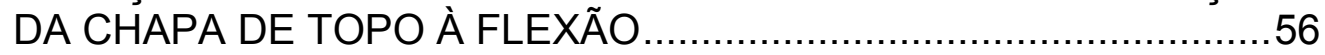

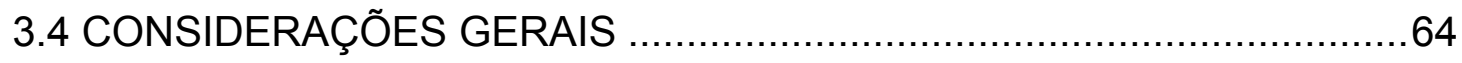

4 METODOLOGIA DO PROGRAMA EXPERIMENTAL ...............................66

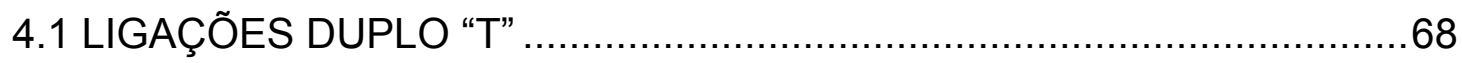

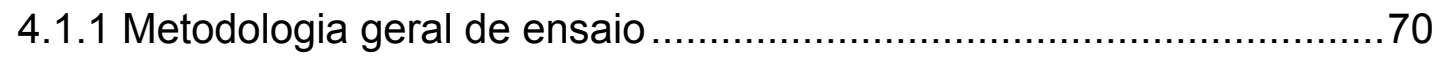

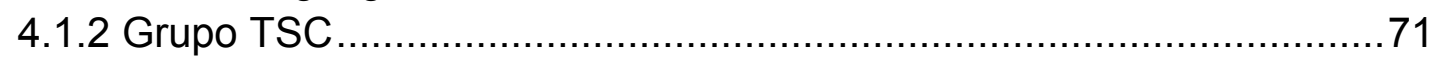

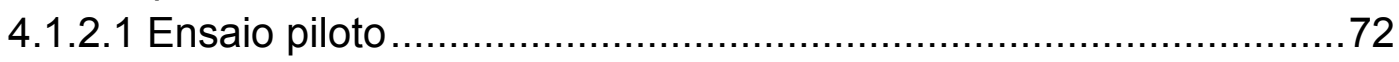

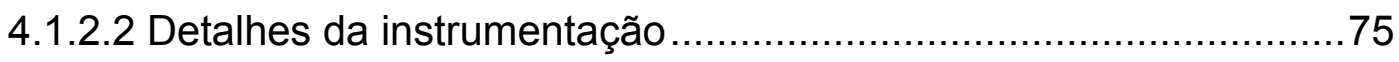

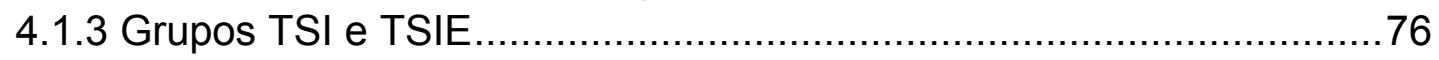


4.2 LIGAÇÕES COM CHAPA DE TOPO ESTENDIDA …...........................79

4.2.1 Montagem dos protótipos e equipamentos utilizados ..........................82

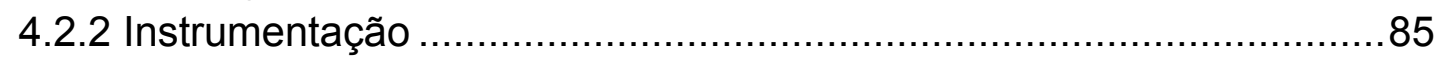

4.2.3 Metodologia de ensaio das ligações com chapa de topo.....................91

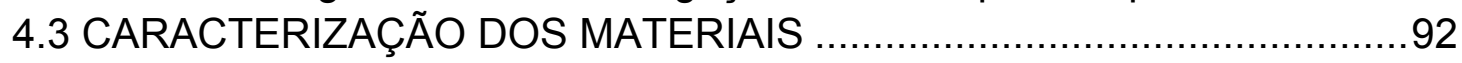

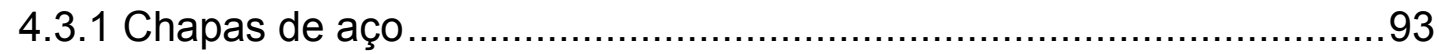

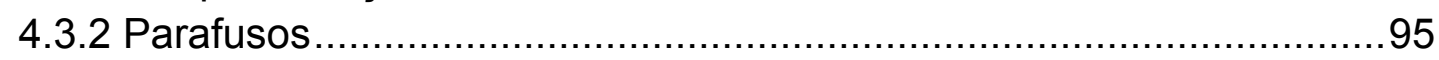

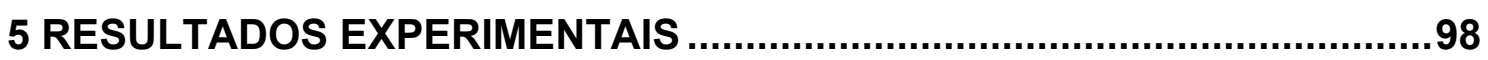

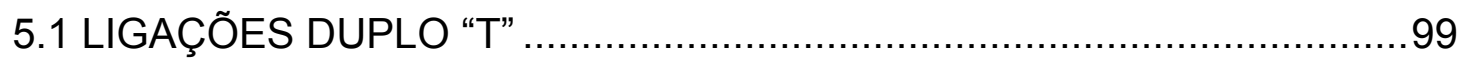

5.1.1 Resultados para o grupo TSC - duplo "T" usual...............................99

5.1.2 Resultados para o grupo TSI - almas perpendiculares ....................111

5.1.3 Resultados para o grupo TSIE - enrijecimento da alma...................115

5.1.4 Comentários gerais sobre os grupos TSC, TSI e TSIE....................118

5.2 LIGAÇÕES COM CHAPA DE TOPO ESTENDIDA .............................119

5.2.1 Rigidez global do conjunto viga-pilar ........................................120

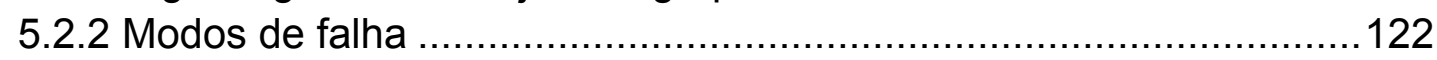

5.2.3 Rigidez rotacional - curvas momento-rotação ……………….........127

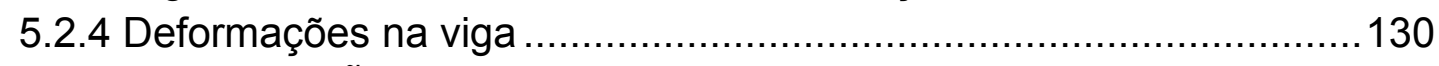

5.3 CONSIDERAÇÕES GERAIS SOBRE OS RESULTADOS

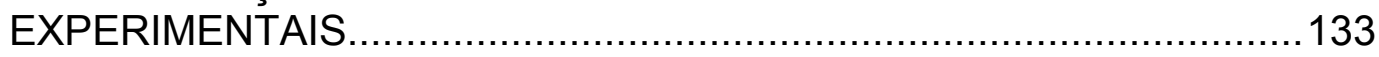

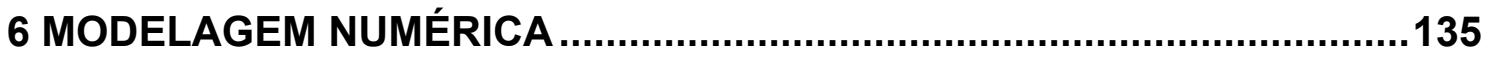

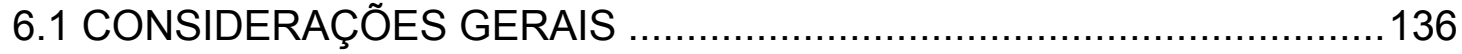

6.2 CRITÉRIOS ADOTADOS NA MODELAGEM NUMÉRICA.....................142

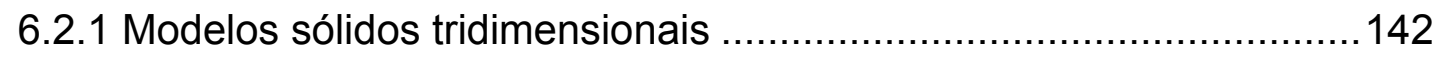

6.2.2 Modelos constitutivos para o aço..................................................144

6.2.3 Descontinuidades geométricas .................................................... 146

6.2.4 Grandes deslocamentos ..........................................................147

6.3 METODOLOGIA DA PREPARAÇÃO DOS MODELOS NUMÉRICOS... 148

6.3.1 Ferramentas auxiliares para a modelagem...................................149

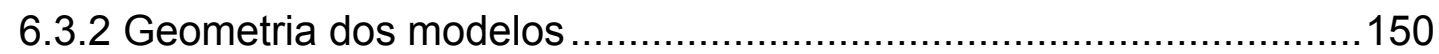

6.3.3 Elementos finitos e discretização..................................................150

6.3.3.1 Elementos volumétricos para a geometria ................................150

6.3.3.1.1 Discretização dos perfis "T", viga, chapa de topo e pilar .......152

6.3.3.1.2 Discretização dos parafusos ................................................ 154

6.3.3.2 Elementos de contato para as descontinuidades geométricas....157

6.3.3.3 Elementos de barra para o acoplamento na viga ........................158

6.3.4 Aplicação dos modelos constitutivos para os materiais .....................160

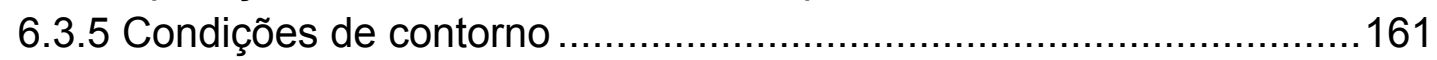

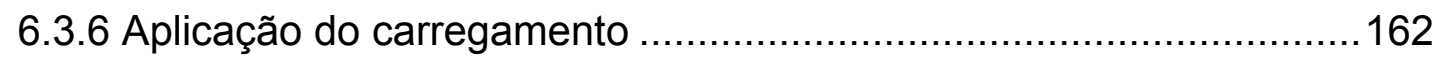

6.3.7 Solução incremental-iterativa......................................................164

6.4 INFLUÊNCIA DE SIMPLIFICAÇÕES DOS MATERIAIS E DA

GEOMETRIA 
6.4.1 Variações das características dos materiais 166

6.4.2 Influência de simplificações na geometria: soldas 172

6.5 APLICABILIDADE DAS RELAÇÕES CONSTITUTIVAS DOS MATERIAIS

PARA A SIMULAÇÃO DOS PARAFUSOS ........................................177

6.6 APLICAÇÃO DA MODELAGEM..................................................186

6.6.1 Modelos numéricos para a representação dos resultados experimentais 186

6.6.1.1 Comparação entre resultados numéricos e experimentais dos grupos TSC e CTEE.

6.6.1.2 Aplicação da modelagem para outras tipologias de ligações duplo "T" e com chapa de topo estendida.

6.6.2 Modelos numéricos para a análise paramétrica..............................197

6.7 COMENTÁRIOS GERAIS SOBRE A MODELAGEM ...........................199

7 ANÁLISE E COMPARAÇÃO DOS RESULTADOS NUMÉRICOS, TEÓRICOS E EXPERIMENTAIS 200

7.1 LINHAS DE PLASTIFICAÇÃO NAS L IGAÇÕES DUPLO "T" ................202

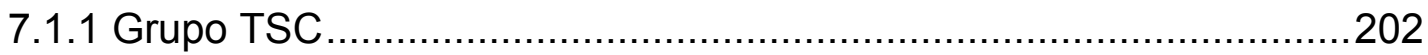

7.1.2 Variações para os grupos TSI e TSIE ..........................................208

7.2 LINHAS DE PLASTIFICAÇÃO NAS LIGAÇÕES COM CHAPA DE TOPO

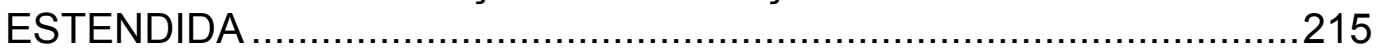

7.3 DISCUSSÃO SOBRE OS MODELOS DE DIMENSIONAMENTO .........219

7.3.1 Capacidade resistente e efeito alavanca nas ligações duplo " $T$ " ......220

7.3.2 Capacidade resistente da chapa de topo........................................224

7.4 ANÁLISE PARAMÉTRICA PRELIMINAR DO COMPORTAMENTO DAS LIGAÇÕES COM CHAPA DE TOPO ESTENDIDA ..............................234

7.4.1 Variações da chapa de topo e dos parafusos ..................................2.235

7.4.2 Variação da distância entre furos e mesa da viga ...........................247

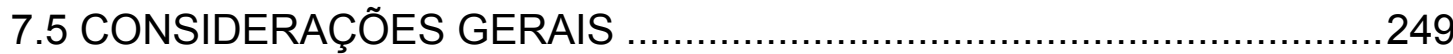

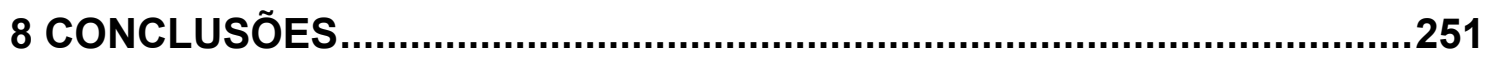

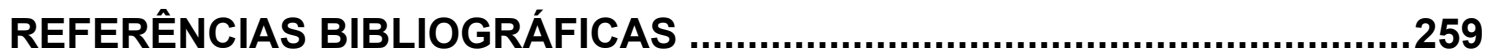




\section{Capítulo}

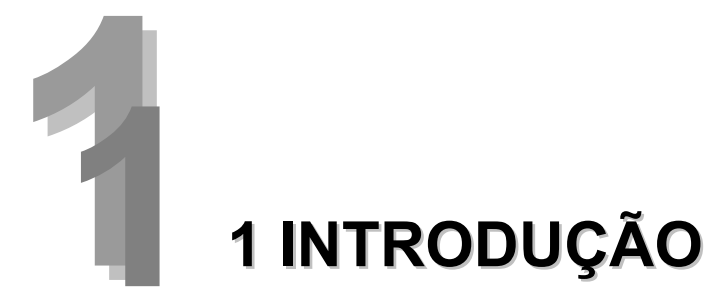

O comportamento semi-rígido das ligações viga-pilar em estruturas metálicas, introduzido a partir da década de 70 nos procedimentos de cálculo da AISC - American Institute of Steel Construction (1980) e mais tarde na metodologia de dimensionamento proposta pela Norma Européia, Eurocode 3 (1993), tornou-se indiscutivelmente um tópico essencial, ao longo dos últimos anos, nas discussões sobre análise estrutural e desempenho global das estruturas.

A partir da década de 80, a difusão da filosofia dos Estados Limites Últimos como alternativa para a avaliação da segurança estrutural contribuiu significativamente para que as ligações fossem classificadas de acordo com parâmetros mais realísticos de rigidez e resistência. Como conseqüência, a prática de análise estrutural incorporou os conceitos do comportamento semirígido na tentativa de melhor representar o comportamento global das estruturas.

O conceito de semi-rigidez e sua aplicação também colocaram em evidência uma contribuição potencial para o dimensionamento de estruturas mais econômicas. Isso pelo fato de que esta consideração permite maior "flexibilidade" no dimensionamento, inserindo as ligações viga-pilar como variáveis que influenciam diretamente no comportamento estrutural. Assim, permitem-se análises mais realísticas da resposta global das estruturas e dos elementos que as formam.

A influência do comportamento semi-rígido nas estruturas metálicas é significativa devido à grande diversidade de configurações e dispositivos que podem ser utilizados nas ligações viga-pilar, conduzindo à introdução de descontinuidades geométricas que, em conjunto com as não linearidades físicas, conduzem a um comportamento não linear da estrutura como um todo. 
Essas características indicam claramente a impossibilidade de se obter ligações idealmente rígidas ou flexíveis como é convencionalmente assumido na análise estrutural. Neste caso, o comportamento intermediário, comumente denominado de "semi-rígido", deve ser considerado à medida que os níveis de continuidade rotacional entre vigas e pilares e de transferência de solicitações de flexão tornam-se aspectos relevantes.

As ligações parafusadas viga-pilar com chapa de topo estendida têm sido estudadas em diversos trabalhos ao longo dos últimos anos e são excelentes exemplos para os fatores citados acima já que, apesar de usualmente consideradas rígidas, podem apresentar os mais variados comportamentos rotacionais dependendo de parâmetros geométricos como espessura da chapa de topo, diâmetro e posicionamento dos parafusos, entre outros, além do elevado grau de interação entre essas variáveis que, convencionalmente, são tratadas de forma isolada.

As dificuldades em se conduzir análises sobre o comportamento deste tipo de ligação são conseqüência do grande número de variáveis existentes, o que obriga a adoção de modelos simplificados para os quais a descrição dos fenômenos envolvidos é mais simples.

Em outras palavras, traduz-se um comportamento complexo em outro melhor conhecido, com penalizações impostas por simplificações que, quando aplicadas aos modelos analíticos utilizados no dimensionamento, conduzem a valores subestimados da capacidade resistente das ligações.

É de fundamental importância enfatizar que a aplicação dos métodos de dimensionamento preza pela praticidade, razão pela qual dificilmente poderiam levar em consideração modelos complexos com todas as combinações de não linearidades que podem ocorrer em uma ligação.

Com todos os fatores mencionados acima, justificam-se as mudanças ocorridas nas últimas décadas nas metodologias aplicadas ao estudo do comportamento das ligações, segundo as quais buscaram-se ferramentas complementares aos estudos experimentais e formulações empíricas.

Assim, é possível observar a utilização cada vez mais freqüente de modelos numéricos, adotados como uma ferramenta racional para a obtenção de relações momento-rotação, para a verificação de metodologias de dimensionamento com base em critérios de plastificação e para a avaliação do 
comportamento localizado de parafusos, chapas de topo, soldas, enfim, dos vários componentes que formam as ligações em estruturas metálicas.

As metodologias de modelagem numérica, na grande maioria dos casos com a descrição de modelos em elementos finitos, têm sido implementadas e modificadas desde a década de 70 a partir do trabalho de Krishnamurthy (1975c), evoluindo sensivelmente no final da década de $90 \mathrm{com}$ o rápido avanço tecnológico dos softwares para análise estrutural e dos microcomputadores.

Esse mesmo avanço tecnológico permitiu o surgimento de uma abordagem mais complexa para o desenvolvimento de análises numéricas, na qual se faz proveito de modelos tridimensionais antes considerados proibitivos pelo grande esforço computacional que requeriam.

Como conseqüência, os modelos numéricos ampliaram a capacidade de representar os diversos mecanismos que governam o comportamento das ligações, o que os consolida cada vez mais como alternativa para estudos paramétricos.

No entanto, a utilização desses modelos complexos na obtenção das características das ligações para a aplicação na análise estrutural não é usual nos procedimentos práticos de projeto, ficando sua utilização ainda restrita a trabalhos acadêmicos.

Situado em todo este contexto, a pesquisa conduzida neste trabalho tem como propósito o estudo de ligações parafusadas viga-pilar com chapa de topo estendida, com a função de discutir o comportamento deste tipo de ligação e sua natureza semi-rígida.

Destacando-se objetivos mais específicos dentro deste escopo, discute-se em particular o comportamento localizado dos parafusos e da chapa de topo e a interdependência da resposta estrutural destes componentes, enfatizando-se sua importância na determinação da capacidade resistente e da rigidez rotacional dessas ligações.

Com ênfase nos modelos analíticos propostos pelo Eurocode 3 (1993) para o dimensionamento da chapa de topo, analisa-se mais especificamente o comportamento de ligações com perfis "T" que são utilizadas para descrever os fenômenos complexos que governam os mecanismos entre a chapa de topo e os parafusos. 
Discutem-se ainda os mecanismos envolvidos na plastificação de cada componente e na transferência de esforços entre vigas e pilares, analisando-se parametricamente a variação da espessura da chapa de topo e do diâmetro e posicionamento dos parafusos, no intuito de possibilitar um melhor entendimento sobre o comportamento dessas ligações e os estados limites a que estão sujeitas.

As discussões apresentadas acima são realizadas utilizando-se tanto de modelos numéricos quanto de resultados experimentais, sendo que os resultados da análise numérica têm como objetivo fornecer subsídios para o desenvolvimento de modelos analíticos ou para o refinamento dos modelos analíticos existentes, fatores importantes na determinação mais precisa da capacidade resistente e da rigidez rotacional dessas ligações.

Os tópicos mencionados acima têm sido objeto de estudo na grande maioria dos trabalhos já desenvolvidos sobre o comportamento das ligações com chapa de topo. No entanto, e ressaltando-se a motivação para essa pesquisa, os modelos analíticos descritos nas normalizações e utilizados amplamente no dimensionamento das ligações são resultado de análises simplificadas.

A utilização de ferramentas atualizadas pode trazer benefícios para o aperfeiçoamento destes modelos analíticos e, neste caso, destaca-se a modelagem numérica proposta neste trabalho como contribuição para o estudo das ligações parafusadas viga-pilar.

Dando início às discussões propostas acima, apresentam-se, no capítulo 2, conceitos básicos e uma revisão histórica sobre as pesquisas relacionadas ao comportamento semi-rígido, destacando-se os diversos tipos de ligações parafusadas viga-pilar e a classificação dessas ligações quanto a parâmetros de rigidez e de resistência.

Especificamente para as ligações parafusadas com chapa de topo, o capítulo 3 é dedicado a apresentar os conceitos do chamado "método dos componentes", proposto pelo Eurocode 3 (1993), enfatizando-se os aspectos teóricos envolvidos na determinação da capacidade resistente das ligações, particularmente para a formulação analítica utilizada no dimensionamento da chapa de topo e na determinação dos modos de falha dos perfis "T", fundamentação teórica para as discussões posteriores. 
Uma vez apresentadas as referências teóricas, no capítulo 4 faz-se a descrição da metodologia empregada no programa experimental deste trabalho, apresentando-se as tipologias dos protótipos e considerações específicas sobre os procedimentos e dispositivos de ensaio.

Os resultados obtidos na análise experimental são apresentados no capítulo 5, no qual discute-se o comportamento observado nas ligações ensaiadas com o objetivo de fornecer subsídios para a validação da modelagem numérica e para a análise dos modelos de dimensionamento.

Na seqüência, apresenta-se a metodologia empregada na modelagem numérica, conteúdo do capítulo 6 , no qual se descrevem particularidades dos modelos numéricos utilizados neste trabalho. São abordados os conceitos, hipóteses e procedimentos adotados na modelagem, alguns aspectos relativos à aplicabilidade dos modelos no estudo das ligações parafusadas e, por fim, define-se a metodologia de modelagem utilizada para a análise complementar dos resultados experimentais e no desenvolvimento da análise paramétrica, cujos resultados são apresentados no capítulo 7.

Finalmente, no capítulo 8 , reúnem-se as conclusões obtidas neste trabalho, enfatizando-se os principais aspectos discutidos sobre 0 comportamento das ligações com chapa de topo estendida e as lacunas a serem preenchidas nessas discussões, que constituem possíveis temas para trabalhos futuros.

Assim, espera-se contribuir para um melhor entendimento do comportamento das ligações parafusadas com chapa de topo e dos modelos disponíveis para reproduzir esse comportamento, com o objetivo maior de difundir a utilização do comportamento semi-rígido na análise das estruturas e para o aprimoramento no dimensionamento das ligações parafusadas em geral. 


\section{Capítulo}

\section{LIGAÇÕES SEMI-RÍGIDAS VIGA-PILAR}

$\mathrm{Na}$ bibliografia especializada relata-se que o primeiro trabalho desenvolvido para avaliar a rigidez de uma ligação foi realizado na Universidade de Illinois, por Wilson \& Moore (1917), impulsionando o interesse no estudo do comportamento semi-rígido das ligações.

A partir da década de 40 , também com a popularização do uso da solda e dos parafusos de alta resistência, diversos estudos têm abordado o comportamento semi-rígido das ligações. As pesquisas sobre o tema foram intensificadas a partir da década de 60 , com a visível necessidade de se incorporar esse comportamento na análise estrutural. Em geral, conforme citou Ribeiro (1998), as abordagens destes estudos tiveram como objetivo:

i. o estabelecimento de modelos teóricos para comparação com resultados experimentais, relativos à determinação da rigidez inicial, resistência e ductilidade;

ii. 0 desenvolvimento de formulações empíricas com base em resultados experimentais;

iii. o desenvolvimento de formulações empíricas, via modelos matemáticos e computacionais, alguns com aferição com base em resultados obtidos em laboratório;

iv. a análise dos efeitos do comportamento estrutural das ligações sobre o desempenho dos elementos conectados e/ou sua influência na resposta global da estrutura; e

v. a inclusão de parâmetros relativos à rigidez inicial das ligações na análise estrutural. 
Um dos pioneiros no estudo das ligações com chapa de topo foi Sherbourne (1961), na Universidade de Cambridge, Inglaterra, sob o patrocínio da British Welding Research Association (BWRA), seguido pelo trabalho de Douty \& McGuire (1965), pioneiros no estudo de ligações com a utilização de perfis "T" parafusados às vigas e pilares e Zoetemeijer \& deBack (1972), cujo modelo para verificação da capacidade resistente de perfis "T" forma a base da metodologia adotada pelo Eurocode 3 (1993) no dimensionamento da chapa de topo à flexão.

Outros trabalhos de grande destaque foram desenvolvidos por Krishnamurthy (1973 a 1979) com base em estudos realizados nas Universidades de Auburn, Vanderbilt e Birmingham, que consistiram na análise de ligações por meio de modelos em elementos finitos com comparações a resultados experimentais.

Examinando a questão das ligações com chapa de topo, Krishnamurthy $(1975,1978,1979)$ estudou a concentração de esforços nas chapas e parafusos e os problemas do "efeito alavanca"1, tendo fundamental importância como referência à metodologia de dimensionamento das ligações parafusadas na Norma Americana, AISC (1980).

No Brasil, as pesquisas com ligações parafusadas foram iniciadas na década de 90 com o trabalho de Prelourentzou (1991), seguido pelos estudos de Queiroz (1992 e 1995) e Ribeiro (1998), que se preocuparam na avaliação da rigidez e na observação dos estados limites últimos aplicáveis às ligações soldadas, com cantoneira de alma e com chapa de topo.

Os resultados experimentais obtidos no trabalho de Ribeiro (1998) foram incluídos no "Steel Connection Data Bank", banco de dados criado por Kishi (1994) que inclui diversos resultados experimentais com tipos variados de ligações. Além disso, esse estudo tem como pioneirismo no Brasil a introdução de modelos tridimensionais em elementos finitos para análises numéricas do comportamento de ligações com chapa de topo.

Ainda mais recente, o trabalho de Maggi (2000) utilizou como referência a análise numérica iniciada por Ribeiro (1998) na determinação de

\footnotetext{
${ }^{1}$ Em ligações parafusadas pode ocorrer um acréscimo de solicitação nos parafusos devido à flexão dos componentes conectados. Esse efeito é comumente conhecido como "efeito alavanca" e será comentado mais adiante.
} 
uma metodologia de modelagem tridimensional, mais generalizada, que pudesse ser utilizada em análises paramétricas.

Os trabalhos de Ribeiro (1998) e Maggi (2000) ressaltaram, assim, a possibilidade de se utilizar a modelagem numérica, a exemplo do trabalho de Krishnamurthy (1975c), como ferramenta para a discussão do comportamento das ligações, tendência observada em diversos trabalhos a partir do início da década de 90.

O panorama geral apresentado acima identifica alguns trabalhos desenvolvidos para o estudo das ligações parafusadas viga-pilar. No entanto, muitos outros autores contribuíram para o melhor entendimento do comportamento dessas ligações e dos conceitos de semi-rigidez.

Para mencionar esses trabalhos e seus autores como referência, a tabela 2.1 resume a evolução das pesquisas sobre as ligações parafusadas viga-pilar, organizando em ordem cronológica os trabalhos e acontecimentos em torno deste tema.

É interessante comentar, previamente, que a nomenclatura utilizada em alguns trabalhos nacionais contém a expressão "ligação viga-coluna" como tradução direta da denominação em inglês "beam-to-column connection". Essa expressão foi modificada para "ligações viga-pilar" entendendo-se que, assim, especifica-se de forma mais adequada, em português, os elementos estruturais envolvidos. 
Tabela 2.1 - Evolução histórica das pesquisas sobre as ligações vigapilar e o comportamento semi-rígido

\section{WILSON \& MOORE (1917)}

Desenvolvimento do primeiro estudo com o objetivo de avaliar a rigidez de uma ligação e sua influência no comportamento da estrutura. O trabalho foi realizado através de ensaios com diversos tipos de ligações rebitadas na Universidade de Illinois, Estados Unidos.

\section{9}

Criação de um amplo programa teórico-experimental pelo Steel Structures Research Committee of Great Britain, para a análise de vários aspectos do comportamento das ligações e das estruturas metálicas. As atividades deste comitê foram interrompidas com o início da Segunda Guerra Mundial.

\section{BATHO \& BATHEMAN (1934)}

Sugeriram a substituição, nas ligações, dos rebites por parafusos de alta resistência.

\section{WILSON \& THOMAS (1938)}

Realizaram estudos sobre fadiga em ligações rebitadas, também constatando a possibilidade de utilização de parafusos de alta resistência.

\section{7}

Criação do Research Council on Riveted and Bolted Structural Joints (RCRBSJ), atualmente denominado de Research Council on Structural Connections (RCSC), nos Estados Unidos. O RCRBSJ reunia órgãos governamentais, universidades, institutos de pesquisa e o setor industrial, tendo por finalidade apoiar e financiar estudos sobre 0 comportamento estrutural das ligações rebitadas e parafusadas.

\section{RCRBSJ (1949)}

Com base em várias pesquisas, o RCRBSJ publica a primeira especificação para ligações utilizando parafusos de alta resistência, na qual permitia-se a substituição de rebites por parafusos, na proporção de um para um.

\section{RUBLE (1959)}

Relacionou e organizou em sua pesquisa uma grande quantidade de trabalhos desenvolvidos na década de 50, resultado da iniciativa da RCRBSJ. Dentre esses trabalhos destacam-se as pesquisas realizadas por Munse et al. (1959a e 1959b) e Vasarhely (1959).

\section{BALL \& HIGGINS (1959)}

Neste trabalho é feita uma discussão sobre os procedimentos de instalação e aperto dos parafusos de alta resistência para a obtenção da protensão mínima especificada pelas normalizações. 


\section{Década de 60}

A partir da década de 60, tanto nos Estados Unidos quanto na Europa, enfatizamse totalmente os estudos de ligações que utilizavam soldas e/ou parafusos de alta resistência como meio de ligação. Neste período, começam a ser desenvolvidos estudos dirigidos ao comportamento de tipos específicos de ligações, como as completamente soldadas.

\section{RCRBSJ (1962)}

É publicada, pela RCRBSJ, uma revisão da especificação para ligações estruturais utilizando parafusos ASTM-A325.

\section{Observações: ligações soldadas}

As ligações completamente soldadas começaram a ser estudadas a partir da publicação de Johnson (1959), pioneiro na realização de estudos experimentais sobre o comportamento estrutural deste tipo de ligação.

Considerada como idealmente rígida, as ligações completamente soldadas passaram a ser utilizadas como parâmetro de controle para a avaliação do desempenho de outras ligações, também consideradas rígidas, com outras configurações. Mostrada esquematicamente na figura 2.1, para as ligações completamente soldadas admitia-se a transmissão do momento fletor através de um binário atuando nas mesas, sendo o esforço cortante transmitido pela alma da viga.

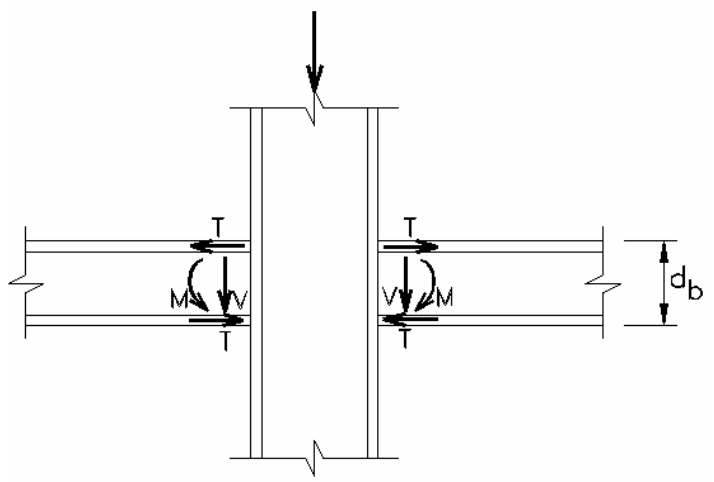

Figura 2.1 - Ligação completamente soldada

Outros estudos importantes sobre o comportamento deste tipo de ligação foram realizados por Beedle \& Christopher (1964), Huang et al. (1973), Regec et al. (1973), Parfitt Jr. \& Chen (1976), Chen \& Patel (1981), Witteveen et al. (1982) e Chen \& Lui (1988a). 


\section{Observações: ligações soldadas e parafusadas}

Parfitt \& Chen (1976), Chen \& Patel (1981) e Chen \& Lui (1988b), desenvolveram algumas pesquisas experimentais nas quais envolviam-se outros meios de ligação, tanto das mesas quanto da alma, entre vigas e pilares. Os protótipos, ensaiados na Lehigh University, Estados Unidos, foram confeccionados mantendo-se a solda nas mesas, sendo a união da alma da viga à mesa do pilar feita através de chapas parafusadas.

Os protótipos ensaiados incluíam ligações apenas soldadas, com e sem dispositivos para absorção de esforços cortantes, como apresentado na figura 2.2(a) e 2.2(b), respectivamente, e três outros tipos de ligação que diferiam entre si apenas pela presença ou não de enrijecedores na alma do pilar e pela utilização de furos padrão ou alongados.

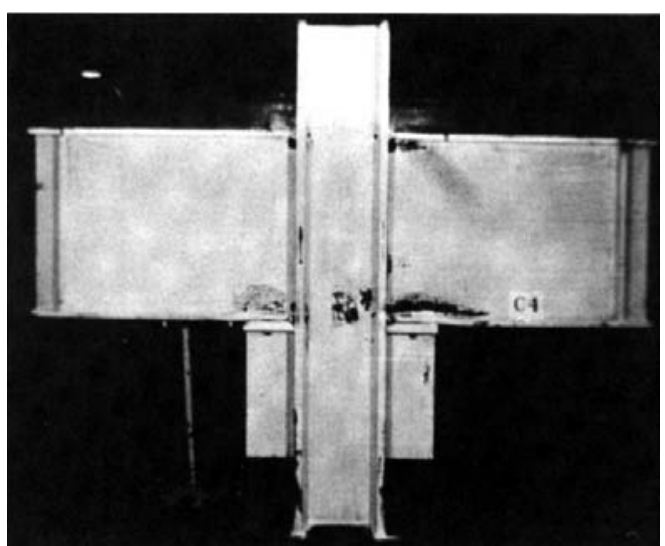

(a)

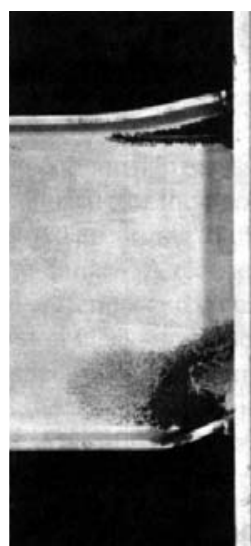

Figura 2.2 - Ligações ensaiadas por CHEN \& LUI (1988a)

\section{SHERBOURNE (1961)}

Considerado como um dos pioneiros no estudo das ligações com chapa de topo, analisou ligações nas quais a transmissão dos esforços da viga para o pilar se davam através de uma chapa soldada à extremidade da viga e parafusada à mesa do pilar, como esquematizado na figura 2.3.

Suas pesquisas foram patrocinadas pela British Welding Research Association (BWRA), na Universidade de Cambridge, Inglaterra.

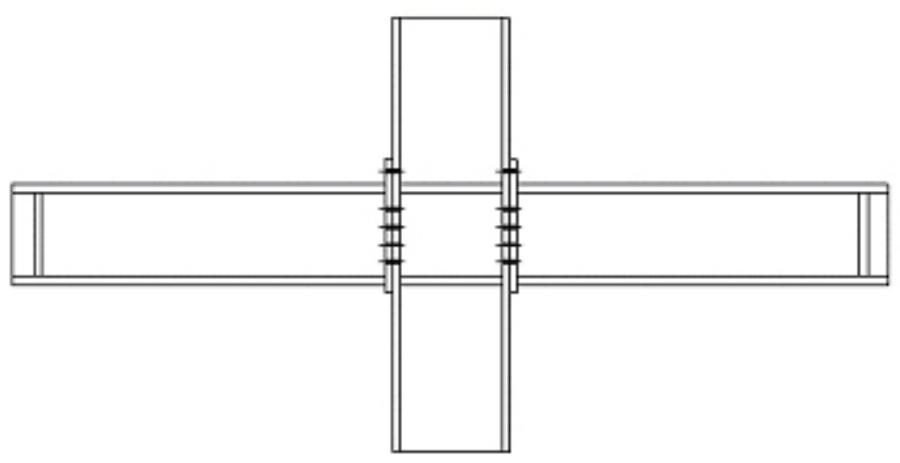

Figura 2.3 - Ligação viga-pilar com chapa de topo 


\section{DOUTY \& McGUIRE (1965)}

Realizaram um importante estudo no qual a ligação entre viga e pilar era feita através de perfis "T", conectados às mesas da viga e do pilar, como esquematizado na figura 2.4. Os autores analisaram tanto o comportamento local quanto global dessas ligações, dando maior ênfase aos casos de solicitação de tração em razão da possibilidade de aparecimento de forças de alavanca nos parafusos. Além disso, estabeleceram um modelo analítico para relacionar as forças de alavanca às forças de tração aplicadas nos perfis "T".

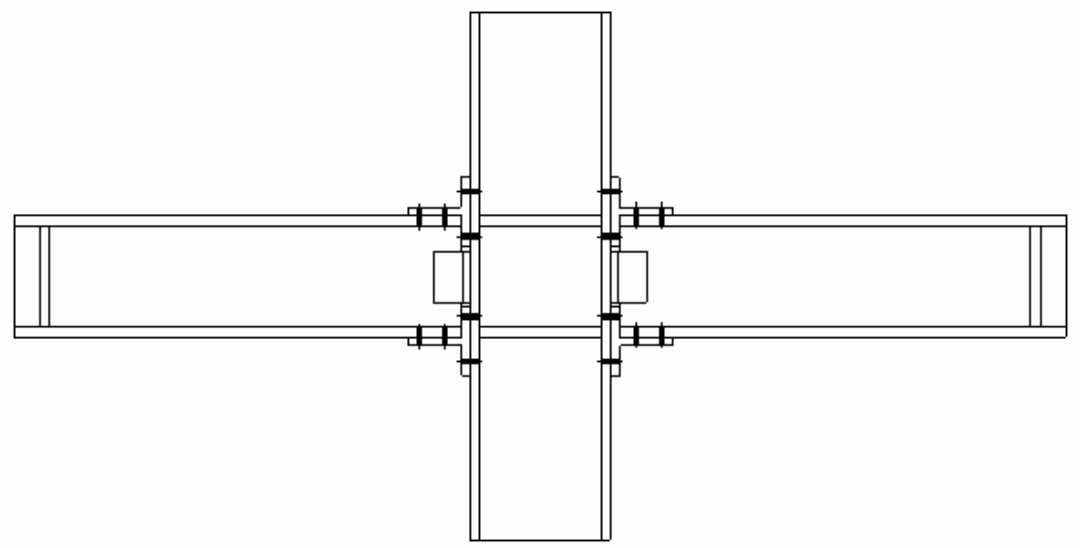

Figura 2.4 - Ligação viga-pilar com perfis "T"

\section{ZOETEMEIJER \& deBACK (1972)}

Este trabalho foi o primeiro a apresentar um modelo de dimensionamento para as ligações com perfis " $T$ ", representando um marco importante na história das pesquisas sobre o comportamento das ligações parafusadas uma vez que os modelos analíticos resultantes desse estudo foram adotados no procedimento proposto pelo Eurocode 3 (1993) para o dimensionamento das ligações com chapa de topo.

Considerando a possibilidade de formação de rótulas plásticas nas mesas dos perfis "T", tanto na intersecção mesa/alma como na proximidade dos furos, Zoetemeijer \& deBack (1972) indicaram 3 possíveis modos de falha, considerando a plastificação da mesa, a ruptura dos parafusos e a interação entre os dois componentes. Essas observações foram feitas após diversos ensaios experimentais nos quais várias configurações de ligações com perfis " $T$ " foram testadas, variando-se a espessura da mesa do perfil "T" e o diâmetro dos parafusos.

As considerações e observações dos autores possibilitaram a obtenção de modelos analíticos para a determinação da capacidade resistente dos perfis " $T$ " segundo os modos de falha propostos.

\section{NAIR et al. (1974)}

Realizaram um estudo analítico-experimental sobre o fenômeno das forças de alavanca, englobando solicitações estáticas e cíclicas para determinar a influência do efeito alavanca através da comparação com o comportamento de ligações com perfis "T" com mesas de grande espessura. Estabeleceram, assim, a eficiência dos parafusos e a relação, sob condições de solicitação última, entre a força de alavanca e o esforço de tração aplicado aos perfis "T". No mesmo trabalho, realizaram um estudo paramétrico dessas ligações utilizando uma análise numérica através de elementos finitos para avaliar a influência do tipo de parafuso utilizado e da espessura da mesa do perfil "T". 


\section{KRISHNAMURTHY (1973 a 1979)}

Realizou diversos trabalhos com base em estudos desenvolvidos nas universidades de Auburn, Vanderbilt e Birmingham, os quais consistiram, basicamente, da análise de ligações via elementos finitos e da comparação dos resultados obtidos com a análise numérica com outros obtidos através de ensaios em laboratório. Examinando a questão das ligações com chapa de topo, estudou a concentração de forças nas ligações e os problemas do efeito alavanca, sendo seu trabalho base da Norma Americana AISC (1980).

\section{CHEN \& LUI (1988a)}

Observando os resultados de ensaios realizados com ligações parafusadas, os autores estabeleceram uma série de conclusões e recomendações de projeto e dimensionamento, constatando que a resistência ao momento fletor dessas ligações poderiam ter um acréscimo de $30 \%$ ou mais quando comparadas à ligações soldadas similares. Isso se dá devido ao aumento da capacidade resistente da seção transversal da viga, proporcionado pela presença das chapas soldadas à mesa do pilar e parafusadas às mesas da viga.

\section{PRELOURENTZOU (1991)}

Pioneiro no estudo experimental de ligações no Brasil, analisou o comportamento de ligações com chapa de topo e de ligações com cantoneira de alma, discutindo a sua classificação quanto à rigidez.

\section{QUEIROZ (1992)}

Pesquisador brasileiro, analisou os estados limites aplicáveis às ligações completamente soldadas e às ligações com chapa de topo, determinando as resistências últimas considerando a presença ou não de enrijecedores no pilar. Propôs também um modelo de dimensionamento segundo o qual são consideradas molas equivalentes ao efeito da ligação - adaptação do modelo proposto por Humer \& Tschemmernegg (1988).

\section{KISHI (1994)}

Analisou diversos métodos de previsão do comportamento momento rotação das ligações, organizando um programa computacional chamado Steel Connection Data Bank (SCDB), um banco de dados que incorpora uma grande quantidade de resultados experimentais disponíveis na literatura especializada, e três diferentes equações de previsão do comportamento momento-rotação para diversos tipos de ligação.

\section{QUEIROZ (1995)}

Analisou as informações disponíveis na bibliografia sobre resistência, rigidez e capacidade de deformação das ligações completamente soldadas utilizando perfis soldados com dimensões da seção transversal diferentes das usuais para perfis laminados. Com resultados de ensaios, realizados no laboratório do Instituto para Construção em Aço e Madeira, da Universidade de Innsbruck, Áustria, efetuou comparações com outros resultados obtidos através de análise elasto-plástica via método dos elementos finitos, apresentando um modelo teórico para a análise de estruturas formadas por barras. 


\section{Observações: modelagem numérica}

A modelagem numérica confirma-se como uma das vertentes para o estudo do comportamento das ligações parafusadas, com o objetivo de estabelecer métodos que levem em conta a rigidez das ligações, por meio de curvas momento-rotação, na análise e dimensionamento das estruturas metálicas.

Alguns trabalhos utilizaram-se de modelos lineares - o que apresentava desvantagens por não representar o comportamento da ligação em toda a faixa da possível variação das rotações - como os trabalhos citados por Kishi (1994), desenvolvidos por Rathbun (1936), Monforton \& Wu (1963) e Lightfoot \& LeMessurier (1974).

Outros, numa tentativa de corrigir as desvantagens dos modelos lineares, propuseram análises com modelos bilineares, nos quais reconhecia-se a redução da rigidez da ligação acima de determinados níveis de rotação relativa entre os elementos conectados. Ribeiro (1998) cita os trabalhos de Lionberger \& Weaver (1969), Romstad \& Subramanian (1970), Tarpy \& Cardinal (1981) e Lui \& Chen (1986).

Utilizando a modelagem numérica através de elementos finitos, pode-se também citar o trabalho de Bahaari \& Sherbourne (1994 e 1996), no qual apresentam uma simulação da ligação, introduzindo conceitos de contato entre as chapas e desenvolvendo uma metodologia para o estudo das relações momento-rotação através de modelos numéricos. Os modelos propostos pelos autores não consideraram, na análise, a deformação dos parafusos, introduzindo-os como vinculações para efeito da protensão.

\section{RIBEIRO (1998)}

Realizou um trabalho teórico-experimental onde ensaiou 28 protótipos, sendo 24 utilizando ligações viga-pilar com chapa de topo. Analisou alguns parâmetros de influência no comportamento momento-rotação da ligação, como espessura da chapa de topo e diâmetro dos parafusos, utilizando também simulações numéricas para comparação dos resultados, nas quais levou em consideração os parafusos em modelos tridimensionais.

\section{BURSI \& JASPART (1997 e 1998)}

Apresentaram diversos aspectos referentes à modelagem numérica como ferramenta para a análise do comportamento das ligações parafusadas em estruturas metálicas, analisando a discretização, tipos de elementos finitos, aspectos relativos à formulação utilizada em diversos tipos de elementos finitos, formulação utilizada para o encruamento dos materiais utilizados e simplificações que podem ser adotadas.

Apresentaram ainda uma modelagem alternativa para os parafusos das ligações por meio de elementos de viga, com modelos para ligações duplo " $T$ " e ligações com chapa de topo estendida, comparando os resultados numéricos com resultados experimentais específicos.

Algumas recomendações dos autores citados foram incorporadas nos modelos utilizados neste trabalho, aproveitando-se os resultados experimentais de ligações duplo "T" para a verificação dos modelos numéricos propostos. 


\section{FAELLA et al. (1998)}

Analisaram a rigidez axial de ligações parafusadas duplo " $T$ " ressaltando a importância na determinação da capacidade resistente dos modelos "T-stub" para o dimensionamento das ligações com chapa de topo. Considerando que a inclusão ou não da protensão inicial nos parafusos influi fortemente no comportamento das ligações parafusadas, realizaram um programa experimental no qual foram testados protótipos de ligações duplo "T" com diferentes níveis de protensão inicial, incluindo protótipos sem protensão.

Os autores identificaram duas situações que consideraram ideais: a primeira, sem protensão inicial e a segunda para uma força de protensão que impedisse, durante toda a fase de carregamento externo, o descolamento da chapa na região tracionada. A equivalência entre o comportamento dos perfis "T" e ligações com chapa de topo também foi avaliada com relação à previsão da rigidez rotacional, utilizando resultados experimentais encontrados na bibliografia existente.

\section{European cooperation in the field of scientific and technical research - COST C1 (1999)}

Diversos trabalhos realizados na Europa foram reunidos desde o ano de 1991 tendo como objetivo unificar a metodologia para a consideração do comportamento das ligações, principalmente com relação ao comportamento semi-rígido, que foi incluído no processo de análise estrutural, modificando os conceitos de dimensionamento das estruturas. De forma geral, o "COST C1" procurou avaliar os diversos dispositivos e configurações existentes para as ligações, organizando e propondo modelos analíticos para dimensionamento e sistemas de classificação para as ligações. Finalmente, todas as recomendações práticas de dimensionamento foram organizadas e publicadas em relatório técnico, finalizado em 1999 com o título: "Control of the semi-rigid behavior of civil engineering structural connections".

\section{LIMA et al. (1999)}

Esse trabalho de pesquisa, recentemente feito no Brasil, refere-se à utilização de ligações semi-rígidas parafusadas na alma do pilar, segundo o seu eixo de menor inércia. Levando em consideração que a análise de pórticos contraventados requer, geralmente, a consideração de ligações rígidas, os autores realizaram um programa experimental para a verificação de alguns parâmetros estruturais como as curvas momento-rotação deste tipo de ligação, distribuição de tensões e mecanismos de colapso. Modelos numéricos em elementos finitos também foram analisados para possibilitar estudos paramétricos e um modelo de dimensionamento, incluindo a rigidez da alma do pilar, foi proposto tendo como base o modelo analítico do Eurocode 3 (1993) para cálculo da rigidez da ligação e as observações oriundas da análise numérica.

\section{PILUSO et al. (2001a e 2001b)}

Nestes trabalhos os autores analisam os estados limites últimos aplicáveis à ligações com perfis " $\mathrm{T}$ " parafusados, propondo modelos teóricos para a previsão das rotações plásticas em ligações parafusadas viga-pilar. Tomando como base o "método dos componentes", ou seja, a divisão da ligação em seus componentes básicos, proposto pelo Eurocode 3 (1993), os autores reafirmam a importância da "teoria Tstub" na determinação da capacidade última das ligações com chapa de topo. 


\section{Continuação... PILUSO et al. (2001a e 2001b)}

Os mecanismos de colapso das ligações duplo "T" foram avaliados, resultando em modelos teóricos para o cálculo das deformações plásticas e capacidade resistente dos perfis "T". Em suas observações, os autores constataram que, além da espessura da chapa de topo e do diâmetro dos parafusos, a distância entre o eixo dos parafusos e a alma do perfil "T" influenciam diretamente a capacidade de deformação da ligação, para qualquer valor de espessura da mesa do perfil "T". Além disso, independentemente da geometria dos parafusos, a capacidade de deformação plástica diminui à medida que a espessura da mesa aumenta, ficando mais rígida à flexão.

A precisão dos modelos propostos foi medida por meio de comparações com resultados experimentais e apresentaram resultados satisfatórios, principalmente na determinação das curvas força-deslocamento para as ligações duplo "T".

\section{ROMANO (2001)}

Apresentou e discutiu o modelo proposto pelo Eurocode 3 (1993), anexo J, para o dimensionamento de ligações parafusadas com chapa de topo, com relação aos procedimentos de determinação da rigidez inicial e da capacidade resistente. Em seu trabalho, analisa o embasamento teórico que deu origem à metodologia de dimensionamento do Eurocode 3 (1993), dando ênfase à "teoria T-stub" e à aplicação dessa teoria na determinação dos perfis "T" equivalentes no cálculo da capacidade resistente da chapa de topo e da mesa do pilar à flexão. Adicionalmente, compara o modelo citado acima com o modelo de dimensionamento apresentado pelo Manual Brasileiro de Construção Metálica (1988), avaliando a precisão dos métodos por meio de resultados experimentais conhecidos.

O desenvolvimento dos trabalhos citados anteriormente permitiu, ao longo do tempo, o aprimoramento do estudo das ligações viga-pilar, possibilitando uma adequação paulatina dos métodos utilizados para o dimensionamento e análise das ligações em estruturas metálicas aos conceitos do comportamento semi-rígido.

As recomendações resultantes de muitos desses trabalhos foram absorvidas por normalizações e em manuais de dimensionamento, como é o caso do MANUAL brasileiro para cálculo de estruturas metálicas (1988), que baseou sua formulação em modelos propostos por Douty \& McGuire (1965), e os trabalhos desenvolvidos por Krishnamurthy (1975 e 1978) que serviram de base para a normalização americana segundo o American Institute of Steel Construction, AISC (1980).

Com uma metodologia considerada moderna, o Eurocode 3 (1993) também estabelece os métodos de dimensionamento para ligações viga-pilar, entre as quais se incluem as ligações com chapa de topo. A utilização da 
"teoria T-stub"2 para substituição das diferentes configurações de plastificação na chapa de topo e na mesa do pilar, observadas por Zoetemeijer \& deBack (1972), foram adotadas como base para o desenvolvimento analítico que deu origem ao método de dimensionamento proposto.

Enfim, a tabela 2.1 tem como objetivo orientar, sucintamente, um histórico dos trabalhos desenvolvidos, bem como enfatizar a evolução dos estudos sobre as ligações viga-pilar, de acordo com os objetivos deste trabalho.

\subsection{COMPORTAMENTO MOMENTO-ROTAÇÃO}

Uma forma de representar o comportamento de uma ligação à flexão é relacionar o momento fletor a que está solicitada com a rotação relativa entre os elementos conectados. Essa relação pode ser esquematizada graficamente por um diagrama momento-rotação, representando a rigidez rotacional da ligação e caracterizando o comportamento semi-rígido.

Simplificadamente, a fim de introduzir alguns conceitos básicos, a figura 3.1 apresenta uma viga com carregamento uniformemente distribuído onde se pode visualizar duas situações: na figura 3.1(a) consideram-se as ligações como teoricamente rígidas, ou seja, sem rotação relativa entre os elementos e momento máximo nos apoios dado pela seguinte expressão:

$$
M_{F}=\frac{q L^{2}}{12}
$$

Contudo, levando-se em conta que a ligação não se comporta como perfeitamente rígida, na figura $3.1(\mathrm{~b})$ está representada uma rotação nos apoios que pode ser entendida como a rotação relativa entre a extremidade da viga e o apoio, a qual provoca uma redução do momento fletor transmitido pela ligação expressa, especificamente para o caso da figura 3.1(b), por:

\footnotetext{
${ }^{2}$ A denominação " $T$-stub" refere-se aos perfis "T".
} 


$$
M_{\theta}=\frac{4 \mathrm{El} \theta}{\mathrm{L}}-\frac{2 \mathrm{El} \theta}{\mathrm{L}}=\frac{2 \mathrm{El} \theta}{\mathrm{L}}
$$

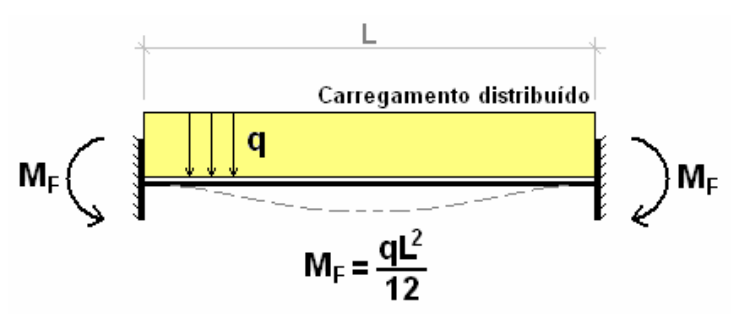

(a)

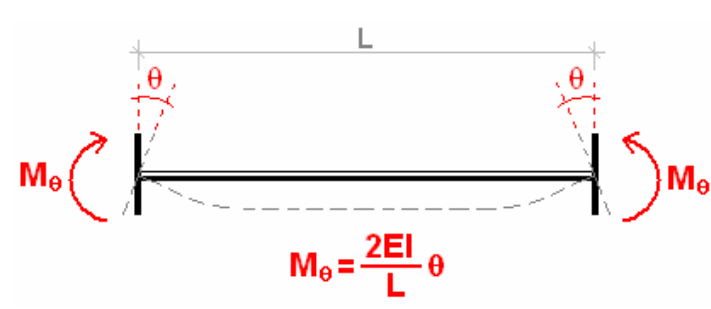

(b)

Figura 3.1 - Ligação rígida ideal e semi-rígida

Desta maneira, o momento que realmente será transmitido pela ligação será obtido com a diferença algébrica dos valores de $\mathbf{M}_{\mathbf{F}}$ e $\mathbf{M}_{\theta}$, ou seja,

$$
M=M_{F}-M_{\theta}=\frac{q L^{2}}{12}-\frac{2 E I \theta}{L}
$$

Considerando a equação 2.3 , para uma ligação teoricamente rígida, $\theta$ $=0$ e $\mathbf{M}=\mathrm{qL}^{2} / 12$, e para uma ligação teoricamente flexível, $\mathbf{M}=0$ e $\theta=q \mathrm{~L}^{3} /(24 \mathrm{EI})$, que corresponde à rotação nos apoios de uma viga bi-apoiada.

Com a formulação básica apresentada acima, observa-se que a semirigidez de uma ligação pode ser entendida como uma parcela de momento total aplicado que, em termos de energia de deformação, é transformado em rotação por deformações localizadas.

No caso das ligações com chapa de topo estendida, essas deformações são provenientes da flexão da chapa na região tracionada, da deformabilidade dos parafusos e da deformabilidade do apoio, citando-se alguns exemplos.

Swanson (1999) exemplifica algumas curvas momento-rotação que estão esquematizadas na figura 2.5 para ligações usualmente utilizadas em edifícios, relacionando a rotação da ligação em função da relação entre o momento total aplicado e o momento de plastificação da viga.

Chama-se a atenção, novamente, para o fato de que as ligações com chapa de topo podem apresentar os mais diversos comportamentos rotacionais em função de parâmetros como a espessura da chapa de topo, o diâmetro dos 
parafusos, o nível de protensão inicial dos parafusos, entre outros. Ressalta-se ainda que essas ligações e as ligações com perfis "T", segundo Swanson (1999), geralmente combinam alta capacidade resistente com uma adequada capacidade rotacional, possibilitando a sua classificação como rígida ou semirígida.

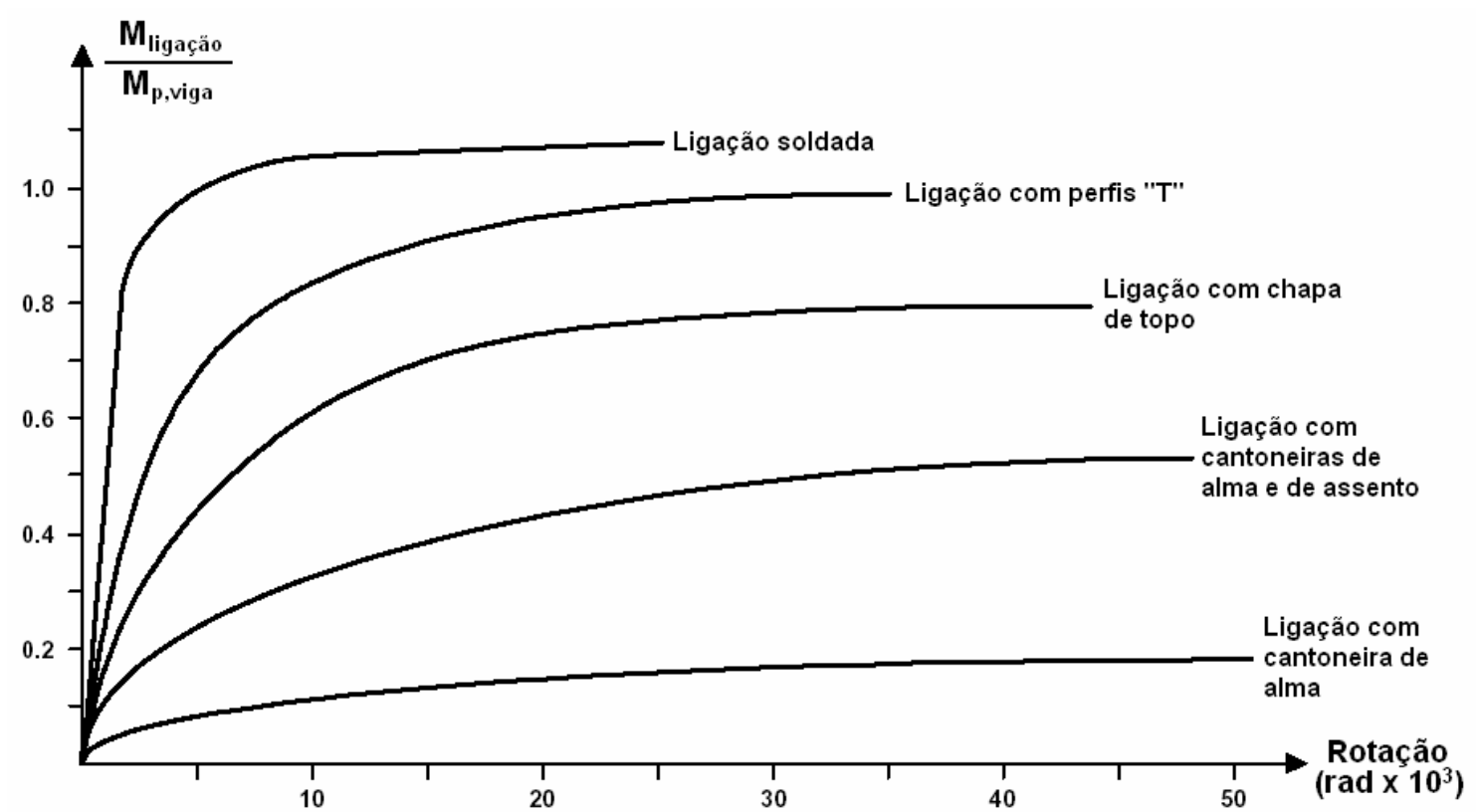

Figura 2.5 - Exemplos de curva momento-rotação para ligações usuais

As ligações soldadas são as que apresentam maior resistência, mas com pouca capacidade rotacional, sendo geralmente classificadas como rígidas. Com comportamento contrário, as ligações com cantoneiras de alma são geralmente classificadas como "rotuladas", com pequena capacidade resistente à flexão e capacidade rotacional elevada.

A análise estrutural, seguindo os conceitos básicos de rigidez, é realizada relacionando-se as forças aplicadas aos deslocamentos e deformações que provocam nos elementos estruturais. Neste caso, para introduzir o comportamento semi-rígido na análise estrutural, é possível utilizar as relações apresentadas na figura 2.5 para representar o comportamento rotacional das ligações, introduzindo na análise a relação entre o momento total aplicado na ligação e a rotação correspondente.

Para a obtenção das relações momento-rotação são utilizados, em geral, quatro métodos, que consistem em análises experimentais ou na 
calibração de curvas com base em resultados experimentais conhecidos e, mais recentemente, na utilização do "método dos componentes", introduzido pelo Eurocode 3 (1993), e na análise de modelos numéricos com elementos finitos.

Os modelos analíticos são mais aplicáveis no caso da análise estrutural, uma vez que ainda não é prático, para cada projeto, obter informações experimentais ou numéricas específicas para cada tipologia de ligação que pode ser utilizada.

Dentre os modelos que utilizam regressões com base em resultados experimentais já existentes, podem-se citar o modelo polinomial de Frye-Morris (Frye e Morris, 1975); os modelos exponenciais propostos por Kish e Chen (1986a, 1986b) e por Kishi et al. (1988a, 1988b); o modelo de RambergOsgood (1943) e o modelo de Richard-Abbott (1975), ressaltando-se que são restritos aos limites dos dados nos quais tiveram base. A descrição destes modelos e exemplos de sua utilização foram apresentados por Kamei (2001).

Estudos mais recentes utilizam como alternativa formulações racionais, a grande maioria apresentando variações do "método dos componentes" no qual se representa o comportamento das partes componentes das ligações por meio de molas, lineares ou não lineares, formando sistemas que são tratados como estruturas para simular o comportamento momento-rotação das ligações.

A figura 2.6 apresenta, esquematicamente, um exemplo de um sistema de molas utilizado para descrever as diversas fontes de deformabilidade de uma ligação com chapa de topo estendida.

Convém salientar que a representação do comportamento das molas, cuja resposta é função de relações força-deslocamento, depende de variáveis que, em alguns casos, se relacionam e interferem no comportamento umas das outras. Como exemplo, a relação força-deslocamento do parafuso é tratada isoladamente, sem se considerar a influência da flexão da chapa de topo.

Enquanto alguns componentes têm comportamentos bem determinados, como é o caso da alma do pilar à compressão, à tração e ao cisalhamento, outros são representados por modelos simplificados e, neste caso, pode-se citar o comportamento dos parafusos e da chapa de topo, 
altamente dependentes entre si e cuja variação pode influenciar significativamente no comportamento global da ligação.

Assim, pequenas variações na rigidez axial das molas relacionadas a esses componentes podem conduzir a variações significativas na determinação da rigidez rotacional da ligação.

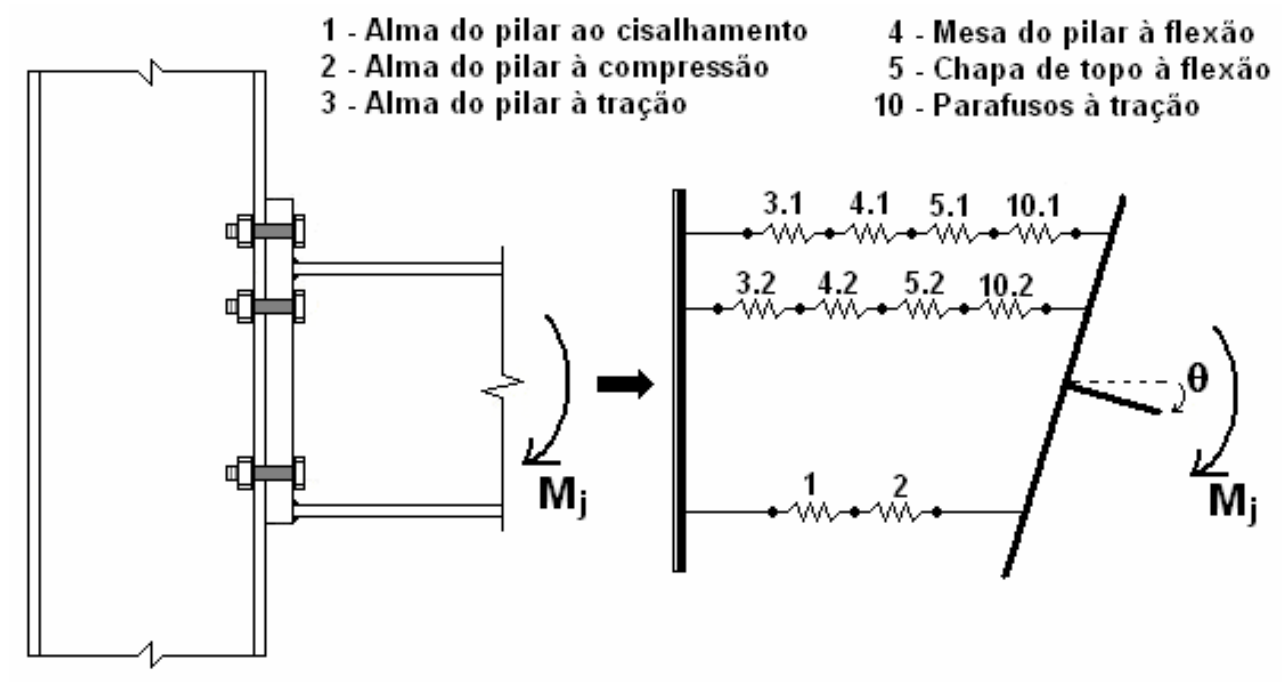

Figura 2.6 - Método dos componentes aplicado a uma ligação com chapa de topo estendida - representação esquemática

Tendo em vista os fatores relacionados acima se justifica, neste trabalho, a ênfase dada ao estudo do comportamento dos parafusos e da chapa de topo e de como esses componentes se relacionam entre si.

É importante enfatizar que os modelos mencionados acima têm como resultado final respostas momento-rotação simplificadas, representadas por relações bilineares ou multilineares que levam em consideração a rigidez inicial, o momento resistente - geralmente a capacidade máxima da ligação como limite de resistência - e a capacidade rotacional das ligações.

Nesse sentido, evidencia-se a natureza não linear do comportamento rotacional das ligações e a necessidade de modelos refinados para sua representação. 


\subsection{CLASSIFICAÇÃO DAS LIGAÇÕES}

A escolha dos critérios utilizados para a classificação das ligações, tanto no que diz respeito aos estados de serviço quanto aos estados limites últimos, representa uma das maiores dificuldades na definição de limites de rigidez e de resistência, pelo fato de não apresentarem uma divisão facilmente observada.

Para os estados limites de utilização, considerações sobre a rigidez inicial das ligações são mais significativas, enquanto que para os estados limites últimos, são de maior importância parâmetros relacionados à resistência e à capacidade rotacional, esta definida como a rotação plástica que a ligação pode apresentar mantendo uma parcela da sua resistência.

Diversos sistemas de classificação disponíveis na literatura foram desenvolvidos com o objetivo de incluir o comportamento semi-rígido das ligações dentro dos parâmetros de rigidez, resistência e capacidade de rotação, mencionados acima. Como referências mais importantes, podem-se citar os propostos pelo AISC (1978) e AISC/LFRD (1986), por Stark \& Bijlaard (1988), pelo Eurocode 3 (1992), por Bjorhovde et al. (1990) e por Nethercot et al. (1998).

Com a função de introduzir alguns conceitos quanto à classificação das ligações viga-pilar, comentam-se a seguir algumas considerações do AISC (1978), do AISC/LRFD (1986) e do Eurocode 3 (1992) para a avaliação da rigidez, resistência e capacidade rotacional das ligações, características já citadas anteriormente e que servem de base para a maioria das classificações mencionadas acima.

As especificações americanas, publicadas em 1978, introduziram algumas hipóteses para considerar os limites de rigidez inicial das ligações e as classificavam em três tipos:

i. Tipo 1: ligações rígidas $\rightarrow$ consideradas como aquelas nas quais é garantida a continuidade da estrutura e as rotações relativas são totalmente restringidas, ou admitem restrição de, no mínimo, 90\% da rotação teórica verificada sob condição de rótula ideal; 
ii. Tipo 2: ligações flexíveis $\rightarrow$ consideradas como ligações nas quais as rotações relativas entre os elementos conectados não são restringidas ou admitem uma restrição no máximo igual a $20 \%$ da rotação ideal teórica, verificada sob condição de rótula ideal; e

iii. Tipo 3: ligações semi-rígidas $\rightarrow$ ligações cujo comportamento está situado entre os limites estabelecidos pelas ligações rígidas e flexíveis.

Em 1986, o AISC/LFRD (1986) propôs uma modificação nessa classificação, segundo a qual considera-se apenas duas classes, denominadas de FR (fully restrained), quando as ligações são consideradas completamente restringidas, e PR (partially restrained), quando admitem rotações relativas entre a viga e o pilar.

As ligações tipo FR mantiveram as condições anteriores para ligações rígidas. As do tipo PR, no entanto, reuniam todas as ligações cuja rigidez considerava-se insuficiente para manter inalterado o ângulo original entre os elementos conectados, englobando as ligações antes classificadas como semirígidas e flexíveis.

Limites específicos da classificação das ligações como FR ou PR foram introduzidos pelo Eurocode 3 (1992) e tiveram base na capacidade resistente dos elementos estruturais considerando o comportamento global da estrutura, sendo que a rigidez era expressa como uma fração da rigidez do elemento que está sendo conectado.

Seguindo este enfoque, as ligações não são tratadas isoladamente, sendo que tanto a rigidez como a resistência da ligação, quando comparadas à rigidez do elemento que está conectando ao pilar, consideram na estrutura o efeito do comportamento não linear. Desta maneira, o sistema de classificação proposto utiliza parâmetros de rigidez e resistência separadamente.

Quanto à rigidez, quando comparadas à rigidez do elemento conectado, as ligações podem ser:
i. rígidas;
ii. semi-rígidas; e
iii. flexíveis. 
Quanto à resistência, as categorias dependem da capacidade das ligações na transmissão de momentos fletores, sendo estas classificadas em:

i. completamente resistentes;

ii. parcialmente resistentes; e

iii. rotuladas.

A metodologia empregada pelo Eurocode 3 (1992) para a determinação dos limites correspondentes para cada categoria mostrada acima também considera o tipo de estrutura na qual está inserida a ligação, com ou sem contraventamento.

Os parâmetros utilizados na classificação das ligações são $\bar{m}$ e $\bar{\theta}$, adimensionais, definidos pelas expressões 2.4 e 2.5 , respectivamente.

$$
\begin{aligned}
& \bar{m}=M / M_{p} \\
& \bar{\theta}=\theta_{r} / \theta_{p}
\end{aligned}
$$

onde: $\quad \theta_{p}=M_{p} \mathrm{~L} / \mathrm{El}$

e $\quad \mathbf{I}=$ momento de inércia da seção transversal da viga;

$\mathbf{L} \quad=$ comprimento da viga;

$\mathbf{M}_{\mathbf{p}}=$ momento de plastificação total da seção transversal; e

$\theta_{\mathbf{r}}=$ rotação da ligação para momento $\mathbf{M}$.

O Eurocode 3 (1992) propõe a utilização do comprimento real da viga para definir a sua rigidez, sendo que as fronteiras das regiões correspondentes às ligações rígidas e semi-rígidas para estruturas contraventadas e não contraventadas estão apresentadas na figura 2.7 . 


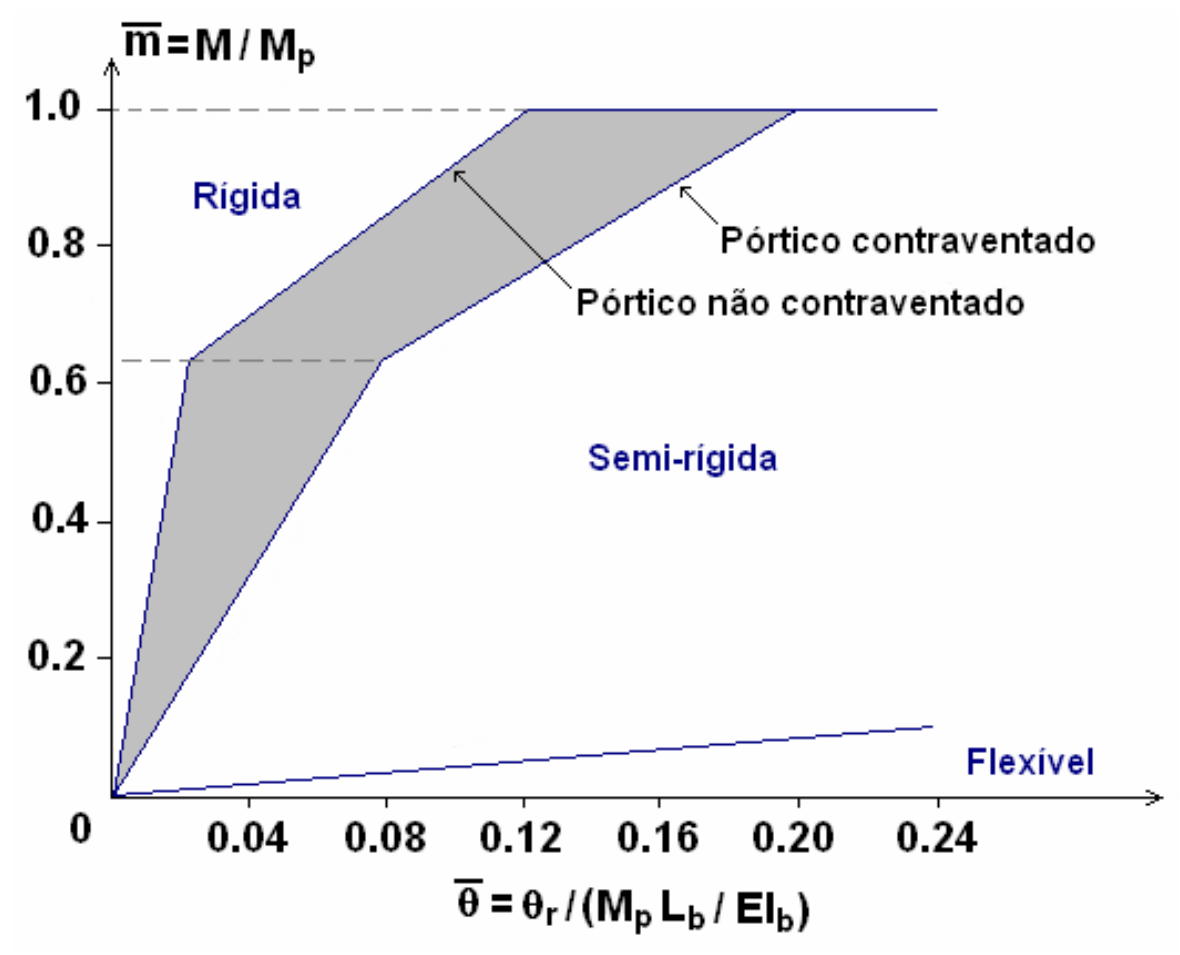

Figura 2.7 - Classificação do Eurocode 3 (1992)

Assim, analisando-se os limites para a classificação das ligações, tem-se que:

i. estruturas não contraventadas:

$\begin{array}{lll}\text { Se } \bar{m}<2 / 3 & \rightarrow & \bar{m}=25 \bar{\theta} \\ \text { Se } 2 / 3<\bar{m} \leq 1,0 & \rightarrow & \bar{m}=\frac{25 \bar{\theta}+4}{7}\end{array}$

ii. estruturas contraventadas:

$\begin{array}{lll}\text { Se } \bar{m}<2 / 3 & \rightarrow & \bar{m}=8 \bar{\theta} \\ \text { Se } 2 / 3<\bar{m} \leq 1,0 & \rightarrow & \bar{m}=\frac{20 \bar{\theta}+3}{7}\end{array}$

Sob o aspecto da resistência, o momento de plastificação total da seção transversal da viga é usado como limite máximo, ressaltando-se que a 
relação $\overline{\mathrm{m}} \times \bar{\theta}$ tem como objetivo representar a não linearidade do comportamento rotacional.

Para a caracterização da ligação flexível, complementando a classificação, são estabelecidos os seguintes limites:

\section{i. quanto à rigidez:}

$$
S_{j} \leq \frac{E l}{2 L}
$$

onde: $\quad \mathbf{S}_{\mathrm{j}}=$ rigidez rotacional secante da ligação;

\section{ii. quanto à resistência:}

$$
\mathrm{M} \leq \frac{\mathrm{M}_{\mathrm{p}}}{4}
$$

O método proposto pelo Eurocode 3 (1992) não utiliza, para a ligação, uma exigência explícita de rotação.

As especificações do AISC (1978), do AISC/LRFD (1986) e do Eurocode 3 (1992) foram utilizadas como referência, neste item, pois representam normalizações de uso corrente e amplamente estudadas e difundidas.

No entanto, classificações como a proposta por Nethercot et al. (1998) podem ser consideradas, atualmente, mais adequadas na representação dos limites de rigidez e resistência, uma vez que também analisam a ligação quanto a sua eficiência estrutural. Apesar de introduzir novas categorias, os conceitos utilizados nestas classificações, de modo geral, seguem os apresentados neste item. 


\subsection{EFEITO ALAVANCA}

Praticamente todas as ligações parafusadas viga-pilar apresentam um fenômeno usualmente conhecido como "efeito alavanca" ou "prying action", cujas características influenciam de forma significativa o comportamento das ligações e os modelos para o dimensionamento.

O "efeito alavanca" refere-se à introdução de forças de tração nos parafusos, adicionais às do carregamento externo, em função de características geométricas das ligações e dos materiais utilizados em cada componente. Essa solicitação adicional nos parafusos é comumente denominada de "força de alavanca".

O mecanismo desse efeito está exemplificado na figura 2.8 , que apresenta, esquematicamente, as forças de alavanca em um perfil "T" solicitado à tração por uma força igual à $2 \mathrm{~T}$.

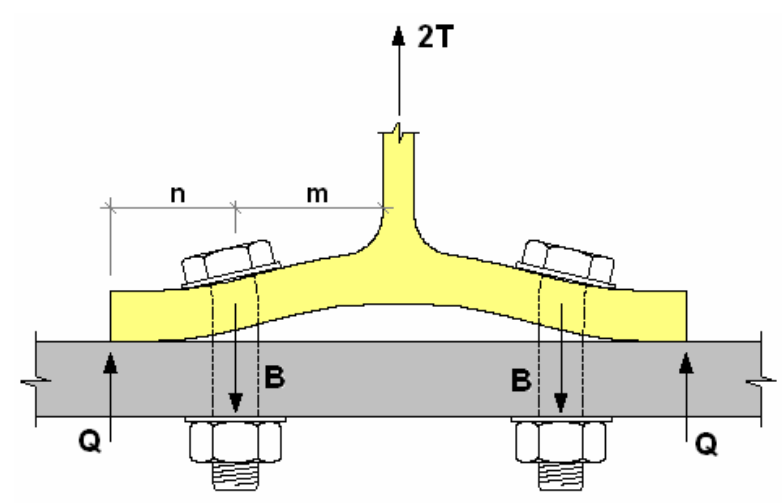

Figura 2.8 - Forças de alavanca em um perfil "T"

Devido aos efeitos de flexão na mesa do perfil "T", forças de reação se desenvolvem nas bordas laterais da mesa, indicadas na figura 2.8 por $\mathbf{Q}$. 0 equilíbrio de forças verticais indica, diretamente, que a solicitação em cada parafuso (B) é a soma expressa por $\mathbf{T}+\mathbf{Q}$.

Swanson (1999) afirma que as "forças de alavanca" podem ter magnitude elevada, com valores de até $50 \%$ da força aplicada por parafuso (T). Neste caso, é uma variável de relevância para o dimensionamento das ligações parafusadas. 


\subsection{CONSIDERAÇÕES GERAIS}

Neste capítulo procurou-se enfatizar o comportamento semi-rígido das ligações viga-pilar e alguns conceitos básicos sobre a representação das relações momento-rotação e sua utilização na análise estrutural e na classificação das ligações.

Com estes conceitos, é de fundamental importância observar que a resposta global das estruturas pode ser influenciada de maneira significativa pelo comportamento semi-rígido e que, na grande maioria dos casos, ainda não é considerada na análise estrutural, apesar de haver um número considerável de pesquisas tratando desse comportamento e da sua representação por meio de modelos analíticos.

A revisão histórica das pesquisas sobre o comportamento semi-rígido teve como objetivo situar a discussão sobre o comportamento das ligações parafusadas viga-pilar com chapa de topo estendida, sobre algumas das variáveis que influenciam na resposta estrutural dessas ligações e sobre o modelo analítico de dimensionamento proposto pelo Eurocode 3 (1993), focos deste trabalho.

Assim, no próximo capítulo serão abordados aspectos mais específicos sobre o comportamento e o dimensionamento dessas ligações, enfatizando-se o "método dos componentes" e os modelos propostos pelo Eurocode 3 (1993) na verificação da capacidade resistente da ligação em função da chapa de topo e dos parafusos. 


\section{Capítulo}

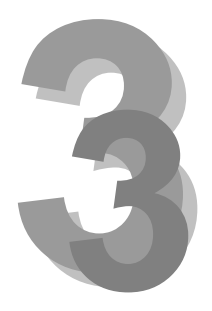

\section{LIGAÇÕES PARAFUSADAS VIGA-PILAR COM CHAPA DE TOPO}

As ligações com chapa de topo podem apresentar um comportamento altamente complexo em função de sua geometria e da interação entre os seus componentes.

Para o caso específico da chapa de topo, a verificação da capacidade resistente, ou do momento resistente da ligação em função desse componente é também função da resistência e da deformabilidade dos parafusos. Assim, a análise da flexão na chapa de topo torna-se um processo também complexo, para o qual toma-se partido de modelos simplificados.

Um dos métodos utilizados para a avaliação da capacidade resistente da chapa de topo à flexão é proposto pelo Eurocode 3 (1993), e faz parte de uma série de verificações inseridas no "método dos componentes" que, como já mencionado no capítulo anterior, trata cada componente da ligação isoladamente.

As discussões sobre os modelos analíticos de dimensionamento, neste trabalho, têm como referência a proposta do Eurocode 3 (1993), em específico para a verificação da chapa de topo à flexão, razão pela qual mostram-se neste capítulo os fundamentos do método e sua aplicação nas verificações relativas à chapa de topo.

Assim, apresentam-se inicialmente os conceitos envolvidos no "método dos componentes" e alguns fundamentos das proposições do Eurocode 3 (1993) para a análise das ligações.

Como o dimensionamento da chapa de topo à flexão utiliza como referência os modos de falha de perfis "T", alguns métodos para a quantificação dos mecanismos entre mesa e parafusos nos perfis "T" são comentados, relativos a uma breve introdução sobre a "teoria T-stub". 
Finalmente, discute-se a aplicação dos modelos analíticos para os perfis "T" no dimensionamento da chapa de topo.

\subsection{FUNDAMENTOS DO EUROCODE 3: O MÉTODO DOS COMPONENTES}

A proposta do Eurocode 3 (1993), com base em diversos estudos realizados na Europa, trouxe diversas modificações nos conceitos para o dimensionamento das ligações.

Preliminarmente, apresenta-se uma série de definições para a caracterização da ligação, itemizadas a seguir, e que podem ser visualizadas na figura 3.1 .

i. componente básico de um nó $\rightarrow$ idealizando-se a ligação como um nó de uma estrutura, o componente é uma parte específica de um nó que desempenha contribuição relevante em uma ou mais das propriedades estruturais do nó;

ii. ligação $\rightarrow$ região da interligação de dois elementos estruturais;

iii. nó $\rightarrow$ conjunto dos componentes básicos que possibilitam a interligação dos elementos estruturais, permitindo a transmissão dos esforços internos - incorpora as características da ligação; e

iv. propriedades estruturais de um nó $\rightarrow$ resistência aos esforços internos, rigidez rotacional e capacidade de rotação.

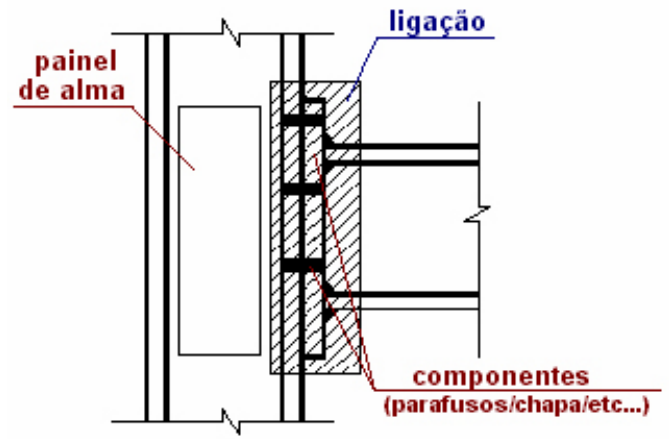

(a) pilar com uma ligação

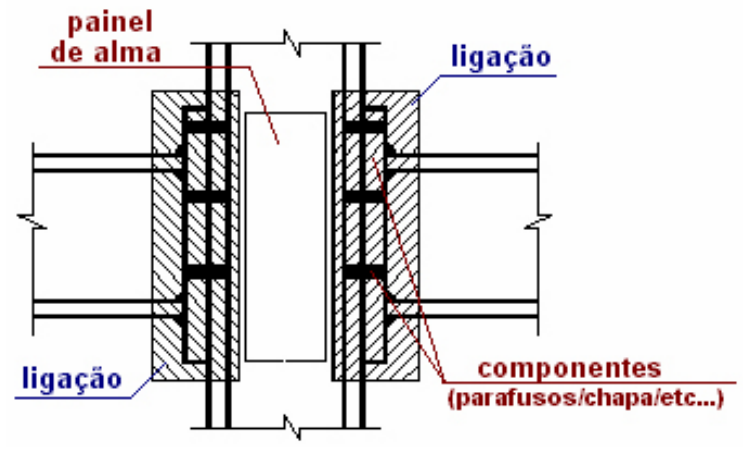

(b) pilar com duas ligações

Figura 3.1 - Ligação viga-pilar com chapa de topo - configuração geral 
O "método dos componentes", idealizado por Zoetemeijer e deBack (1972) e introduzido pelo Eurocode 3 (1993), apresenta sua inovação no conceito de que a resposta da ligação é determinada pelas propriedades mecânicas dos seus componentes. Nesse caso, as ligações são consideradas como uma série de elementos básicos, estando estes distribuídos em 3 regiões distintas: zona tracionada, zona comprimida e zona de cisalhamento. Um "componente", neste caso, não é apenas o elemento em si, mas sim uma combinação entre o elemento e a fonte de deformação, em função do tipo de solicitação.

A verificação da ligação é subdividida em 15 verificações agrupadas pelo tipo de solicitação. A tabela 3.1 apresenta essas verificações que são indicadas na figura 3.2 .

Tabela 3.1 - Verificações de resistência nos elementos da ligação

\begin{tabular}{|c|c|c|}
\hline \multirow{4}{*}{ Região } & Ref. fig. 3.2 & Verificação \\
\hline \multirow{4}{*}{ Tracionada } & $\mathbf{a}$ & Tração nos parafusos \\
\cline { 2 - 3 } & $\boldsymbol{b}$ & Flexão da chapa de topo \\
\cline { 2 - 3 } & $\boldsymbol{c}$ & Flexão da mesa do pilar \\
\cline { 2 - 3 } & $\boldsymbol{d}$ & Tração na alma da viga \\
\cline { 2 - 3 } & $\boldsymbol{f}$ & Tração na alma do pilar \\
\hline \multirow{4}{*}{$\begin{array}{c}\text { Cisalhamento } \\
\text { Horizontal }\end{array}$} & $\boldsymbol{g}$ & Solda mesa/chapa de topo \\
\hline \multirow{3}{*}{\begin{tabular}{c} 
Comprimida \\
\cline { 2 - 3 }
\end{tabular}} & $\boldsymbol{h}$ & Solda alma/chapa de topo \\
\cline { 2 - 3 } & $\boldsymbol{j}$ & Cisalhamento no painel \\
\cline { 2 - 3 } & $\boldsymbol{k}$ & Solda mesalma do pilar \\
\cline { 2 - 3 } & $\boldsymbol{I}$ & Enrugamento da alma do pilar \\
\hline \multirow{2}{*}{$\begin{array}{c}\text { Cisalhamento } \\
\text { Vertical }\end{array}$} & $\boldsymbol{m}$ & Flambagem da alma do pilar \\
\cline { 2 - 3 } & $\boldsymbol{n}$ & Solda alma/chapa de topo \\
\cline { 2 - 3 } & $\boldsymbol{o}$ & Pressão de contato (mesa ou chapa) \\
\hline
\end{tabular}

O método também considera que pode haver uma distribuição plástica das forças de tração nos parafusos, substituindo a abordagem tradicional que considera apenas uma distribuição triangular em direção à região comprimida, como esquematizado na figura 3.3. 


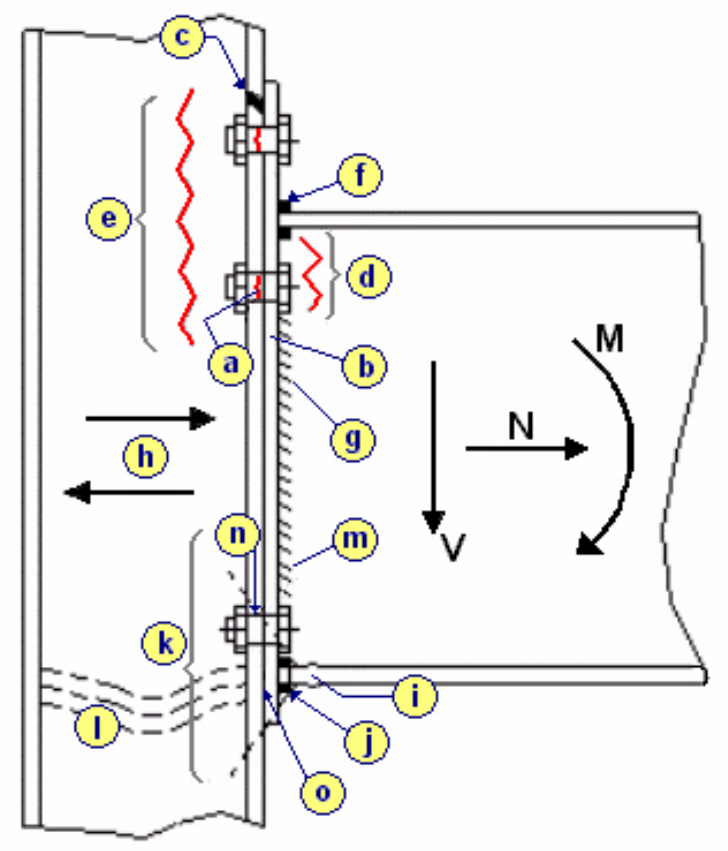

Figura 3.2 - Regiões para verificação da resistência em uma ligação viga-pilar com chapa de topo

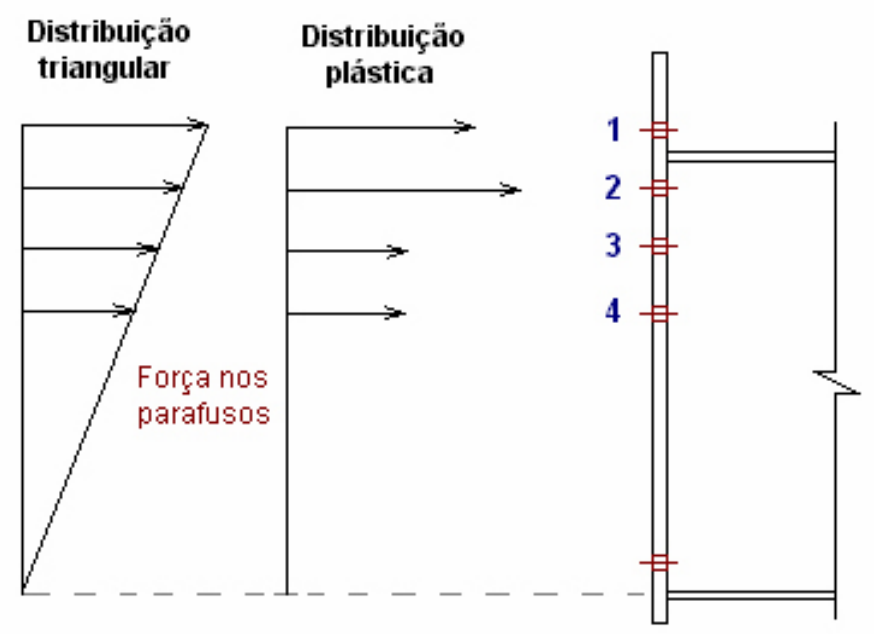

Figura 3.3 - Distribuição plástica das forças nas linhas de parafusos

A filosofia do método, da maneira como foi colocada acima, assume que a força em qualquer linha de parafusos é determinada por sua resistência potencial. As forças não são alocadas nos parafusos em função do braço de alavanca em relação ao centro de rotação. Com essa abordagem, as linhas de parafusos próximas a regiões enrijecidas, como nas proximidades das mesas de vigas ou de enrijecedores, são mais solicitadas. 
A capacidade resistente é função não só das características dos parafusos, mas é calculada levando-se em consideração todos os elementos resistentes que interagem na região verificada.

Os itens apresentados a seguir fazem referência à região tracionada da ligação, cuja verificação tanto à flexão quanto à tração depende da equivalência entre a ligação com chapa de topo e a resistência de perfis "T".

Uma vez que o método inclui todos os componentes da ligação, a capacidade resistente de cada linha de parafusos é verificada, independentemente, para a flexão da chapa de topo, para a flexão da mesa do pilar, para a capacidade resistente da alma do pilar à tração e para a capacidade resistente, também à tração, da alma da viga, adotando-se o menor valor encontrado.

Especificamente para a verificação da flexão da chapa de topo e da mesa do pilar, a metodologia proposta adota a utilização de perfis "T" equivalentes ("equivalent T-stubs") para a consideração do comportamento encontrado em torno dos parafusos, caracterizado pela formação de charneiras plásticas.

Uma publicação da SCI/BCSA (1996) apresenta diversas tabelas para a caracterização das linhas de escoamento e cálculo do comprimento efetivo de perfis "T" equivalentes, como apresentado na figura 3.4, para as linhas de parafusos atuando isoladamente ou em grupo.

A capacidade resistente à flexão da mesa do pilar ou da chapa de topo é calculada verificando-se a resistência do perfil " $T$ " equivalente, em função da força de tração atuante em uma linha ou grupo de linhas de parafusos.

Especificamente para a flexão na região tracionada, Zoetemeijer \& deBack (1972) indicam três possíveis modos de colapso, apresentados esquematicamente na figura 3.5 , que são:

i. Modo $1 \rightarrow$ formação de rótula plástica na mesa do pilar ou na chapa de topo;

ii. Modo $2 \rightarrow$ formação de rótula plástica na mesa do pilar ou na chapa de topo, acompanhado da ruptura dos parafusos; e

iii. Modo $3 \rightarrow$ ruptura dos parafusos. 

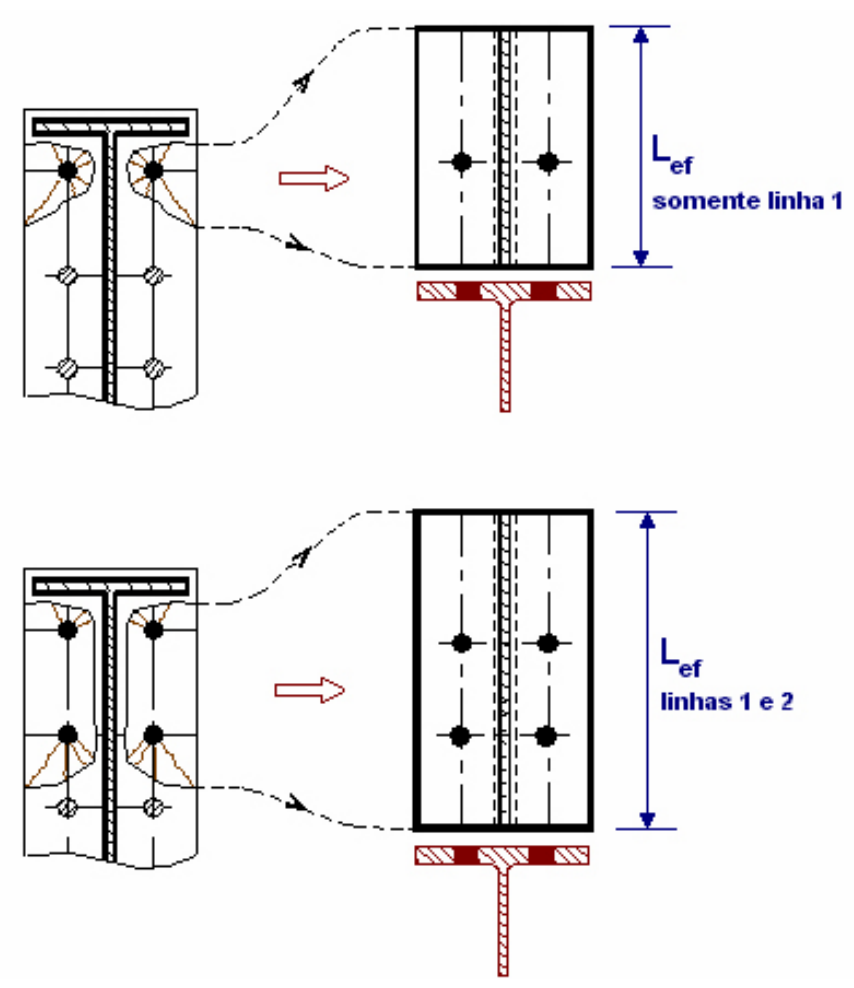

Figura 3.4 - Perfis “T” equivalentes

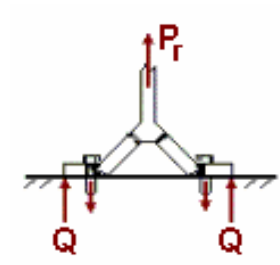

Modo 1

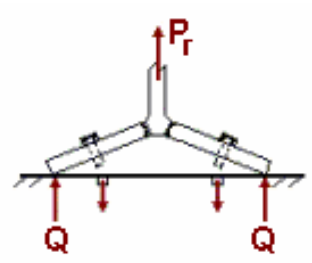

Modo 2

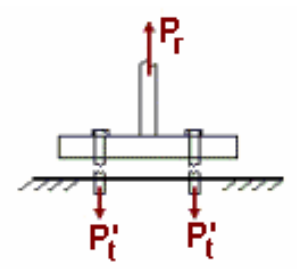

Modo 3

Chapa fina,

Parafuso com grande diâmetro

Chapa espessa,

Parafuso com pequeno diâmetro

Figura 3.5 - Modos de falha para os perfis "T"- Flexão da mesa do pilar ou da chapa de topo e resistência dos parafusos

As expressões analíticas para o cálculo da capacidade resistente da chapa de topo em cada modo de falha são função da capacidade resistente dos perfis "T" equivalentes. Aspectos teóricos que fundamentam a metodologia proposta são apresentados nos próximos itens, principalmente no que diz respeito às considerações sobre o comportamento dos perfis "T" e sua aplicabilidade ao dimensionamento da chapa de topo. 


\subsection{CAPACIDADE RESISTENTE DE PERFIS “T”}

"T-stub" é a denominação usual para os perfis "T", e a ligação duplo "T", ou "T-stub connection", representa um modelo clássico de dimensionamento, sendo esquematizada na figura 3.6. Segundo Ribeiro (1998) e Romano (2001), o impulso às pesquisas sobre o comportamento das ligações com chapa de topo foi dado com o início dos estudos sobre as ligações que utilizavam perfis "T" para conectar as mesas das vigas à mesa do pilar.

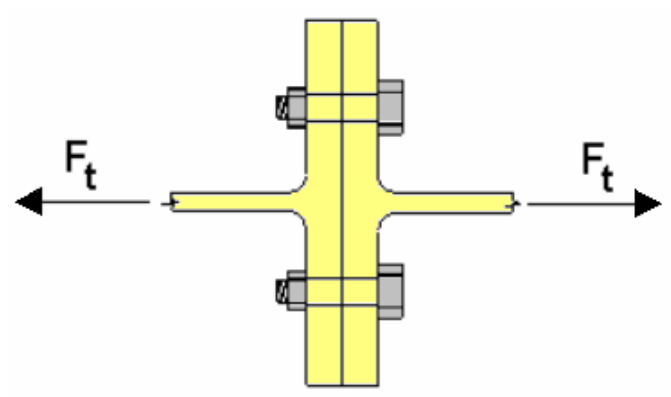

Figura 3.6 - Ligação duplo "T"

Para as ligações duplo "T" é usual considerar que a força de tração total seja dividida igualmente entre os parafusos. Intuitivamente, também é comum considerar que a soma das forças de tração em cada parafuso seja igual à força aplicada na ligação.

No entanto, o carregamento externo pode, dependendo das características geométricas e dos materiais dos elementos conectados, ocasionar a flexão da mesa do perfil "T", causando o aparecimento das "forças de alavanca" comentadas no capítulo anterior e esquematizadas, novamente, na figura 3.7.

A observação experimental das ligações duplo "T" permitiu a definição dos 3 modos de falha descritos anteriormente e também a aplicação destes modos de falha como um modelo simplificado para a análise da flexão da chapa de topo e da mesa do pilar, com base em perfis "T" equivalentes.

Segundo Swanson (1999), para a determinação da capacidade resistente dos perfis "T", diversos modelos podem ser encontrados na literatura. A grande maioria destes modelos tem base nos trabalhos de Kulak et al. (1987), Nair et al. (1974), Douty e McGuire (1965) e Jaspart (1991). 


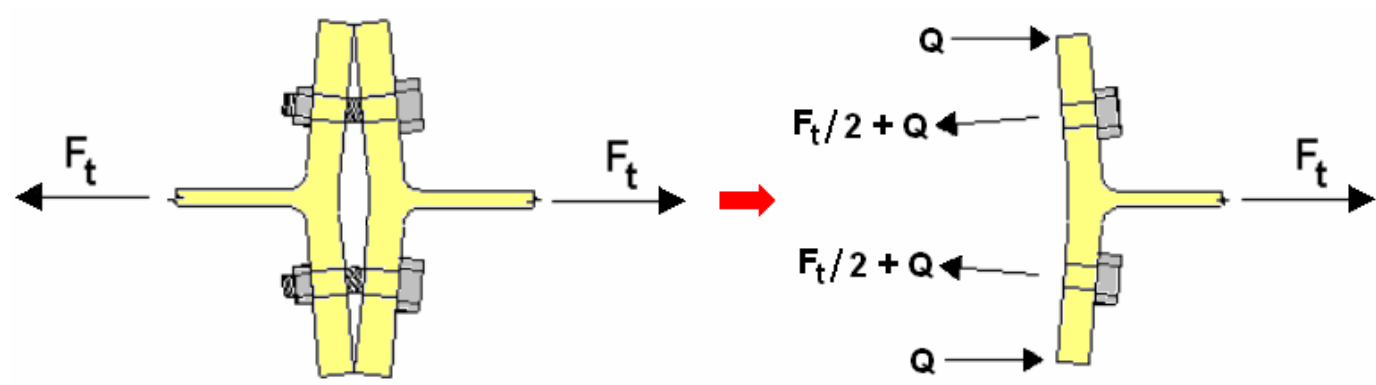

Figura 3.7 - Distribuição de forças na ligação duplo "T" - forças de alavanca

No entanto, o modelo proposto por Kulak et al. (1987) tem sido utilizado amplamente, com previsões, segundo Swanson (1999), satisfatórias quando comparadas a resultados experimentais.

Os aspectos teóricos que envolvem cada modo de falha para os perfis "T" são apresentados a seguir. Na seqüência, também são apresentados os modelos analíticos para a determinação da capacidade resistente e das forças de alavanca propostos por Kulak et al. (1987), Swanson (1999) e o modelo do Eurocode 3 (1993), para futuras comparações.

\subsubsection{Modo 1: formação da rótula plástica na linha de parafusos}

Neste modo de colapso a espessura da mesa do perfil "T" é o fator determinante, admitindo-se que a força de alavanca atinge seu valor máximo $\left(\mathbf{Q}_{\text {máx }}\right)$ com a formação da rótula plástica na linha dos parafusos. O modo de falha 1 está caracterizado na figura 3.8.

Tomando-se apenas um lado da ligação tem-se:

$$
\begin{aligned}
& Q_{\text {máx }} \times n=M_{p} \quad \text {, ou } \\
& Q_{\text {máx }}=\frac{M_{p}}{n}
\end{aligned}
$$



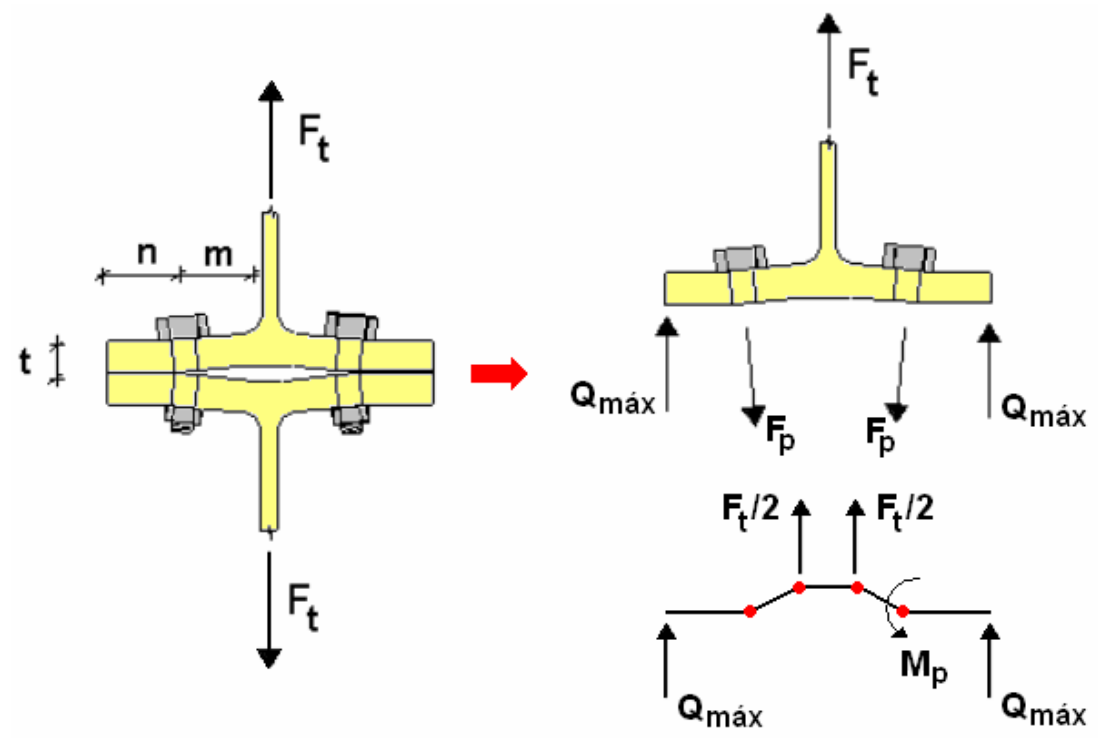

Figura 3.8 - Caracterização do modo de falha 1

Por equilíbrio de momentos tem-se:

$$
\begin{aligned}
& \frac{F_{t}}{2} \times m-Q_{\text {máx }} \times n-M_{p}=0 \text {, e utilizando a equação 3.1, } \\
& \frac{F_{t}}{2} \times m-\frac{M_{p}}{n} \times n-M_{p}=0 \\
& \frac{F_{t}}{2}=\frac{2 M_{p}}{m}
\end{aligned}
$$

onde: $\quad \mathbf{F}_{\mathbf{t}} \rightarrow$ força de tração última da ligação;

$\mathbf{M}_{\mathbf{p}} \rightarrow$ momento de plastificação da mesa do perfil "T" $=\mathrm{L} \cdot \mathrm{t}^{2} \cdot \mathrm{f}_{\mathrm{y}} / 4$;

t $\rightarrow$ espessura da mesa do perfil "T";

$\mathbf{L} \rightarrow$ comprimento da mesa do perfil "T", paralelo à alma.

Para os dois lados da ligação tem-se:

$$
F_{t}=\frac{F_{t}}{2}+\frac{F_{t}}{2}=\frac{4 M_{p}}{m}
$$




\subsubsection{Modo 2: formação de rótula plástica na intersecção mesa/alma com simultânea ruptura dos parafusos}

Neste modo de colapso o fator determinante é a capacidade última dos parafusos. Não é admitida a formação de rótula plástica na linha de parafusos, que passa a acontecer, conforme esquematizado na figura 3.9, somente na interseção mesa/alma do perfil "T", antes ou simultaneamente à ruptura dos parafusos.
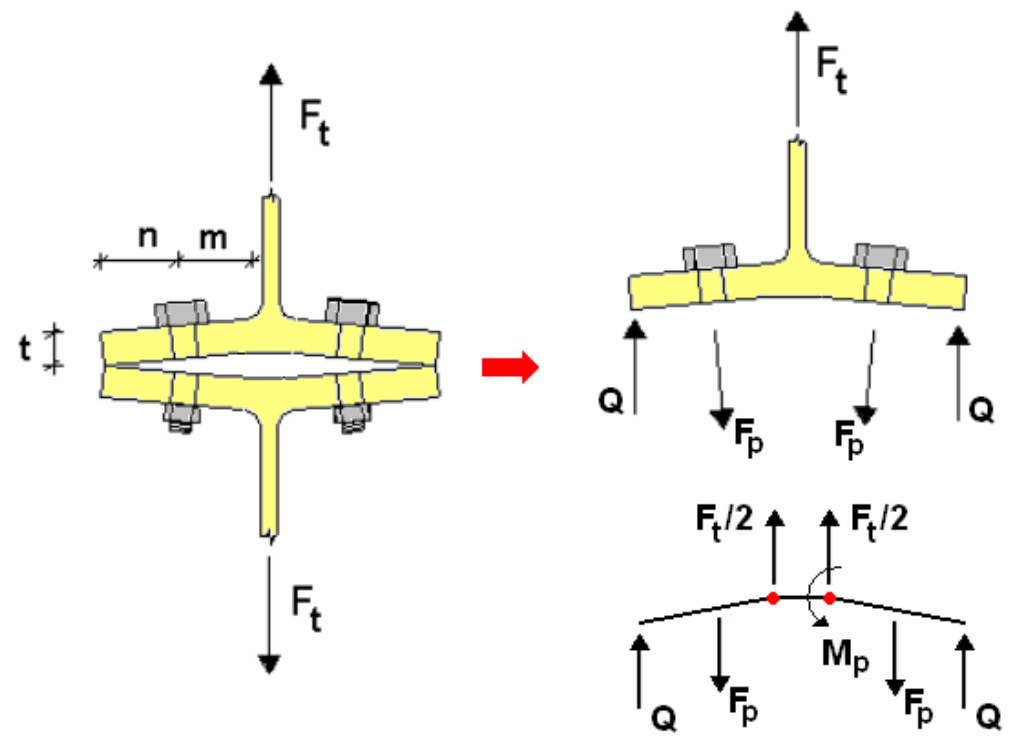

Figura 3.9 - Caracterização do modo de falha 2

Para um lado da ligação, tem-se:

$$
\begin{aligned}
& \frac{F_{t}}{2}=F_{p}-Q \quad, \text { ou } \\
& Q=F_{p}-\frac{F_{t}}{2}
\end{aligned}
$$

onde: $\quad \mathbf{F}_{\mathbf{p}} \rightarrow$ força de tração última dos parafusos.

Por equilíbrio de momentos fletores tem-se:

$$
\frac{F_{t}}{2} \times m-Q \times n=M_{p} \quad \text {, e substituindo } \mathbf{Q} \text { na expressão } 3.4, \text { tem-se }
$$




$$
\begin{aligned}
& \frac{F_{t}}{2} \times m-\left(F_{p}-\frac{F_{t}}{2}\right) \times n=M_{p} \\
& \frac{F_{t}}{2} \times(m+n)=M_{p}+n \times F_{p} \\
& \frac{F_{t}}{2}=\frac{M_{p}+n \times F_{p}}{m+n}
\end{aligned}
$$

A força total, considerando-se os dois lados da ligação, é dada por:

$$
\mathrm{F}_{\mathrm{t}}=\frac{2 \mathrm{M}_{\mathrm{p}}+\mathrm{n} \times \sum \mathrm{F}_{\mathrm{p}}}{\mathrm{m}+\mathrm{n}}
$$

\subsubsection{Modo 3: colapso dos parafusos}

Neste mecanismo, esquematizado na figura 3.10, o fator determinante é a pequena deformabilidade da mesa do perfil "T" à flexão em relação à deformabilidade dos parafusos o que permite a solicitação dos parafusos preferencialmente à tração, sem ocorrência de forças de alavanca. Admite-se que a formação de rótula plástica não ocorre na mesa do perfil "T".
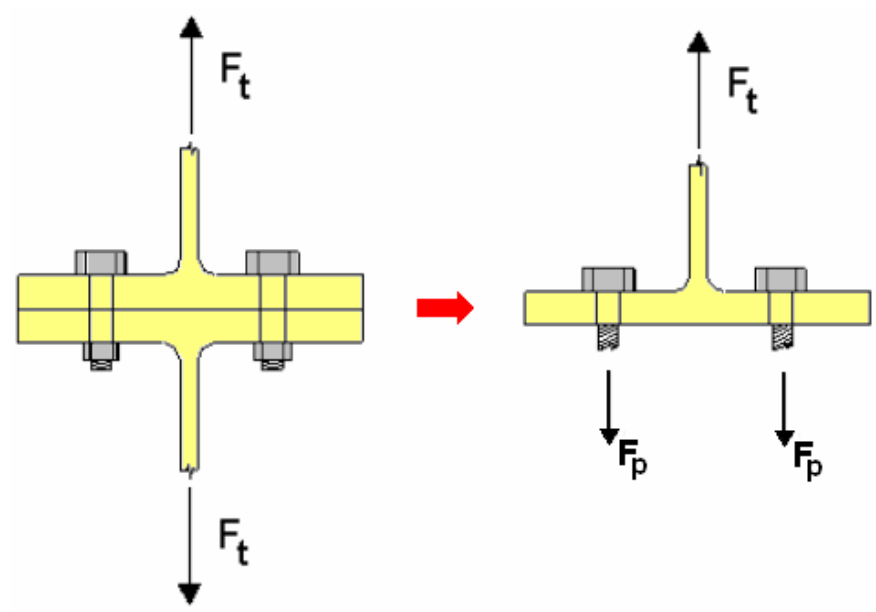

Figura 3.10 - Caracterização do modo de falha 3

Novamente, para apenas um lado da ligação: 


$$
\frac{F_{t}}{2}=F_{p}
$$

A força total para a ligação completa é expressa por:

$$
\mathrm{F}_{\mathrm{t}}=\sum \mathrm{F}_{\mathrm{p}}
$$

\subsubsection{Modelos analíticos para a determinação da resistência de perfis "T"}

A seguir são apresentadas as formulações propostas por Kulak et al. (1987), por Swanson (1999) e pelo Eurocode 3 (1993) para a determinação da capacidade resistente e das forças de alavanca de perfis "T". É interessante comentar que o modelo de Swanson (1999), com base em diversos resultados experimentais, propõe uma modificação do modelo de Kulak et al. (1987).

Para todos os modelos se considera o mecanismo do "efeito alavanca", apresentado na figura 3.11, sendo:

$$
\begin{aligned}
& \mathbf{T}=\text { força de tração, aplicada ao perfil "T", por parafuso; } \\
& \mathbf{Q}=\text { força de alavanca por parafuso; } \\
& \mathbf{B}=\text { força de tração total no parafuso; e } \\
& \mathbf{g}_{\mathbf{t}}=\text { distância entre os eixos dos parafusos tracionados; }
\end{aligned}
$$

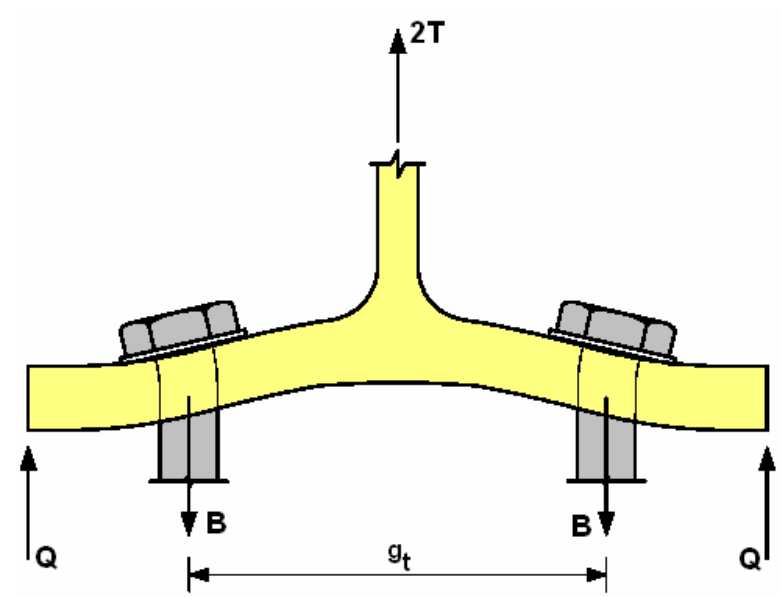

Figura 3.11 - Mecanismo de flexão da mesa do perfil "T" e "efeito alavanca" 
Considerando-se a força em cada parafuso e a largura do perfil "T" no plano perpendicular ao da figura 3.11, na direção paralela à alma, adota-se uma largura de contribuição da mesa $(\mathbf{p})$ para um par de parafusos tracionados que pode ser calculada por meio da expressão:

$$
\mathrm{p}=\frac{2 \mathrm{~W}_{\mathrm{T}-\text { stub }}}{\mathrm{n}_{\mathrm{tb}}}
$$

onde: $\quad \mathrm{W}_{\mathrm{T} \text {-stub }}=$ largura da mesa do perfil "T" paralela a seção da alma;

$\mathrm{n}_{\mathrm{tb}}=$ número de parafusos tracionados conectados à mesa do perfil "T".

Vale ressaltar que, nas formulações apresentadas nos próximos itens, não foi considerado o coeficiente de minoração da resistência dos materiais.

Além disso, como a notação utilizada pelos autores citados acima é diferente para cada modelo, optou-se por padronizar a simbologia utilizada nas formulações para este trabalho.

\subsubsection{Modelo de Kulak et al. (1987)}

O modelo desenvolvido por Kulak, Fisher e Struik (1987) é o mais utilizado para obtenção da resistência última de perfis “T”, sendo que existem variações desse modelo no AISC (1994) e no Eurocode 3 (1993).

Este modelo considera que a força de tração no parafuso $(\mathbf{B})$ age na face interna do fuste, na região mais próxima a alma do perfil "T", como indicado na figura 3.12. Esta suposição tem base na forma como são distribuídas as tensões na cabeça do parafuso junto à mesa, devido a sua flexão, indicadas na figura 3.13 .

Desta forma, toda formulação de equilíbrio tem base nas dimensões n' e m', determinadas pelas equações abaixo, com $n^{\prime} \leq 1.25 m$.

$$
n^{\prime}=\left(n+\frac{d_{b}}{2}\right)
$$




$$
m^{\prime}=\left(m-\frac{d_{b}}{2}\right)
$$

sendo: $\quad \mathbf{n}$ = distância entre o eixo do parafuso e a borda da mesa do perfil "T"; $\mathbf{m}$ = distância entre o eixo do parafuso à face da alma do perfil "T"; $\mathbf{d}_{\mathbf{b}}=$ diâmetro nominal dos parafusos.

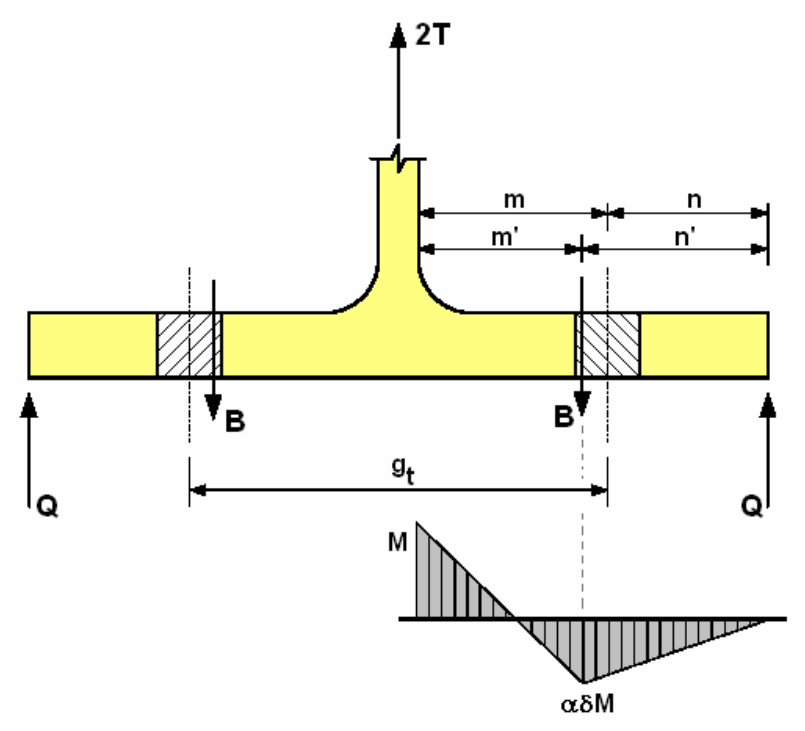

Figura 3.12 - Distribuição de momentos na mesa e posição das forças nos parafusos

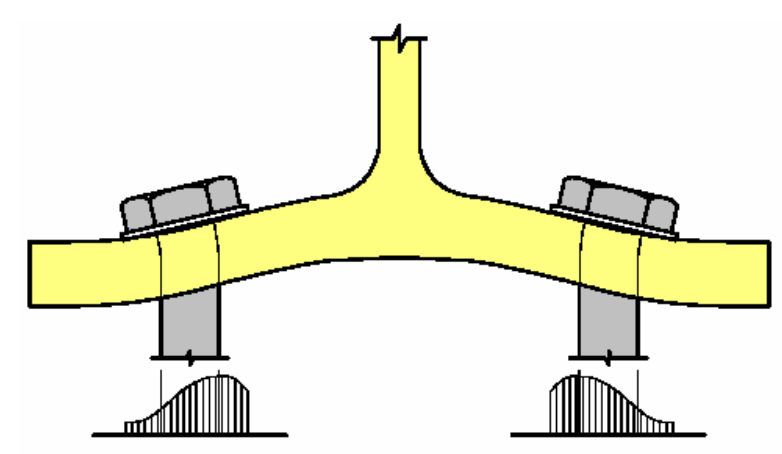

Figura 3.13 - Distribuição de tensões nas cabeças dos parafusos

Ainda é levada em consideração a redução da resistência do material da mesa devida à presença dos furos, por meio do parâmetro $\delta$, expresso por:

$$
\delta=1-\frac{d_{h}}{p}
$$


As equações de equilíbrio na mesa baseiam-se em um modelo de viga, onde o momento fletor na intersecção mesa-alma é tomado como $\mathbf{M}$ e o momento na linha do parafuso como $\alpha \delta \mathbf{M}$, e assim:

$$
\begin{aligned}
& (1+\alpha \delta) \mathrm{M}=\mathrm{Tm}^{\prime} \\
& \alpha \delta \mathrm{M}=\mathrm{Qn}^{\prime} \\
& \mathrm{T}+\mathrm{Q}=\mathrm{B}
\end{aligned}
$$

O parâmetro $\alpha$ é a relação entre o momento fletor na intersecção mesa-alma e o momento na linha do parafuso e indica o nível da "força de alavanca" no perfil "T". Segundo Swanson (1999), fisicamente o parâmetro $\alpha$ é limitado entre os valores de 0 e 1 . $O$ valor 1 é atingido se o parafuso é rígido o suficiente para que a mesa comporte-se como uma viga bi-apoiada entre o furo e a intersecção mesa-alma e o valor de 0 resulta quando ocorre a separação total da mesa com relação ao apoio.

$\mathrm{Na}$ formulação, porém, $\alpha$ não é limitado. Desta forma, se $\alpha \leq 0$ então as forças de alavancas são zero. Caso $\alpha \geq 1$, as forças de alavanca são maximizadas. Se $0<\alpha<1$, ocorrerá uma combinação de plastificação da mesa e efeito alavanca no parafuso.

Por meio da equação 3.13 e adotando $\mathbf{M}$ como sendo o momento de plastificação da mesa, calcula-se o parâmetro $\alpha$ por meio da seguinte expressão:

$$
\alpha=\left(\frac{1}{\delta}\right)\left(\frac{4 \mathrm{Tm}^{\prime}}{\mathrm{pt}_{\mathrm{f}}{ }^{2} \mathrm{f}_{\mathrm{y}}}-1\right)
$$

onde: $\quad \mathbf{t}_{\mathbf{f}}=$ espessura da mesa do perfil " $T$ ";

$\mathbf{f}_{\mathrm{y}}=$ tensão de escoamento do aço.

Desta forma, manipulando as equações $3.13,3.14$ e 3.15, determinase a força de alavanca por parafuso $(\mathbf{Q})$ utilizando-se a seguinte equação: 


$$
\mathrm{Q}=\mathrm{T}\left(\frac{\alpha \delta}{1+\alpha \delta}\right)\left(\frac{\mathrm{m}^{\prime}}{\mathrm{n}^{\prime}}\right)
$$

Definida a força $\mathbf{Q}$, a força aplicada em cada parafuso (T) é calculada pelo menor valor das equações $3.18,3.19$ e 3.20, apresentadas abaixo, que correspondem aos modos de falha 1, 2 e 3, respectivamente.

$$
\begin{aligned}
& T=\frac{(1+\delta)}{4 m^{\prime}} \mathrm{pf}_{\mathrm{y}} \mathrm{t}_{\mathrm{f}}{ }^{2} \\
& \mathrm{~T}=\frac{\mathrm{B}_{\mathrm{n}} \mathrm{n}^{\prime}}{\mathrm{n}^{\prime}+\mathrm{m}^{\prime}}+\frac{\mathrm{pf}_{\mathrm{y}} \mathrm{t}_{\mathrm{f}}{ }^{2}}{4\left(\mathrm{n}^{\prime}+\mathrm{m}^{\prime}\right)} \\
& \mathrm{T}=\mathrm{B}_{\mathrm{n}}
\end{aligned}
$$

sendo: $\quad \mathbf{B}_{\mathbf{n}}=$ resistência a tração do parafuso

\subsubsection{Modelo de Swanson (1999) - Kulak et al. Modificado}

O modelo proposto por Kulak et al. (1987), segundo Swanson (1999), consegue prever com bastante êxito a resistência da mesa e a força de alavanca nos perfis "T". Entretanto, Swanson (1999) modificou a dimensão "m" para considerar a solda da intersecção mesa-alma ou o raio de curvatura para os perfis laminados, que tem rigidez suficiente, segundo o autor, para alterar a posição da rótula plástica nessa região. Desta forma, para o modelo de Swanson (1999) a dimensão "m", além do reposicionamento da força atuante no parafuso, é diminuída de $\mathbf{0 , 5} \mathbf{r}$, onde $\mathbf{r}$ é a garganta efetiva da solda ou o raio de curvatura no caso de perfis laminados.

\subsubsection{Eurocode 3 (1993)}

O modelo proposto pelo Eurocode 3 (1993) é uma variação da teoria desenvolvida por Kulak et al. (1987). Este modelo sugere os mesmos modos de falha, porém com algumas diferenças na formulação. 
Para o Eurocode 3 (1993), as dimensões "n" e "m" (figura 3.12) são medidas a partir do eixo do parafuso. Além disso, a norma européia não considera a redução da resistência do material da mesa devida a furação para os parafusos, descrita pelo parâmetro $\delta$ e a dimensão "m" é diminuída de $\mathbf{0 , 8}$, diferentemente do proposto por Kulak et al. (1987) e por Swanson (1999), conforme esquematizado na figura 3.14.

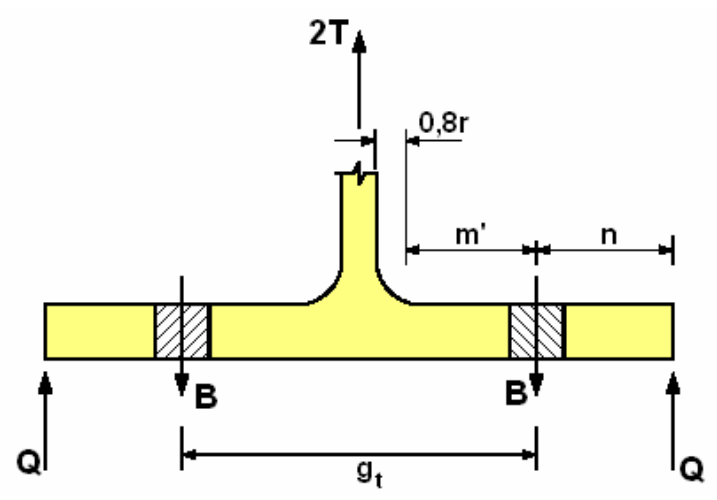

Figura 3.14 - Distribuição de forças no modelo do Eurocode 3 (1993)

Com essas considerações, o Eurocode 3 (1993) recomenda o cálculo da tração aplicada ao perfil "T" por parafuso $(\mathbf{T})$ por meio do menor valor dado pelas equações $3.21,3.22$ e 3.23 , novamente para os três modos de falha, respectivamente.

$$
\begin{aligned}
T & =\frac{p f_{y} t_{f}{ }^{2}}{2 m^{\prime}} \\
T & =\frac{B_{n} n}{n+m^{\prime}}+\frac{p f_{y} t_{f}{ }^{2}}{4\left(n+m^{\prime}\right)} \\
T & =B_{n}
\end{aligned}
$$

A metodologia de cálculo da resistência da mesa e da força de alavanca, no entanto, é a mesma proposta por Kulak et al. (1987).

Os modelos analíticos propostos por Kulak et al. (1987), por Swanson (1999) e pelo Eurocode 3 (1993), conforme apresentados nesse item, serão discutidos no capítulo 7, juntamente com comparações aos resultados experimentais e numéricos obtidos neste trabalho. 


\subsection{APLICAÇÃO DOS MODELOS DE PERFIS “T” PARA A VERIFICAÇÃO DA CHAPA DE TOPO À FLEXÃO}

As ligações viga-pilar, usualmente, possuem planos tracionados perpendiculares entre si, ou seja, a mesa da viga forma um ângulo de 90 graus com a alma do pilar. As ligações duplo "T", por sua vez, possuem planos de tração coplanares.

Imaginando uma ligação parafusada entre um perfil "T" e a mesa de um pilar, Zoetemeijer \& deBack (1972) afirmam não ser possível o aparecimento de forças de alavanca $\mathbf{Q}_{1}$ (mesa do perfil "T") e $\mathbf{Q}_{2}$ (mesa do pilar) independentemente uma da outra, devido aos impedimentos impostos pela rigidez relativa entre a mesa do perfil "T" e a mesa do pilar. As forças $\mathbf{Q}_{1} \mathrm{e}$ $\mathbf{Q}_{\mathbf{2}}$ estão indicadas na figura 3.15 e as possíveis deformações nos dois elementos, esquematizadas na figura 3.16.

Considerando-se duas situações distintas, os autores citados acima consideram o desenvolvimento de um sistema de forças de alavanca simétricas, obtendo a configuração da figura 3.17 para o caso em que a mesa do pilar apresenta maior deformabilidade à flexão do que a mesa do perfil "T".

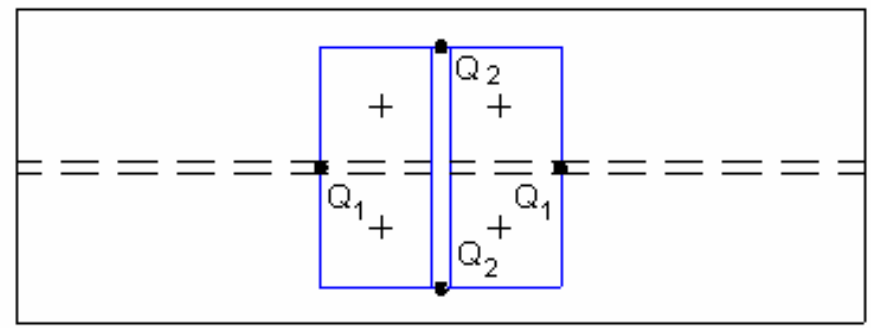

Figura 3.15 - Posição improvável das forças de alavanca em ligações com planos perpendiculares

Em contrapartida, a situação oposta leva à configuração apresentada na figura 3.18, havendo uma distribuição ótima das forças de alavanca somente quando há um equilíbrio da deformabilidade à flexão, como apresentado na figura 3.19.

Como conclusão direta, Zoetemeijer \& deBack (1972) indicam a impossibilidade de se prever antecipadamente onde ocorre a formação do primeiro mecanismo plástico. 


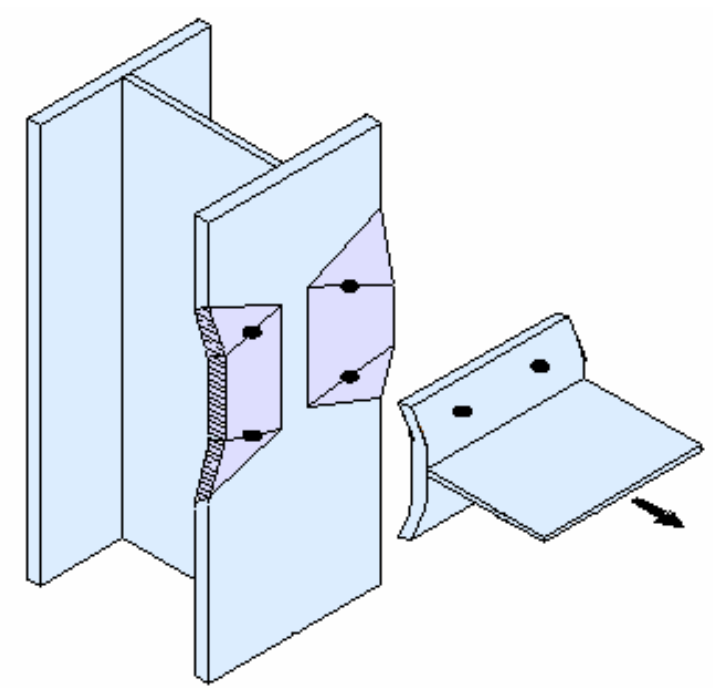

Figura 3.16 - Deformações na mesa do pilar e na mesa do perfil "T"

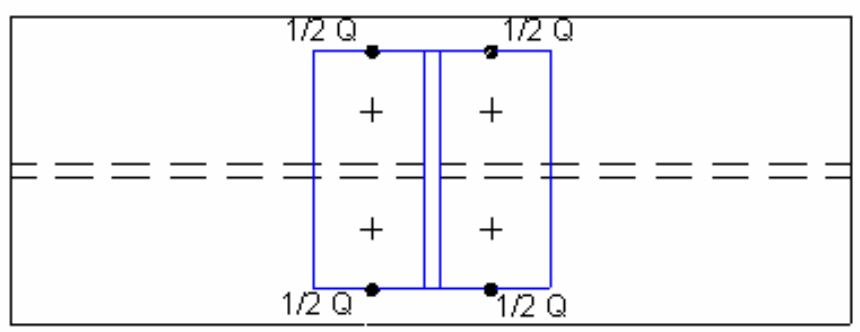

Figura 3.17 - Forças de alavanca - mesa do perfil "T" mais rígida em relação à mesa do pilar

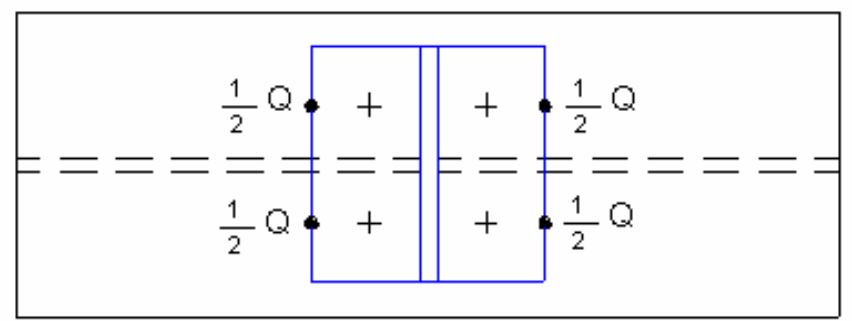

Figura 3.18 - Forças de alavanca - mesa do perfil "T" menos rígida em relação à mesa do pilar

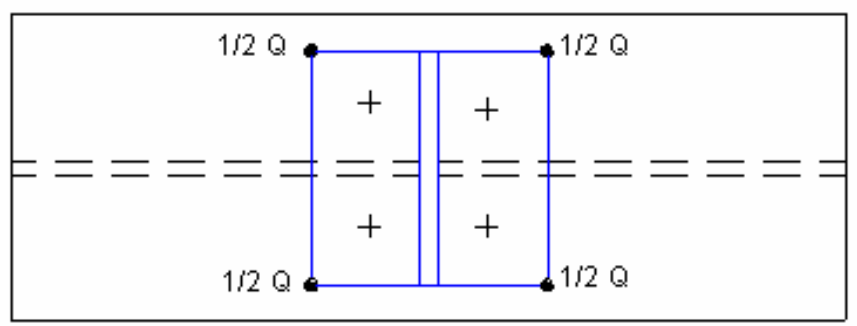

Figura 3.19 - Distribuição ótima 
A solução apresentada, como já comentado anteriormente, é o cálculo da força máxima de tração para cada elemento separadamente, adotando-se a capacidade da ligação como o menor valor calculado.

Segundo Zoetemeijer (1974), testes com ligações de perfis "T" parafusados à mesa de perfis "I" permitem verificar a ocorrência de mecanismos de colapso muito semelhantes aos modos de falha 1 e 2 previstos para as ligações duplo "T", denominados respectivamente de modos A e B.

A partir das configurações plásticas de tensão observadas nos ensaios, Zoetemeijer (1974) analisa os mecanismos de colapso A e B fazendo a equivalência da mesa do pilar a um comprimento efetivo da mesa de um perfil “T” sem enrijecimento, capaz de transmitir o mesmo esforço de tração.

Essas considerações permitiram o desenvolvimento de expressões analíticas com as quais é possível a determinação da capacidade resistente à tração para a mesa do pilar e, com analogia, para a chapa de topo, como é indicado nos métodos de cálculo propostos pelo Eurocode 3 (1993). Os modelos analíticos para os modos A e B são esquematizados nas figuras 3.20 e 3.21, respectivamente.
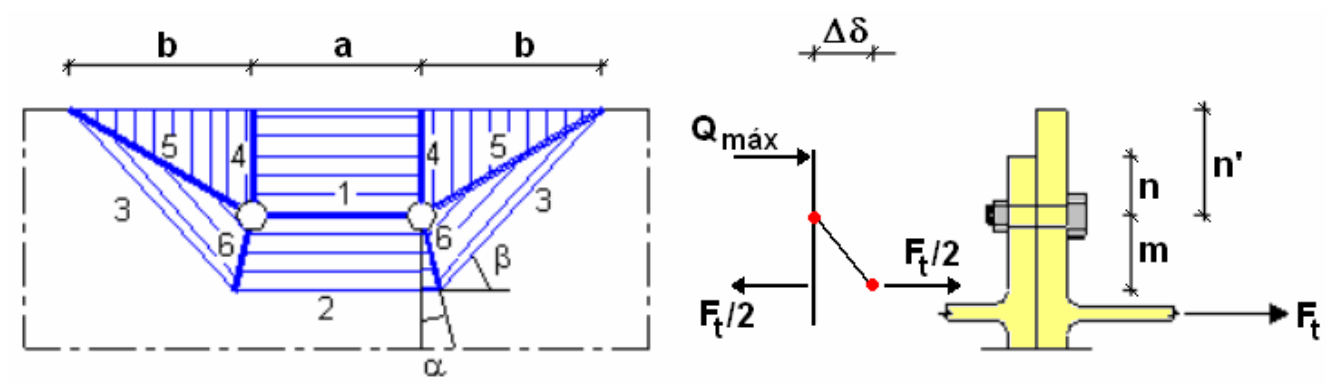

Figura 3.20 - Modelo analítico para o mecanismo de colapso A (modo 1)

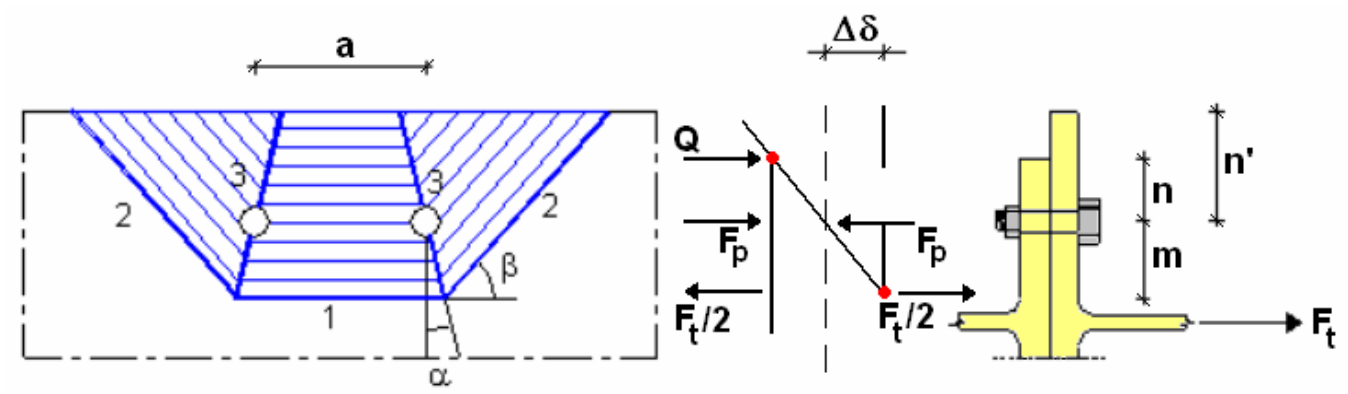

Figura 3.21 - Modelo analítico para o mecanismo de colapso B (modo 2) 
Para os modelos apresentados nas figuras 3.20 e 3.21 e considerando a existência de charneiras plásticas e a formação de linhas de plastificação (indicadas pelas linhas azuis nas figuras acima), a solução do problema consiste em determinar o valor das variáveis $\alpha$ e $\beta$ que conduzem à menor capacidade de tração para os dois modos de colapso, A e B.

Romano (2001) indica que Zoetemeijer (1974) obteve a capacidade resistente à tração da mesa do pilar partindo do princípio da igualdade entre a energia interna de deformação $(\Delta \mathbf{E})$ e o trabalho efetuado pela força externa $(\Delta \mathrm{T})$, ou seja, utilizando o Princípio dos Trabalhos Virtuais.

Para a determinação da energia de deformação total $\left(\sum \Delta \mathbf{E}_{\mathbf{i}}\right)$, considera-se que a energia de deformação para cada linha de plastificação ("yield line") é determinada pela multiplicação do momento de plastificação na linha por sua respectiva rotação, sendo o momento de plastificação para cada linha determinado pelo produto entre seu comprimento e o momento de plastificação linear $\mathbf{m}_{\mathbf{p}}$, tomado por unidade de comprimento.

Para demonstrar, resumidamente, esse desenvolvimento, a equação 3.24 representa a energia de deformação total para o modo de colapso A considerando as 6 linhas de plastificação e a equação 3.25 fornece o trabalho efetuado pela força externa $\mathbf{F}_{\mathbf{t}}$.

$$
\begin{aligned}
& \sum_{i=1}^{6} \Delta E_{i}=2 \cdot\left\{\begin{array}{l}
\frac{a}{m}+\frac{m+n^{\prime}}{m} \cdot \frac{\cos \alpha}{\operatorname{sen} \beta \cdot \cos (\beta-\alpha)}+ \\
+\operatorname{tg} \alpha+\cot g \beta+\frac{\operatorname{sen} \beta}{\cos \alpha \cdot \cos (\beta-\alpha)}
\end{array}\right\} \cdot \Delta \delta \cdot m_{p} \\
& \Delta T=\frac{F_{t}}{2} \cdot \Delta \delta
\end{aligned}
$$

Assim, considerando-se $\Delta \mathrm{E}=\Delta \mathrm{T}$ obtém-se:

$$
\frac{F_{t}}{2} \cdot \Delta \delta=2 \cdot\left\{\begin{array}{l}
\frac{a}{m}+\frac{m+n^{\prime}}{m} \cdot \frac{\cos \alpha}{\operatorname{sen} \beta \cdot \cos (\beta-\alpha)} \\
+\operatorname{tg} \alpha+\operatorname{cotg} \beta+\frac{\operatorname{sen} \beta}{\cos \alpha \cdot \cos (\beta-\alpha)}
\end{array}\right\} \cdot \Delta \delta \cdot m_{p}
$$


Segundo a equação 3.26 , minimizar $\boldsymbol{F}_{\mathbf{t}}$ implica em minimizar a parcela à direita da igualdade. Sendo tal parcela função de $\alpha$ e $\beta$, para se determinar o valor mínimo de $\boldsymbol{F}_{\mathbf{t}}$, deve-se minimizar a expressão em função das variáveis $\alpha \mathrm{e}$ $\beta$, segundo as condições dadas por:

$$
\begin{aligned}
& \frac{\partial \sum_{\mathrm{i}=1}^{6} \Delta \mathrm{E}_{\mathrm{i}}}{\partial \alpha}=0 \quad \mathrm{e} \\
& \frac{\partial \sum_{\mathrm{i}=1}^{6} \Delta \mathrm{E}_{\mathrm{i}}}{\partial \beta}=0
\end{aligned}
$$

O desenvolvimento algébrico dessas condições conduz a um sistema de equações, apresentado por Romano (2001), que fornece as seguintes expressões:

$$
\begin{aligned}
& \cos \beta=\frac{1}{2 \cdot \sqrt{\frac{m+n^{\prime}}{m}}} \\
& \operatorname{sen} \beta=\sqrt{1-\frac{m}{4 \cdot\left(m+n^{\prime}\right)}} \\
& \cos \alpha=\frac{\sqrt{4 m^{2}+4 m n^{\prime}-m^{2}}}{2 m+2 n^{\prime}} \\
& \operatorname{sen} \alpha=\frac{\sqrt{4 m n^{\prime}+4 n^{\prime 2}+m^{2}}}{2 m+2 n^{\prime}}
\end{aligned}
$$

A substituição das expressões 3.29 a 3.32 na equação 3.26 fornece

$$
F_{t} \cdot m=4 \cdot\left(a+\frac{6 m+8 n^{\prime}}{\sqrt{3+\frac{4 n^{\prime}}{m}}}\right) \cdot m_{p}
$$

lembrando que $\mathbf{m}$ representa uma dimensão geométrica e $\mathbf{m}_{\mathbf{p}}$ é o momento de plastificação por unidade de comprimento. 
Segundo Zoetemeijer (1974), para valores práticos de m e n' a equação 3.33 pode ser considerada, aproximadamente, como:

$$
F_{t} \cdot m=4 \cdot\left(a+4 m+1,25 n^{\prime}\right) \cdot m_{p}
$$

Para o mecanismo de colapso B, obtém-se, de forma similar:

$$
F_{t}=\frac{2 \cdot\left(a+5,5 m+4 n^{\prime}\right) \cdot m_{p}+n \cdot \sum F_{p}}{m+n^{\prime}}
$$

Observando-se as expressões 3.34 e 3.35, os fatores que multiplicam $\mathbf{m}_{\mathrm{p}}$ (momento de plastificação por unidade de comprimento) podem ser definidos como os comprimentos efetivos para os modos de colapso A e B.

De fato, comparando-se as equações 3.3 e 3.34 e as equações 3.6 e 3.35, conclui-se que:

$$
\begin{aligned}
& M_{p}=\left(a+4 m+1,25 n^{\prime}\right) m_{p} \text { e que } \\
& M_{p}=\left(a+5,5 m+4 n^{\prime}\right) \cdot m_{p}
\end{aligned}
$$

representando, respectivamente, os momentos de plastificação para os modos de colapso A e B.

Para efeitos de dimensionamento, o valor do comprimento efetivo deve ser observado também em função do valor da força de alavanca $\mathbf{Q}$, sendo portanto necessário determinar a sua contribuição.

A influência da força de alavanca máxima $\left(\mathbf{Q}_{\text {máx }}\right)$ no momento de plastificação para o modo A, equação 3.36, pode ser avaliada pela análise do equilíbrio de uma parte da mesa do pilar, considerando-se as linhas de escoamento 1 e 5 e o bordo livre e desconsiderando-se a transmissão de esforços de torção e forças cortantes, como esquematizado na figura 3.22.

Além disso, é possível reescrever a equação 3.3, que descreve o modo de falha 1, para considerar uma parcela de momento referente à força de alavanca $\mathbf{Q}_{\text {máx }}$, denominada de $\mathbf{M}_{\mathbf{p}}{ }^{\text {, }}$, conforme a seguinte expressão: 


$$
F_{t}=\frac{2\left(M_{p}+M_{p}^{\prime}\right)}{m}
$$

sendo: $Q_{\text {máx }}=\frac{M_{p}^{\prime}}{n}$

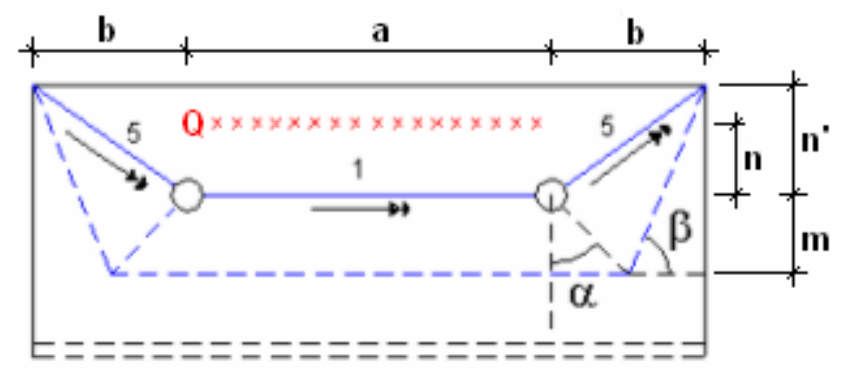

Figura 3.22 - Equilíbrio de momentos na mesa do pilar - simetria

O momento de plastificação total para o modo $\mathbf{A}$, com base na equação 3.36, fica expresso por:

$$
M_{p}+M_{p}^{\prime}=2\left(a+4 m+1,25 n^{\prime}\right) m_{p}
$$

O equilíbrio de momentos, da figura 3.22, requer que:

$$
\mathrm{Q}_{\text {máx }} \cdot \mathrm{n}=\mathrm{m}_{\mathrm{p}} \cdot \mathrm{a}+2 \mathrm{~m}_{\mathrm{p}} \cdot \mathrm{b}
$$

onde: $\quad b=m \cdot \tan \alpha+\frac{m+n^{\prime}}{\operatorname{sen} \beta}$

Substituindo-se as relações de seno e cosseno para $\alpha$ e $\beta$ em 3.42 tem-se:

$$
b=\frac{m^{2}+2 m n^{\prime}+2 \cdot\left(m+n^{\prime}\right) \cdot \sqrt{m^{2}+m n^{\prime}}}{\sqrt{3 m^{2}+4 m n^{\prime}}}
$$

O valor de $\mathbf{Q}_{\max }$ é obtido substituindo-se a 3.43 em 3.41, obtendo-se: 


$$
Q_{\text {máx }} \cdot n=\left(a+2 \cdot \frac{m^{2}+2 m n^{\prime}+2 \cdot\left(m+n^{\prime}\right) \cdot \sqrt{m^{2}+m n^{\prime}}}{\sqrt{3 m^{2}+4 m n^{\prime}}}\right) \cdot m_{p}
$$

Segundo Zoetemeijer (1974), para valores práticos de m e n', a equação 3.44 pode ser adotada como:

$$
Q_{\text {máx }} \cdot n=\left(a+4 m+2,5 n^{\prime}\right) \cdot m_{p}
$$

Considerando-se a equação 3.40, para o mecanismo de colapso A tem-se a seguinte expressão para $\mathbf{M}_{\mathbf{p}}$ :

$$
M_{p}=(a+4 m) m_{p}
$$

Com os valores obtidos para os momentos de plastificação e os comprimentos efetivos correspondentes, podem-se fazer duas afirmações:

i. Considerar $\mathbf{M}_{\mathrm{p}}=\left(\mathrm{a}+\mathbf{5 , 5 m}+\mathbf{4} \mathrm{n}^{\prime}\right) \mathbf{m}_{\mathrm{p}}$ (comprimento efetivo igual à $\left.a+5,5 m+4 n^{\prime}\right)$ implica em admitir um pequeno fator de segurança contra a ruptura dos parafusos;

ii. Considerar $\mathbf{M}_{\mathrm{p}}=(\mathbf{a}+\mathbf{4 m}) \mathbf{m}_{\mathrm{p}}$ (comprimento efetivo $=\mathbf{a}+\mathbf{4 m}$ ) implica em admitir um grande fator de segurança contra a ruptura dos parafusos.

Assim, para propósitos de dimensionamento, Zoetemeijer (1974) recomenda a consideração do comprimento efetivo igual à $\left(a+4 m+1,25 n^{\prime}\right)$, afirmando que este valor tem conduzido a resultados satisfatórios quando comparado a resultados experimentais.

As demonstrações apresentadas para os modos de colapso A e B, como referência para o trabalho de Zoetemeijer (1974), foram indicadas como exemplo na determinação dos comprimentos equivalentes que permitem, teoricamente, a aplicação dos modos de falha de perfis "T" com base nas charneiras plásticas observadas na mesa do pilar e na chapa de topo. 
Os conceitos apresentados neste item podem ser estendidos para a determinação de perfis "T" equivalentes com base em diferentes configurações de plastificação nesses dois componentes.

O desenvolvimento dos procedimentos apresentados anteriormente, com mais detalhes, pode ser encontrado no trabalho de Romano (2001).

\subsection{CONSIDERAÇÕES GERAIS}

O entendimento dos conceitos adotados para a formulação analítica que permite a equivalência entre as ligações duplo "T" e as ligações com chapa de topo é fundamental para a observação do comportamento da chapa de topo e para a avaliação dos modelos de dimensionamento.

Os fundamentos teóricos que dão base à metodologia de cálculo proposta pelo Eurocode 3 (1993) influenciam não só a verificação da capacidade resistente, mas também os cálculos para previsão da rigidez das ligações com chapa de topo pela definição das curvas momento-rotação.

É interessante ressaltar que o cálculo dos comprimentos equivalentes para os perfis "T" não são satisfatórios para todas as configurações de ligação, necessitando de estudos mais detalhados, principalmente com relação às linhas de plastificação que se formam na região dos furos à medida que a deformabilidade da chapa de topo aumenta com relação aos parafusos.

Bursi \& Jaspart (1998) apresentam uma comparação entre resultados de momento resistente de ensaios com ligações com chapa de topo estendida e os mesmos resultados calculados pelo Eurocode 3 (1993). Os autores indicam que o modelo analítico subestima a capacidade da ligação em até $25 \%$ para chapas finas, nas quais há um complexo campo de deslocamentos, resultando no modo de falha 1 . Os resultados tornam-se mais próximos à medida que a espessura da chapa de topo cresce, ou seja, na medida em que o modo de falha passa a ser comandado pela ruptura dos parafusos, com o desaparecimento do "efeito alavanca".

Os limites entre o que se considera por "chapas finas" ou "chapas grossas" também não são especificados, uma vez que dependem da geometria 
da chapa de topo e dos parafusos utilizados na ligação, ou seja, da deformabilidade relativa entre esses componentes.

Além disso, há discrepâncias com relação aos cálculos da rigidez inicial da ligação, novamente subestimada. Neste caso, Bursi \& Jaspart (1998) afirmam que os modelos analíticos permanecem a favor da segurança para casos de carregamento estático. Para carregamentos dinâmicos, no entanto, essa afirmação pode não ser verdadeira, devido à inversão de esforços na ligação e às variações da capacidade rotacional, cujos valores máximos o método não é capaz de predizer.

Além disso, apesar de haver algumas observações sobre a perpendicularidade entre a mesa do perfil "T" ou a mesa da viga e à alma do pilar, como comentado por Zoetemeijer \& deBack (1972), as variações de resistência e deformabilidade para os perfis "T" levam sempre em consideração a ligação duplo "T" usual, na qual os planos de tração são coplanares.

Para a ligação duplo "T" usual as configurações esperadas de forças de alavanca e a flexão das mesas são qualitativamente bem definidas. No entanto, não existe menção de como variações da tipologia dos perfis "T", em analogia às configurações encontradas nas ligações com chapa de topo, podem modificar as linhas de plastificação e os "efeitos de alavanca".

O programa experimental e a modelagem numérica propostos neste trabalho incluíram análises com ligações com chapa de topo estendida e ligações duplo "T" com diferentes tipologias, para possibilitar discussões sobre o processo de plastificação dos componentes relacionados à chapa de topo e aos parafusos.

Essas discussões podem levar, futuramente, à incorporação de novos conceitos e a refinamentos na formulação analítica existente, principalmente no que diz respeito ao cálculo da resistência e rigidez das ligações.

A descrição dos procedimentos específicos de cálculo para a verificação das ligações segundo as recomendações do Eurocode 3 (1993) e também para a utilização do "método dos componentes" na obtenção das relações momento-rotação pode ser encontrada nos trabalhos de Ribeiro (1998), de Maggi (2000) e de Romano (2001). 


\section{Capítulo}

\section{METODOLOGIA DO PROGRAMA EXPERIMENTAL}

A metodologia adotada neste trabalho segue um enfoque numéricoexperimental e utiliza a análise numérica como base para as discussões sobre o comportamento das ligações com chapa de topo. Lembrando o contexto do qual este trabalho faz parte e também de seus objetivos, os modelos numéricos são utilizados em todas as fases do estudo proposto, como complemento da análise experimental, para o desenvolvimento da análise paramétrica e para as discussões sobre o dimensionamento da chapa de topo.

Os modelos experimentais são utilizados, primordialmente, para a observação do comportamento global das ligações estudadas, gerando também resultados de controle para os modelos numéricos. Os resultados experimentais se referem, principalmente, à rigidez global das ligações, aos campos de deslocamento descritos pela chapa de topo, deformações localizadas em pontos estratégicos da chapa de topo e a observação dos estados limites últimos. Devido às restrições encontradas na instrumentação, seja pela grande quantidade de extensômetros e transdutores, seja pela inacessibilidade dos equipamentos de leitura, os modelos numéricos são utilizados juntamente com os experimentais para fornecerem dados adicionais dos mecanismos de plastificação, "forças de alavanca" nos parafusos e concentrações de tensão.

Uma vez que se faz a utilização simultânea de resultados experimentais e numéricos nas discussões sobre o comportamento das ligações com chapa de topo, optou-se por descrever a metodologia aplicada neste trabalho pela apresentação, inicialmente, da tipologia dos protótipos experimentais utilizados, dos objetivos específicos de cada grupo de protótipos e os equipamentos e procedimentos utilizados nos ensaios, enfatizando-se que 
os protótipos do programa experimental servirão de base para a modelagem numérica.

No programa experimental deste trabalho foram utilizadas duas séries distintas de protótipos com ligações parafusadas, que são:

i. Ligações duplo "T"; e

ii. Ligações com chapa de topo estendida.

O primeiro tipo (i) teve como objetivo prover dados sobre a resistência e rigidez de perfis "T" parafusados, formando uma ligação em duplo "T" comumente conhecida como "T-stub". Este tipo de ligação tem importância significativa no dimensionamento da chapa de topo uma vez que configurações de colapso de perfis "T" são utilizadas, simplificadamente, para a obtenção da resistência da chapa de topo à flexão de acordo com o que foi apresentado no capítulo 3. Assim, essa série foi utilizada para a observação dos modos de falha propostos pelo Eurocode 3 (1993) e, mais adiante, para as discussões sobre os modelos analíticos de dimensionamento.

O segundo tipo (ii) teve como objetivo fornecer dados globais do comportamento das ligações com chapa de topo para possibilitar observações paramétricas, qualitativas, quanto à variação da espessura da chapa de topo, além de comparações com os resultados numéricos. De acordo com o escopo deste trabalho, procurou-se dar ênfase às ligações com chapa de topo estendida.

Todos os protótipos foram fornecidos pela empresa Brafer Construções Metálicas S.A. e confeccionados com chapas de aço ASTM-A36, soldadas. Os parafusos utilizados foram os de alta resistência do tipo ASTM$A 325$, com forças iniciais de protensão aplicadas em todos os protótipos com o auxílio de torquímetros, segundo as recomendações da NBR 8800 (1986). Detalhes dos protótipos e dos procedimentos adotados nos ensaios das duas séries experimentais são descritos a seguir. 


\subsection{LIGAÇÕES DUPLO “T”}

As ligações duplo " $T$ " consistiram de protótipos de pequena dimensão e foram utilizados para a observação dos modos de falha descritos pelo Eurocode 3 (1993), que representam possíveis configurações de colapso aplicáveis à chapa de topo quando esta é solicitada à flexão. Considerando como objetivo, hipoteticamente, a caracterização do colapso do perfil "T" para aplicação no dimensionamento da chapa de topo, as referências bibliográficas consultadas no desenvolvimento deste trabalho mostram que é comum a adoção da tipologia apresentada na figura 4.1, na qual dois perfis " $T$ " são conectados por parafusos para ensaios de tração.

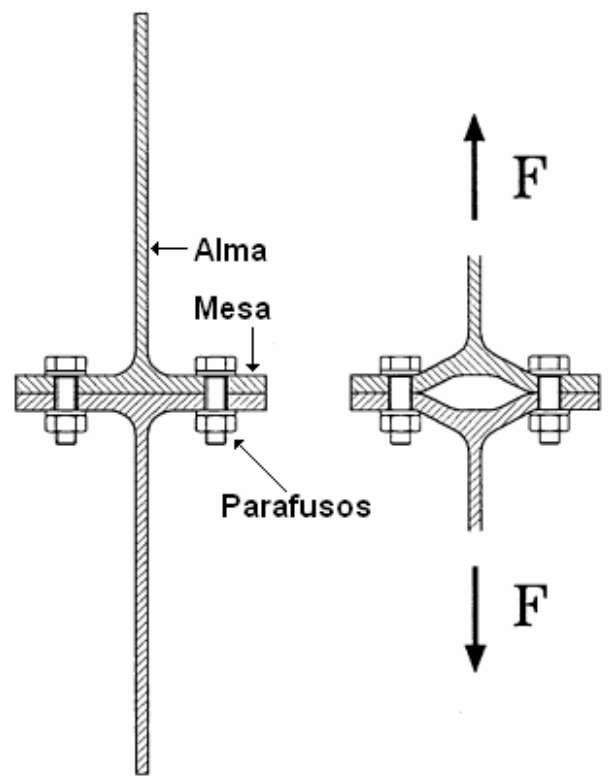

Figura 4.1 - Tipologia usual da ligação duplo "T"

A validade dessa tipologia de ensaio na caracterização do perfil " $T$ " como componente da ligação apresenta algumas discordâncias, uma vez que a flexibilidade dos perfis conectados tem influência significativa no comportamento dessa ligação, principalmente se estes perfis, ou a montagem do duplo "T", não forem perfeitamente simétricos, o que ocorre em geral. Além disso, essa tipologia foi, e ainda é, utilizada comumente para o estudo dos perfis " $T$ " aplicados à chapa de topo sem a consideração de que, em uma ligação viga-pilar, os elementos conectados possuem flexibilidades diferentes e 
até mesmo variações de tipologia, o que pode modificar os mecanismos de plastificação e de colapso.

É interessante ressaltar que para a caracterização do perfil "T" como componente de ligações que utilizam este dispositivo para unir vigas e pilares, testes com o perfil "T" conectado a um apoio rígido tornam-se mais adequados, uma vez que a rigidez do perfil "T" isolado torna-se um dado mais interessante.

Assim, a metodologia adotada no programa experimental desta série teve como princípio observar o comportamento da ligação duplo "T" simulando a flexibilidade da chapa de topo conectada à mesa do pilar e também as variações de tipologia que podem ser encontradas na região tracionada dessas ligações, como a perpendicularidade entre mesa da viga e alma do pilar, a presença de enrijecedores na alma do pilar e os efeitos de enrijecimento da chapa de topo pela alma da viga.

Dentro dessa série foram realizados 50 ensaios com 25 configurações diferentes de ligações, testadas aos pares e divididas em três grupos. $O$ primeiro grupo, denominado de TSC, é formado por perfis "T" com almas coplanares, sem enrijecimento, simulando a região da chapa de topo na altura da mesa tracionada da viga, com variações da espessura da mesa e do diâmetro dos parafusos, a fim de se obter diferentes modos de falha.

O segundo grupo, denominado de TSI, é formado por perfis "T" dispostos com as almas perpendiculares para simular o posicionamento da mesa da viga com relação à alma do pilar nas ligações com chapa de topo.

O terceiro e último grupo, denominado de TSIE, utiliza a mesma configuração do grupo TSC, com a inclusão de enrijecimento em um dos lados no plano perpendicular à alma. Os grupos TSI e TSIE tiveram como objetivo fornecer dados para análises comparativas com o grupo TSC.

De maneira geral, a configuração da região tracionada da ligação com chapa de topo estendida foi tomada como base para a geometria dos perfis " $T$ " para representar adequadamente o trecho estendido da chapa de topo, sua simetria com relação à mesa da viga e os parafusos tracionados, conforme esquematizado na figura 4.2 . 


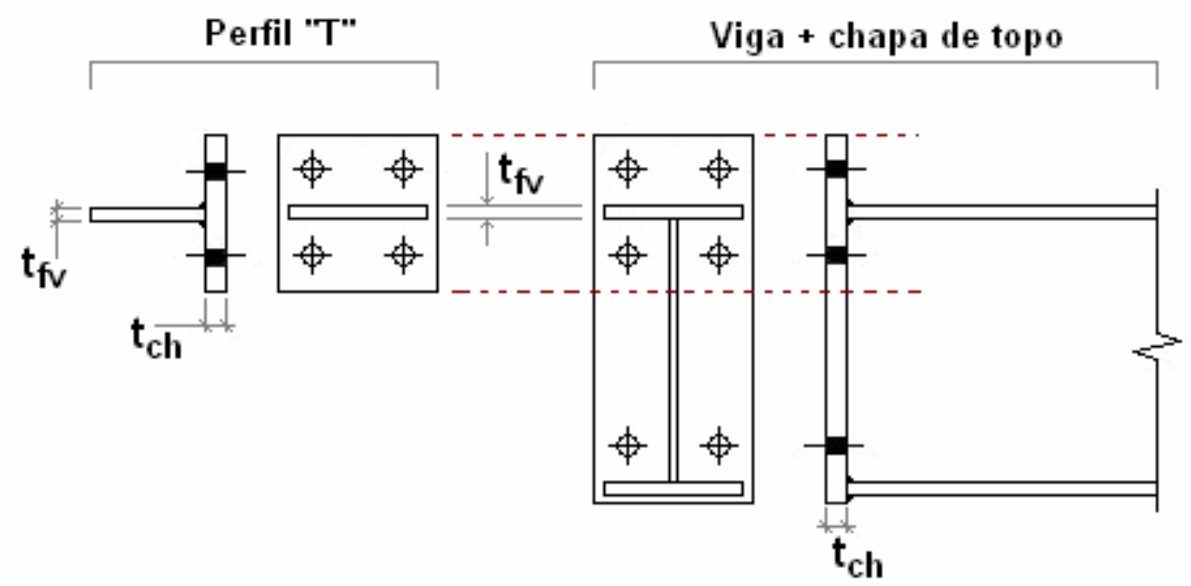

Figura 4.2 - Geometria esquemática dos perfis "T"

A metodologia de ensaio para as ligações duplo "T" e os detalhes de cada grupo estão apresentados nos próximos itens.

\subsubsection{Metodologia geral de ensaio}

Os ensaios com as ligações duplo "T" foram realizados em equipamento universal INSTRON, com capacidade nominal máxima de tração de $1200 \mathrm{kN}$. Todos os ensaios foram realizados com controle de deslocamento a uma velocidade constante de $\mathbf{0 , 0 5} \mathbf{m m} / \mathbf{s}$, o que se observou ser adequada para este ensaio.

Resumidamente, a seqüência de ensaio foi iniciada pela montagem da ligação pela união dos perfis "T" aos pares, seguindo as especificações de cada grupo. Após o posicionamento da ligação no atuador hidráulico as forças de protensão foram aplicadas com a ajuda de um torquímetro, seguindo-se as recomendações da NBR 8800 (1986). Após a aplicação da protensão a instrumentação foi posicionada, iniciando-se o ensaio até o colapso da ligação.

A figura 4.3 apresenta um protótipo do grupo TSC preparado para o início do ensaio. 


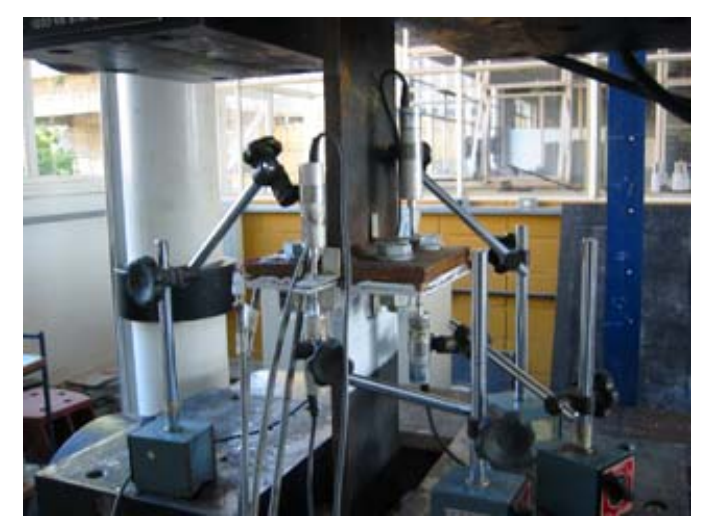

Figura 4.3 - Instrumentação em um protótipo de ligação duplo "T"

\subsubsection{Grupo TSC}

Para o grupo TSC incluiu-se a variação tanto da espessura da mesa do perfil "T" quanto do diâmetro dos parafusos, a fim de se obter diferentes modos de falha. Dentro desse grupo foram realizados 22 ensaios com 11 protótipos diferentes, nos quais a espessura da mesa foi variada entre 12,5 e $25,0 \mathrm{~mm}$ e o diâmetro dos parafusos de 12,5 à $19,0 \mathrm{~mm}$. A geometria típica para um protótipo do grupo TSC pode ser visualizada na figura 4.4 e a descrição da geometria, na tabela 4.1 .
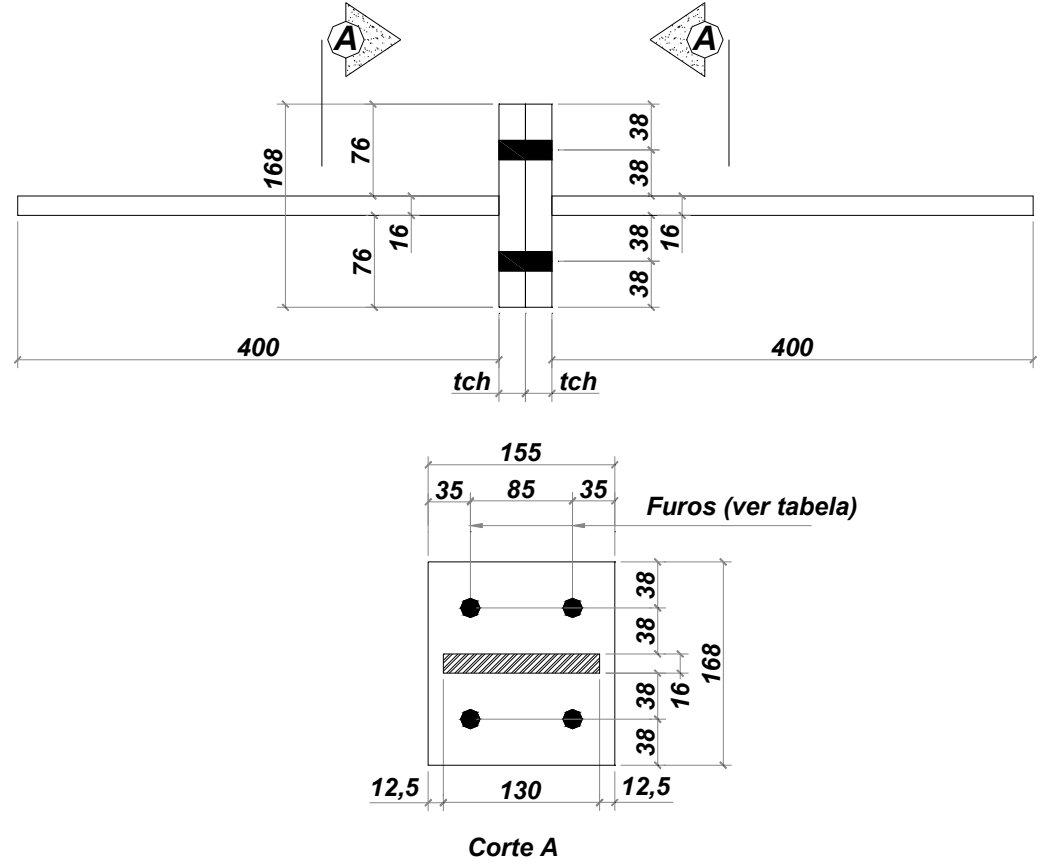

Figura 4.4 - Geometria do grupo TSC 
Tabela 4.1 - Configurações do grupo TSC

\begin{tabular}{|c|c|c|c|c|}
\hline \multicolumn{5}{|c|}{ Grupo TSC $(\mathbf{m m})$} \\
\hline Protótipo & $\mathbf{d}_{\mathbf{b}}$ & $\mathbf{d}_{\text {Furo }}$ & $\mathbf{t}_{\mathbf{c h}}$ & quant. \\
\hline TSC1 & 12,5 & 14,0 & 12,5 & 2 \\
\hline TSC2 & 12,5 & 14,0 & 16,0 & 2 \\
\hline TSC3 & 12,5 & 14,0 & 19,0 & 2 \\
\hline TSC4 & 16,0 & 18,0 & 12,5 & 2 \\
\hline TSC5 & 16,0 & 18,0 & 16,0 & 2 \\
\hline TSC6 & 16,0 & 18,0 & 19,0 & 2 \\
\hline TSC7 & 16,0 & 18,0 & 22,4 & 2 \\
\hline TSC8 & 19,0 & 21,0 & 16,0 & 2 \\
\hline TSC9 & 19,0 & 21,0 & 19,0 & 2 \\
\hline TSC10 & 19,0 & 21,0 & 22,4 & 2 \\
\hline TSC11 & 19,0 & 21,0 & 25,0 & 2 \\
\hline
\end{tabular}

\subsubsection{Ensaio piloto}

Um dos protótipos do par TSC5 foi utilizado para um ensaio piloto com o qual se procurou avaliar se os pontos escolhidos para verificação das deformações nas chapas eram adequados, assim como verificar a metodologia de fixação e protensão, velocidade de ensaio e, finalmente, avaliar a qualidade dos protótipos, principalmente quanto à simetria.

Dessa forma, foram utilizados extensômetros do tipo roseta nas mesas dos perfis "T" e extensômetros uniaxiais ${ }^{3}$ nas almas para a observação das deformações nestas chapas. Extensômetros também foram utilizados em um dos parafusos do protótipo TSC5-1 - o número 1 indica o primeiro par do protótipo TSC5 - para a calibração do torquímetro.

Neste ensaio não foram utilizados transdutores. Um esquema da instrumentação utilizada é apresentado na figura 4.5. O protótipo preparado para o início do ensaio pode ser visualizado na figura 4.6, na qual se observa a grande quantidade de pontos utilizados na coleta de dados.

\footnotetext{
${ }^{3}$ Ao longo do texto, os extensômetros do tipo roseta serão denominados simplesmente por "rosetas", ficando a denominação "extensômetros" aplicada aos extensômetros uniaxiais.
} 


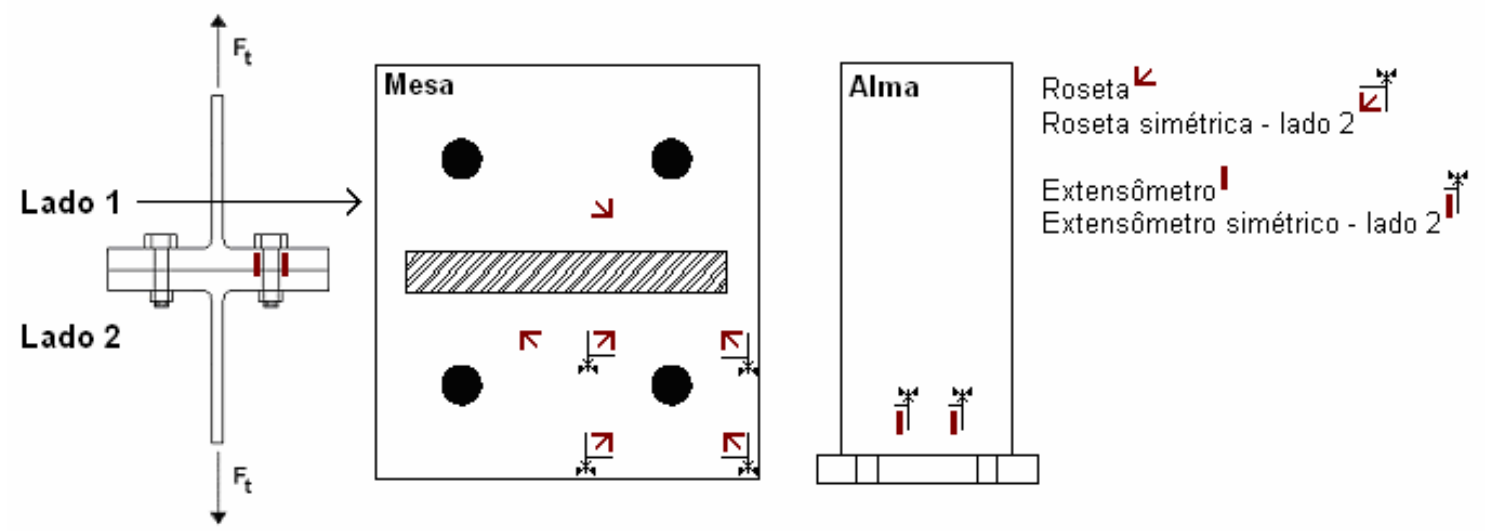

Figura 4.5 - Esquema da instrumentação do ensaio piloto - TSC5-1

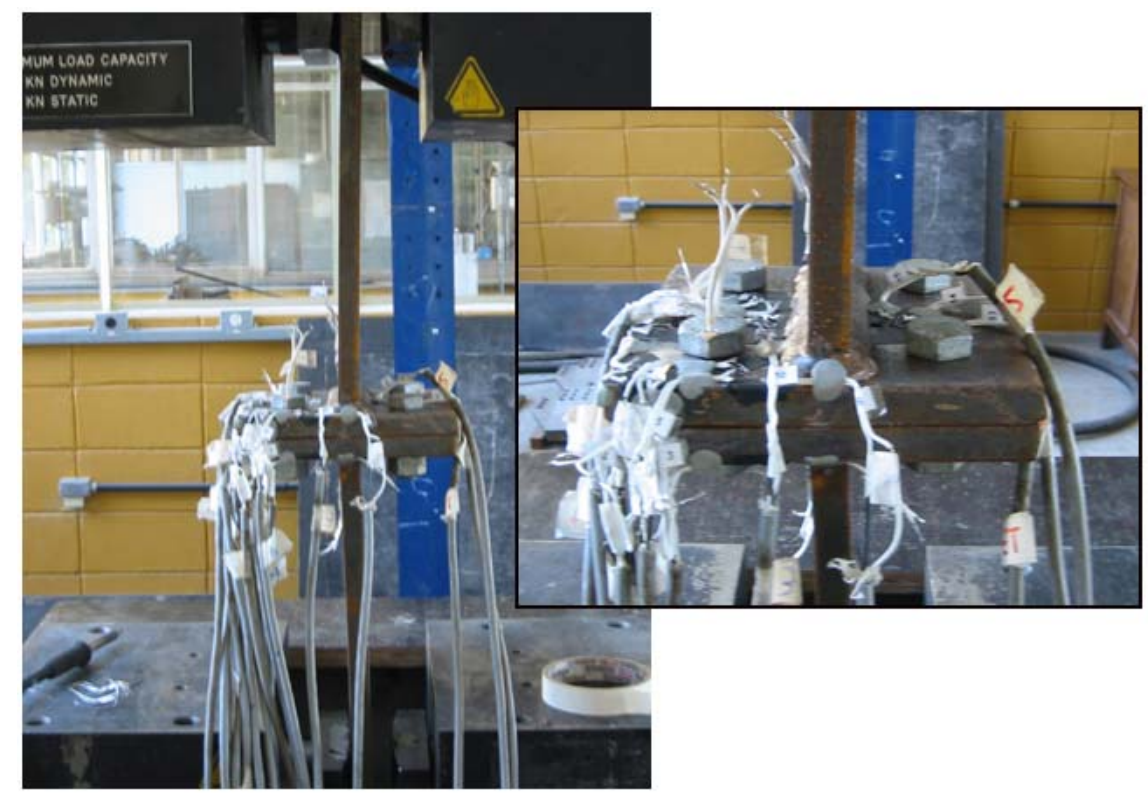

Figura 4.6 - Protótipo TSC5-1 preparado para o ensaio

De maneira geral, o comportamento do protótipo durante o ensaio foi o esperado, havendo uma abertura visível das mesas na intersecção mesaalma. No entanto, durante a fase de posicionamento do protótipo, observou-se uma falta de perpendicularidade entre a mesa e a alma que foi observada para todos os protótipos, em diferentes proporções.

Neste caso, descartou-se a possibilidade de se observar simetria para essa série de ensaios. A assimetria no protótipo TSC5-1 pode ser observada nas figuras 4.7 e 4.8, que apresentam as deformações nas direções perpendicular e paralela à alma, respectivamente, em função da força total aplicada à ligação, coletadas nas rosetas indicadas nos gráficos 
correspondentes. A denominação $(\mu \mathbf{e})$ refere-se às deformações multiplicadas por $10^{6}$.

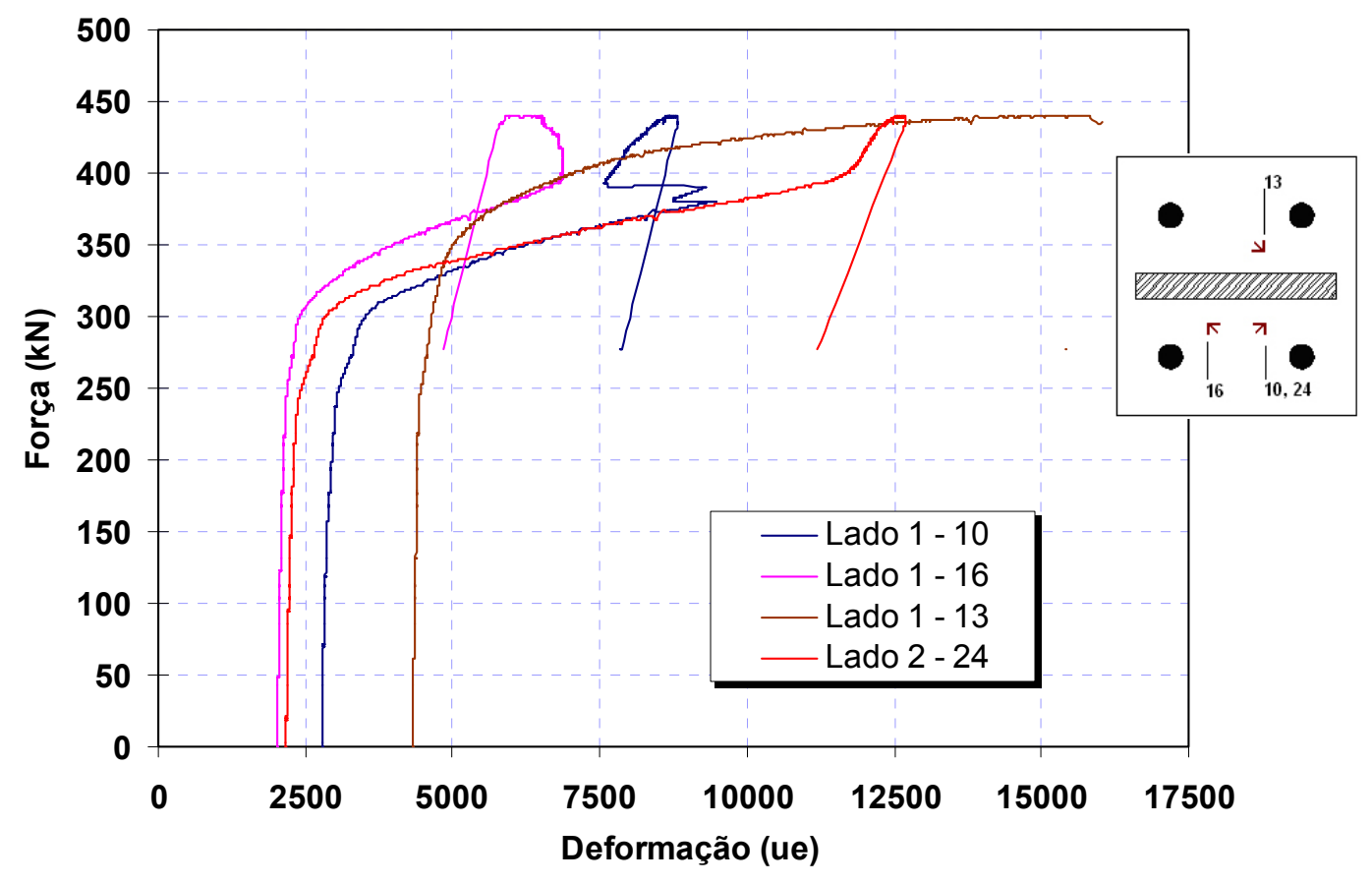

Figura 4.7 - Deformações na direção perpendicular à alma - TSC5-1

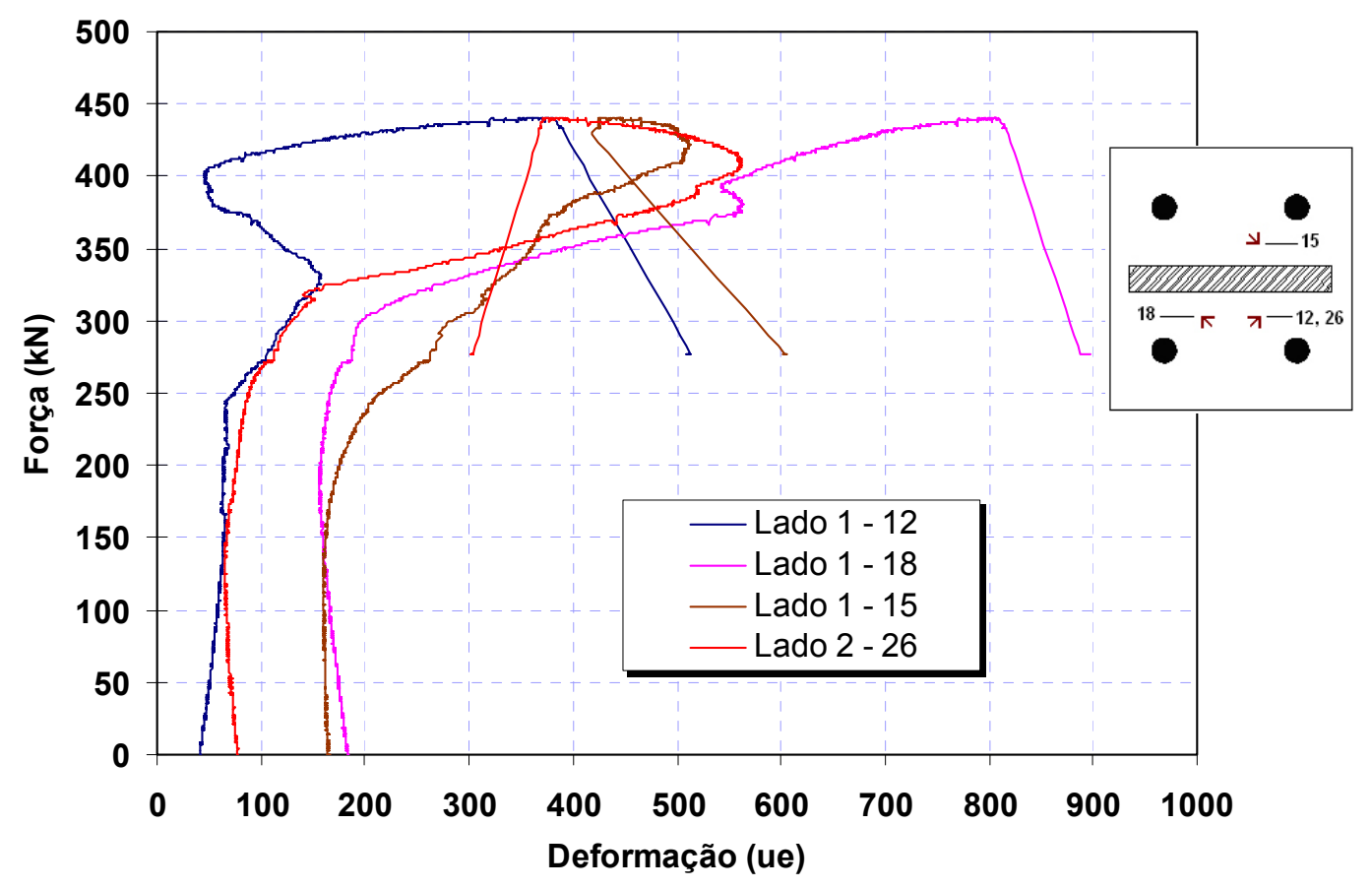

Figura 4.8 - Deformações na direção paralela à alma - TSC5-1 
Devido à falta de simetria e considerando que as comparações entre os resultados experimentais e numéricos é realizada por relações globais, como as curvas força-deslocamento, optou-se por simplificar a instrumentação.

A figura 4.9 apresenta as deformações principais obtidas nas rosetas 1, 2, 3 e 4. Observa-se claramente que as solicitações máximas ocorrem nas proximidades da intersecção mesa-alma (rosetas 2 e 4) e, segundo as figuras 4.7 e 4.8, na direção perpendicular à alma. Neste caso, optou-se por utilizar apenas dois extensômetros nas posições das rosetas 2 e 4, na direção perpendicular à alma, que serão utilizados como ponto de verificação das deformações na mesa e como indicativo da plastificação das mesas em torno dos furos.

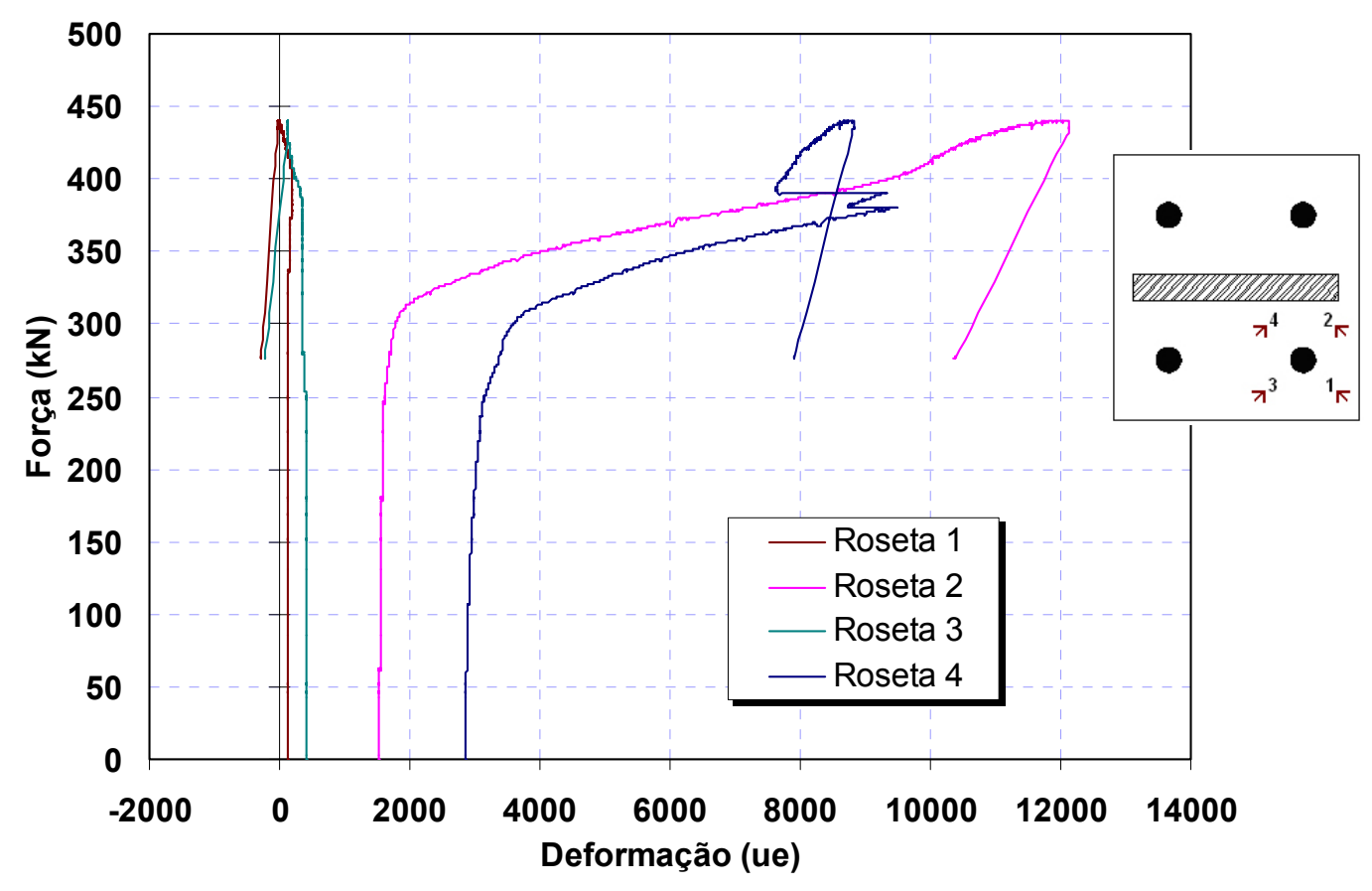

Figura 4.9 - Deformações máximas em torno dos furos - TSC5-1

\subsubsection{Detalhes da instrumentação}

De maneira geral, além dos extensômetros determinados pelo ensaio piloto, foram utilizados transdutores de deslocamento para obter 0 deslocamento relativo entre as mesas dos perfis "T". Foram utilizados 4 
transdutores, posicionados simetricamente em relação ao lado 1 e lado 2 das ligações (vide figura 4.5), 2 na borda das mesas e 2 na região central.

A figura 4.10 apresenta um detalhe da instrumentação no protótipo TSC5-2 como exemplo do posicionamento dos transdutores, utilizado como padrão para o grupo TSC.

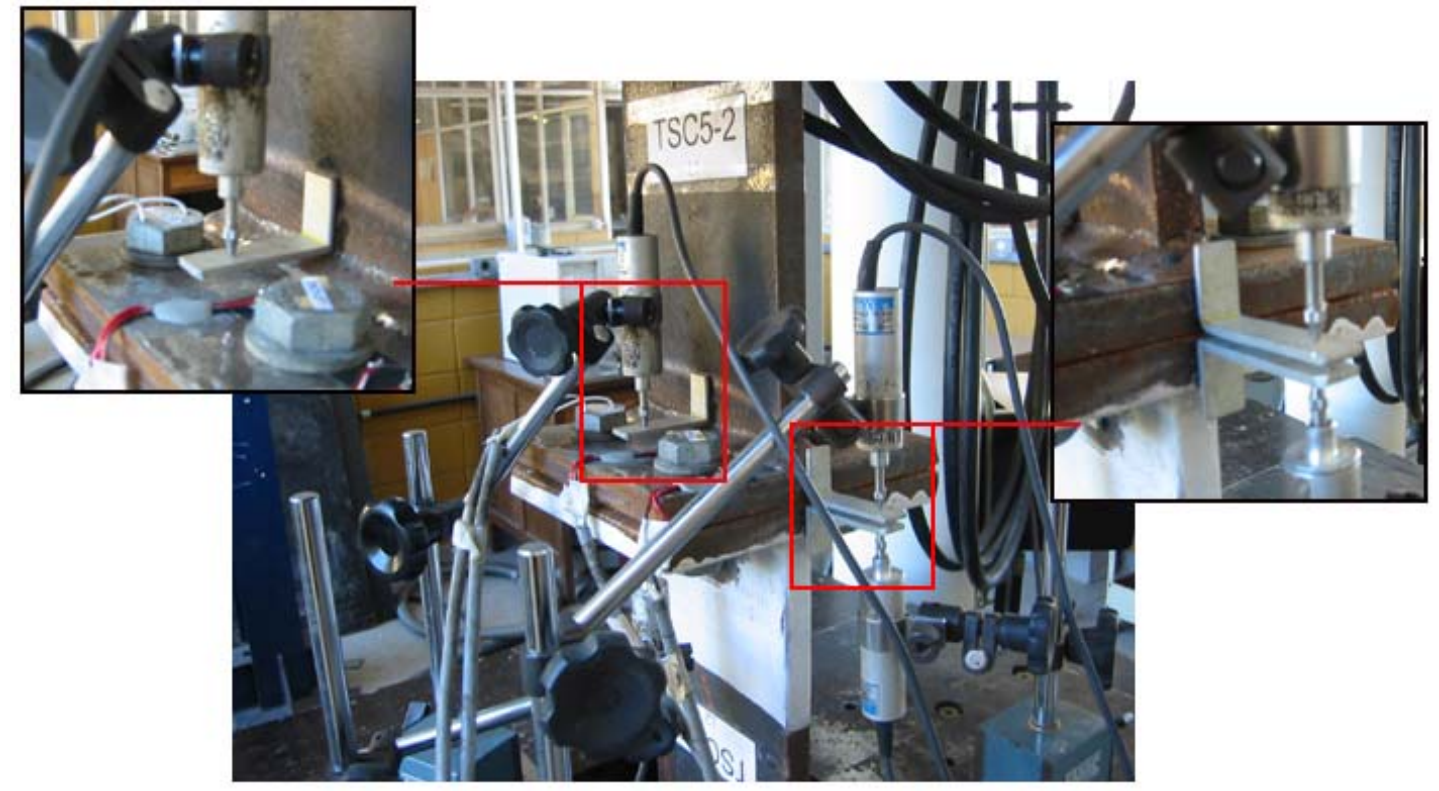

Figura 4.10 - Posicionamento padrão dos transdutores para o grupo TSC

\subsubsection{Grupos TSI e TSIE}

O grupo TSI, formado por perfis "T" com almas perpendiculares entre si, foi utilizado para simular a perpendicularidade entre a alma do pilar e a mesa tracionada da viga em uma ligação com chapa de topo, com o objetivo de fornecer dados sobre essa configuração para análises comparativas com o grupo TSC e para as análises paramétricas que serão realizadas no decorrer deste trabalho.

Além disso, foi imposta uma diferença de rigidez entre os dois lados da ligação com a utilização de mesas com diferentes espessuras. Com isso, simula-se a diferença de espessura entre a mesa do pilar e a chapa de topo, comumente encontrada nas ligações realizadas em edifícios, nas quais também é comum a utilização de pilares com mesas de menor espessura que 
a chapa de topo. Detalhes da geometria deste grupo podem ser visualizados na figura 4.11 e as configurações, na tabela 4.2, totalizando 16 protótipos.

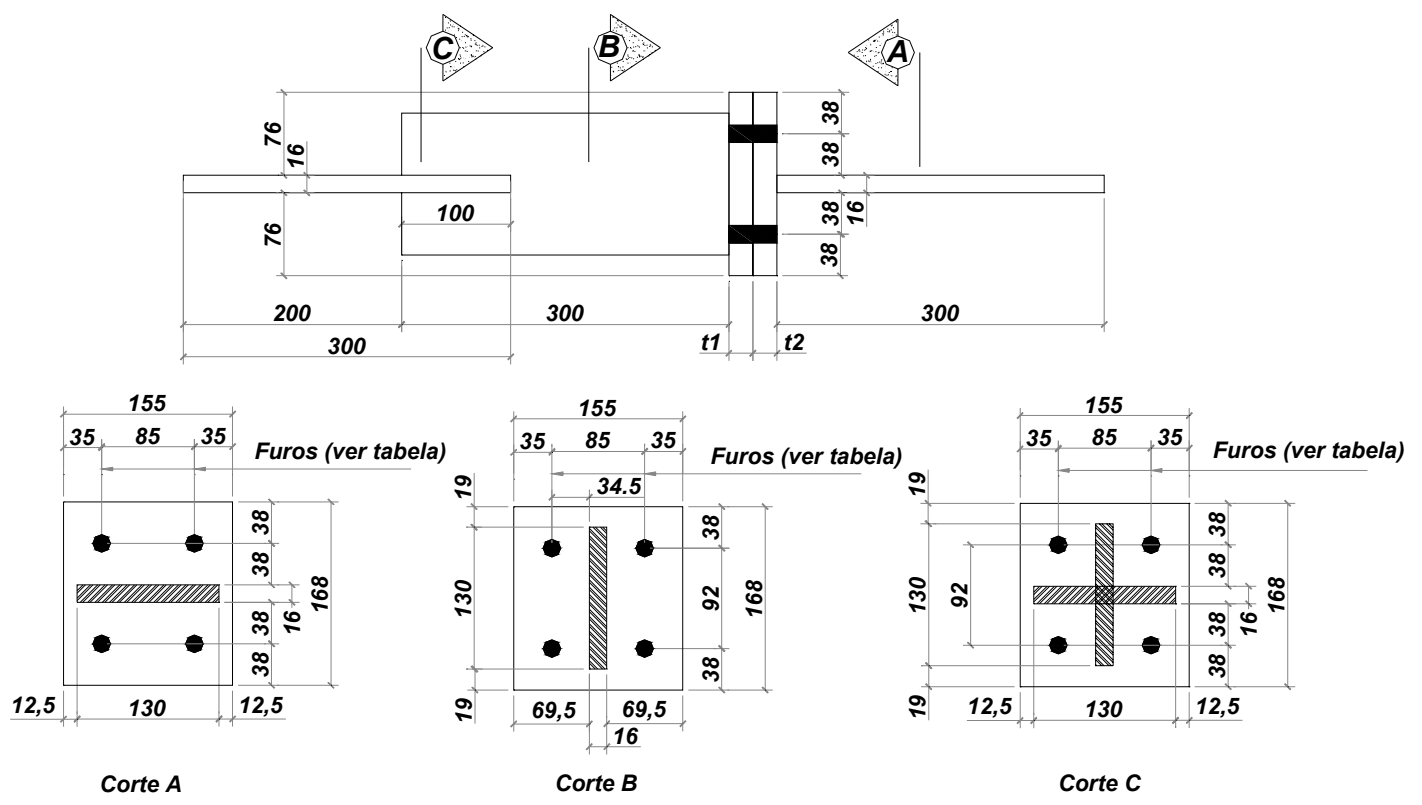

Figura 4.11 - Geometria do grupo TSI

Tabela 4.2 - Configurações do grupo TSI

\begin{tabular}{|c|c|c|c|c|c|}
\hline \multicolumn{7}{|c|}{ Grupo TSI (mm) } \\
\hline \multirow{2}{*}{ Protótipo } & \multirow{2}{*}{$\mathbf{d}_{\mathbf{b}}$} & $\mathbf{d}_{\text {Furo }}$ & \multicolumn{2}{|c|}{$\mathbf{t}_{\mathbf{c h}}$} & \multirow{2}{*}{ quant. } \\
\cline { 4 - 5 } & & & $\mathbf{t}_{\mathbf{1}}$ & $\mathbf{t}_{\mathbf{2}}$ & \\
\hline TSI1 & 16,0 & 18,0 & 12,5 & 19,0 & 2 \\
\hline TSI2 & 16,0 & 18,0 & 16,0 & 19,0 & 2 \\
\hline TSI3 & 16,0 & 18,0 & 19,0 & 19,0 & 2 \\
\hline TSI4 & 16,0 & 18,0 & 22,4 & 19,0 & 2 \\
\hline TSI5 & 19,0 & 21,0 & 16,0 & 22,4 & 2 \\
\hline TSI6 & 19,0 & 21,0 & 19,0 & 22,4 & 2 \\
\hline TSI7 & 19,0 & 21,0 & 22,4 & 22,4 & 2 \\
\hline TSI8 & 19,0 & 21,0 & 25,0 & 22,4 & 2 \\
\hline
\end{tabular}

A instrumentação no grupo TSI seguiu o mesmo padrão utilizado para o grupo TSC. Os transdutores posicionados nas bordas dos flanges, neste caso, não coletam dados do maior deslocamento relativo da extremidade, que ocorre na borda perpendicular. No entanto os dados dos transdutores centrais podem ser utilizados para futuras comparações.

A figura 4.12 apresenta o posicionamento do protótipo TSI6-1 para o início do ensaio, com detalhes da instrumentação. 

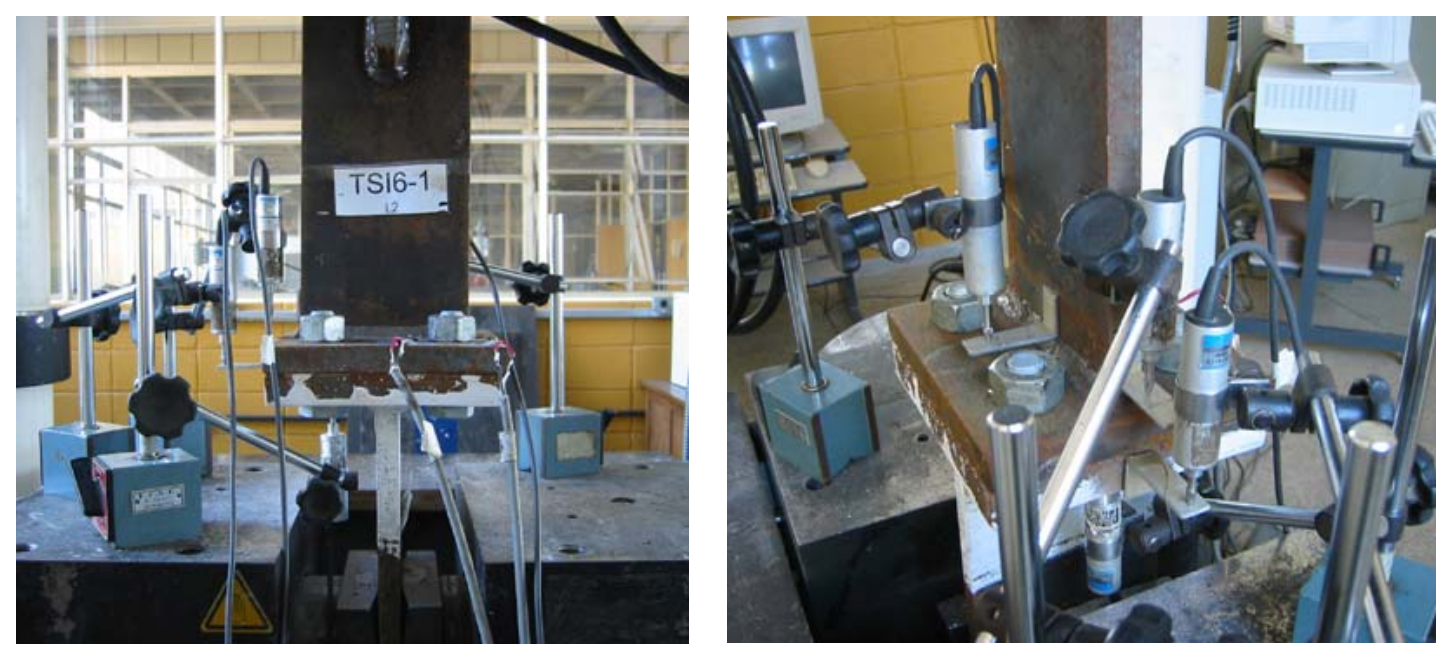

Figura 4.12 - Posicionamento e instrumentação nos protótipos do grupo TSI

O terceiro e último grupo, denominado de TSIE, utiliza a mesma configuração do grupo TSC, com a inclusão de enrijecimento em um dos lados no plano perpendicular à alma. Com este grupo foi possível observar a influência do enrijecimento, que pode ser representativo tanto para os enrijecedores da alma do pilar quanto para a alma da viga, fazendo-se a equivalência à ligação com chapa de topo. A geometria e configurações para esse grupo estão apresentadas, respectivamente, na figura 4.13 e na tabela 4.3.

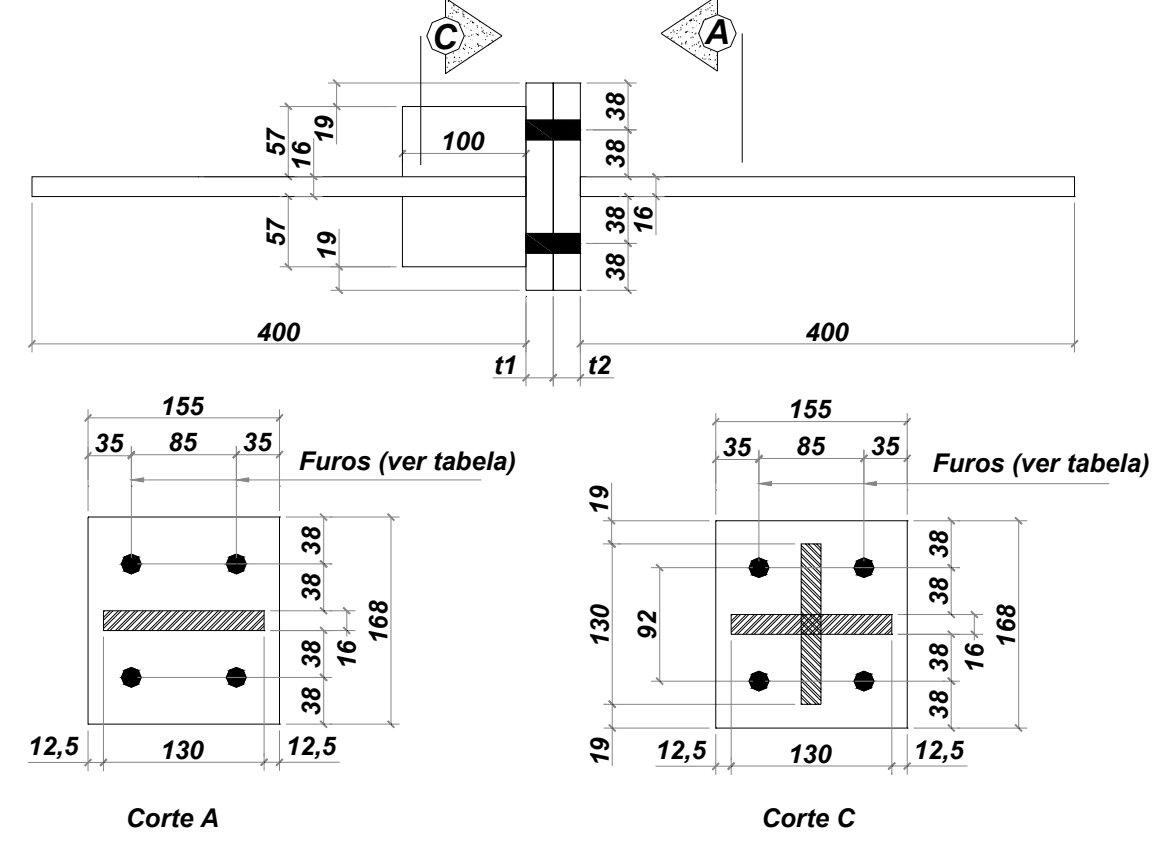

Figura 4.13 - Geometria do grupo TSIE 
Tabela 4.3 - Configurações do grupo TSIE

\begin{tabular}{|c|c|c|c|c|c|}
\hline \multicolumn{7}{|c|}{ Grupo TSIE (mm) } \\
\cline { 1 - 5 } Protótipo & \multirow{2}{*}{$\mathbf{d}_{\mathbf{b}}$} & \multirow{2}{*}{$\mathbf{d}_{\text {Furo }}$} & \multicolumn{2}{|c|}{$\mathbf{t}_{\mathbf{c h}}$} & \multirow{2}{*}{ quant. } \\
\cline { 4 - 5 } & & & $\mathbf{t}_{\mathbf{1}}$ & $\mathbf{t}_{\mathbf{2}}$ & \\
\hline TSIE1 & 16,0 & 18,0 & 16,0 & 16,0 & 2 \\
\hline TSIE2 & 16,0 & 18,0 & 16,0 & 19,0 & 2 \\
\hline TSIE3 & 19,0 & 21,0 & 16,0 & 22,4 & 2 \\
\hline TSIE4 & 19,0 & 21,0 & 19,0 & 19,0 & 2 \\
\hline TSIE5 & 19,0 & 21,0 & 19,0 & 22,4 & 2 \\
\hline TSIE6 & 19,0 & 21,0 & 19,0 & 25,0 & 2 \\
\hline
\end{tabular}

Uma visão geral do protótipo TSIE3-1 com a instrumentação é apresentada na figura 4.14 .

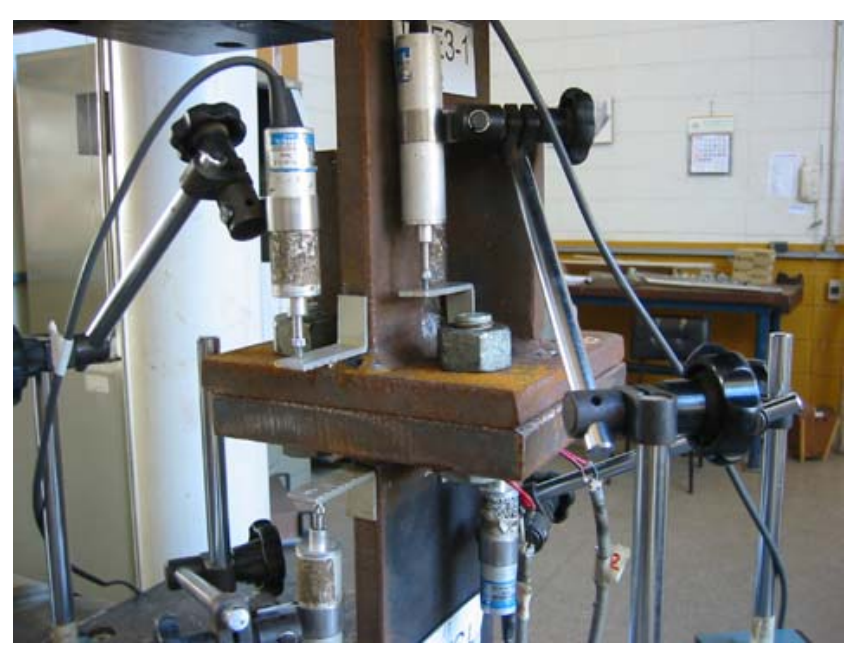

Figura 4.14 - Instrumentação dos protótipos do grupo TSIE

\subsection{LIGAÇÕES COM CHAPA DE TOPO ESTENDIDA}

Em todos os protótipos de ligações com chapa de topo foram utilizadas vigas do tipo VS 250x37, soldadas a chapas de extremidade e conectadas a um pilar do tipo CVS $300 \times 70$ por meio de parafusos de alta resistência, ASTM-A325, de $16,0 \mathrm{~mm}$ de diâmetro, formando a configuração cruciforme esquematizada na figura 4.15.

A configuração cruciforme permite o ensaio simultâneo de um par de ligações com a aplicação do carregamento sobre o pilar, simulando o carregamento nas vigas por meio de aparelhos de apoio. Essa configuração também foi utilizada por Ribeiro (1998), com vigas de mesmo perfil, e 
considerando os resultados obtidos pelo autor observa-se que, para as espessuras de chapa de topo e diâmetros de parafusos escolhidos, obtém-se o colapso dos parafusos como estado limite último. Todos os protótipos tiveram o pilar enrijecido na alma, nas faces internas das mesas e na altura das mesas da viga. Vale a pena ressaltar que, em função da configuração cruciforme, a mesa tracionada da viga é posicionada na região inferior, ficando invertida também a extensão da chapa de topo.

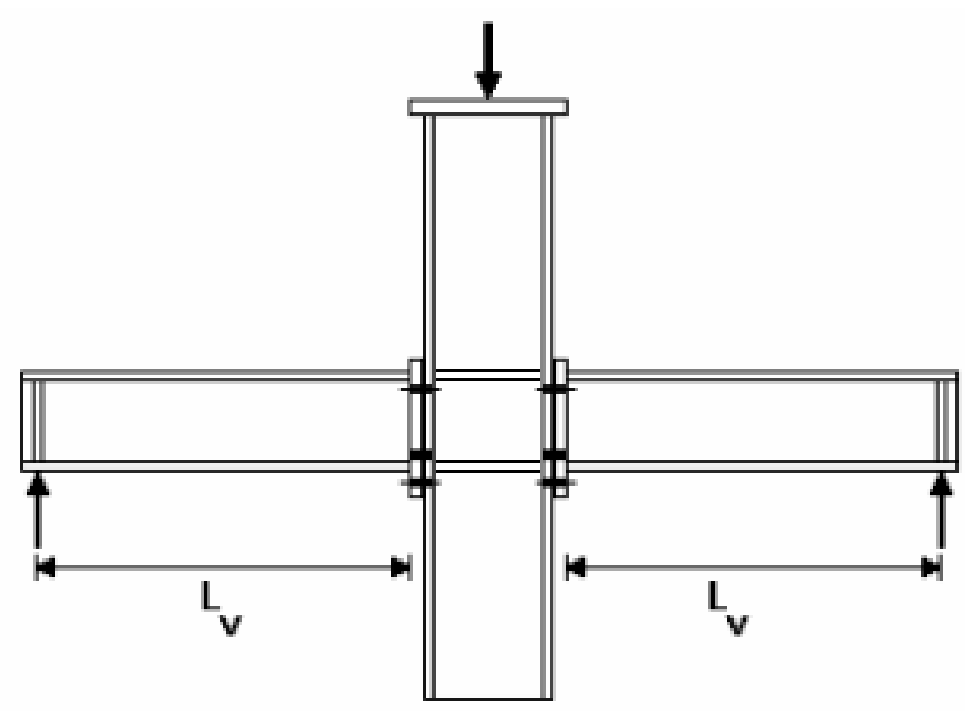

Figura 4.15 - Representação esquemática dos protótipos cruciformes

As ligações com chapa de topo formaram apenas um grupo, denominado de CTEE, que consistiu de 6 protótipos ensaiados aos pares com a variação da geometria da chapa de topo, com espessuras de 16,0, 19,0 e 25,0 $\mathrm{mm}$. Na tabela 4.4 apresentam-se as denominações dos protótipos e os modos de falha calculados segundo o Eurocode 3 (1993) na verificação da chapa de topo à flexão.

Tabela 4.4 - Configurações do grupo CTEE e modos de falha

\begin{tabular}{|c|c|c|c|c|c|}
\hline \multirow{2}{*}{ Protótipo } & \multirow{2}{*}{$\begin{array}{c}\mathbf{t}_{\mathrm{ch}} \\
\mathbf{( m m})\end{array}$} & \multicolumn{2}{|c|}{ Linha 1 (externa) } & \multicolumn{2}{c|}{ Linha 2 (interna) } \\
\cline { 3 - 6 } & $\mathbf{F}_{\mathbf{p}} \mathbf{( k N )}$ & Modo & $\mathbf{F}_{\mathbf{p}}(\mathbf{k N})$ & Modo \\
\hline CTEE1 & 16,0 & 116,39 & 2 & 181,00 & 3 \\
\hline CTEE2 & 19,0 & 131,36 & 2 & 181,00 & 3 \\
\hline CTEE3 & 25,0 & 169,00 & 2 & 181,00 & 3 \\
\hline
\end{tabular}


Há um interesse particular de se verificar o comportamento da ligação para o modo de falha 2, no qual há interação entre chapa de topo e parafusos na caracterização do colapso, e para o modo de falha 1 , caracterizado pela plastificação da chapa de topo na região dos furos. Para este último, deveriam ser adotadas espessuras menores para a chapa de topo, o que, em termos práticos, não é coerente para o conjunto chapa de topo e pilar. No entanto, para a chapa de topo de $16,0 \mathrm{~mm}$, a capacidade resistente calculada para o modo 2 é suficientemente próxima a do modo 1 para as observações experimentais propostas.

As dimensões em planta da chapa de topo estendida dependem do diâmetro dos parafusos $\left(\mathbf{d}_{\mathbf{b}}\right)$ mantendo, segundo as recomendações da NBR 8800 (1986), distâncias mínimas de $\mathbf{2} \mathbf{d}_{\mathbf{b}}$ entre os furos e as extremidades da chapa de topo e entre os furos e a face da mesa da viga, e de $\mathbf{3} \mathbf{d}_{\mathbf{b}}$ entre centros de furos. Assim, um esquema das dimensões adotadas para as chapas de topo nos protótipos, considerando-se parafusos de $16,0 \mathrm{~mm}$, é apresentado na figura 4.16 .

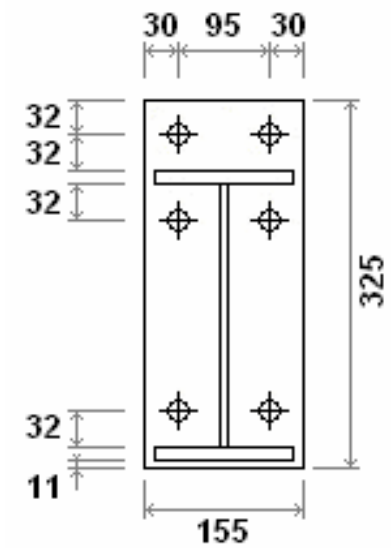

Chapa de topo para parafusos de $16,0 \mathrm{~mm}$
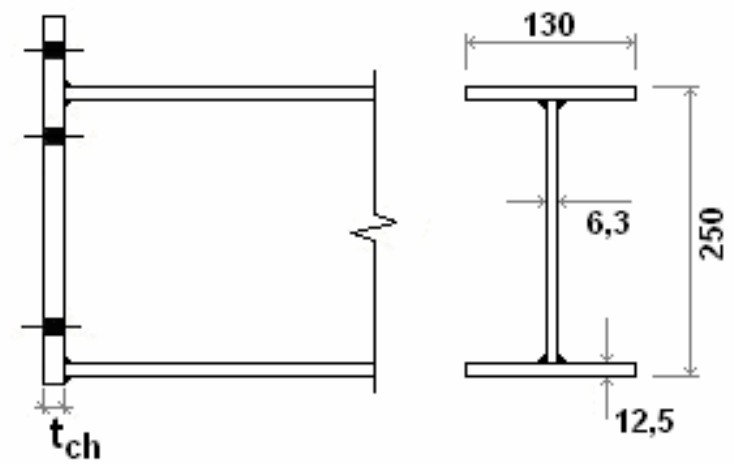

Viga VS $250 \times 37$

Figura 4.16 - Gabarito da chapa de topo para parafusos de $16,0 \mathrm{~mm}$

Quanto ao dimensionamento dos protótipos, vale ressaltar que foi utilizada a mesma configuração dos protótipos ensaiados por Ribeiro (1998), com o cuidado de se verificar a seção transversal do pilar e a contribuição dos enrijecedores na alma do mesmo, já que foram utilizados no programa 
experimental deste trabalho pilares do tipo CVS 300x70, menos rígidos que os pilares CVS 350x105 utilizados pelo autor.

Além disso, a chapa de topo de cada protótipo foi verificada à flexão segundo a metodologia proposta pelo Eurocode 3 (1993), observando-se que os modos de falha previstos pelo código europeu atendiam aos objetivos do programa experimental deste trabalho que são de simular diferentes modos de falha para futuras comparações com os resultados analíticos e numéricos.

As dimensões gerais dos protótipos CTEE podem ser visualizadas esquematicamente na figura 4.17 .

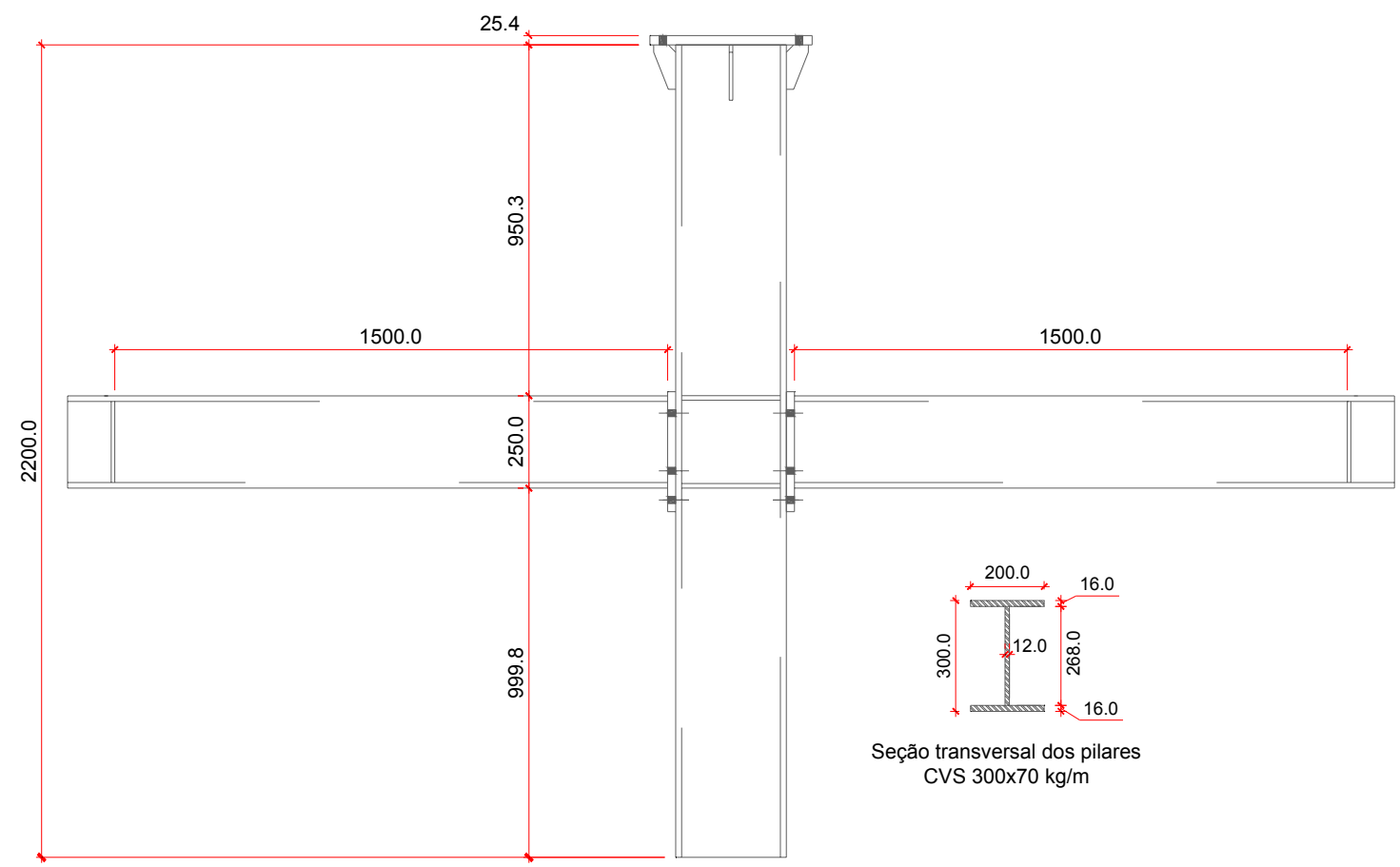

Figura 4.17 - Dimensões gerais dos protótipos CTEE

A seguir, são apresentados os detalhes referentes aos equipamentos utilizados, à instrumentação dos protótipos, sua montagem e a metodologia empregada na sistemática dos ensaios.

\subsubsection{Montagem dos protótipos e equipamentos utilizados}

Foi utilizado um pórtico de reação composto por dois pilares $P S$ $300 \times 83 \mathrm{~kg} / \mathrm{m}$ e uma viga $P S 450 \times 76 \mathrm{~kg} / \mathrm{m}$, enrijecida na região central, com um 
vão total de $\mathbf{0 , 9 5} \mathrm{m}$. A altura total do pórtico de reação é de $\mathbf{4 , 4} \mathrm{m}$, com uma altura disponível de $3,956 \mathrm{~m}$ até a superfície inferior da viga, onde foi posicionado um atuador hidráulico servo-controlado marca INSTRON, com capacidade para $\mathbf{5 0 0} \mathbf{~ k N}$. O pórtico de reação, para o vão e a altura líquida especificados acima, tem capacidade nominal de $\mathbf{3 5 0}$ kN. Esse conjunto vigapilares é fixado à laje de reação por meio de aparelhos de apoio soldados às bases dos pilares.

Alguns detalhes do pórtico de reação podem ser observados nas figuras 4.18(a) e 4.18(b) que ilustram, respectivamente, o apoio do pórtico fixado à laje de reação e o atuador posicionado na viga do pórtico de reação.

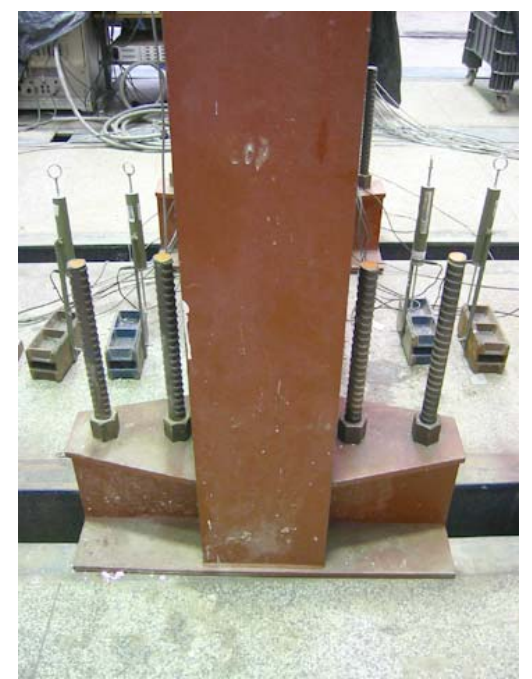

(a)

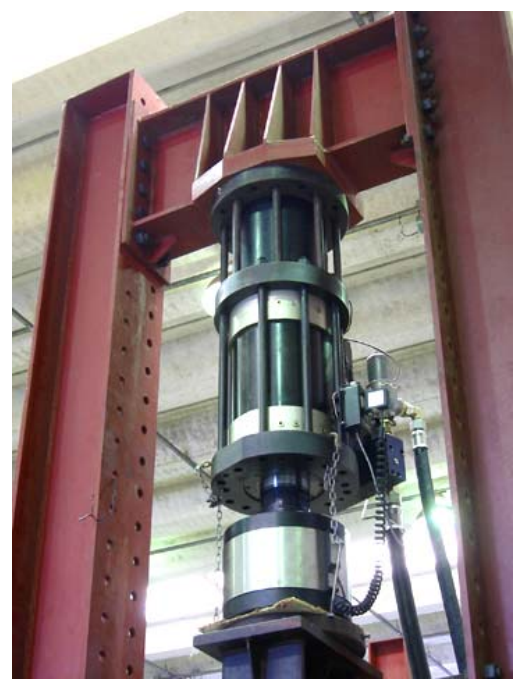

(b)

Figura 4.18 - Detalhes da fixação do pórtico e do posicionamento do atuador

Para o apoio da extremidade das vigas, foram utilizados dois pórticos menores fabricados no programa experimental de Ribeiro (1998), cujo posicionamento nos protótipos pode ser observado na figura 4.19.

Alguns detalhes do pórtico de apoio são ilustrados na figura 4.20(a), na qual se observam os consolos que, parafusados à mesa superior das vigas do apoio, foram concebidos para constituir um "vínculo de garfo"; e na figura 4.20(b) que apresenta o aparelho de apoio, constituído por chapas e um sólido cilíndrico, posicionados sob o enrijecedor de apoio com a finalidade de permitir a rotação livre da extremidade da viga. 


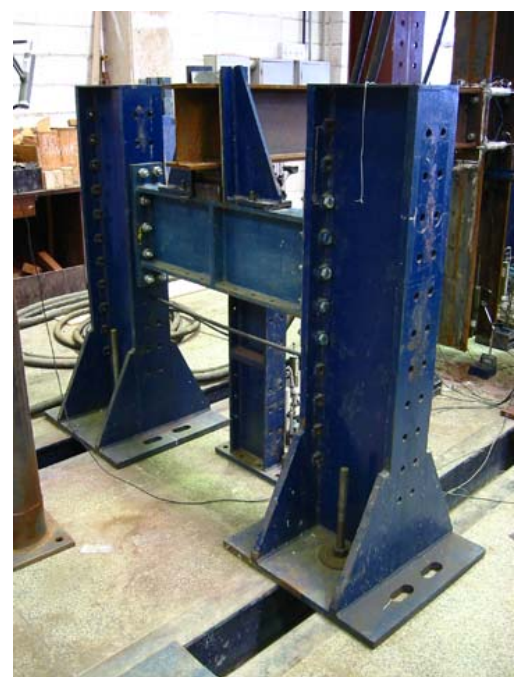

Figura 4.19 - Pórtico de apoio das vigas na montagem do protótipo

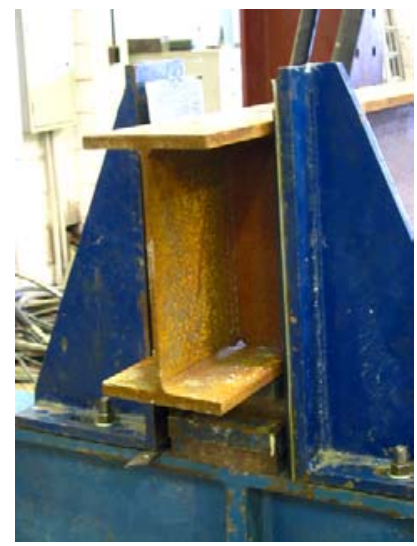

(a)

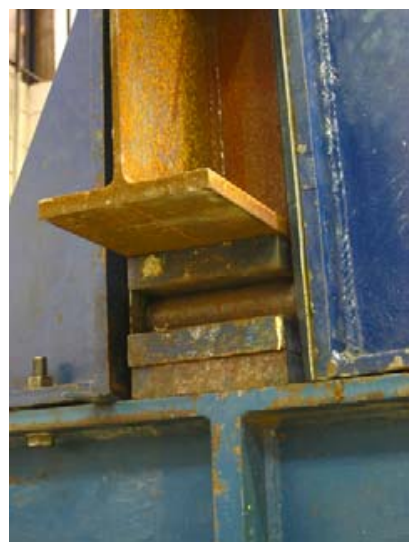

(b)

Figura 4.20 - Detalhes do consolo e do aparelho de apoio das vigas

$\mathrm{Na}$ figura 4.20 também se observa a existência de tiras de chapas finas, colocadas entre as extremidades laterais da viga e as faces do consolo. Estas chapas foram engraxadas e têm a finalidade de facilitar a rotação da viga junto ao consolo.

Finalmente, bastões metálicos parafusados foram fixados nos pilares do pórtico de reação e ajustados para alinhar o pilar no plano do pórtico, mantendo a sua verticalidade. A figura 4.21 indica um detalhe deste dispositivo, ressaltando-se que também foram utilizadas chapas finas engraxadas no contato entre os bastões e a alma do pilar. 

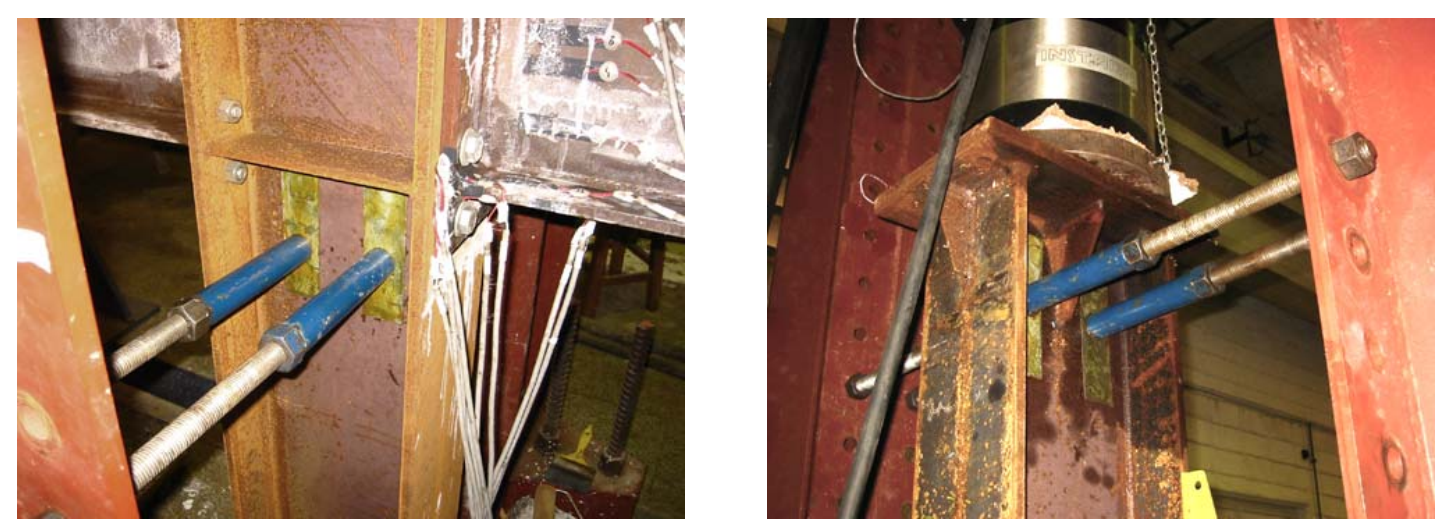

Figura 4.21 - Detalhes do travamento lateral do pilar

Apenas para ilustrar a configuração final da montagem dos protótipos, a figura 4.22 apresenta uma visão geral de um dos protótipos, na qual se visualizam os pórticos de reação e de apoio das vigas, o atuador hidráulico e a ligação viga-pilar do protótipo cruciforme. Enfatiza-se, ainda, que todos os protótipos deste grupo seguem a mesma configuração de montagem.

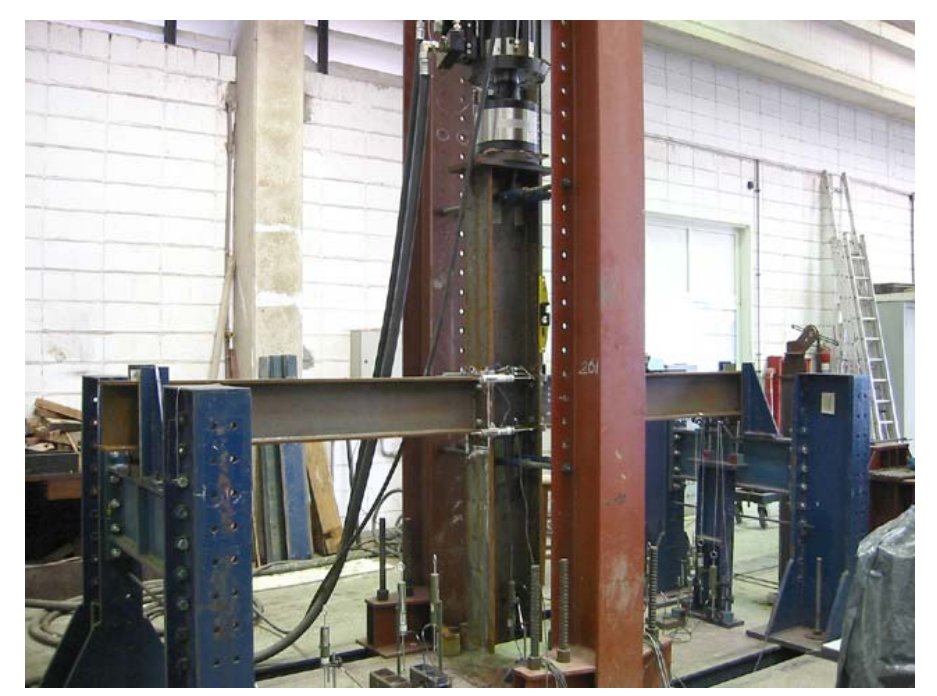

Figura 4.22 - Visão geral da montagem dos protótipos da série CTEE

\subsubsection{Instrumentação}

A instrumentação nos protótipos das ligações com chapa de topo estendida foi feita com base na obtenção dos seguintes resultados:

i. deformações nas mesas comprimida e tracionada das vigas, ao longo da largura, para observação das tensões nesta região; 
ii. deformações na alma das vigas, ao longo da altura, para observação da mudança de posição da linha neutra;

iii. deformações nas chapas de topo para acompanhamento da plastificação e controle das deformações para comparações com os resultados numéricos;

iv. deslocamentos horizontais da chapa de topo na altura da mesa tracionada da viga e também do pilar na altura dos enrijecedores para observação da abertura das chapas com relação ao pilar;

v. deslocamentos verticais do pilar e das vigas para observação da rotação e curvatura da viga, bem como da rigidez do conjunto vigapilar, por meio das curvas força-deslocamento; e

vi. rotação da viga nas proximidades da chapa de topo, por meio de inclinômetro.

A localização e respectiva numeração dos extensômetros, rosetas, transdutores de deslocamento e do inclinômetro estão esquematizadas, respectivamente, nas figuras 4.23 e 4.24, destacando-se a posição dos transdutores 26 e 28 cuja distância à chapa de topo foi variada de $\mathbf{2 0} \mathrm{mm}$ para $200 \mathrm{~mm}$ nas repetições de cada protótipo, conforme indicado nas figuras 4.24 e 4.25 .

A abertura relativa da chapa de topo e os deslocamentos verticais do pilar e ao longo da viga também foram utilizados para o cálculo da rotação da ligação. Chama-se a atenção para o fato de que as relações momento-rotação, utilizadas usualmente para definir a rigidez da ligação à flexão, podem ser obtidas considerando-se diversas definições de rotação.

Uma dessas definições leva em conta a abertura da chapa de topo na região tracionada, calculando-se a rotação da chapa de topo pela consideração de que o centro de rotação da mesma está localizado no plano médio da mesa comprimida da viga. Outra definição de rotação que pode ser considerada é calculada considerando-se os deslocamentos verticais relativos entre pontos, na viga ou na viga e pilar, próximos à região da ligação. 


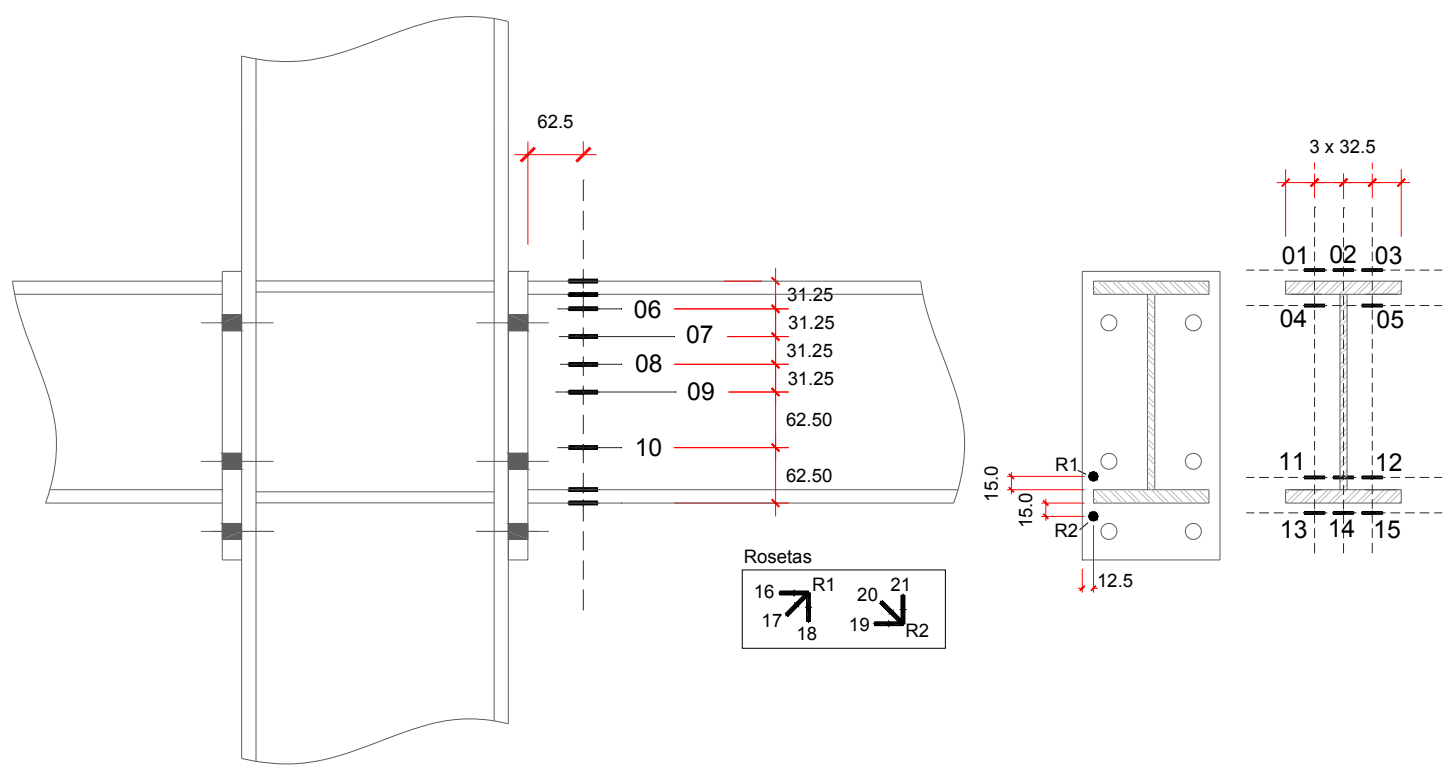

Figura 4.23 - Extensômetros na viga e rosetas na chapa de topo

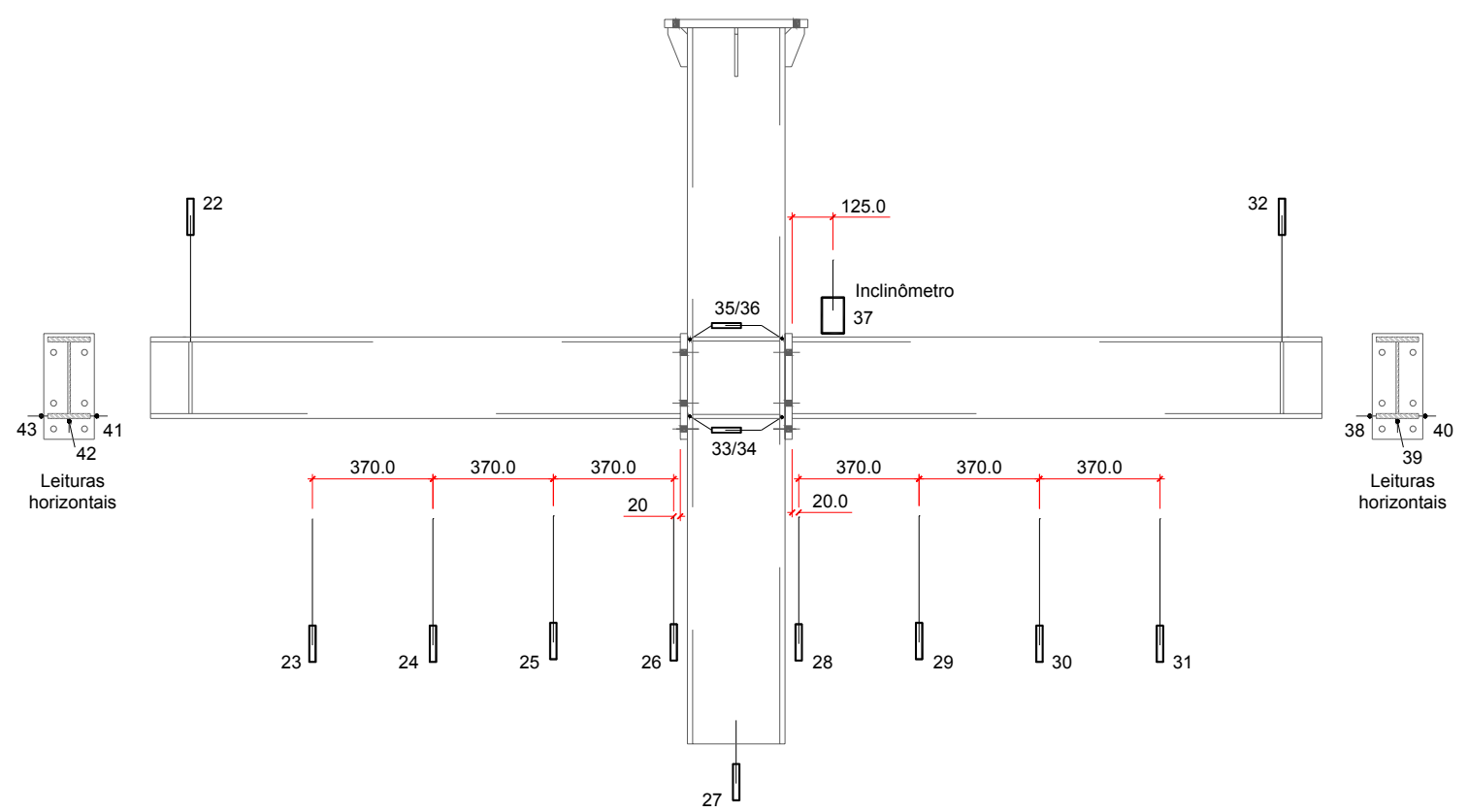

Figura 4.24 - Transdutores de deslocamento e inclinômetro nos protótipos com chapa de topo - primeiro protótipo de cada par

Esse aspecto em especial é justificativa para a mudança da posição dos transdutores 26 e 28 que, no primeiro sub-grupo - dentro do qual foram ensaiados os primeiros protótipos de cada par - foram colocados próximos à chapa de topo para verificar possíveis escorregamentos da ligação. A análise preliminar dos dados coletados pelos transdutores revelou que 0 escorregamento não ocorre para esses protótipos, permitindo o 
reposicionamento destes transdutores para as repetições de cada configuração. Nesta nova posição, os transdutores 26 e 28, juntamente com o transdutor 27, fornece os deslocamentos verticais relativos entre as vigas e o pilar para o cálculo da rotação da ligação na viga.

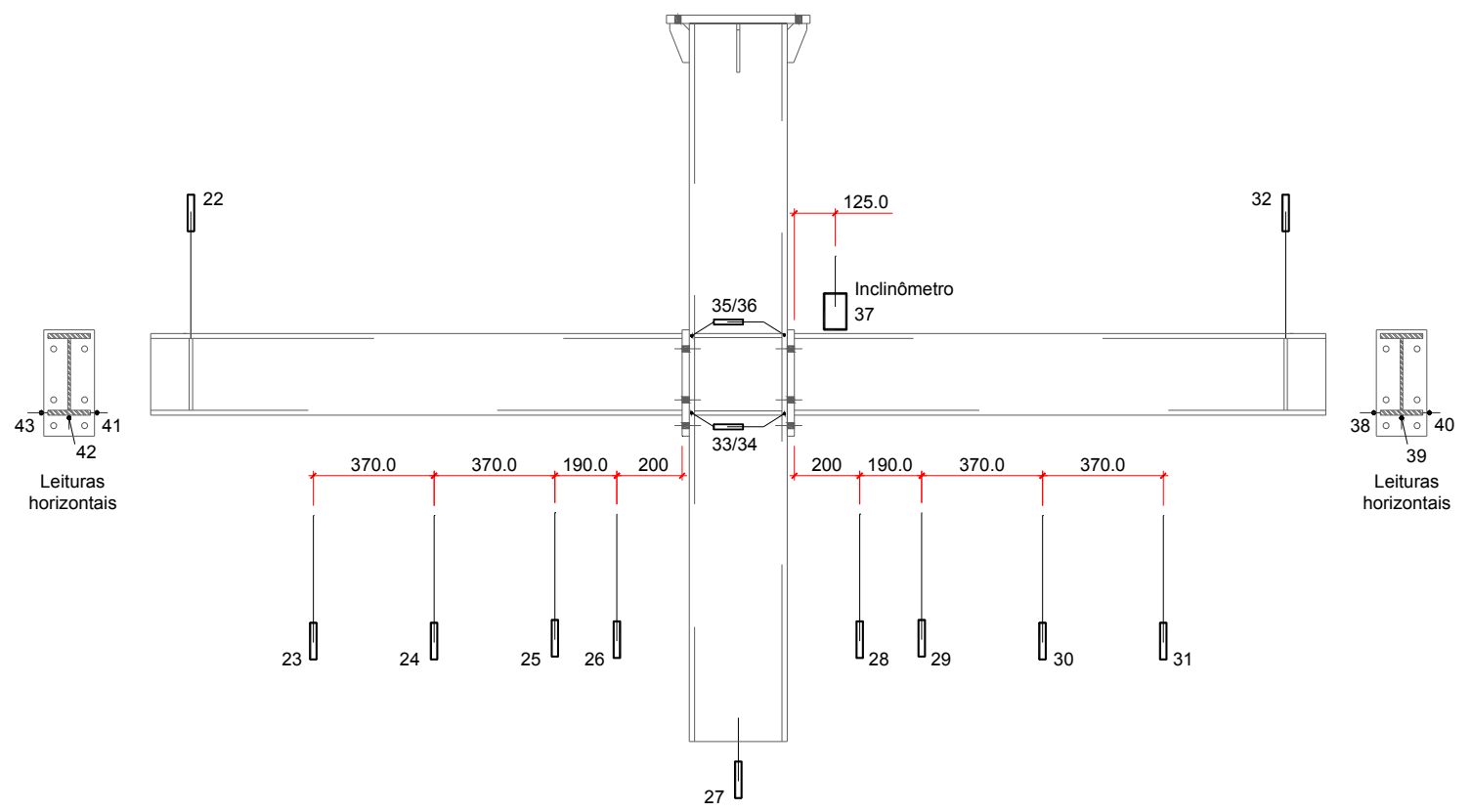

Figura 4.25 - Transdutores de deslocamento e inclinômetro nos protótipos com chapa de topo - repetições de cada par

Na seqüência, são apresentados alguns detalhes da instrumentação, iniciando-se pela ilustração, na figura 4.26, do posicionamento dos extensômetros e rosetas. Devido às repetições realizadas para cada geometria dos protótipos e à simetria esperada da configuração cruciforme, a colocação de extensômetros e rosetas foi realizada apenas em um dos lados do protótipo cruciforme.

A figura 4.27, por sua vez, permite a observação do posicionamento final da instrumentação nos protótipos, contendo todos os equipamentos utilizados na coleta de dados. Assim, pode-se visualizar a extensometria, os transdutores de deslocamento, o inclinômetro e todo o aparato utilizado para a fixação destes dispositivos, lembrando que essa configuração foi utilizada para todos os protótipos dessa série. Além disso, na figura 4.28 é possível visualizar, com mais detalhes, o posicionamento dos transdutores ao longo da 
viga e dos transdutores para leitura dos deslocamentos horizontais e verticais no pilar.
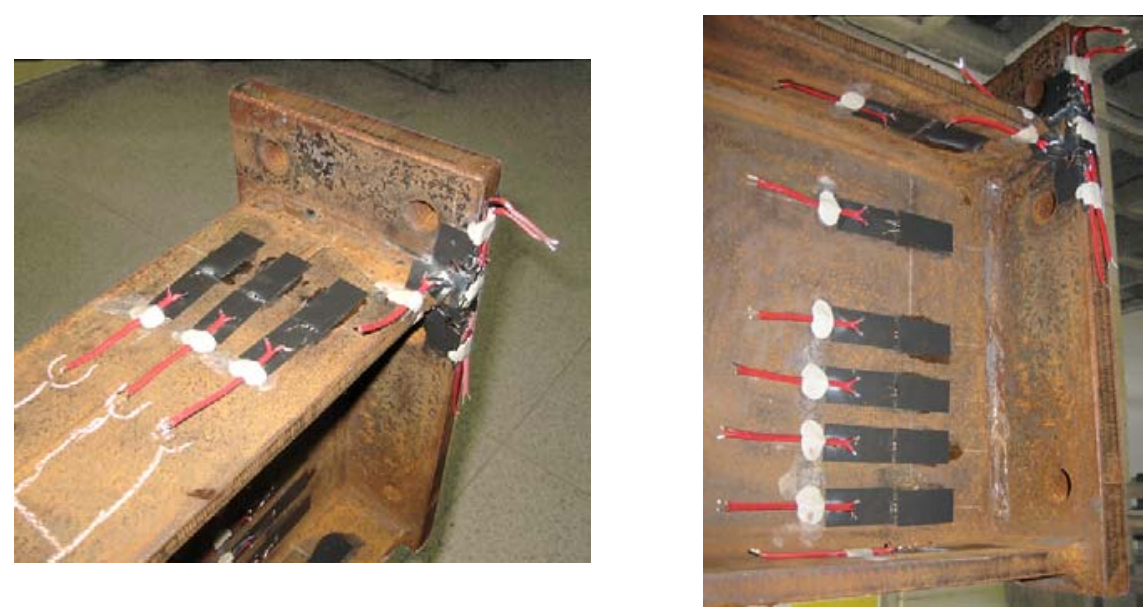

Figura 4.26 - Detalhes dos extensômetros e rosetas nos protótipos com chapa de topo

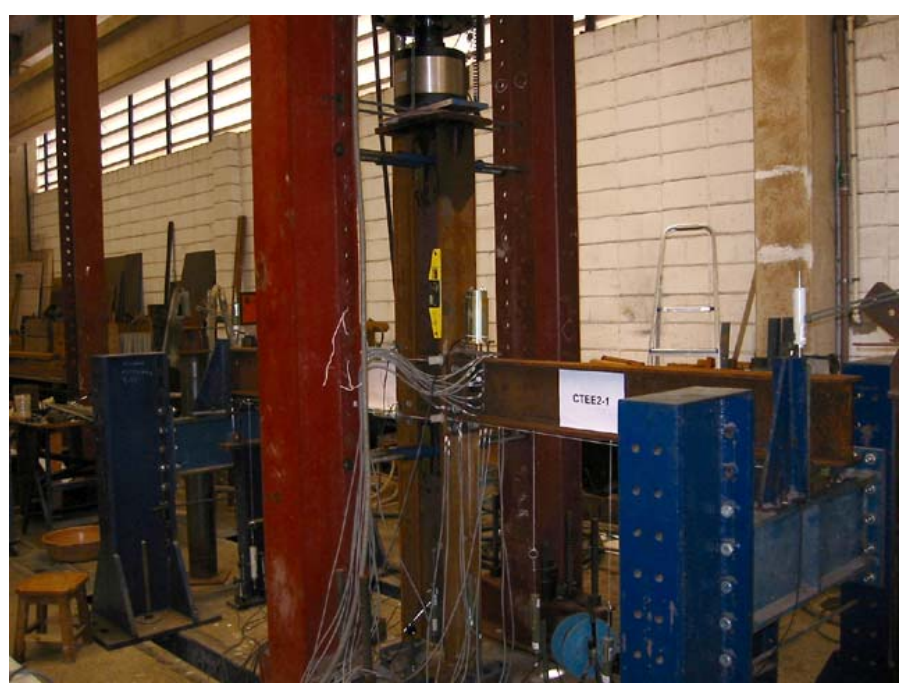

Figura 4.27 - Visão geral da instrumentação no protótipo CTEE2-1

Um detalhe importante a ser comentado refere-se à coleta dos deslocamentos horizontais da chapa de topo, realizada por meio dos transdutores 37 a 42. Ao contrário da metodologia empregada por Ribeiro (1998), que realizava a leitura destes deslocamentos por meio de um único transdutor posicionado entre as chapas de topo do protótipo cruciforme, os deslocamentos horizontais foram obtidos isoladamente para cada lado do protótipo, por meio de um mecanismo de transferência dos deslocamentos horizontais para deslocamentos verticais utilizando-se tirantes e bases magnéticas com pequenos parafusos, como indicado na figura 4.29. 


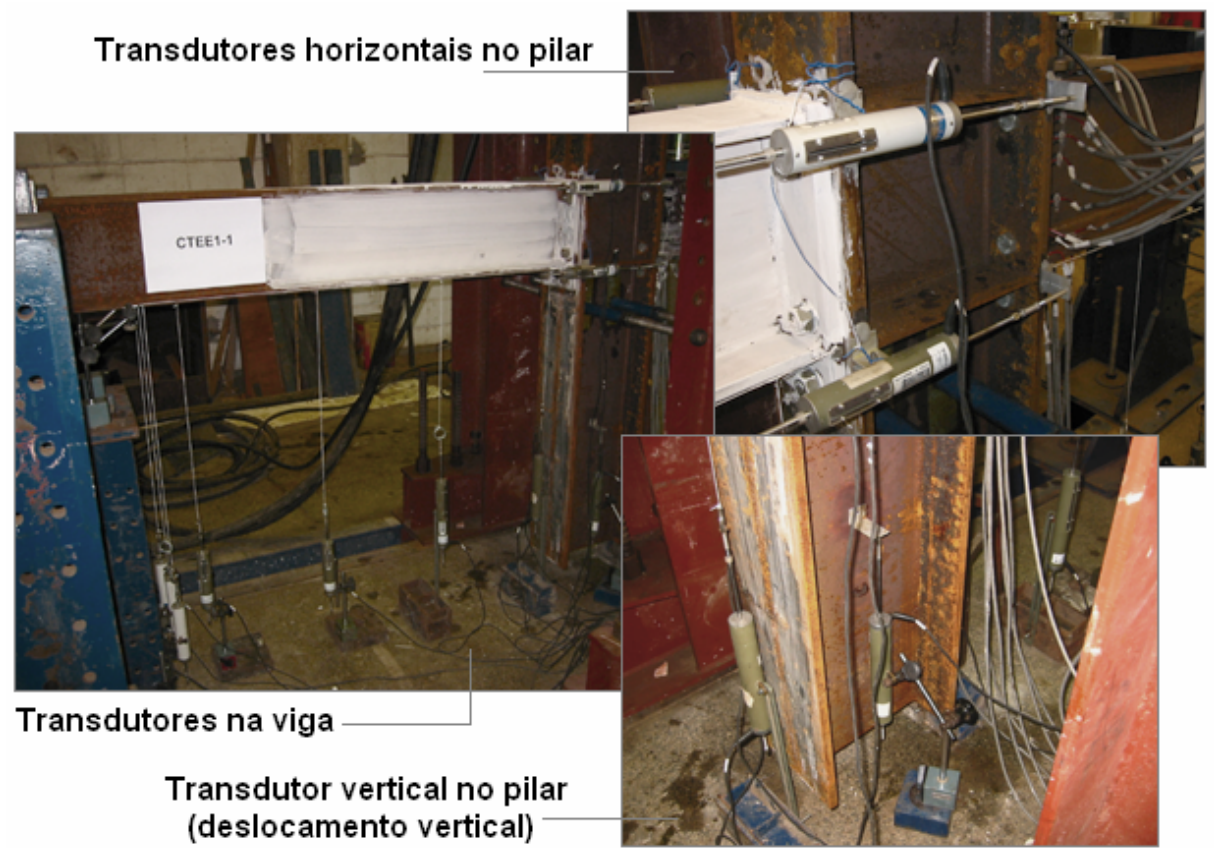

Figura 4.28 - Detalhes do posicionamento dos transdutores nas vigas e pilar
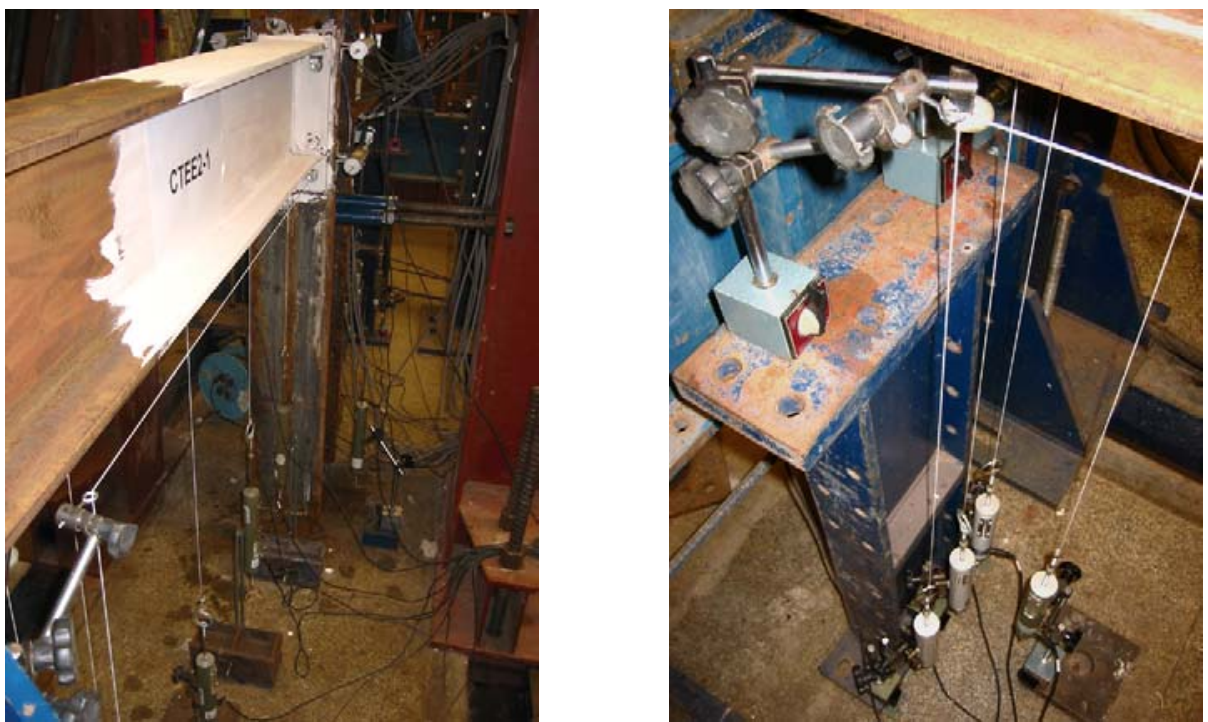

Figura 4.29 - Detalhes da transferência dos deslocamentos horizontais da chapa de topo para os transdutores verticais

A utilização de tirantes também foi utilizada para a leitura dos deslocamentos verticais pois permitem a minimização dos erros provocados pelo deslocamento horizontal das vigas. No caso dos deslocamentos horizontais da chapa de topo, a distância entre o ponto de leitura e os transdutores é necessária, já que seria impraticável posicionar os transdutores diretamente nas chapas. 


\subsubsection{Metodologia de ensaio das ligações com chapa de topo}

De maneira geral, o procedimento empregado nos ensaios das ligações com chapa de topo seguiu a seguinte seqüência:

i. Após posicionado cada protótipo, todos os pontos de leitura de dados foram conectados ao sistema de aquisição de dados, procedendo-se à calibração de transdutores, extensômetros e do inclinômetro, além do deslocamento do pistão e da célula de carga do atuador hidráulico. Todas as leituras foram zeradas para o início dos procedimentos;

ii. Com o atuador ainda recolhido, procedeu-se a protensão dos parafusos, conforme as recomendações na NBR 8800 (1986), com o auxílio de um torquímetro. Após a aplicação da protensão, foram efetuadas 5 leituras com o objetivo de registrar as deformações iniciais na chapa de topo e na viga devidas à protensão. Todas as leituras foram zeradas novamente, após o posicionamento do atuador para o início do ensaio;

iii. Na seqüência, iniciou-se o escorvamento do protótipo, fase na qual foi aplicada uma força total no protótipo de $10 \mathrm{kN}$, aproximadamente $6 \%$ da força total esperada de $170 \mathbf{k N}$, de acordo com a observação dos resultados experimentais obtidos por Ribeiro (1998). Essa fase teve como objetivo eliminar possíveis folgas, permitindo a acomodação do protótipo. O escorvamento foi feito com controle de deslocamento, a uma velocidade constante de $\mathbf{0 , 0 1} \mathrm{mm} / \mathrm{s}$, e 10 leituras foram realizadas nesta fase, 5 para a força total de 10 kN e mais 5 após a retirada do carregamento, mantendo o atuador posicionado para a continuação do ensaio. Após essas leituras, os instrumentos foram novamente calibrados e zerados;

iv. Finalmente, iniciou-se o carregamento do protótipo até o seu colapso, novamente com controle de deslocamento com velocidade constante de $\mathbf{0 , 0 1} \mathbf{m m} / \mathrm{s}$ e leituras da instrumentação efetuadas automaticamente a cada segundo. 
Como critérios para o colapso do protótipo foram adotados a ruptura dos parafusos de qualquer um dos lados da ligação ou deslocamentos excessivos do pilar, chapas de topo ou vigas que fossem julgados prejudiciais aos equipamentos utilizados e à segurança do ensaio. Para isso, o acompanhamento do ensaio foi feito por meio do equipamento de leitura, que permitia a visualização direta dos deslocamentos e deformações nos pontos de coleta de dados, além de inspeções visuais diretamente no protótipo.

De maneira geral, e antecipando observações gerais sobre os resultados experimentais, comprovou-se a manutenção da verticalidade do pilar e o colapso dos protótipos foi caracterizado, sem exceção, pela ruptura dos parafusos.

Apenas como ilustração, na figura 4.30 apresenta-se o protótipo CTEE1-1 durante o ensaio, já em estágios avançados de carregamento, no qual é possível observar visivelmente o deslocamento vertical do pilar, bem como a curvatura das vigas.

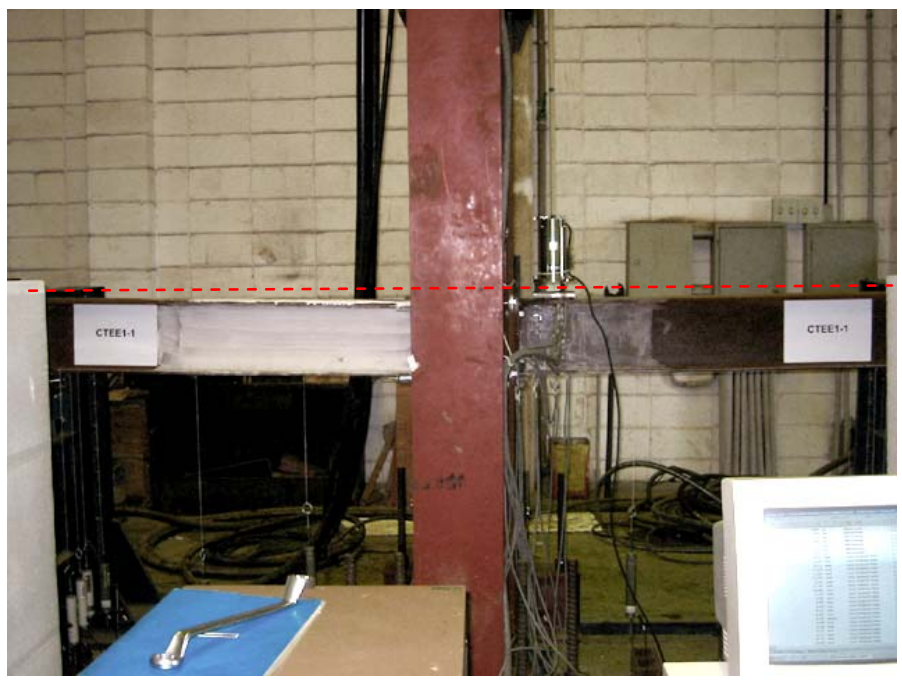

Figura 4.30 - Deformada do protótipo CTEE1-1 durante o ensaio

\subsection{CARACTERIZAÇÃO DOS MATERIAIS}

Os ensaios de caracterização foram realizados visando levantar dados das relações tensão-deformação dos materiais das chapas e da rigidez axial dos parafusos utilizados nos ensaios. Essa caracterização, em particular neste trabalho, tem o propósito específico de fornecer padrões para as curvas 
tensão-deformação do aço ASTM-A36 e dos parafusos ASTM-A325 para a aplicação na modelagem numérica, principalmente para as análises paramétricas. Por essa razão, a caracterização foi feita com número reduzido de corpos de prova.

\subsubsection{Chapas de aço}

Para a caracterização das chapas de aço, foram extraídos 8 corpos de prova em tiras da extremidade da alma do protótipo TSC1-1, cujas dimensões, esquematizadas na figura 4.31, seguem as especificações da norma americana ASTM E8M (1997). Os corpos de prova extraídos estão mostrados na figura 4.32 .

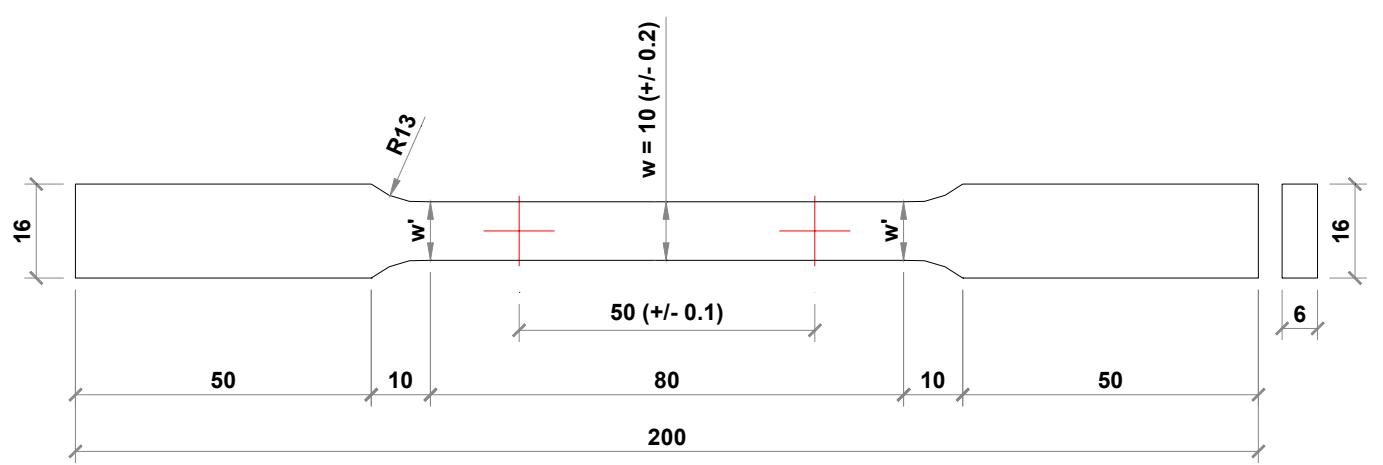

Figura 4.31 - Dimensões dos corpos de prova em tira - aço ASTM-A36

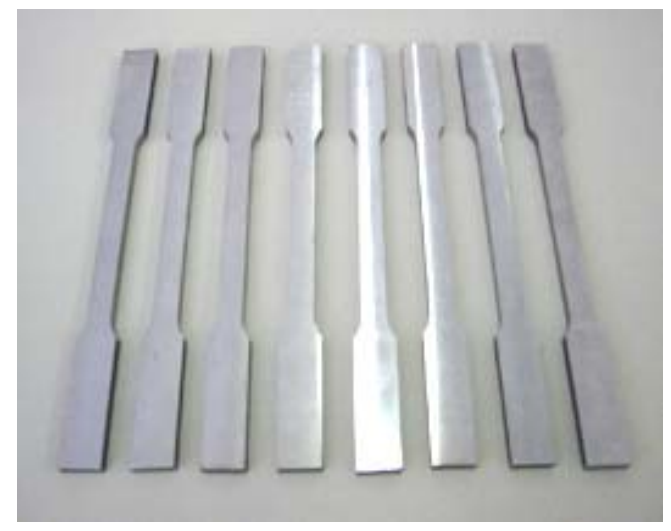

Figura 4.32 - Corpos de prova extraídos

Os ensaios foram realizados em atuador EMIC DL 10000, disponibilizado pelo Departamento de Materiais da Escola de Engenharia de 
São Carlos, com capacidade de 100 kN. Para a instrumentação, foi utilizado um extensômetro do tipo "clip-gage", marca EMIC, para leitura de deformações, conforme pode ser observado na figura 4.33, que apresenta um corpo de prova preparado para o início do ensaio.
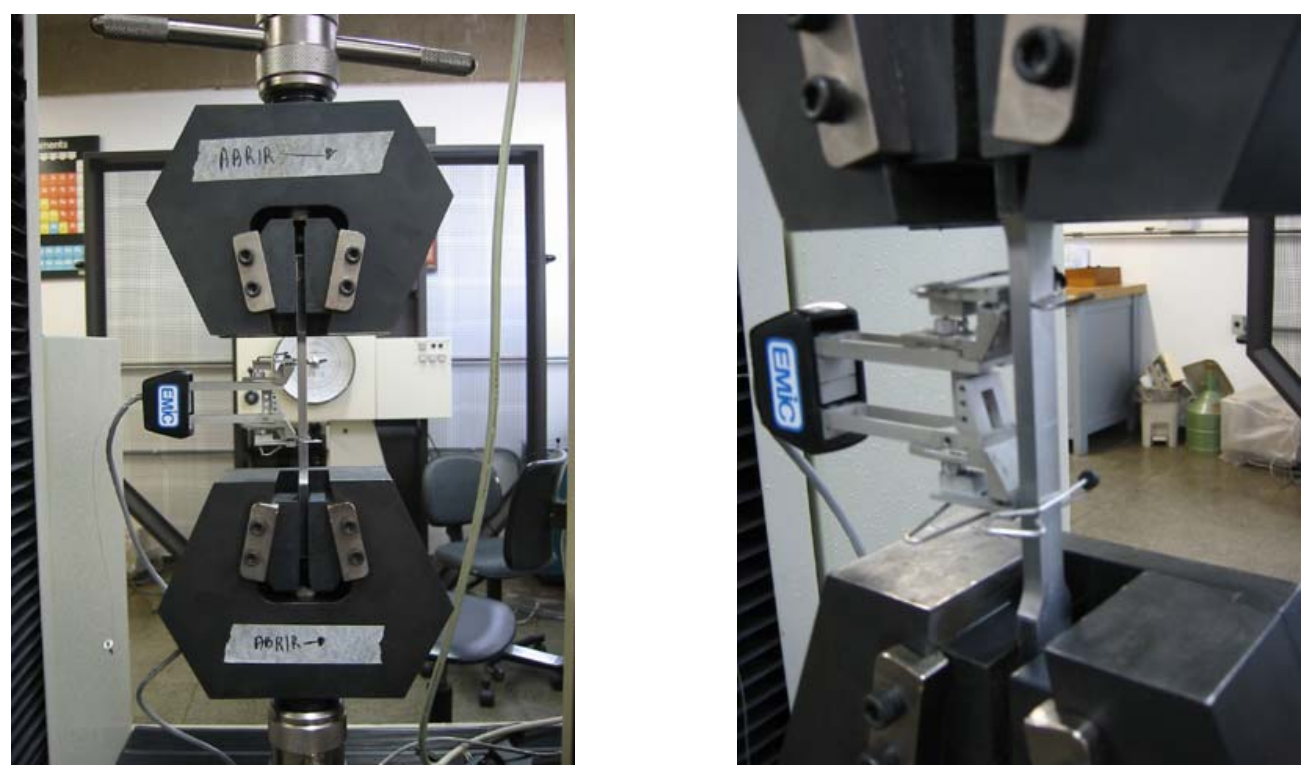

Figura 4.33 - Corpo de prova preparado para o início do ensaio

Foram ensaiados 4 corpos de prova, sendo que 1 foi reprovado devido a um escorregamento da garra do atuador durante o ensaio, realizado com controle de deslocamento seguindo as recomendações da ASTM E8M (1997), com velocidade inicial constante de $1 \mathrm{~mm} / \mathrm{min}$, aumentada para 6 $\mathrm{mm} / \mathrm{min}$ após o escoamento do material. As curvas tensão-deformação convencionais obtidas para os três corpos de prova válidos estão apresentadas na figura 4.34 .

As variações observadas nas curvas para os três corpos de prova foram consideradas pequenas e, considerando os corpos de prova CP-2 e CP4 como mais representativos, a tensão de escoamento convencional do material e a tensão máxima foram estabelecida em $f_{y}=296 \mathrm{MPa}$ e $\mathbf{f}_{\max }=\mathbf{5 0 0}$ MPa, respectivamente.

O módulo de elasticidade, computado no trecho inicial da fase elástica, foi obtido com valores de, aproximadamente, E = $207500 \mathrm{MPa}$. Como o extensômetro utilizado no ensaio tem um limite de deslocamento de $\mathbf{1 3 , 0}$ mm, a deformação total na ruptura não foi observada durante o ensaio, sendo 
que as curvas da figura 4.34 são limitadas à deformação de $\mathbf{0 , 2 6}$. No entanto, a tensão na ruptura $\left(\mathbf{f}_{\mathbf{r}}\right)$ foi obtida e o alongamento $(\% \Delta \mathbf{L})$ final dos corpos de prova calculado, estando os resultados listados na tabela 4.5 , onde $\mathbf{A}_{b}$ e $\mathbf{L}_{b}$ são, respectivamente, a área e comprimento base do corpo de prova.

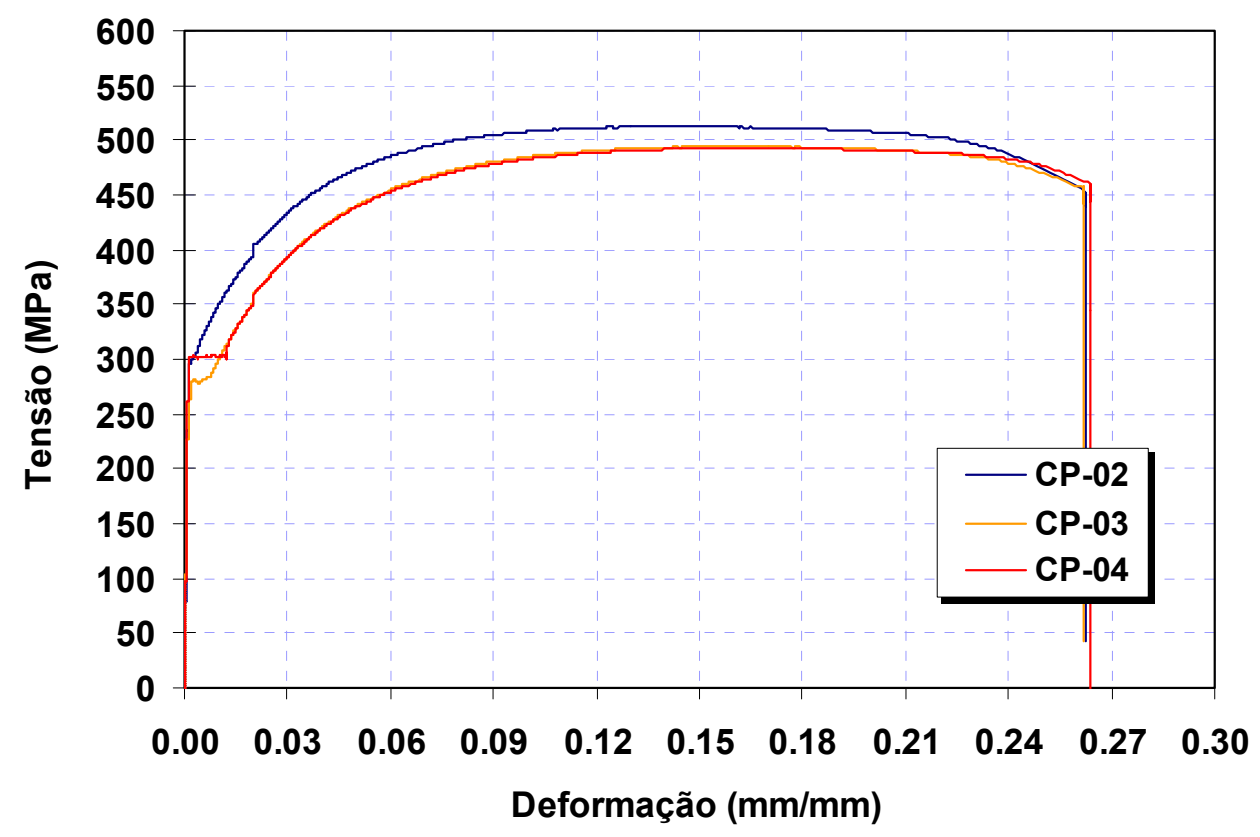

Figura 4.34 - Curvas tensão-deformação das chapas caracterizadas

Tabela 4.5 - Resultados dos corpos de prova das chapas de aço ASTM-A36

\begin{tabular}{|c|c|c|c|c|c|c|c|}
\cline { 2 - 8 } \multicolumn{1}{c|}{} & $\begin{array}{c}\mathbf{A}_{\mathbf{b}} \\
\left(\mathbf{m m}^{\mathbf{2}} \mathbf{c}\right.\end{array}$ & $\begin{array}{c}\mathbf{L}_{\mathbf{b}} \\
(\mathbf{m m})\end{array}$ & $\mathbf{\%} \Delta \mathbf{L}$ & $\begin{array}{c}\mathbf{f}_{\mathbf{y}} \\
(\mathbf{M P a})\end{array}$ & $\begin{array}{c}\mathbf{f}_{\text {máx }} \\
(\mathbf{M P a})\end{array}$ & $\begin{array}{c}\mathbf{f}_{\mathbf{r}} \\
(\mathbf{M P a})\end{array}$ & $\begin{array}{c}\mathbf{E} \\
\mathbf{( M P a})\end{array}$ \\
\hline CP-02 & 59,920 & 49,610 & 36,41 & 304,5 & 512,7 & 347,0 & 216000 \\
\hline CP-03 & 59,478 & 49,850 & 40,43 & 280,8 & 494,2 & 338,6 & 199800 \\
\hline CP-04 & 60,158 & 49,580 & 38,30 & 302,6 & 492,5 & 340,2 & 207700 \\
\hline Média & 59,852 & 49,680 & 38,38 & 296,0 & 499,8 & 342,0 & 207500 \\
\hline
\end{tabular}

\subsubsection{Parafusos}

Os ensaios com os parafusos foram realizados com um aparato especial no qual é possível encaixar o conjunto parafuso-porca-arruelas, simulando a configuração usual desse dispositivo em uma ligação.

Este aparato foi confeccionado durante o trabalho de Maiola (1999) de acordo com as especificações da norma ASTM F606 (1995) e está 
apresentado na figura 4.35, na disposição de ensaio e num detalhe juntamente com um parafuso ensaiado.
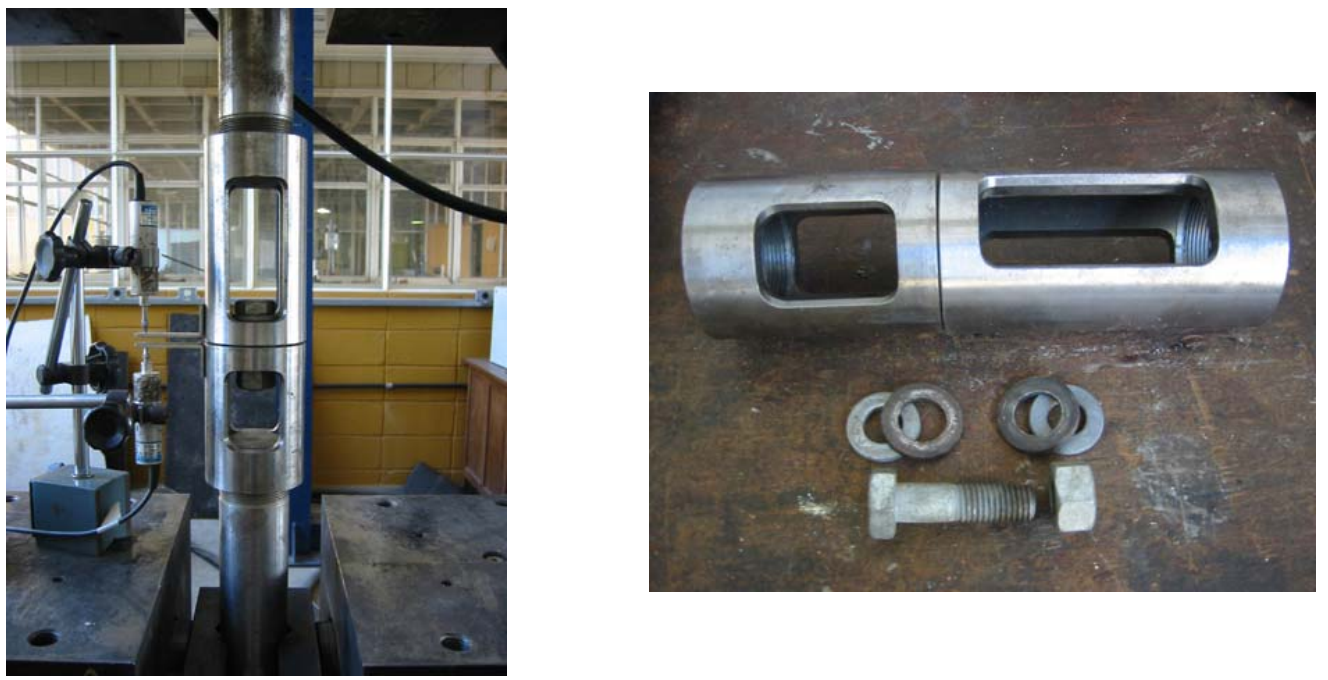

Figura 4.35 - Dispositivo para ensaio dos parafusos

O conjunto foi ensaiado à tração em atuador marca INSTRON, mesmo dos ensaios com as ligações duplo "T", aplicando-se uma velocidade constante de $\mathbf{0 , 0 2} \mathbf{m m} / \mathbf{s}$, também de acordo com as especificações da ASTM F606 (1995). A leitura do deslocamento relativo entre as bases das duas canecas foi obtida com a utilização de transdutores posicionados simetricamente à seção transversal. Com os dados dos transdutores e da força total aplicada, obtém-se as curvas força-alongamento para os 6 conjuntos ensaiados, das quais 3 mais representativas estão apresentadas na figura 4.36 .

As relações tensão-deformação para esse conjunto podem ser obtidas uma vez escolhida a área de referência para cálculo da tensão em função da força total aplicada. Um aspecto que deve ser enfatizado novamente é a utilização dessas relações para a padronização de curvas tensãodeformação para a modelagem numérica, o que implica na consideração das hipóteses da modelagem numérica para a escolha dos parâmetros a serem utilizadas na obtenção das relações tensão-deformação.

Assim, os resultados apresentados na figura 4.36 serão utilizados, posteriormente, para a definição dos padrões de modelos constitutivos que serão utilizados nas análises numéricas e discussões dos próximos capítulos. 


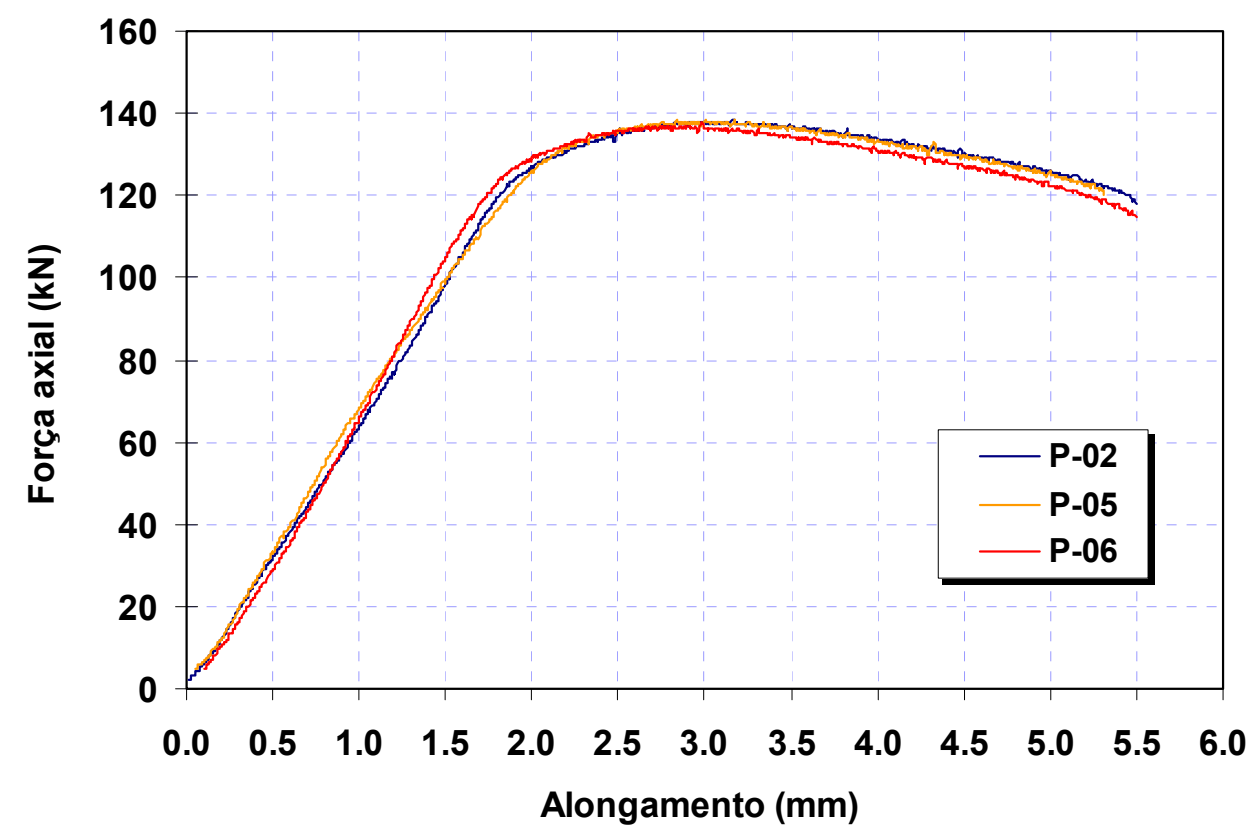

Figura 4.36 - Curvas força-alongamento para os parafusos

Apenas como referência, na tabela 4.6 são listadas as características geométricas dos corpos de prova ensaiados, assim como alguns resultados específicos. $A_{b}$ refere-se à área bruta dos fustes, $L_{0}$ é o comprimento de referência inicial, $\% \Delta \mathbf{L}$ é o alongamento total, $\mathbf{P}_{\text {máx }}$ a força máxima aplicada $\mathrm{e}$ $\mathbf{P}_{\mathbf{r}}$ a força na ruptura.

Tabela 4.6 - Geometria e resultados da caracterização dos parafusos

\begin{tabular}{|c|c|c|c|c|c|}
\cline { 2 - 6 } \multicolumn{1}{c|}{} & $\begin{array}{c}\mathbf{A}_{\mathbf{b}} \\
\mathbf{( m m}^{2} \mathbf{)}\end{array}$ & $\begin{array}{c}\mathbf{L}_{\mathbf{o}} \\
\mathbf{( m m})\end{array}$ & $\mathbf{\%} \mathbf{L}$ & $\begin{array}{c}\mathbf{P}_{\text {máx }} \\
\mathbf{( k N )}\end{array}$ & $\begin{array}{c}\mathbf{P}_{\mathbf{r}} \\
\mathbf{( k N )}\end{array}$ \\
\hline P-02 & 206,12 & 39,20 & 14,90 & 139,0 & 118,0 \\
\hline P-03 & 203,58 & 39,40 & 13,60 & 141,0 & 123,0 \\
\hline P-04 & 203,58 & 39,54 & 16,03 & 137,0 & 112,0 \\
\hline P-05 & 203,58 & 39,90 & 14,31 & 139,0 & 120,0 \\
\hline P-06 & 201,06 & 39,70 & 14,84 & 138,0 & 115,0 \\
\hline Média & 203,58 & 39,55 & 14,74 & 138,8 & 117,6 \\
\hline
\end{tabular}

Vale lembrar que os dados apresentados acima se referem à deformabilidade do parafuso considerando a flexibilidade da rosca, porca, cabeça e arruelas e, portanto, não representam diretamente as características do aço dos parafusos de alta resistência ASTM-A325, utilizados neste programa experimental. 


\section{Capítulo}

\section{RESULTADOS EXPERIMENTAIS}

O enfoque dado a esta pesquisa no comportamento das ligações com chapa de topo estendida e nos modelos analíticos para o dimensionamento da chapa de topo à flexão conduziu a escolha de duas séries experimentais, como descrito no capítulo anterior.

As ligações duplo " $T$ " foram inseridas para a observação experimental dos modos de falha dos perfis " $T$ ", que servem de base para a verificação da capacidade resistente da chapa de topo como um componente da ligação, de acordo com a metodologia proposta pelo Eurocode 3 (1993). As variações de tipologia das ligações duplo "T", fazendo-se a analogia com a região tracionada da ligação com chapa de topo, também foram introduzidas no programa experimental para se observar possíveis modificações no comportamento dos perfis "T".

A série das ligações com chapa de topo estendida, por sua vez, foi utilizada para a observação do comportamento global por meio das relações momento-rotação para a ligação e força-deslocamento para a viga, para a medição de deformações e deslocamentos na viga e na chapa de topo e para a geração de dados de controle para os modelos numéricos.

Enfim, este capítulo é dedicado a apresentar os resultados experimentais obtidos para estes dois tipos de ligação parafusada, destacandose os objetivos específicos de cada série de ensaios.

Uma observação adicional torna-se de extrema importância para o correto entendimento do texto apresentado neste capítulo e nos capítulo posteriores. Nas discussões sobre o comportamento das ligações duplo "T" e das ligações com chapa de topo faz-se, com freqüência, a utilização do termo "ductilidade" e seus derivados. Assim como na caracterização dos materiais, esse termo está relacionado à capacidade de deformação e foi utilizado, nas 
discussões apresentadas, como sinônimo de "capacidade rotacional" para as ligações com chapa de topo estendida e de "deformabilidade" para as ligações duplo "T". Entende-se que, assim, torna-se mais fácil a comparação da capacidade de deformação entre essas ligações.

\subsection{LIGAÇÕES DUPLO “T”}

As ligações duplo "T" foram investigadas considerando-se seu comportamento global, por meio das curvas força-deslocamento, as deformações localizadas nas mesas e os tipos de ruptura associados às combinações entre a mesa dos perfis "T" e os parafusos, com a finalidade de discutir os modos de falha dessas ligações.

Os resultados para os grupos TSC, TSI e TSIE são apresentados a seguir, discutindo-se ainda a tipologia das ligações duplo "T" e a validade dos conceitos utilizados na representação dos estados limites últimos para essas ligações.

\subsubsection{Resultados para o grupo TSC - duplo "T" usual}

Observando-se, inicialmente, a variação da espessura da mesa dos perfis "T", a figura 5.1 apresenta as curvas força-deslocamento para os protótipos TSC1, TSC2 e TSC3, com parafusos de 12,5 mm. A rigidez dos protótipos, por meio das curvas força-deslocamento, será utilizada como indicativo do comportamento global dessas ligações e também de suas variações.

Para o subgrupo dos protótipos TSC1 à TSC3 observa-se pouca variação da rigidez inicial, conseqüência da protensão dos parafusos. O protótipo TSC1, com mesa de $12,5 \mathrm{~mm}$ de espessura, é mais dúctil e apresenta maior contribuição da mesa na deformabilidade da ligação. Com o aumento da espessura da mesa, os parafusos têm sua capacidade de deformação maximizada, havendo limitações para a deformabilidade do protótipo TSC3. 
Esse comportamento pode ser associado a dois fatores: o primeiro, com relação à solicitação dos parafusos, tem razão direta na diminuição do efeito alavanca uma vez que a mesa tem menor deformabilidade à flexão, aumentando a capacidade resistente dos protótipos TSC2 e TSC3; o segundo indica a grande dependência do comportamento da ligação à rigidez relativa entre a mesa e os parafusos, uma vez que a mesa do protótipo TSC3, de 19,0 mm, permite que os parafusos sejam solicitados preferencialmente à tração, com uma queda acentuada de resistência antes do colapso devida à plastificação mais uniforme da seção líquida dos parafusos.

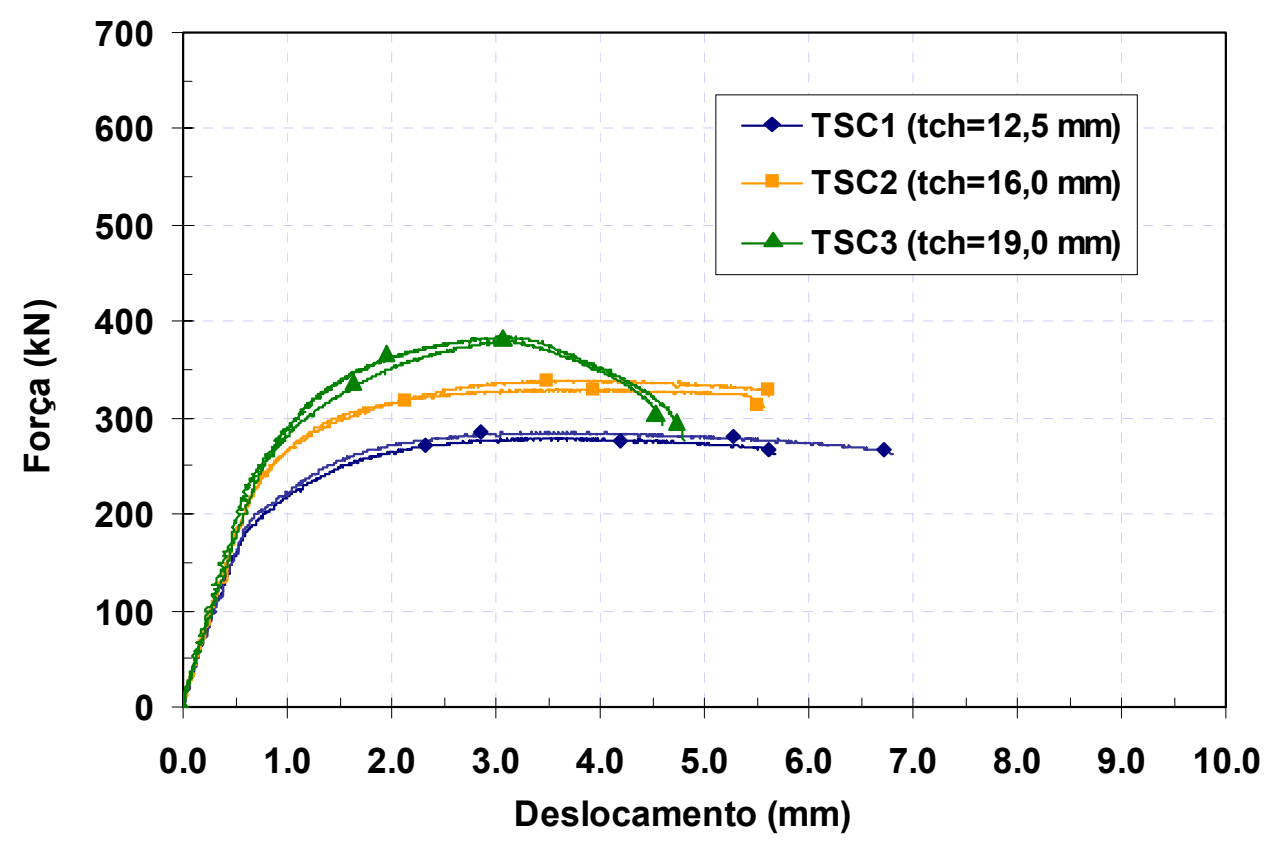

Figura 5.1 - Curvas força-deslocamento para os protótipos TSC com parafusos de $12,5 \mathrm{~mm}$

Na figura 5.1 representa-se o deslocamento total da ligação duplo "T", incluindo-se as deformações da alma. Neste caso, representa-se o deslocamento do atuador hidráulico que foi utilizado como referência para as relações força-deslocamento de todos os protótipos desta série.

As figuras 5.2(a) e 5.2(b) apresentam, respectivamente, as deformações dos protótipos TSC1 e TSC3 após o colapso, percebendo-se claramente a mudança de configuração das mesas com o aumento da espessura. 


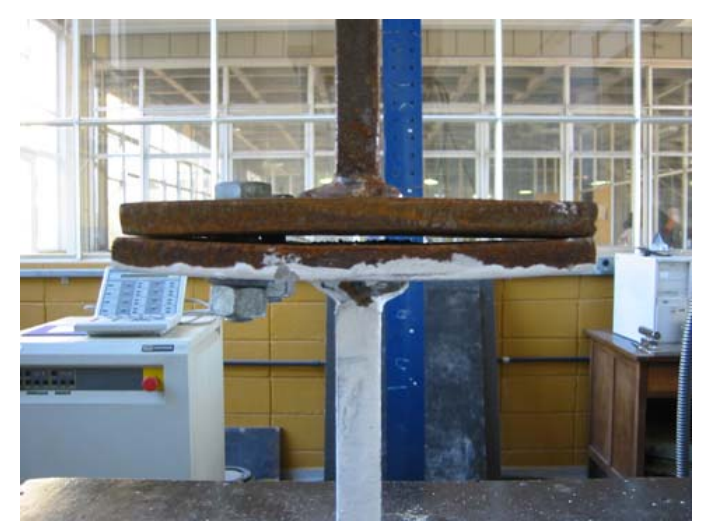

(a) TSC1

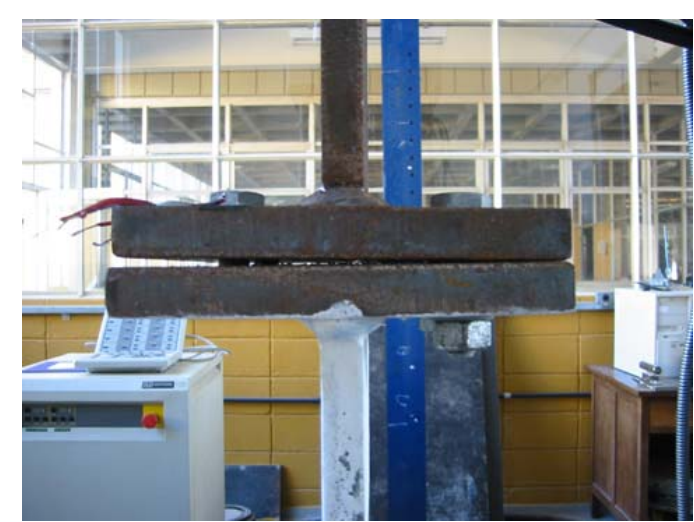

(b) TSC3

Figura 5.2 - Deformações dos protótipos TSC1 e TSC3 após o colapso

Apesar de haver uma indicação visível do desaparecimento do "efeito alavanca" nos parafusos, a ductilidade do protótipo TSC3 é diminuída sensivelmente, reafirmando a rigidez elevada à flexão da mesa de $19,0 \mathrm{~mm}$ com relação à rigidez axial dos parafusos de $12,5 \mathrm{~mm}$, que seguem o comportamento observado nos diagramas força-deslocamento da caracterização dos parafusos com solicitações predominantes de tração.

Dessa forma, é possível caracterizar o modo de falha $\mathbf{3}$, representando a ruptura dos parafusos como estado limite último, visível no protótipo TSC3.

Convém ressaltar que todos os protótipos do programa experimental foram ensaiados até o colapso dos parafusos, mesmo para as ligações em que a mesa apresentou deformações elevadas, para as quais caracteriza-se o modo de falha 1. Devido às condições do ensaio e às imperfeições dos protótipos, não se observou a ruptura conjunta de todos os parafusos, caracterizando-se como colapso a ruptura de um ou mais parafusos tracionados na ligação.

Dentro do sub-grupo com parafusos de $16,0 \mathrm{~mm}$, as curvas forçadeslocamento dos protótipos TSC4, TSC5, TSC6 e TSC7 estão mostradas na figura 5.3.

Chama-se a atenção para o fato de que os resultados dentro desse sub-grupo, considerando os protótipos de cada par, não são tão uniformes quanto os observados para o primeiro sub-grupo, com parafusos de $12,5 \mathrm{~mm}$. 


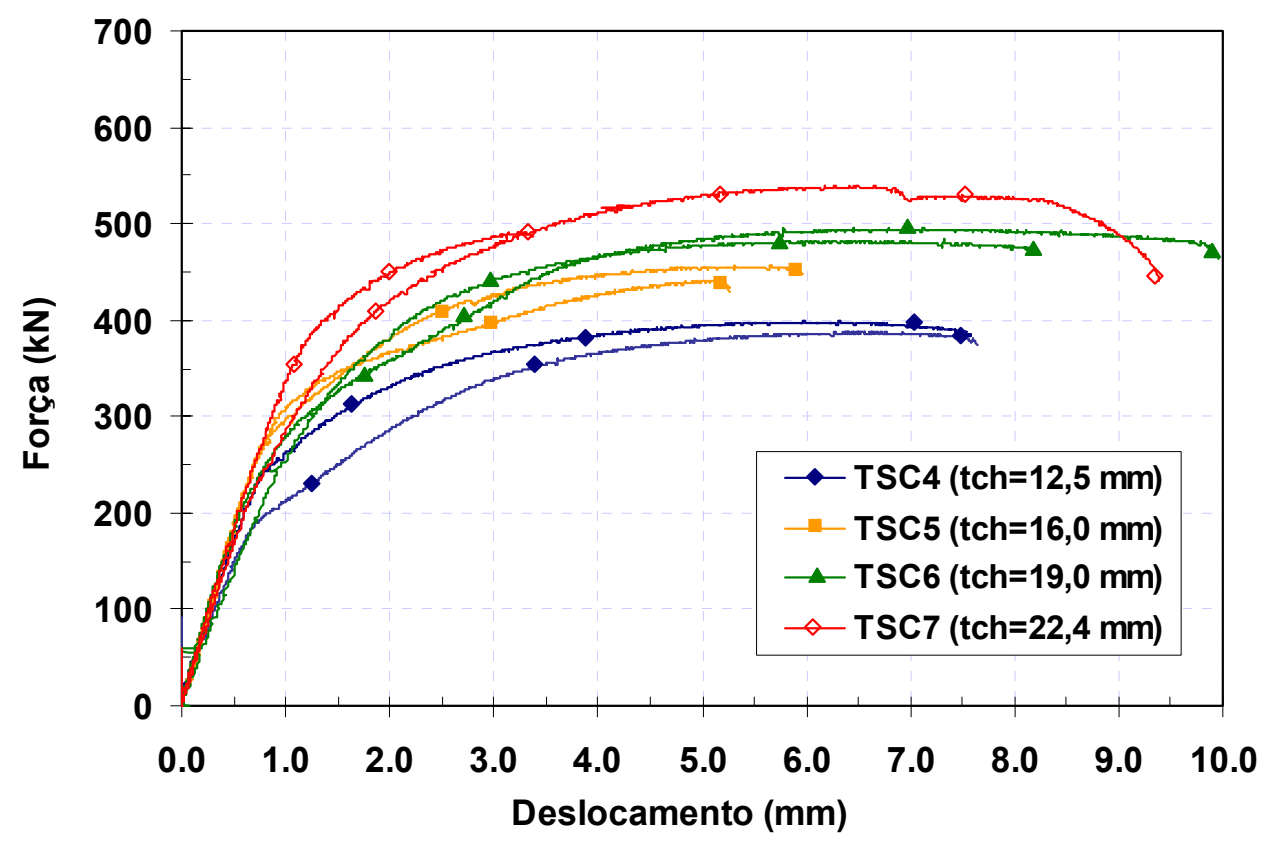

Figura 5.3 - Curvas força-deslocamento para os protótipos TSC com parafusos de $16,0 \mathrm{~mm}$

Analisando-se as curvas na figura 5.3 é possível se observar um pequeno escorregamento nos protótipos TSC4, TSC5 e TSC6, causado pelas imperfeições de montagem comentadas no capítulo anterior.

Como grande parte dos protótipos apresentou falta de alinhamento entre as almas e também falta de perpendicularidade entre mesa e alma, observou-se a ocorrência de solicitações de flexão nas mesas no momento da fixação no atuador. Neste caso, surgiram forças adicionais, paralelas às mesas, que devem ter provocado o escorregamento à medida que a força de protensão inicial nos parafusos era superada.

Para o protótipo TSC7 não se observou esse escorregamento. No entanto, o primeiro protótipo do par não foi solicitado até a ruptura dos parafusos pois, antes disso, houve o esmagamento e deslizamento da rosca, conseqüência de se ter utilizado um parafuso com pequeno comprimento de rosca.

Com relação à rigidez deste sub-grupo, comportamento semelhante aos observados entre os protótipos TSC2 e TSC3 ocorre entre os protótipos TSC4 e TSC5. Para os protótipos TSC6 e TSC7, o "efeito alavanca" é menor permitindo que os parafusos sejam solicitados predominantemente à tração, com aumento da capacidade de deformação. 
Para referenciar os modos de falha previstos para os protótipos descritos acima, na tabela 5.1 apresentam-se os valores da capacidade resistente à tração $(\mathbf{T})$ e a quantificação das forças de alavanca $(\mathbf{Q})$ das ligações duplo "T" calculados segundo o Eurocode 3 (1993) para cada parafuso.

Tabela 5.1 - Capacidade resistente, forças de alavanca e modos de falha do grupo TSC calculados segundo o Eurocode 3 (1993)

\begin{tabular}{|c|c|c|c|}
\hline Protótipo & $\mathbf{T}(\mathbf{k N})$ & $\mathbf{Q}(\mathbf{k N})$ & Modo de falha \\
\hline TSC1 & 56,73 & 19,21 & $\mathbf{2}$ \\
\hline TSC2 & 68,65 & 7,28 & $\mathbf{2}$ \\
\hline TSC3 & 75,93 & - & $\mathbf{3}$ \\
\hline TSC4 & 65,43 & 26,17 & $\mathbf{1}$ \\
\hline TSC5 & 95,58 & 28,82 & $\mathbf{2}$ \\
\hline TSC6 & 106,44 & 17,96 & $\mathbf{2}$ \\
\hline TSC7 & 119,16 & 5,25 & $\mathbf{2}$ \\
\hline
\end{tabular}

Analisando-se mais detalhadamente a resposta deste sub-grupo, o protótipo TSC4, assim como o protótipo TSC1 do sub-grupo anterior, tem na mesa a maior fonte de deformabilidade para a ligação. De fato, o estado limite último do protótipo TSC1 é previsto para o modo de falha 2, enquanto o protótipo TSC4 apresenta o modo de falha 1.

A variação do modo de falha e a variação da deformabilidade dos parafusos e da mesa dos perfis "T" pode ser visualizada na figura 5.4, que ilustra as deformações nas mesas dos protótipos TSC4, TSC5 e TSC6.

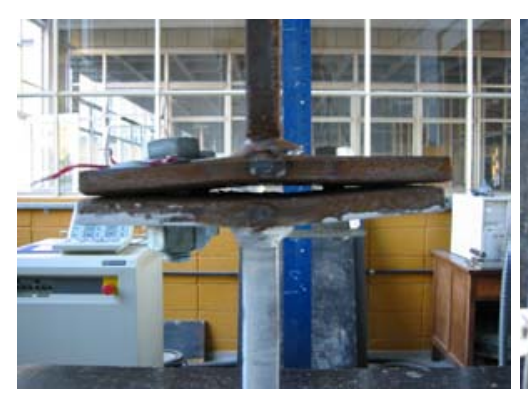

(a) TSC4

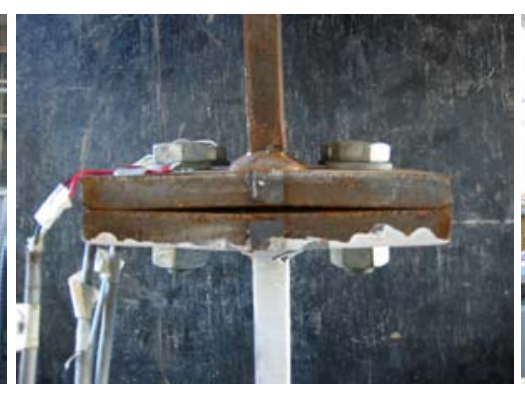

(b) TSC5

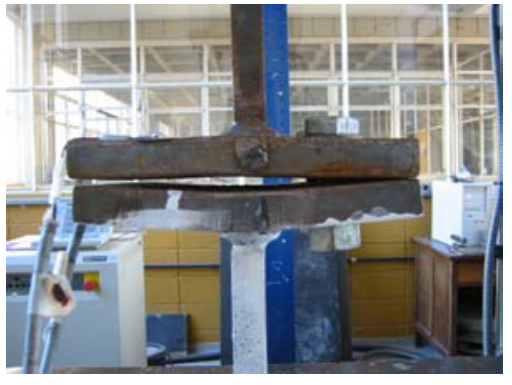

(c) TSC6

Figura 5.4 - Deformações nas mesas dos protótipos TSC4, TSC5 e TSC 6 após o colapso 
Com os gráficos das figuras 5.1 e 5.3 e os valores apresentados na tabela 5.1, as seguintes observações podem ser feitas com base na resistência e na deformabilidade dos protótipos.

i. Os limites de resistência para os perfis "T" são função da capacidade resistente dos parafusos e do "efeito alavanca", ou seja, do tipo de solicitação a que estão sujeitos os parafusos. Quanto maior o diâmetro dos parafusos e maior a espessura da mesa, maior a capacidade resistente à tração da ligação duplo "T";

ii. Os limites de deformação axial também são função do "efeito alavanca", mas são influenciados, principalmente, pela relação entre a deformabilidade dos parafusos e a deformabilidade da mesa dos perfis "T". Assim, quando a ligação passa do modo de falha 1 para o modo de falha 2 , há uma diminuição da deformabilidade, observada entre os protótipos TSC4 e TSC5. No entanto, entre o modo de falha 2 e o modo de falha 3 , duas situações distintas podem ocorrer: na primeira, quando a deformação à flexão da mesa é muito inferior à deformação axial dos parafusos, há uma queda contínua na ductilidade dos protótipos; na segunda, havendo uma relação mais equilibrada entre mesa e parafusos há também um ganho de ductilidade, devido à deformabilidade da mesa.

Essas observações, apesar de qualitativas, indicam a existência de uma relação ótima entre espessura de mesa e diâmetro de parafusos para a maximização da deformabilidade e manutenção de requisitos mínimos de resistência.

Outra observação interessante pode ser feita com as figuras 5.5 e 5.6 que indicam, respectivamente, as forças de tração $(\mathbf{T})$ e a "força de alavanca" (Q) por parafuso, calculados segundo o Eurocode 3 (1993) e obtidas experimentalmente. Para os protótipos, a força de tração (T) é calculada dividindo-se a força máxima no ensaio pelo número de parafusos da ligação neste caso, 4. As forças de alavanca são obtidas pela diferença entre a força 
de tração aplicada por parafuso e a força que o parafuso suportaria sob tração simples, ou seja, sem efeitos de alavanca.

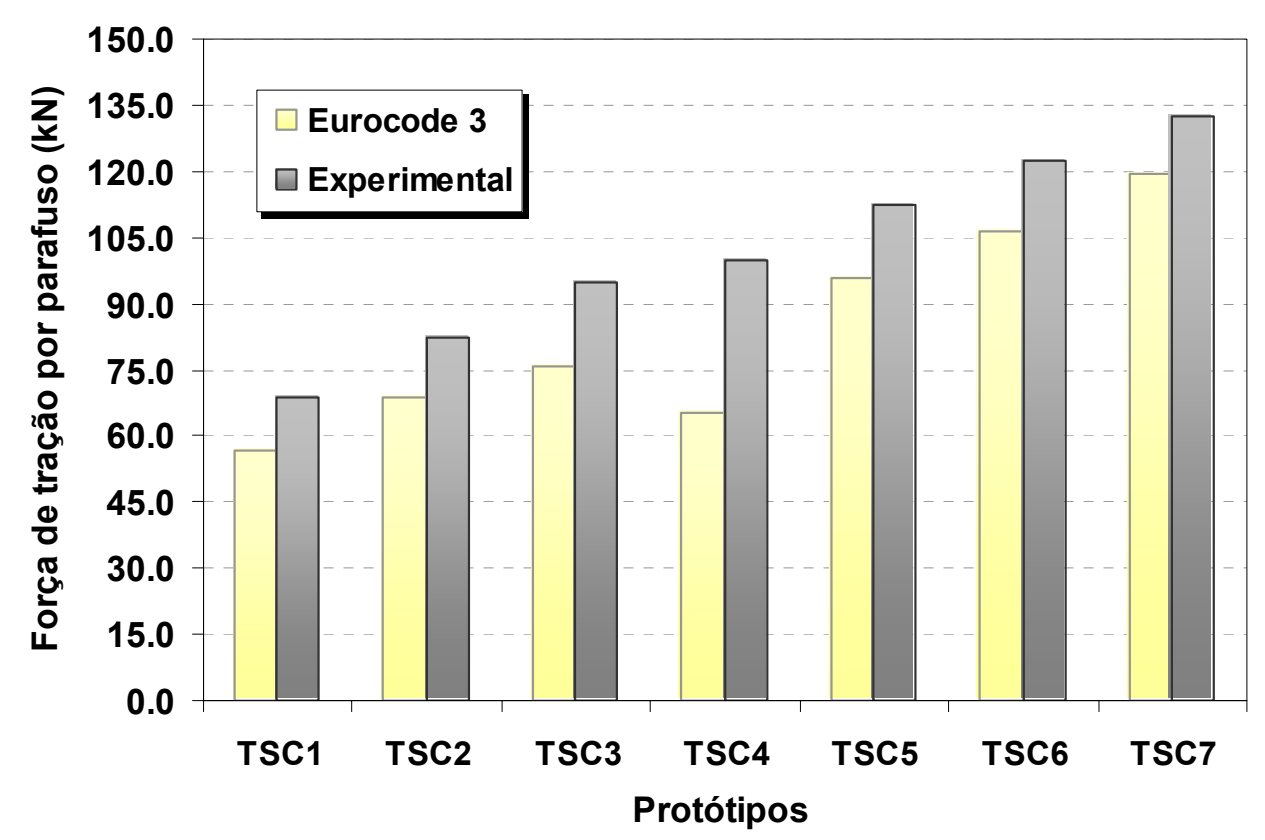

Figura 5.5 - Forças de tração nos parafusos dos protótipos TSC

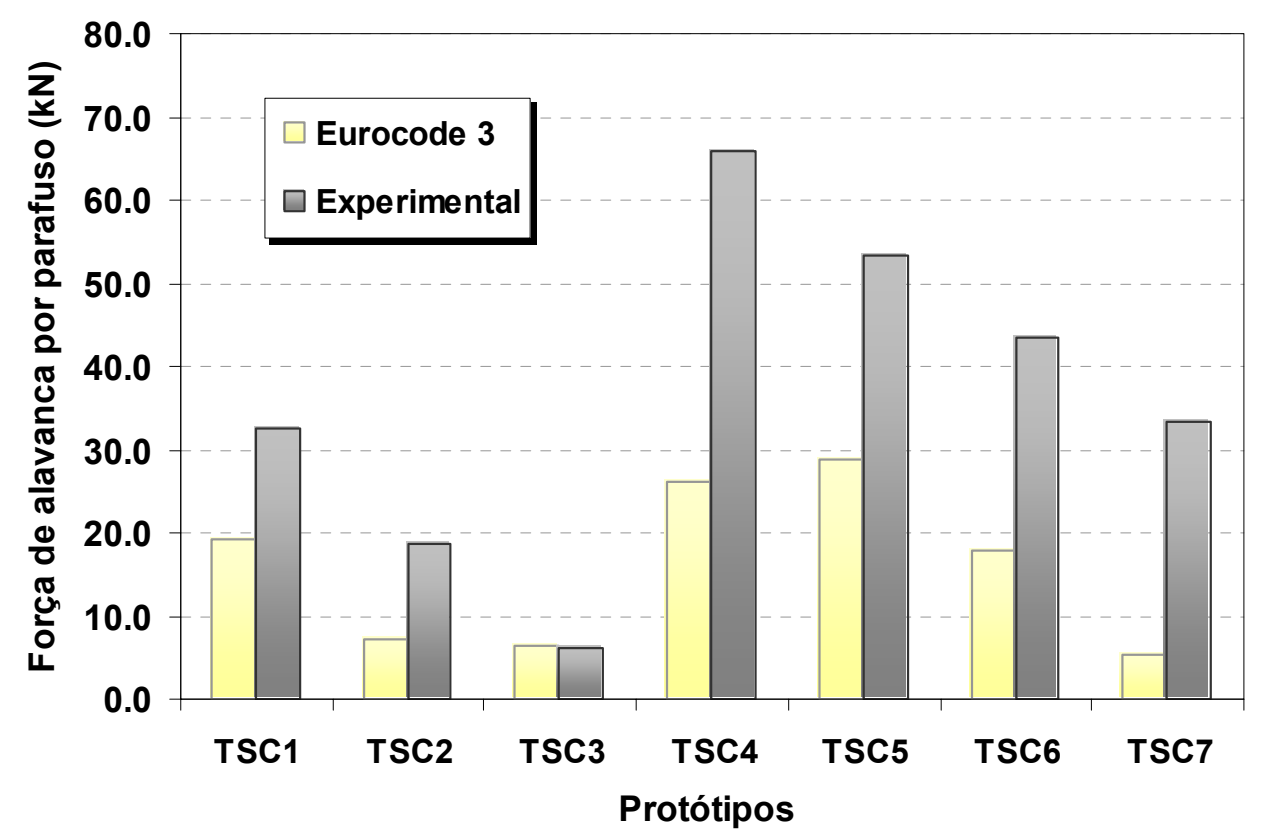

Figura 5.6 - Forças de alavanca nos parafusos dos protótipos TSC

Os resultados experimentais, nos gráficos acima, seguem um padrão bem definido para a capacidade resistente e para as forças de alavanca nos parafusos. Esse padrão refere-se a um aumento da resistência à medida que 
se aumenta a espessura da mesa dos perfis "T" e o diâmetro dos parafusos e uma diminuição quase proporcional das forças de alavanca com o aumento da espessura da mesa, dentro de um sub-grupo de parafusos.

Neste caso, reforça-se a idéia de que a resistência dos protótipos e o "efeito alavanca" depende significativamente da interação entre parafusos e mesa dos perfis "T" como contribuintes na deformabilidade da ligação duplo "T".

Os resultados analíticos, por sua vez, mostram valores desproporcionais com relação às forças de alavanca e, em geral, conservadores com relação à resistência dos perfis "T".

Tratando-se de modelos analíticos de dimensionamento, o fato de serem conservadores é um ponto positivo ao desconsiderarem imperfeições, tensões residuais e diferenças na resistência dos materiais utilizados, ressaltando-se que os valores analíticos e experimentais se aproximam na medida em que a ligação se aproxima do modo de falha 3. Por outro lado, reforça-se a complexidade de se tratar analiticamente os mecanismos de transferência de esforços e o "efeito alavanca".

Especificamente para o protótipo TSC4, a previsão da capacidade resistente pelo Eurocode 3 (1993) é significativamente menor que a resistência observada experimentalmente, o que indica uma previsão incorreta do modo de falha.

Para complementar a observação dos modos de falha, a figura 5.7 ilustra, para os protótipos TSC4-1 e TSC5-2, as deformações nos extensômetros 1 e 2, posicionados perpendicularmente à alma nas mesas de um dos lados dos protótipos conforme indicado na figura.

Para o protótipo TSC5-2, a deformação é significativamente maior no centro com relação à extremidade lateral, indicando a flexão nos dois planos da mesa para esse protótipo e uma tendência de plastificação dos furos para o centro e para a lateral, característica do modo de falha 2.

Como o deslocamento axial do protótipo TSC5-2 é menor que a do protótipo TSC4-1 e as deformações no protótipo TSC4-1 são menores que as do TSC5-2, até com uma maior uniformidade, percebe-se uma modificação na plastificação da mesa, cuja flexão é acentuada na direção perpendicular à alma. 


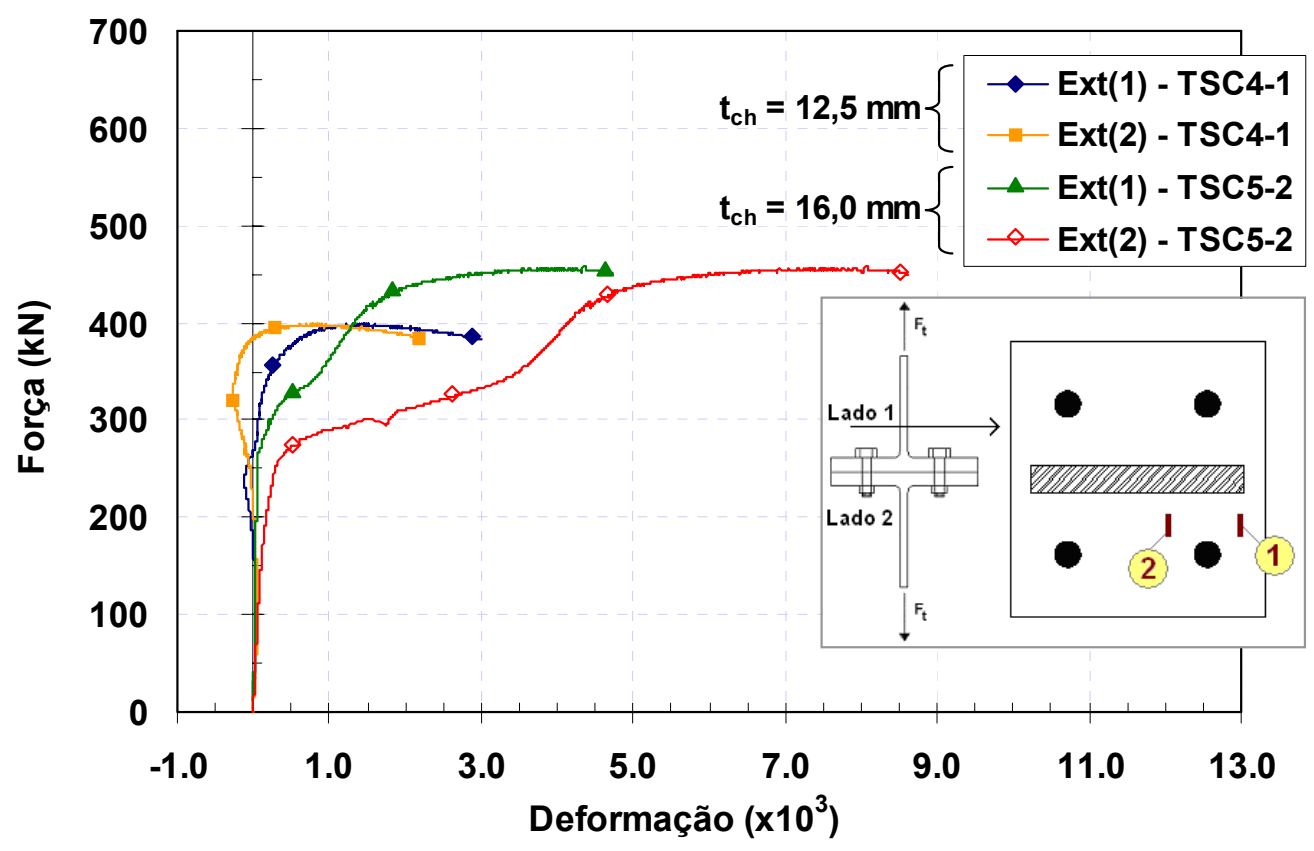

Figura 5.7 - Deformações nas mesas dos protótipos TSC4 e TSC5

O protótipo TSC4-2 foi pintado com uma mistura de água e cal e, na figura 5.8, é possível visualizar a formação de uma linha de plastificação entre os furos, paralela à alma do perfil "T", além de um detalhe da ruptura de um parafuso por solicitações de tração combinadas com flexão.
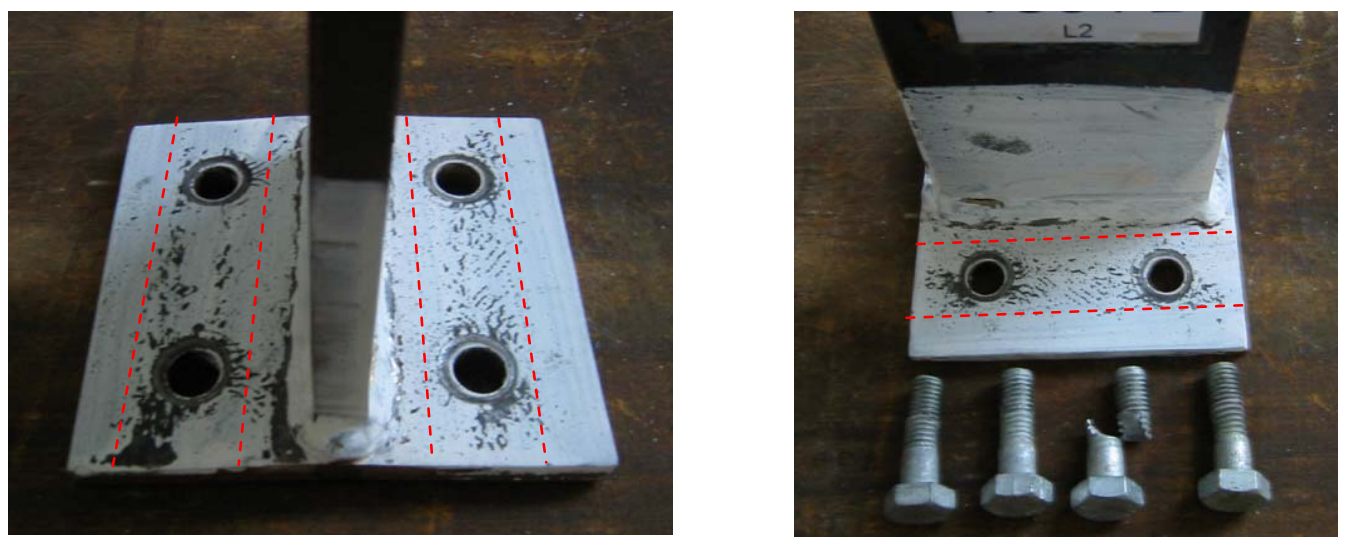

Figura 5.8 - Linhas de plastificação na mesa do protótipo TSC4-2 e detalhe da ruptura do parafuso

As deformações para os protótipos TSC6 e TSC7 nas mesmas posições da mesa (figura 5.7) estão mostradas na figura 5.9. 


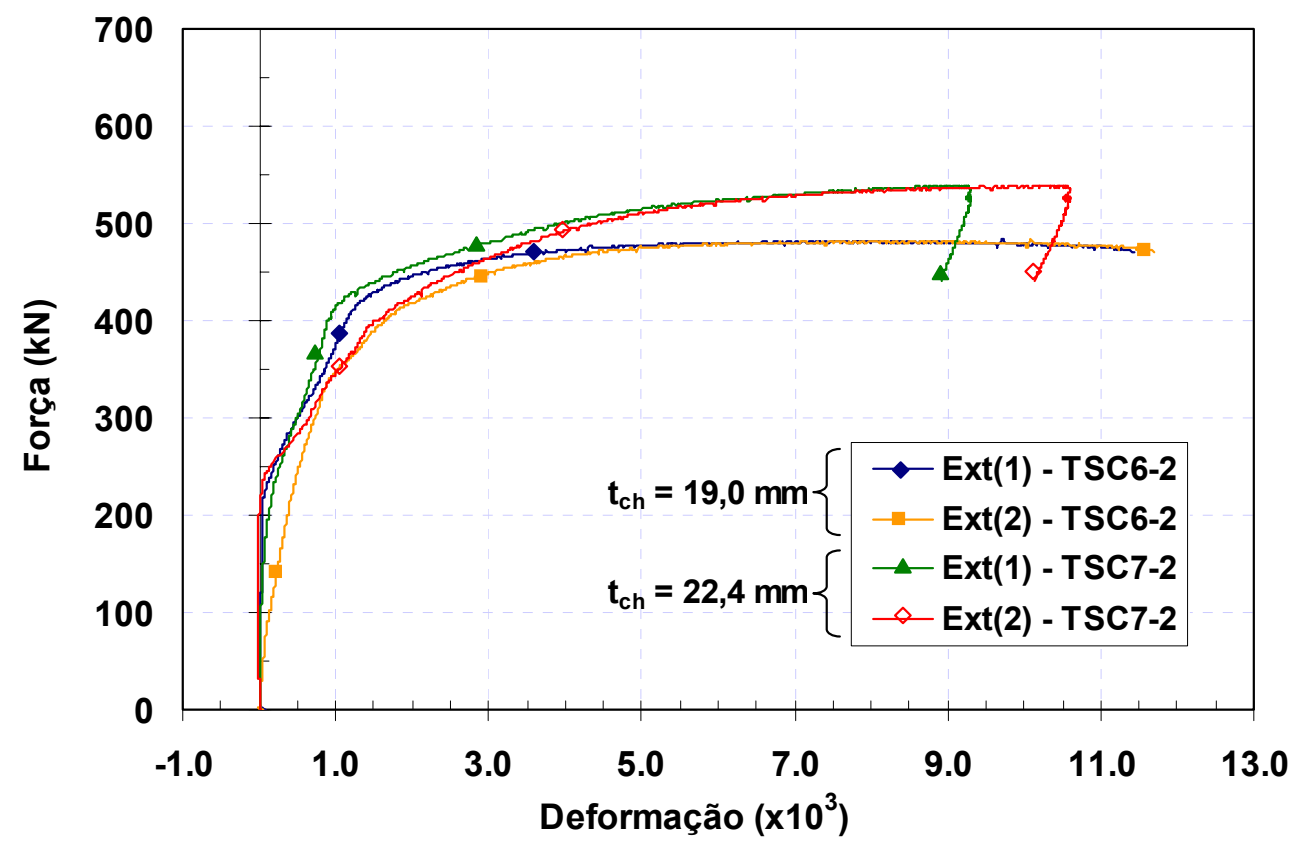

Figura 5.9 - Deformações nas mesas dos protótipos TSC6 e TSC7

Para os protótipos TSC6 e TSC7, a flexão na mesa também é pronunciadamente maior na direção perpendicular à alma devido ao aumento da espessura da mesa. Neste caso, as deformações voltam a ser uniformes no centro e na lateral, havendo uma diminuição da flexão na mesa do protótipo TSC7, característica do modo de falha 3.

No sub-grupo com parafusos de $19,0 \mathrm{~mm}$ não foi possível solicitar todos os modelos até o colapso devido à plastificação da alma dos perfis "T", com exceção do protótipo TSC8 no qual houve a ruptura dos parafusos, evidenciando a existência de forças de alavanca acentuadas neste protótipo, com mesa de $16,0 \mathrm{~mm}$ de espessura.

Quanto à rigidez inicial, pequenas variações foram observadas neste sub-grupo. Como o torquímetro utilizado na protensão dos parafusos de 19,0 mm possuía apenas controle visual do torque, por relógio graduado, pequenas variações da força de protensão podem ter ocorrido, influenciando o trecho inicial das curvas força-deslocamento, apresentadas na figura 5.10 para os protótipos TSC8, TSC9, TSC10 e TSC11. 


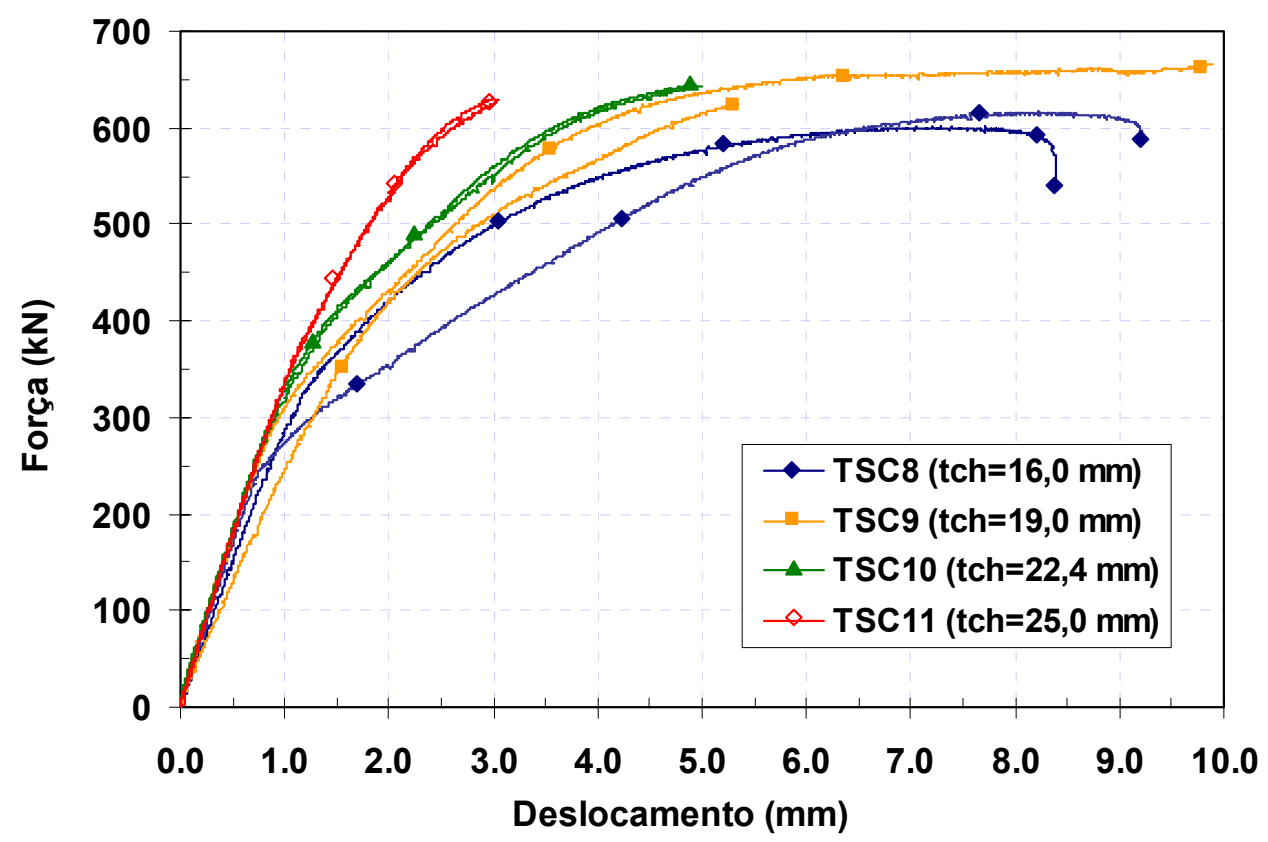

Figura 5.10 - Curvas força-deslocamento para os protótipos TSC com parafusos de $19,0 \mathrm{~mm}$

Com o escoamento da alma, há uma limitação de resistência para os protótipos TSC9, TSC10 e TSC11, com um aumento significativo da deformabilidade devido ao patamar de escoamento do material da alma. Com o encruamento da alma, poderia se esperar um novo acréscimo de resistência e, possivelmente, a ruptura dos parafusos, mas os ensaios foram interrompidos uma vez que a plastificação da alma já caracteriza um estado limite último. Novamente, observam-se escorregamentos nos protótipos TSC8 e TSC9.

Mantendo-se a espessura da mesa constante e variando-se o diâmetro dos parafusos, tem-se como padrão um aumento de resistência e de ductilidade em diferentes proporções, como pode ser observado na figura 5.11 para os protótipos TSC1 e TSC4, com mesa de 12,5 mm e parafusos de $12,5 \mathrm{e}$ $16,0 \mathrm{~mm}$, respectivamente, e na figura 5.12 para os protótipos TSC2, TSC5 e TSC8, com mesa de 16,0 mm e parafusos de 12,5, 16,0 e 19,0 mm, respectivamente.

Para os protótipos com mesa de $12,5 \mathrm{~mm}$, há um aumento proporcional entre resistência e ductilidade. Para os protótipos com mesa de $16,0 \mathrm{~mm}$, no entanto, a proporção entre as curvas é observada apenas para o aumento de resistência e para a ductilidade entre os protótipos TSC5 e TSC8. A variação da ductilidade do protótipo TSC2 para o TSC5 é mínima, 
destacando-se que, no caso do protótipo TSC2, a deformabilidade à flexão da mesa é maior com relação à deformabilidade axial dos parafusos.

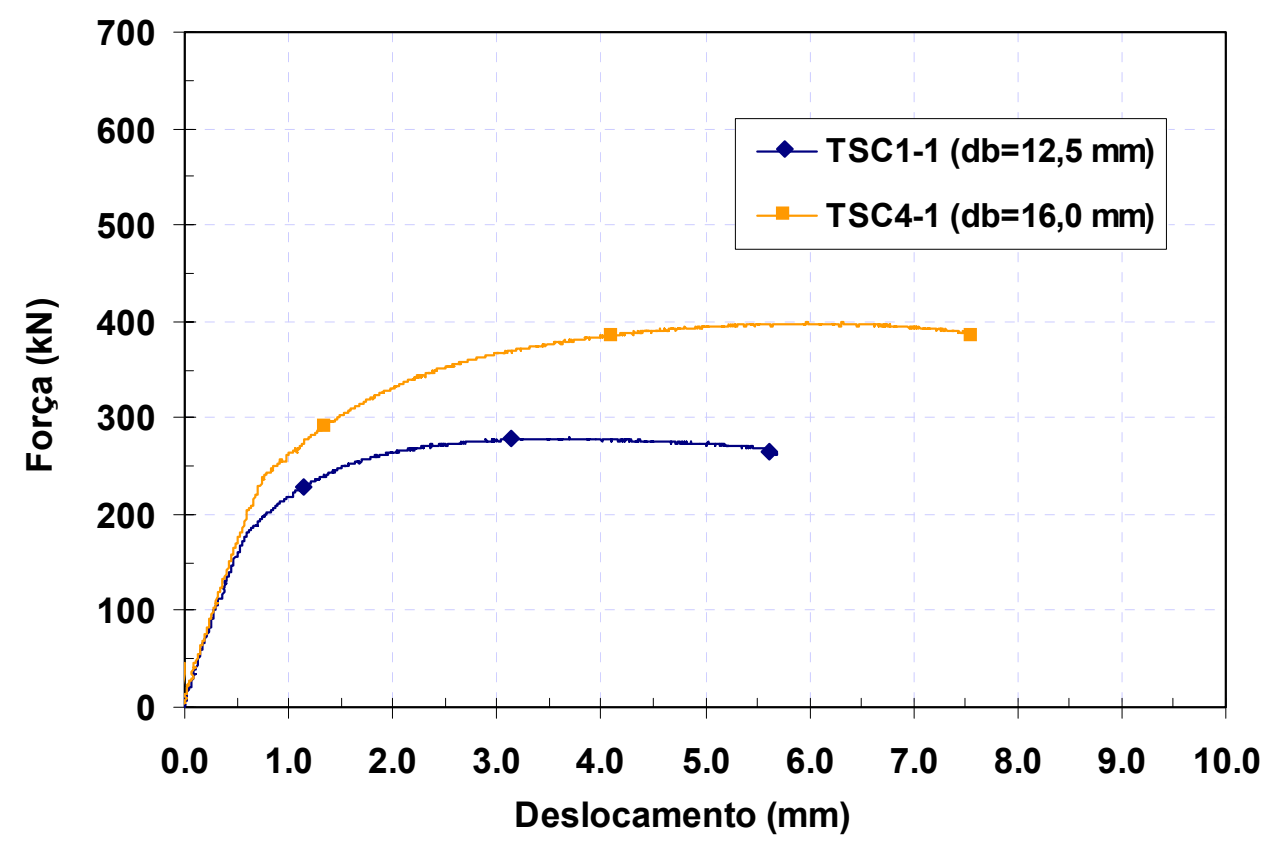

Figura 5.11 - Curvas força-deslocamento para os protótipos TSC com mesa de $12,5 \mathrm{~mm}$ de espessura - variação dos parafusos

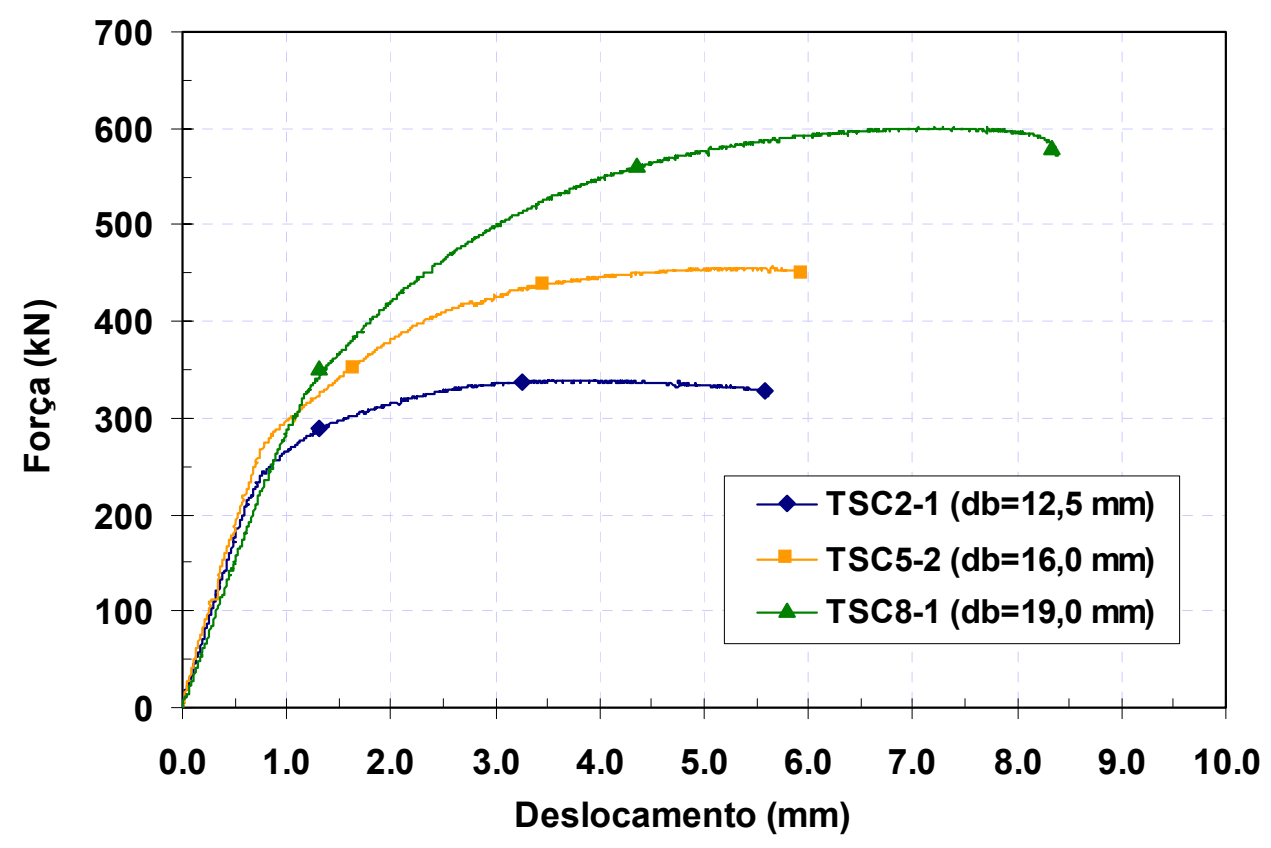

Figura 5.12 - Curvas força-deslocamento para os protótipos TSC com mesa de $16,0 \mathrm{~mm}$ de espessura - variação dos parafusos 


\subsubsection{Resultados para o grupo TSI - almas perpendiculares}

Os resultados do grupo TSI são importantes para a verificação do comportamento da ligação duplo "T" com a mudança de posição entre as almas dos perfis "T", seguindo a configuração usual da ligação com chapa de topo se considerados a viga e o pilar.

Enfatizando-se, novamente, aspectos globais, na figura 5.13 são apresentadas as curvas força-deslocamento para os protótipos TSI. Como os resultados dos pares, para esse grupo, foram mais uniformes que no grupo TSC, indicam-se apenas as curvas obtidas no primeiro ensaio de cada par, a menos do protótipo TSI4-1 que apresentou interferências na coleta de dados, sendo substituído pelo protótipo TS14-2. Para os protótipos TSI5 à TSI8, o ensaio foi interrompido pelos mesmos motivos dos protótipos TSC com parafusos de $19,0 \mathrm{~mm}$.

A representação esquemática da geometria dos protótipos da série TSI também é indicada na figura 5.13.

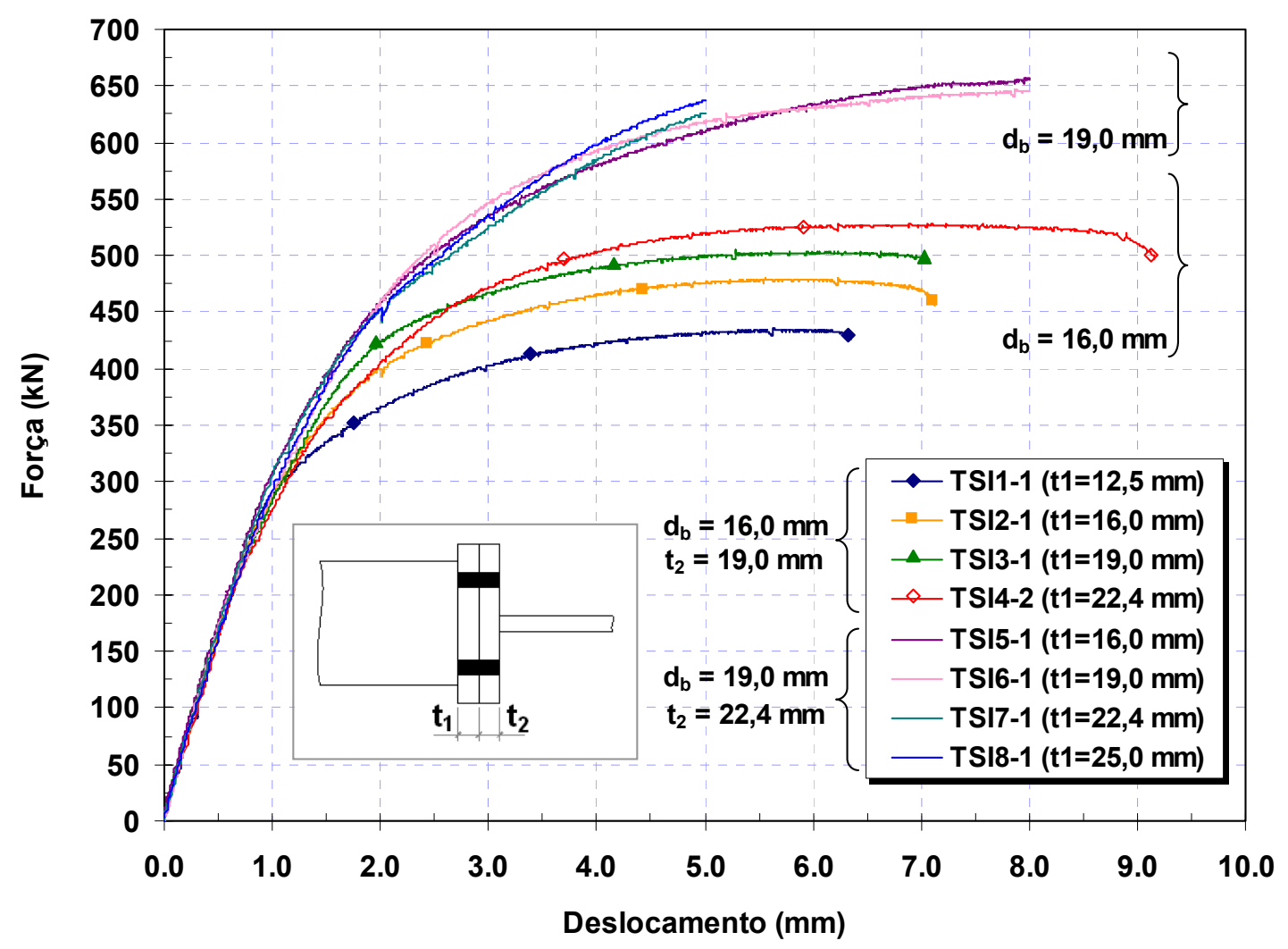

Figura 5.13 - Curvas força-deslocamento para os protótipos TSI 
Assim como para os protótipos do grupo TSC, não há modificação da rigidez inicial para o grupo TSI, inclusive para o aumento do diâmetro dos parafusos, conseqüência da força de protensão inicial aplicada.

No entanto, ao contrário do grupo TSC, o aumento da espessura da mesa dos perfis "T" provocou pequenos acréscimos na ductilidade e na resistência das ligações dentro de cada sub-grupo de parafusos. Um ganho de resistência significativo pode ser visualizado com o aumento do diâmetro dos parafusos, de 16,0 para $19,0 \mathrm{~mm}$.

A figura 5.14 apresenta as deformações no protótipo TSI1-1 após o colapso e no protótipo TSI6-1 antes do término do ensaio.

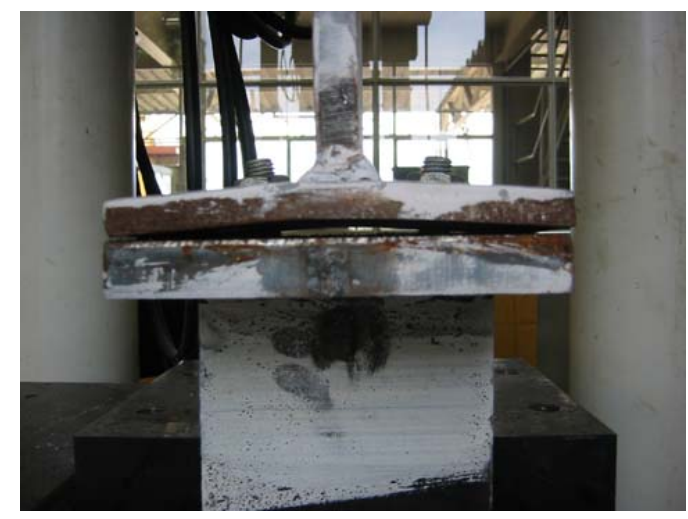

(a) TSI1-1

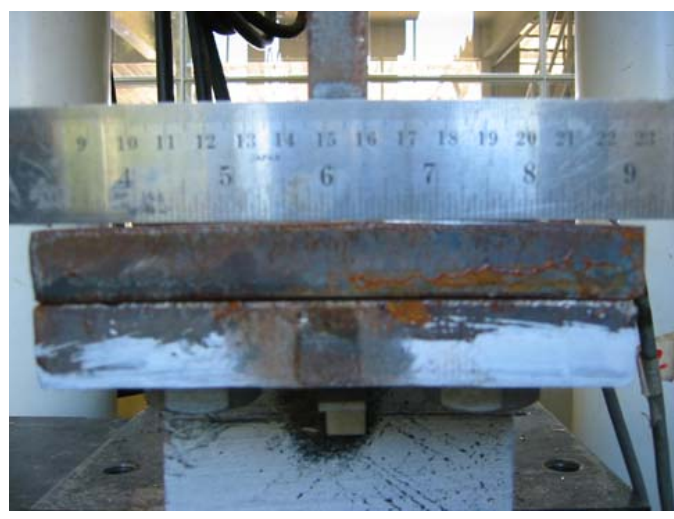

(b) TSI6-1

Figura 5.14 - Deformações das mesas dos protótipos TSI1-1 e TSI6-1

É interessante observar que, devido às diferenças de braço de alavanca para os parafusos e da espessura da mesa entre os perfis "T" desses protótipos, a deformação se concentra em uma das mesas, modificando a interação entre mesa e parafusos na caracterização do colapso.

Comparando-se os grupos TSC e TSI pela consideração da menor espessura de mesa, o protótipo TSI1, com mesas de 12,5 e 19,0 mm de espessura e parafusos de $16,0 \mathrm{~mm}$, tem um pequeno ganho de ductilidade com relação ao protótipo TSC4, com mesas de $12,5 \mathrm{~mm}$. O protótipo TSI2, com mesas de 16,0 e 19,0 mm, no entanto, apresenta um aumento significativo de ductilidade quando comparado ao protótipo TSC5, com mesas de 16,0 mm, como pode ser visualizado na figura 5.15. 


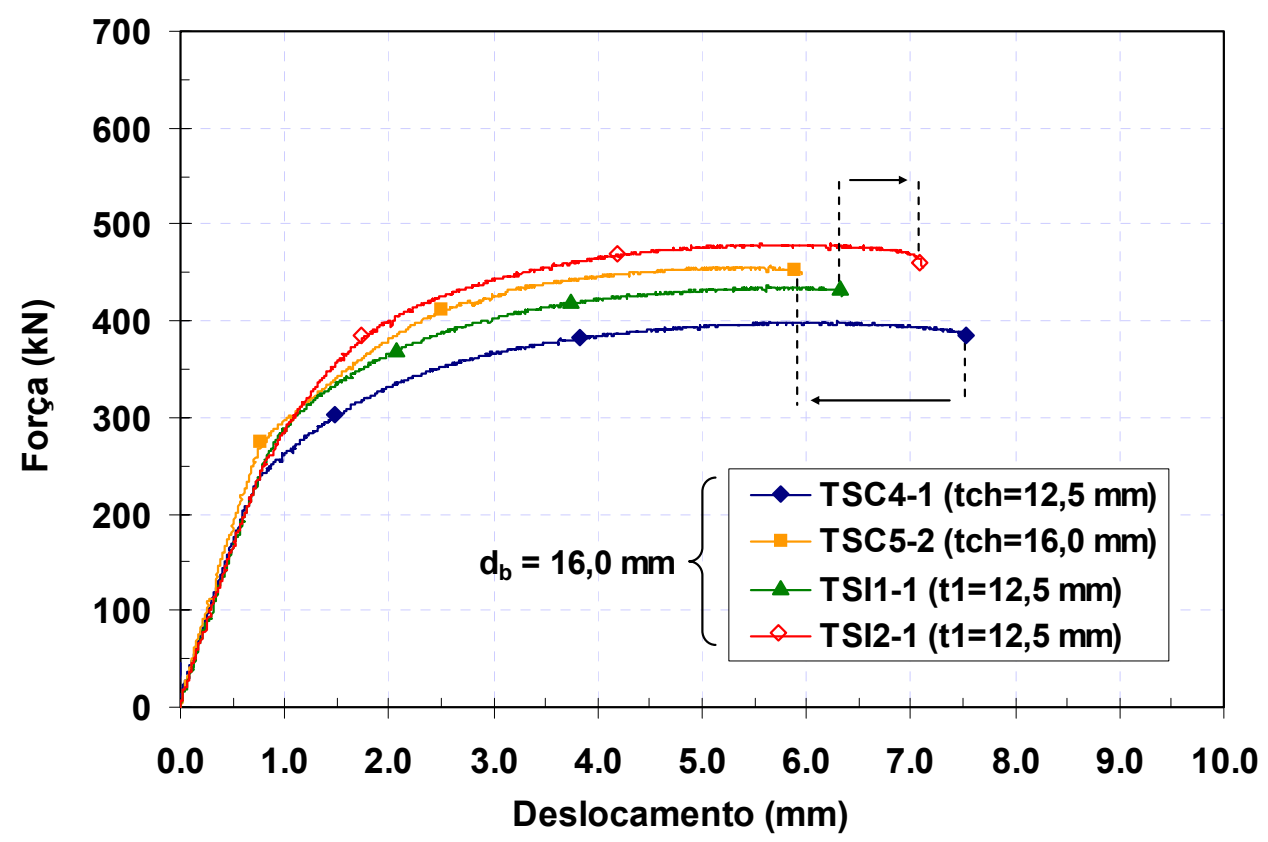

Figura 5.15 - Variação de ductilidade entre os protótipos TSI e TSC

Enfatiza-se que, neste caso, a influência do "efeito alavanca" na variação do modo de falha dos perfis "T" é menor e a solicitação nos parafusos passa a ser menos influenciada por esforços de flexão quando comparadas aos protótipos TSC4 e TSC5. Assim, caracteriza-se a flexão mais pronunciada na direção perpendicular à alma dos perfis "T" como um padrão de deformação para as mesas, não influenciada significativamente pela interação em mesa e parafusos.

No entanto, é possível observar uma variação nos padrões de plastificação da mesa, que ocorreu de forma sistemática para o grupo TSI. A figura 5.16 ilustra a plastificação nas mesas do protótipo TSI1-2 juntamente com detalhes dos parafusos após a ruptura.
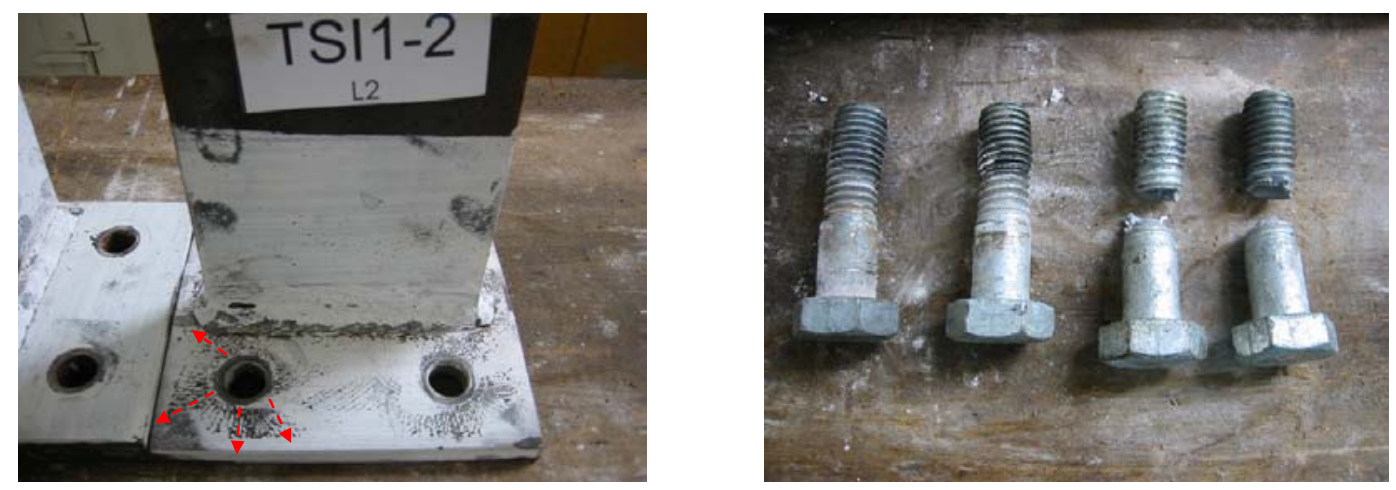

Figura 5.16 - Plastificação e detalhes dos parafusos no protótipo TSI1-2 
$\mathrm{Na}$ figura 5.16 identificam-se marcas que indicam a tendência de plastificação dos furos para a borda nas mesas, na direção perpendicular à alma do perfil "T" e para a região central da borda entre os furos. No detalhe dos parafusos, a seção de ruptura indica a menor influência da flexão destes componentes. Esse padrão foi verificado para todos os protótipos do grupo TSI. As linhas de plastificação nos protótipos TSI2 e TSI3 podem ser visualizadas nas figuras $5.17(\mathrm{a})$ e $5.17(\mathrm{~b})$.

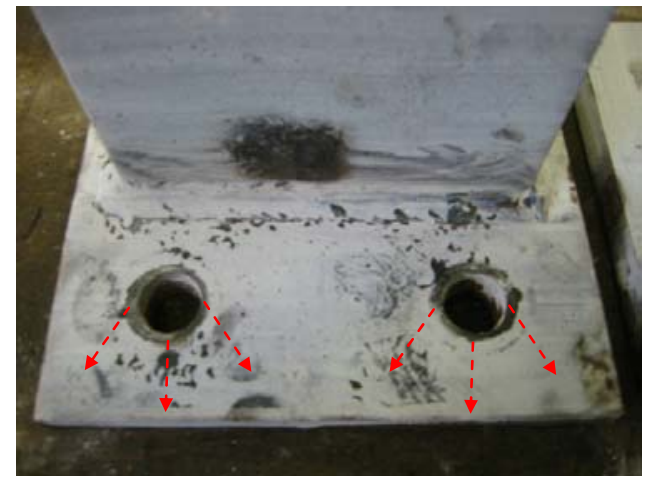

(a) TSI2-2

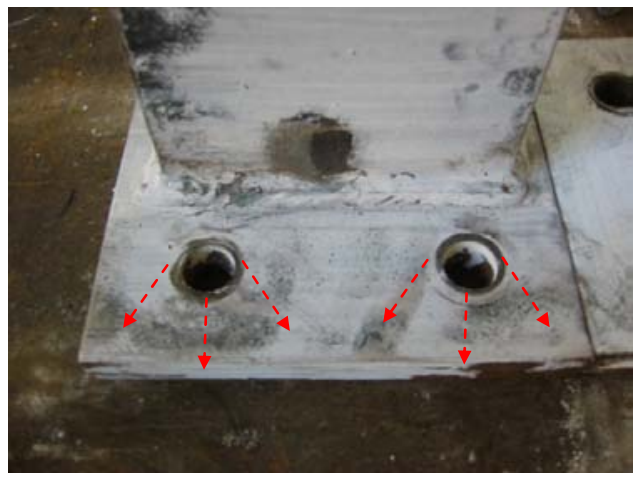

(b) TSI3-2

Figura 5.17 - Linhas de plastificação nas mesas dos protótipos TSI2-2 e TSI3-2

Para observar a variação nas deformações das mesas entre os protótipos TSC e TSI, apresenta-se, na figura 5.18, os dados coletados nos extensômetros 1, 2, 3, e 4, indicados na figura, na direção perpendicular à alma para cada lado da ligação dos protótipos TSI3-1 e TSC6-2, ambos com mesas de $19,0 \mathrm{~mm}$ de espessura e parafusos de $16,0 \mathrm{~mm}$.

Para o protótipo TSI3-1 há uma diminuição significativa para a deformação no lado 1 , pelo aumento de flexibilidade da mesa no lado 2 . As deformações no lado 2, com relação ao protótipo TSC6-2, apresentam um aumento significativo no centro da mesa nos estágios iniciais de plastificação.

No entanto a deformação no centro tende a uniformizar-se com a deformação na borda, o que indica a flexão predominante segundo a direção perpendicular à alma, apesar da plastificação ter iniciado na região central em direção aos furos. 


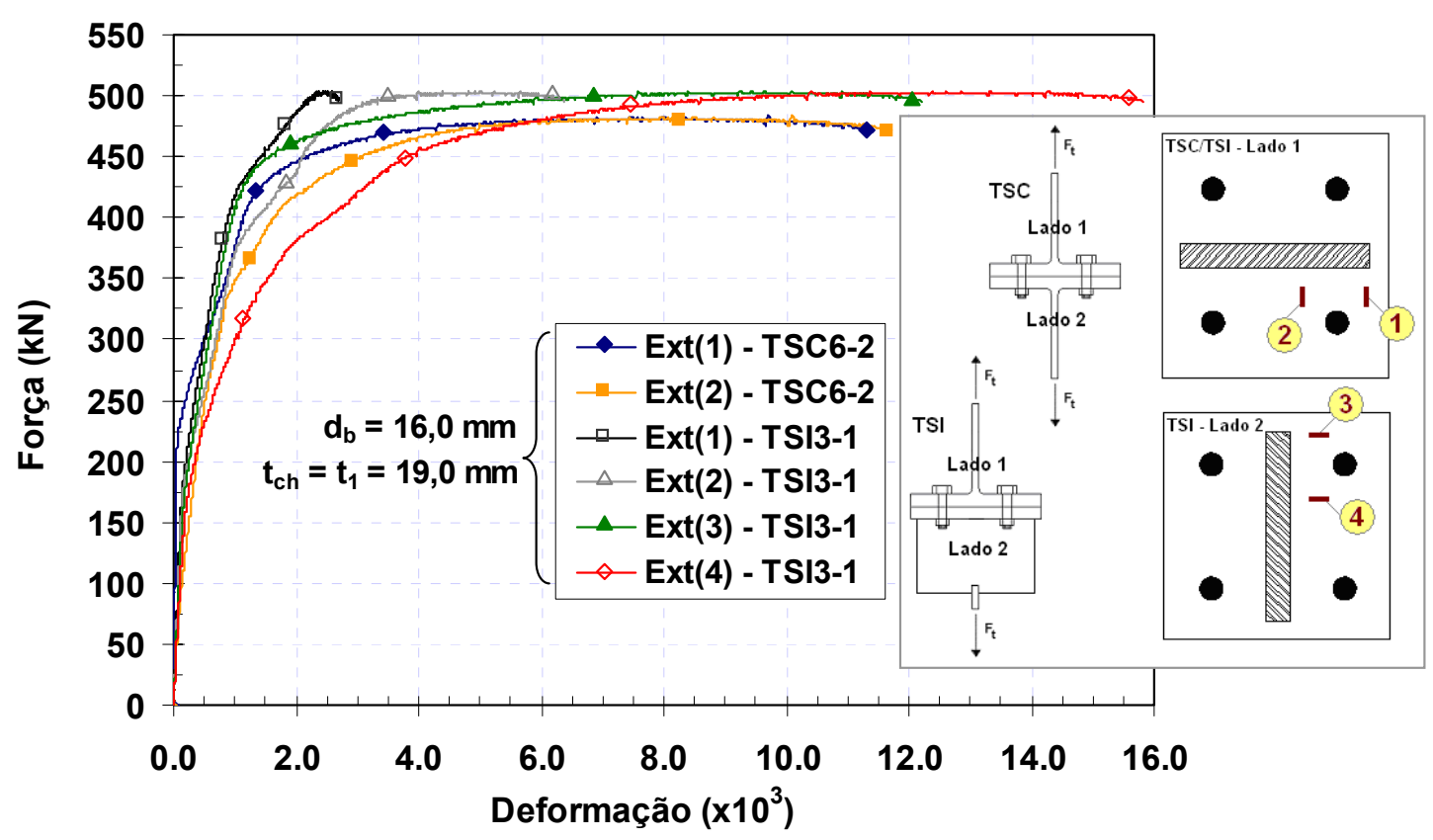

Figura 5.18 - Deformações nas mesas dos protótipos TSI3-1 e TSC6-2

Considerando-se a utilização dos modos de falha para os perfis "T" no dimensionamento da chapa de topo à flexão, aplicados usualmente às ligações duplo "T", a variação da tipologia pela perpendicularidade entre as almas dos perfis "T" não modifica de forma significativa a resistência dos protótipos.

No entanto, observou-se variações nos padrões de plastificação das mesas e na interação entre mesa e parafusos, o que conduziu à variações na magnitude do "efeito alavanca" e da ductilidade dos protótipos.

\subsubsection{Resultados para o grupo TSIE - enrijecimento da alma}

Para o grupo TSIE foi possível observar a influência do enrijecimento da alma que não modifica significativamente o comportamento global da ligação com relação ao grupo TSC, a menos de um ganho de resistência.

A figura 5.19 apresenta as curvas força-deslocamento para os protótipos do grupo TSIE, ressaltando que os protótipos com parafusos de 19,0 mm não foram ensaiados até o colapso. 


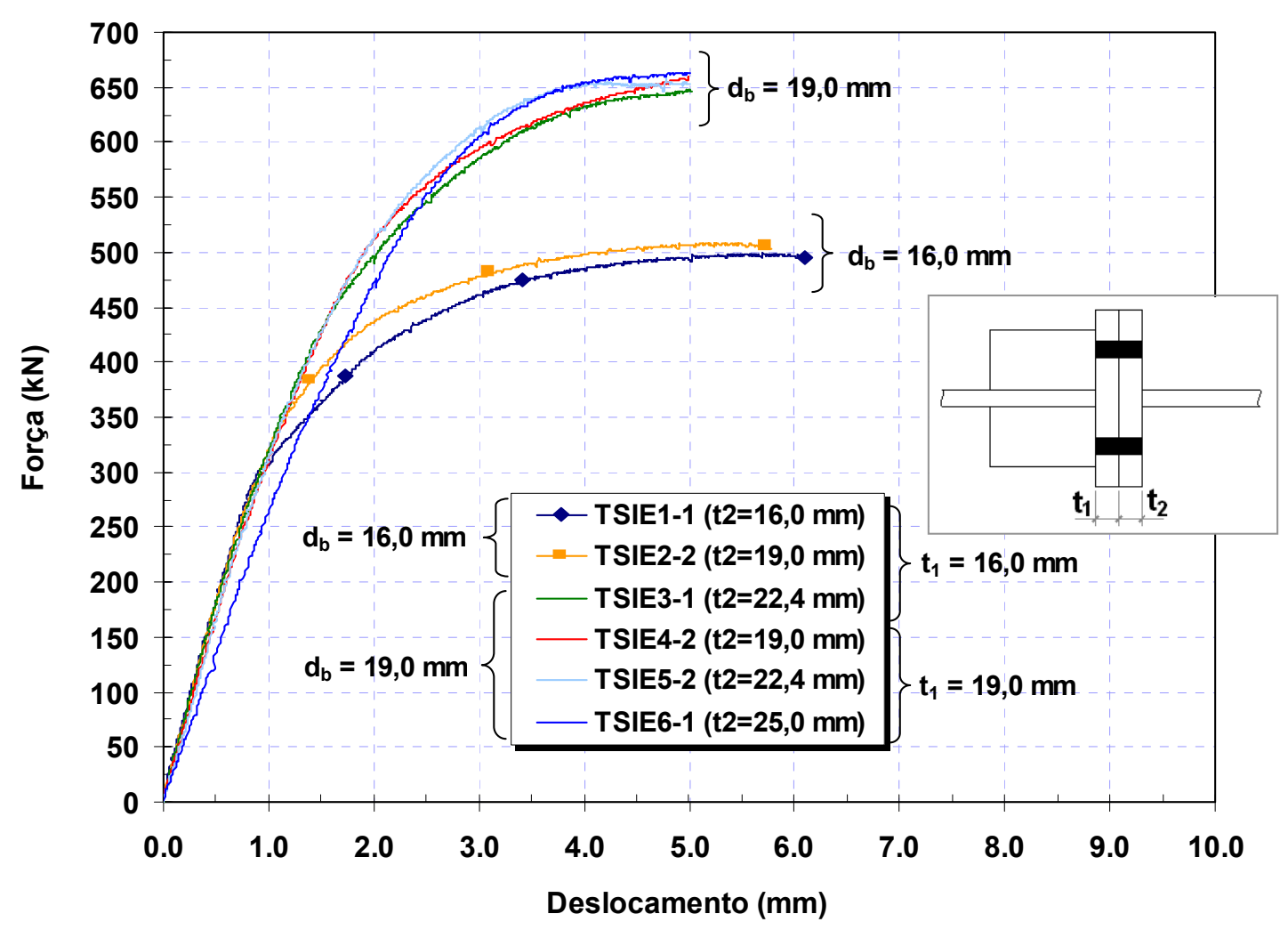

Figura 5.19 - Curvas força-deslocamento para os protótipos TSIE

Para os protótipos com parafusos de $16,0 \mathrm{~mm}$, o aumento da espessura da mesa provoca uma leve diminuição da ductilidade, com um pequeno aumento de resistência. Para o sub-grupo com parafusos de 19,0 $\mathrm{mm}$, o aumento da capacidade resistente é visível.

$\mathrm{Na}$ figura 5.20 apresenta-se uma comparação entre as curvas forçadeslocamento dos protótipos TSIE1-1 e TSC5-2, ambos com mesas e parafusos de $16,0 \mathrm{~mm}$.

Para esses dois protótipos, observa-se o aumento da capacidade resistente com a inclusão do enrijecimento, ressaltando-se a manutenção da ductilidade entre os protótipos TSIE1-1 e TSC5-2, o que também ocorre de maneira sistemática entre os dois grupos.

A inclusão do enrijecimento diminui de forma significativa a deformabilidade da mesa para o lado enrijecido da ligação duplo "T". Neste caso, espera-se que as deformações sejam concentradas na mesa não enrijecida, cuja plastificação deve acontecer em taxas mais elevadas. 


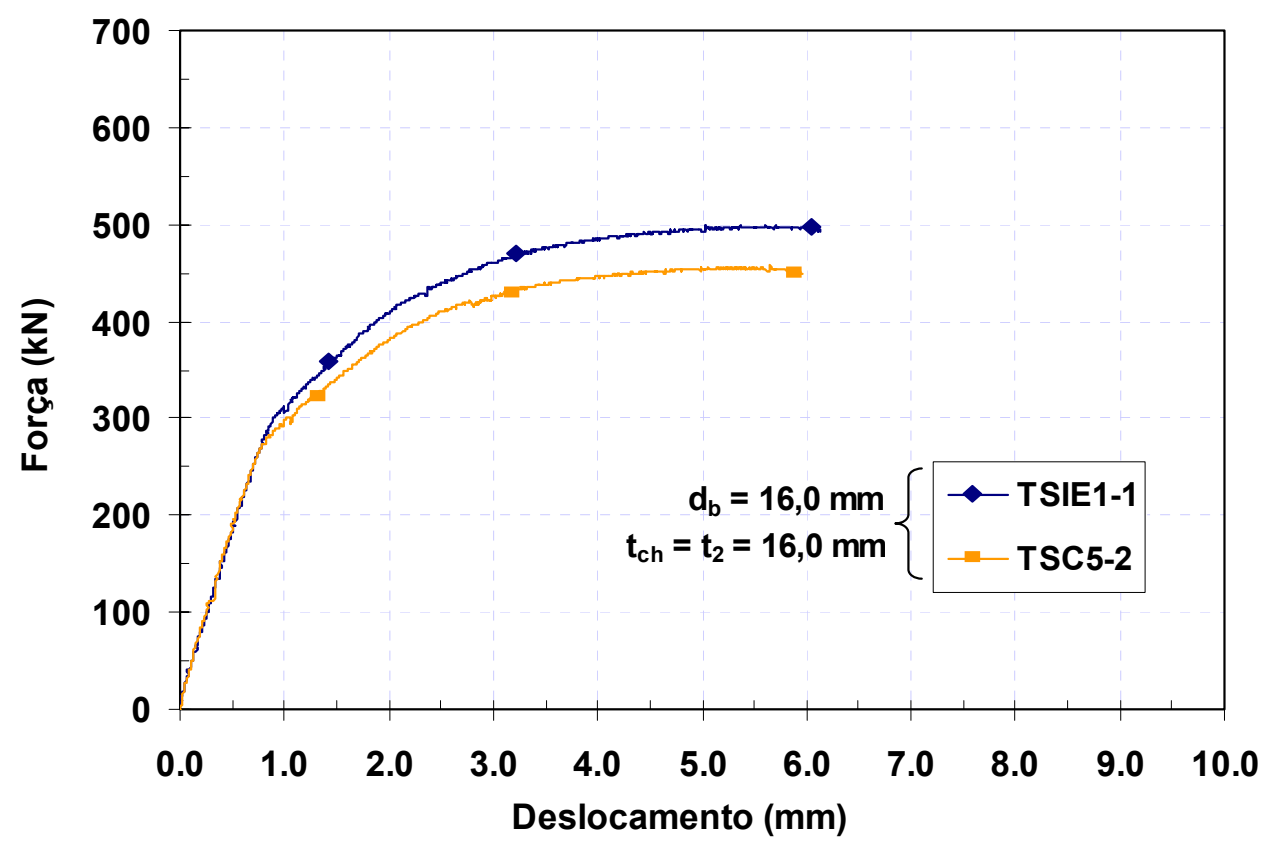

Figura 5.20 - Curvas força-deslocamento para os protótiopos TSIE1 e TSC5

No entanto, não há indicações de que os padrões de plastificação na mesa dos protótipos TSIE sofram modificações quando comparados aos protótipos similares do grupo TSC, já que não há variações significativas de ductilidade como observado na figura 5.20.

Outro indicativo de que os padrões de plastificação não são alterados é o aumento de resistência da ligação que, apesar de pequena, sugere uma diminuição do "efeito alavanca".

Para exemplificar a configuração das deformações para o grupo TSIE, na figura 5.21 são ilustradas duas vistas para o protótipo TSIE1-1 logo após o colapso dos parafusos.

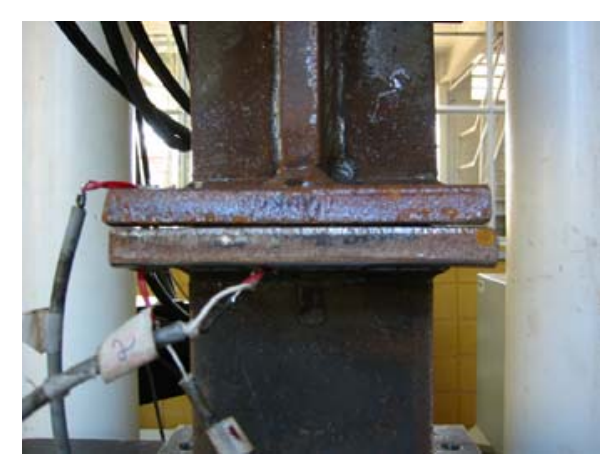

(a) Visão lateral

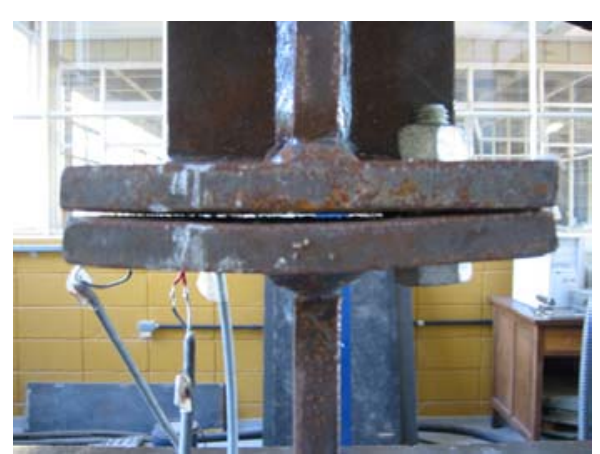

(b) Visão frontal

Figura 5.21 - Deformações nas mesas do protótipo TSIE1-1 após o colapso 


\subsubsection{Comentários gerais sobre os grupos TSC, TSI e TSIE}

Apenas para ilustrar, de forma geral, a variação de comportamento entre os protótipos de ligações duplo "T", a figura 5.22 apresenta as curvas força-deslocamento para os três grupos, especificamente para os protótipos com parafusos de $16,0 \mathrm{~mm}$.

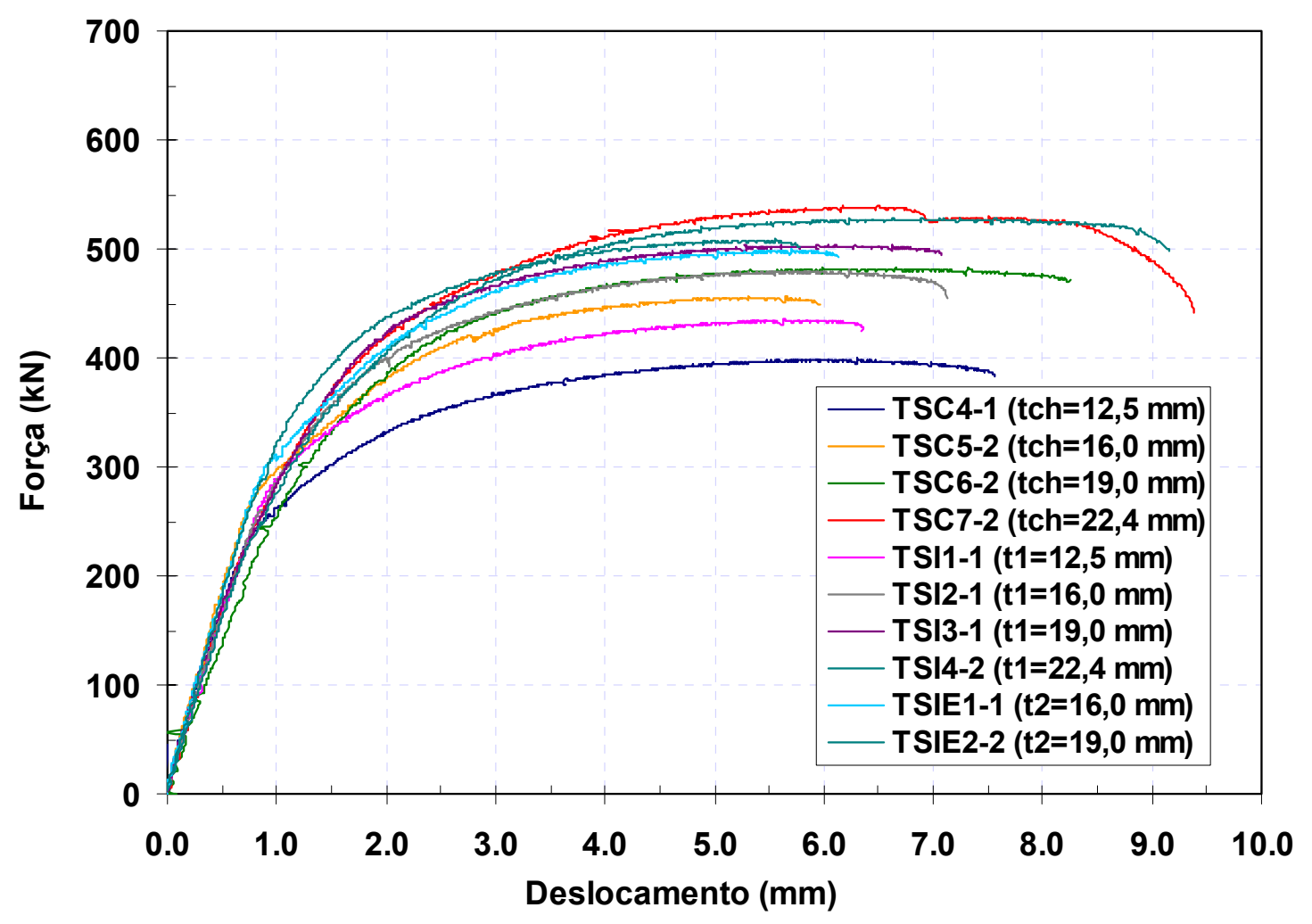

Figura 5.22 - Curvas força-deslocamento para os protótipos TSC, TSI e TSIE com parafusos de $16,0 \mathrm{~mm}$

Em uma comparação geral, é possível se concluir que a capacidade resistente das ligações duplo "T", independentemente da tipologia analisada, tem uma faixa de variação cujo patamar superior é bem definido, em função da capacidade resistente dos parafusos à tração.

O patamar inferior é função da intensidade dos "efeitos de alavanca", que dependem da interação entre as mesas dos perfis "T" e os parafusos e, portanto, não é facilmente determinada. No entanto, a tendência de crescimento da resistência com o aumento da espessura da mesa do perfil "T" é uniforme, mesmo considerando-se as mudanças de tipologia. 
O mesmo não ocorre com a ductilidade. De acordo com o exposto no capítulo 3, os limites de ductilidade para essas ligações não são tratados pelos modelos analíticos e dependem, novamente, da intensidade dos "efeitos de alavanca" que, por sua vez, é função da deformabilidade da mesa dos perfis "T" com relação à deformabilidade dos parafusos.

Como a variação de ductilidade não é uniforme, é coerente supor que há variações nos modos de falha em função das variações das linhas de plastificação, utilizadas na metodologia proposta por Zoetemeijer \& deBack (1972) para a equivalência entre os perfis "T" e a chapa de topo.

A observação dos resultados para as ligações duplo "T" também permite concluir que não há, pelo menos em termos do comportamento global, variações significativas da capacidade resistente e da ductilidade dos protótipos com a variação de tipologia.

\subsection{LIGAÇÕES COM CHAPA DE TOPO ESTENDIDA}

As ligações com chapa de topo estendida foram observadas experimentalmente com o objetivo principal de gerar dados para comparações com os modelos numéricos e para se comprovar comportamentos já conhecidos deste tipo de ligação, como as variações na rigidez inicial, a mudança de posição da linha neutra na viga, os efeitos da protensão nos parafusos e a variação qualitativa do "efeito alavanca".

Além disso, foi possível analisar algumas considerações sobre o comportamento momento-rotação dessas ligações, geralmente calculado a partir da rotação da chapa de topo, mas que pode variar para a chapa de topo e para a viga em função da localização dos pontos de referência para cálculo da rotação global do conjunto viga-pilar.

Ressalta-se, novamente, que os resultados experimentais obtidos para essa série são utilizados apenas para a observação global do comportamento dessas ligações, sem a intenção de conduzir a análises paramétricas ou para discussão dos métodos de dimensionamento da chapa de topo. 
Fazendo-se referência ao capitulo anterior, os protótipos ensaiados foram denominados de CTEE1, CTEE2 e CTEE3, com chapas de topo de 16,0, 19,0 e $\mathbf{2 5 , 0} \mathrm{mm}$ de espessura, respectivamente, e parafusos de $16,0 \mathrm{~mm}$.

\subsubsection{Rigidez global do conjunto viga-pilar}

A rigidez da ligação influencia diretamente na resistência e na ductilidade do conjunto viga-pilar e as relações força-deslocamento para a extremidade da viga podem ser utilizadas para a observação do comportamento desse conjunto.

A figura 5.23 apresenta as relações força-deslocamento vertical para os protótipos do grupo CTEE, fazendo-se uma comparação geral para os deslocamentos máximos obtidos entre o pilar e a extremidade das vigas.

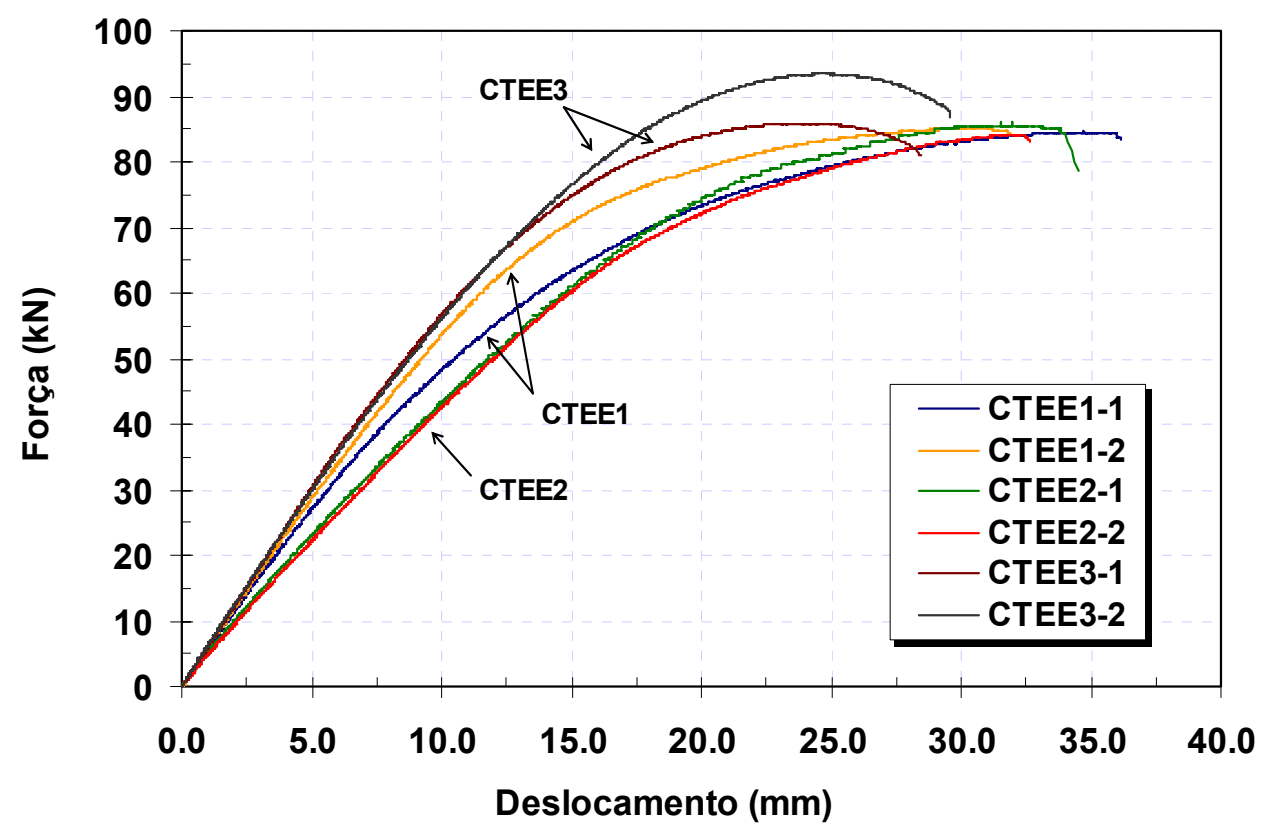

Figura 5.23 - Curvas força-deslocamento global para os protótipos CTEE

Os protótipos foram ensaiados aos pares e, uma vez que se adotou a configuração cruciforme, os resultados para cada protótipo são também referentes a um par de ligações correspondentes aos dois lados do protótipo cruciforme. Neste caso, foram observadas algumas variações no 
comportamento entre os protótipos de cada par, mas em geral, não houve variações significativas entre as ligações para o mesmo protótipo.

Assim, os resultados apresentados na figura 5.23 se referem à média dos valores obtidos para cada lado do protótipo cruciforme e serão utilizados, a menos quando especificado, para a apresentação dos resultados experimentais.

Devida à variação da espessura da chapa de topo há uma variação, como já esperado, da resistência e da ductilidade entre os protótipos. No entanto, observa-se também uma variação da rigidez inicial, ao contrário do observado para a série de ligações duplo "T", para as quais o trecho inicial das curvas força-deslocamento era função das forças de protensão e não da espessura da mesa dos perfis "T".

Nas curvas da figura 5.23, o aumento da rigidez inicial é visível entre os protótipos CTEE2 e CTEE3, com chapas de topo de 19,0 e $\mathbf{2 5 , 0} \mathbf{m m}$, respectivamente. Para os protótipos CTEE1-1 e CTEE1-2, com chapa de topo de 16,0 mm, observa-se comportamentos intermediários e que também variaram entre os dois protótipos do par. Ao contrário do que poderia se esperar, a rigidez, e até mesmo a resistência dos protótipos CTEE1 são mais elevadas que as dos protótipos CTEE2, com chapa mais espessa.

Como descrito no capítulo anterior, a protensão nos parafusos foi aplicada, em todos os protótipos, com o auxílio de um torquímetro, para se eliminar possíveis variações das forças de protensão entre os protótipos.

Além disso, algumas observações realizadas durante a montagem dos ensaios com relação à geometria dos protótipos, revelaram imperfeições significativas, principalmente nos perfis das vigas. As almas de diversos perfis apresentaram empenamento e algumas mesas, apesar de paralelas, não foram soldadas na mesma linha, até mesmo provocando uma falta de perpendicularidade entre o eixo longitudinal da viga e o pilar.

A figura 5.24 apresenta alguns detalhes do posicionamento da extremidade de uma das vigas do protótipo CTEE1-1, na fase final de montagem, onde se visualiza os calços colocados nos vínculos de garfo para permitir o alinhamento do aparelho de apoio com as faces laterais das mesas. A flexão da alma também pode ser visualizada. 

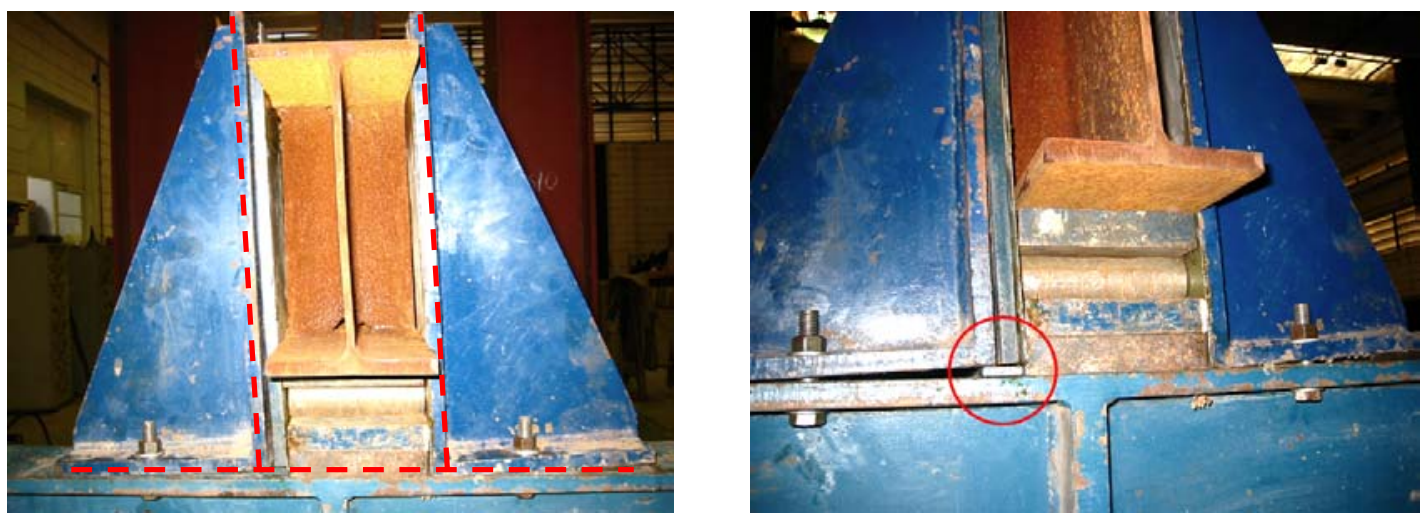

Figura 5.24 - Imperfeições na geometria das vigas do protótipo CTEE1-1

Nestas condições, as imperfeições dos perfis podem ser a causa das variações observadas nas curvas globais força-deslocamento para as vigas, uma vez que a rigidez inicial depende, basicamente, das forças de protensão e da geometria dos protótipos.

A ductilidade dos protótipos também é influenciada por essas imperfeições, já que o deslocamento vertical da viga é função da plastificação de sua seção transversal que também pode ter variado entre os protótipos.

No entanto, é possível identificar uma queda de ductilidade com o aumento da espessura da chapa de topo, mesmo comportamento observado no protótipo TSC3, que pode ser atribuído a uma pequena deformabilidade da chapa de topo com relação aos parafusos.

Como conseqüência, tem-se uma diminuição do "efeito alavanca" que também permite um aumento da resistência, limitada pela capacidade máxima dos parafusos à tração. Comparando-se os protótipos CTEE3-1 e CTEE3-2, há uma diferença significativa de resistência. Neste caso, também é possível atribuir essa diferença às imperfeições geométricas observadas no protótipo CTEE3-1 que, além da viga, apresentava um empenamento na chapa de topo.

\subsubsection{Modos de falha}

As variações dos modos de falha para os protótipos dessa série podem ser observadas, com mais detalhes, pelos tipos de ruptura dos parafusos. Para futuras comparações, a figura 5.25 indica um esquema do 
protótipo cruciforme e também as ligações de cada protótipo, correspondentes ao lado (A) e ao lado (B).

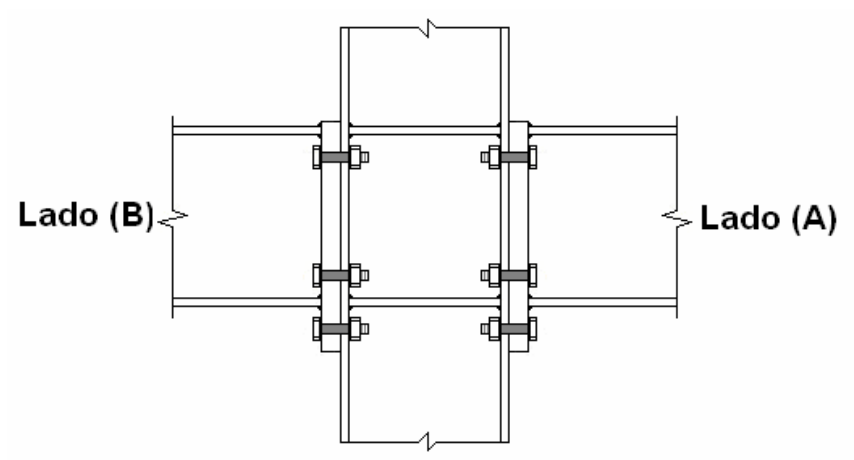

Figura 5.25 - Indicação dos lados do protótipo cruciforme

Observando-se o tipo de colapso dos parafusos para os protótipos dessa série, as figuras 5.26(a) e 5.26(b) indicam, respectivamente, a flexão na chapa de topo do lado (B) do protótipo CTEE1-2 em estágios avançados de carregamento e a deformação do lado $(\mathbf{A})$ do mesmo protótipo após a ruptura dos parafusos.

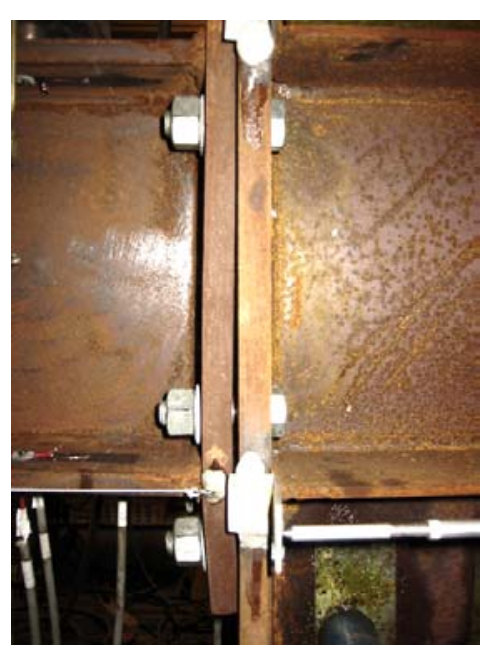

(a)

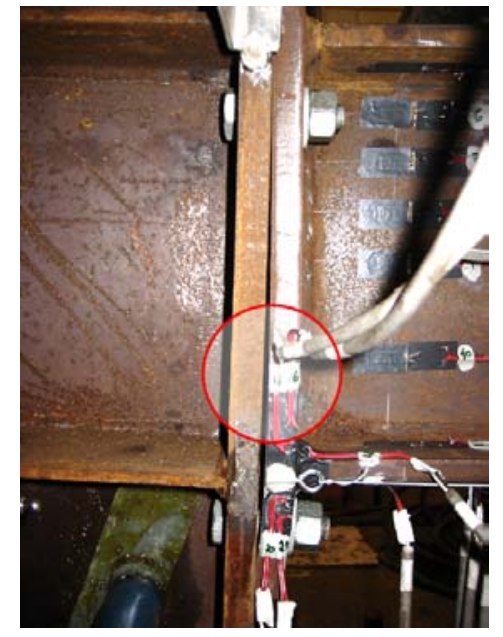

(b)

Figura 5.26 - Deformações na chapa de topo e ruptura dos parafusos no protótipo CTEE1-2

A chapa de $16,0 \mathrm{~mm}$ de espessura, combinada aos parafusos de 16,0 $\mathrm{mm}$, apresenta uma flexão visível na região tracionada. Na figura 5.26 também é possível visualizar o contato entre a extremidade inferior da chapa de topo e a mesa do pilar, o que indica a existência de forças de alavanca nos parafusos. 
De fato, o colapso do protótipo CTEE1-2 foi caracterizado pela ruptura dos parafusos tracionados da linha de parafusos interna às mesas da viga, como indicado na figura 5.26(b). O "efeito alavanca", neste caso, provoca um aumento da solicitação nos parafusos internos, que passam a limitar a capacidade resistente da ligação.

A flexão na extensão da chapa de topo é mais acentuada do que na região interna às mesas, justamente pelo enrijecimento da chapa de topo devido à alma da viga. Assim, os parafusos internos às mesas são solicitados à tração. A figura 5.27(a) apresenta um detalhe da região tracionada para o protótipo CTEE1-2 e a figura 5.27(b) uma caracterização da ruptura à tração de um parafuso da linha interna.

Nos protótipos CTEE1, a flexão na extensão da chapa de topo é visível e indica a solicitação dos parafusos por esforços combinados de tração e flexão. Apesar disso, a solicitação à tração dos parafusos da linha interna foi preponderante às solicitações de flexo-tração nos parafusos da linha externa (na extensão da chapa).

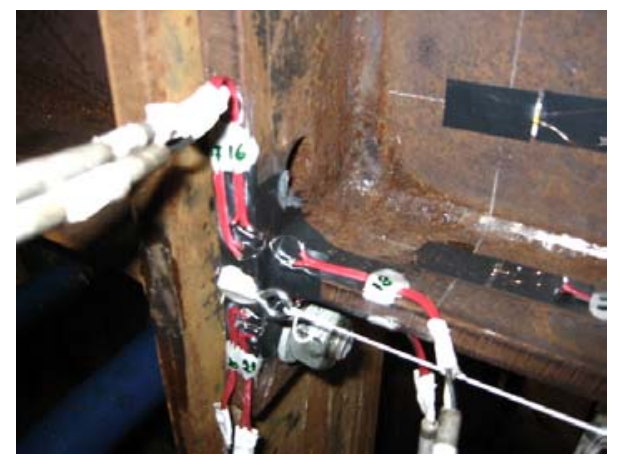

(a)

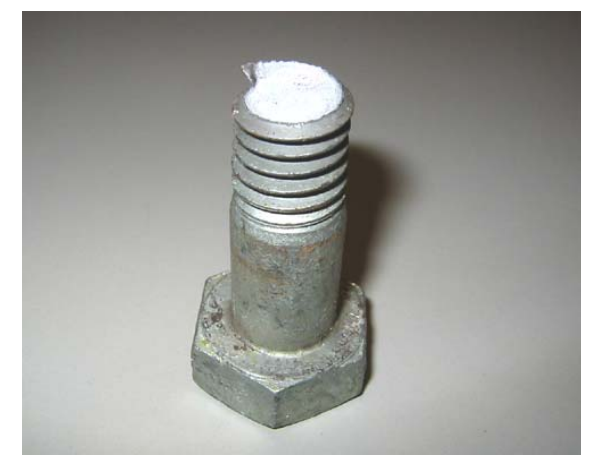

(b)

Figura 5.27 - Detalhe da região tracionada e da ruptura à tração dos parafusos do protótipo CTEE1-2

Para os protótipos CTEE2 a ruptura dos parafusos não ocorre de maneira isolada para a linha interna, mas em conjunto com os parafusos na extensão da chapa de topo.

À medida que a espessura da chapa de topo aumenta, espera-se um decréscimo do "efeito alavanca". Assim, é possível que a solicitação nos parafusos da linha interna ainda seja maior que os da linha externa, mas com um equilíbrio maior entre a capacidade resistente das duas linhas devido às 
diferenças de solicitação, de tração para a linha interna e de flexo-tração para a linha externa.

A figura 5.28(a) ilustra, para o protótipo CTEE2-1, a flexão da chapa de topo destacando a ruptura das duas linhas de parafusos no lado (A). Um detalhe dos parafusos da linha externa do mesmo protótipo, nos quais é possível observar as seções de ruptura nos parafusos por flexo-tração, é mostrado na figura 5.28(b).

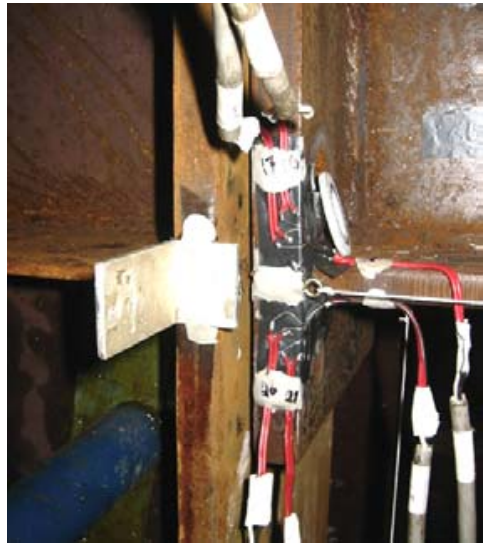

(a)

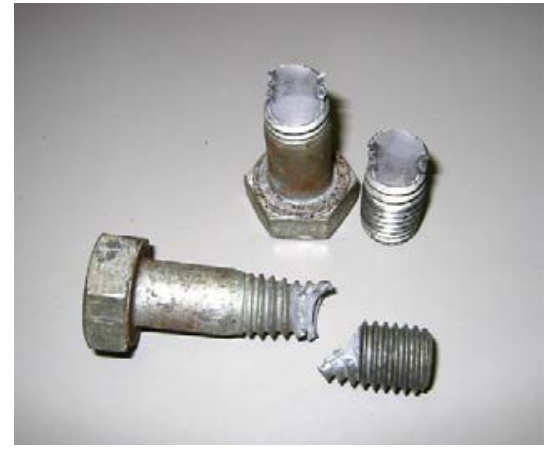

(b)

Figura 5.28 - Detalhe da região tracionada e da ruptura dos parafusos do protótipo CTEE2-1

Para o protótipo CTEE2-2 apresenta-se, na figura 5.29(a), as deformações na chapa de topo do lado $(\mathbf{B})$, ressaltando-se que não houve a ruptura dos parafusos na extensão da chapa de topo. No entanto, é possível visualizar a ruptura de um parafuso da linha interna por tração, na figura 5.29(b).

Um comportamento diferente pode ser observado para os protótipos CTEE3. A chapa de topo de $\mathbf{2 5 , 0} \mathbf{m m}$ de espessura, em combinação com os parafusos de $16,0 \mathrm{~mm}$, tem espessura suficientemente alta para eliminar 0 "efeito alavanca", como pode ser observado na figura 5.30(a) para o lado (B) do protótipo CTEE3-2.

Uma vez eliminado o "efeito alavanca", espera-se uma distribuição mais uniforme de forças entre os parafusos da região tracionada e, de fato, o colapso da ligação nos protótipos CTEE3 se deu pela ruptura de todos os parafusos tracionados. 


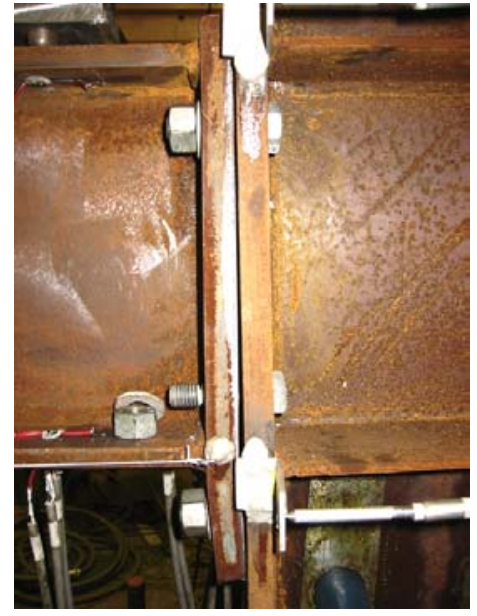

(a)

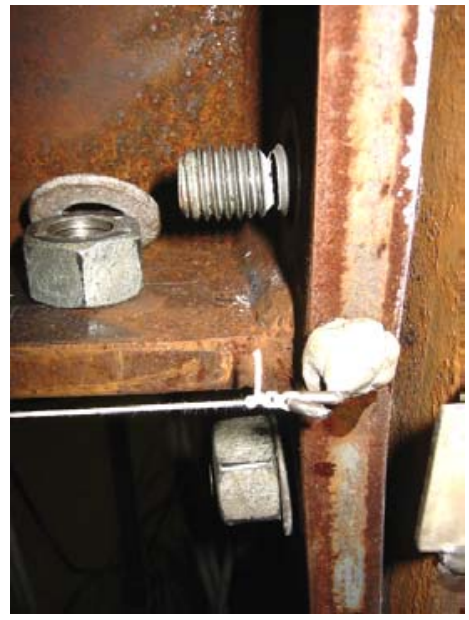

(b)

Figura 5.29 - Detalhe da região tracionada e da ruptura dos parafusos do protótipo CTEE2-2

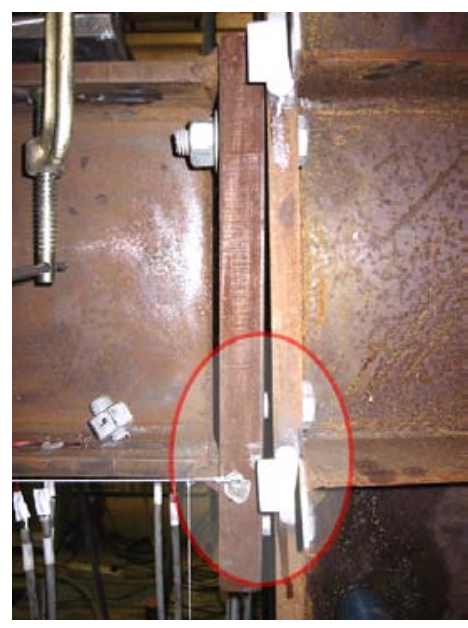

(a)

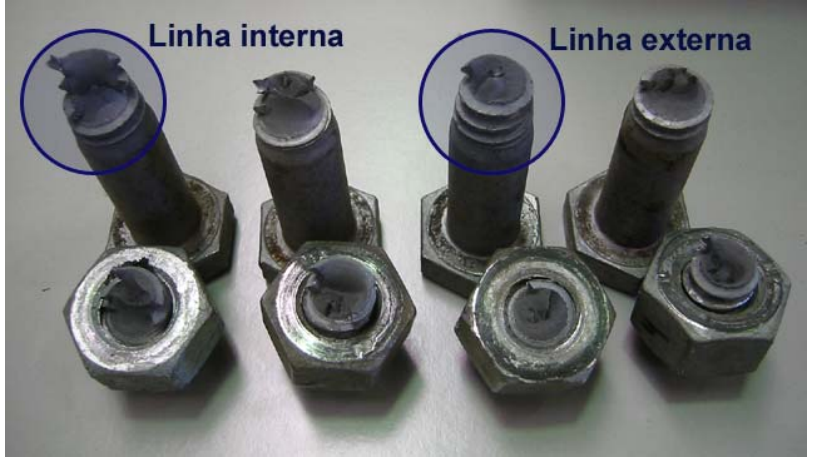

(b)

Figura 5.30 - Detalhe da região tracionada e da ruptura dos parafusos do protótipo CTEE3-2

No detalhe da figura $5.30(\mathrm{~b})$, para a linha externa identifica-se facilmente a seção de ruptura por tração. Para a linha interna, apesar de não ser uniforme, a seção de ruptura não caracteriza o colapso por flexão, indicando que todos os parafusos são solicitados predominantemente à tração. 


\subsubsection{Rigidez rotacional - curvas momento-rotação}

A rigidez rotacional das ligações, representadas pelos diagramas momento-rotação, indicam a capacidade da ligação em transferir o momento aplicado entre vigas e pilares.

A figura 5.31 ilustra, esquematicamente, as deformações para uma ligação com chapa de topo estendida considerando o protótipo cruciforme, juntamente com indicações de rotações para a ligação, calculadas por meio de deslocamentos relativos da chapa de topo e da viga.

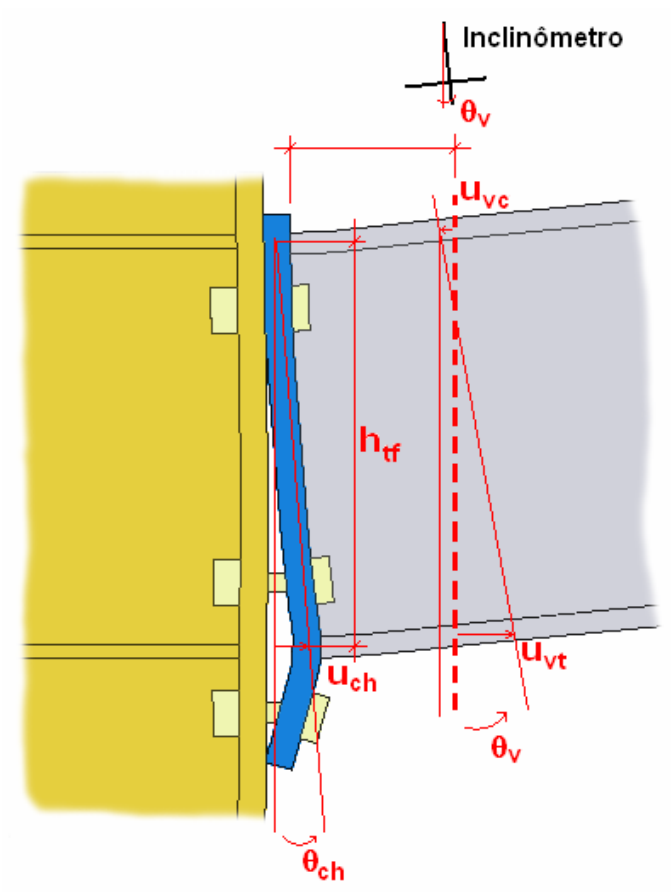

Figura 5.31 - Representação esquemática para o cálculo da rotação da ligação

Para o cálculo da rotação é usual considerar como hipótese o centro de rotação da ligação localizado na altura do plano médio da mesa comprimida da viga e, como referência, a abertura da chapa de topo com relação ao pilar na altura do plano médio da mesa tracionada.

Assim, a rotação $\phi_{c h}$ é calculada pela relação entre a abertura da chapa de topo e a distância entre os planos médios das mesas ( $\left.\mathbf{h}_{\mathrm{tf}}\right)$, considerando pequenas rotações.

A grande maioria dos trabalhos encontrados na literatura utiliza esse procedimento, com base em resultados experimentais, para o cálculo da rotação da ligação. 
No entanto, na figura 5.31 observa-se que o ponto de rotação da chapa de topo está localizado acima da mesa comprimida, o que ocorre em geral. No caso de chapas de topo mais rígidas com relação aos parafusos, como no caso dos protótipos CTEE3, o comportamento da chapa se aproxima da consideração anterior. No caso de chapas mais flexíveis, no entanto, as deformações nas chapas são localizadas na região tracionada, conduzindo possivelmente a valores subestimados de rotação.

Uma alternativa para o cálculo da rotação, um pouco menos usual, é a utilização de deslocamentos relativos em uma seção da viga próxima à ligação. O cálculo da rotação $\phi_{\mathbf{v}}$ é realizado com a mesma altura de referência $\left(\mathbf{h}_{\mathrm{tf}}\right)$. Para este caso, foi utilizado um inclinômetro posicionado na mesa comprimida da viga do lado (A) dos protótipos CTEE, distante $125,0 \mathrm{~mm}$ da face da chapa de topo $\left(\mathbf{d}_{\mathbf{v}}\right)$, para a medição direta da inclinação da viga, correspondente à rotação $\phi_{\mathbf{v}}$.

A figura 5.32 apresenta as curvas momento-rotação para os protótipos dessa série obtidos com o inclinômetro.

Assim como nas curvas força-deslocamento, observa-se que as curvas momento-rotação obtidas com o inclinômetro são influenciadas pela plastificação da viga. Os padrões das curvas na figura 5.32 são os mesmos das curvas força-deslocamento, inclusive com as diferenças encontradas na figura 5.23 .

A fim de se comparar a rotação na viga $\left(\phi_{\mathrm{v}}\right)$ e a rotação da chapa de topo $\left(\phi_{\mathrm{ch}}\right)$, a figura 5.33 apresenta as curvas momento-rotação para alguns protótipos considerando a abertura relativa entre a chapa de topo e a mesa do pilar na região tracionada. Para as chapas de topo foram obtidas três leituras de abertura, duas nas bordas laterais e uma no centro. Para o cálculo da rotação foi considerada a média entre os três valores.

De maneira geral, as curvas obtidas pela abertura das chapas têm rigidez inicial um pouco maior e ductilidade mais elevada, mas se aproximam para a leitura da rotação da viga na seção distante de $125,0 \mathrm{~mm}$ da chapa de topo - correspondente à metade da altura da viga. 


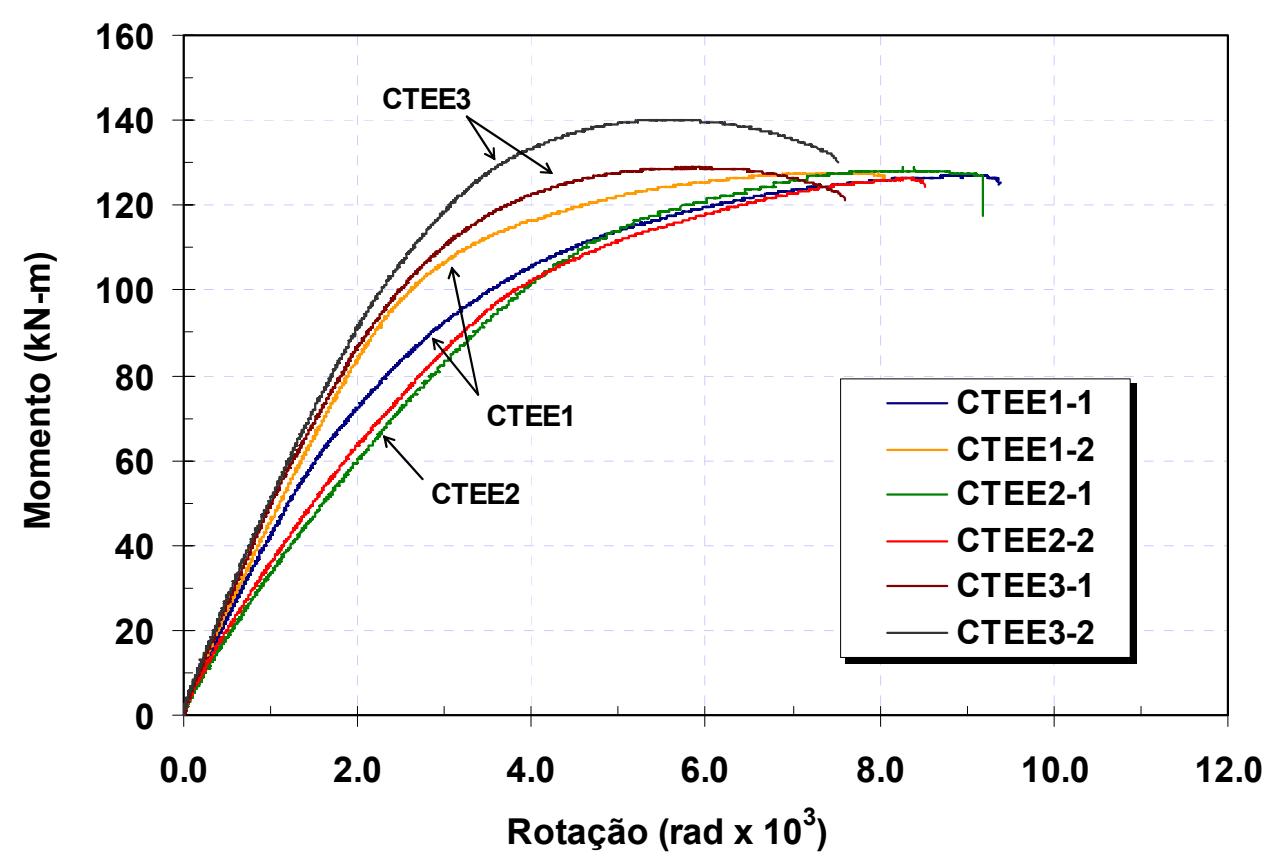

Figura 5.32 - Curvas momento-rotação para os protótipos CTEE - inclinômetro

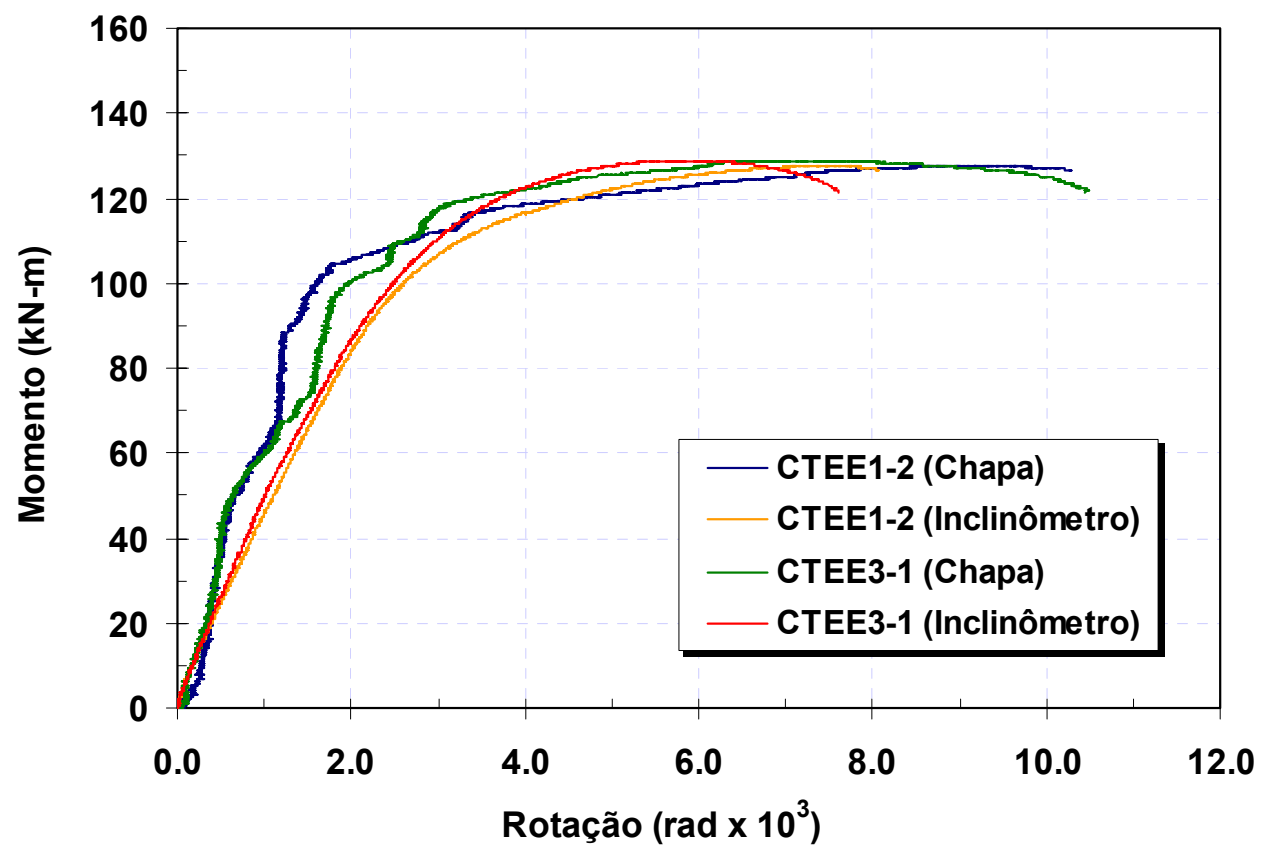

Figura 5.33 - Curvas momento-rotação para a chapa de topo e para o inclinômetro

Observando-se a figura 5.33, as curvas momento-rotação para a chapa não são suaves, apresentando diversas interferências. Devido às imperfeições iniciais, as bordas das chapas na região tracionada tiveram aberturas assimétricas, até mesmo maiores do que na região central, para a qual se esperavam deslocamentos maiores. 
Outro fator, também importante, é o fato de que as leituras foram realizadas por meio de tirantes, com transferência de deslocamentos horizontais para verticais. Como os deslocamentos são pequenos, pode haver variações na leitura dos transdutores. Com esses fatores, não é possível avaliar se houve problemas na instrumentação. Apesar disso, é possível verificar a tendência das curvas.

A validade da aplicação destas curvas, tanto para a chapa de topo quanto para a viga, na descrição da rigidez rotacional dessas ligações tem sido discutida em alguns trabalhos recentes (em fase de elaboração) ${ }^{4}$. Para a análise estrutural não há comparações relatadas entre a transferência de momentos entre vigas e pilares devido à aplicação das curvas momentorotação calculadas acima para estruturas de pórticos que considerem a semirigidez da ligação.

Dessa forma, as curvas apresentadas na figura 5.33 indicam a rigidez rotacional dos protótipos ensaiados sem a garantia de que, quando aplicadas em uma análise estrutural simplificada, reproduzam adequadamente a transferência parcial do momento fletor entre os elementos conectados e a rigidez global da ligação viga-pilar.

\subsubsection{Deformações na viga}

A leitura das deformações na viga foi realizada em uma seção distante $62,5 \mathrm{~mm}$ da face da chapa de topo, correspondente à $1 / 4$ da altura da viga.

Como resultado dessas deformações, um dado interessante das observações experimentais é o acompanhamento da posição da linha neutra naquela seção transversal, ao longo da altura da viga, ilustradas nas figuras 5.34, 5.35 e 5.36 para os protótipos CTEE1-2, CTEE2-2 e CTEE3-1, respectivamente. Nas figuras, são apresentadas as distribuições de deformação na alma da viga no lado $(\mathbf{A})$ dos protótipos para três valores de

\footnotetext{
${ }^{4}$ Figueiredo, L. M. B. Ligações Mistas Viga-Pilar - Análise Teórica e Experimental (título provisório). Trabalho de Doutoramento a ser concluído na Escola de Engenharia de São Carlos, USP, em 2004.
} 
momento aplicado na ligação, correspondentes à $\mathbf{0 , 6} \mathbf{M}_{\mathrm{p}}, \mathbf{0 , 8} \mathbf{M}_{\mathrm{p}}$ e $\mathbf{0 , 9} \mathrm{M}_{\mathrm{p}}$, este último próximo ao colapso da ligação, onde $\mathbf{M}_{\mathrm{p}}$ é o momento de plastificação da seção transversal da viga, de aproximadamente $140 \mathrm{kNm}$, considerando-se que o material das chapas tem tensão de escoamento de, aproximadamente, $300 \mathrm{MPa}$, de acordo com a caracterização dos materiais.

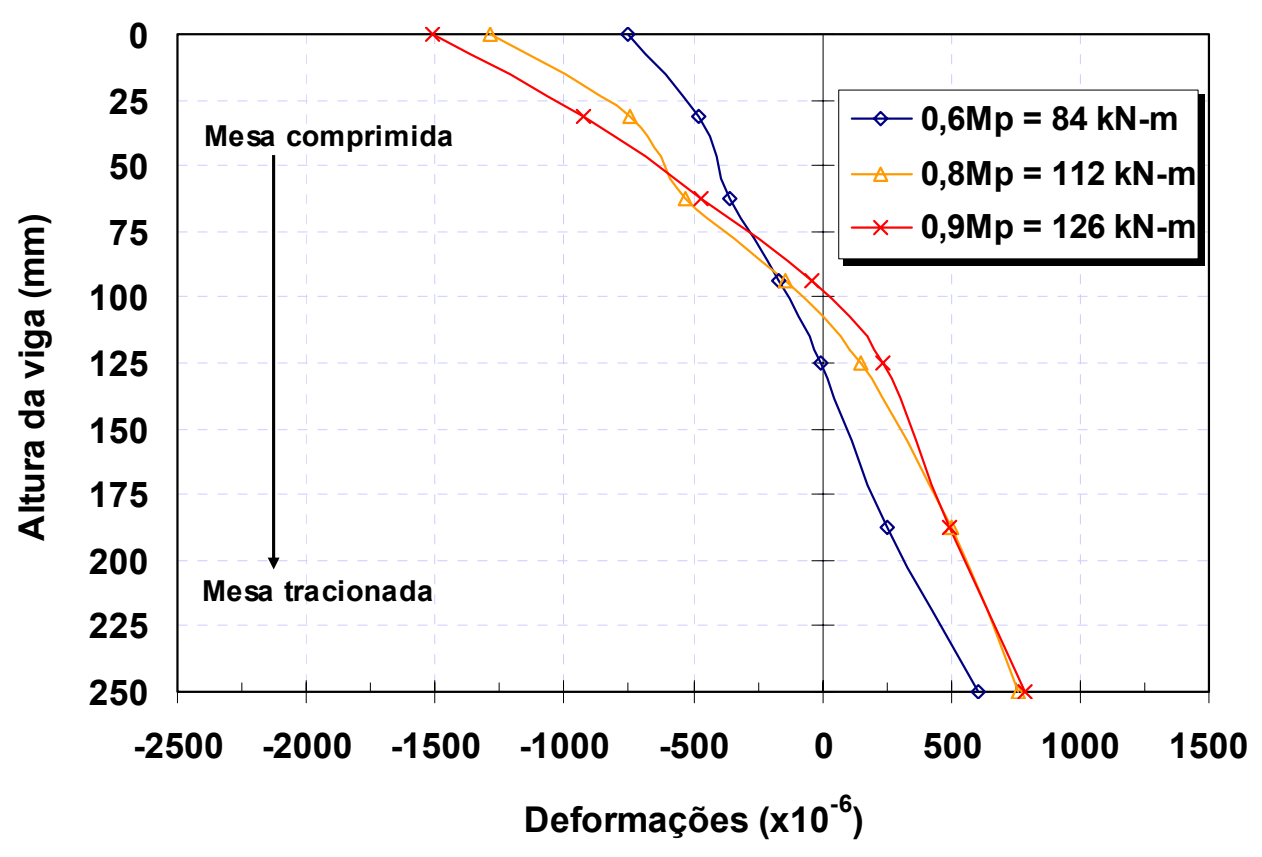

Figura 5.34 - Deformações na alma ao longo da altura da viga para o protótipo CTEE1-2

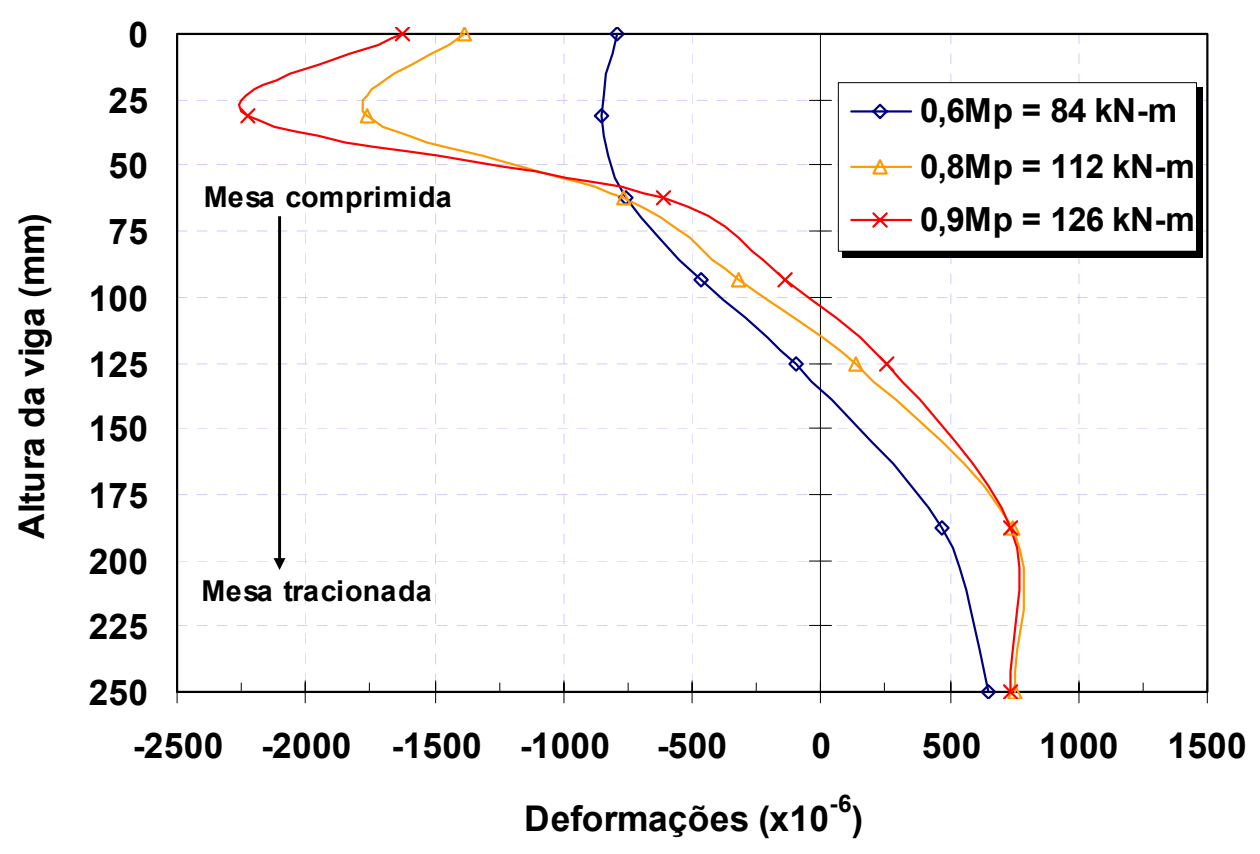

Figura 5.35 - Deformações na alma ao longo da altura da viga para o protótipo CTEE2-2 


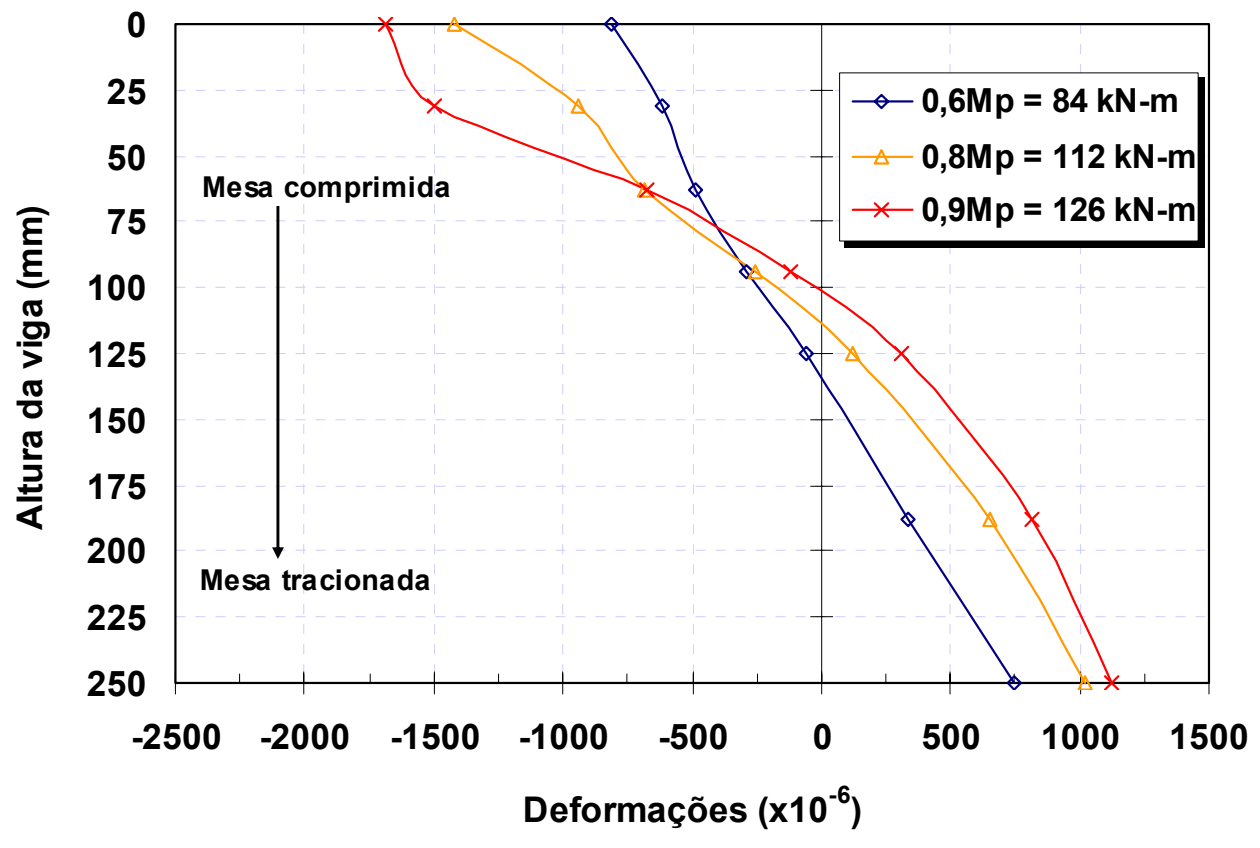

Figura 5.36 - Deformações na alma ao longo da altura da viga para o protótipo CTEE3-1

À medida que o carregamento cresce, é visível um reposicionamento da linha neutra na seção considerada, devido à flexão da chapa de topo na região tracionada. No entanto, essa variação da linha neutra é pequena para essa seção.

Considerando-se seções mais próximas à chapa de topo, espera-se que o reposicionamento da linha neutra em direção à mesa comprimida da viga seja um pouco mais acentuado. Apesar disso, observa-se que o momento resistente da ligação é inferior ao momento de plastificação da viga e, neste caso, a plastificação da seção transversal da viga não ocorre ao longo de toda a altura da alma.

Desta maneira, as deformações apresentadas nas figuras 5.34 à 5.36 indicam que considerar o plano médio da mesa comprimida como ponto de rotação para a chapa de topo pode se tornar uma simplificação grosseira.

As deformações no protótipo CTEE2-2, indicadas na figura 5.35, apresentam valores maiores com relação aos protótipos CTEE1-2 e CTEE3-1 nas proximidades da mesa comprimida. Considerando-se as curvas forçadeslocamento para os protótipos CTEE2, a menor rigidez inicial desses protótipos pode ser atribuída a uma plastificação não uniforme da seção 
transversal da viga, quando comparada aos protótipos CTEE1 e CTEE3, conseqüência das imperfeições iniciais.

Apesar disso, observa-se o aumento da deformabilidade da viga na medida em que se aumenta a espessura da chapa de topo, ou seja, na medida em que as deformações da chapa tornam-se menores.

\subsection{CONSIDERAÇÕES GERAIS SOBRE OS RESULTADOS EXPERIMENTAIS}

De maneira geral, os protótipos das ligações duplo "T" permitiram a observação de diferentes modos de falha e de algumas características do comportamento dos perfis "T", como a flexão da mesa e a interdependência entre as deformabilidades da mesa à flexão e dos parafusos à tração.

A observação e a comprovação experimental dos modos de falha propostos por Zoetemeijer e deBack (1972), juntamente com as comparações preliminares aos modelos analíticos propostos pelo Eurocode 3 (1993), são de fundamental importância para indicar os estados limites últimos a que estes componentes estão sujeitos, bem como ressaltar a complexidade dos mecanismos envolvidos na transferência de esforços, principalmente devido ao "efeito alavanca".

A série de ligações com chapa de topo permitiu uma visualização do comportamento global dessas ligações e, de forma mais qualitativa, das variações dos modos de falha a que estão sujeitas.

No entanto, algumas interferências nos resultados experimentais para o grupo CTEE foram observadas, devidas às imperfeições geométricas observadas nos protótipos durante a montagem. Considerando-se casos práticos, essas imperfeições não estão fora da realidade da construção civil, mas em se tratando de protótipos experimentais, inviabilizaram a comparação mais detalhada entre os protótipos.

Neste caso, as comparações com os resultados dos modelos numéricos, apresentadas no próximo capítulo, serão realizadas em função de comportamentos globais, como as curvas força-deslocamento, lembrando que não é função da modelagem reproduzir com exatidão um resultado 
experimental específico, mas sim de simular adequadamente os mecanismos observados experimentalmente e que regem o comportamento dessas ligações. 


\section{Capítulo}

\section{MODELAGEM NUMÉRICA}

Nos primeiros capítulos enfatizou-se a grande complexidade do comportamento das ligações parafusadas e a crescente utilização de modelos numéricos como ferramenta de apoio na análise dessas ligações.

Ressaltando-se esse aspecto em especial, este capítulo é dedicado à apresentação da metodologia adotada no desenvolvimento e aplicação dos modelos numéricos que foram utilizados, neste trabalho, para o estudo do comportamento das ligações com chapa de topo. Assim, discutem-se alguns aspectos da modelagem relacionados à definição da geometria, aos tipos de elementos finitos utilizados, à representação das relações constitutivas dos materiais e como variações desses fatores influenciam na resposta numérica.

Apresentam-se, ainda, discussões mais abrangentes sobre a representatividade dos modelos propostos e a aplicação da modelagem numérica na análise do comportamento das ligações parafusadas em geral, enfatizando-se estudos paramétricos. Com isso, busca-se definir técnicas de modelagem que possam ser adotadas como referência para trabalhos futuros, além de firmar a utilização de modelos numéricos como importantes ferramentas no estudo do comportamento das ligações parafusadas.

Todos os modelos numéricos foram analisados com o software ANSYS $^{\circledR 5}$, utilizando-se ainda um software específico para o préprocessamento, denominado de TrueGrid $^{\circledR 6}$, que tornou possível ganhos significativos de produtividade na fase de construção da malha de elementos finitos. Os detalhes das etapas desse desenvolvimento são descritos a seguir.

\footnotetext{
${ }^{5}$ Marca registrada de ANSYS, Inc.

${ }^{6}$ Marca registrada de $X Y Z$ Scientific Applications, Inc.
} 


\subsection{CONSIDERAÇÕES GERAIS}

Citou-se, no início deste trabalho, que os avanços tecnológicos de softwares e hardwares no final da década de 90 possibilitaram a utilização de modelos numéricos complexos, eliminando barreiras importantes como, por exemplo, o tempo de processamento de modelos tridimensionais, proibitivos há duas décadas atrás e reduzidos a poucas horas atualmente.

No entanto, diversos detalhes referentes à modelagem numérica ainda são alvo de discussões, pois apresentam dificuldades que nada tem a ver com a complexidade de geometria ou o tamanho da malha de elementos finitos, mas sim com as idealizações e simplificações inerentes a todo modelo numérico, em maior ou menor grau. Como exemplo, pode-se citar a descrição constitutiva dos materiais, os critérios de plasticidade, os tipos de integração numérica, os tipos de elementos finitos, enfim, tudo que esteja relacionado com os modelos teóricos utilizados na análise.

É muito importante enfatizar que diversas características reais dificilmente podem ser incluídas na modelagem. Lembrando que a maioria dos modelos numéricos mencionados neste trabalho tem como base ligações reais ou protótipos experimentais, tais características reais podem ser imperfeições nas chapas ou na montagem dos perfis, tensões residuais e até mesmo falta de controle na aplicação das forças iniciais de protensão dos parafusos, que independem do software ou do hardware utilizado.

Todos os fatores mencionados acima estão presentes nas discussões da grande maioria dos estudos mais recentes que têm relação com a aplicação da modelagem numérica, principalmente porque são esses fatores que controlam a qualidade dos resultados numéricos e a representatividade dos modelos tridimensionais de ligações parafusadas.

A metodologia de modelagem apresentada neste capítulo representa mais uma etapa na tentativa de aperfeiçoar os modelos numéricos já existentes e, dito isso, tomou como base dois trabalhos em particular: o primeiro, desenvolvido por Ribeiro (1998), que apresenta um estudo experimental voltado à análise das ligações com chapa de topo e também o desenvolvimento, pioneiro no Brasil, de modelos tridimensionais dessas 
ligações; e o trabalho apresentado por Maggi (2000), cujas referências são ainda mais significativas e que, com base nos protótipos experimentais do trabalho anterior, teve como objetivo desenvolver modelos tridimensionais em elementos finitos que fossem representativos do comportamento das ligações com chapa de topo, complementando a análise numérica iniciada por Ribeiro (1998).

A metodologia da análise numérica proposta por Maggi (2000) foi, então, utilizada como base para a definição de um padrão de modelagem que permitisse a obtenção de modelos mais realísticos e também otimizados, visando a sua utilização em análises paramétricas.

Para explicitar a evolução da modelagem nos dois trabalhos citados acima e também as simplificações adotadas pelos autores correspondentes, na figura 6.1 são apresentadas três curvas momento-rotação provenientes dos resultados numéricos e experimentais de Ribeiro (1998) e da análise numérica de Maggi (2000) para uma ligação com chapa de topo de $\mathbf{2 2 , 4} \mathbf{m m}$ de espessura e parafusos de $\mathbf{1 6 , 0} \mathrm{mm}$ de diâmetro, denominada de CT1A-4, cuja tipologia segue os padrões dos protótipos experimentais descritos no capítulo 4.

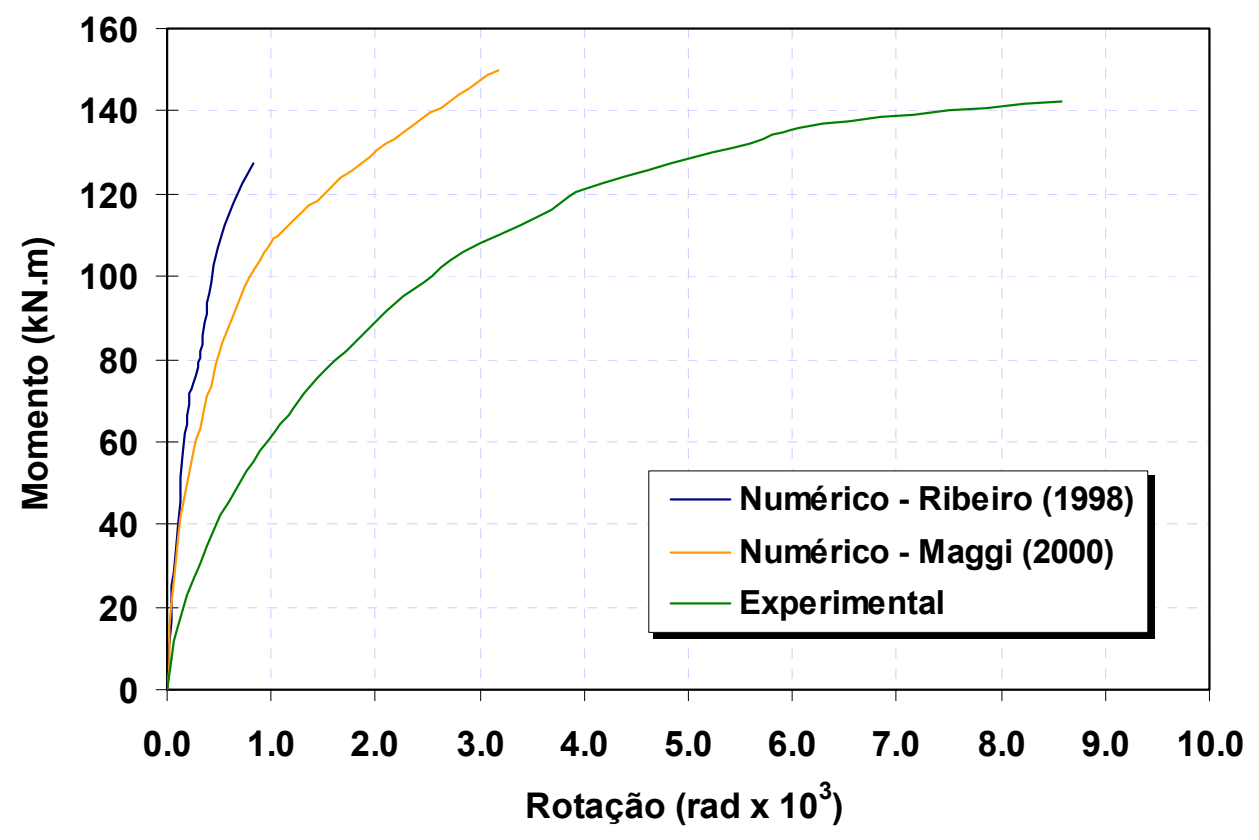

Figura 6.1 - Curvas momento-rotação - ligação com chapa de topo CT1A-4 
O primeiro aspecto que se observa na figura 6.1 é a maior rigidez inicial dos modelos numéricos com relação ao resultado experimental que ocorreu de forma sistemática para todos os modelos analisados pelos dois autores. No entanto, é possível visualizar uma melhoria no comportamento do modelo numérico de Maggi (2000), obtida pela inclusão da deformabilidade da mesa do pilar, fator não considerado na análise numérica de Ribeiro (1998).

Discutindo-se esse aspecto em especial, para os modelos numéricos propostos por Ribeiro (1998), analisados com o software LUSAS $^{\circledR 7}$ e cuja forma típica da geometria é apresentada na figura 6.2, considerava-se apenas parte do pilar na região da ligação pela simulação da mesa como apoio totalmente rígido, constituído apenas com elementos de contato coincidentes com a face posterior da chapa de topo - razão pela qual não é visível na figura. 0 carregamento correspondente à protensão inicial era simulado pela aplicação de forças nos fustes dos parafusos, fazendo com que a cabeça do parafuso pressionasse a chapa de topo contra os elementos de contato que representavam a mesa do pilar. Na seqüência, aplicavam-se restrições na região posterior dos fustes e forças na extremidade da viga para solicitar a ligação à flexão.

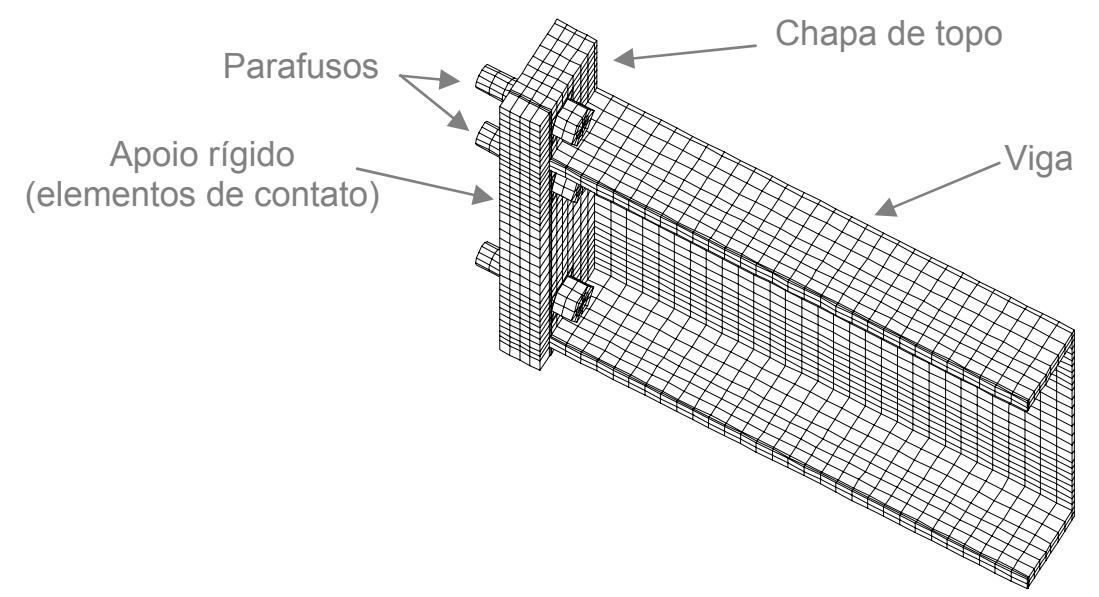

Figura 6.2 - Modelo numérico utilizado por Ribeiro (1998)

\footnotetext{
${ }^{7}$ Marca registrada de Finite Element Analysis Ltd.
} 
Com essas características, eliminou-se qualquer deslocabilidade da mesa do pilar, limitando-se a deformabilidade dos parafusos o que, conseqüentemente, provocou um aumento da rigidez rotacional da ligação.

De maneira geral, a metodologia proposta por Maggi (2000) procurou eliminar a simplificação descrita acima, com algumas mudanças na modelagem da geometria, principalmente com relação ao parafuso e à mesa do pilar, e na forma de aplicação dos carregamentos. A figura 6.3 apresenta uma visão geral dos modelos numéricos propostos por Maggi (2000), salientando-se que foram analisados com o software ANSYS ${ }^{\circledR}$.

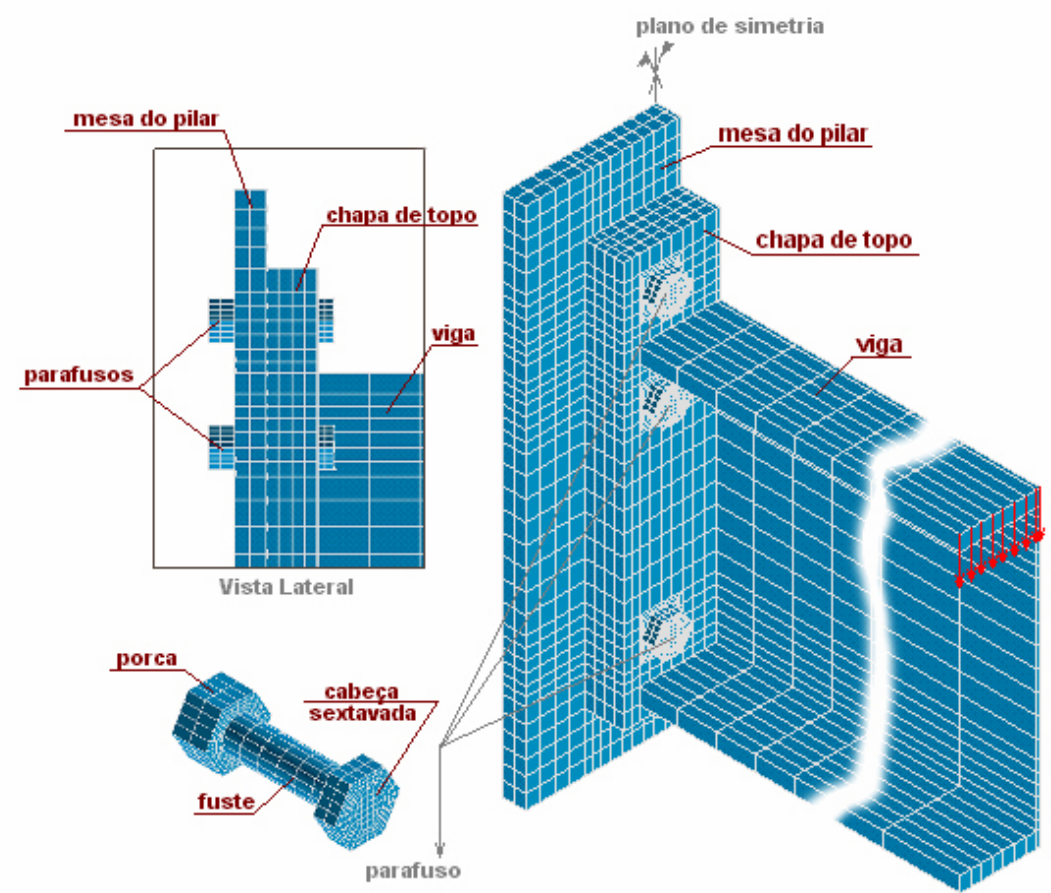

Figura 6.3 - Modelo numérico utilizado por Maggi (2000)

Na figura 6.3 observa-se claramente a discretização da mesa do pilar com elementos sólidos e as modificações introduzidas por Maggi (2000) na modelagem dos parafusos, os quais eram simulados como um único sólido constituído pela cabeça sextavada, fuste e porca, mantendo-se a geometria especificada para os parafusos de alta resistência ASTM-A325 em função do diâmetro nominal. Além disso, as restrições impostas à face posterior da mesa do pilar foram incluídas apenas na região da alma, nas três direções de 
translação, e na direção longitudinal do modelo para as regiões dos enrijecedores, simulando o protótipo cruciforme utilizado por Ribeiro (1998).

Com essa configuração, a protensão inicial foi simulada por meio da aplicação de variações negativas de temperatura no fuste que, ao retrair-se, estabelecia as restrições necessárias à chapa de topo e à viga através dos elementos de contato, sem limitar a deslocabilidade dos parafusos nem da mesa do pilar. Salienta-se que essa metodologia se apresentou altamente satisfatória, com uma adequada simulação da protensão dos parafusos.

Um outro aspecto interessante de ser comentado com relação a esses dois trabalhos foi a inclusão, em ambas as análises, da não linearidade física dos materiais das chapas e parafusos através de descrições bilineares para a relação tensão-deformação, dado essencial para a análise não linear dos modelos, cuja representação esquemática é apresentada na figura 6.4.

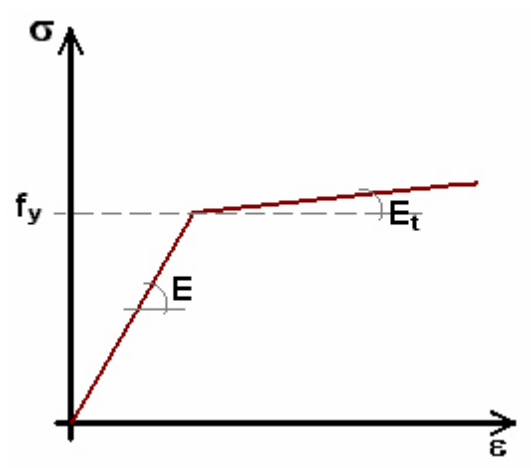

Figura 6.4 - Representação esquemática da relação bilinear tensão-deformação

Os diagramas bilineares, em geral, descrevem o modelo constitutivo dos materiais através do módulo de elasticidade longitudinal $(\mathbf{E})$, da tensão de escoamento $\left(\mathbf{f}_{\mathbf{y}}\right)$ e de um módulo plástico $\left(\mathbf{E}_{\mathbf{t}}\right)$, sem considerar limites de deformação ou de tensão. Assim, mesmo permitindo representar a perda de rigidez dos elementos após o escoamento do material, não permite a utilização de nenhum critério de ruptura, o que obviamente prejudica a redistribuição de tensões e a correta representação dos estados limites últimos na resposta numérica.

A influência da utilização desta relação constitutiva pode ser claramente comprovada nas curvas momento-rotação da figura 6.1, apresentadas anteriormente, segundo as quais se observa uma limitação 
significativa no desenvolvimento das deformações plásticas e, conseqüentemente, na deformabilidade do modelo.

Apesar dessas simplificações, o comportamento qualitativo dos modelos utilizados por Maggi (2000) foi considerado satisfatório, o que pode ser visualizado na tabela 6.1 que apresenta uma série de resultados obtidos pelo autor na sua análise numérica, variando-se a espessura da chapa de topo e o diâmetro dos parafusos.

Tabela 6.1 - Deformação nas ligações - MAGGI (2000)

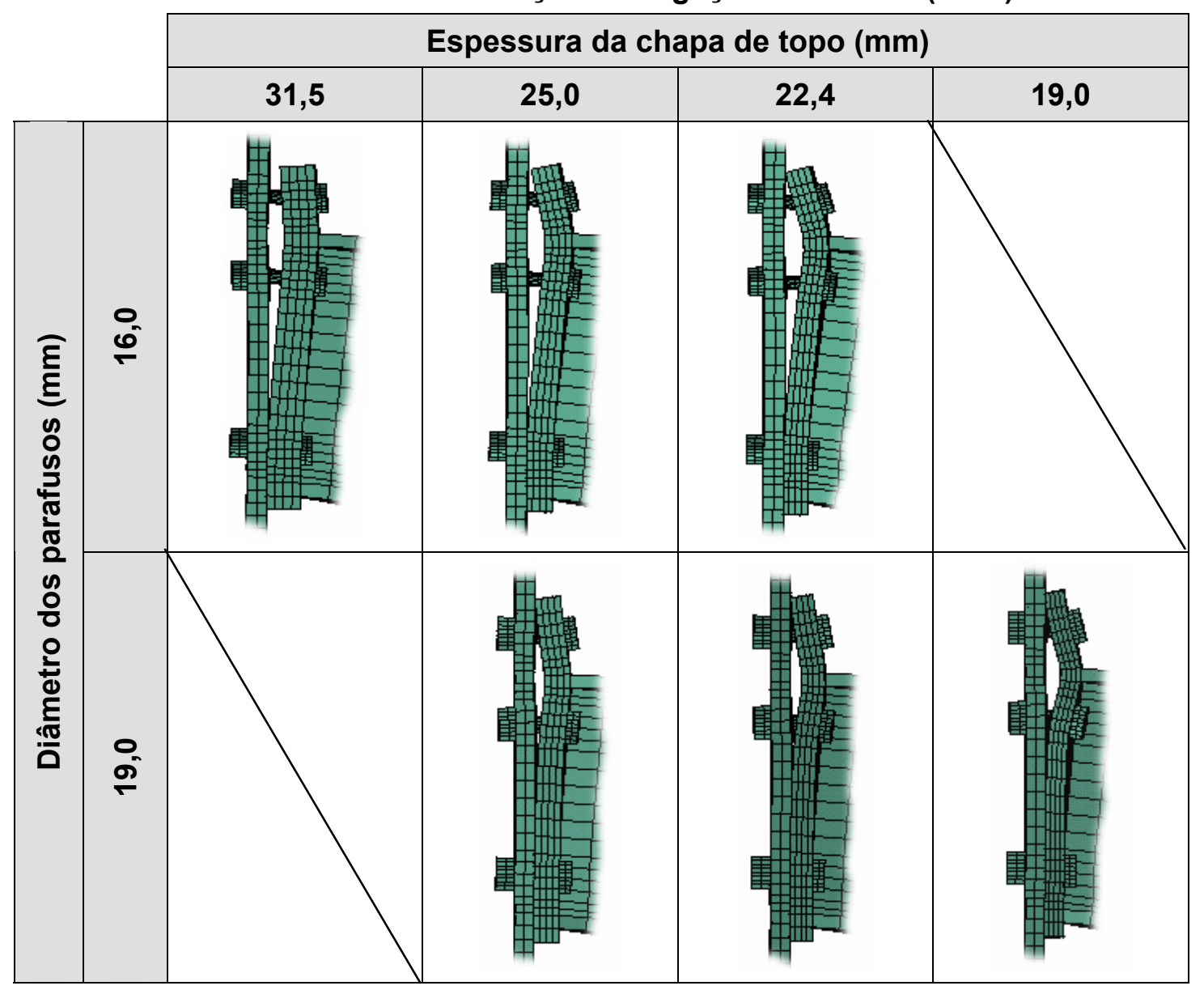

No decorrer deste capítulo, os principais tópicos avaliados nos modelos propostos por Maggi (2000) são:

i. Os elementos finitos utilizados na modelagem da geometria;

ii. Os elementos de contato, para modelagem das descontinuidades geométricas; 
iii. Os modelos constitutivos para o aço; e

iv. A otimização da malha e do tempo de processamento.

Com enfoque nesses itens apresentam-se, em seguida, a metodologia de modelagem adotada neste trabalho e as discussões referentes à aplicação da modelagem no estudo do comportamento das ligações parafusadas com chapa de topo.

\subsection{CRITÉRIOS ADOTADOS NA MODELAGEM NUMÉRICA}

A representatividade da modelagem numérica depende de uma série de critérios, dos quais os mais significativos são a escolha dos elementos finitos - o que define a tipologia e a complexidade da discretização, a escolha dos modelos de plasticidade dos materiais com as respectivas descrições constitutivas da relação tensão-deformação e a adequação da geometria de alguns componentes para simular comportamentos específicos, como é o caso dos parafusos.

Esses três fatores influenciam diretamente nos mecanismos utilizados para simular o comportamento das ligações estudadas e, tratando-se especialmente do aspecto qualitativo, são de fundamental importância na validação dos resultados numéricos, viabilizando assim a utilização da modelagem em análises paramétricas.

Ressaltadas essas características, os próximos itens apresentam critérios importantes para a definição e entendimento da metodologia empregada na análise numérica, cujos detalhes específicos são descritos mais adiante.

\subsubsection{Modelos sólidos tridimensionais}

Para os modelos numéricos, a capacidade de representar realisticamente o comportamento estrutural das ligações com chapa de topo é 
uma característica intimamente ligada à possibilidade de se eliminar simplificações, entre elas as relacionadas com a geometria dos modelos.

Citando-se como exemplo, a análise numérica conduzida por Bahaari \& Sherbourne (1994), já em meados da década de 90, foi realizada com modelos bidimensionais utilizando elementos finitos de casca para representar vigas, pilares e chapas de topo, acrescentando ainda a utilização de elementos finitos de mola na simulação do comportamento de parafusos, claramente uma metodologia simplificada.

Os modelos 2D apresentam uma série de características práticas do ponto de vista computacional, uma vez que a sua discretização é mais rápida, acompanhada de eficiência computacional - uma vez que o tempo de processamento, em geral, é significativamente menor do que para modelos 3D - e rápida obtenção de resultados. No entanto, há fenômenos que podem ser visualizados e compreendidos com maior facilidade e com um grau elevado de detalhes se modelos tridimensionais forem utilizados.

Considerando-se a natureza dos resultados que se pretende obter, a adoção de modelos tridimensionais é ainda mais representativa pela possibilidade de simular determinados mecanismos de transferência de esforços que, muitas vezes por impossibilidades numéricas, não podem ser considerados em tipos específicos de elementos finitos bidimensionais.

A distribuição das deformações plásticas ao longo da espessura da chapa de topo, por exemplo, pode ser facilmente observada em elementos volumétricos, ao contrário de elementos de casca. Da mesma forma, dificilmente se observariam as deformações e os esforços de flexão que geralmente ocorrem nos parafusos por meio da utilização de elementos de mola e, novamente, elementos volumétricos surgem como alternativa.

Assim, adotando como princípio básico a melhor representatividade dos modelos tridimensionais, todos os componentes das ligações, isto é, viga, pilar, parafusos, entre outros, foram simulados de acordo com suas características geométricas, seguindo uma metodologia de modelagem 3D. 


\subsubsection{Modelos constitutivos para o aço}

A rigidez inicial das ligações, ou dos modelos das ligações, depende das características elásticas dos materiais, das características geométricas e da tipologia do carregamento a que estão submetidos os seus componentes.

Por outro lado, a caracterização da plasticidade, ou seja, o desenvolvimento de deformações plásticas e a redistribuição de tensões, assim como a caracterização do colapso, dependem somente dos modelos constitutivos utilizados na simulação da plasticidade dos materiais.

Como a rigidez inicial e a caracterização dos estados limites últimos são fatores que se deseja simular, é de fundamental importância utilizar relações constitutivas que tenham a capacidade de representar adequadamente o comportamento plástico dos materiais.

Como alternativa à utilização de diagramas bilineares, cujas limitações já foram comentadas anteriormente, optou-se pela adoção de diagramas multilineares da relação tensão-deformação que, com aproximações por trechos lineares, é capaz de simular as diversas etapas da plastificação do aço incluindo patamares de escoamento (se existentes), os efeitos de encruamento - positivos ou negativos, correspondentes aos efeitos comumente conhecidos como "hardening" e "softening", respectivamente - e até mesmo os limites de deformação e de tensão para caracterizar o colapso.

O software ANSYS ${ }^{\circledR}$ permite a utilização de diversos tipos de modelos constitutivos multilineares, dentre os quais adotou-se um modelo com encruamento isótropo, capaz de reproduzir a plasticidade do aço utilizando as tensões equivalentes de von Mises como critério de plastificação, largamente conhecido.

Assim, duas relações típicas para as curvas tensão-deformação do aço, multilineares, são mostradas nas figuras 6.5(a) e 6.5(b) representando esquematicamente possíveis configurações para simular os diagramas do aço das chapas e dos parafusos. Esses dois modelos constitutivos foram propostos por Bahaari \& Sherbourne (1996) e Kulak et al. (1987), respectivamente, a menos do trecho final descendente indicado na figura como "colapso". 
Após a tensão máxima $\mathbf{f}_{\mathrm{u}}$, o trecho descendente no diagrama tensãodeformação representa uma sofisticação das relações constitutivas apresentadas anteriormente com relação à sua aplicação nas simulações numéricas, já que pode representar a ruptura do material.

Como o colapso nos modelos é obtido, usualmente, pela falta de convergência da solução numérica, o que geralmente ocorre em estágios avançados de carregamento quando a solução não linear torna-se instável, a adoção de trechos descendentes com inclinação acentuada facilita a caracterização da instabilidade global do modelo numérico e, assim, dos estados limites últimos das ligações analisadas.

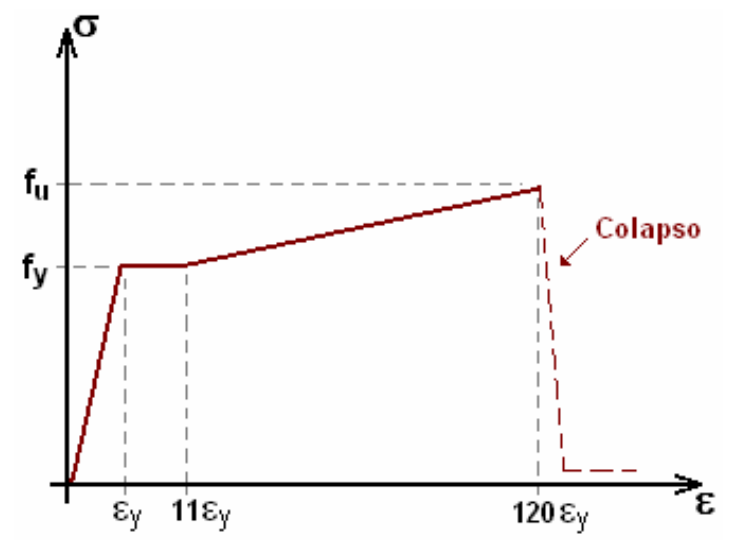

(a)

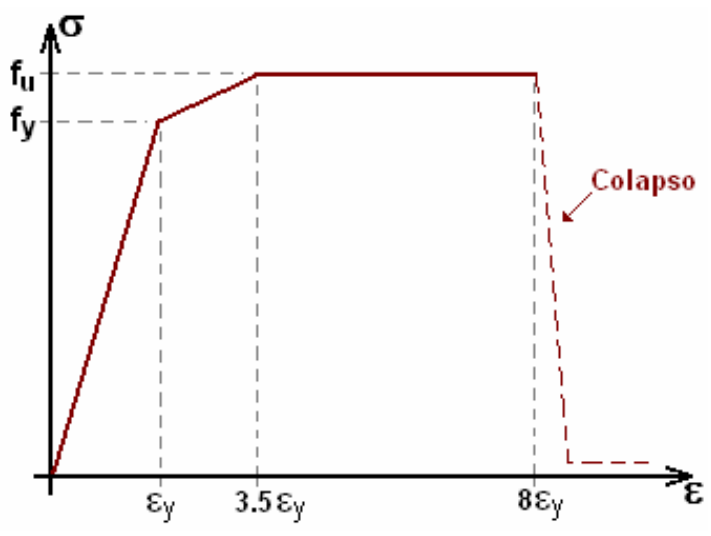

(b)

Figura 6.5 - Curvas tensão-deformação esquemáticas para o aço das chapas e dos parafusos

As curvas padronizadas por Bahaari \& Sherbourne (1996) e Kulak et al. (1987), com a modificação apresentada na figura 6.5, foram utilizadas como ponto de partida para a descrição das relações constitutivas dos materiais das chapas e dos parafusos nos modelos apresentados neste capítulo. No entanto, essas relações serão analisadas mais adiante, em um item específico, no qual se discute a sua aplicabilidade considerando-se as características específicas da modelagem numérica proposta. 


\subsubsection{Descontinuidades geométricas}

As ligações parafusadas, em função da tipologia que apresentam, são fonte de diversas descontinuidades geométricas. Nas ligações com chapa de topo a ausência de um monolitismo fica evidenciada pelo grande número de componentes isolados que, quando agrupados, dão forma à ligação.

Neste caso, uma simulação representativa deve considerar essas descontinuidades geométricas, razão pela qual todos os modelos numéricos propostos neste trabalho incluíram elementos finitos especiais, denominados de "elementos de contato", para simular as diversas interfaces que compõem o modelo.

A figura 6.6 ilustra as interfaces consideradas em um modelo típico do trabalho de Maggi (2000), que representam:

i. o contato entre a região posterior da chapa de topo e a face da mesa do pilar (1);

ii. o contato entre a cabeça dos parafusos e a chapa de topo (2);

iii. o contato entre a porca dos parafusos e a mesa do pilar (3); e

iv. o contato entre o fuste dos parafusos e a parede dos furos, tanto na chapa de topo quanto na mesa do pilar (4).

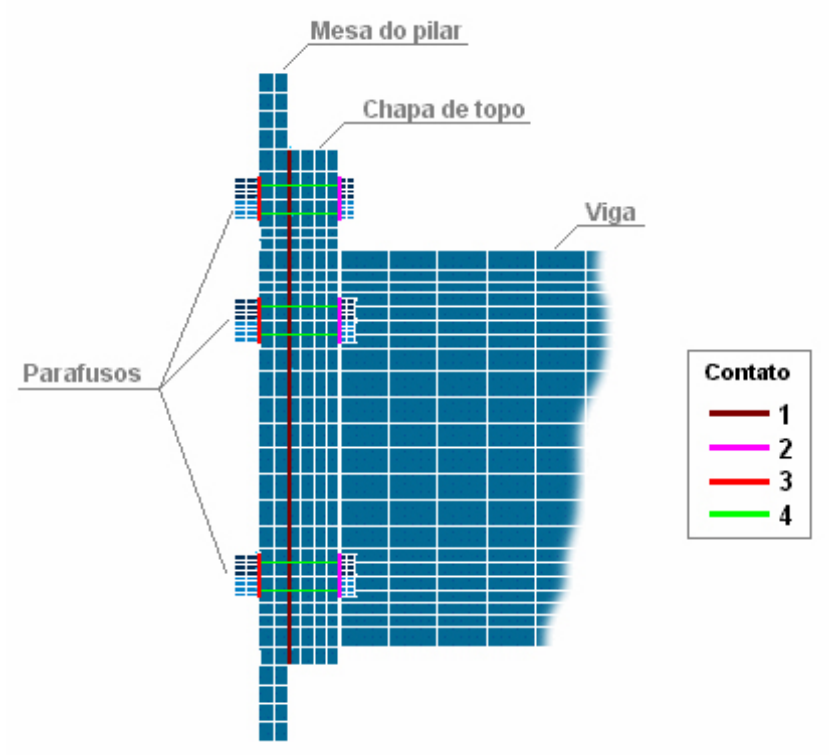

Figura 6.6 - Superfícies de contato típicas para o modelo de ligação com chapa de topo discretizados por Maggi (2000) 
De maneira geral, as interfaces apresentadas acima são as existentes na região da ligação com chapa de topo e são suficientes para simular o contato entre os componentes.

Nessa simulação, é interessante notar que as restrições formais no modelo são impostas apenas na mesa do pilar e nas superfícies de simetria, ou seja, a viga, a chapa de topo e os parafusos não têm vinculações iniciais. Com a aplicação do carregamento, seja com protensão inicial ou não nos parafusos, é função dos elementos de contato permitir a imposição de restrições na chapa de topo e na viga por meio dos parafusos, a fim de garantir a estabilidade da solução numérica. Ainda, permite-se a simulação da função real do parafuso, utilizado como conector entre a chapa de topo e a mesa do pilar.

A metodologia descrita nos próximos itens mantém a discretização dos "elementos de contato" nas interfaces da figura 6.6, apesar de haver mudanças na discretização do pilar. Além disso, os furos na chapa de topo e no pilar foram simulados segundo as recomendações da NBR 8800 (1996), prevendo o furo padrão e as folgas com relação ao fuste dos parafusos.

Neste caso, o atrito entre os componentes, cuja formulação segue a teoria clássica de Mohr-Coulomb, também foi considerado nas interfaces, atribuindo-se um coeficiente de atrito estático igual à 0,3 para os elementos de contato.

\subsubsection{Grandes deslocamentos}

Segundo Bahaari \& Sherbourne (1996) e Bursi \& Jaspart (1998), a inclusão da consideração de grandes deslocamentos não modifica significativamente os resultados numéricos, principalmente com relação ao comportamento global das ligações. É claro que essa afirmação ainda é dependente das características geométricas e da descrição dos materiais, fatores que influenciam significativamente na deformabilidade da chapa de topo, parafusos e vigas.

No entanto, é importante observar que a consideração de grandes deslocamentos deve apresentar maior representatividade na convergência da 
solução numérica para a determinação dos estados limites últimos das ligações, tendo em vista que estão sujeitas, usualmente, a efeitos de segunda ordem, que podem gerar instabilidades localizadas. Assim, esse efeito foi incluído na análise numérica.

\subsection{METODOLOGIA DA PREPARAÇÃO DOS MODELOS NUMÉRICOS}

A preparação dos modelos numéricos consiste, basicamente, de procedimentos relacionados às seguintes fases:

i. Montagem da malha com os elementos finitos adotados, correspondente à geometria dos modelos;

ii. Definição das relações constitutivas dos materiais;

iii. Definição das condições de contorno;

iv. Aplicação do carregamento; e

v. Definição dos parâmetros para a solução numérica.

Para descrever didaticamente as etapas listadas acima, serão utilizados como exemplo dois tipos de modelos numéricos, cujas tipologias seguirão os grupos TSC e CTEE do programa experimental, referentes aos protótipos de ligações duplo "T" e de ligações com chapa de topo estendida, respectivamente. $\mathrm{O}$ desenvolvimento dessas etapas tem como objetivo definir a metodologia a ser empregada na preparação dos modelos numéricos, como contribuição deste trabalho.

É conveniente enfatizar que os procedimentos detalhados a seguir são referentes a aspectos qualitativos da modelagem, não se atendo em nenhum momento aos comandos ou procedimentos específicos dos softwares utilizados no pré-processamento e na análise.

Ressalta-se ainda que, nesta fase, não há preocupação em validar os modelos numéricos comparando-os com resultados experimentais. Tais comparações serão feitas mais adiante após terem sido discutidos os tópicos 
relevantes ao comportamento dos modelos, principalmente quanto às relações constitutivas dos materiais.

\subsubsection{Ferramentas auxiliares para a modelagem}

O processo de simulação numérica é iniciado por uma fase que, comumente, denomina-se de "pré-processamento", na qual se definem a geometria dos modelos, a discretização, o carregamento e as condições de contorno. Em geral, o tempo gasto nesta fase depende da complexidade dos modelos, consumindo grande parte do tempo total da análise numérica.

Para a análise paramétrica, a variação das características geométricas é um aspecto importante e, neste caso, é desejável a utilização de ferramentas que possibilitem a parametrização dos modelos numéricos, permitindo um pré-processamento rápido ao haver necessidade de mudanças, por exemplo, da espessura da chapa de topo ou do diâmetro dos parafusos.

Dessa forma, utilizou-se um software específico para o préprocessamento, denominado de TrueGrid $^{\circledR}$, que juntamente com o software de análise, permitiu a construção rápida das malhas por meio de arquivos parametrizados.

Os procedimentos para a preparação dos modelos seguem as seguintes etapas:

i. A partir de um arquivo texto com as definições da geometria, com o software TrueGrid $^{\circledR}$ gera-se um outro arquivo texto, denominado de "malha.inp", com a definição de todos os nós e elementos finitos;

ii. Para cada tipologia de modelo, utiliza-se de outro arquivo texto com as definições de tipos de elementos finitos, materiais, carregamentos, vinculações e opções gerais para a análise, criado utilizando-se a linguagem APDL utilizada pelo software ANSYS $^{\circledR}$, que incorpora o arquivo "malha.inp", gerando o modelo numérico completo, já pronto para o início da análise. 
Para exemplificar os ganhos obtidos no pré-processamento com a utilização deste procedimento, a mudança da geometria das ligações antes dessa parametrização consumia, para a variação somente da espessura da chapa de topo, em torno de 30 minutos. Com a utilização dessas ferramentas adicionais, a preparação de um modelo completo pode ser feita em aproximadamente 5 minutos, viabilizando a análise paramétrica proposta neste trabalho.

\subsubsection{Geometria dos modelos}

Os modelos apresentados nos próximos itens foram preparados com base nas geometrias apresentadas no capítulo 4 para os protótipos dos grupos TSC e CTEE, levando em consideração os critérios gerais adotados para a modelagem numérica. Assim, procurou-se manter, na modelagem, as características geométricas dos perfis "T", das vigas, da chapa de topo, dos parafusos e do pilar, mantendo-se também o vão de 1,50 $\mathrm{m}$ das vigas e a altura total de 2,20 $\mathrm{m}$ do pilar dos protótipos CTEE.

\subsubsection{Elementos finitos e discretização}

\subsubsection{Elementos volumétricos para a geometria}

A utilização de elementos volumétricos para a modelagem dos componentes geométricos caracteriza a metodologia de modelagem tridimensional e, no que diz respeito às características desses elementos finitos, algumas considerações devem ser feitas para que sua escolha seja adequada, de acordo com suas hipóteses e formulação. Além disso, é de fundamental importância adequar o tipo de elemento finito à região da ligação que se está simulando, para que a resposta numérica seja satisfatória, em função da solicitação a que cada componente está submetido. 
Para a discretização da ligação foram escolhidos elementos volumétricos, hexaédricos, com 8 nós e três graus de liberdade de translação (nos eixos globais $\mathrm{X}, \mathrm{Y}$ e Z) por nó, que simulam satisfatoriamente os diversos componentes e ainda as leis constitutivas não lineares dos materiais, já que utilizam formulações de integração total, considerando 8 pontos de integração (pontos de Gauss). No entanto, esses elementos podem apresentar uma resposta numérica desfavorável em problemas dominados por esforços de flexão, devido a um efeito numérico denominado comumente de "shear locking", que provoca o aumento de rigidez do elemento finito.

Sendo o campo de deslocamentos definido por funções de interpolação linear, a formulação padrão não é capaz de incluir efeitos de curvatura ao longo do elemento, o que aumenta significativamente sua rigidez à flexão. No caso específico da chapa de topo, onde a resposta sob flexão é acentuada, o enrijecimento dos elementos finitos tende a aumentar a rigidez da ligação como um todo, prejudicando a resposta global do modelo.

Esse efeito pode ser minimizado pela utilização de elementos com funções de interpolação quadráticas, com conseqüente aumento do número de nós por elemento. No entanto, Bursi \& Jaspart (1998) indicam que, para problemas de plasticidade, é necessário que os elementos finitos permitam descontinuidades no campo de deslocamento devido ao desenvolvimento de linhas de plastificação, ou linhas de escoamento. Neste caso, elementos com interpolação linear apresentam melhores resultados quando comparados a elementos de ordem mais alta, que são mais representativos em análises elásticas, lineares ou não.

Os mesmos autores comentam que o efeito "shear locking" também pode ser minimizado com a utilização de elementos finitos lineares cuja formulação leve em consideração "modos incompatíveis" de deslocamento. Tais elementos possuem graus de liberdade adicionais, fictícios, e utilizam campos mistos de deslocamento para minimizar o aumento natural de rigidez do elemento hexaédrico.

Na biblioteca do software ANSYS ${ }^{\circledR}$, o elemento finito denominado de "SOLID45" atende às observações feitas acima, apresentando em sua formulação funções de interpolação lineares e modos incompatíveis de 
deslocamento, ativado pela opção "Extra displacement shapes". Com essas opções, é possível eliminar o efeito "shear locking" mantendo todos os pontos de integração do elemento, o que é adequado para a obtenção da resposta não linear do elemento finito. A representação esquemática do "SOLID45" é apresentada na figura 6.7 .

Além disso, Bursi \& Jaspart (1998) recomendam a utilização de, no mínimo, 3 linhas de elementos ao longo da espessura do volume a ser modelado, sendo suficiente, segundo os autores, para a obtenção de bons resultados para a flexão oblíqua na chapa de topo.

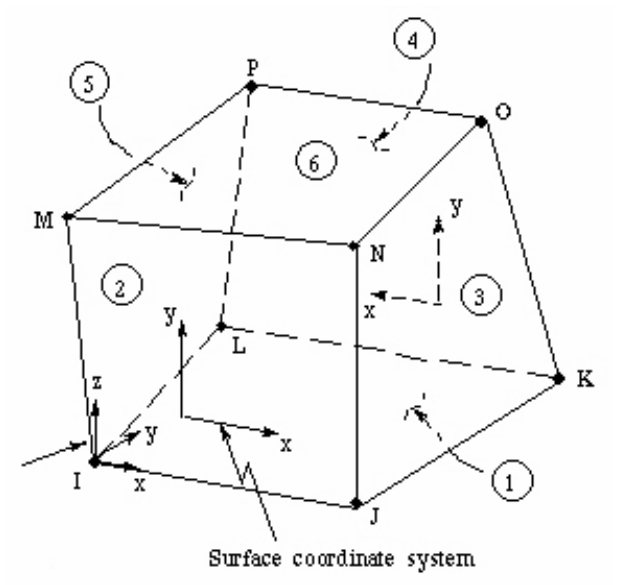

Figura 6.7 - Elemento volumétrico SOLID45 (ANSYS ${ }^{\circledR}$ Documentation)

\subsection{Discretização dos perfis "T", viga, chapa de topo e pilar}

Com a função de otimizar os modelos, a malha desses componentes tomou partido da simetria encontrada nos protótipos, com a inclusão adequada de condições de contorno. Para ilustrar, inicialmente, a discretização destes componentes, na figura 6.8 pode ser observada a malha de elementos para um perfil "T", duplamente simétrico, e nas figuras 6.9(a) e 6.9(b), respectivamente, a discretização para o conjunto viga/chapa de topo - simétrico com relação ao plano médio da alma da viga - e para o pilar, também simétrico com relação ao plano médio perpendicular a sua alma, lembrando da configuração cruciforme. 


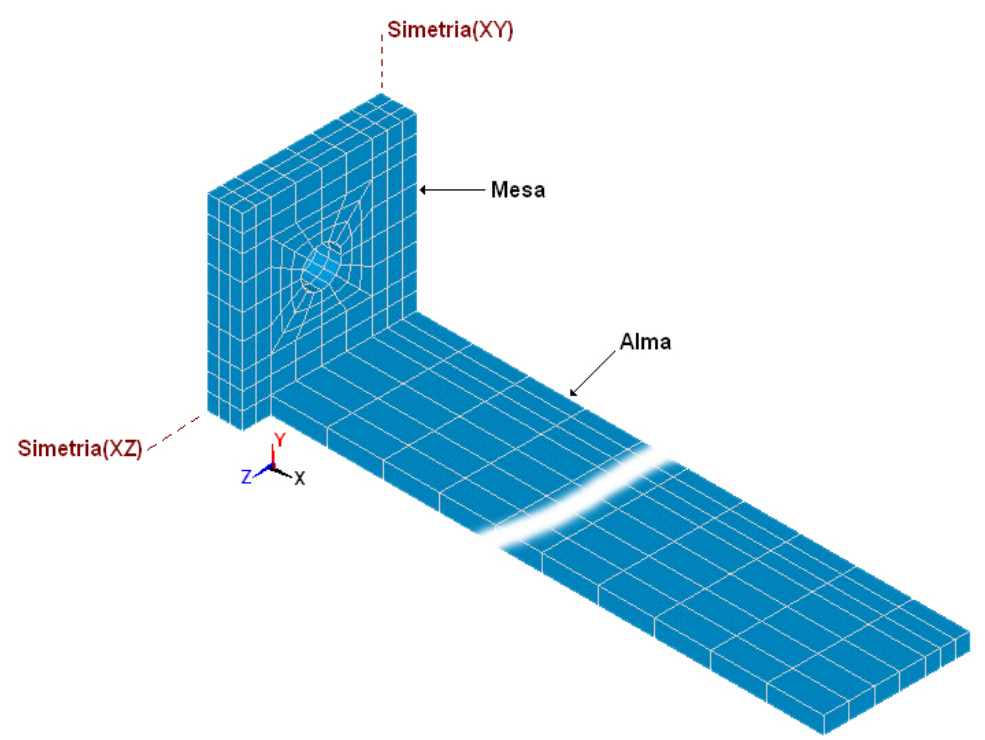

Figura 6.8 - Discretização do perfil "T”"

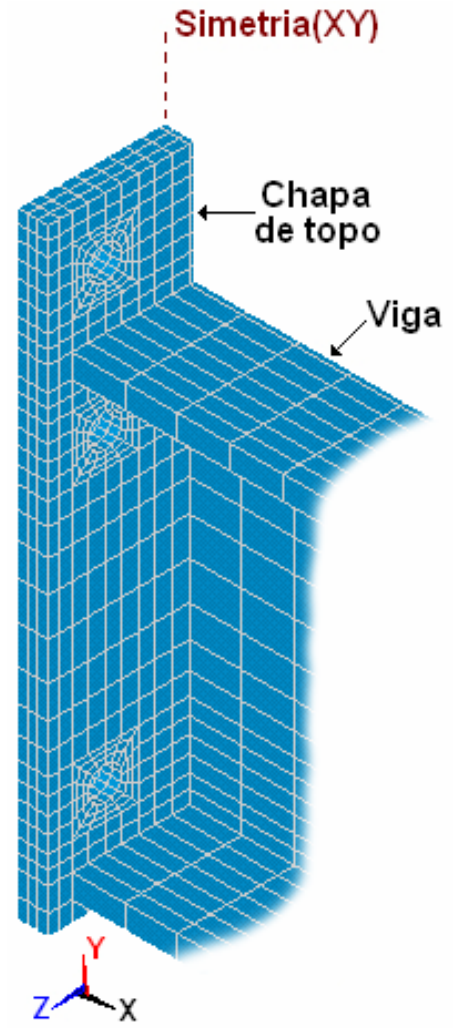

(a)

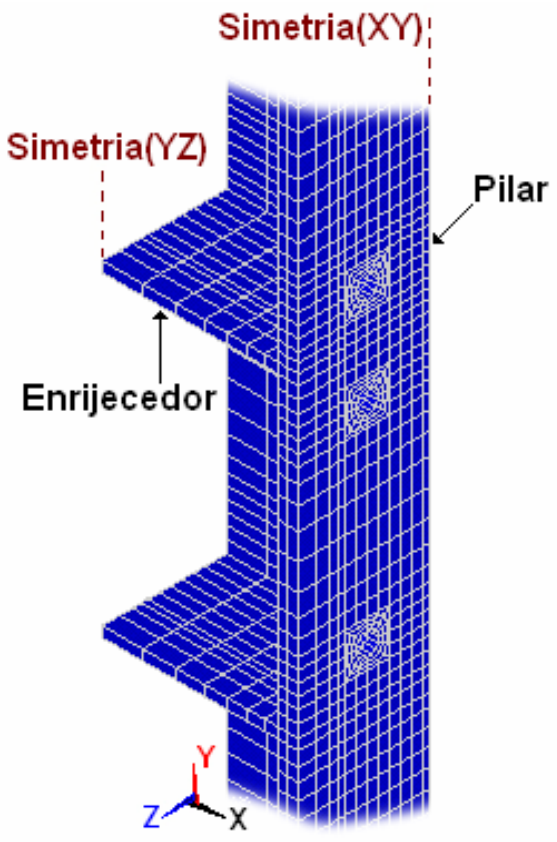

(b)

Figura 6.9 - Discretização da viga, chapa de topo e pilar

Nas figuras apresentadas acima, observa-se que a discretização foi feita de forma regular, com alguns cuidados quanto à complexidade da malha e à distribuição e tamanho dos elementos finitos. 
Como a análise numérica inclui as características plásticas dos materiais, é um fator determinante para a qualidade da resposta numérica permitir uma discretização mais cuidadosa nas regiões onde se espera gradientes elevados de tensão. Dessa forma, regiões com concentrações de tensão e regiões com níveis elevados de plastificação devem possuir malhas mais refinadas, ou seja, com maior número de elementos finitos.

Neste caso, merecem destaque a intersecção da viga com a chapa de topo e as regiões dos furos, estas últimas com a particularidade de fazerem parte das interfaces de contato com os parafusos. De maneira geral, a preocupação com a malha dessas regiões foi a de proporcionar, ao máximo possível, mudanças suaves do tamanho dos elementos, a fim de se minimizar descontinuidades na resposta numérica. Essa consideração vale para todo o modelo, no qual se utilizaram malhas mais pobres em regiões onde a plastificação não ocorre.

A figura 6.10 ilustra alguns detalhes da região tracionada da chapa de topo, ressaltando-se que não foram consideradas as soldas na discretização proposta. A influência dessa consideração será analisada mais adiante.

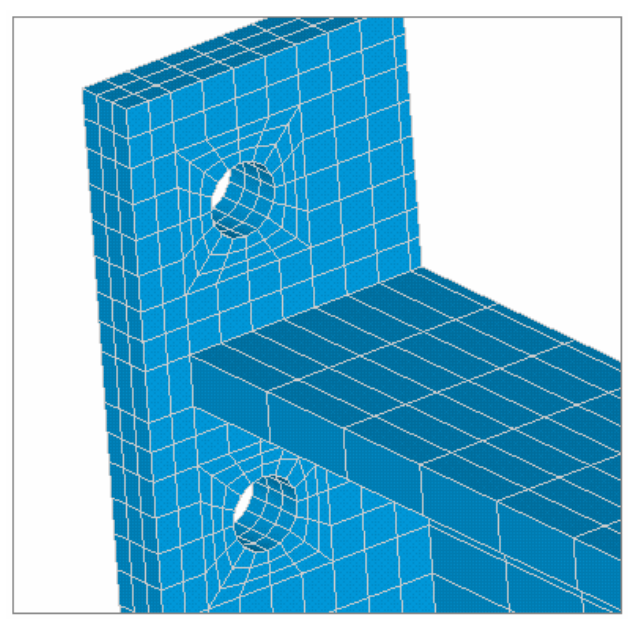

Figura 6.10 - Detalhes das malhas da viga e da chapa de topo

\subsection{Discretização dos parafusos}

A discretização dos parafusos depende, além da geometria, de considerações sobre a adequação da malha à tipologia do modelo numérico. 
Como os parafusos reais não possuem características geométricas homogêneas devido à existência da rosca, fatores como o diâmetro efetivo a ser considerado, bem como o comprimento efetivo do fuste, são de extrema importância para garantir a representatividade da resposta numérica e a simulação das condições a que estão submetidos os parafusos como conectores entre chapa de topo e mesa do pilar.

Considerando-se que o modelo do parafuso será discretizado de acordo com o proposto por Maggi (2000), com as características geométricas da cabeça e da porca de acordo com as especificações da ASTM-A325 (1986), duas condições básicas devem ser seguidas:

i. Como a modelagem inclui a folga nos furos, é necessário que o fuste do parafuso mantenha o diâmetro nominal. Essa condição garante a simulação adequada do contato entre o fuste e os furos no caso de haver escorregamento, de acordo com a geometria observada nos protótipos; e

ii. O comprimento total do fuste deve ser igual à soma das espessuras dos componentes que estão sendo conectados para permitir o contato entre esses componentes e as faces da cabeça e da porca, ao mesmo tempo em que se permite a liberdade de deslocamento dos parafusos, seguindo a metodologia proposta por Maggi (2000).

A figura 6.11 apresenta a malha adotada para os parafusos na qual se observam os detalhes da cabeça, da porca sextavada e o fuste circular com diâmetro nominal, correspondente à área bruta do parafuso.

Se por um lado essas considerações adequam o modelo do parafuso ao tipo de simulação proposta, por outro lado influenciam na resposta dos parafusos quanto à força máxima resistente e à deformabilidade, já que não simulam geometricamente a diminuição da área na região da rosca, nem a flexibilidade dos fios de rosca e arruelas. 


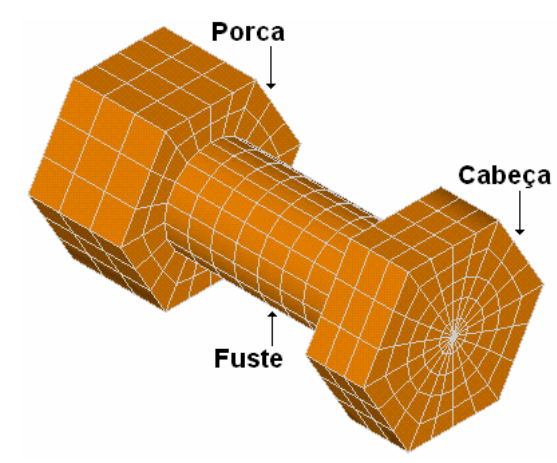

Figura 6.11 - Discretização dos parafusos

Assim, deve-se analisar criteriosamente os modelos constitutivos que são aplicados aos parafusos do modelo para que os mesmos tenham a capacidade de representar a resistência e a ductilidade das ligações, mantendo a configuração mostrada na figura 6.11. Essa discussão será realizada em item específico, ainda neste capítulo.

É válido lembrar que, em se tratando de um modelo de parafuso, é possível adotar simplificações - como a uniformização do fuste considerando a área bruta - desde que adaptações sejam feitas para manter o comportamento deste componente próximo à realidade experimental.

Antecipando a configuração final da malha dos modelos, as figuras 6.12 e 6.13 ilustram, respectivamente, os modelos das ligações duplo "T" e das ligações com chapa de topo, com todos os componentes.

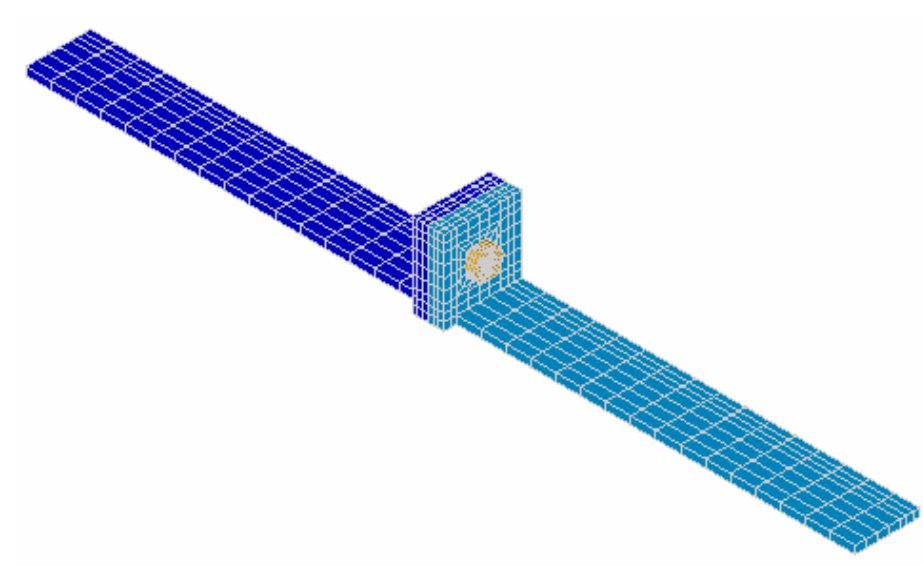

Figura 6.12 - Modelo da ligação duplo "T" - TSC 


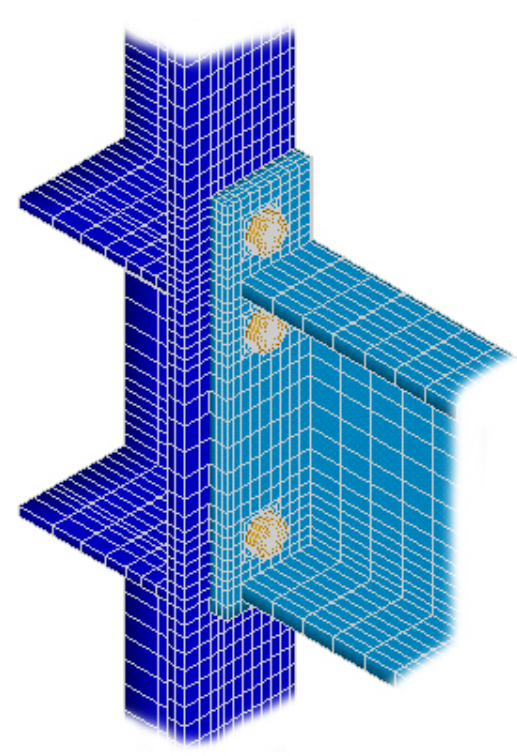

Figura 6.13 - Modelo da ligação com chapa de topo estendida - CTEE

\subsubsection{Elementos de contato para as descontinuidades geométricas}

Os elementos de contato utilizados por Maggi (2000) discretizavam as interfaces levando em consideração contatos do tipo "nó-superfície", que permitiam somente a utilização de formulações com base em funções de penalidade ("penalty functions") para a definição do equilíbrio da solução numérica. Segundo essa formulação, quando há penetração entre os nós e as superfícies que formam uma interface, forças são impostas internamente aos elementos para estabelecer uma condição de equilíbrio na qual se minimizem as penetrações. Não havendo penetrações, não há a imposição de forças internas, visto que os elementos de contato não possuem rigidez à tração, permitindo a livre abertura entre os elementos que compõem a interface.

Durante o estudo para otimização destes modelos, optou-se por modificar o elemento de contato existente por outros que representassem contatos superfície-superfície. Segundo essa metodologia, são utilizados dois tipos de elementos finitos da biblioteca do software ANSYS ${ }^{\circledR}$ : TARGE169, que define a superfície alvo da interface, e CONTA173 para a superfície na qual o contato será inspecionado. Cada grupo de elementos TARGE169 e CONTA173 que formam um par de contato são identificados por índices correspondentes, e pode ser ilustrado esquematicamente na figura 6.14. 


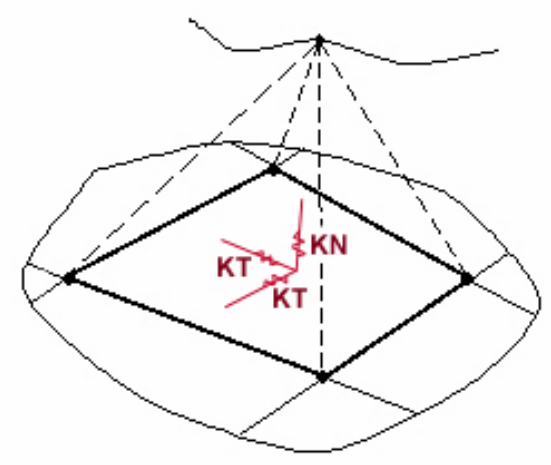

Figura 6.14 - Representação esquemática de um par de contato (ANSYS ${ }^{\circledR}$ Documentation)

A formulação do contato superfície-superfície permite, além das funções de penalidade, a utilização conjunta de multiplicadores de Lagrange, melhorando potencialmente a convergência da solução numérica nas interfaces, que apresentaram soluções mais estáveis. Além disso, enfatiza-se a grande dependência do comportamento do contato e da convergência da solução não linear com relação à rigidez normal (KN) imposta aos elementos de contato nó-superfície, o que não ocorre de forma significativa para o contato superfície-superfície, adotado neste trabalho.

Como já comentado anteriormente, além da consideração da rigidez normal (perpendicular) do contato, incluiu-se nessa análise a rigidez tangencial para levar em consideração forças de escorregamento entre as interfaces, necessárias nos modelos devido à presença das folgas nos furos e da possibilidade de haver escorregamento entre a chapa de topo e a mesa do pilar, ou entre as mesas dos perfis "T". Assim, como parâmetro adicional incluiu-se o coeficiente de atrito estático, igual à $\mathbf{0 , 3}$, utilizando-se valores unitários para as rigidezes de contato, normal e tangencial, considerados satisfatórios por indicação do software ANSYS $^{\circledR}$ (s.d.) sobre os elementos de contato utilizados.

\subsubsection{Elementos de barra para o acoplamento na viga}

Nos modelos analisados por Ribeiro (1998) e por Maggi (2000), a viga foi discretizada com elementos volumétricos ao longo de todo o seu 
comprimento, para compatibilizar o modelo numérico com o protótipo experimental.

Como grande parte dos elementos da viga permanecem em regime elástico-linear, é interessante diminuir os graus de liberdade do modelo pela substituição dos elementos em parte da viga, mantendo o seu comprimento.

Neste caso, a solução adotada nos modelos CTEE foi a substituição de 2/3 da viga, a contar pela extremidade livre, por elementos de barra, transmitindo adequadamente a rotação e os deslocamentos para a malha de elementos volumétricos por meio de equações de contorno. Um detalhe da região de transição é apresentado na figura 6.15.

Como a malha do modelo leva em conta a simetria da ligação com relação ao plano médio da alma da viga, foram utilizados elementos de viga bidimensionais, com translações verticais no plano da alma da viga e rotação segundo o eixo ortogonal ao mesmo plano, tomando-se o cuidado de incluir os parâmetros de área e inércia somente para a região modelada.

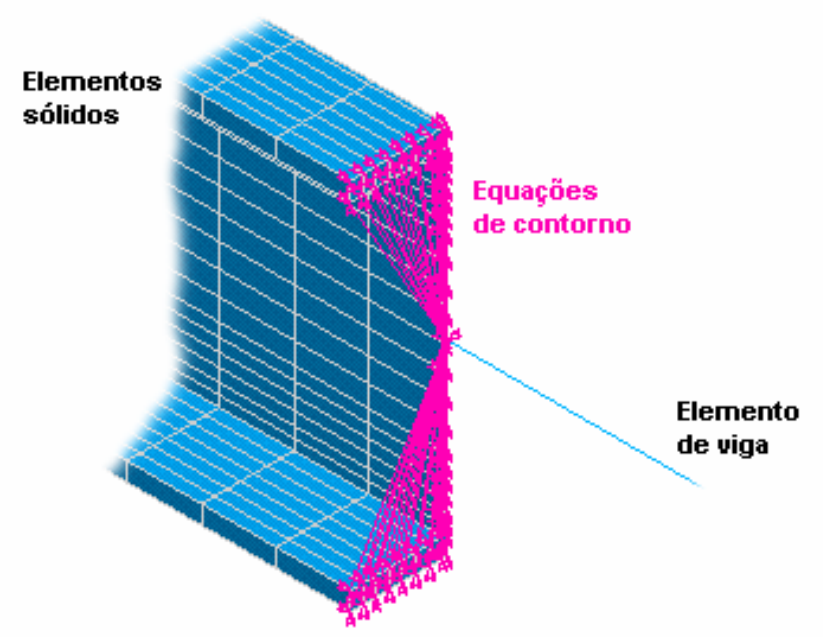

Figura 6.15 - Detalhe das equações de contorno para transferência de rotação e deslocamento entre elementos de barra e elementos sólidos

No acoplamento mostrado na figura 6.15 observou-se uma região de perturbação na distribuição de tensões, razão pela qual se optou por preservar, no mínimo, uma distância da chapa de topo igual à 2 vezes a altura da viga para a conexão com os elementos de barra, representando o último terço do comprimento da viga. 
Uma visão geral esquemática do modelo para ligações com chapa de topo está apresentada na figura 6.16 incluindo os elementos de barra, na qual se observa, ainda, toda a geometria que foi discretizada.

O mesmo procedimento poderia ser utilizado para simular as extremidades do pilar. No entanto, o ganho computacional obtido durante o processamento, mesmo para a substituição dos elementos volumétricos da viga, não foram significativos nos últimos estágios da análise numérica.

Por esse motivo, a simulação do pilar manteve os elementos volumétricos, ficando o acoplamento entre elementos sólidos e elementos de barra, na viga, indicado para futuras análises que envolvam a inclusão da ligação discretizada em análises de pórticos.

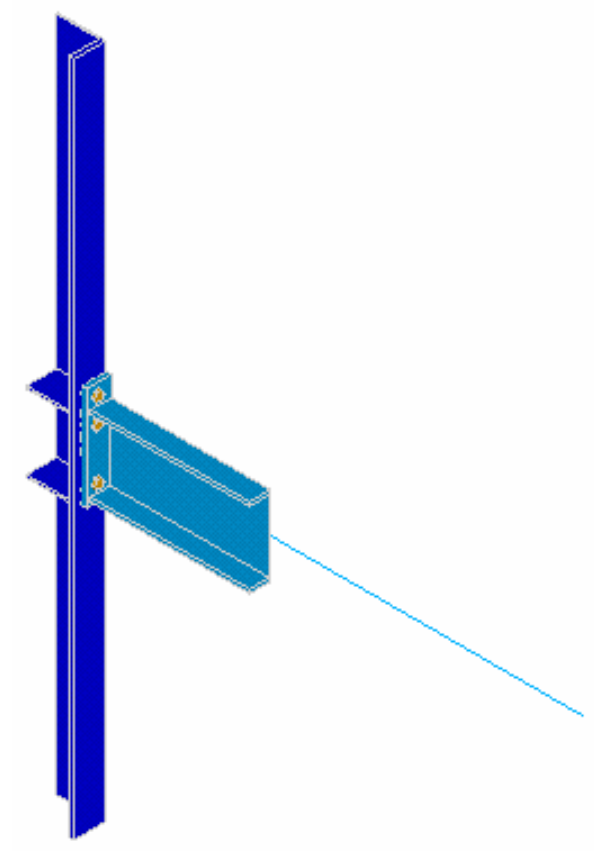

Figura 6.16 - Visão esquemática dos modelos com chapa de topo

\subsubsection{Aplicação dos modelos constitutivos para os materiais}

A descrição das relações constitutivas foi feita, basicamente, relacionando-se os pares tensão-deformação para o material atribuído a cada elemento. De maneira geral, foram utilizados dois tipos de materiais: o primeiro, 
atribuído às chapas em geral, ou seja, para toda a viga, chapa de topo, pilar, enrijecedores e perfis "T"; e outro para o material dos parafusos.

Como ponto de partida para a obtenção de resultados numéricos e objetivando discussões preliminares sobre o comportamento dos modelos, foram utilizados os padrões de materiais propostos por Bahaari \& Sherbourne (1996) e por Kulak et al. (1987), mostrados anteriormente com a inclusão do trecho final de "colapso", com os valores nominais de tensão dos aços ASTMA36 e ASTM-A325, atribuídos respectivamente às chapas e aos parafusos.

A tabela 6.2 indica os valores do módulo de elasticidade longitudinal $(\mathbf{E})$, do coeficiente de Poisson $(v)$, da tensão de escoamento $\left(\mathbf{f}_{\mathbf{y}}\right)$ e da tensão última $\left(\mathbf{f}_{\mathrm{u}}\right)$, bem como os pares correspondentes de tensão $(\sigma)$ e deformação $(\varepsilon)$ calculados a partir das curvas padronizadas para cada material. O par tensãodeformação final foi calculado impondo-se uma tensão quase nula com um acréscimo de $1 \%$ da deformação sobre a deformação anterior, com a função de provocar problemas na convergência da solução numérica e, assim, caracterizar o colapso.

Tabela 6.2 - Relações tensão-deformação preliminares para os materiais

\begin{tabular}{|c|c|c|c|c|}
\hline & & & $\sigma(\mathrm{MPa})$ & $\varepsilon(\mathrm{mm} / \mathrm{mm})$ \\
\hline \multirow{4}{*}{$\begin{array}{c}\text { Chapas } \\
\text { ASTM-A36 }\end{array}$} & \multirow{4}{*}{$\begin{array}{c}E=205000 \mathrm{MPa} \\
v=0.3 \\
f_{y}=250 \mathrm{MPa} \\
f_{u}=400 \mathrm{MPa}\end{array}$} & \multirow{4}{*}{$\varepsilon_{y}=0,001220$} & 250,0 & 0,001220 \\
\hline & & & 250,0 & 0,013420 \\
\hline & & & 400,0 & 0,146400 \\
\hline & & & 0,1 & 0,147864 \\
\hline \multirow{4}{*}{$\begin{array}{c}\text { Parafusos } \\
\text { ASTM-A325 }\end{array}$} & \multirow{4}{*}{$\begin{array}{c}E=205000 \mathrm{MPa} \\
v=0.3 \\
f_{y}=635 \mathrm{MPa} \\
f_{u}=825 \mathrm{MPa}\end{array}$} & \multirow{4}{*}{$\varepsilon_{y}=0,003098$} & 635,0 & 0,003098 \\
\hline & & & 825,0 & 0,010843 \\
\hline & & & 825,0 & 0,024784 \\
\hline & & & 0,1 & 0,025032 \\
\hline
\end{tabular}

\subsubsection{Condições de contorno}

As restrições impostas aos modelos representam, de maneira geral, as condições de simetria e as restrições de apoio.

Para os modelos das ligações duplo "T", são impedidas as translações nas direções $\mathbf{Y}$ e $\mathbf{Z}$ globais ao longo do modelo, representando, 
respectivamente, a simetria com relação aos planos $\mathbf{X Y}$ e $\mathbf{X Z}$. Além disso, todas as translações foram impedidas na extremidade da alma de um dos perfis "T" para simular o apoio.

Para os modelos das ligações com chapa de topo, a simetria da ligação com relação ao plano médio da alma da viga foi simulada da mesma maneira, restringindo-se ainda a alma do pilar ao longo de sua altura na direção $\mathbf{X}$ global para simular a simetria do protótipo cruciforme no plano $\mathbf{Y Z}$. Para restringir o deslocamento do pilar na direção vertical, vinculações nas três direções foram impostas na seção transversal das extremidades superior e inferior.

É interessante observar que, neste caso, a simulação foi feita restringindo-se o pilar, e não a extremidade da viga como descrito nos procedimentos experimentais. No entanto, as duas configurações são equivalentes no mecanismo de transferência de esforços.

\subsubsection{Aplicação do carregamento}

Fazendo uma correspondência ao programa experimental, todos os protótipos foram solicitados após a protensão dos parafusos. Neste caso, o carregamento nos modelos numéricos foi aplicado em duas fases distintas, sendo a primeira a protensão inicial.

Chamando-se a atenção, novamente, para a tipologia da malha dos parafusos e a maneira como são posicionados no modelo numérico, a protensão inicial foi realizada impondo-se, como artifício, variações negativas de temperatura nos fustes dos parafusos. Devido à simulação da cabeça e da porca dos parafusos e das restrições de contato impostas para esses dois elementos nas interfaces entre a mesa do pilar e a chapa de topo, tensões de tração se desenvolvem ao longo do fuste à medida que este tende a se retrair.

Assim, também surgem pressões de contato entre a chapa de topo e a mesa do pilar simulando os efeitos da protensão inicial, inclusive para os parafusos. Como característica adicional do material dos parafusos, foi adotado um coeficiente de dilatação térmica, também fictício, de $1 \times 10^{-5}$. 
A força total de protensão, de acordo com as especificações da NBR 8800 (1996), é função do diâmetro nominal dos parafusos e corresponde à $70 \%$ da força obtida com a multiplicação da área bruta pela tensão de escoamento nominal do aço. Para os modelos numéricos, a força total de protensão é função da variação de temperatura e também da deformabilidade das chapas que o parafuso conecta.

Com essa consideração, foram elaborados diagramas que, com base na força total de protensão desejada, relacionam a variação total de temperatura com o comprimento total do fuste dos parafusos, cujo valor é a soma das espessuras das chapas conectadas. A representação desses diagramas pode ser observada na figura 6.17 para os parafusos com diâmetros de $12,5,16,0$ e $19,0 \mathrm{~mm}$, cujas relações temperatura-comprimento foram utilizadas na determinação da variação negativa de temperatura a ser aplicada nos fustes na fase de protensão dos modelos numéricos.

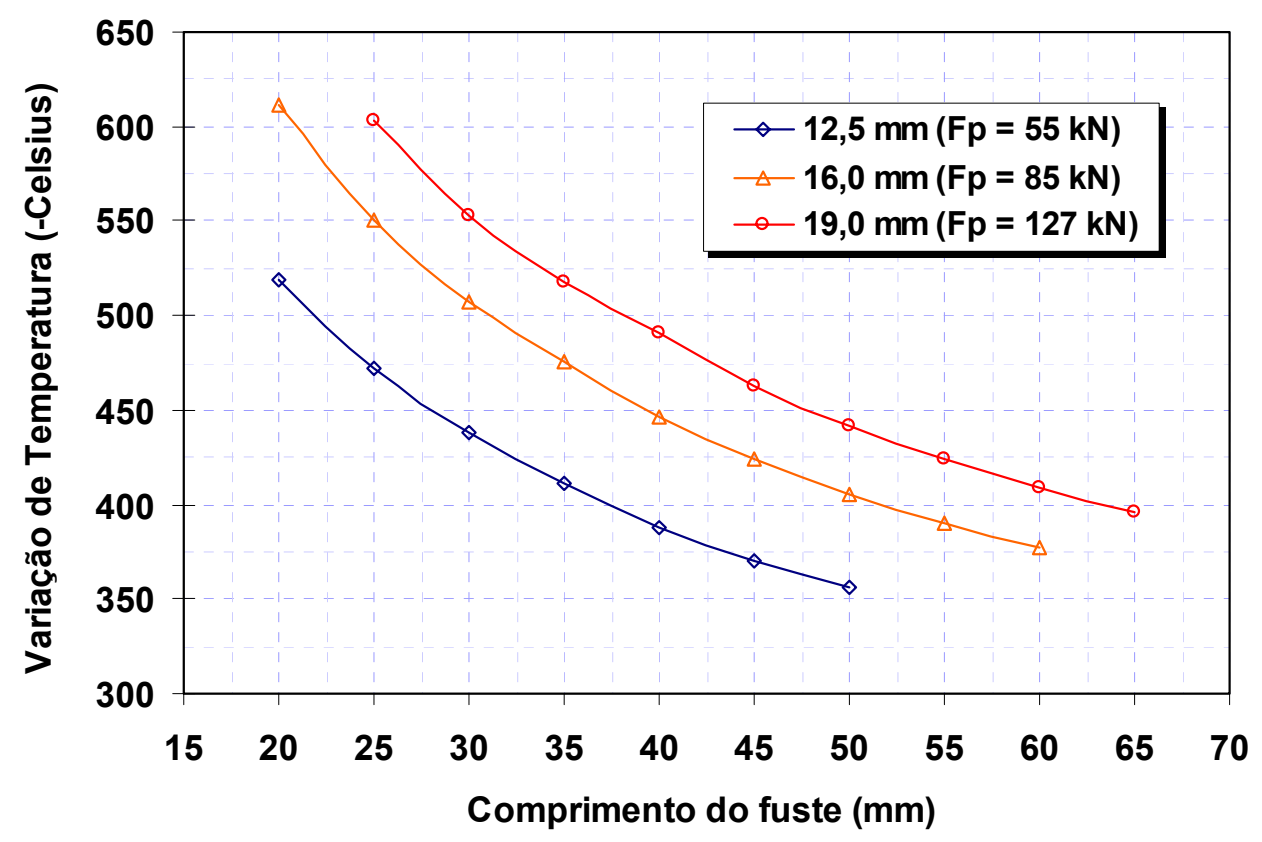

Figura 6.17 - Diagramas temperatura-comprimento para a aplicação da protensão

É importante comentar que todos os modelos constitutivos aplicados na modelagem são independentes da temperatura e, portanto, a aplicação de diferenciais de temperatura não influencia as leis constitutivas não-lineares, 
representando apenas um artifício para impor as forças necessárias de protensão.

Após essa fase, procede-se com o carregamento dos modelos, mantendo-se os procedimentos utilizados no programa experimental. Uma característica da metodologia aplicada neste estudo é a aplicação do carregamento por meio da imposição controlada de deslocamentos, utilizada em todos os modelos numéricos.

Dessa forma, para o carregamento dos modelos das ligações duplo "T", aplicaram-se deslocamentos na extremidade oposta ao apoio, segundo a direção axial, de modo a tracionar os parafusos. Assim, o deslocamento total aplicado foi de $\mathbf{2 0 , 0} \mathbf{m m}$ na direção do eixo global $X$, ressaltando-se que esse valor é superestimado para servir como padrão para todos os modelos.

Da mesma forma, para os modelos de ligações com chapa de topo estendida foram aplicados deslocamentos na extremidade livre da viga, na direção do eixo global $Y$, a fim de solicitar a ligação à flexão e à esforços cortantes. Para essas ligações, o deslocamento vertical total aplicado foi de $100,0 \mathrm{~mm}$, o que corresponde à, aproximadamente, 10 vezes o limite de deslocamento vertical em serviço conforme a NBR 8800 (1986). Esse valor também foi padronizado para esses modelos.

Para se obter a força equivalente aplicada basta obter a força total de reação nos pontos de imposição do deslocamento. Essa metodologia para aplicação do carregamento nos perfis "T" e nas vigas foi considerada satisfatória uma vez que aumenta a estabilidade da solução numérica, diminuindo os problemas de convergência e, conseqüentemente, o tempo total de processamento.

\subsubsection{Solução incremental-iterativa}

Apenas a título de observação, comentam-se algumas características gerais sobre o processo de análise dos modelos, uma vez concluídas as etapas descritas anteriormente. 
Como o modelo incorpora a plasticidade dos materiais e a discretização de interfaces de contato, a solução numérica torna-se não linear e, neste caso, requer subdivisões do carregamento em incrementos a partir dos quais se realiza um processo iterativo para chegar às condições de equilíbrio para o modelo.

A convergência da solução para cada incremento do carregamento depende de critérios previamente estabelecidos e, no caso específico desta modelagem, utilizaram-se critérios de convergência em força e deslocamento segundo o método "L2-norm" disponível no software utilizado. Segundo esse método, as forças - e deslocamentos - internas e externas dos elementos são comparadas pela raiz quadrada da soma dos quadrados e, sendo a diferença menor que a tolerância especificada no método, atinge-se a convergência, passando-se para o incremento seguinte. A tolerância, neste caso, foi imposta com valores de $1 \times 10^{-3}$ tanto para força como para deslocamentos, mostrandose adequados para a análise.

É claro que o valor de cada incremento é importante, uma vez que o processo iterativo ocorre em cada subdivisão do carregamento. Neste caso, padronizaram-se incrementos iniciais de $\mathbf{0 , 3 3 \%}$ para aplicação das variações de temperatura - correspondente à fase de protensão - e de $\mathbf{0 , 1} \%$ e $\mathbf{0 , 0 5} \%$, respectivamente, para a aplicação do carregamento nas ligações duplo "T" e nas ligações com chapa de topo. Os incrementos podem variar entre $\mathbf{0 , 0 1 \%} \mathrm{e}$ $15 \%$, dependendo de como o software analisa o processo de convergência, utilizando-se a opção de incrementos automáticos.

Lembrando, novamente, do trecho final descendente dos diagramas tensão-deformação aplicados ao modelo numérico, é interessante enfatizar que a queda brusca da tensão para níveis próximos de zero caracterizam uma variação extremamente acentuada na rigidez dos elementos para a qual, segundo os critérios de convergência adotados, dificilmente se atingirá o equilíbrio. Neste caso, o trecho final descendente nas relações tensãodeformação serve como artifício para caracterizar o colapso das ligações, simulado dentro do processo de solução como um problema de convergência. 


\subsection{INFLUÊNCIA DE SIMPLIFICAÇÕES DOS MATERIAIS E DA GEOMETRIA}

Como um dos objetivos da modelagem é a realização de estudos paramétricos, uma das características importantes para a metodologia da análise numérica é a padronização de alguns fatores. Sendo a análise voltada, principalmente, para variações na geometria das ligações, as características dos materiais devem ser uniformizadas.

Essa uniformização também é necessária uma vez que dificilmente, para cada modelo, seria possível utilizar dados de caracterização dos materiais que, além disso, sofrem variações significativas dentro de um mesmo grupo de ensaios. Considerando essas variações, é aceitável em uma análise paramétrica a padronização dos modelos constitutivos, considerando-se ainda que é usual no dimensionamento a utilização de valores nominais de tensão, especificados pelas normalizações, que representam valores mínimos geralmente abaixo da capacidade resistente real dos elementos.

Sabendo desse aspecto, é importante analisar os efeitos da variação de algumas características dos materiais na modelagem, para permitir uma avaliação das mudanças de comportamento dos modelos.

Um outro fator, não menos importante, é a simplificação adotada na geometria pela eliminação das soldas na discretização dos modelos, uma vez que é intuitivo se esperar um aumento de rigidez dos modelos pela presença das soldas, principalmente para os perfis "T".

\subsubsection{Variações das características dos materiais}

Tomando-se como base um modelo de ligação duplo "T", com mesa de $16,0 \mathrm{~mm}$ e parafusos de $16,0 \mathrm{~mm}$ (TSC5), e as relações constitutivas apresentadas nos itens 6.2 .2 e 6.3.4, foram avaliadas modificações em 5 variáveis: para o material das chapas, variou-se à tensão de escoamento $\left(\mathbf{f}_{\mathbf{y}}\right) \mathrm{e}$ o tamanho do patamar de escoamento e para os parafusos foram variadas a tensão máxima ou tensão última $\left(\mathbf{f}_{\mathbf{u}}\right)$, a deformação última $\left(\varepsilon_{\mathbf{u}}\right)$ e a inclinação do diagrama tensão-deformação logo após a plastificação, entre a tensão de escoamento e a tensão máxima. Cada variável foi modificada isoladamente. 
Analisando-se, inicialmente, a variação do material das chapas, a tabela 6.3 indica os valores utilizados como referência para a definição dos pares tensão-deformação bem como a identificação dos modelos, e a figura 6.18 as curvas força-deslocamento para os modelos numéricos correspondentes, incluindo-se, apenas para simples observação, as curvas obtidas experimentalmente para os protótipos TSC5-1 e TSC5-2 $\left(\mathbf{t}_{\mathrm{ch}}=16,0\right.$ $\left.\mathrm{mm} ; \mathbf{d}_{\mathrm{b}}=\mathbf{1 6 , 0} \mathrm{mm}\right)$, de igual geometria, denominados simplesmente por TSC5 no gráfico ${ }^{8}$.

Tabela 6.3 - Parâmetros para variação do material das chapas

\begin{tabular}{|c|c|c|c|}
\hline Modelo & $\begin{array}{c}\mathbf{f}_{\mathrm{y}} \\
(\mathrm{MPa})\end{array}$ & $\begin{array}{l}\text { Patamar de } \\
\text { escoamento }\end{array}$ & Observações \\
\hline Cfy1 & 250,0 & \multirow{3}{*}{$11 \varepsilon_{\mathrm{y}}{ }^{*}$} & Padrão do item 6.3.4 $\left(f_{u}=400 \mathrm{MPa}\right)$ \\
\hline Cfy2 & 300,0 & & Aumento proporcional da tensão última com a \\
\hline Cfy3 & 350,0 & & tensão de escoamento \\
\hline Cpa1 & \multirow{2}{*}{250,0} & $\varepsilon_{\mathrm{y}}$ & Sem patamar de escoamento \\
\hline Cpa2 & & $20 \varepsilon_{\mathrm{y}}$ & - \\
\hline
\end{tabular}

$\varepsilon_{\mathrm{y}}$ é a deformação correspondente à tensão de escoamento $\mathbf{f}_{\mathrm{y}}$.

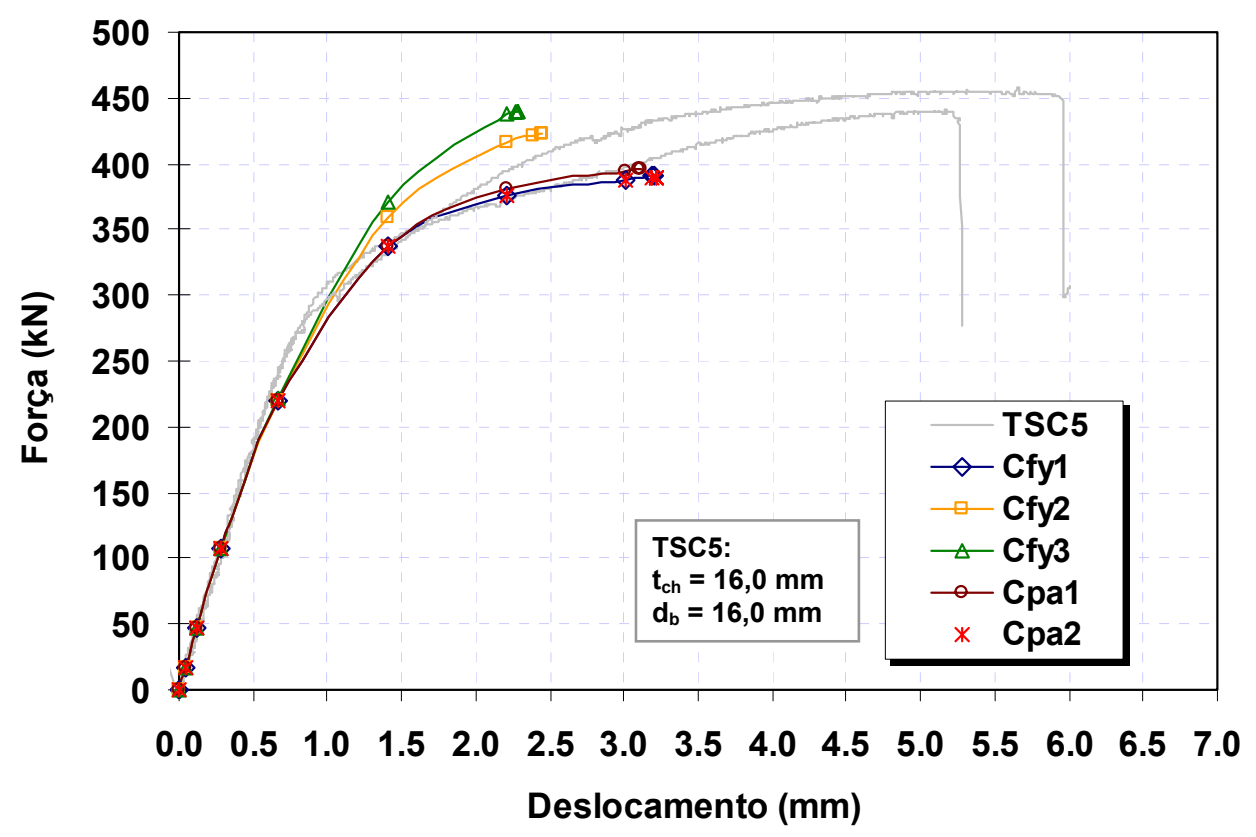

Figura 6.18 - Curvas força-deslocamento para a variação do material das chapas

${ }^{8}$ Todos os protótipos experimentais foram ensaiados aos pares. Neste caso, os resultados experimentais, quando apresentados aos pares, serão denominados pela nomenclatura dos protótipos, ficando subentendido que se refere a ambos os protótipos de cada par. 
Com o aumento da tensão de escoamento da chapa, a rigidez do modelo cresce devido ao aumento de rigidez da chapa à flexão, com conseqüente diminuição da ductilidade, uma vez que os parafusos atingem antecipadamente a sua capacidade resistente. No entanto, o aumento de rigidez não é proporcional ao aumento da tensão de escoamento.

A variação do tamanho do patamar de escoamento, por sua vez, não influi significativamente no comportamento do modelo.

$\mathrm{Na}$ caracterização experimental do aço ASTM-A36, apresentada no capítulo 4, observa-se que a tensão de escoamento tem valores em torno de $300 \mathrm{MPa}$, e considerando essa variação como mais provável dentro de uma amostra geral, utiliza-se as considerações dos modelos Cfy1 e Cfy2 com relação ao material das chapas para se verificar as variações citadas para o material dos parafusos, cujos parâmetros estão definidos na tabela 6.4.

Tabela 6.4 - Parâmetros para variação do material dos parafusos

\begin{tabular}{|c|c|c|c|c|c|}
\hline Chapa & Modelo & $\begin{array}{c}\mathbf{f}_{\mathrm{u}} \\
(\mathrm{MPa})\end{array}$ & $\varepsilon_{\mathrm{u}}$ & $\varepsilon_{1}$ & Observações \\
\hline \multirow{7}{*}{ Cfy1 } & P1fu1 & 750,0 & \multirow{2}{*}{$8 \varepsilon_{\mathrm{y}}$} & \multirow{2}{*}{$3,5 \varepsilon_{\mathrm{y}}$} & \multirow{14}{*}{$\begin{array}{c}\varepsilon_{1} \text { representa a deformação } \\
\text { no instante em que a tensão } \\
\text { máxima }\left(f_{u}\right) \text { é atingida, ou seja, é a } \\
\text { deformação máxima do trecho } \\
\text { compreendido entre } f_{y} \text { e } f_{u} \text {. }\end{array}$} \\
\hline & P1fu2 & 825,0 & & & \\
\hline & P1eu1 & & $8 \varepsilon_{y}$ & & \\
\hline & P1eu2 & 825,0 & $12 \varepsilon_{\mathrm{y}}$ & $3,5 \varepsilon_{y}$ & \\
\hline & P1eu3 & & $16 \varepsilon_{\mathrm{y}}$ & & \\
\hline & P1e1 & 8250 & $16 \mathrm{~s}$ & $3,5 \varepsilon_{y}$ & \\
\hline & P1e2 & $0<0,0$ & $10 \varepsilon_{y}$ & $7 \varepsilon_{\mathrm{y}}$ & \\
\hline \multirow{7}{*}{ Cfy2 } & P2fu1 & 750,0 & \multirow{2}{*}{$8 \varepsilon_{\mathrm{y}}$} & \multirow{2}{*}{$3,5 \varepsilon_{y}$} & \\
\hline & P2fu2 & 825,0 & & & \\
\hline & P2eu1 & \multirow{3}{*}{825,0} & $8 \varepsilon_{y}$ & \multirow{3}{*}{$3,5 \varepsilon_{y}$} & \\
\hline & P2eu2 & & $12 \varepsilon_{\mathrm{y}}$ & & \\
\hline & P2eu3 & & $16 \varepsilon_{\mathrm{y}}$ & & \\
\hline & P2e1 & \multirow{2}{*}{825,0} & \multirow{2}{*}{$16 \varepsilon_{\mathrm{y}}$} & $3,5 \varepsilon_{\mathrm{y}}$ & \\
\hline & P2e2 & & & $7 \varepsilon_{\mathrm{y}}$ & \\
\hline
\end{tabular}

Para verificar, primeiramente, a variação da tensão última do material do parafuso, apresentam-se as curvas força-deslocamento para os modelos P1fu1, P1fu2, P2fu1 e P2fu2 na figura 6.19. 


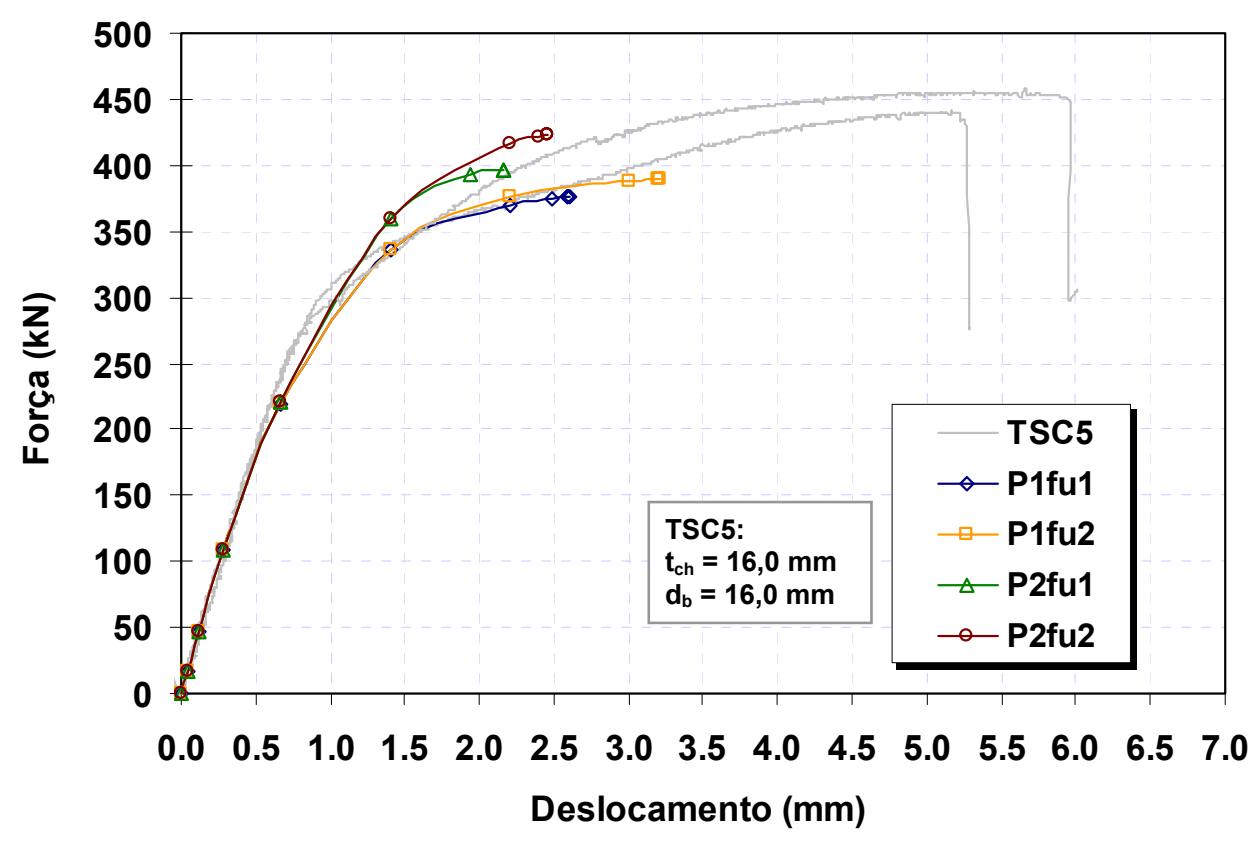

Figura 6.19 - Curvas força-deslocamento para a variação da tensão última dos parafusos

A capacidade resistente dos parafusos é função da tensão máxima que suportam e, neste caso, há variações nos patamares máximos de resistência para o modelo com variações da tensão última aplicada aos parafusos. No entanto, essas diferenças são mais sensíveis com o aumento da tensão de escoamento das chapas. Isso se deve à rigidez relativa entre chapas e parafusos, que modifica as deformações nesses componentes.

Assim, para os modelos P1fu1 e P1fu2, a mesa do perfil "T" inicia a plastificação antes da mesa dos modelos P2fu1 e P2fu2 e, neste caso, os elementos das mesas possuem deformações maiores para o mesmo carregamento. Isso se traduz num aumento visível de ductilidade, enquanto não se tem um aumento significativo de resistência. Com o aumento da tensão de escoamento das chapas, o ganho de resistência pela modificação da tensão última nos parafusos torna-se visível, pois os parafusos tornam-se fontes mais significativas da deformabilidade do modelo.

Entre esses modelos, a diferença de resistência tende a diminuir se forem observadas as curvas força-deslocamento apresentadas na figura 6.20, para a variação da deformação última dos parafusos. 


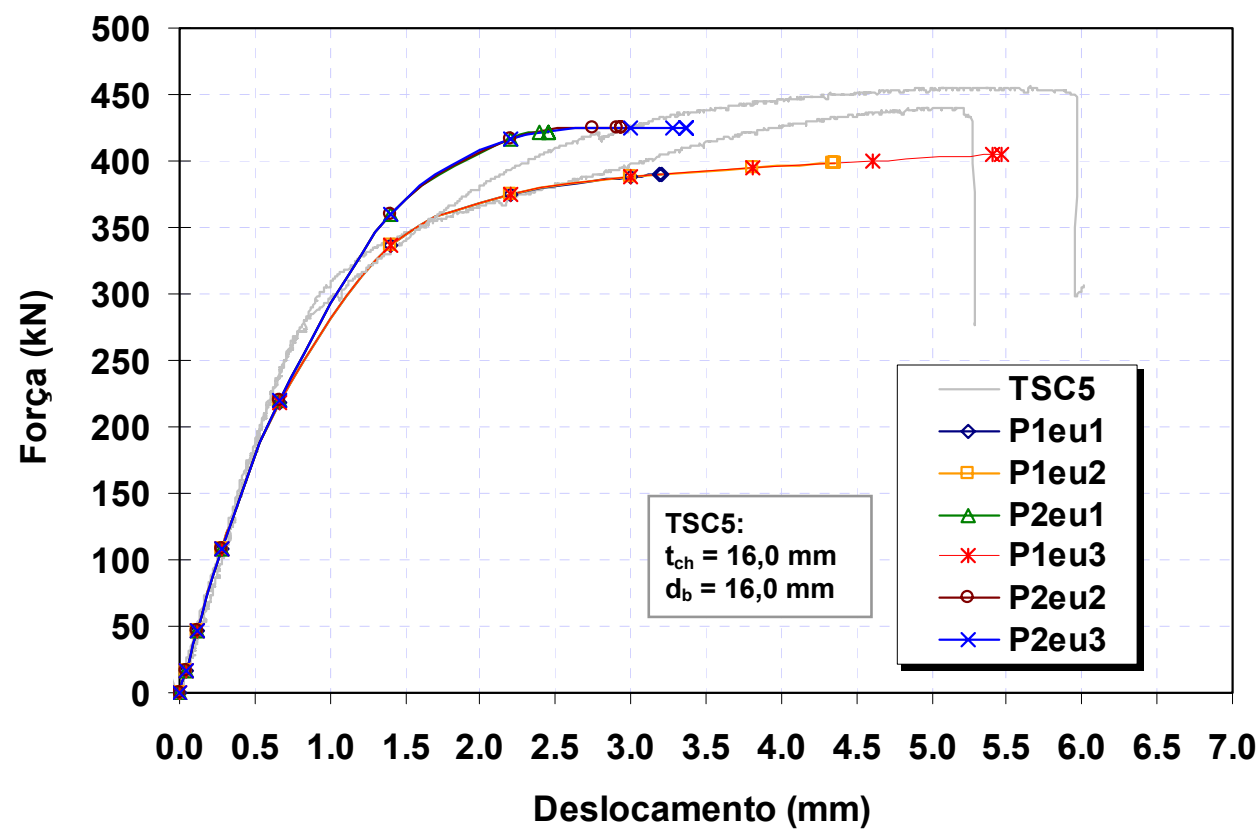

Figura 6.20 - Curvas força-deslocamento para a variação da deformação última dos parafusos

O aumento da deformação última comanda a ductilidade do modelo, como esperado, que também é dependente, de forma bem visível, da deformabilidade relativa entre chapas e parafusos.

$\mathrm{Na}$ figura 6.20 é nítida a variação de ductilidade entre os modelos que, para as chapas com tensão de escoamento de $250 \mathrm{MPa}$, se aproximou coincidentemente da ductilidade do protótipo experimental.

Como as chapas caracterizadas possuem tensão de escoamento de, aproximadamente, $300 \mathrm{MPa}$, as curvas para os modelos com essa característica ganham resistência, mas perdem grande parte da ductilidade, permitindo concluir que, se consideradas chapas com tensão de escoamento maior que as nominais, automaticamente seria necessário aumentar a deformação última do parafuso, de forma a tornar o modelo mais representativo em termos de resistência e também de ductilidade.

Conseqüentemente, o padrão de deformação última proposto por Kulak et al. (1987) para os parafusos, igual à $\mathbf{8} \varepsilon_{\mathbf{y}}$, subestima a capacidade de deformação do parafuso.

Em resumo, as mudanças nos modelos constitutivos provocam variações pequenas na resistência dos modelos, mas variações pronunciadas na ductilidade, o que também pode ser comprovado nas curvas da figura 6.21 , 
nas quais se observa pequena variação das forças axiais nos parafusos entre os diversos modelos.

A última série de comparações refere-se à variação da deformação após o início da plastificação dos parafusos e, conforme pode ser observado na figura 6.22, não tem influência significativa no comportamento dos modelos.

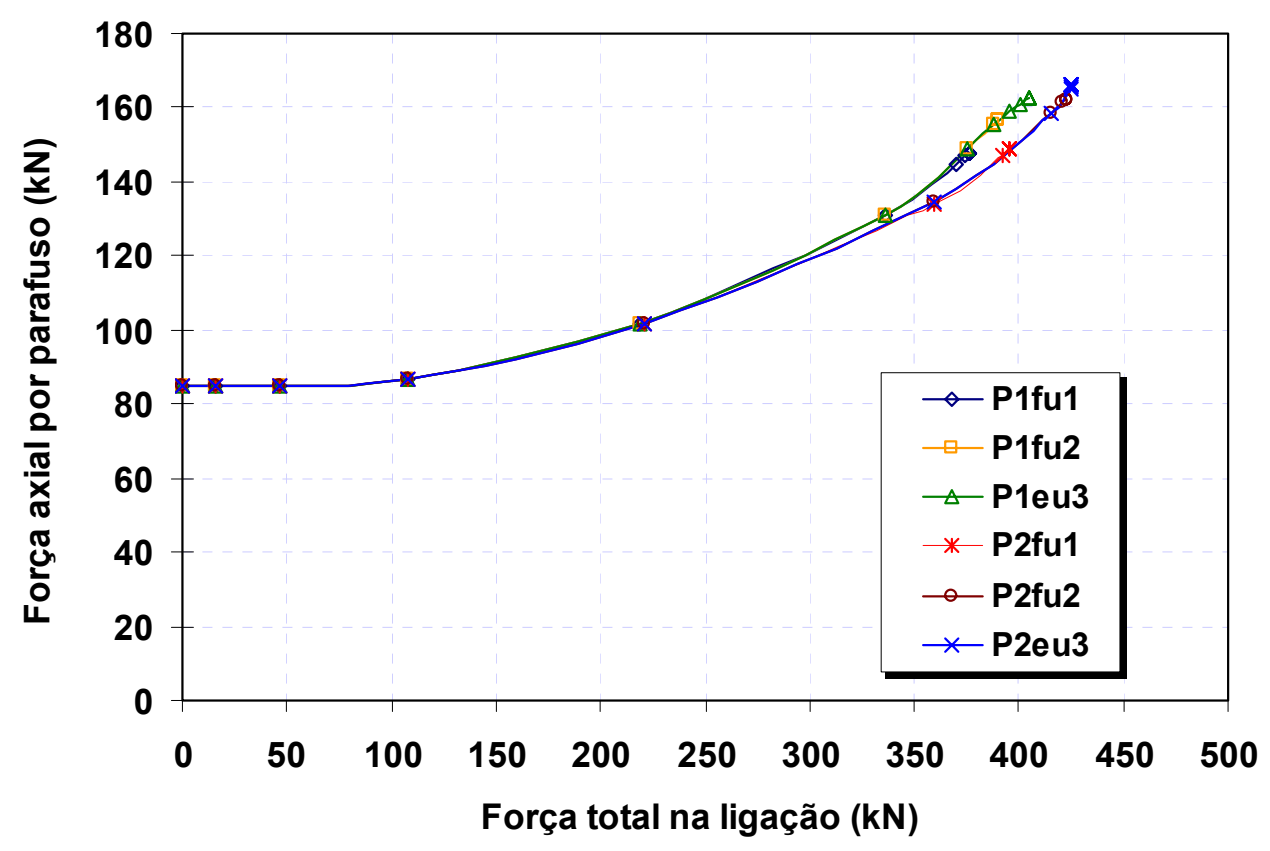

Figura 6.21 - Forças axiais nos parafusos para variação dos materiais

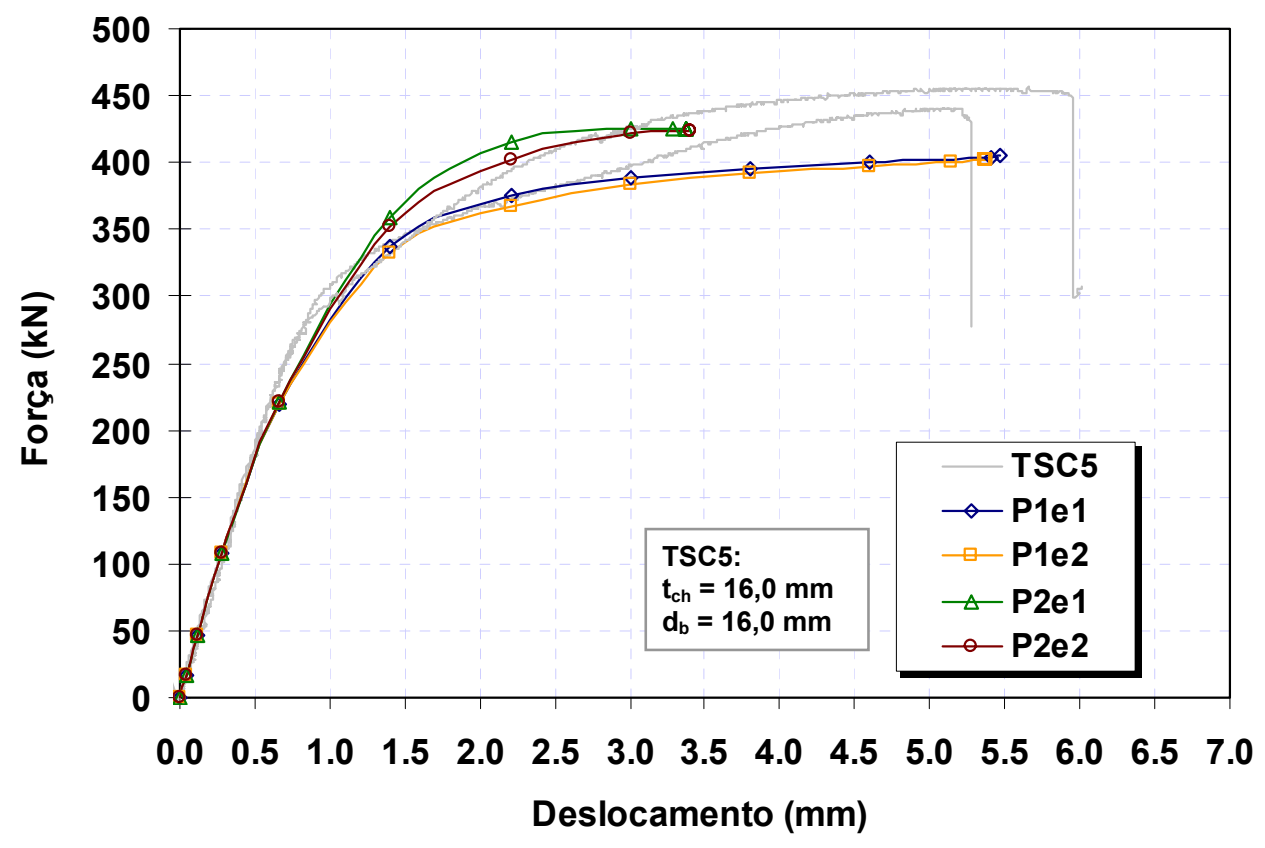

Figura 6.22 - Curvas força-deslocamento para a variação da deformação após o início da plastificação dos parafusos 
Com a análise das variações de rigidez no modelo TSC5 em função das variações de alguns parâmetros de resistência e de ductilidade impostos pelos diagramas tensão-deformação, é possível perceber que a adoção de relações constitutivas padronizadas pode conduzir a mudanças significativas no comportamento dessas ligações.

Para comparações entre os resultados numéricos e experimentais, e até mesmo para o estudo dos resultados numéricos como complemento aos resultados de ensaio, recomenda-se que a descrição constitutiva dos materiais seja feita, sempre que possível, com dados de caracterização.

Em se tratando de análises paramétricas, a padronização dos modelos constitutivos deve ser feita para isolar, adequadamente, as variáveis que estão sendo estudadas. No entanto, é necessário assumir que algumas características do comportamento das ligações são válidas apenas dentro dos limites estabelecidos pelo estudo, e não para extrapolações de resultados experimentais. É o caso da ductilidade das ligações que, como observado anteriormente, apresenta variações relativamente grandes para mudanças não tão expressivas das características dos materiais das chapas e dos parafusos.

\subsubsection{Influência de simplificações na geometria: soldas}

Outros fatores que podem apresentar variações significativas na modelagem são a espessura e a resistência das soldas entre as chapas, principalmente se especificadas como soldas de penetração total.

Todos os protótipos ensaiados neste trabalho e, conseqüentemente, as tipologias adotadas como base para a modelagem, são formados por perfis soldados. As soldas utilizadas na intersecção entre viga e chapa de topo são de penetração total e, inspecionando-se os protótipos, é visível a variação de espessura, o que pode influenciar no comportamento global do modelo, assim como no comportamento localizado de alguns componentes, principalmente da chapa de topo e da mesa dos perfis "T" sob flexão.

Assim, a desconsideração das soldas na geometria dos modelos numéricos é um procedimento recomendável, indicando a necessidade de se 
verificar a influência dessa simplificação para avaliar as possíveis variações do comportamento dos modelos.

Utilizando-se, novamente, o modelo TSC5 e também os modelos com base nos protótipos TSC4, TSC6, e TSC7, com parafusos de 16,0 $\mathrm{mm}$ e mesas com espessura, respectivamente, de 12,5 , 19,0 e $22,4 \mathrm{~mm}$, são analisadas as respostas globais força-deslocamento considerando a relação constitutiva do modelo $\mathrm{P}_{1 \mathrm{eu}}{ }^{9}$, descrito no item anterior.

Para estes modelos duas geometrias foram discretizadas: a primeira, de acordo com o descrito no item 6.3.3.1, sem a consideração das soldas; e a segunda com a discretização de uma face inclinada na intersecção mesa/alma dos perfis "T", com lados de comprimento igual à $\mathbf{8 , 0} \mathbf{m m}$, simulando 0 enrijecimento da mesa pela solda sem modificar as características dos materiais. Detalhes da geometria modificada para a solda podem ser visualizados na figura 6.23 .
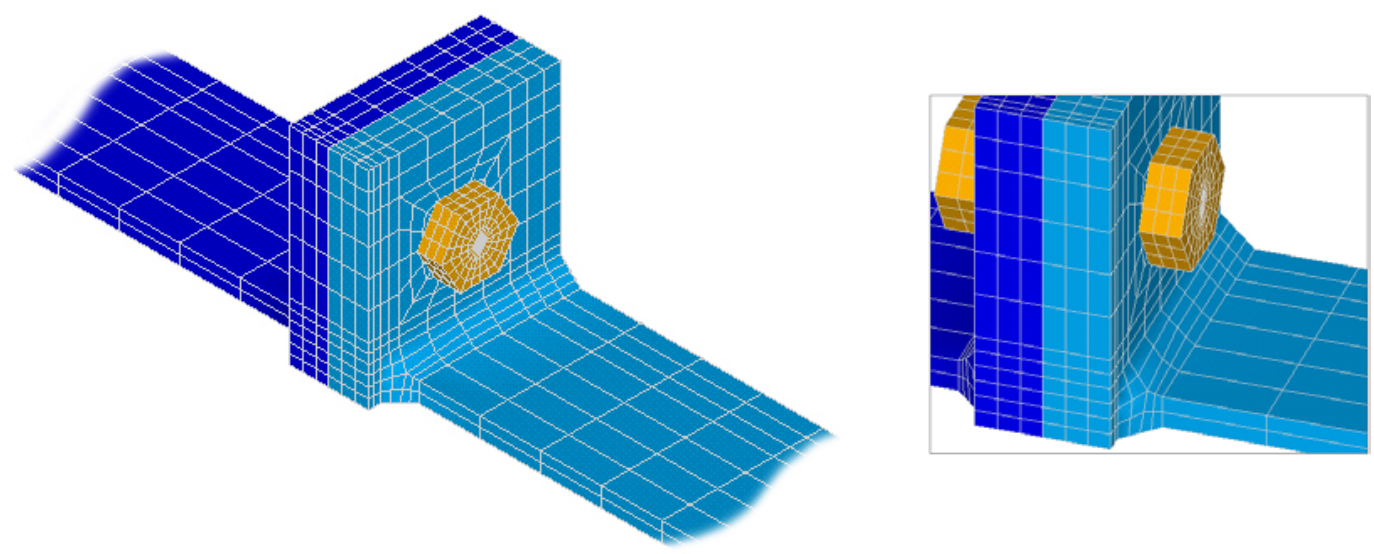

Figura 6.23 - Discretizações da geometria para considerar a solda

Comparando os modelos sem solda, denominados de "simplificados", e os modelos com solda, as figuras 6.24 à 6.27 apresentam os resultados numéricos para os modelos TSC4 à TSC7, conforme indicado nas figuras. Novamente, apresentam-se também as curvas experimentais para os protótipos correspondentes. 


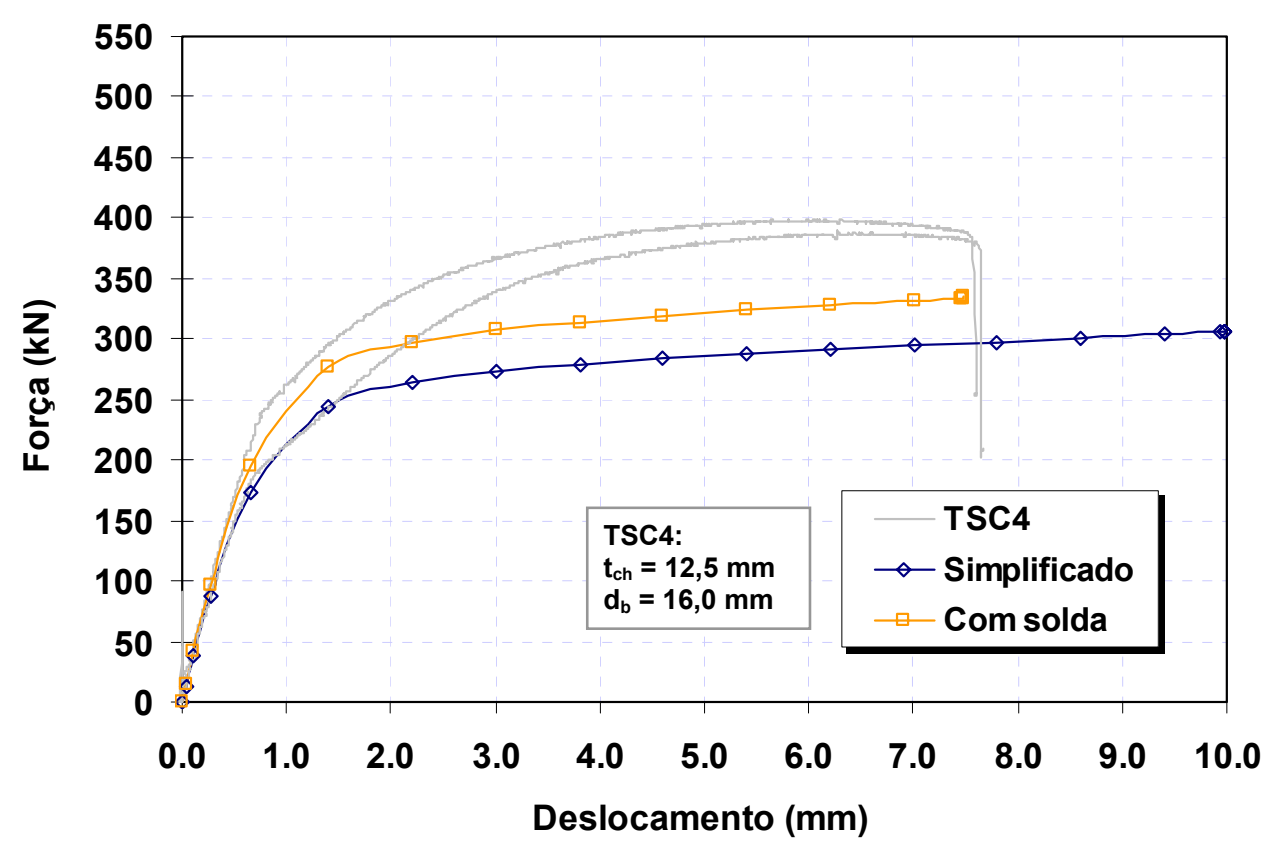

Figura 6.24 - Modelos com e sem solda com base no protótipo TSC4

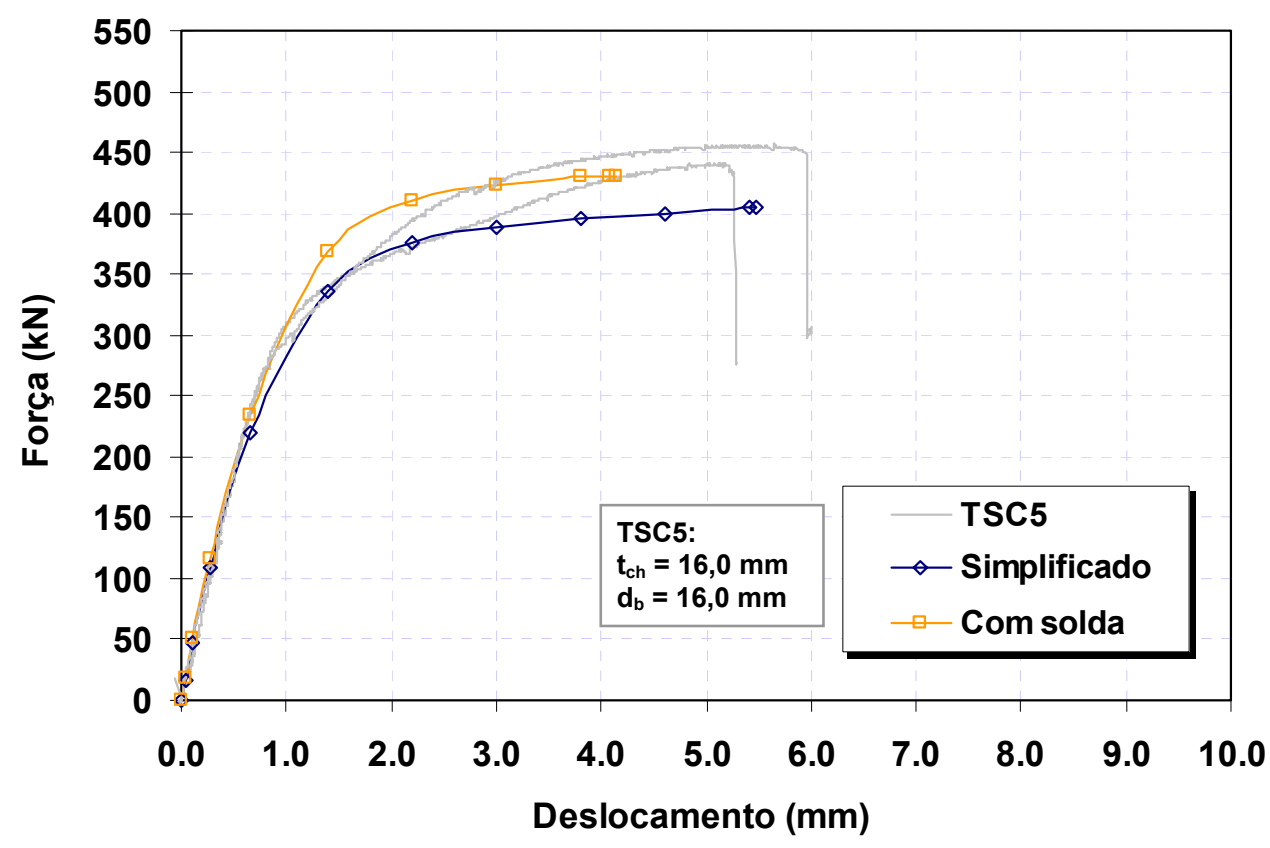

Figura 6.25 - Modelos com e sem solda com base no protótipo TSC5

\footnotetext{
${ }^{9}$ Vide tabelas 6.3 e 6.4
} 


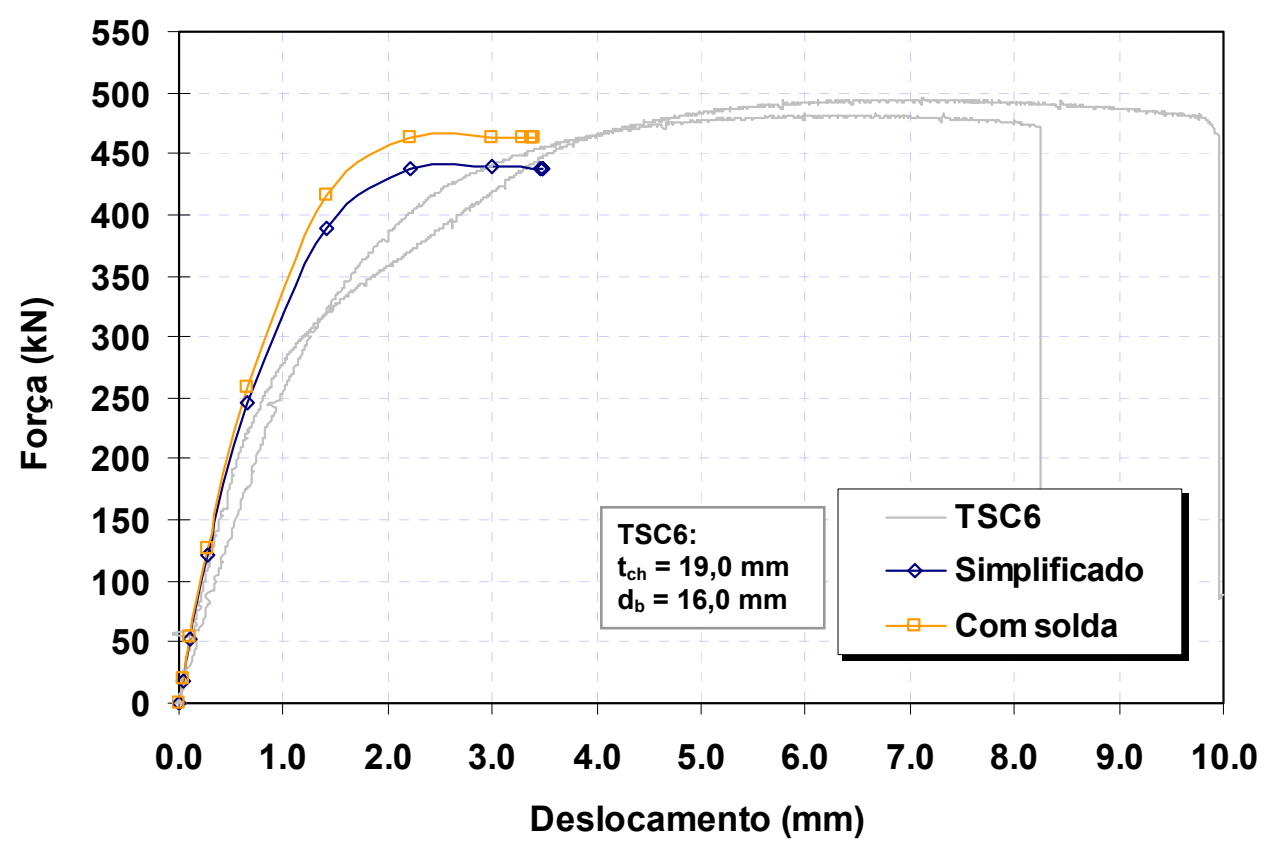

Figura 6.26 - Modelos com e sem solda com base no protótipo TSC6

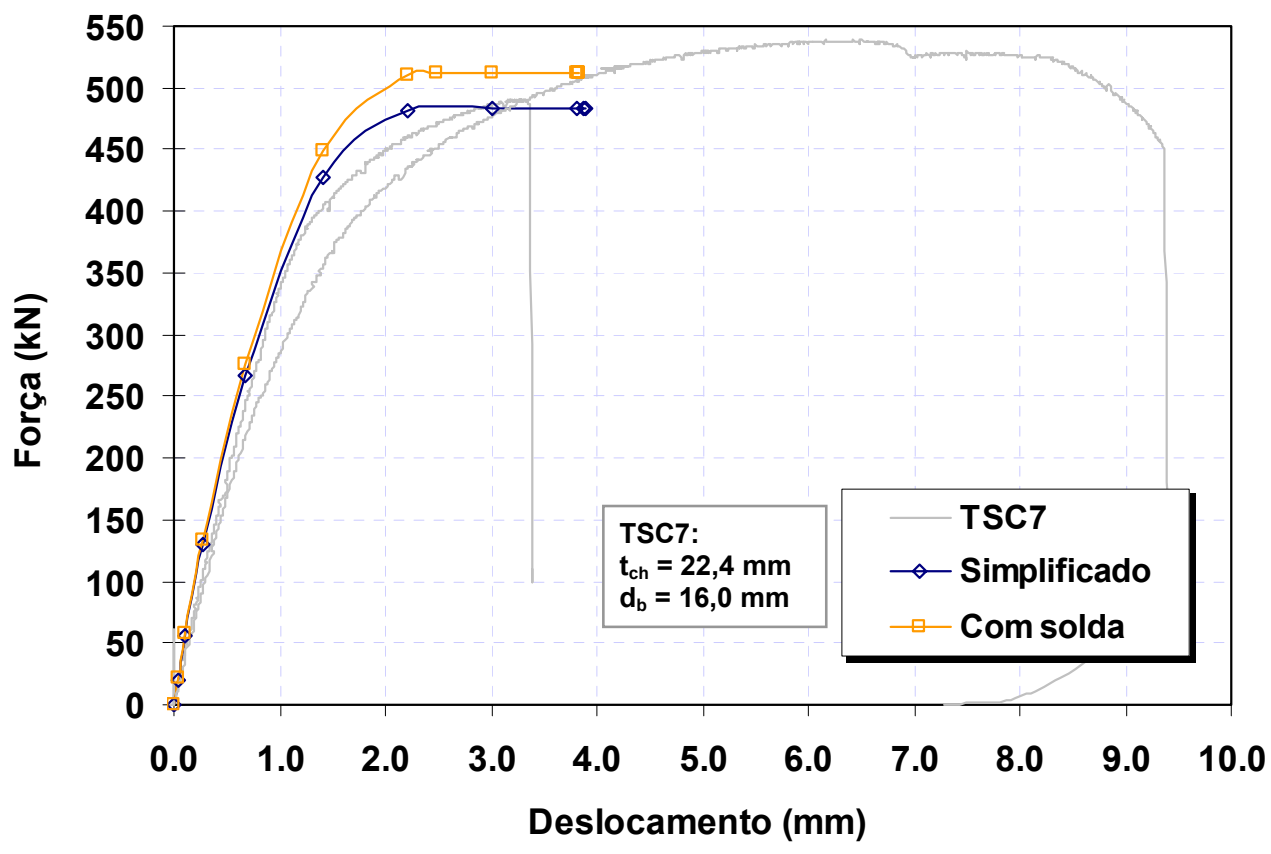

Figura 6.27 - Modelos com e sem solda com base no protótipo TSC7

De maneira geral, observa-se um aumento da resistência dos modelos com o enrijecimento da mesa, que ocorre de forma sistemática e uniforme. A rigidez inicial não é influenciada. No entanto nota-se que, para os modelos TSC4 e TSC5, há uma diminuição significativa de ductilidade, influência não observada nos modelos TSC6 e TSC7, cujas mesas são mais 
espessas. Assim, a variação de ductilidade para os modelos TSC4 e TSC5 deve-se à variação do efeito alavanca devido ao enrijecimento das mesas.

Um outro fator interessante é que, para o modelo TSC4, há uma diferença significativa entre a resistência do protótipo experimental e o resultado numérico, diferença que diminui significativamente conforme aumenta a espessura da mesa, quase desaparecendo para o modelo TSC7.

Antecipando alguns comentários sobre a representatividade da modelagem, esse aspecto é um indicativo da dificuldade de se representar o comportamento dos materiais por relações uniaxiais tensão-deformação, lembrando que os parafusos no modelo TSC4 estão sujeitos a esforços combinados de tração e flexão visíveis na figura 6.28, que apresenta as forças axiais por parafuso para os modelos TSC4 e TSC7, com e sem a consideração da solda, percebendo-se nitidamente a redução da capacidade resistente do modelo TSC4 em função da solicitação nos parafusos.

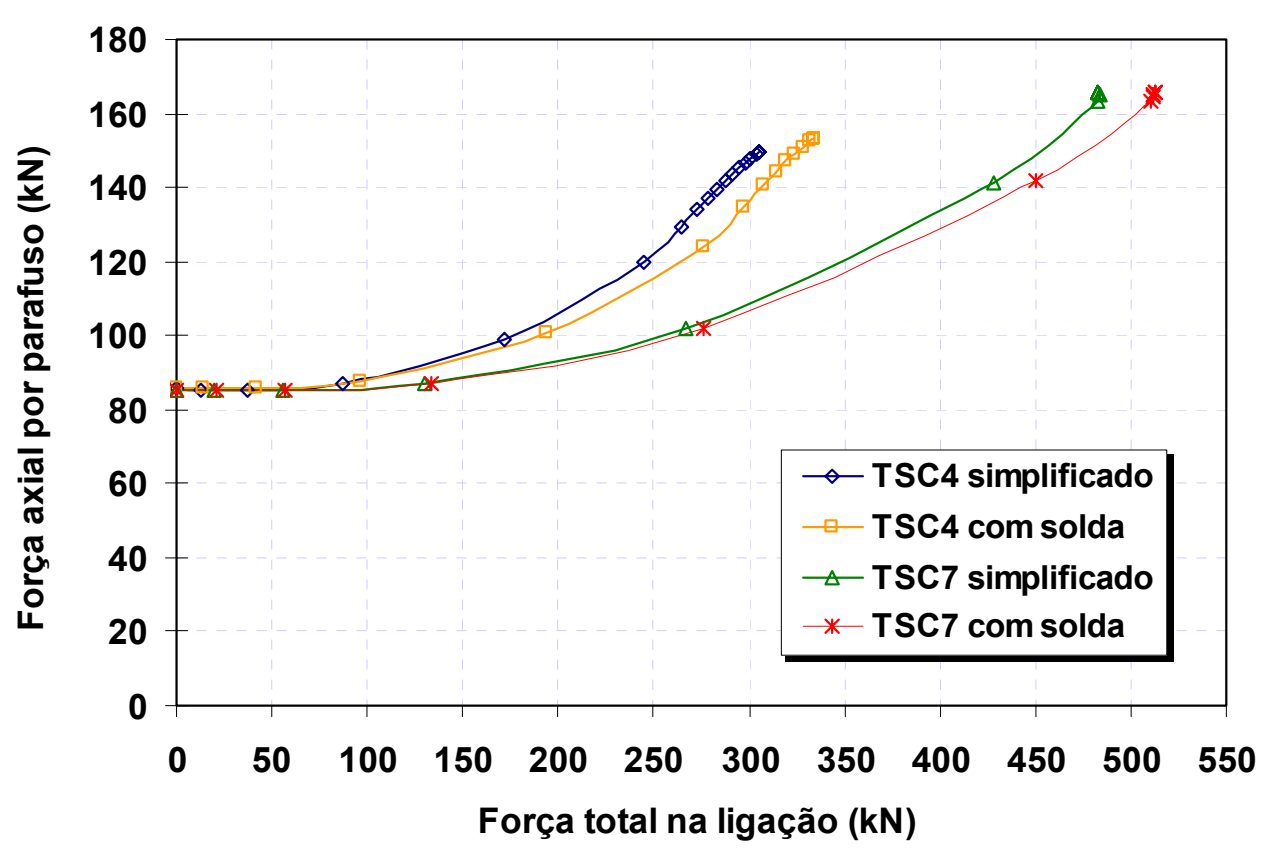

Figura 6.28 - Forças axias nos parafusos - modelos TSC4 e TSC7 com e sem solda

A menos da ductilidade, a variação da força axial nos parafusos e a resistência dos modelos podem ser desconsideradas, assumindo-se que os modelos subestimam a capacidade resistente da ligação e estão, assim, a favor da segurança nas análises paramétricas. 
Essa afirmação justifica também a utilização dos valores de tensões nominais para os materiais adotados nas análises e, assim, não será considerada a discretização da solda nos modelos numéricos.

Como os modelos de ligações duplo "T" têm sua dimensão reduzida em relação aos modelos de ligações com chapa de topo, espera-se que as variações provocadas acima produzam efeitos mais significativos. Estas simplificações são, portanto, aplicadas a todos os modelos, valendo as discussões realizadas acima.

\subsection{APLICABILIDADE DAS RELAÇÕES CONSTITUTIVAS DOS MATERIAIS PARA A SIMULAÇÃO DOS PARAFUSOS}

A caracterização do comportamento numérico dos parafusos requer algumas considerações iniciais devido às características geométricas destes componentes que, ao contrário das chapas, não são homogêneas.

A capacidade resistente dos parafusos, por exemplo, depende da diminuição da área bruta na região da rosca, cuja área efetiva é geralmente $\mathbf{2 5 \%}$ inferior à área calculada pelo diâmetro nominal do parafuso. A deformabilidade dos parafusos, por sua vez, é influenciada pela distribuição da rosca no corpo do parafuso e pela flexibilidade das arruelas usualmente utilizadas junto às porcas, características que contribuem significativamente para a ductilidade do parafuso.

Como a modelagem proposta para o parafuso ainda é simplificada, visto que não seria prático incluir todas as suas características geométricas, são necessárias algumas considerações quanto aos modelos constitutivos aplicados a estes componentes, cuja geometria nos modelos foi padronizada.

Para dar início a essa discussão, na figura 6.29 estão apresentadas as curvas força-alongamento para os parafusos de $16,0 \mathrm{~mm}$ caracterizados no programa experimental, juntamente com uma curva simplificada, denominada de "curva padrão", traçada sobre os resultados experimentais e formada por trechos lineares ligando 4 pontos, identificados no gráfico.

Da "curva padrão" é direta a obtenção de uma relação tensãodeformação convencional considerando-se as características gerais dos 
ensaios, da mesma maneira que para os ensaios de caracterização das chapas de aço. Sendo a força total no parafuso $\mathbf{P}$ e o alongamento $\Delta \mathbf{L}$, tomando-se como referência um comprimento inicial $L_{0}$ e uma área $A_{0}$, os valores convencionais da tensão $(\sigma)$ e da deformação $(\varepsilon)$ são calculados, respectivamente, por:

$$
\begin{aligned}
& \sigma=\frac{P}{A_{0}} \quad e \\
& \varepsilon=\frac{\Delta L}{L_{0}}
\end{aligned}
$$

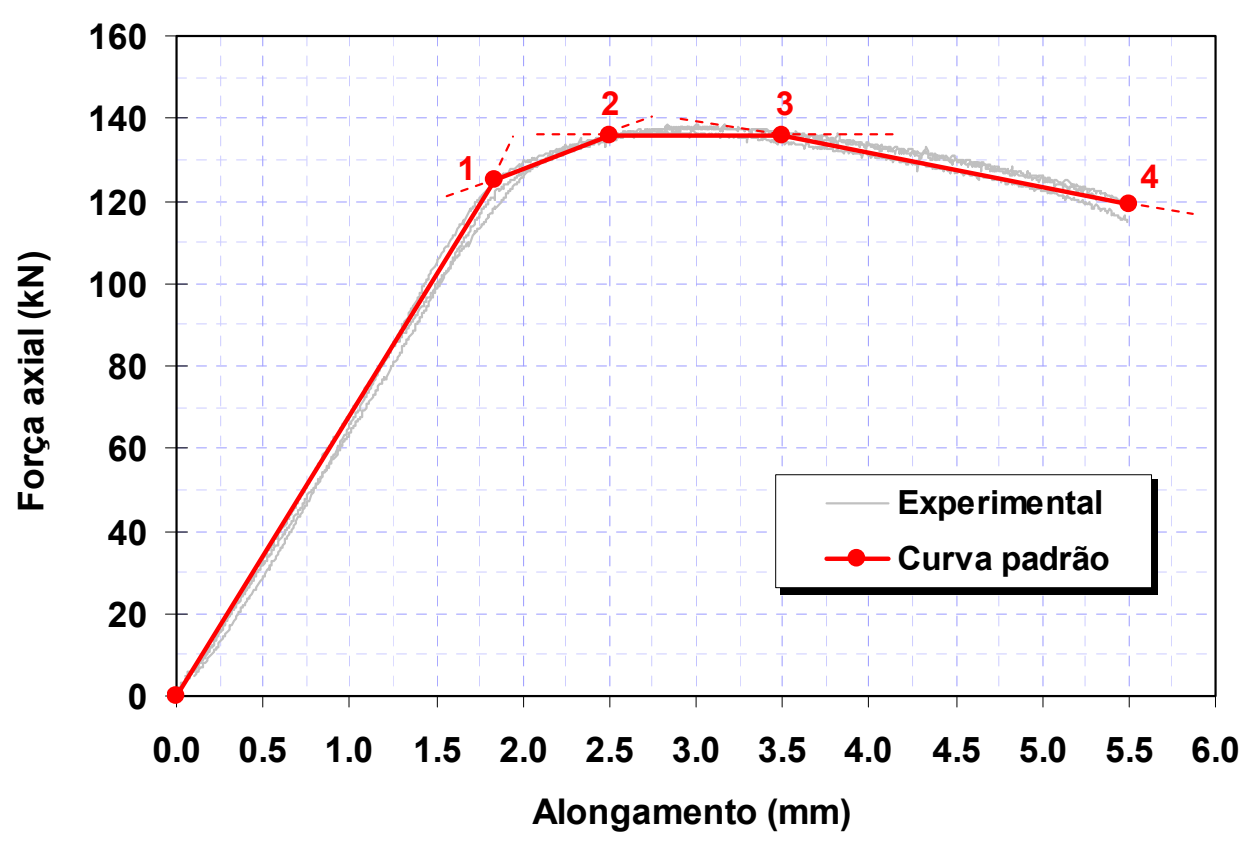

Figura 6.29 - Curvas experimentais e padrão para a relação força-alongamento dos parafusos ASTM A325 de $16,0 \mathrm{~mm}$

A tabela 6.5 indica os valores para os pares tensão-deformação considerando-se um comprimento inicial $\mathrm{L}_{0}=39,0 \mathrm{~mm}$ - aproximado da caracterização experimental - e as áreas bruta e efetiva do parafuso de 16,0 mm de diâmetro. A área efetiva é obtida multiplicando-se a área bruta por 0,75.

Na tabela 6.5 é possível observar, claramente, que as curvas tensãodeformação obtidas possuem uma grande inclinação inicial $\left(\mathbf{E}_{\mathbf{f}}-\right.$ módulo de elasticidade fictício), em torno de 13 vezes menor que o módulo de elasticidade especificado para o aço, usualmente de $205000 \mathrm{MPa}$. 
Tabela 6.5 - Pares tensão-deformação da caracterização dos parafusos de $16,0 \mathrm{~mm}$ para área bruta e área específica

\begin{tabular}{|c|c|c|c|c|c|c|c|}
\hline \multirow{2}{*}{$P(\mathbf{k N})$} & \multirow{2}{*}{$\Delta \mathrm{L}(\mathrm{mm})$} & \multicolumn{3}{|c|}{ Área bruta: $A_{0}=201.06 \mathrm{~mm}^{2}$} & \multicolumn{3}{|c|}{ Área efetiva: $A_{0}=150.80 \mathrm{~mm}^{2}$} \\
\hline & & $\sigma(\mathrm{MPa})$ & $\varepsilon(\mathrm{mm} / \mathrm{mm})$ & $E_{f}(\mathrm{MPa})$ & $\sigma(\mathrm{MPa})$ & $\varepsilon(\mathrm{mm} / \mathrm{mm})$ & $E_{f}(\mathrm{MPa})$ \\
\hline 125,0 & 1,844 & 621,60 & 0,047282 & \multirow{4}{*}{13146} & 828,93 & 0,047282 & \multirow{4}{*}{17531} \\
\hline 136,0 & 2,500 & 676,30 & 0,064103 & & 901,88 & 0,064103 & \\
\hline 136,0 & 3,500 & 676,30 & 0,089744 & & 901,88 & 0,089744 & \\
\hline 119,0 & 5,500 & 591,70 & 0,141026 & & 789,14 & 0,141026 & \\
\hline
\end{tabular}

Tomando-se os valores de tensão para a área bruta, os pares tensãodeformação apresentados na tabela 6.5 representam, dessa forma, as características do material de um corpo de prova homogêneo com comprimento inicial de $39,0 \mathrm{~mm}$ e área de $201,06 \mathrm{~mm}^{2}$, e que pode reproduzir a mesma curva força-alongamento obtida no ensaio dos parafusos.

Em termos de aplicação para o modelo numérico, é de extrema importância verificar a representatividade das relações constitutivas utilizadas, discutindo-se assim a capacidade deste modelo em reproduzir as deformabilidades do fuste, da rosca e das arruelas, incorporadas no modelo do parafuso, que é simulado como um sólido homogêneo.

Para auxiliar nessa discussão, preparou-se um modelo numérico simples com um parafuso isolado, solicitado à tração, com a função de permitir uma "caracterização numérica" deste componente. Assim, imposta uma relação tensão-deformação, procurou-se verificar a resposta força-alongamento do parafuso, comparando-a com a "curva padrão" da figura 6.29.

O parafuso representa o adotado nos modelos, considerando-se um único sólido composto pela cabeça e porca sextavadas e o fuste com diâmetro nominal de $16,0 \mathrm{~mm}$ correspondendo à área bruta. $O$ fuste tem comprimento de $\mathbf{3 9 , 0} \mathbf{~ m m}$, mantendo-se as características geométricas das especificações para a cabeça e a porca. Para simular os furos, incluíram-se duas arruelas circulares em contato com as faces da cabeça e da porca, nas quais foram aplicadas as restrições de apoio e o carregamento. As arruelas foram simuladas como apoios rígidos atribuindo-se materiais lineares com módulo de elasticidade suficientemente alto (aproximadamente $100000 \mathrm{MPa}$ ) para não 
influenciar na resposta do parafuso. Detalhes deste modelo podem ser observados na figura 6.30 .

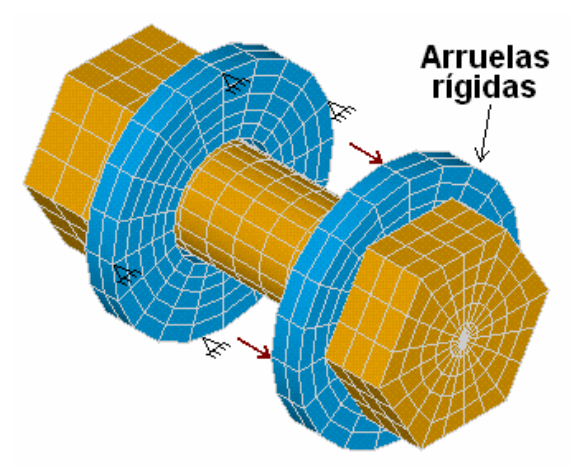

Figura 6.30 - Modelo numérico para o parafuso isolado

Um outro fator importante a ser considerado deve-se ao fato de que, na obtenção das relações tensão-deformação convencionais, utiliza-se como referência a área inicial $\mathbf{A}_{0}$, desconsiderando-se a estricção da seção transversal do parafuso na região de ruptura. Uma vez que se incluiu a não linearidade geométrica na análise, a diminuição da área de referência pode ser considerada por meio de correções nos valores de deformação e tensão, expressos por:

$$
\begin{aligned}
& \mathrm{e}=\ln (1+\varepsilon) \quad \mathrm{e} \\
& \mathrm{s}=\sigma(1+\varepsilon)
\end{aligned}
$$

onde: $\quad$ e = deformação natural (corrigida);

$\mathrm{s}=$ tensão verdadeira (corrigida);

$\sigma=$ tensão convencional; e

$\varepsilon=$ deformação convencional.

As relações corrigidas serão denominadas de "verdadeiras" e são obtidas sempre com base nas relações convencionais, que são aquelas descritas pelas equações 6.1 e 6.2 e obtidas com base na área e comprimento de referência inicial. As relações "verdadeiras" levam em consideração a 
diminuição da área da seção transversal e, neste caso, são representativas do comportamento observado experimentalmente.

Para as primeiras observações, foram aplicadas as relações tensãodeformação itemizadas abaixo, cujos valores são apresentados na tabela 6.6:

i. (PM1.c) $\rightarrow$ considera a relação convencional calculada para a área bruta apresentada na tabela 6.5 , de acordo com o diagrama força-alongamento experimental;

ii. (PM2.v) $\rightarrow$ considera a relação verdadeira calculada para a área bruta, de acordo com o diagrama força-alongamento experimental, mas adotando um comprimento inicial de referência para cálculo das deformações igual à $65,0 \mathrm{~mm}$, igual ao somatório do comprimento do fuste $(39,0 \mathrm{~mm})$, da cabeça $(10,0 \mathrm{~mm})$ e da porca (16,0 mm). Mantêm-se os valores de tensão da relação PM1.c. A relação verdadeira é calculada após a obtenção da relação convencional, atualizando-se, também, o valor do módulo de elasticidade fictício $\left(E_{\mathrm{f}}\right)$; e

iii. (PM3.v) $\rightarrow$ considera a relação verdadeira com base no PM1.c, mas adotando o módulo de elasticidade fictício $\left(\mathbf{E}_{\mathrm{f}}\right)$ igual à 205000 MPa, usual para o módulo de elasticidade do aço dos parafusos. A deformação no ponto 1 da "curva padrão" é recalculada e os outros pontos são transladados de acordo com o novo valor da deformação do ponto 1 . Os valores de tensão também são mantidos.

A figura 6.31 apresenta a "curva padrão" juntamente com os resultados numéricos das relações força-alongamento para os modelos descritos anteriormente. 
Tabela 6.6 - Pares tensão-deformação - PM1.c, PM2.v e PM3.v

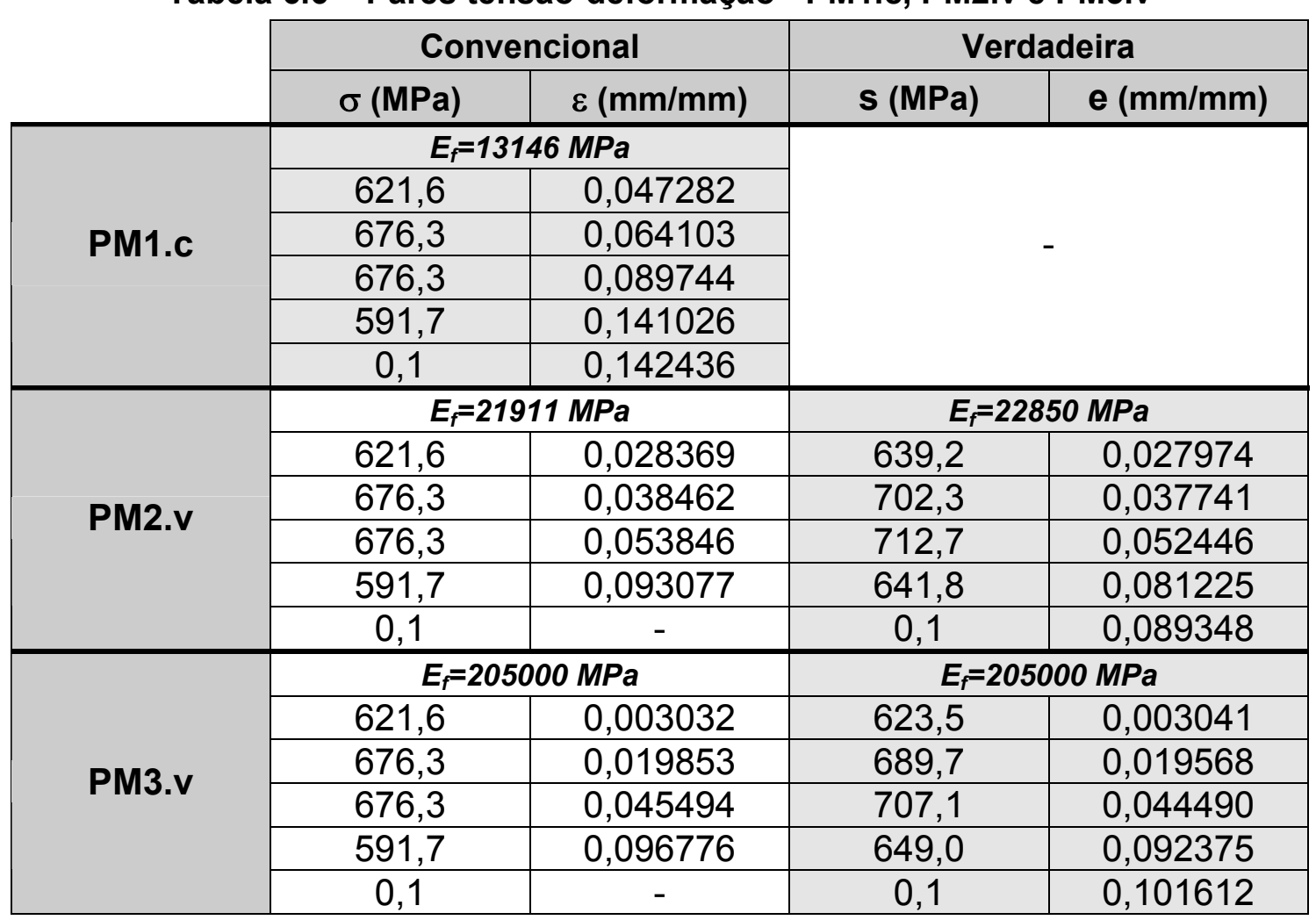

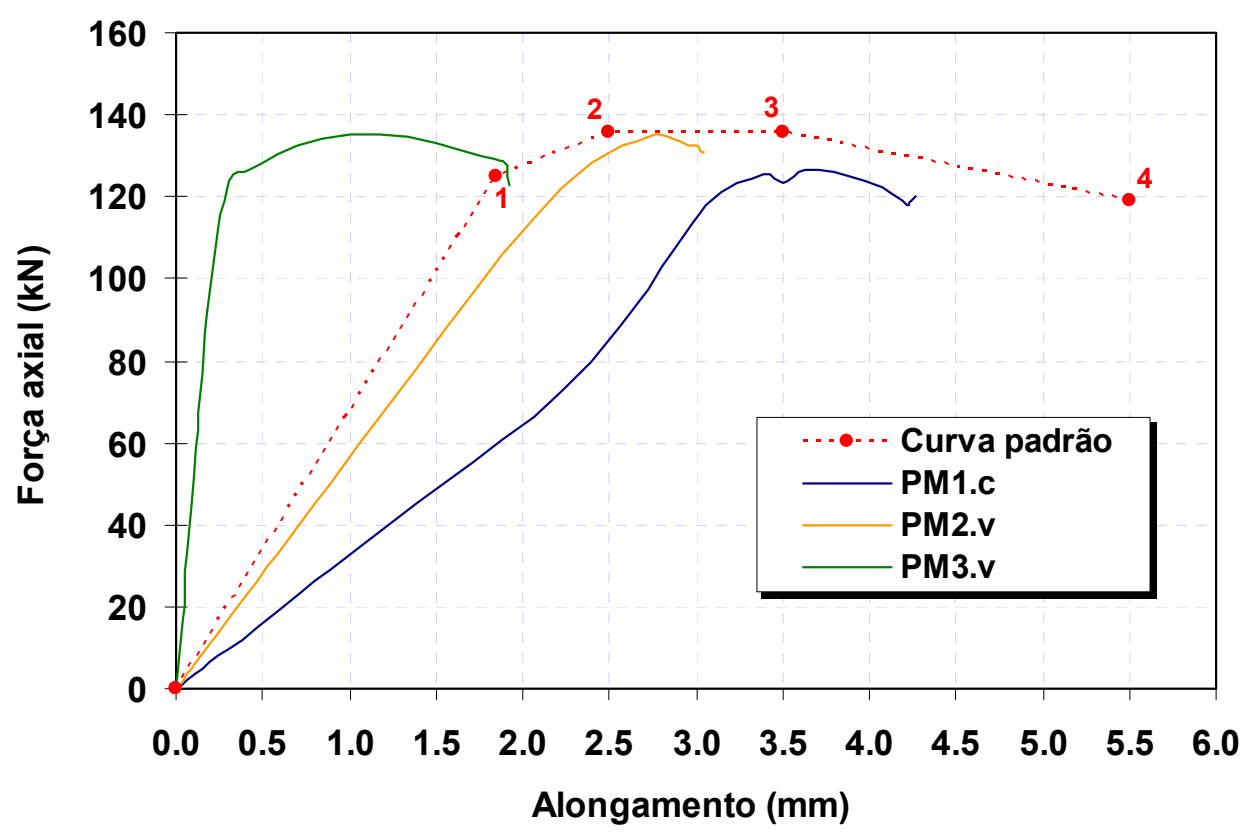

Figura 6.31 - Curvas força-alongamento para os modelos PM1.c, PM2.v e PM3.v

O comportamento do parafuso obtido para o modelo PM1.c é claramente mais flexível que o da "curva padrão", concluindo-se que não é possível estabelecer uma relação direta entre as curvas obtidas considerando a deformabilidade do parafuso real e os modelos constitutivos aplicados ao 
modelo sólido do parafuso. No entanto, as curvas para os modelos PM2.v e PM3.v permitem visualizar possíveis artifícios para adaptar essas relações, a primeira escolhendo-se comprimentos de referência maiores que o comprimento do fuste e a segunda aumentando-se o módulo de elasticidade longitudinal.

Para o modelo PM2.v, a aproximação ao trecho inicial da "curva padrão" é significativamente melhor. No entanto, comprimentos de referência maiores levam ao cálculo de deformações menores para a mesma tensão, o que limita a ductilidade do parafuso, visível na figura 6.31.

Para o modelo PM3.v, a rigidez inicial da curva força-alongamento é significativamente mais alta que a da curva padrão, mas como as deformações são transladadas em função da deformação do ponto 1 (figura 6.29), apenas o trecho inicial da curva é modificado com uma diminuição proporcional do alongamento, mantendo-se as inclinações da "curva padrão".

Essa é uma característica interessante pois permite supor que a adaptação do modelo constitutivo para o parafuso pode ser feita em função de apenas dois fatores: o módulo de elasticidade longitudinal do aço e a deformação máxima obtida nos ensaios.

Além disso, as curvas dos modelos PM2.v e PM3.v conseguem representar os níveis de força da "curva padrão", com a conclusão imediata de que a força no parafuso é representativa, assim como a modelagem considerando o diâmetro nominal do fuste. Neste caso, não há necessidade de modificações na descrição das tensões, sendo conveniente lembrar que as relações constitutivas desses modelos são relações verdadeiras, calculadas em função das relações convencionais.

Em função das observações realizadas no modelo PM3.v, outros três modelos foram analisados, com as seguintes definições para o material:

i. (PM4.v) $\rightarrow$ relação verdadeira, obtida com base no PM3.v, com a adoção do valor da deformação experimental máxima para o ponto 4. Mantém-se o módulo fictício $E_{f}=205000 \mathrm{MPa}$ e as deformações dos pontos 1 e 2. A deformação do ponto 3 é aumentada proporcionalmente à deformação do ponto 4; 
ii. (PM5.v) $\rightarrow$ relação verdadeira, obtida com base no PM4.v, adotando-se módulo de elasticidade fictício $\mathbf{E}_{\mathrm{f}}=\mathbf{5 0 0 0 0} \mathrm{MPa}$ e com translação dos pontos 2, 3 e 4 em função da deformação do ponto $1 ; \mathrm{e}$

iii. (PM6.v) $\rightarrow$ relação verdadeira, obtida com base no PM4.v, adotando-se módulo de elasticidade fictício $\mathbf{E}_{\mathrm{f}}=25000 \mathrm{MPa}$ e com translação dos pontos 2, 3 e 4 em função da deformação do ponto 1.

Os valores dos pares tensão-deformação para os modelos listados acima estão descritos na tabela 6.7 e as curvas força-alongamento obtidas para esses modelos são apresentadas na figura 6.32.

O aumento da deformação última para os modelos constitutivos dos parafusos apenas aumenta a ductilidade do modelo, mantendo-se as inclinações da "curva padrão".

Tabela 6.7 - Pares tensão-deformação - PM4.v, PM5.v e PM6.v

\begin{tabular}{|c|c|c|c|c|}
\hline & \multicolumn{2}{|c|}{ Convencional } & \multicolumn{2}{|c|}{ Verdadeira } \\
\hline & $\sigma(\mathrm{MPa})$ & $\varepsilon(\mathrm{mm} / \mathrm{mm})$ & $\mathrm{S}(\mathrm{MPa})$ & e $(\mathrm{mm} / \mathrm{mm})$ \\
\hline & \multicolumn{2}{|c|}{$E_{f}=205000 \mathrm{MPa}$} & \multicolumn{2}{|c|}{$E_{f}=205000 \mathrm{MPa}$} \\
\hline \multirow{5}{*}{ PM4.v } & 621,6 & 0,003032 & 623,5 & 0,003041 \\
\hline & 676,3 & 0,019853 & 689,7 & 0,019658 \\
\hline & 676,3 & 0,060244 & 717,0 & 0,058499 \\
\hline & 591,7 & 0,141026 & 675,1 & 0,131928 \\
\hline & 0,1 & - & 0,1 & 0,138524 \\
\hline \multirow{6}{*}{ PM5.v } & \multicolumn{2}{|c|}{$E_{f}=50000 \mathrm{MPa}$} & \multicolumn{2}{|c|}{$E_{f}=50000 \mathrm{MPa}$} \\
\hline & 621,6 & 0,012432 & 629,3 & 0,012587 \\
\hline & 676,3 & 0,029253 & 696,1 & 0,028833 \\
\hline & 676,3 & 0,069644 & 723,4 & 0,067326 \\
\hline & 591,7 & 0,150426 & 680,7 & 0,140132 \\
\hline & 0,1 & - & 0,1 & 0,141533 \\
\hline \multirow{6}{*}{ PM6.v } & \multicolumn{2}{|c|}{$E_{f}=25000 \mathrm{MPa}$} & \multicolumn{2}{|c|}{$E_{f}=25000 \mathrm{MPa}$} \\
\hline & 621,6 & 0,024864 & 637,1 & 0,025482 \\
\hline & 676,3 & 0,041685 & 704,5 & 0,040839 \\
\hline & 676,3 & 0,082076 & 731,8 & 0,078881 \\
\hline & 591,7 & 0,162858 & 688,1 & 0,150881 \\
\hline & 0,1 & - & 0,1 & 0,152389 \\
\hline
\end{tabular}




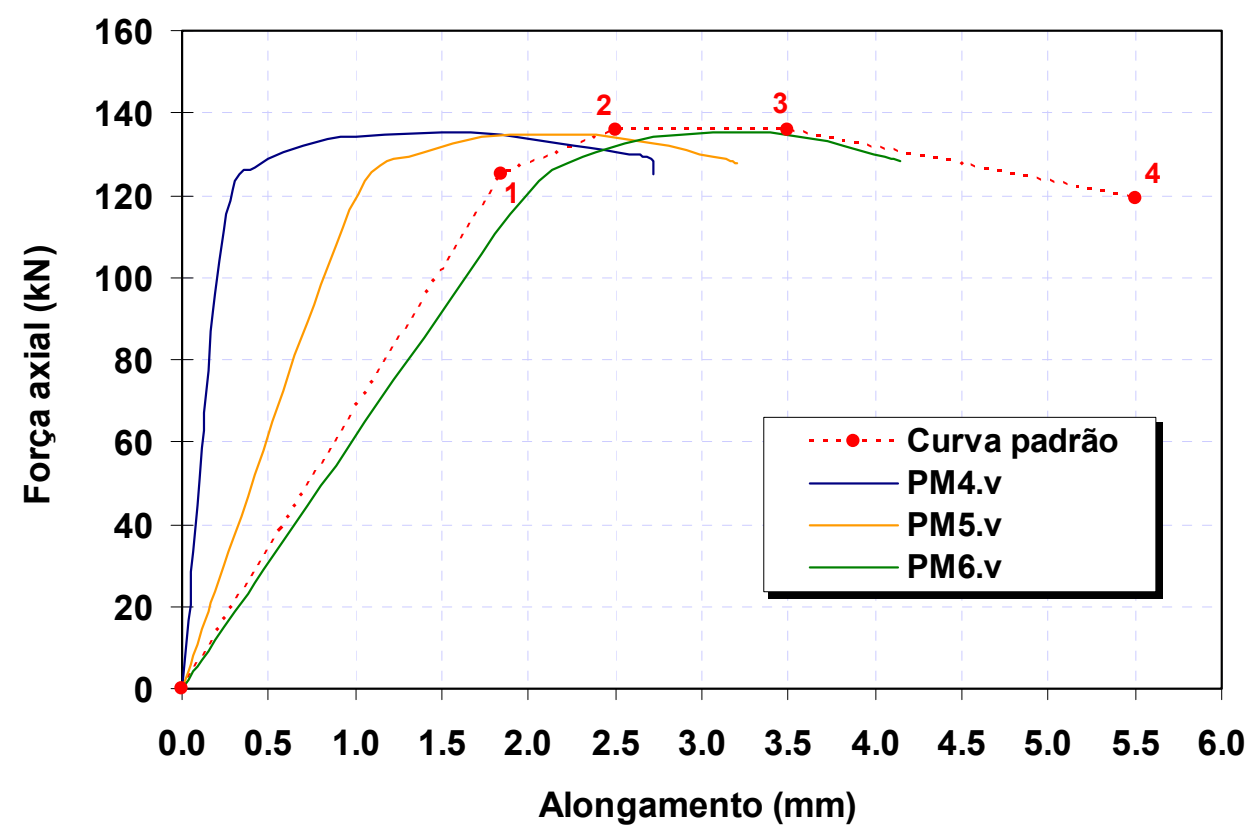

Figura 6.32 - Curvas força-alongamento para os modelos PM4.v, PM5.v e PM6.v

O ajuste do módulo de elasticidade longitudinal permite a aproximação das curvas que, para o modelo PM6.v foi extremamente satisfatória para representar a relação força-alongamento da curva experimental. Além disso, verifica-se que o comportamento força-alongamento do modelo sólido do parafuso é governado principalmente pelo módulo de elasticidade, sendo que o aumento da deformação última no modelo constitutivo do parafuso pode ser utilizado como artifício para representar a ductilidade do modelo, uma vez que governa o comportamento posterior às tensões máximas, representativas da resistência destes componentes.

Assim, pode-se concluir que:

i. Os pares força-alongamento e, conseqüentemente, os pares tensão-deformação das curvas experimentais, podem ser utilizados como padrão para a definição do modelo constitutivo a ser utilizado na análise numérica para o parafuso, a menos do trecho inicial elástico;

ii. O módulo de elasticidade longitudinal das relações tensãodeformação governam significativamente o comportamento elástico do parafuso. Se mantidas as proporções de deformação plástica da 
caracterização experimental, é possível simular satisfatoriamente o comportamento força-alongamento do parafuso pela manutenção do módulo de elasticidade fictício $\mathbf{E}_{\mathrm{f}}=205000 \mathrm{MPa}$, igual ao módulo de elasticidade do aço, e a adoção da deformação última obtida na caracterização, que governa o comportamento no estado limite último;

iii. Independentemente das deformações, as forças obtidas na caracterização podem ser aplicadas diretamente no modelo do parafuso considerando a área bruta. Além disso, é necessário utilizar relações tensão-deformação verdadeiras, obtidas pelas equações (6.3) e (6.4), quando estas são calculadas convencionalmente pelas equações (6.1) e (6.2); e

iv. Observando-se que a modelagem leva em consideração a área bruta e a ruptura, em geral, se dá na área líquida dos parafusos, a tensão nominal de ruptura, usualmente adotada como $825 \mathrm{MPa}$ para os parafusos ASTM-A325, deve sofrer uma redução para simular adequadamente a força resistente do parafuso nos modelos numéricos.

Assim, utiliza-se a relação constitutiva do modelo PM4.v para padronizar o material dos parafusos na análise paramétrica.

\subsection{APLICAÇÃO DA MODELAGEM}

\subsubsection{Modelos numéricos para a representação dos resultados experimentais}

Para se comparar o comportamento dos modelos numéricos com os resultados experimentais é coerente aplicar características as mais próximas possíveis das observadas nos protótipos experimentais, principalmente no que diz respeito às relações constitutivas dos materiais.

Assim, adotam-se para os materiais das chapas as relações tensãodeformação obtidas na caracterização experimental e, para os parafusos, as 
definições do modelo PM4.v, apresentadas na tabela 6.7. A tabela 6.8 resume as relações utilizadas, ressaltando-se que serão aplicadas nos modelos as tensões e deformações "verdadeiras" calculadas pelas equações 6.3 e 6.4.

Tabela 6.8 - Pares tensão-deformação convencionais e verdadeiros para os modelos da análise experimental

\begin{tabular}{|c|c|c|c|c|}
\hline & \multicolumn{2}{|c|}{ Convencional } & \multicolumn{2}{|c|}{ Verdadeira } \\
\hline \multirow{9}{*}{$\begin{array}{c}\text { Chapas } \\
\text { ASTM-A36 }\end{array}$} & $\sigma(\mathrm{MPa})$ & $\varepsilon(\mathrm{mm} / \mathrm{mm})$ & s (MPa) & e $(\mathrm{mm} / \mathrm{mm})$ \\
\hline & \multicolumn{2}{|c|}{$E=205000 \mathrm{MPa}$} & \multicolumn{2}{|c|}{$E=205000 \mathrm{MPa}$} \\
\hline & 300,0 & 0,001463 & 300,0 & 0,001462 \\
\hline & 300,0 & 0,012500 & 303,8 & 0,012423 \\
\hline & 400,0 & 0,032755 & 413,1 & 0,032230 \\
\hline & 490,0 & 0,090000 & 534,1 & 0,086178 \\
\hline & 490,0 & 0,240000 & 607,6 & 0,215111 \\
\hline & 340,0 & 0,310000 & 445,4 & 0,270027 \\
\hline & 0,1 & - & 0,1 & 0,272727 \\
\hline \multirow{7}{*}{$\begin{array}{l}\text { Parafusos } \\
\text { ASTM-A325 }\end{array}$} & $\sigma(\mathrm{MPa})$ & $\varepsilon(\mathrm{mm} / \mathrm{mm})$ & $\mathrm{s}(\mathrm{MPa})$ & e $(\mathrm{mm} / \mathrm{mm})$ \\
\hline & \multicolumn{2}{|c|}{$E=205000 \mathrm{MPa}$} & \multicolumn{2}{|c|}{$E=205000 \mathrm{MPa}$} \\
\hline & 621,6 & 0,003032 & 621,6 & 0,003032 \\
\hline & 676,3 & 0,019853 & 689,7 & 0,019658 \\
\hline & 676,3 & 0,060244 & 717,0 & 0,058499 \\
\hline & 591,7 & 0,141026 & 675,2 & 0,131928 \\
\hline & 0,1 & - & 0,1 & 0,133247 \\
\hline
\end{tabular}

Uma simplificação mantida para estes modelos é a desconsideração do enrijecimento promovido pela solda, que não será discretizada conforme as discussões apresentadas anteriormente.

\subsubsection{Comparação entre resultados numéricos e experimentais dos grupos TSC e CTEE}

Para verificar, preliminarmente, o comportamento dos modelos numéricos, serão feitas algumas comparações entre os resultados numéricos e experimentais para alguns protótipos dos grupos TSC e CTEE. Pretende-se, dessa forma, avaliar a resposta numérica com a aplicação da metodologia descrita ao longo deste capítulo.

Inicialmente para os modelos TSC, na figura 6.33 são apresentadas as curvas força-deslocamento para os protótipos TSC1 e TSC3, com mesas de 
12,5 e $19,0 \mathrm{~mm}$ de espessura, respectivamente, e parafusos de $12,5 \mathrm{~mm}$, juntamente com os resultados numéricos correspondentes. Os resultados experimentais, na legenda, estão seguidos pela letra "E" e os numéricos, pela letra "N".

Na figura 6.34 são apresentadas as curvas experimentais e numéricas para os protótipos TSC4 e TSC7, com parafusos de $\mathbf{1 6 , 0} \mathrm{mm}$ e mesas de, respectivamente, $\mathbf{1 2 , 5}$ e $\mathbf{2 2 , 4} \mathbf{m m}$.

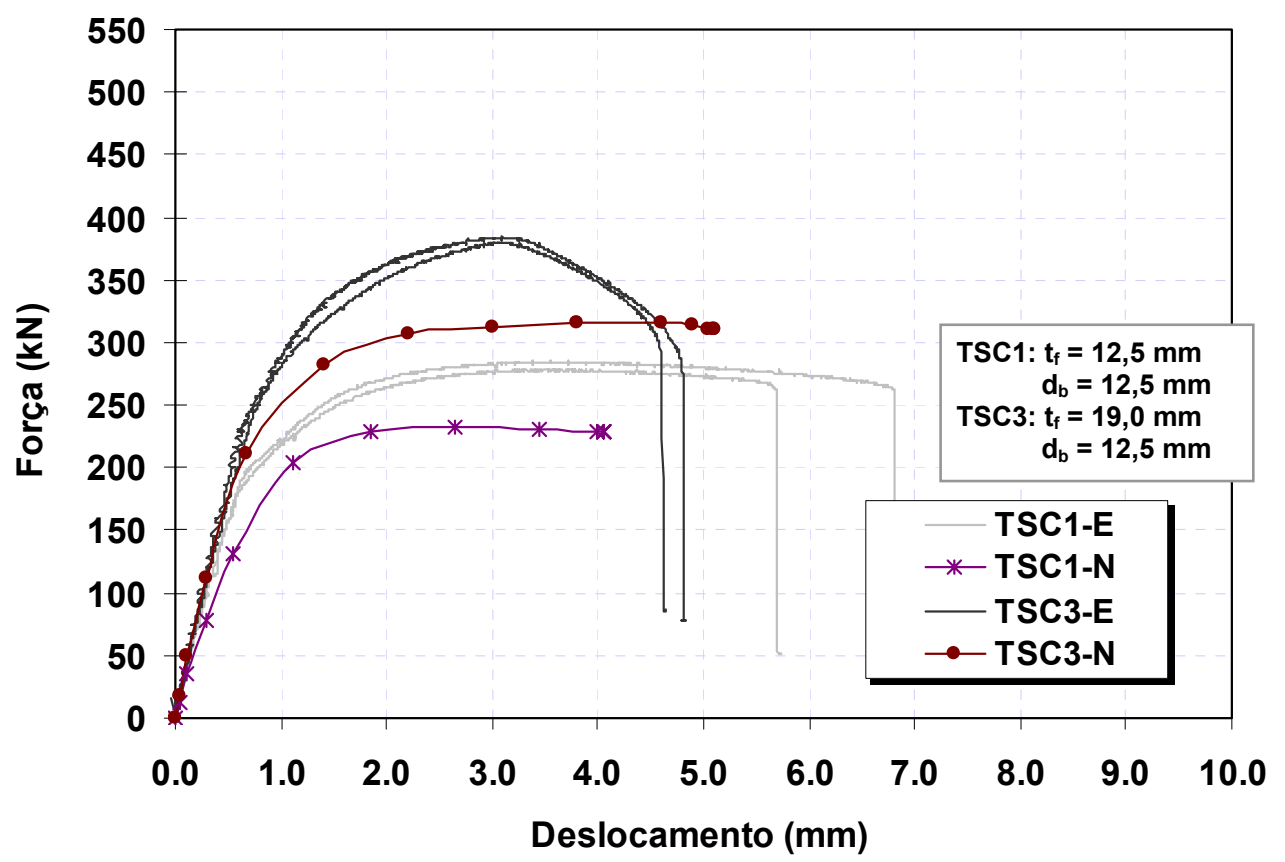

Figura 6.33 - Curvas força-deslocamento numéricas e experimentais para os protótipos TSC1 e TSC3

Observando-se os gráficos é visível a variação entre resultados numéricos e experimentais que, pelas simplificações e hipóteses adotadas na modelagem, já era esperada em termos quantitativos, ou seja, em termos de valores de resistência e ductilidade.

A variação de ductilidade é função da deformabilidade dos parafusos imposta pela deformação última do diagrama tensão-deformação e, como já discutido anteriormente, também sofre influência significativa do tipo de solicitação a que está sujeito este componente. 


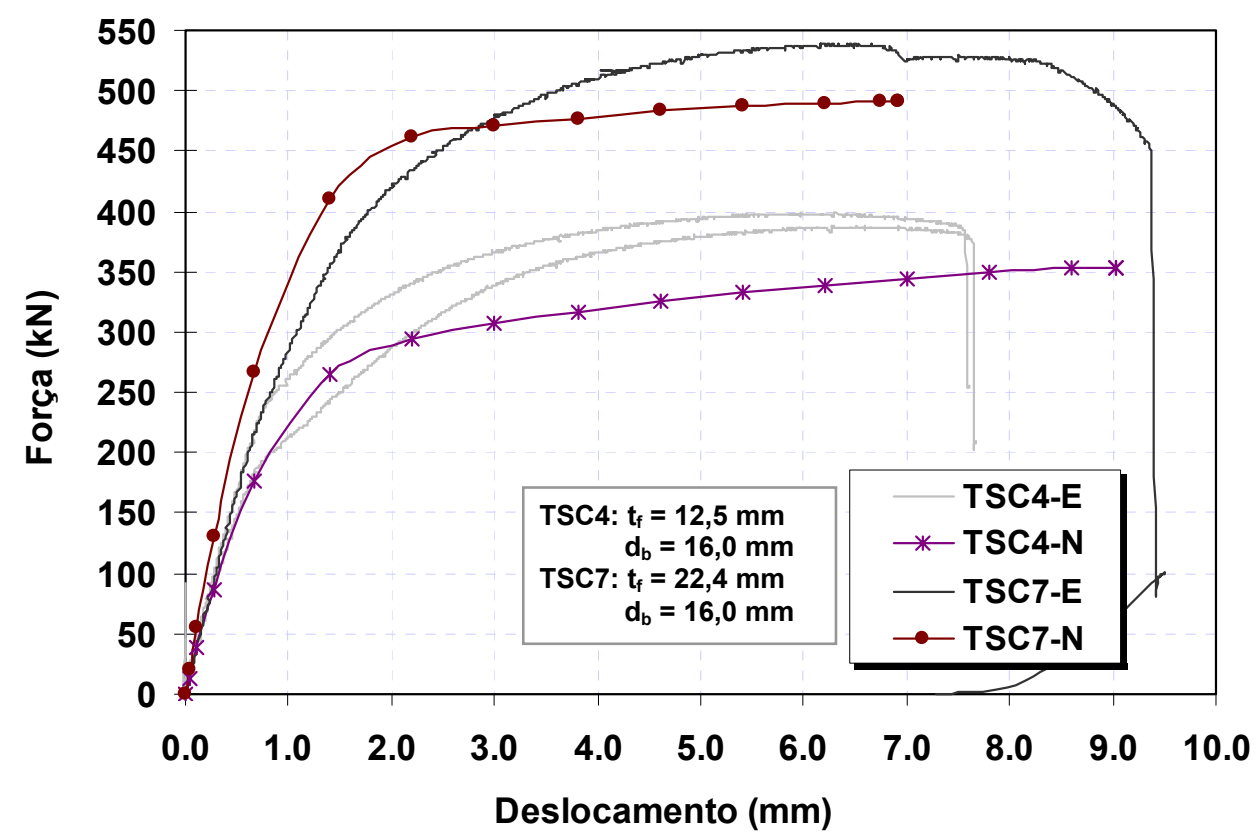

Figura 6.34 - Curvas força-deslocamento numéricas e experimentais para os protótipos TSC4 e TSC7

Sob a influência dos mesmos fatores, a variação de resistência entre os modelos numéricos e os protótipos é também função das simplificações adotadas na geometria, com a eliminação das soldas. Além disso, devido à pequena amostra utilizada na caracterização dos materiais - cujo objetivo maior era verificar padrões de curvas tensão-deformação - pode haver variações das características das chapas, incluindo-se também as imperfeições gerais nos protótipos observadas durante os ensaios. Soma-se ainda a existência, nos protótipos, de tensões residuais nos materiais das chapas que não são consideradas nos modelos constitutivos da simulação numérica.

Apesar disso, a rigidez inicial dos modelos, bem como a tendência de plastificação, podem ser consideradas satisfatórias do ponto de vista qualitativo, suficiente para permitir a utilização destes modelos na avaliação, também qualitativa, da distribuição de tensões nos componentes da ligação, na formação das linhas de escoamento e na observação do "efeito alavanca", como pode ser visualizado na figura 6.35, que apresenta as deformações na região da ligação para os modelos apresentados acima. Os deslocamentos foram majorados em 3 vezes para melhor visualização. 


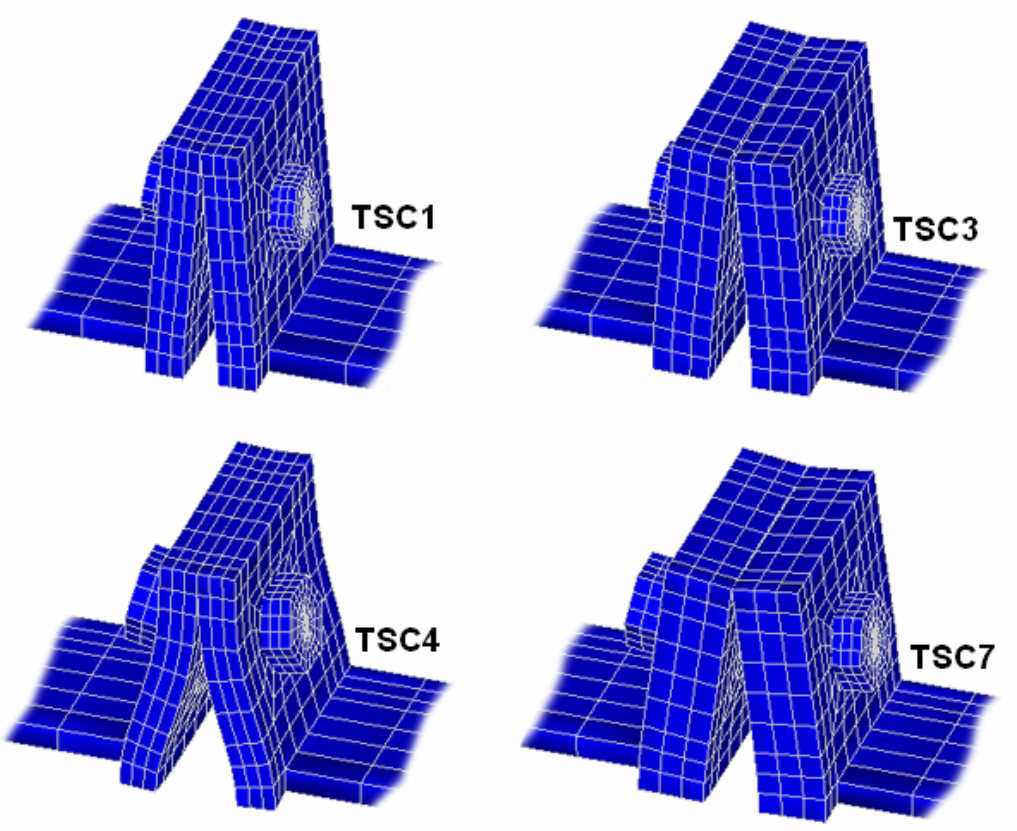

Figura 6.35 - Deformadas para os modelos de protótipos TSC

Para os modelos do grupo CTEE, a figura 6.36 apresenta as curvas força-deslocamento para a extremidade da viga dos modelos numéricos e dos protótipos CTEE1 e CTEE3, com chapas de topo de espessura igual à 16,0 e $25,0 \mathrm{~mm}$, respectivamente, e parafusos de $16,0 \mathrm{~mm}$.

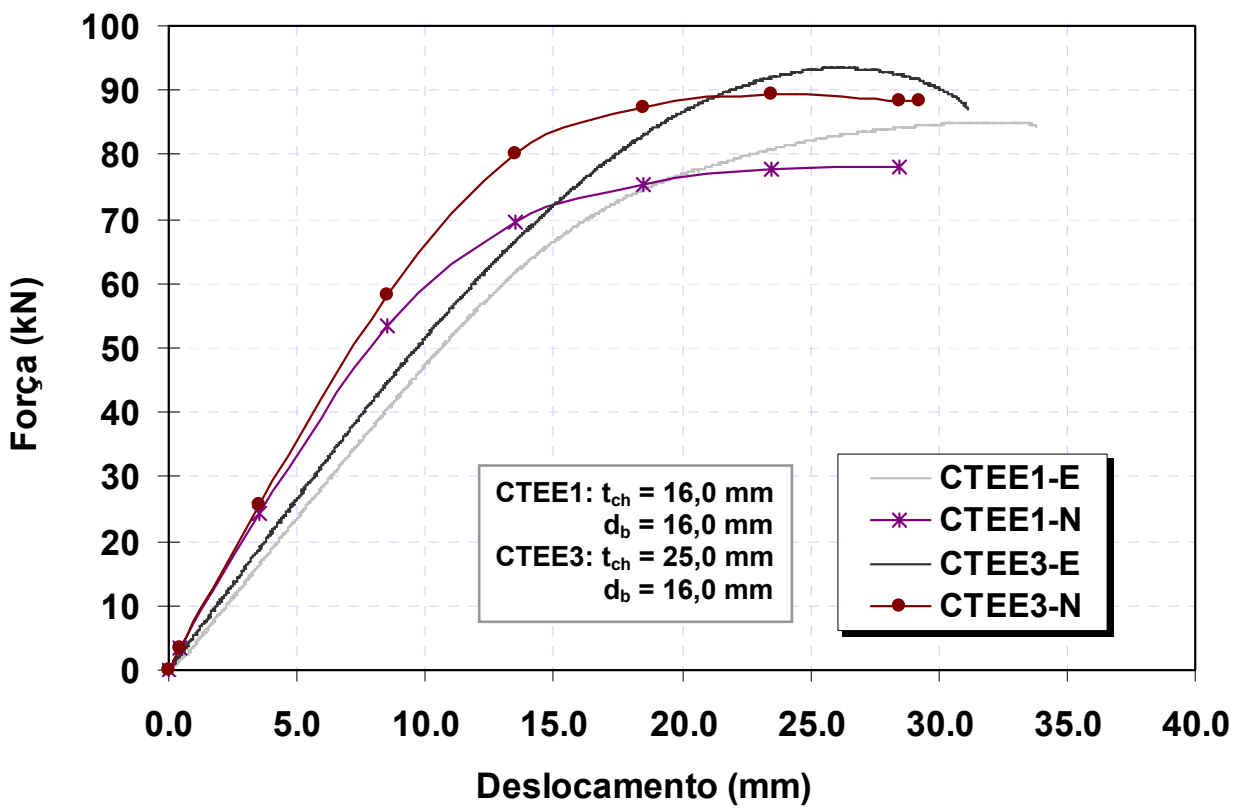

Figura 6.36 - Curvas força-deslocamento na extremidade da viga para os resultados numéricos e experimentais - CTEE1 e CTEE3 
Novamente se observam algumas variações entre os resultados numéricos e experimentais ressaltando-se que, para o modelo CTEE3, a representatividade tanto para a capacidade resistente quanto para a ductilidade da ligação aumenta, uma vez que o parafuso é solicitado preferencialmente à tração. Mais uma vez, fatores como imperfeições iniciais, tensões residuais e variações nas características dos materiais das chapas impõem diferenças entre os resultados numéricos e experimentais.

Em geral, estas variações também ocorrem para leituras mais localizadas, o que pode ser visualizado na figura 6.37, que indica as curvas momento-rotação dos modelos CTEE1 e CTEE3, obtidas nos protótipos por meio de um inclinômetro posicionado na mesa comprimida da viga e calculadas, nos modelos numéricos, pelo deslocamento vertical relativo da mesa comprimida na distância correspondente ao inclinômetro.

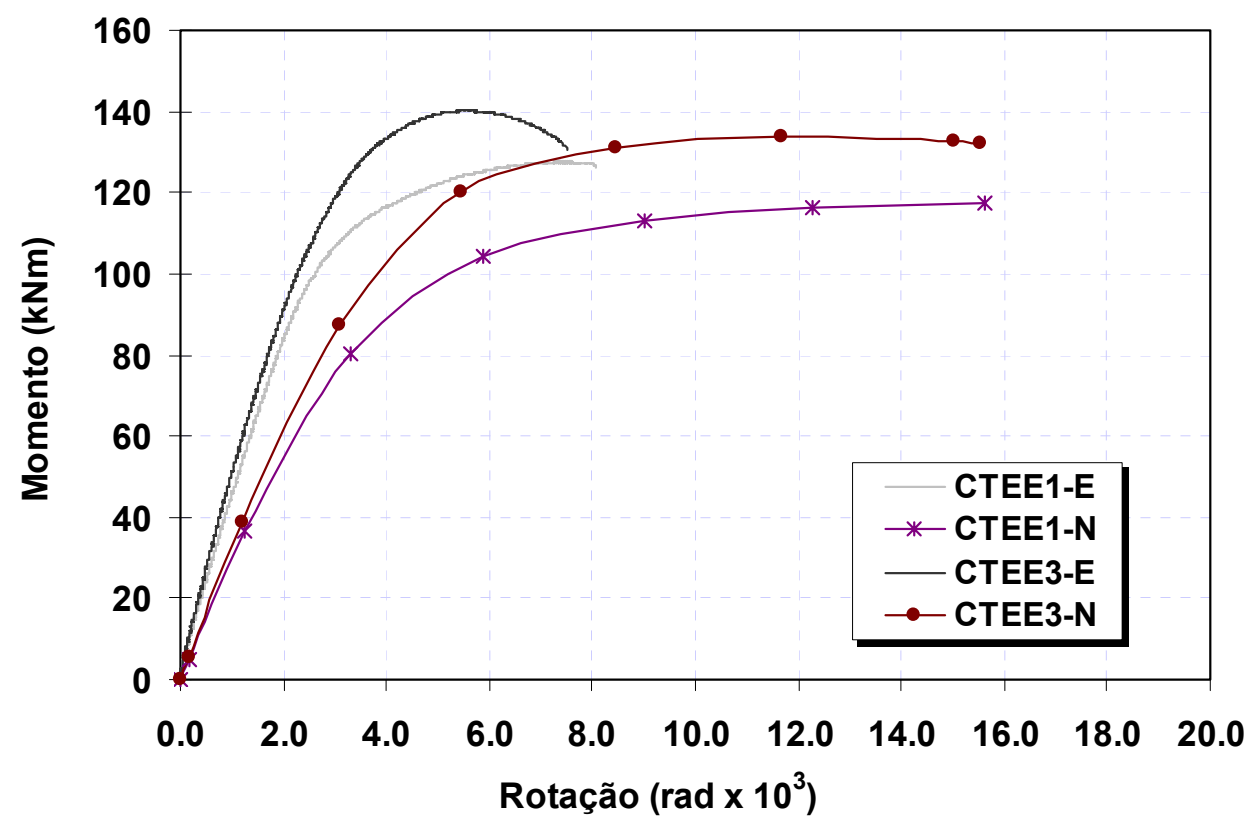

Figura 6.37 - Curvas momento-rotação para os resultados numéricos e experimentais - CTEE1 e CTEE3

Ao contrário da rigidez global indicada pelas curvas forçadeslocamento, a rigidez rotacional da ligação na posição do inclinômetro é menor nos modelos numéricos, ressaltando a significativa variação da ductilidade, provavelmente causada pela mudança nos esforços dos parafusos. 
Ressaltando, novamente, o aspecto qualitativo, as aberturas das chapas para esses modelos podem ser observadas na figura 6.38 e ilustram as deformações na região da ligação em estágios próximos à ruptura dos parafusos. Desta vez os deslocamentos foram ampliados em 5 vezes.
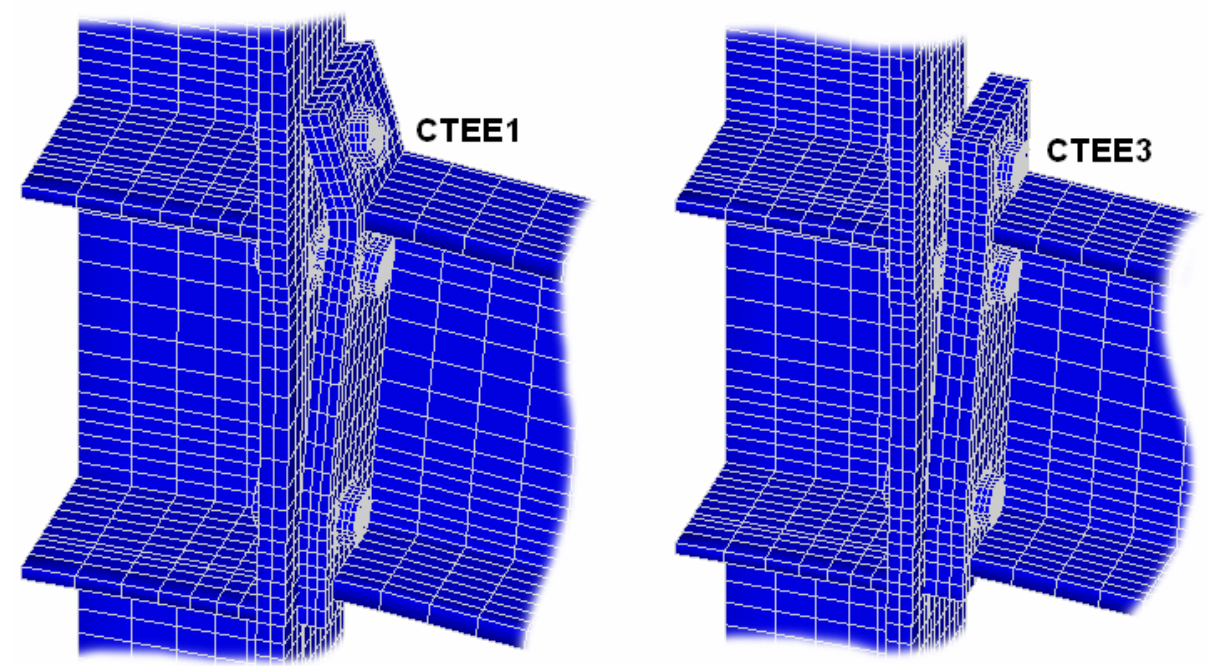

Figura 6.38 - Deformadas para os modelos CTEE1 e CTEE3

Assim, apesar das diferenças entre resultados numéricos e experimentais, indica-se a possibilidade de se utilizar a modelagem proposta para estudos qualitativos e paramétricos, visto a sua capacidade em representar as variações do comportamento dessas ligações com as mudanças de geometria, neste caso em específico, para variações da espessura da chapa de topo.

\subsubsection{Aplicação da modelagem para outras tipologias de ligações duplo "T" e com chapa de topo estendida}

Como os materiais influenciam significativamente a resposta numérica e a caracterização dos materiais dos protótipos TSC e CTEE não foi realizada estatisticamente, com amostragens mais amplas, escolheram-se outros resultados experimentais para a aplicação da metodologia de modelagem proposta neste trabalho. 
Assim, dois modelos adicionais foram analisados, referentes a uma ligação com chapa de topo, denominada de BCC2 e apresentada por Calado \& Castiglioni (1996), e a uma ligação duplo "T", testada por Bursi \& Jaspart (1998) e denominada de T1. Essas duas ligações, além de apresentarem tipologias diferentes dos modelos estudados anteriormente, contém informações detalhadas das características dos materiais das vigas, pilares, chapas de topo e parafusos e, portanto, serão utilizadas para verificar, adicionalmente, a metodologia de modelagem e a representatividade dos modelos.

A configuração dos protótipos BCC2 e T1 estão ilustradas, respectivamente, nas figuras 6.39 e 6.40, juntamente com uma visão geral das malhas adotadas nos modelos numéricos correspondentes. Convém salientar que em ambos os protótipos foram utilizadas vigas com perfis laminados, razão pela qual se visualiza, na figura 6.40 , a concordância suave entre a alma e a mesa do perfil "T".
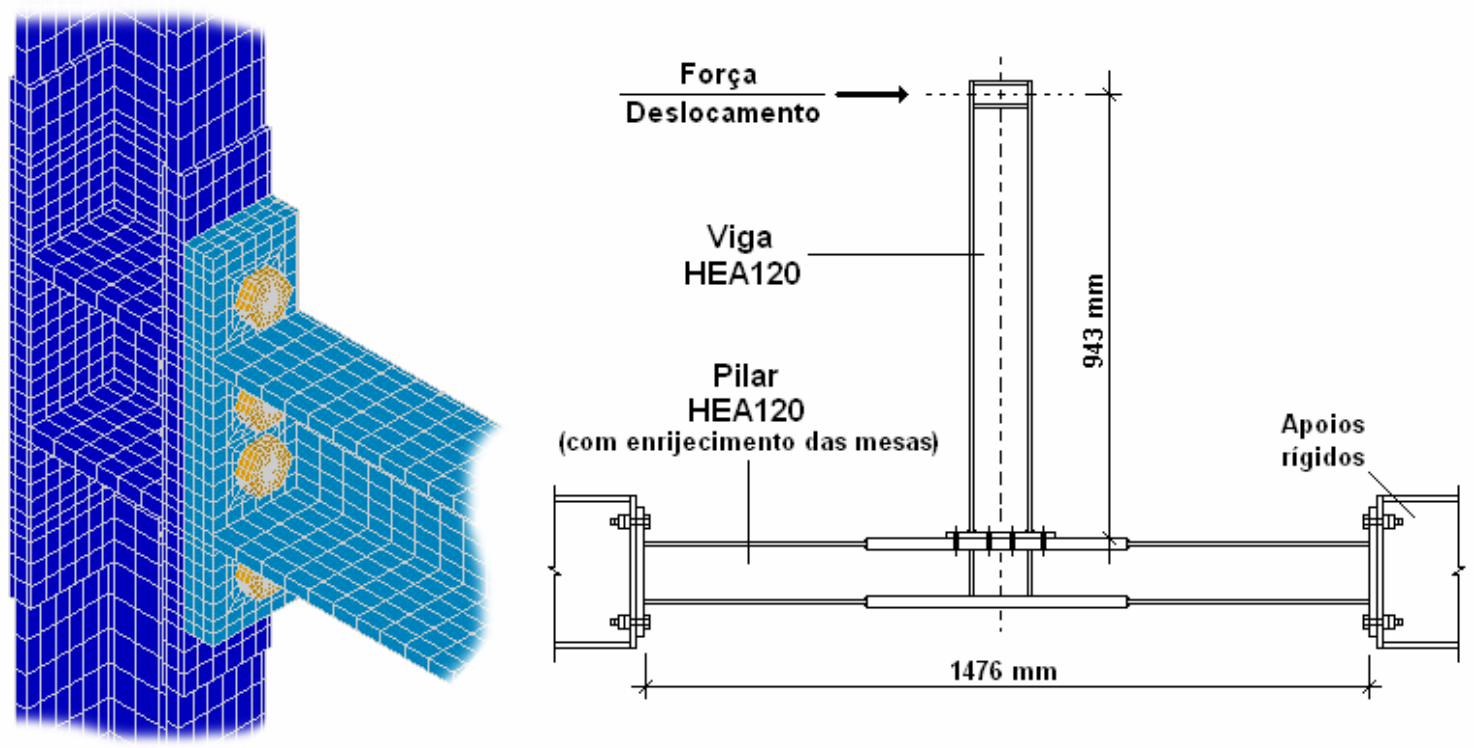

Figura 6.39 - Configuração do protótipo e visão geral da malha - BCC2 


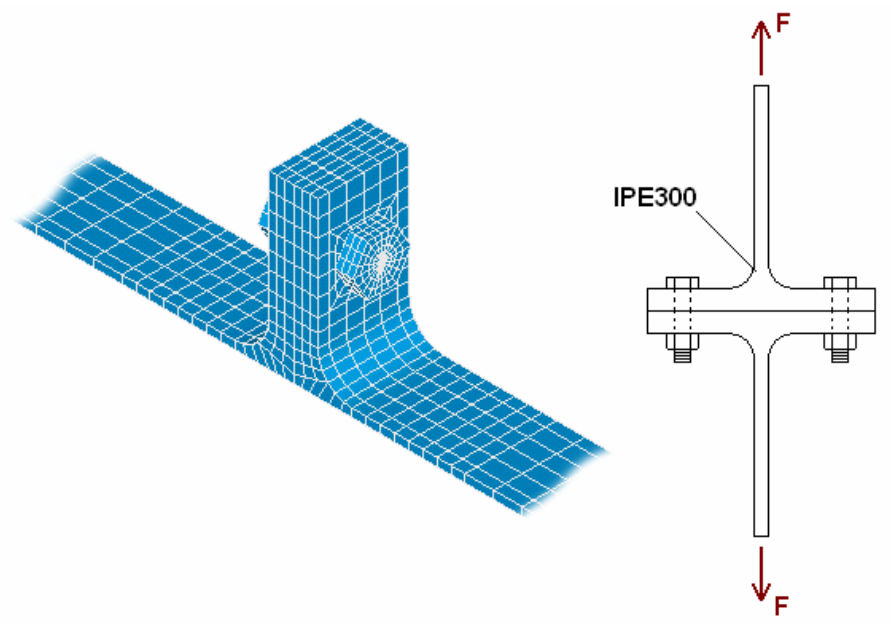

Figura 6.40 - Configuração do protótipo e visão geral da malha - T1

Por questões de praticidade na preparação da malha, no modelo BCC2 foi desconsiderada essa geometria para a viga, adotando-se os procedimentos utilizados nos protótipos CTEE. Também se desconsiderou a simulação da solda entre a viga e a chapa de topo.

Ressalta-se que a configuração de ensaio e a geometria dos protótipos foram mantidas nos modelos de acordo com a descrição do programa experimental correspondente. As simetrias de ambos os protótipos também foram utilizadas e a protensão inicial dos parafusos foi aplicada apenas para o modelo BCC2.

Analisando-se, novamente, o comportamento global desses modelos, na figura 6.41 apresentam-se as curvas numérica e experimental para a relação força-deslocamento do modelo BCC2 para a extremidade da viga. $\mathrm{O}$ modelo BCC2 possui chapa de topo com espessura de $\mathbf{2 0 , 0} \mathbf{m m}$ e parafusos do tipo $\mathbf{M 1 2}$, de $\mathbf{1 2 , 0} \mathbf{m m}$. Na figura 6.42, apresenta-se a comparação de resultados para as curvas força-deslocamento do modelo T1, cujo perfil "T" foi extraído de um perfil de padrão europeu, tipo IPE300, também com parafusos M12. 


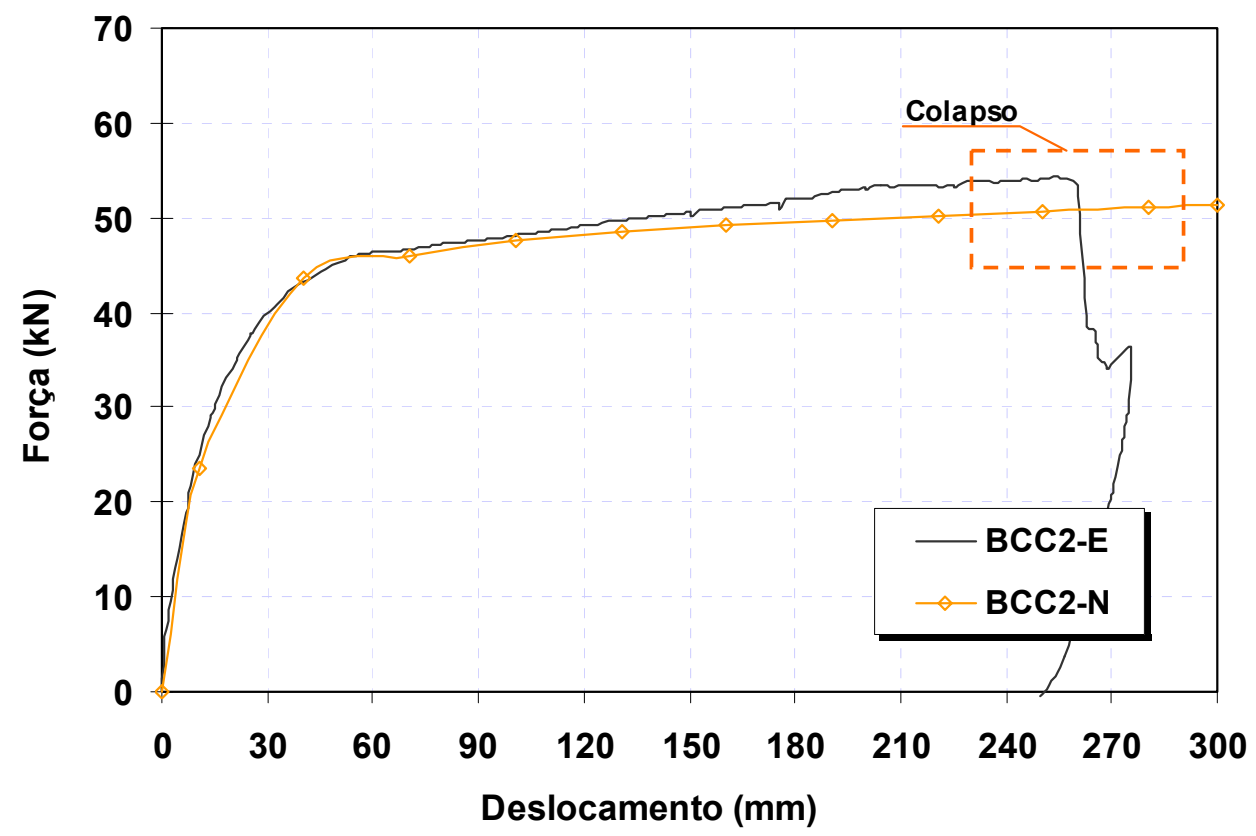

Figura 6.41 - Curvas força-deslocamento numérica e experimental para a extremidade da viga do protótipo BCC2

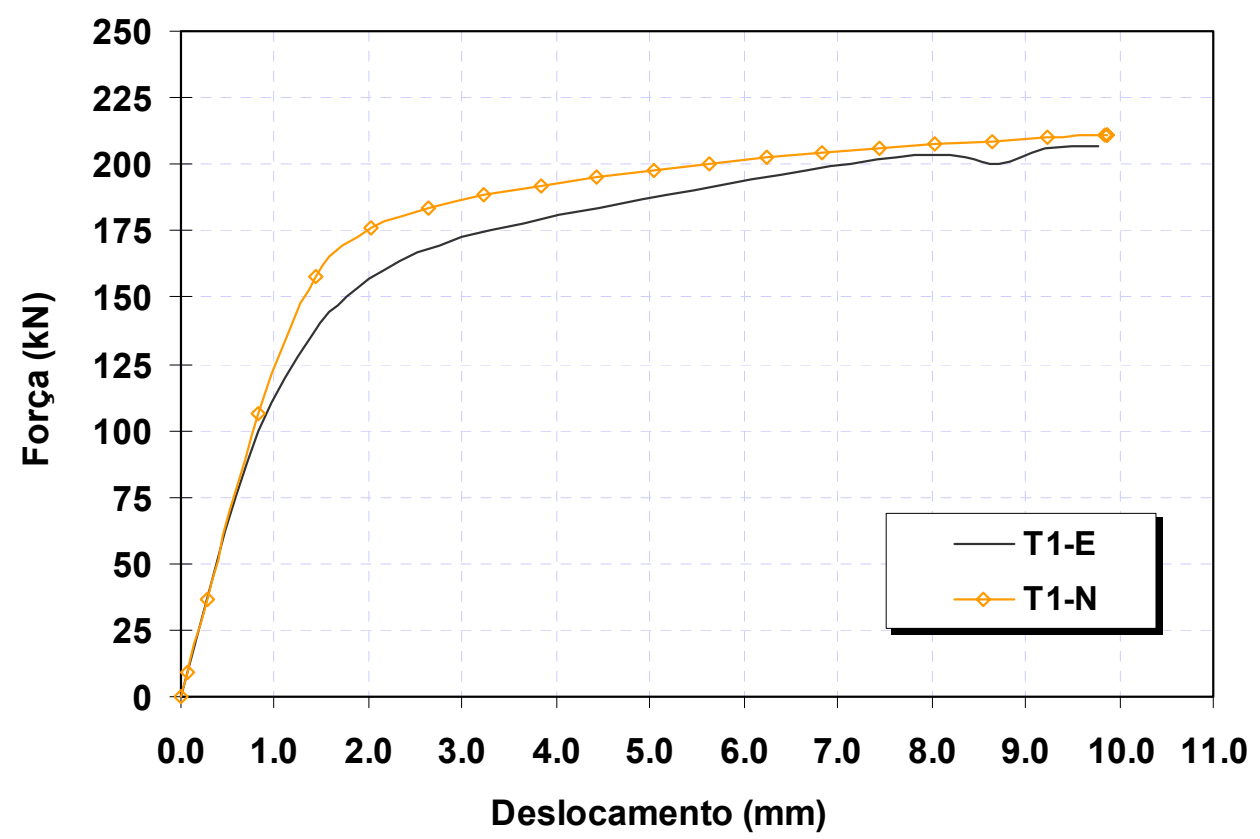

Figura 6.42 - Curvas força-deslocamento numérica e experimental para o protótipo T1

As curvas força-deslocamento apresentam resultados numéricos altamente satisfatórios para os modelos BCC2 e T1, notando-se a representatividade tanto da rigidez inicial como do comportamento plástico dos modelos numéricos. 
Em especial para o modelo $\mathbf{T 1}$, a simulação dos materiais com a inclusão do trecho de "colapso" provocou a instabilidade no modelo em regiões muito próximas do colapso do protótipo, o que implica na validação deste modelo, também, na representação da ductilidade desta ligação.

Para o modelo BCC2, a deformabilidade foi maior que a observada no protótipo experimental, mas neste caso ressalta-se que a ductilidade desta ligação é proveniente da instabilidade localizada da mesa comprimida da viga, não havendo ruptura dos parafusos.

Conforme apresentado por Calado \& Castiglioni (1996), a ruptura deste protótipo se deu por rasgamento da mesa tracionada, com instabilidade local da mesa comprimida da viga, o que também ocorreu no modelo numérico como pode ser visto na figura 6.43 , onde se ilustra um detalhe da deformação da região da ligação e uma visão geral da configuração deformada do modelo, com deslocamentos em escala 1:1.
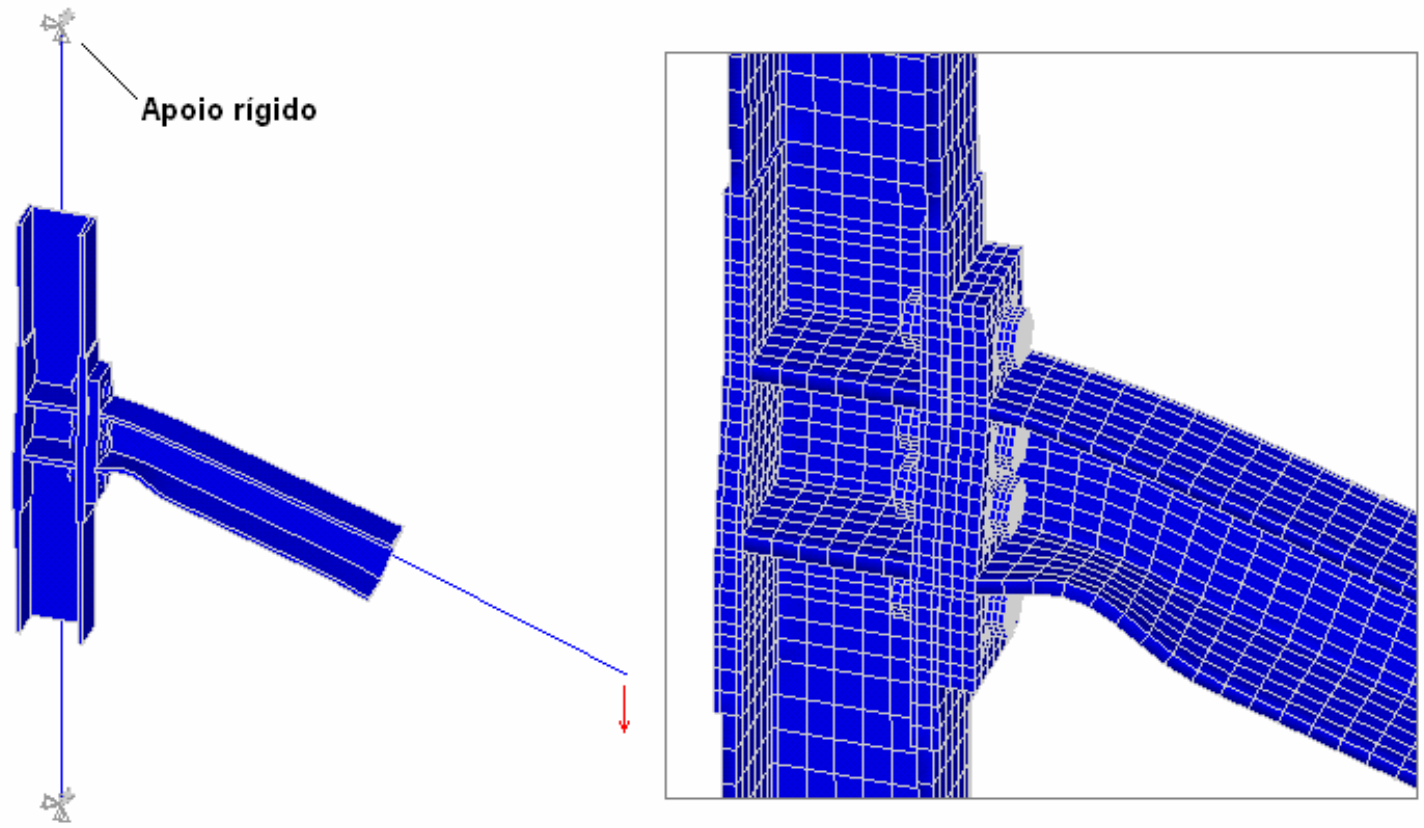

Figura 6.43 - Visão geral e detalhe da deformada para o modelo BCC2

Apesar de não simular o rasgamento, o modelo BCC2 é capaz de representar os efeitos de segunda ordem na mesa comprimida da viga. Um outro detalhe mais geral é a discretização do pilar que, à exemplo da viga, teve 
sua continuidade modelada por elementos de barra, com as transferências de deslocamento e rotação realizadas segundo o descrito no item 6.3.3.3.

Com os resultados apresentados acima, é possível concluir que os modelos numéricos possuem a capacidade de representar, adequadamente, os mecanismos de transferência de esforços e de colapso. As diferenças quantitativas entre resultados numéricos e experimentais advêm de diversos fatores que não podem ser controlados na totalidade, sofrendo forte influência, em especial, das características dos materiais.

Assim, a metodologia de modelagem pode ser considerada adequada e, neste caso, pode ser utilizada com validade em análises paramétricas.

\subsubsection{Modelos numéricos para a análise paramétrica}

Para a análise paramétrica as características dos materiais foram padronizadas, adotando-se relações tensão-deformação com base nos materiais aplicados aos modelos que serão utilizados nas discussões dos resultados experimentais. Neste caso, adotaram-se as tensões nominais dos aços ASTM-A36 e ASTM-A325, mantendo-se a proporcionalidade das deformações com relação à deformação de início de plastificação $\left(\varepsilon_{y}\right)$.

As tensões nominais especificadas para os materiais representam valores mínimos de resistência e, como já comentado anteriormente, podem variar de forma significativa, principalmente para o material das chapas.

No entanto, o dimensionamento das peças estruturais é realizado, usualmente, aplicando-se as tensões nominais nas formulações propostas. Assim, justifica-se a adoção dos valores nominais de tensão para a análise paramétrica.

Assim, utilizando-se das relações tensão-deformação da caracterização experimental das chapas e a discutida no modelo PM4.v para os parafusos, as figuras 6.44 e 6.45 apresentam a padronização das relações constitutivas para o material das chapas e dos parafusos, respectivamente. 


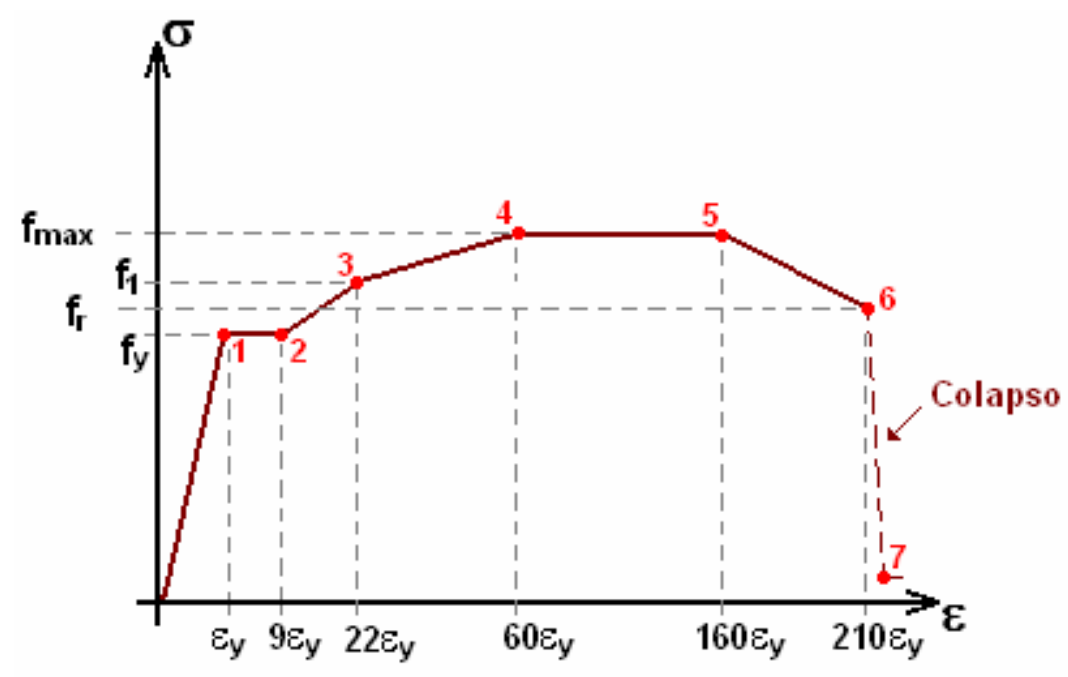

Figura 6.44 - Padronização do material das chapas para a análise paramétrica

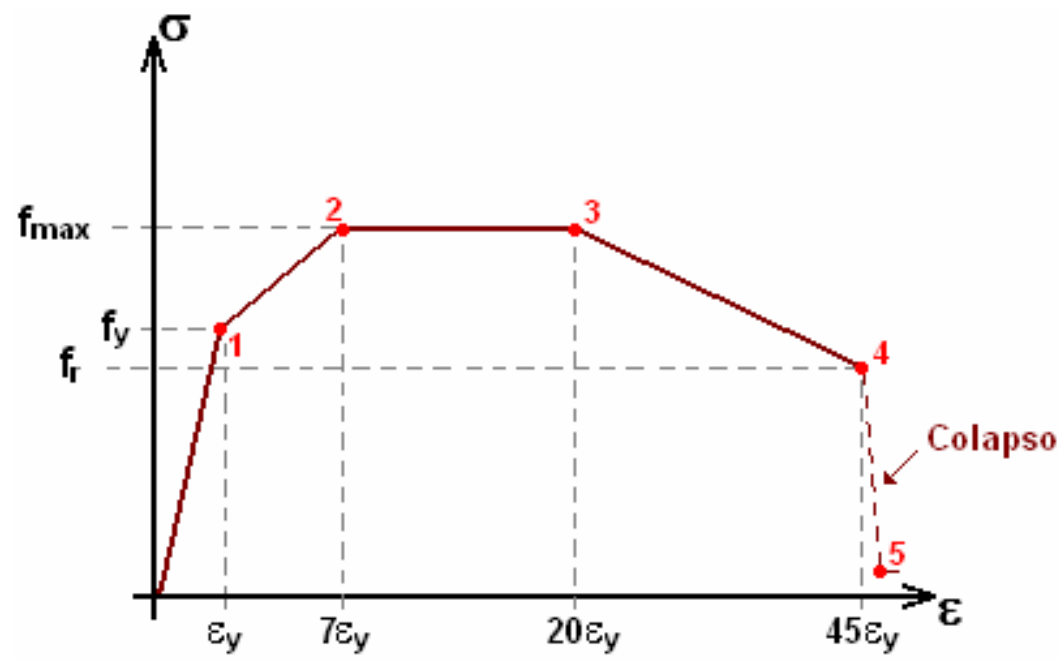

Figura 6.45 - Padronização do material dos parafusos para a análise paramétrica

A tabela 6.9 resume as relações para os pares tensão-deformação convencionais e os valores tensão-deformação verdadeiros adotados nos pontos correspondentes para os modelos da análise paramétrica. 
Tabela 6.9 - Pares tensão-deformação para a análise paramétrica

\begin{tabular}{|c|c|c|c|c|c|}
\hline \multirow{2}{*}{ Material } & \multirow[b]{2}{*}{ Ponto } & \multicolumn{2}{|c|}{ Relações convencionais } & \multicolumn{2}{|c|}{ Valores verdadeiros } \\
\hline & & $\sigma$ & $\varepsilon$ & $\mathbf{s}(\mathrm{MPa})$ & e $(\mathrm{mm} / \mathrm{mm})$ \\
\hline \multirow{8}{*}{$\begin{array}{c}\text { Chapas } \\
\text { ASTM-A36 }\end{array}$} & \multicolumn{5}{|c|}{$E=205000 \mathrm{MPa}-f_{y, \text { nominal }}=250 \mathrm{MPa}-f_{u, \text { nominal }}=400 \mathrm{MPa}$} \\
\hline & 1 & $f_{y}$ & $\varepsilon_{\mathrm{y}}$ & 250,0 & 0,001220 \\
\hline & 2 & $f_{y}$ & $9 \varepsilon_{\mathrm{y}}$ & 252,8 & 0,010920 \\
\hline & 3 & $f_{y}+0,5\left(f_{u}-f_{y}\right)$ & $22 \varepsilon_{\mathrm{y}}$ & 333,7 & 0,026486 \\
\hline & 4 & $f_{u}$ & $60 \varepsilon_{y}$ & 429,3 & 0,070645 \\
\hline & 5 & $\mathrm{f}_{\mathrm{u}}$ & $160 \varepsilon_{y}$ & 478,1 & 0,178314 \\
\hline & 6 & $f_{y}+0,2\left(f_{u}-f_{y}\right)$ & $210 \varepsilon_{\mathrm{y}}$ & 351,7 & 0,228091 \\
\hline & 7 & 0,1 & $1,01\left(210 \varepsilon_{\mathrm{y}}\right)$ & 0,1 & 0,230372 \\
\hline \multirow{6}{*}{$\begin{array}{l}\text { Parafusos } \\
\text { ASTM-A325 }\end{array}$} & \multicolumn{5}{|c|}{$E=205000 \mathrm{MPa}-f_{y, \text { nominal }}=635 \mathrm{MPa}-f_{u, \text { nominal }}=825 \mathrm{MPa}$} \\
\hline & 1 & $\mathrm{f}_{\mathrm{y}}$ & $\varepsilon_{\mathrm{y}}$ & 635,0 & 0,003098 \\
\hline & 2 & $f_{y}+0,25\left(f_{u}-f_{y}\right)$ & $7 \varepsilon_{\mathrm{y}}$ & 697,3 & 0,021454 \\
\hline & 3 & $f_{y}+0,25\left(f_{u}-f_{y}\right)$ & $20 \varepsilon_{y}$ & 724,8 & 0,060116 \\
\hline & 4 & $f_{y}-0,15\left(f_{u}-f_{y}\right)$ & $45 \varepsilon_{\mathrm{y}}$ & 691,1 & 0,130511 \\
\hline & 5 & 0,1 & $1,01\left(45 \varepsilon_{\mathrm{y}}\right)$ & 0,1 & 0,131816 \\
\hline
\end{tabular}

\subsection{COMENTÁRIOS GERAIS SOBRE A MODELAGEM}

No próximo capítulo, a metodologia de modelagem apresentada será utilizada para a análise complementar dos resultados experimentais, para a discussão dos modelos analíticos de dimensionamento e para a análise paramétrica preliminar do comportamento das ligações com chapa de topo estendida.

Convém enfatizar que as discussões realizadas neste capítulo tiveram como principal característica a definição de uma metodologia de modelagem que pudesse ser aplicada, de forma mais geral, aos modelos de ligações parafusadas. Por isso, não houve a preocupação de se calibrar, em termos quantitativos, os resultados numéricos com os resultados experimentais.

Apesar dos modelos numéricos serem aplicados, neste trabalho, em ligações com chapa de topo estendida e ligações duplo "T", espera-se ter contribuído com uma ferramenta adicional para o estudo das ligações parafusadas em geral. 


\section{Capítulo}

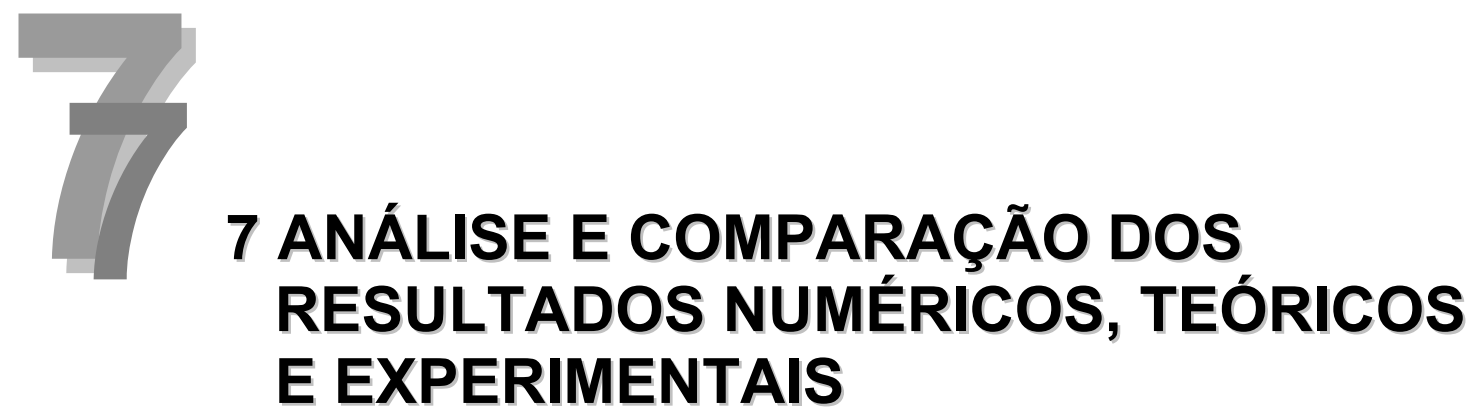

Neste capítulo são apresentados os resultados da análise numérica realizada com a utilização da modelagem proposta no capítulo anterior, juntamente com as discussões sobre os modelos analíticos propostos pelo Eurocode 3 (1993) para o dimensionamento da chapa de topo, cujos resultados teóricos são comparados aos resultados numéricos e experimentais.

As observações realizadas anteriormente mostraram que os modelos numéricos são capazes de representar os mecanismos envolvidos no comportamento dessas ligações, indicando a viabilidade de se utilizar a modelagem numérica como complemento para a análise experimental e como ferramenta para estudos paramétricos.

Seguindo os objetivos deste trabalho, o programa experimental incluiu ligações duplo " $T$ " e ligações com chapa de topo estendida para a observação dos modos de falha e suas variações em função das características geométricas dessas ligações, ressaltando-se a utilização de modelos de dimensionamento que descrevem o comportamento e a capacidade resistente da chapa de topo por meio da equivalência ao comportamento de perfis "T".

Se por um lado o programa experimental permitiu a visualização do comportamento global, dos estados limites últimos, da capacidade resistente e do "efeito alavanca" nessas ligações, pouco se pôde observar quanto às distribuições de tensão e, mais especificamente, quanto aos padrões de plastificação das mesas dos perfis "T" e da chapa de topo.

Toda a metodologia desenvolvida para possibilitar a equivalência entre os perfis " $T$ " e a chapa de topo tem como base o estudo dessas linhas de plastificação e, neste caso, a modelagem numérica pode ser utilizada para a 
observação dos mecanismos de distribuição de esforços entre os componentes da ligação para, enfim, permitir a discussão dos modelos analíticos de dimensionamento.

Com estas observações, apresenta-se uma série de resultados obtidos com modelos numéricos que foram utilizados na simulação dos protótipos experimentais analisados neste trabalho, incluindo também extrapolações desses protótipos para geometrias que não foram ensaiadas.

Os resultados numéricos são apresentados, primeiramente, para as ligações duplo "T" e, em seguida, para as ligações com chapa de topo, com o objetivo de se verificar a variação das linhas de plastificação com as variações de geometria, identificando-se os níveis de interação entre a mesa e os parafusos nos perfis "T" e entre a chapa de topo e os parafusos nas ligações viga-pilar.

Para as ligações duplo "T" também se observam as variações de comportamento em função das mudanças de tipologia, seguindo a geometria dos grupos TSC, TSI e TSIE do programa experimental.

Com base nesses resultados e comparações entre resultados numéricos e teóricos, discutem-se os modelos analíticos para a determinação da capacidade resistente e das forças de alavanca nos perfis " $T$ " e os procedimentos para a determinação dos perfis " $T$ " equivalentes no dimensionamento da chapa de topo.

Finalmente, apresentam-se os resultados de uma análise paramétrica preliminar do comportamento das ligações com chapa de topo estendida, com variações da espessura da chapa de topo e do diâmetro e posicionamento dos parafusos, cujo objetivo é indicar padrões de comportamento para essas ligações em função da variação dos modos de falha considerando-se os efeitos da protensão inicial nos parafusos.

É interessante ressaltar, novamente, que os modelos analíticos descritos no capítulo 3 não consideram a existência de forças iniciais de protensão. A análise paramétrica desenvolvida neste trabalho tem como objetivo indicar a possibilidade de estudos específicos para a determinação de modelos analíticos mais refinados, que levem em consideração os efeitos da protensão e representem, de forma mais adequada, a interação entre chapa de topo e parafusos. 


\subsection{LINHAS DE PLASTIFICAÇÃO NAS L IGAÇÕES DUPLO “T”}

Os protótipos das ligações duplo "T" foram analisados de acordo com a variação da espessura da mesa dos perfis "T" e do diâmetro dos parafusos.

Os modelos numéricos, com base nesses protótipos, tiveram a mesma variação desses parâmetros, com a inclusão de outros modelos com diferentes espessuras de mesa para ampliar a variação dos protótipos e, assim, permitir uma observação mais abrangente da variação dos modos de falha e das linhas de plastificação.

Apenas como referência para a visualização dos modelos, toda vista apresentada em torno da borda externa em direção ao plano de simetria será denominada de "vista externa". Quando os modelos forem apresentados em torno do plano de simetria, olhando-se na direção da borda lateral dos perfis "T", será utilizada a denominação "vista interna", conforme apresentado na figura 7.1 .

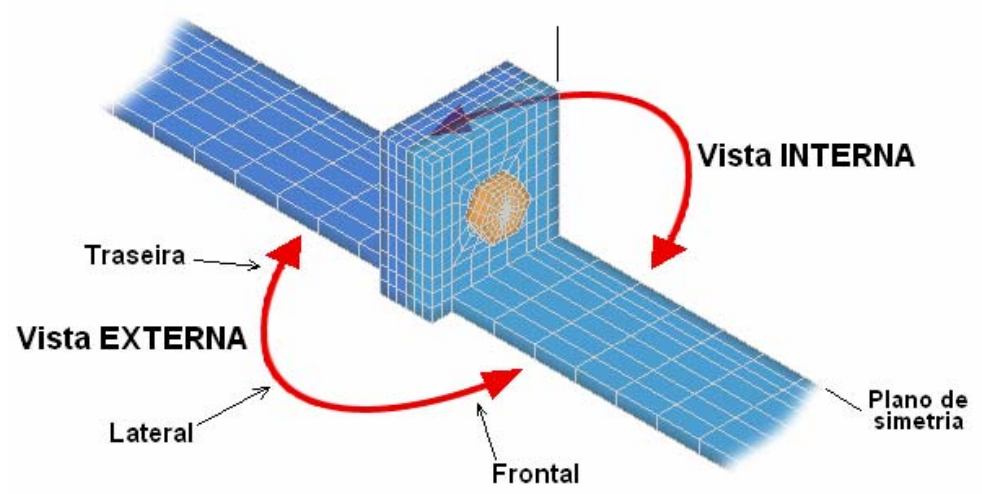

Figura 7.1 - Referências para a visualização dos modelos de ligação duplo "T"

\subsubsection{Grupo TSC}

Analisando-se os modelos para o grupo TSC, correspondentes à ligação duplo "T" usual, a tabela 7.1 indica as combinações de espessura de mesa $\left(\mathbf{t}_{\mathbf{f}}\right)$ e diâmetro de parafusos $\left(\mathbf{d}_{\mathbf{b}}\right)$, bem como a nomenclatura utilizada para a identificação dos modelos e a correspondência aos protótipos experimentais. 
Tabela 7.1 - Modelos numéricos para o grupo TSC

\begin{tabular}{|c|c|c|c|}
\hline Modelo & $\begin{array}{l}\text { Protótipo } \\
\text { correspondente }\end{array}$ & $t_{f}(\mathbf{m m})$ & $d_{b}(m m)$ \\
\hline TSC-T095-P125 & - & 9,5 & \multirow{5}{*}{12,5} \\
\hline TSC-T125-P125 & TSC1 & 12,5 & \\
\hline TSC-T160-P125 & TSC2 & 16,0 & \\
\hline TSC-T190-P125 & TSC3 & 19,0 & \\
\hline TSC-T224-P125 & - & 22,4 & \\
\hline TSC-T095-P160 & - & 9,5 & \multirow{6}{*}{16,0} \\
\hline TSC-T125-P160 & TSC4 & 12,5 & \\
\hline TSC-T160-P160 & TSC5 & 16,0 & \\
\hline TSC-T190-P160 & TSC6 & 19,0 & \\
\hline TSC-T224-P160 & TSC7 & 22,4 & \\
\hline TSC-T250-P160 & - & 25,0 & \\
\hline
\end{tabular}

Como referência para as comparações dos modelos listados acima, as figuras 7.2 e 7.3 apresentam as relações força-deslocamento para os subgrupos com parafusos de 12,5 e 16,0 mm, respectivamente, evidenciando a variação do comportamento da ligação duplo "T" com a variação da espessura da mesa dos perfis "T".

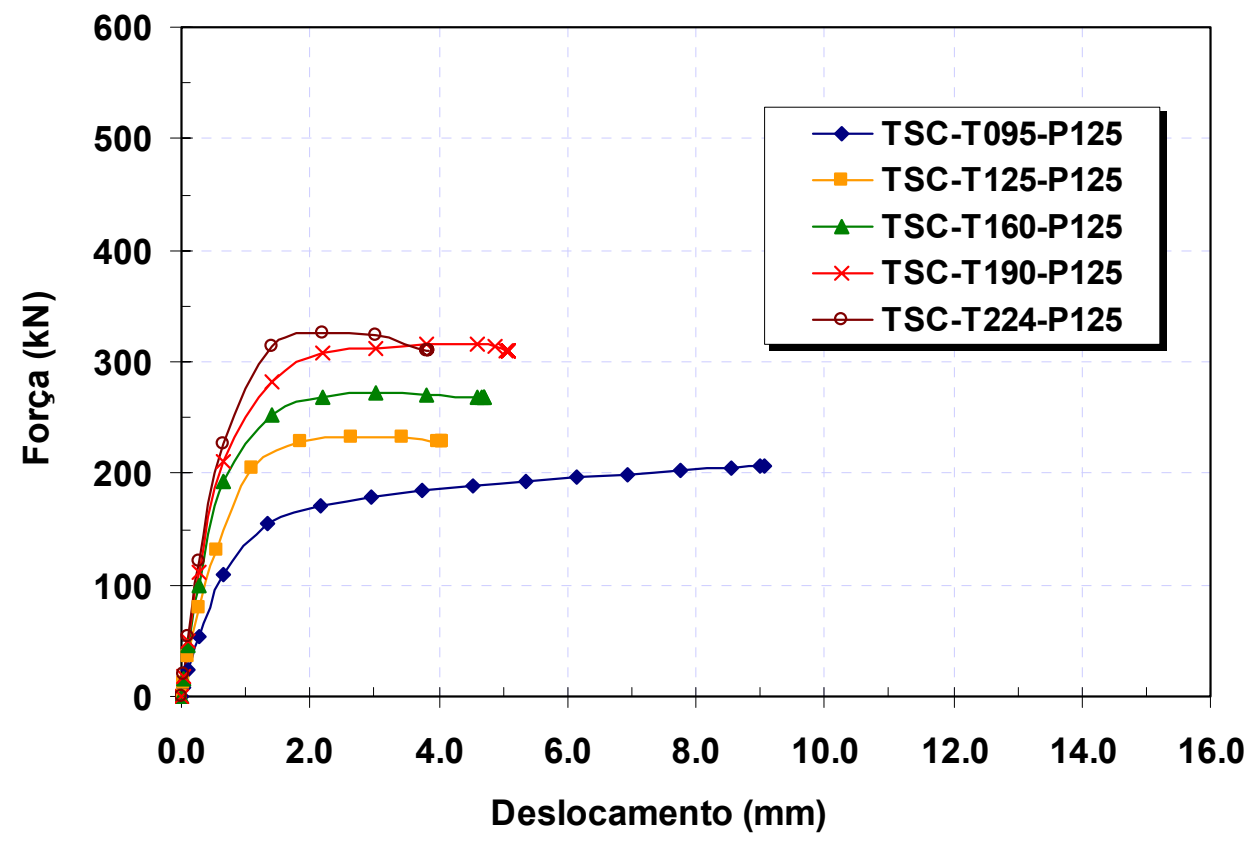

Figura 7.2 - Curvas força-deslocamento para os modelos TSC com parafusos de $12,5 \mathrm{~mm}$

As variações da espessura da mesa dos perfis "T" para cada diâmetro de parafuso considerado causam variações de resistência e ductilidade para as 
ligações duplo "T", em função da deformabilidade relativa entre esses componentes, que modificam o modo de falha.

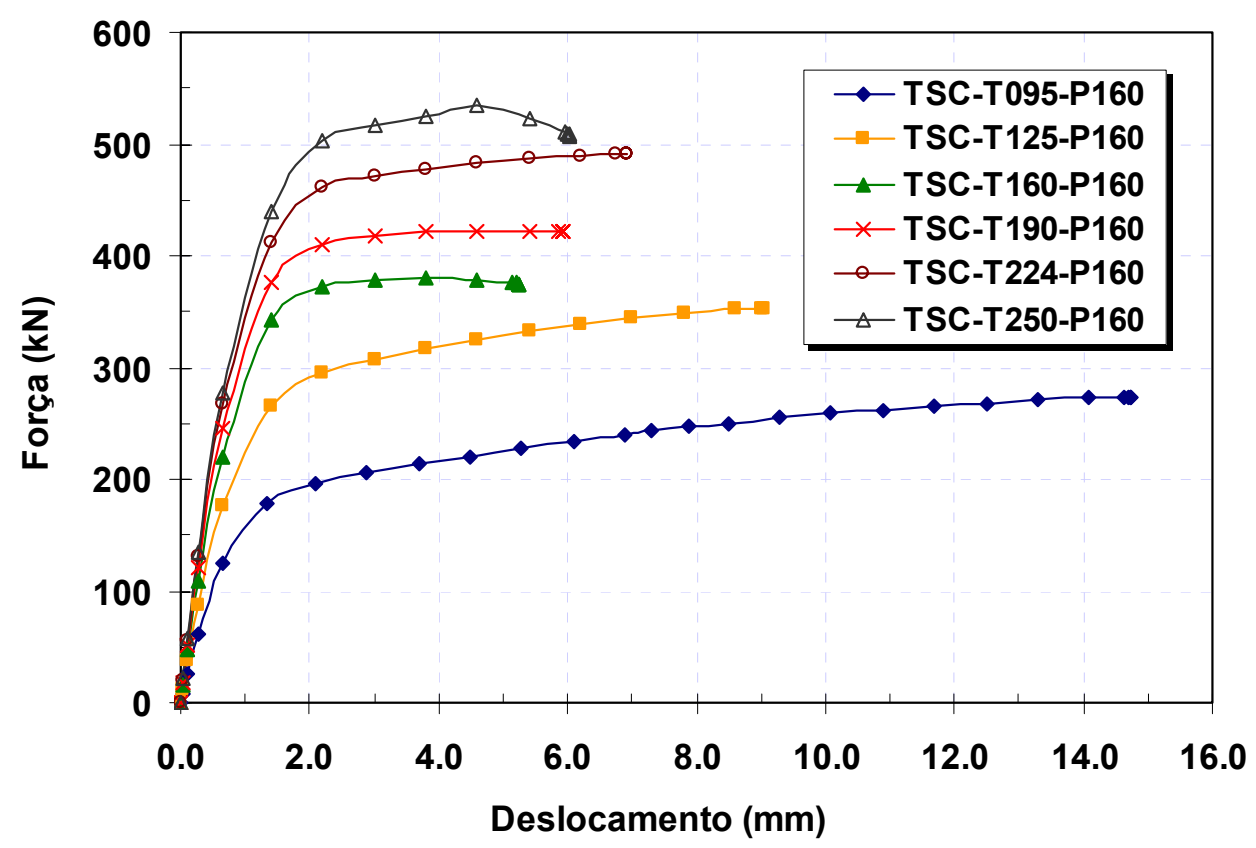

Figura 7.3 - Curvas força-deslocamento para os modelos TSC com parafusos de $16,0 \mathrm{~mm}$

Para se verificar a correspondência entre a plastificação observada nas mesa dos perfis "T" e as hipóteses relacionadas a cada modo de falha proposto por Zoetemeijer \& deBack (1972), a figura 7.4 apresenta uma comparação entre as tensões plásticas equivalentes nas mesas dos modelos TSC-T095-P125, TSC-T125-P125 e TSC-T190-P125, na configuração próxima ao colapso. As deformações foram aumentadas em 2 vezes para melhor visualização.

As tensões plásticas equivalentes referem-se às tensões de von Mises cujos valores são acima da tensão de escoamento especificada para o material. No caso das chapas, a tensão de escoamento tem valor de, aproximadamente, $300 \mathrm{MPa}$, segundo a caracterização experimental dos materiais.

A distribuição das tensões plásticas equivalentes pode ser utilizada como referência para a observação das linhas de plastificação, ou seja, indicam a tendência de plastificação das mesas. 

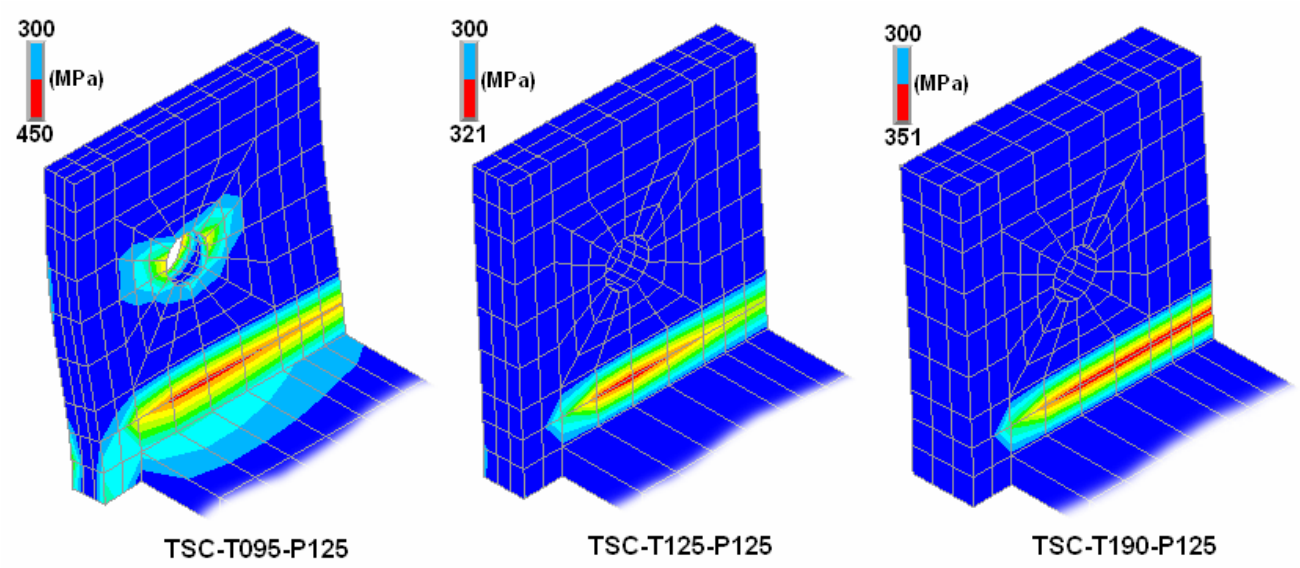

Figura 7.4 - Tensões plásticas equivalentes nas mesas dos modelos TSC-T095P125, TSC-T125-P125 e TSC-T190-P125 - vista externa frontal

Também como referência, a figura 7.5 ilustra, novamente, os modos de falha para os perfis "T".

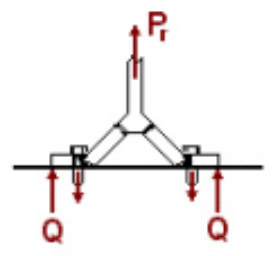

Modo 1

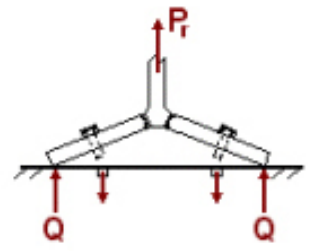

Modo 2

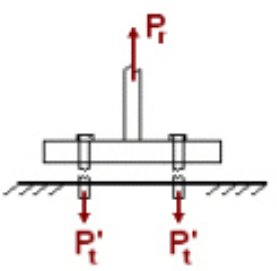

Modo 3

Figura 7.5 - Modos de falha para os perfis "T"

À medida que a espessura da mesa cresce, sua deformabilidade com relação aos parafusos diminui significativamente e, neste caso, é visível uma modificação na flexão da mesa.

Na mesa do modelo TSC-T095-P125 existe um ponto de inflexão bem definido na linha dos furos o que indica a formação de duas rótulas plásticas, uma na linha dos furos e outra na intersecção mesa/alma. Em uma simples comparação, a distribuição de tensões no modelo TSC-T095-P125 é condizente com a hipótese utilizada para o modo de falha 1.

Para o modo de falha 2 , admite-se que a rótula plástica se forma somente na intersecção mesa/alma, identificando-se entre os modelos TSCT095-P125 e TSC-T125-P125 uma variação na interação entre mesa e parafusos, ou seja, uma variação entre os modos de falha 1 e 2. Essa variação, observando-se a figura 7.2, tem como conseqüência uma diminuição 
acentuada na ductilidade dos modelos, em função da variação do mecanismo de plastificação da mesa.

Entre os modos de falha 2 e 3, não há variações nas linhas de plastificação, exceto por uma distribuição mais uniforme das tensões plásticas ao longo da largura da mesa.

No entanto, é interessante observar que a flexão na mesa é predominante na direção perpendicular à alma e, em conjunto com a deformabilidade do parafuso, aumenta a plastificação na intersecção mesa/alma, provavelmente até o limite em que a flexão na mesa é suficientemente pequena para eliminar o "efeito alavanca".

Neste caso, a interação entre mesa e parafusos causa um aumento na ductilidade dos modelos, também visível na figura 7.2.

Um outro aspecto interessante nas hipóteses que fundamentam os modos de falha é a variação da "força de alavanca" que, para o modo de falha 1, admite-se como máxima, desaparecendo no modo de falha 3. A figura 7.6 apresenta as forças de tração médias na seção média dos parafusos para os 3 modelos da figura 7.4, onde é possível verificar a variação do efeito alavanca comparando-se as forças médias com a força teórica $F^{*}$, calculada pela divisão uniforme da força total na ligação pelos parafusos tracionados.

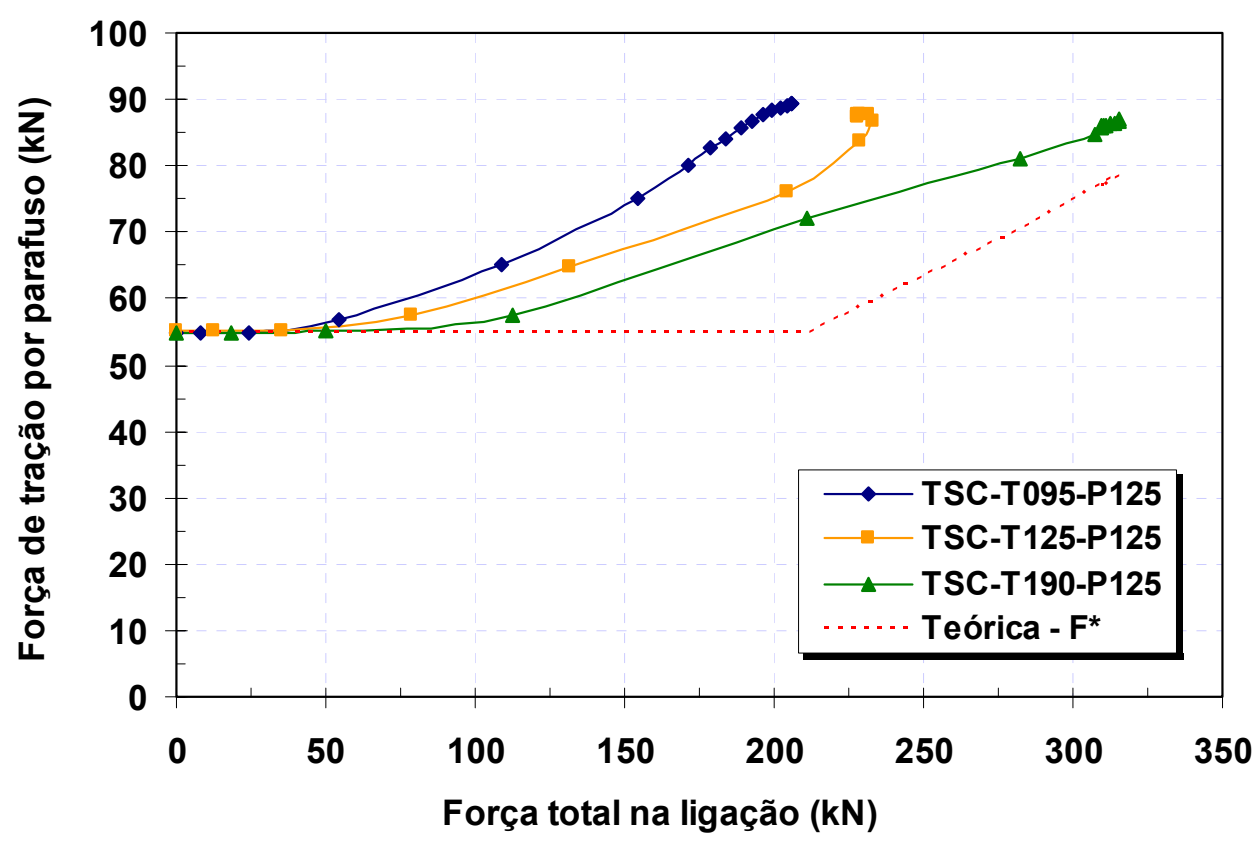

Figura 7.6 - Forças de tração nos parafusos dos modelos TSC-T095-P125, TSC-T125-P125 e TSC-T190-P125 
Para os modelos com parafusos de $16,0 \mathrm{~mm}$, todas as afirmações realizadas acima são verdadeiras, apenas com variações nos limites entre os modos de falha em função da variação de geometria, tanto da mesa quanto do parafuso.

Comparando-se as tensões plásticas equivalentes para os modelos com parafusos de $16,0 \mathrm{~mm}$, apresentados na figura 7.7 também para a configuração próxima ao colapso, observa-se as mesmas tendências para as mudanças nas linhas de plastificação na medida em que a espessura da mesa aumenta, ou seja, na medida em que a deformabilidade da mesa torna-se pequena com relação à deformabilidade dos parafusos.

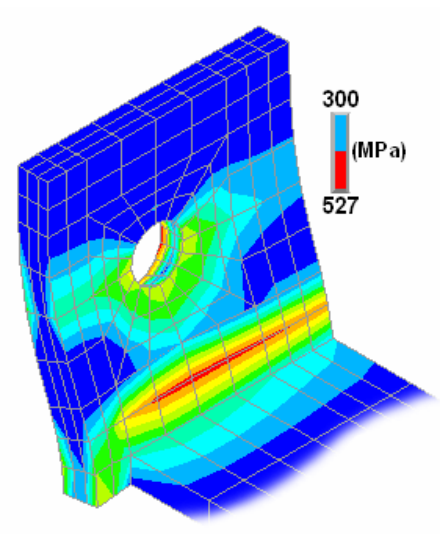

TSC-T095-T160

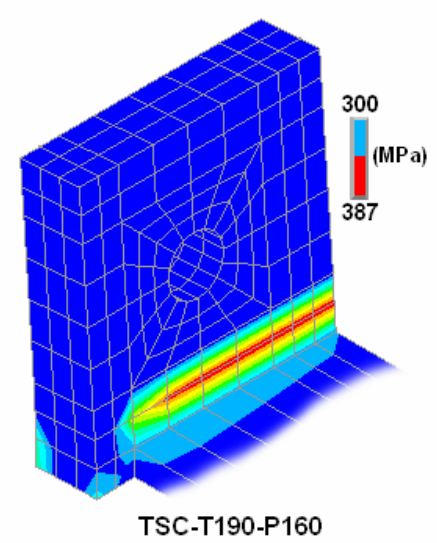

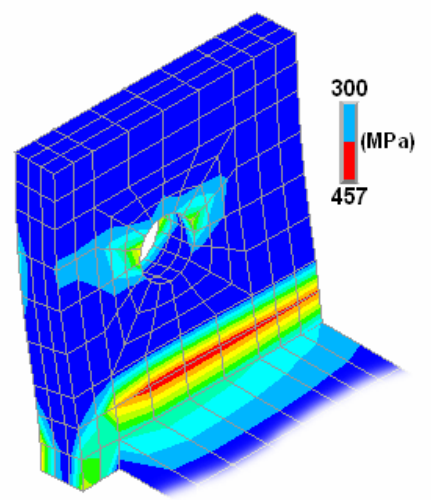

TSC-T125-P160

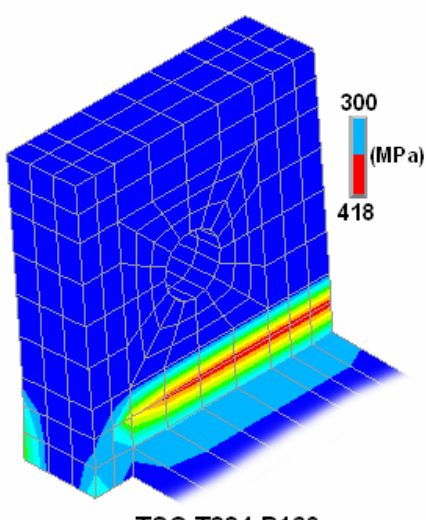

TSC-T224-P160

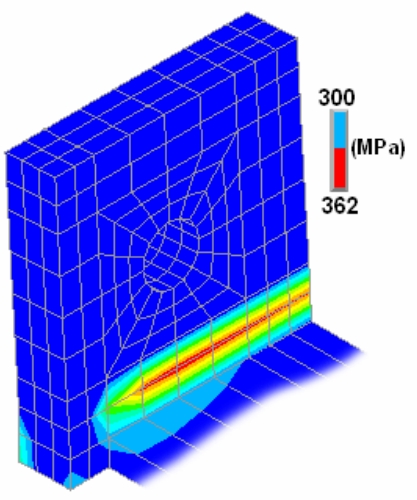

TSC-T160-P160

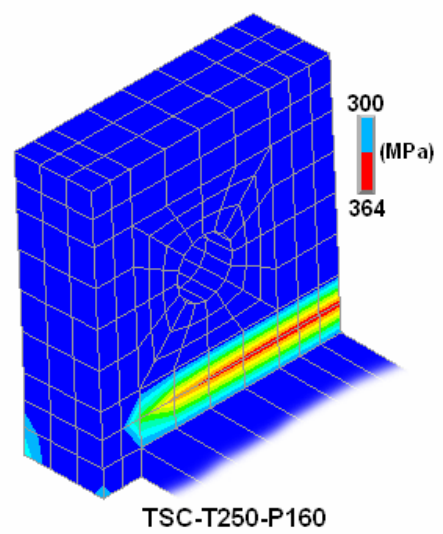

Figura 7.7 - Tensões plásticas equivalentes nas mesas dos modelos TSC com parafusos de $16,0 \mathrm{~mm}$ - vista externa frontal

Desconsiderando-se os aspectos que tornam as combinações acima usuais ou não em termos práticos, com os modelos do sub-grupo com parafusos de $16,0 \mathrm{~mm}$ é possível visualizar variações um pouco mais abrangentes. 
Neste caso, chama-se a atenção para a configuração do modelo TSCT095-P160, cujas linhas de plastificação indicam mais claramente a formação do mecanismo plástico entre a linha dos furos e a intersecção mesa/alma, com a predominância da flexão na direção perpendicular à alma.

Além disso, para o modelo TSC-T250-P160 é possível se identificar uma região limite entre os modos de falha 2 e 3, já que a flexão da mesa é pequena com uma diminuição visível nos níveis de tensão na intersecção mesa/alma.

Um aspecto interessante na observação das linhas de plastificação para os modelos acima é que as variações entre os modos de falha são similares mesmo com o aumento no diâmetro dos parafusos e causam comportamentos também semelhantes para a variação de resistência e ductilidade nos dois sub-grupos, considerando-se as curvas forçadeslocamento apresentadas nas figuras 7.2 e 7.3.

\subsubsection{Variações para os grupos TSI e TSIE}

Para os grupos TSI e TSIE, seguindo a mesma filosofia adotada nos modelos do grupo TSC, foram analisadas combinações de geometria com base nos protótipos experimentais.

O programa experimental para estes dois grupos, no entanto, foi realizado com a adoção de espessuras diferentes entre as mesas para simular a diferença de espessura entre a chapa de topo e a mesa do pilar, usual nas ligações com chapa de topo.

Para os modelos numéricos desses dois grupos essa diferença foi desconsiderada, adotando-se mesas de espessuras iguais para todas as ligações duplo "T". Entende-se que, assim, a comparação entre os modelos numéricos quanto às linhas de plastificação é mais adequada e considera-se que os modelos, com essas modificações, fazem parte de extrapolações das geometrias utilizadas no programa experimental.

A tabela 7.2 indica as características das mesas e dos parafusos para os grupos TSI e TSIE, apontando também a identificação dos modelos e protótipos experimentais correspondentes. 
Tabela 7.2 - Modelos numéricos para os grupos TSI e TSIE

\begin{tabular}{|c|c|c|c|}
\hline Modelo & $\begin{array}{c}\text { Protótipo } \\
\text { correspondente }\end{array}$ & $t_{f}(\mathbf{m m})$ & $d_{b}(m m)$ \\
\hline TSI-T125-P160 & - & 12,5 & \multirow{5}{*}{16,0} \\
\hline TSI-T160-P160 & - & 16,0 & \\
\hline TSI-T190-P160 & TSI3 & 19,0 & \\
\hline TSI-T224-P160 & - & 22,4 & \\
\hline TSI-T250-P160 & - & 25,0 & \\
\hline TSIE-T125-P160 & - & 12,5 & \multirow{5}{*}{16,0} \\
\hline TSIE-T160-P160 & TSIE1 & 16,0 & \\
\hline TSIE-T190-P160 & - & 19,0 & \\
\hline TSIE-T224-P160 & - & 22,4 & \\
\hline TSIE-T250-P160 & - & 25,0 & \\
\hline
\end{tabular}

Primeiramente para o grupo TSI, novamente é interessante se fazer uma comparação geral em torno do comportamento global dessas ligações e as do grupo TSC. Assim, na figura 7.8, apresentam-se as curvas forçadeslocamento para os dois grupos, utilizando-se os modelos de igual espessura da mesa e diâmetro dos parafusos.

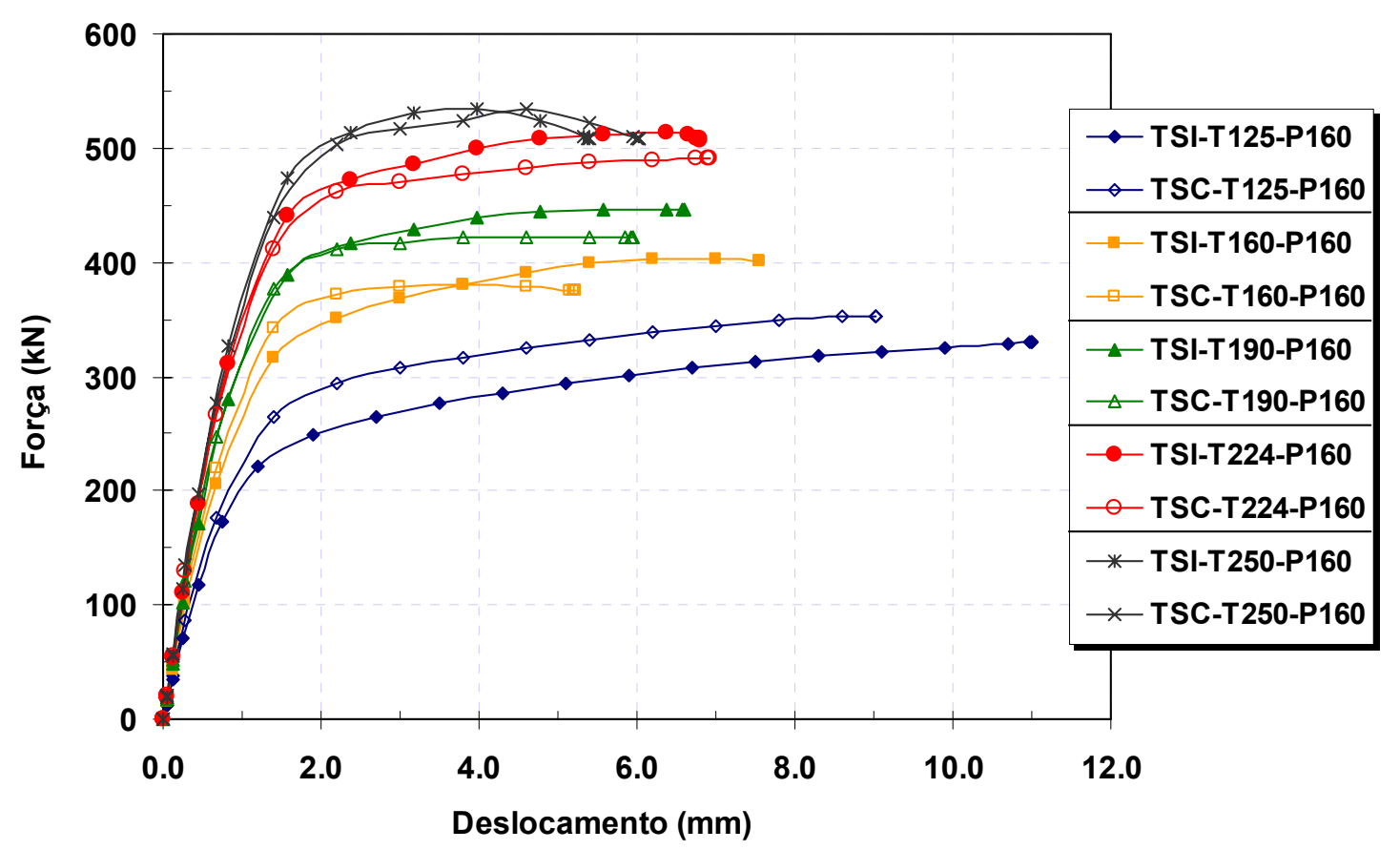

Figura 7.8 - Comparação das curvas força-deslocamento entre os modelos TSC e TSI

Para as curvas apresentadas acima é possível se observar diferentes variações entre os modelos TSI e TSC. O comportamento mais uniforme é verificado para os modelos com mesas de espessura maior, cuja limitação de 
resistência e de ductilidade depende da capacidade dos parafusos, com a eliminação do "efeito alavanca".

A maior variação ocorre no extremo inferior, para as menores espessuras da mesa. Neste caso, observa-se que a capacidade resistente do modelo TSI-T125-P160 é reduzida quando comparada a do modelo TSC-T125P160.

Entre esses dois extremos, os modelos TSI apresentam um ganho de ductilidade e de resistência com relação aos modelos TSC, o que novamente indica uma variação na distribuição plástica dos esforços entre as mesas e os parafusos.

Examinando-se com mais detalhes o modelo TSI-T125-P160, na figura 7.9 são ilustradas as deformações para a região da ligação, juntamente com a distribuição das tensões plásticas equivalentes nas mesas.

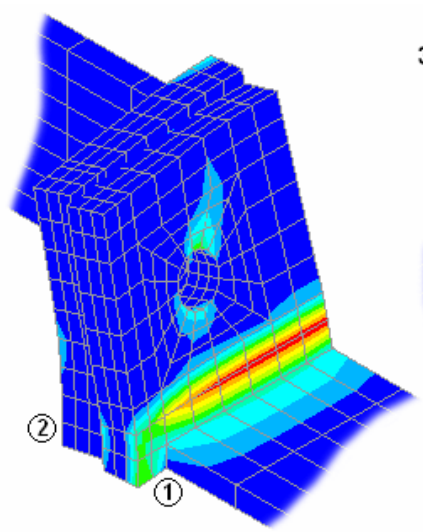

Vista externa frontal

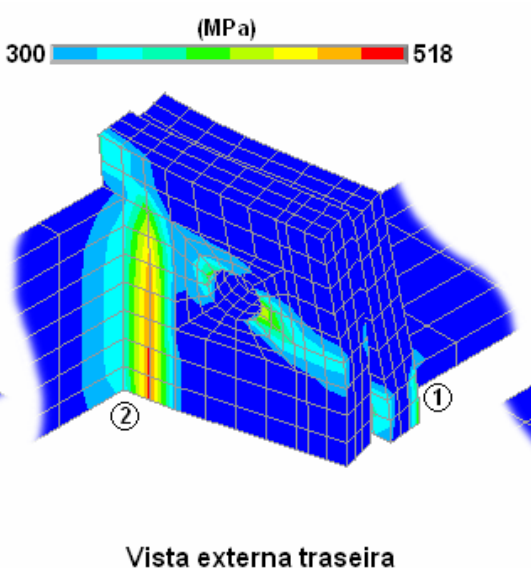

Vista externa traseira

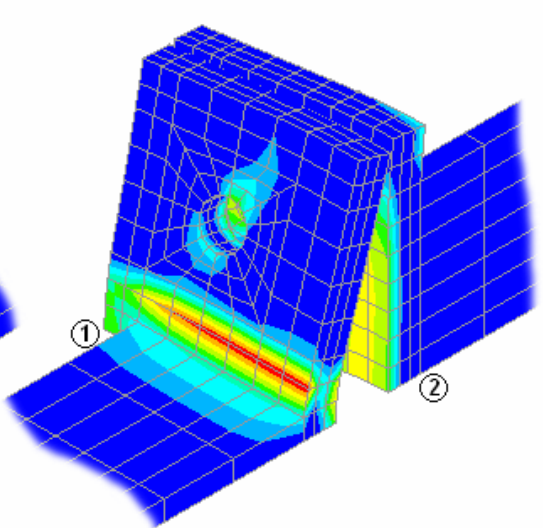

Vista interna frontal

Figura 7.9 - Tensões plásticas equivalentes nas mesas do modelo TSI-T125-P160

Na figura 7.9 se observa uma variação das linhas de plastificação em torno dos furos, causada por uma distorção das mesas devida à flexão nas duas direções do seu plano.

A plastificação na intersecção mesa/alma mantém os padrões observados para os modelos TSC e sua intensidade para cada lado da ligação é função da distância entre o centro do furo e a face da alma. Para o lado 1, observa-se uma plastificação mais acentuada na intersecção mesa/alma já que esse lado da ligação tem um braço de alavanca para os parafusos maior que o 
lado 2, modificando também a intensidade da plastificação na linha oblíqua que passa pelos furos.

A configuração das deformações observadas no modelo TSI-T125P160 varia novamente com o aumento da espessura da mesa, o que pode ser visualizado na figura 7.10 que apresenta também as tensões plásticas equivalentes nas mesas dos modelos TSI-T160-P160 e TSI-T190-P160.
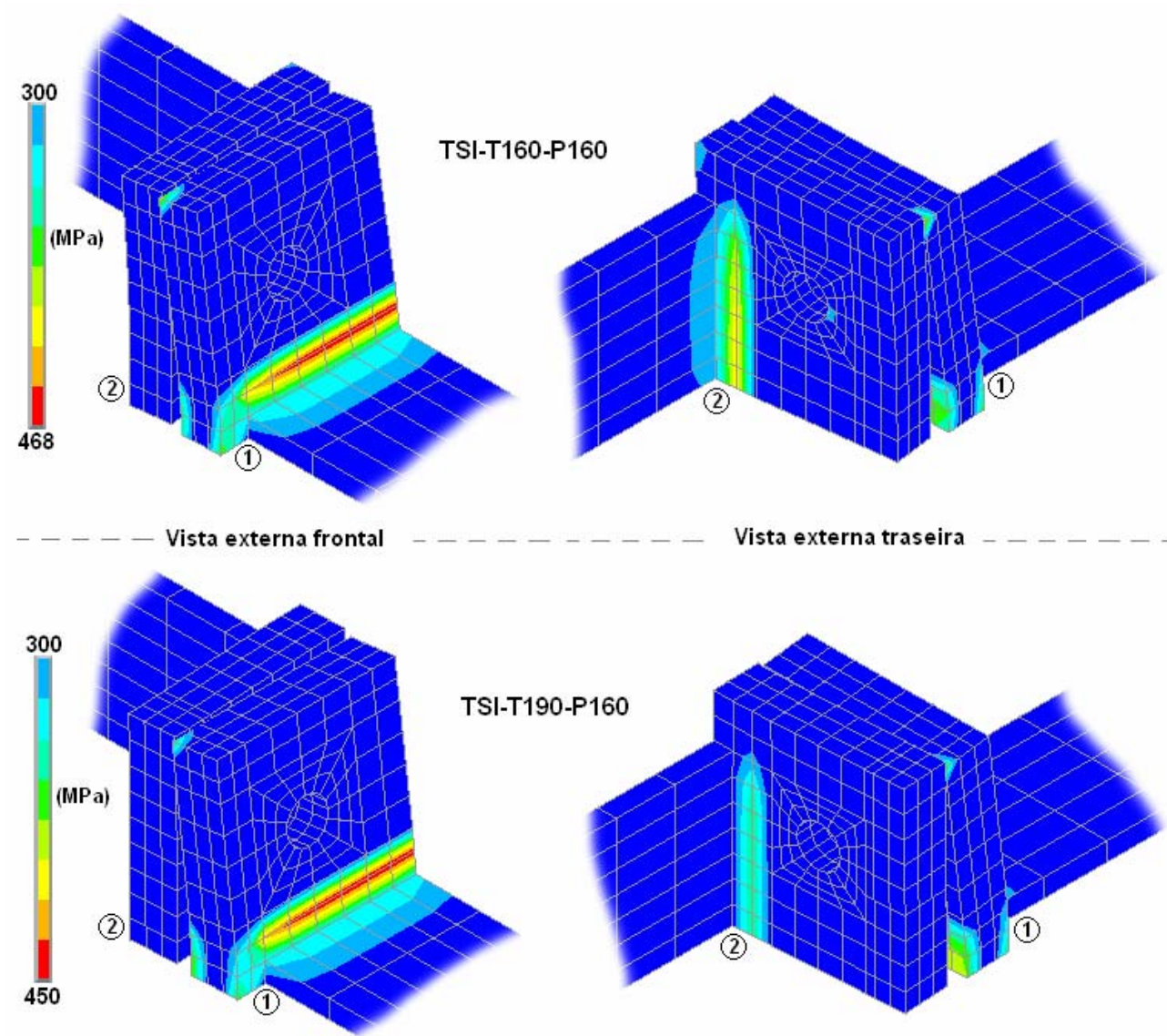
Vista externa traseira

Figura 7.10 - Tensões plásticas equivalentes nas mesas dos modelos TSI-T160-P160 e TSI-T190-P160

A plastificação na intersecção mesa/alma ainda é função do braço de alavanca dos parafusos para cada lado da ligação. No entanto, a deformabilidade das mesas diminui significativamente com relação aos parafusos, havendo uma concentração de tensões na borda externa do lado $\mathbf{1}$ ponto de apoio entre as mesas e responsável pelas "forças de alavanca".

A configuração das deformações permite ainda uma observação importante quanto ao modelo TSI-T125-P160, no qual percebe-se que as mesas, devido a sua deformabilidade, tem um apoio muito mais uniforme nas 
suas bordas. Ao mesmo tempo em que se espera uma diminuição do "efeito alavanca", as solicitações de tração nos parafusos são combinadas com a flexão em duas direções, diminuindo significativamente a capacidade resistente do modelo. Essa afirmação pode ser observada na figura 7.11, que apresenta uma comparação das forças de tração médias nos parafusos entre os modelos TSI-T125-P160, TSI-T160-P160 e TSI-T190-P160.

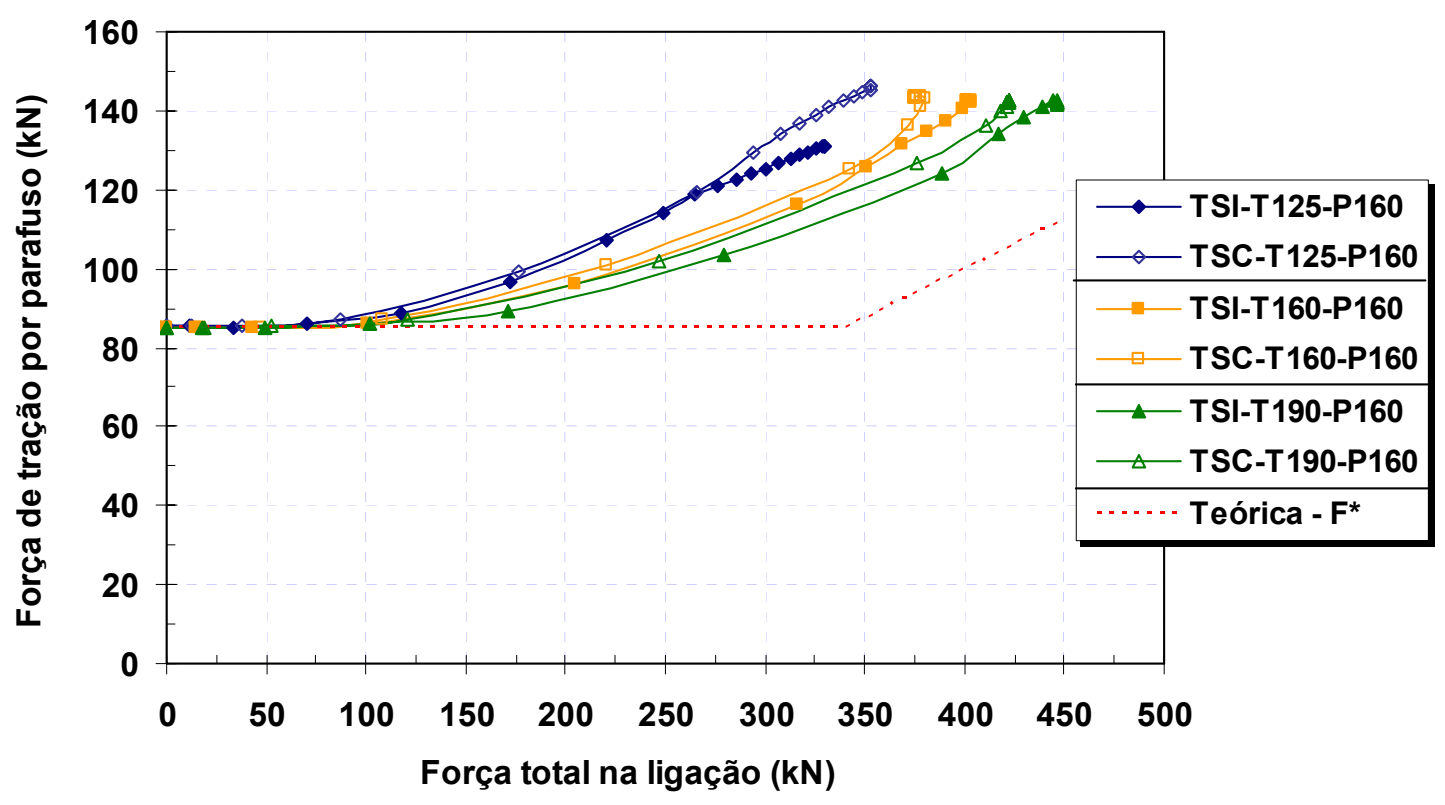

Figura 7.11 - Forças de tração nos parafusos dos modelos TSI-T125-P160, TSI-T160-P160 e TSI-T190-P160

A menos do modelo TSI-T125-P160, a distribuição de esforços nos parafusos entre os grupos TSI e TSC é similar, com uma diminuição do "efeito alavanca" para os modelos TSI, o que explica a maior ductilidade deste grupo.

Para o grupo TSIE, no qual os planos de tração são coplanares com enrijecimento de um dos lados da ligação, as variações das linhas de plastificação seguem os padrões do grupo TSC.

A figura 7.12 ilustra a variação do comportamento global entre os grupos TSIE e TSC, observando-se em geral um aumento da capacidade resistente entre os modelos para a mesma espessura de mesa e o mesmo padrão para as variações de ductilidade, apesar de menos acentuadas para o grupo TSIE. 


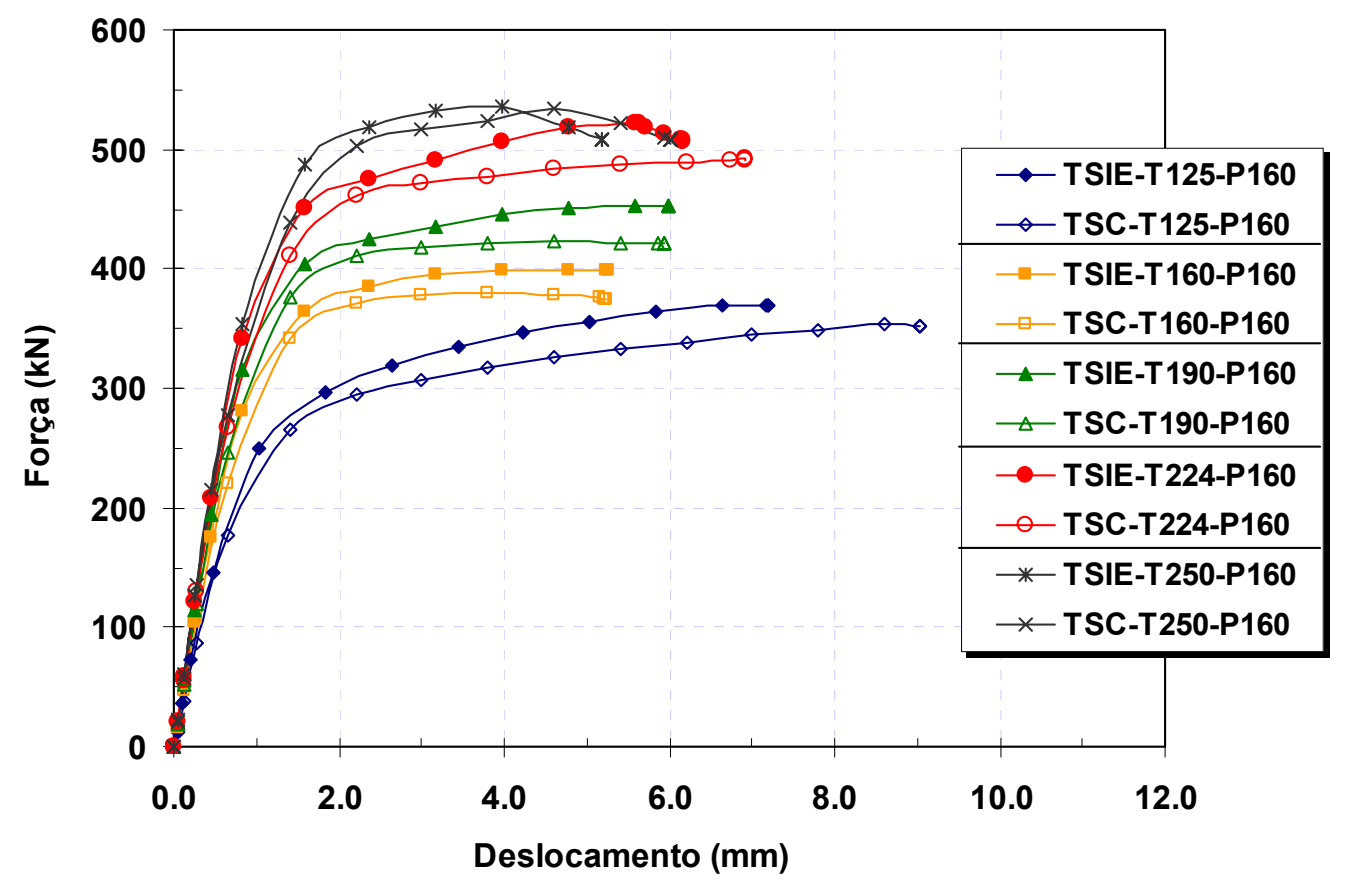

Figura 7.12 - Comparação das curvas força-deslocamento entre os modelos TSC e TSIE

Assim, estas variações não são provenientes de mudanças nos mecanismos de plastificação das mesas, mas sim de sua intensidade para o lado não enrijecido, já que o lado enrijecido dos modelos TSIE não contribui com a deformabilidade da ligação.

Pode-se afirmar, neste caso, que o aumento de resistência e as variações mais suaves de ductilidade são conseqüência da diminuição do "efeito alavanca" nos parafusos.

Para ilustrar esses comentários, a figura 7.13 apresenta as forças de tração para os parafusos dos modelos TSIE-T125-P160, TSIE-T160-P160 e TSIE-T190-P160, comparando-os com os resultados dos modelos TSC correspondentes.

Na figura 7.14 são apresentadas as deformações para os modelos TSIE-T125-P160 e TSIE-T190-P160, a fim de se ilustrar as linhas de plastificação para o grupo TSIE. 


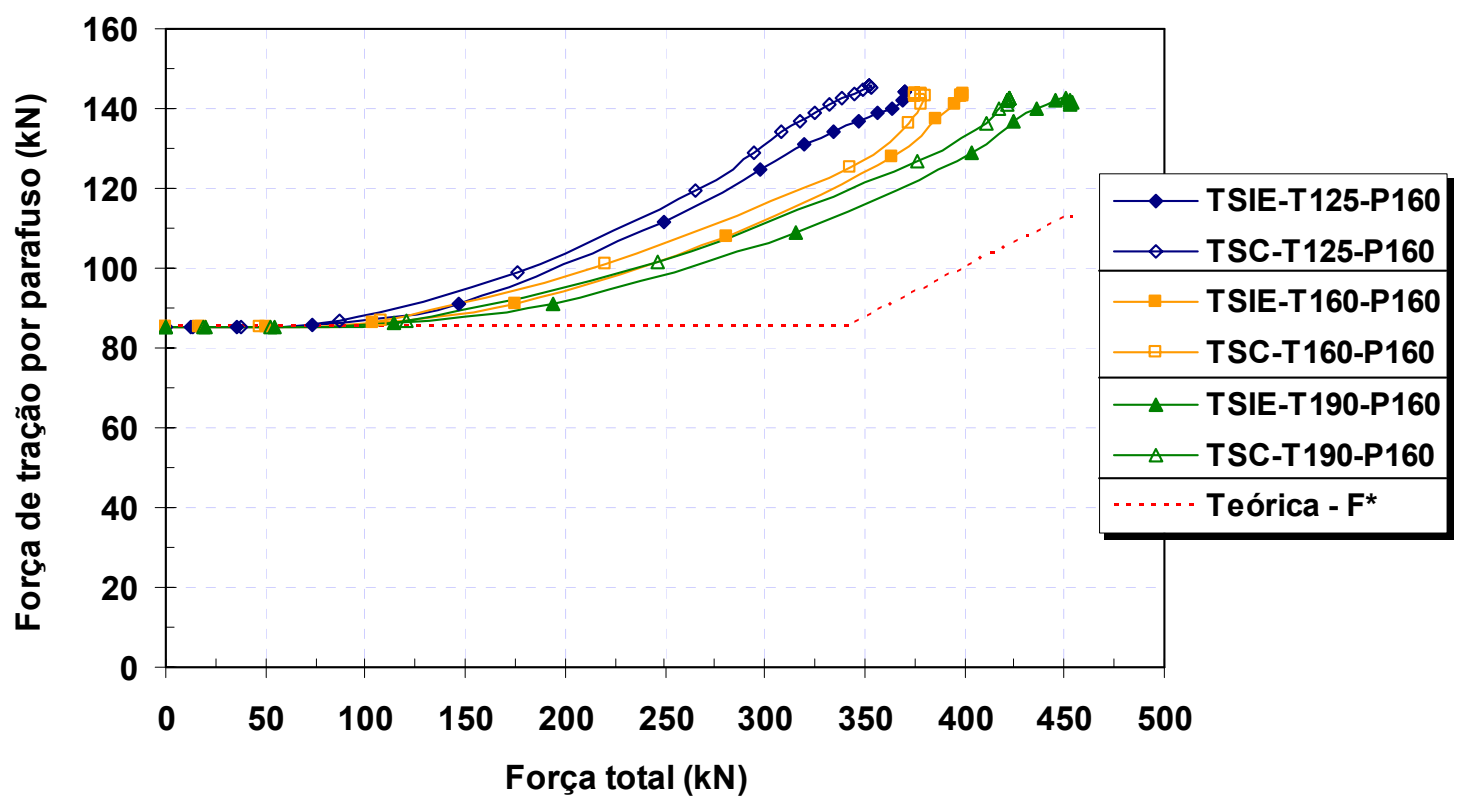

Figura 7.13 - Forças de tração nos parafusos dos modelos TSIE-T125-P160, TSIE-T160-P160 e TSIE-T190-P160
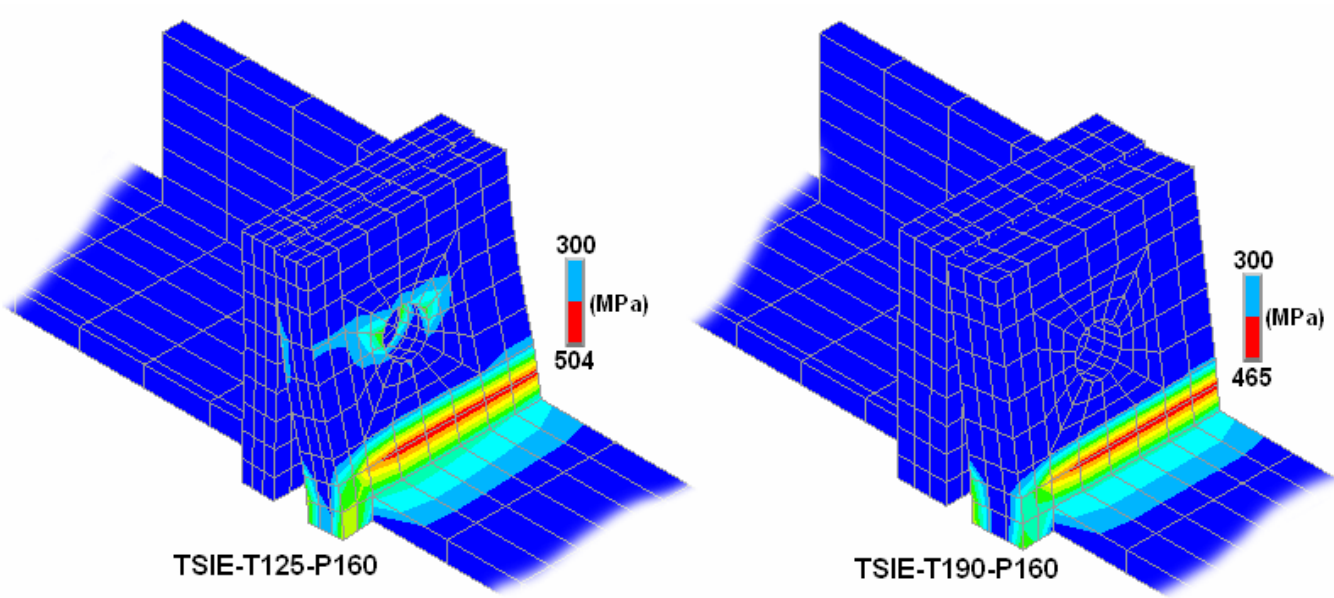

Figura 7.14 - Tensões plásticas equivalentes nas mesas dos modelos TSIE-T125-P160 e TSIE-T190-P160

As ligações duplo "T" dos grupos TSI e TSIE, fazendo-se uma analogia às ligações viga-pilar com chapa de topo, podem sem relacionadas, respectivamente, às ligações com pilares não enrijecidos e enrijecidos no interior das mesas.

As observações realizadas com os resultados numéricos indicaram que, em termos do comportamento global, as variações de resistência e ductilidade entre os 3 grupos não é significativa a ponto de inviabilizar a utilização da ligação duplo "T" usual na determinação dos modos de falha para a chapa de topo. 
De maneira geral, a ligação duplo "T" usual, do grupo TSC, é a menos resistente quando comparada aos grupos TSI e TSIE e a que apresenta as variações mais acentuadas de comportamento devido às variações na interação entre a mesa e os parafusos. Esse aspecto é diretamente relacionado à redução dos "efeitos de alavanca", observada nos grupos TSI e TSIE.

A única exceção dentro dos resultados analisados refere-se ao modelo TSI-T125-P160 que, devido à grande deformabilidade das mesas, impõe aos parafusos solicitações acentuadas de flexão nas duas direções, modificando significativamente os padrões de plastificação em torno dos furos.

\subsection{LINHAS DE PLASTIFICAÇÃO NAS LIGAÇÕES COM CHAPA DE TOPO ESTENDIDA}

Uma vez identificados os modos de falha nos perfis "T", é interessante avaliar a distribuição das tensões plásticas na chapa de topo das ligações vigapilar, já que a determinação da capacidade resistente deste componente, em conjunto com os parafusos, depende de modelos simplificados com base na capacidade resistente de perfis "T" equivalentes para cada linha de parafusos.

A tabela 7.3 indica a geometria utilizada para a chapa de topo e para o diâmetro dos parafusos nos modelos utilizados para a observação das linhas de plastificação na chapa de topo, com base nos protótipos experimentais.

Tabela 7.3 - Modelos numéricos para o grupo CTEE

\begin{tabular}{|c|c|c|c|}
\hline Modelo & $\begin{array}{c}\text { Protótipo } \\
\text { correspondente }\end{array}$ & $t_{c h}(m m)$ & $d_{b}(m m)$ \\
\hline CTEE-T095-P160 & - & 9,5 & \multirow{6}{*}{16,0} \\
\hline CTEE-T125-P160 & - & 12,5 & \\
\hline CTEE-T160-P160 & CTEE1 & 16,0 & \\
\hline CTEE-T190-P160 & CTEE2 & 19,0 & \\
\hline CTEE-T224-P160 & - & 22,4 & \\
\hline CTEE-T250-P160 & CTEE3 & 25,0 & \\
\hline
\end{tabular}

Para os modelos listados acima é interessante, novamente, visualizar as configurações plásticas das tensões próximas ao colapso para identificar as linhas de plastificação da chapa de topo. 
Com as indicações observadas nos perfis "T" para os modos de falha, a figura 7.15 ilustra a distribuição de tensões plásticas equivalentes na chapa de topo para o modelo CTEE-T095-P160.

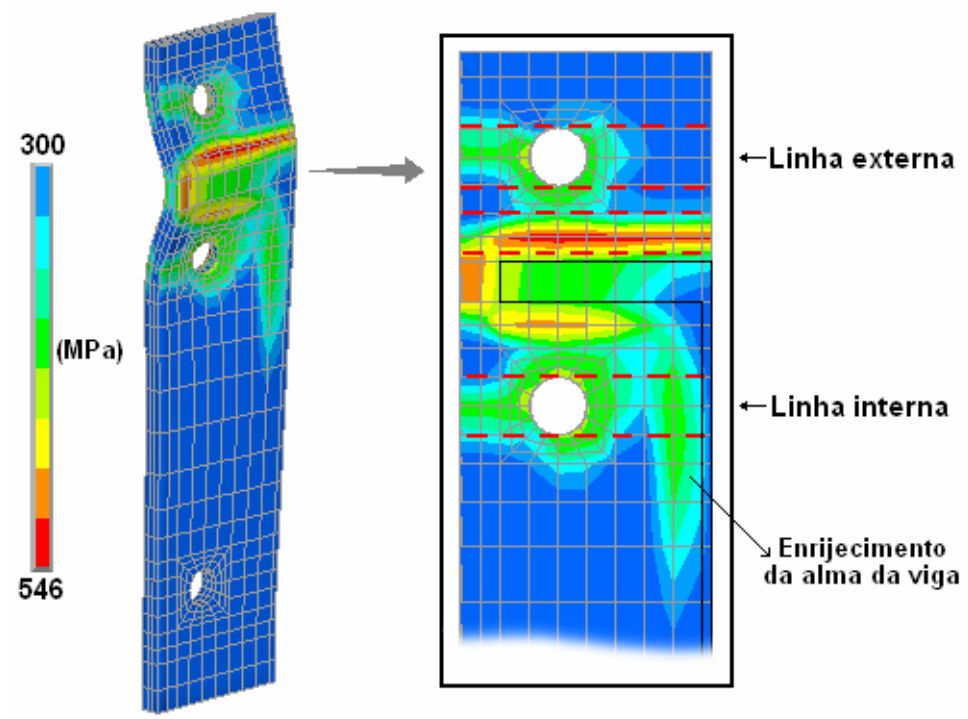

Figura 7.15 - Tensões plásticas equivalentes na chapa de topo do modelo CTEE-T095-P160 - vista externa frontal

Como convenção, a linha de parafusos na extensão da chapa de topo será denominada de "linha externa" e na região entre as mesas da viga receberá a denominação de "linha interna".

No detalhe da figura 7.15 observa-se a formação de linhas de plastificação muito semelhantes às do modo 1, principalmente para a linha externa. Assim, há uma concentração de deformações na altura da linha externa e na intersecção chapa de topo/mesa da viga devida à flexão acentuada da extensão da chapa.

No entanto, para a linha externa a plastificação ocorre a partir do furo predominantemente para a borda da chapa de topo, diferente do observado para o modelo de ligação duplo "T", TSC-T095-P160, no qual toda a linha é plastificada. Considerando-se que a largura total da chapa de topo é similar a dos perfis "T", pode-se afirmar que a chapa de topo está submetida à flexão em duas direções fora do seu plano, o que não ocorre para o perfil "T" correspondente do grupo TSC.

Para a linha interna, as deformações na intersecção chapa/mesa são menores devido ao enrijecimento promovido pela alma da viga, que impede a 
flexão localizada da chapa de topo nessa região. Como conseqüência do enrijecimento, há uma direção predominante de flexão para a região interna às mesas da viga o que causa uma redistribuição das tensões em direção à alma, com um aumento das deformações à flexão na linha interna de parafusos.

Com o aumento da espessura da chapa de topo, de 9,5 para 12,5 e $16,0 \mathrm{~mm}$, a variação das linhas de plastificação ocorre na mesma tendência observada para as ligações duplo "T", apenas com intensidade diferente entre as linhas interna e externa de parafusos, o que pode ser visualizado na figura 7.16, que apresenta as tensões plásticas equivalentes nas chapas de topo dos modelos CTEE-T125-P160 e CTEE-T160-P160, também próximo ao colapso.

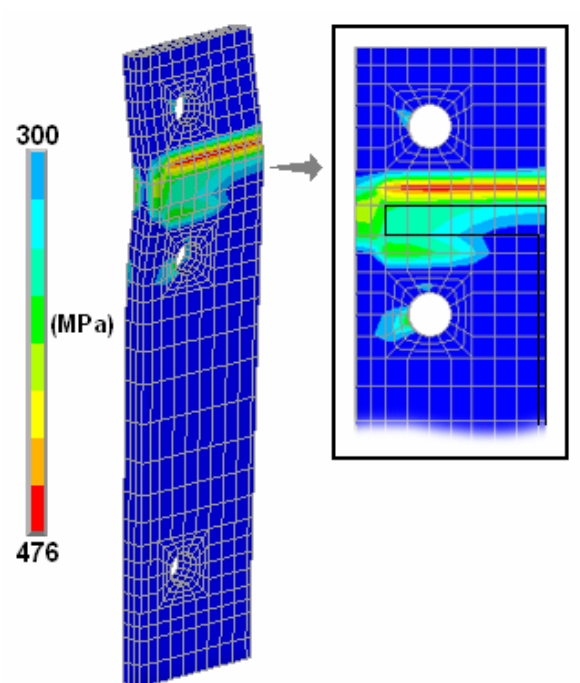

CTEE-T125-P160

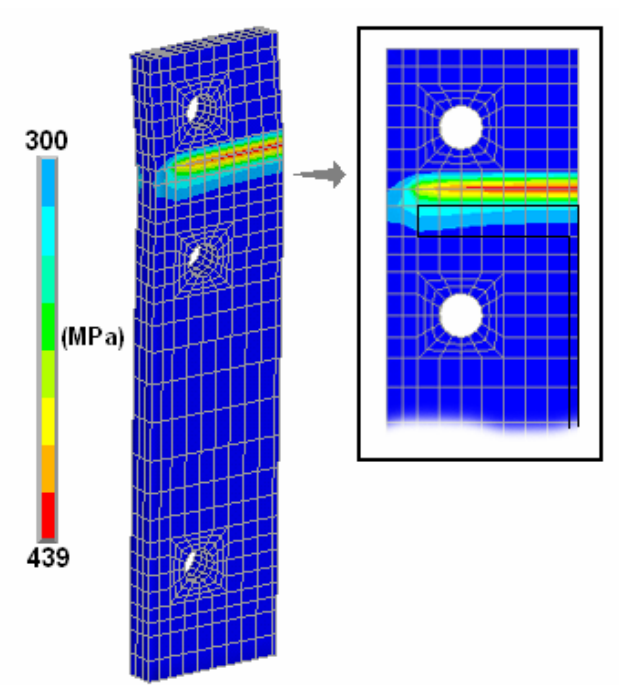

CTEE-T160-P160

Figura 7.16 - Tensões plásticas equivalentes na chapa de topo dos modelos CTEE-T125-P160 e CTEE-T160-P160 - vista externa frontal

Para o modelo CTEE-T125-P160 ainda se observa uma tendência de plastificação junto ao furo da linha interna, mas em níveis bem menores do que para a chapa de $\mathbf{9 , 5} \mathbf{m m}$. Para a linha externa, a plastificação junto à intersecção chapa/mesa já caracteriza o modo de falha 2 para a extensão da chapa de topo, que não tem enrijecimento.

Para o modelo CTEE-T160-P160, a linha interna apresenta uma deformabilidade suficientemente pequena para minimizar a flexão da chapa de topo nessa região, enquanto se observa uma diminuição gradativa das deformações para a extensão da chapa de topo nas proximidades da borda lateral. 
Para ilustrar os efeitos da variação de comportamento para a chapa de topo em função das mudanças nos modos de falha apresenta-se, na figura 7.17, as curvas momento-rotação para os modelos do grupo CTEE. A rotação foi calculada com base na abertura da chapa de topo no plano médio da mesa tracionada da viga, considerando-se o plano médio da mesa comprimida como centro de rotação. $\mathbf{M}_{\mathbf{p}}$ é o momento de plastificação da viga.

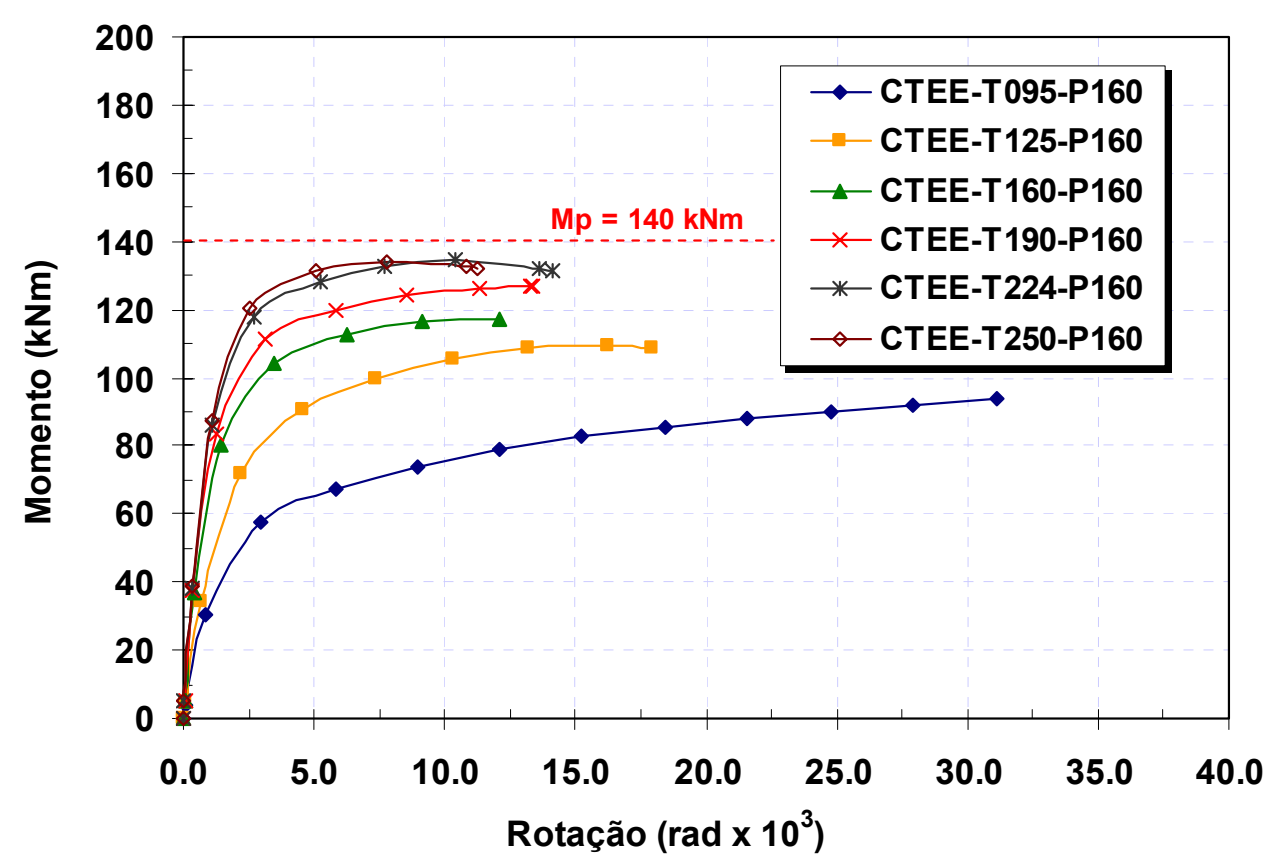

Figura 7.17 - Curvas momento-rotação para os modelos do grupo CTEE

A variação de resistência e de ductilidade para as ligações com chapa de topo, em função da interação entre a chapa de topo e os parafusos, é muito semelhante às variações do comportamento global para as ligações duplo "T". Na verdade, os grupos TSC e CTEE apresentam, qualitativamente, o mesmo comportamento em função da deformabilidade da chapa de topo.

Destaca-se, na figura 7.17 , que a ductilidade atinge um ponto de mínimo para o modelo CTEE-T160-P160, com as mesmas características de chapa de topo e parafusos que o modelo TSC-T160-P160, também um ponto de ductilidade mínima para o grupo TSC, na passagem do modo de falha 1 para o modo de falha 2.

Assim, é possível se identificar um limite entre os modos de falha $1 \mathrm{e}$ 2, que representa um ponto de equilíbrio entre a contribuição das deformações 
da chapa de topo à flexão e dos parafusos à tração na deformabilidade da ligação.

As observações realizadas acima também reforçam o fato de que a aplicação dos modos de falha dos perfis "T" para a chapa de topo, como proposto pelo Eurocode 3 (1993), é coerente com relação aos mecanismos de transferência dos esforços entre a chapa de topo e os parafusos.

Com estas considerações, ainda é necessário avaliar os procedimentos propostos pelo Eurocode 3 (1993) e os modelos analíticos para a quantificação da capacidade resistente da chapa de topo, fatores que são discutidos no próximo item.

\subsection{DISCUSSÃO SOBRE OS MODELOS DE DIMENSIONAMENTO}

A análise das linhas de plastificação e a correspondência dos mecanismos envolvidos em cada modo de falha permitiu a visualização de como o comportamento dos perfis "T" e da chapa de topo varia em função de características geométricas.

Além disso, os resultados numéricos validam a aplicação dos modos de falha observados nos perfis "T" como uma alternativa para a descrição dos mecanismos de plastificação da chapa de topo e da interação entre a chapa de topo e os parafusos, já que apresentam modos de falha similares e variações similares no comportamento dessas ligações.

O processo de aplicação da "teoria T-stub", comentado no capítulo 3, utiliza as configurações plásticas em torno das linhas de parafusos na chapa de topo para determinar um perfil "T" cuja capacidade resistente represente o conjunto de parafusos analisado, aplicando em seguida os modelos analíticos desenvolvidos para os perfis “T”, cuja aplicação é mais simples.

Como já comentado anteriormente, essa metodologia é conceitualmente inovadora e interessante, mas geralmente conduz a valores conservadores para a capacidade das ligações, visto as simplificações introduzidas em cada etapa do processo de dimensionamento que, para o caso da chapa de topo, é dividido entre a determinação do perfil "T" equivalente e a determinação da capacidade resistente desse perfil "T". 
Assim, os modelos analíticos apresentados no capítulo 3 para a determinação dos modos de falha nos perfis "T" serão discutidos inicialmente, enfatizando-se a comparação de resultados analíticos com os obtidos experimental e numericamente.

Em seguida, discute-se a metodologia proposta pelo Eurocode 3 (1993) para a determinação dos perfis "T" equivalentes e sua aplicação na verificação da capacidade resistente da chapa de topo e na rigidez rotacional das ligações.

\subsubsection{Capacidade resistente e efeito alavanca nas ligações duplo "T”}

Utilizando-se os modelos analíticos propostos por Kulak et al. (1987), pelo Eurocode 3 (1993) e por Swanson (1999), a tabela 7.4 apresenta os valores teóricos obtidos para a capacidade resistente $(\mathbf{T})$ e "força de alavanca" (Q) para os modelos de ligação duplo "T" do grupo TSC, listados na tabela 7.1, com parafusos de $16,0 \mathrm{~mm}$. Indica-se também o modo de falha para cada modelo junto aos valores da força de tração, ressaltando-se que as forças são relativas a cada parafuso da ligação.

Tabela 7.4 - Capacidade resistente e "forças de alavanca" teóricas para os modelos TSC com parafusos de $16,0 \mathrm{~mm}$

\begin{tabular}{|c|c|c|c|c|c|c|}
\hline \multirow[t]{2}{*}{ Modelo } & \multicolumn{2}{|c|}{$\begin{array}{c}\text { Kulak et al. } \\
\text { (1987) }\end{array}$} & \multicolumn{2}{|c|}{$\begin{array}{c}\text { Eurocode } 3 \\
\text { (1993) }\end{array}$} & \multicolumn{2}{|c|}{$\begin{array}{c}\text { Swanson } \\
\text { (1999) }\end{array}$} \\
\hline & $\mathrm{T}(\mathrm{kN})$ & $Q(\mathrm{kN})$ & $\mathrm{T}(\mathrm{kN})$ & $Q(\mathrm{kN})$ & $\mathrm{T}(\mathrm{kN})$ & $Q(k N)$ \\
\hline TSC-T095-P160 & $30,9^{1}$ & 8,8 & $41,6^{1}$ & 13,8 & $42,2^{1}$ & 8,8 \\
\hline TSC-T125-P160 & $53,5^{1}$ & 15,2 & $72,1^{1}$ & 23,9 & $73,0^{1}$ & 15,2 \\
\hline TSC-T160-P160 & $87,7^{1}$ & 24,8 & $98,1^{2}$ & 25,9 & $105,8^{2}$ & 18,2 \\
\hline TSC-T190-P160 & $102,7^{2}$ & 21,3 & $107,8^{2}$ & 16,2 & $114,7^{2}$ & 9,3 \\
\hline TSC-T224-P160 & $113,4^{2}$ & 10,6 & $120,7^{2}$ & 3,3 & $124,0^{3}$ & - \\
\hline TSC-T250-P160 & $122,9^{2}$ & 1,1 & $124,0^{3}$ & - & $124,0^{3}$ & - \\
\hline
\end{tabular}

Além disso, devido às características geométricas dos modelos numéricos, não foram consideradas as soldas nos modelos analíticos propostos pelo Eurocode 3 (1993) e por Swanson (1999). 
Na tabela 7.4 observa-se que os valores da capacidade resistente para os parafusos cresce à medida que a espessura da mesa dos perfis "T" aumenta. Essa característica deveria ser conseqüência de uma queda nas forças de alavanca, o que não ocorre para os modelos descritos acima para o modo de falha 1.

Isso ocorre devido à natureza da formulação para o efeito alavanca que, como comentado no capítulo 3 , é descrita por um parâmetro $\alpha$ com valores entre 0 e 1, respectivamente para situações com "efeito alavanca" nulo e máximo. Para o modo de falha 1 , a limitação da capacidade resistente é dada pelo momento de plastificação das mesas $\left(\mathbf{f}_{\mathbf{y}}=300 \mathrm{MPa}\right)$, com $\alpha$ constante e igual à 1. Neste caso, o valor teórico da "força de alavanca" no modo 1 é proporcional à força de tração $\mathbf{T}$, o que não representa fisicamente 0 comportamento do perfil "T".

O método proposto por Kulak et al. (1987) mostrou-se o mais conservador com relação à capacidade resistente dos parafusos e, comparando-se os valores analíticos com os obtidos pelo Eurocode 3 (1993) apresenta diferenças de 25\% para o modelo TSC-T095-P160 e de até 35\% para o modelo TSC-T125-P160. Essas diferenças diminuem significativamente à medida que a espessura da mesa aumenta.

O modelo de Kulak et al. (1987) modificado por Swanson (1999) foi o que apresentou resultados mais elevados para a capacidade resistente das ligações duplo "T", um pouco acima dos valores previstos pelo Eurocode 3 (1993).

As figuras 7.18 e 7.19 apresentam, respectivamente, comparações entre os valores das forças nos parafusos $(\mathbf{T})$ e as forças de alavanca $(\mathbf{Q})$ obtidas analiticamente, comparando-as com os valores máximos obtidos nos resultados numéricos e experimentais correspondentes.

As forças de alavanca calculadas com base nos resultados numéricos e experimentais foram obtidas pela diferença entre a força total de tração aplicada nos modelos e a força que teoricamente a ligação suportaria considerando-se os quatro parafusos sob tração simples, ou seja, sem efeitos de alavanca. 


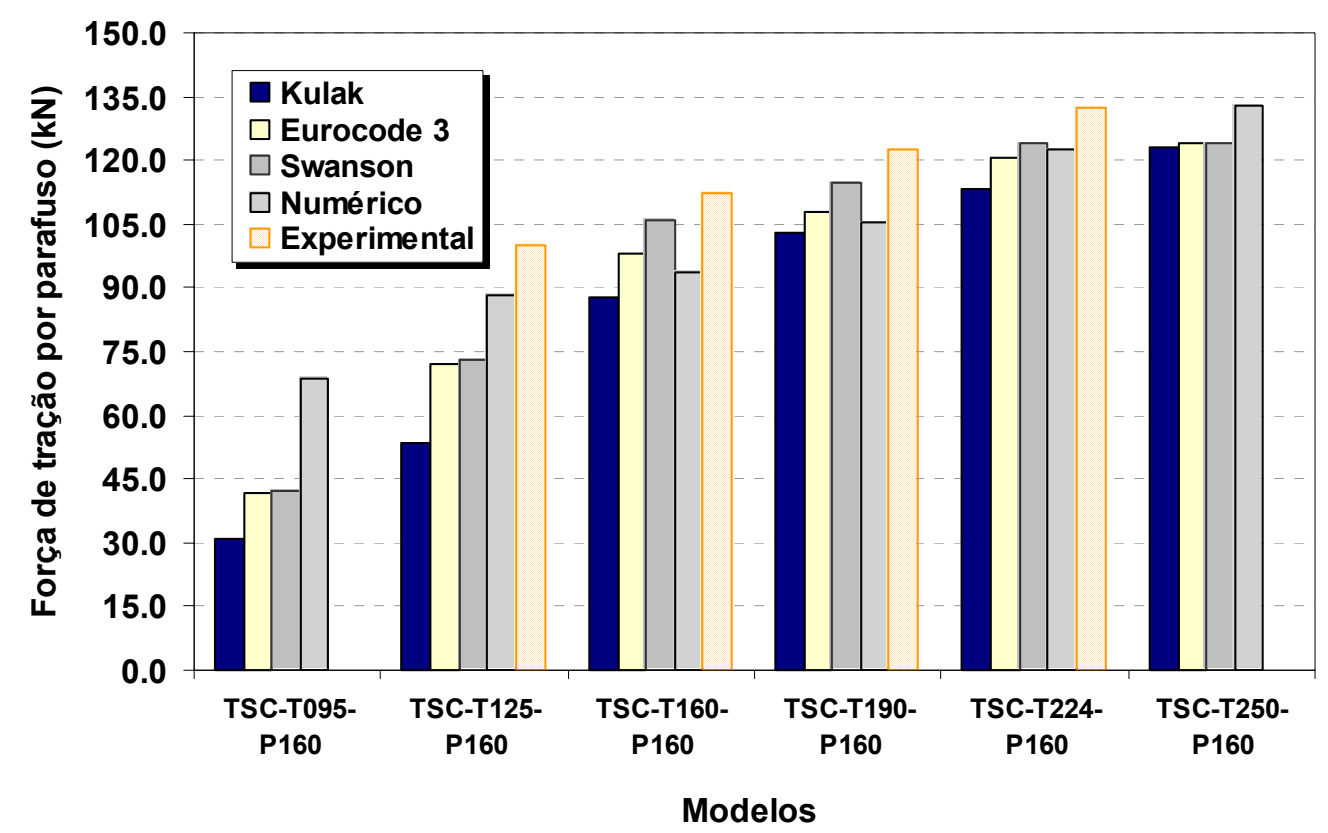

Figura 7.18 - Forças de tração nos parafusos e valores teóricos da capacidade resistente

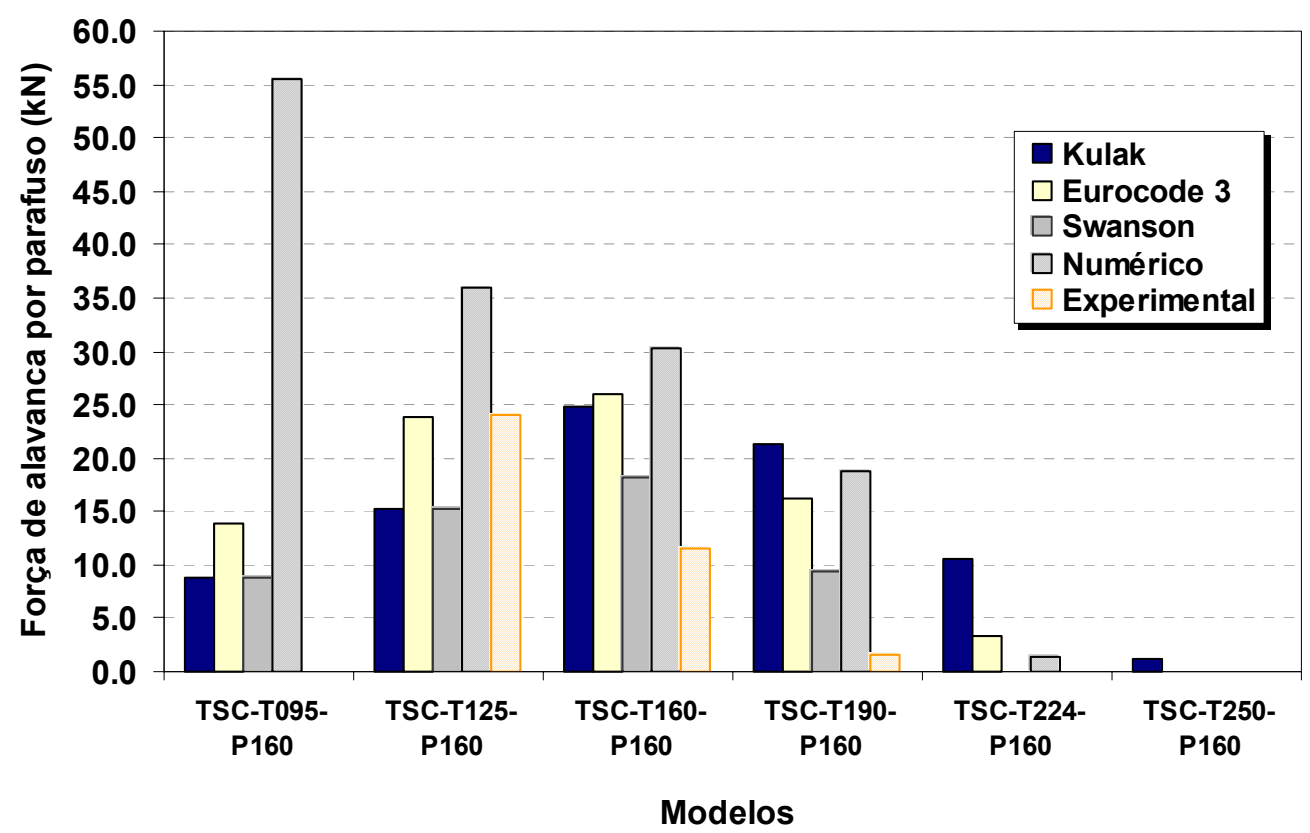

Figura 7.19 - Valores teóricos, numéricos e experimentais para as forças de alavanca nos parafusos

A menos das diferenças entre os resultados numéricos e experimentais, já comentadas no capítulo 6 , há um padrão bem definido para a resistência dos perfis "T" e para as forças de alavanca nos parafusos. Esse padrão refere-se a um aumento da resistência à medida que se aumenta a espessura da mesa dos perfis "T" e uma diminuição quase proporcional das forças de alavanca. 
No entanto, os resultados analíticos mostram valores bem discrepantes entre si com relação às forças de alavanca e, em geral, conservadores com relação à resistência dos perfis "T", observada pela força total de tração nos parafusos calculada a partir dos resultados experimentais.

Tratando-se de modelos analíticos de dimensionamento, o fato de serem conservadores é um ponto positivo ao levar em consideração diversas imperfeições que podem existir em uma ligação real, como por exemplo, defeitos de montagem e tensões residuais.

Analisando-se mais detalhadamente as formulações analíticas apresentadas e os valores calculados para a força de tração nos parafusos, o modelo de Kulak et al. (1987) não leva em consideração a contribuição da solda na rigidez do perfil "T", considerada no modelo de Swanson (1999) por uma redução no braço de alavanca do parafuso por uma parcela igual à $0.5 r$, onde $r$ é a garganta efetiva da solda, e por uma parcela de $0.8 r$ no modelo proposto pelo Eurocode 3 (1993).

Mesmo com relação aos resultados numéricos, que foram incluídos porque também não consideram a solda, há diferenças significativas para o modo de falha 1. No entanto, a consideração da solda para o modo 1 nos modelos do Eurocode 3 (1993) e de Swanson (1999) é mais representativa para os valores teóricos do que as diferenças de consideração ou não da solda na modelagem, o que indica ser um fator importante na determinação do mecanismo que se forma na mesa dos perfis "T".

Além disso, é interessante ressaltar que as hipóteses utilizadas para essas formulações não levam em consideração os efeitos da protensão inicial dos parafusos que podem modificar a configuração das forças ao longo da largura do perfil "T". Para observar esse aspecto, a figura 7.20 ilustra as pressões de contato entre os perfis "T" para os modelos TSC-T095-P160 e TSC-T125-P160, ambos dentro do modo de falha 1.

Em especial para o modelo TSC-T095-P160, a consideração de que a força de alavanca é aplicada nas bordas da mesa pode ser uma hipótese conservadora, visto que a distribuição de momento na seção que passa pelo furo também depende da distância entre o ponto de atuação da força no parafuso e a borda superior da mesa. 


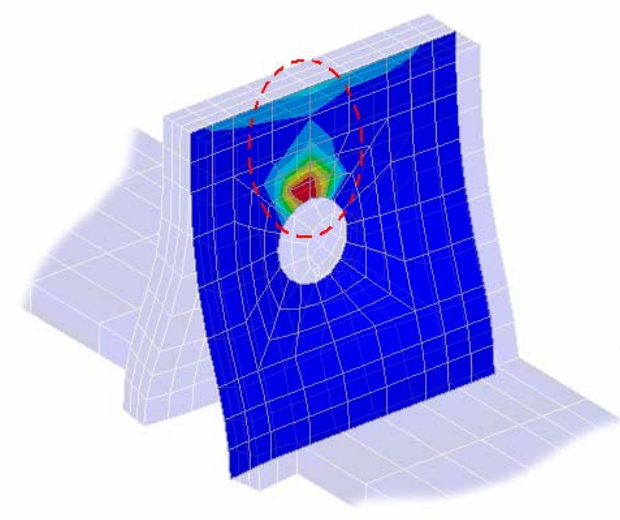

TSC-T095-P160

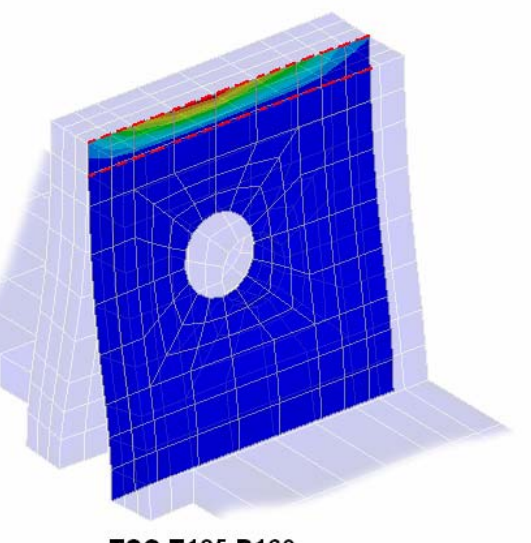

TSC-T125-P160

Figura 7.20 - Pressões de contato nos modelos TSC-T095-P160 e TSC-T125-P160

Os modelos analíticos apresentados acima têm como característica comum uma dificuldade em representar os mecanismos de plastificação do modo 1, visivelmente mais complexo do que o modo de falha 3 cuja limitação depende apenas da resistência à tração dos parafusos.

Assim, a capacidade resistente dos perfis "T" é bem determinada para o modo de falha 3 , e subestimada principalmente para o modo de falha 1 , cuja característica principal é a limitação da capacidade resistente em função do momento de plastificação da mesa, geralmente muito abaixo da resistência da mesa devido ao encruamento do seu material e aos efeitos de membrana que são visíveis na figura 7.20 .

Devido a estas simplificações, já se insere um certo conservadorismo na determinação da capacidade resistente das ligações com chapa de topo que, em diferentes níveis, leva à utilização de chapa de topo mais espessas para as quais a capacidade resistente é máxima e bem determinada.

\subsubsection{Capacidade resistente da chapa de topo}

A metodologia proposta pelo Eurocode 3 (1993) para a verificação da chapa de topo à flexão supõe a equivalência entre os mecanismos formados para cada linha de parafusos na chapa de topo e os modos de falha apresentados para os perfis “T”, conforme apresentado no capítulo 3 . 
Dessa forma, antes da aplicação dos modelos analíticos mencionados acima, é necessária a determinação de um comprimento efetivo para um perfil "T" cujas características representem a capacidade resistente de cada linha de parafusos, que depende das linhas de plastificação observadas na chapa de topo.

Para avaliar essa metodologia são apresentados os resultados analíticos para os modelos do grupo CTEE, com parafusos de 16,0 mm, para os quais se dá ênfase aos modelos CTEE-T095-P160, CTEE-T125-P160 e CTEE-T160-P160, com chapas mais finas, nos quais a interação entre a chapa de topo e os parafusos provocam mecanismos semelhantes aos considerados para os modos de falha 1 e 2 nos perfis "T".

Seguindo a metodologia de cálculo proposta pelo Eurocode 3 (1993), a tabela 7.5 resume os valores calculados para o comprimento equivalente dos perfis "T" para as linhas "externa" e "interna" dos parafusos dos modelos numéricos. Ilustram-se também os padrões de plastificação que deram origem aos valores do comprimento equivalente $L_{\text {eff, }}$, ressaltando-se que esses valores dependem apenas da geometria da chapa de topo, não variando em função da sua espessura e na formulação adotada para os perfis "T" é igual à variável p, referente à largura tributária do perfil "T" para cada parafuso.

Não foram aplicados os coeficientes de segurança para os materiais, nem para o escoamento da chapa nem para a ruptura do parafuso à tração. As soldas entre a chapa de topo e a viga também foram desconsideradas para adequar o cálculo aos modelos numéricos.

Os padrões de plastificação apresentados na tabela 7.5 indicam a tendência de redistribuição dos esforços na chapa de topo em função da sua geometria.

Para a extensão da chapa, os valores de comprimento equivalente seguem uma ordem crescente em função dos modos de falha observados para os perfis "T", desde a formação das rótulas plásticas entre o furo e a intersecção chapa/mesa até um padrão de plastificação circular, que teoricamente só ocorreria se a deformabilidade da chapa fosse desprezível com relação aos parafusos na região dos furos. 
Tabela 7.5 - Comprimentos equivalentes e linhas de plastificação para os modelos do grupo CTEE com parafusos de $16,0 \mathrm{~mm}$

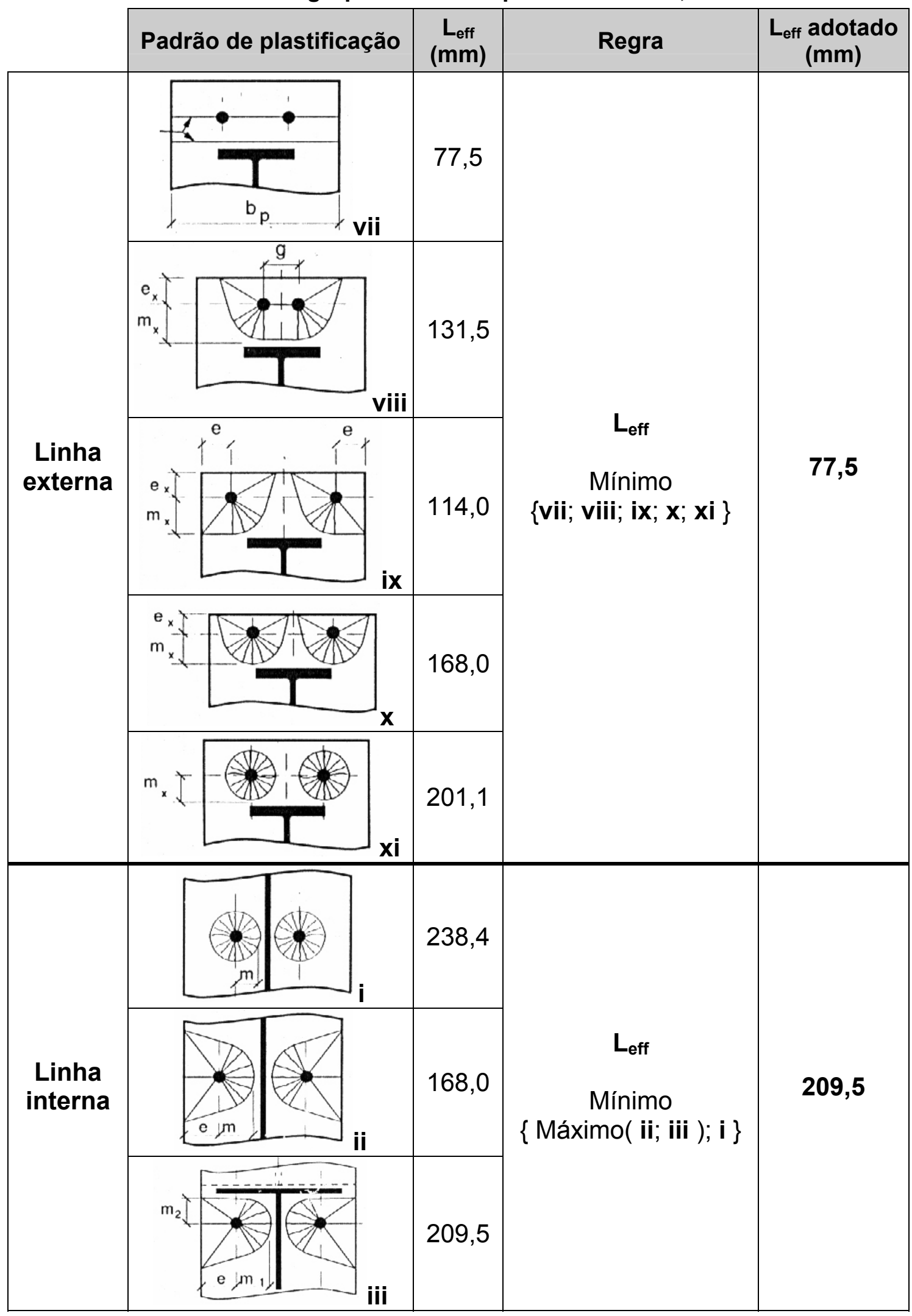

Para a linha interna, a configuração (i) reproduz a situação descrita acima para o padrão circular, sendo que entre as configurações (ii) e (iii) 
adota-se a que tiver maior enrijecimento, já que tanto a mesa quanto a alma da viga contribuem para a capacidade resistente naquela região.

Os valores da capacidade resistente $\left(\mathbf{P}_{\mathbf{r}}\right)$ para cada linha de parafusos dos modelos CTEE, para cada modo de falha, em função da variação da espessura da chapa de topo e adotando-se os valores encontrados de $L_{\text {eff }}$ da tabela7.5, estão listados na tabela 7.6.

O momento resistente teórico é calculado pelo equilíbrio de momentos com relação ao plano médio da mesa comprimida da viga e considerando-se a capacidade resistente limite de cada linha de parafusos. Os procedimentos para cálculo do momento resistente podem ser encontrados no Eurocode 3 (1993) e, com mais detalhes, no trabalho de Romano (2001).

Tabela 7.6 - Capacidade resistente para as linhas de parafusos dos modelos do grupo CTEE

\begin{tabular}{|c|c|c|c|c|c|}
\hline \multirow{2}{*}{ Modelo } & \multirow{2}{*}{ Linha* } & \multicolumn{3}{|c|}{ Capacidade resistente $-P_{r}(k N)$} & \multirow{2}{*}{$\begin{array}{c}M_{r, d} \\
(k N m)\end{array}$} \\
\hline & & Modo 1 & Modo 2 & Modo 3 & \\
\hline \multirow{2}{*}{ СTEE-T095-P160 } & Ext. & 46,1 & 95,3 & 248,8 & \multirow{2}{*}{37,5} \\
\hline & Int. & 124,5 & 144,6 & 248,8 & \\
\hline \multirow{2}{*}{ CTEE-T125-P160 } & Ext. & 79,8 & 132,1 & 248,8 & \multirow{2}{*}{55,9} \\
\hline & Int. & 215,6 & 170,1 & 248,8 & \\
\hline \multirow{2}{*}{ CTEE-T160-P160 } & Ext. & 130,7 & 146,4 & 248,8 & \multirow{2}{*}{77,6} \\
\hline & Int. & 353,3 & 208,5 & 248,8 & \\
\hline \multirow{2}{*}{ CTEE-T190-P160 } & Ext. & 184,3 & 161,3 & 248,8 & \multirow{2}{*}{94,1} \\
\hline & Int. & 498,0 & 249,0 & 248,8 & \\
\hline \multirow{2}{*}{ CTEE-T224-P160 } & Ext. & 256,2 & 181,4 & 248,8 & \multirow{2}{*}{99,6} \\
\hline & Int. & 692,4 & 303,2 & 248,8 & \\
\hline \multirow{2}{*}{ CTEE-T250-P160 } & Ext. & 319,0 & 199,0 & 248,8 & \multirow{2}{*}{104,0} \\
\hline & Int. & 862,5 & 350,7 & 248,8 & \\
\hline
\end{tabular}

Analisando-se a tabela acima, observa-se que há diferenças sistemáticas entre as forças de tração calculadas para as linhas "externa" e "interna", referentes aos modos de falha 1 e 2.

Essa característica pode ser entendida mais facilmente se a capacidade resistente para cada modo de falha for associada a uma 
"resistência potencial", ou seja, um valor limite para as forças de tração em uma linha de parafusos em função da deformabilidade da chapa.

Teoricamente, para o modelo CTEE-T095-P160 a extensão da chapa de topo tem uma deformabilidade muito maior do que a região entre as mesas da viga e, neste caso, a solicitação nos parafusos da linha externa será limitada pelo momento de plastificação da chapa de topo.

Os parafusos da linha interna, por sua vez, desenvolvem melhor sua capacidade à tração já que a mesa e a alma da viga conferem um enrijecimento àquela região, diminuindo a deformabilidade da chapa de topo.

A figura 7.21 apresenta as forças de tração nos parafusos obtidas para o modelo CTEE-T095-P160 comparando-as com a "resistência potencial" analítica da tabela 7.6. Cabe ressaltar que os valores analíticos, para efeito de comparação, são divididos por dois, já que se referem à resistência de toda a linha de parafusos.

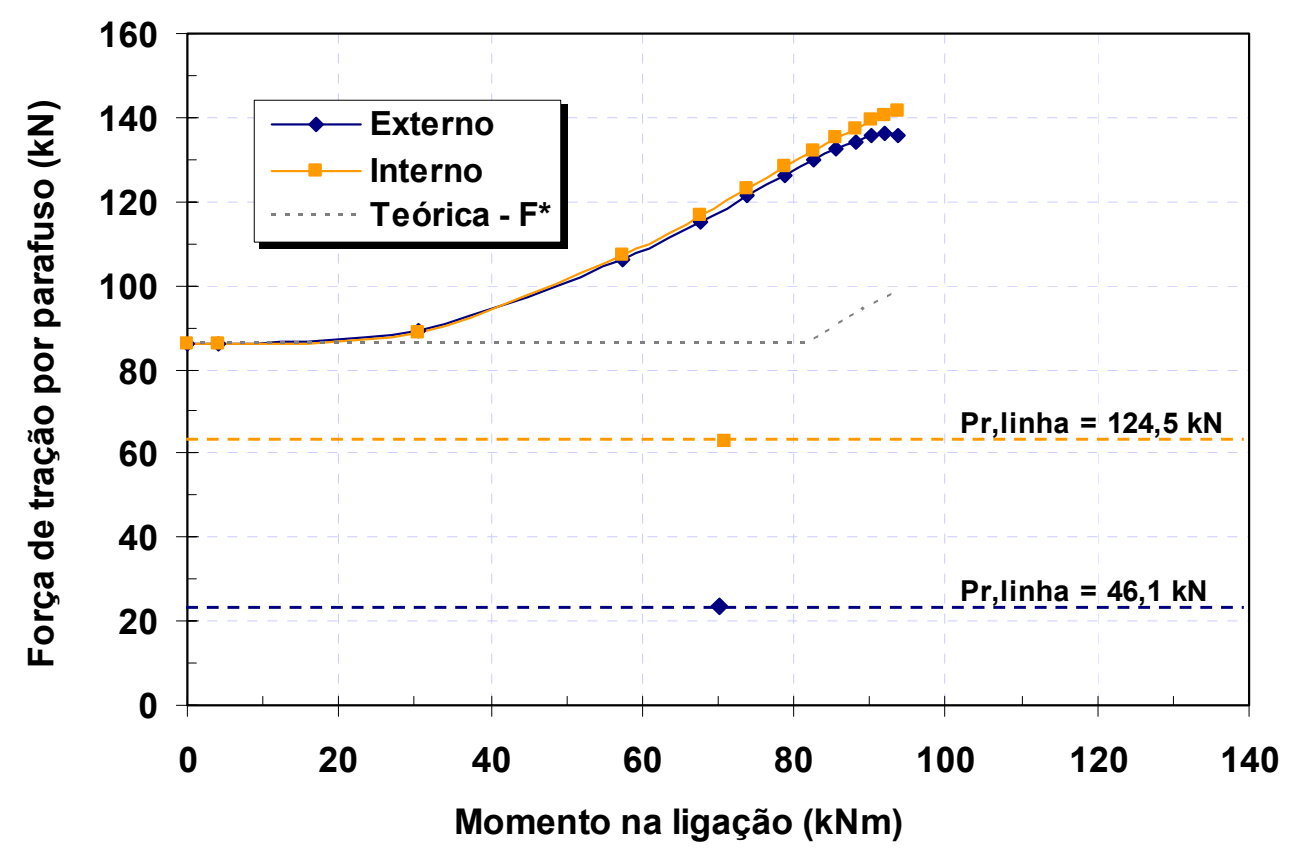

Figura 7.21 - Forças de tração teóricas e no modelo CTEE-T095-P160

Para este modelo, a capacidade resistente é muito limitada, principalmente para a linha externa que sofre influência da deformabilidade da chapa de topo. 
Conforme já comentado anteriormente, o modelo CTEE-T095-P160 apresenta momento resistente baixo com uma elevada ductilidade, o que indica uma plastificação prematura da chapa de topo.

Com relação a esse aspecto em especial, a figura 7.22 ilustra a relação momento-rotação para a chapa de topo do modelo CTEE-T095-P160 com a marcação de três pontos sobre a curva que indicam o início da plastificação na chapa de topo (a), a formação da primeira rótula plástica (b) e a formação completa do mecanismo plástico na intersecção chapa/mesa (c), ilustrando a distribuição de tensões plásticas equivalentes na chapa de topo. $\mathbf{M}_{\mathbf{p}}$ é o momento de plastificação da viga e $\mathbf{M}_{\mathbf{r}}$ é o momento resistente analítico da ligação, da tabela 7.6.

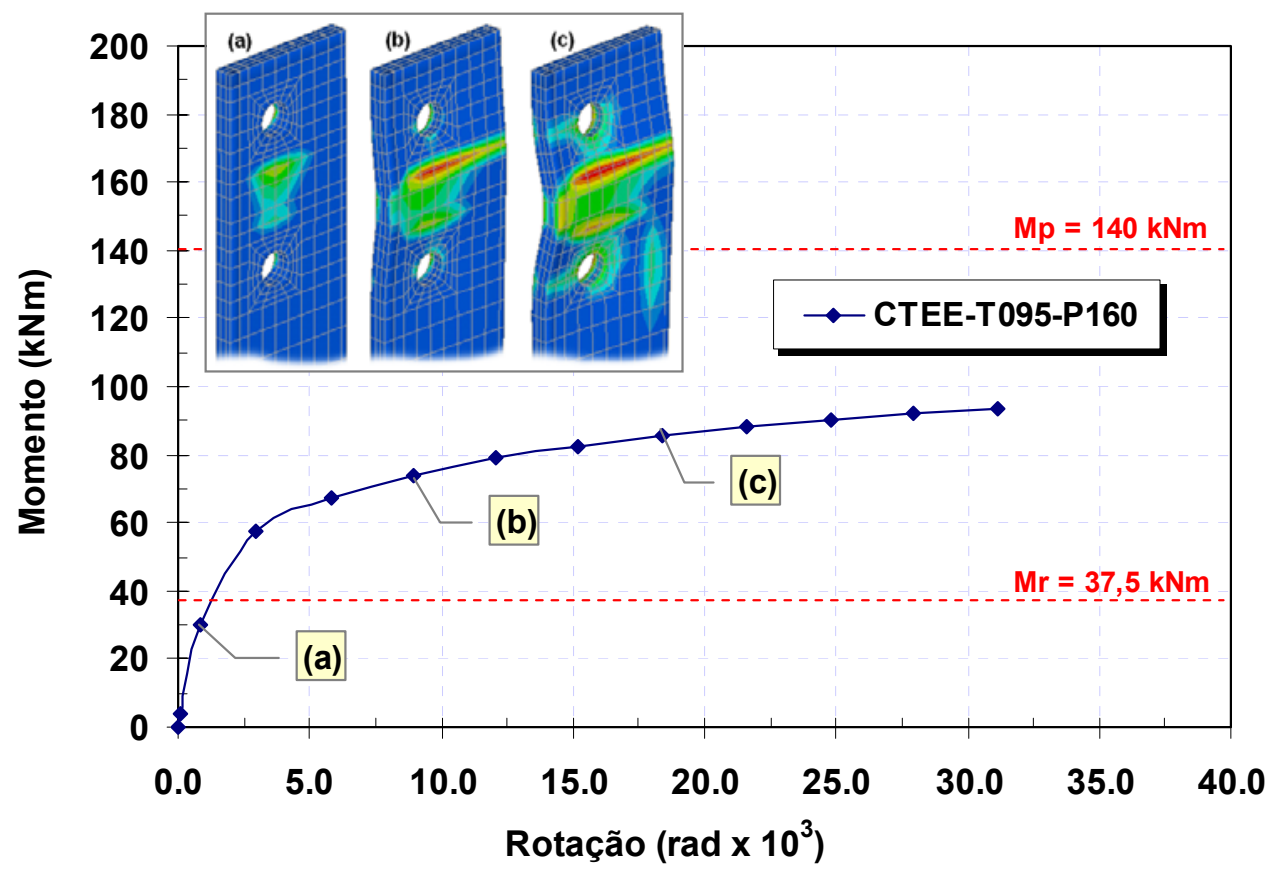

Figura 7.22 - Curva momento-rotação do modelo CTEE-T095-P160 com indicações da plastificação da chapa de topo

Fazendo-se uma inspeção para diversas seções da chapa de topo, observa-se que a plastificação ocorre logo no início do carregamento, mas a formação da primeira rótula plástica se dá com um momento de aproximadamente $\mathbf{7 0}$ kN.m, na altura da mesa tracionada da viga. Para o mesmo carregamento, as forças médias de tração nos parafusos são de, aproximadamente, $120 \mathbf{~ k N}$, pela figura 7.21 . 
Como a adoção do momento de plastificação da chapa deve ser considerada como um estado limite último, uma vez que a formação de mecanismos plásticos deve ser evitada, reforça-se 0 fato de que 0 comprimento efetivo utilizado para a configuração de plastificação (vii) não representa o mecanismo observado na chapa de topo, sendo conservador e, assim, não permitindo que os parafusos desenvolvam sua resistência potencial.

Essa afirmação é particularmente interessante considerando-se a existência das forças de protensão inicial e pelo fato de que as forças de tração são distribuídas uniformemente entre os parafusos do modelo CTEE-T095$\mathbf{P 1 6 0}$, devido à plastificação da chapa de topo.

Além disso, o ponto (b) indica a possibilidade de se considerar o momento resistente em regime plástico, com um limite superior próximo de $\mathbf{7 0}$ kN.m, praticamente o dobro do calculado para a ligação.

Como já comentado anteriormente, não se considera se é ou não convencional a combinação de geometria do modelo CTEE-T095-P160, mas utiliza-se esse modelo como exemplo para uma situação evitada usualmente na prática que, como observado na discussão acima, é significativamente mais resistente em comparação com os valores do modelo teórico utilizado.

As diferenças encontradas entre os resultados teóricos e numéricos diminuem com o aumento da espessura da chapa de topo, não pela modificação dos comprimentos efetivos em função das linhas de plastificação, mas devido à crescente contribuição da chapa de topo pelo aumento do momento de plastificação, proporcional ao quadrado da espessura da chapa.

Na figura 7.23 são apresentadas as forças médias nos parafusos dos modelos CTEE-T125-P160 e CTEE-T160-P160, novamente com as indicações dos valores teóricos da tabela 7.6.

O comportamento para esses modelos é semelhante ao apresentado para o modelo CTEE-T095-P160, tanto para a distribuição de esforços nos parafusos quanto para a distribuição da plastificação da chapa ao longo do carregamento, com exceção dos valores dos esforços, o que pode ser visualizado nas figuras 7.24 e 7.25 nas curvas momento-rotação para os modelos CTEE-T125-P160 e CTEE-T160-P160, respectivamente. 


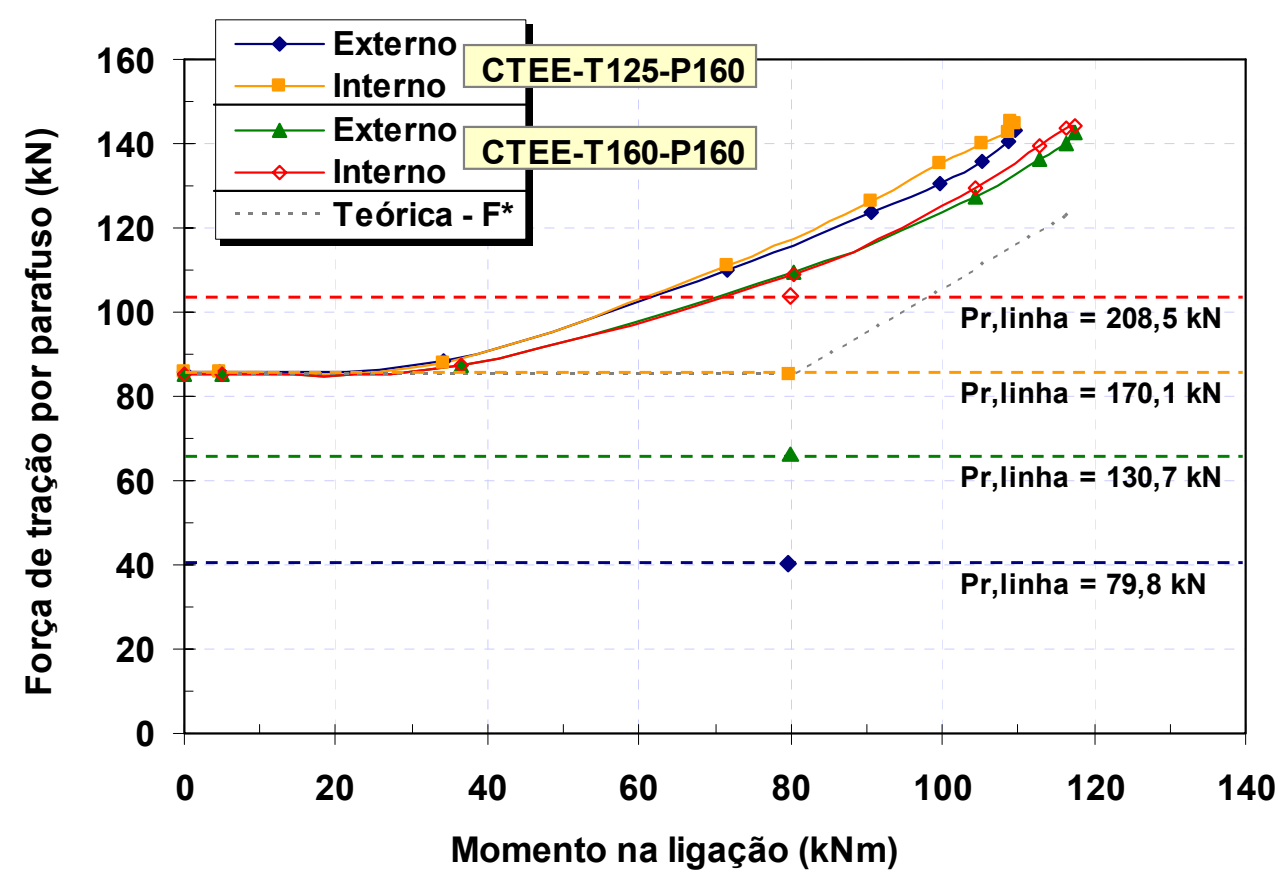

Figura 7.23 - Forças de tração teóricas e nos modelos CTEE-T125-P160 e CTEE-T160-P160

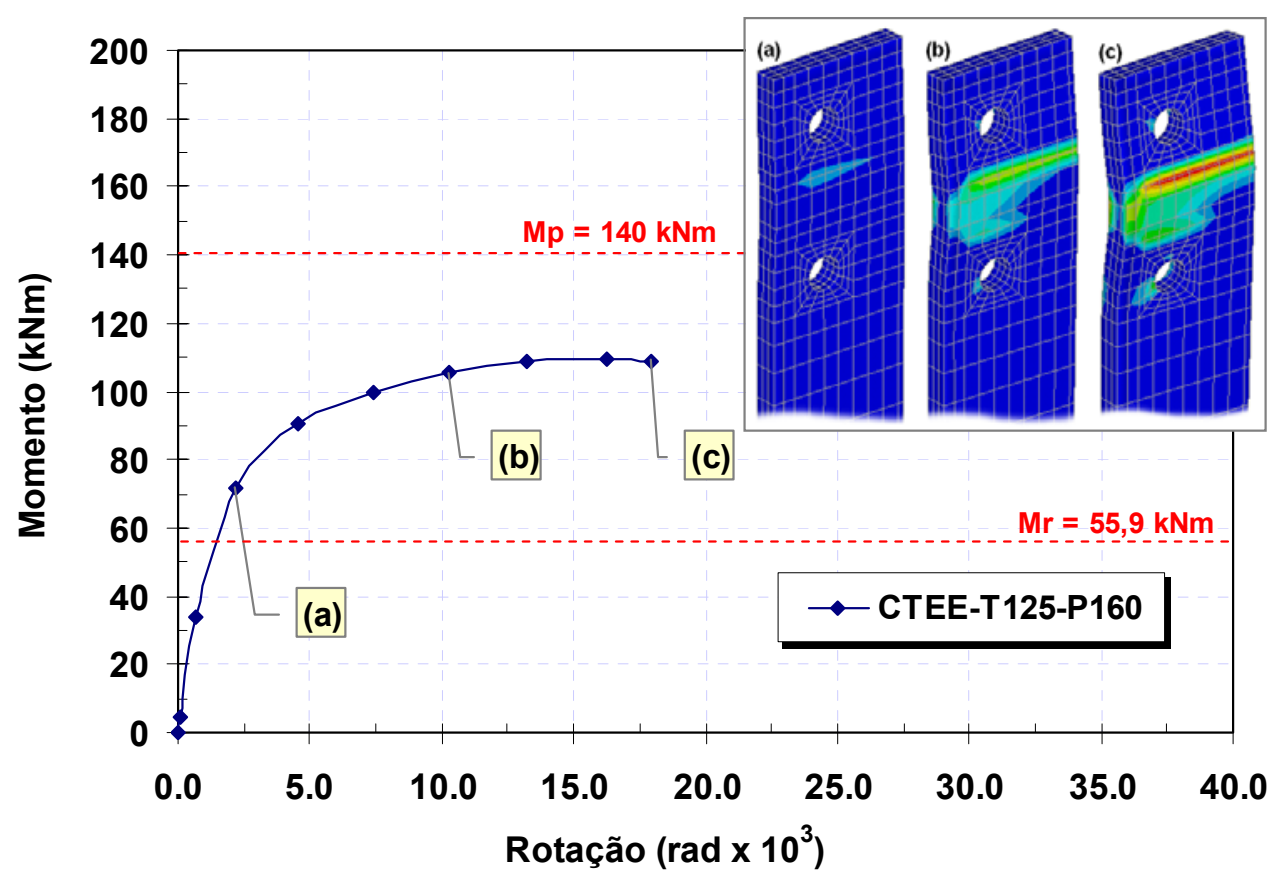

Figura 7.24 - Curva momento-rotação do modelo CTEE-T125-P160 com indicações da plastificação da chapa de topo

Para o modelo CTEE-T160-P160, a formação de um mecanismo plástico é iniciada na altura da mesa tracionada da viga, próximo ao plano de simetria, mas fica concentrada nesta região. Como já observado anteriormente, 
esse modelo representa um limite inferior para a ductilidade, indicando também um limite entre os modos de falha 1 e 2.

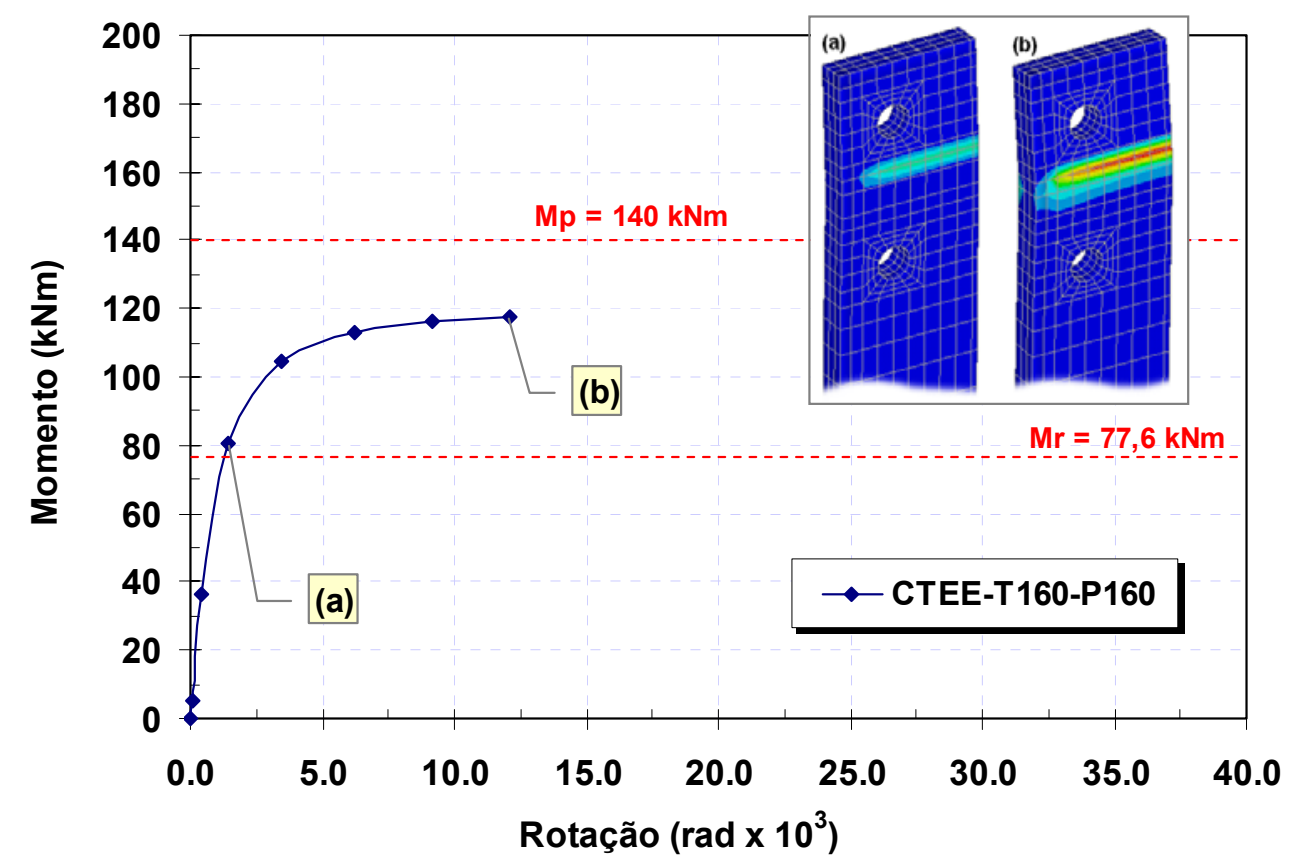

Figura 7.25 - Curva momento-rotação do modelo CTEE-T160-P160 com indicações da plastificação da chapa de topo

Para os modelos com chapas de espessura maior que $16,0 \mathrm{~mm}$, a plastificação na chapa é mínima, mas ainda com resultados teóricos que limitam a capacidade resistente da linha de parafusos na extensão da chapa. A figura 7.26 apresenta as curvas momento-rotação para os modelos CTEET190-P160, CTEE-T224-P160 e CTEE-T250-P160, a fim de ilustrar o momento resistente teórico para essas ligações.

Como complemento para esta análise, a figura 7.27 apresenta a variação da capacidade resistente analítica para cada modo de falha em função da espessura da chapa de topo, para os parafusos externos e internos, representando um espaço de solução para a geometria da chapa de topo dos modelos listados na tabela 7.6.

Com a identificação dos pontos limites entre os modos de falha observa-se que a máxima capacidade resistente para os parafusos externos (ponto B) só é atingida com espessuras de chapa bem maiores que para os parafusos internos (ponto D), indicando uma deformabilidade muito maior na 
extensão da chapa de topo que não ocorreu nos modelos numéricos. O mesmo ocorre com os limites entre os modos de falha 1 e 2.

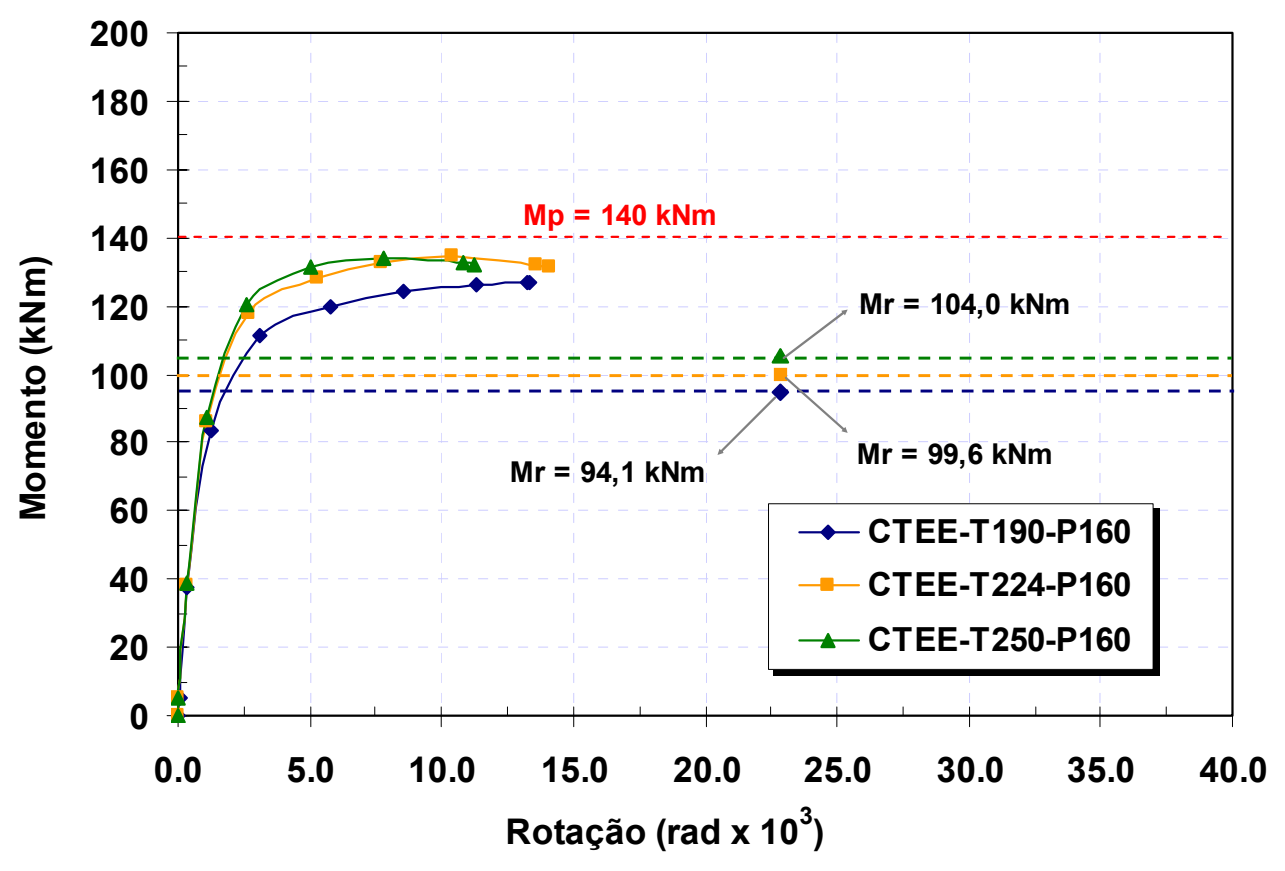

Figura 7.26 - Curvas momento-rotação para os modelos CTEE-T190-P160, CTEE-T224-P160 e CTEE-T250-P160

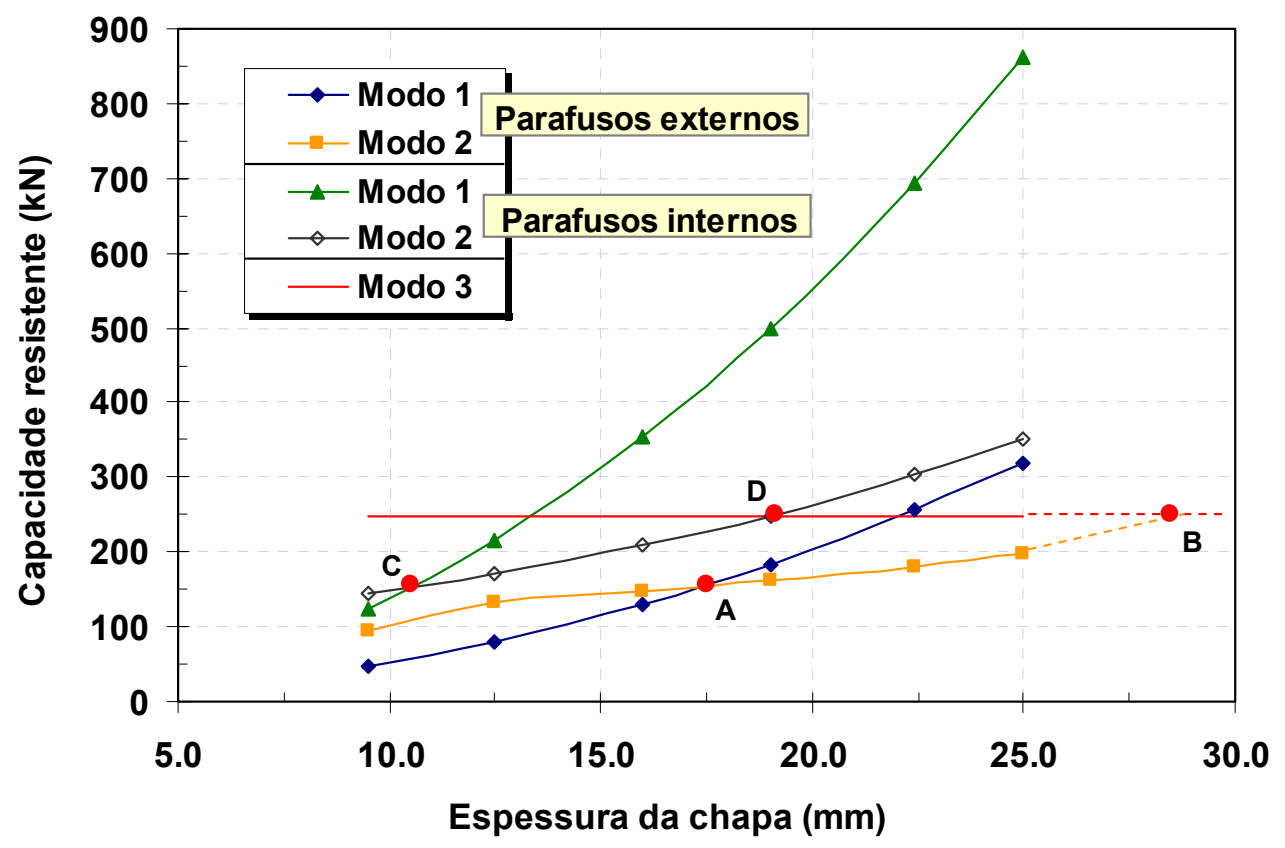

Figura 7.27 - Capacidade resistente em função da espessura da chapa de topo para os parafusos externos e internos

Com todas essas observações, é interessante ressaltar novamente que os padrões da plastificação na chapa de topo variam conforme a 
combinação entre a espessura da chapa e o diâmetro dos parafusos, o que não é considerado na metodologia proposta pelo Eurocode 3 (1993).

Como conseqüência, a variação da deformabilidade entre as linhas de parafusos é superestimada, com capacidades resistentes reduzidas na extensão da chapa de topo, o que não foi observado nos modelos numéricos com a aplicação da protensão inicial.

\subsection{ANÁLISE PARAMÉTRICA PRELIMINAR DO COMPORTAMENTO DAS LIGAÇÕES COM CHAPA DE TOPO ESTENDIDA}

Nos itens anteriores, diversas observações foram realizadas quanto à influência da variação da espessura da chapa de topo e do diâmetro dos parafusos, com ênfase em uma geometria fixa da chapa de topo para os parafusos de $16,0 \mathrm{~mm}$.

A análise da variação desses dois parâmetros permitiu a observação de padrões para a plastificação da chapa de topo, o que sugere a existência de padrões para os mecanismos de transferência de esforços entre a chapa de topo e os parafusos, principalmente na determinação dos modos de falha e no "efeito alavanca".

Para avaliar, adicionalmente, algumas variações na geometria da chapa de topo e também no diâmetro dos parafusos, outros modelos foram incluídos na análise numérica para a realização de uma análise paramétrica preliminar, cujo objetivo, além de confirmar os padrões observados nos itens anteriores, são de aplicar a modelagem numérica em uma análise mais geral, segundo o escopo deste trabalho.

Assim, os resultados numéricos são apresentados em função das relações globais momento-rotação da chapa de topo, da distribuição de esforços nos parafusos e de comparações qualitativas da distribuição de tensões e deformações nos parafusos e na chapa de topo.

Ressalta-se, novamente, que para essa análise utilizaram-se características nominais para os materiais de chapas e parafusos, considerando-se que são os usualmente adotados no dimensionamento. 


\subsubsection{Variações da chapa de topo e dos parafusos}

A análise paramétrica foi realizada, inicialmente, com variações da espessura da chapa de topo e do diâmetro dos parafusos, tomando-se como referência a tipologia e a geometria das vigas e pilares dos protótipos experimentais descritos no capítulo 4.

$\mathrm{Na}$ observação desses dois parâmetros foram utilizadas 2 séries de modelos. A primeira série, denominada de E1, foi dividida em $\mathbf{3}$ grupos nos quais variou-se a espessura da chapa de topo de $\mathbf{9 , 5}$ a $31,5 \mathrm{~mm}$, com parafusos de 12,5, 16,0 e 19,0 mm de diâmetro, utilizando a geometria da chapa de topo dos modelos CTEE em função dos parafusos de $\mathbf{1 6 , 0} \mathbf{m m}$.

A segunda série, denominada de E2, é formada de apenas 1 grupo com as mesmas variações da chapa de topo e parafusos de 19,0 mm, considerando-se a geometria da chapa em função das dimensões mínimas recomendadas (NBR 8800, 1986) para estes parafusos.

As características geométricas e a identificação de cada modelo das séries E1 e E2 estão listadas na tabela 7.7 e 7.8, respectivamente. As dimensões esquemáticas para as chapas de topo correspondentes às duas séries são apresentadas na figura 7.28, juntamente com a indicação da geometria da viga.

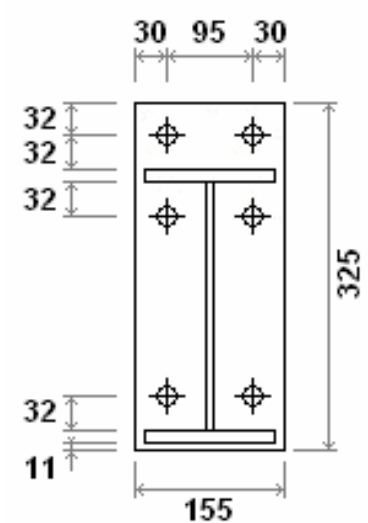

Série E1

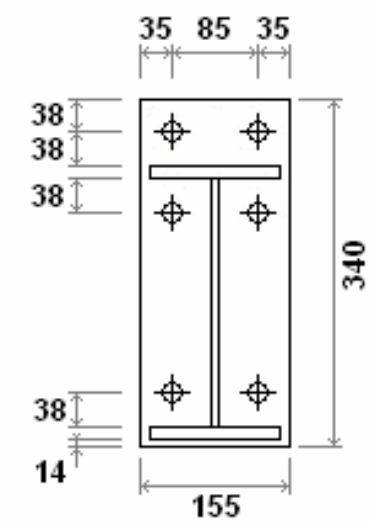

Série E2
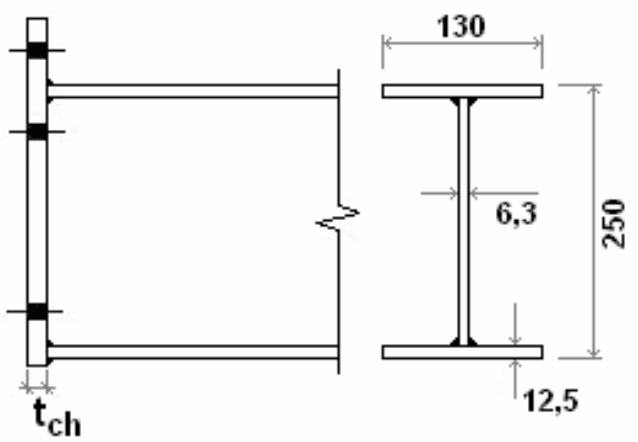

Viga VS $250 \times 37$

Figura 7.28 - Dimensões das chapas de topo para as séries E1 e E2 
Tabela 7.7 - Modelos numéricos para a série E1

\begin{tabular}{|c|c|c|c|c|}
\hline Série & Grupo & Modelo & $d_{b}(\mathrm{~mm})$ & $t_{\mathrm{ch}}(\mathrm{mm})$ \\
\hline \multirow{19}{*}{ E1 } & \multirow{6}{*}{1} & E1P-T095-P125 & \multirow{6}{*}{12,5} & 9,5 \\
\hline & & E1P-T125-P125 & & 12,5 \\
\hline & & E1P-T160-P125 & & 16,0 \\
\hline & & E1P-T190-P125 & & 19,0 \\
\hline & & E1P-T224-P125 & & 22,4 \\
\hline & & E1P-T250-P125 & & 25,0 \\
\hline & \multirow{7}{*}{2} & E1P-T095-P160 & \multirow{7}{*}{16,0} & 9,5 \\
\hline & & E1P-T125-P160 & & 12,5 \\
\hline & & E1P-T160-P160 & & 16,0 \\
\hline & & E1P-T190-P160 & & 19,0 \\
\hline & & E1P-T224-P160 & & 22,4 \\
\hline & & E1P-T250-P160 & & 25,0 \\
\hline & & E1P-T315-P160 & & 31,5 \\
\hline & \multirow{6}{*}{3} & E1P-T125-P190 & \multirow{6}{*}{19,0} & 12,5 \\
\hline & & E1P-T160-P190 & & 16,0 \\
\hline & & E1P-T190-P190 & & 19,0 \\
\hline & & E1P-T224-P190 & & 22,4 \\
\hline & & E1P-T250-P190 & & 25,0 \\
\hline & & E1P-T315-P190 & & 31,5 \\
\hline
\end{tabular}

Tabela 7.8 - Modelos numéricos para a série E2

\begin{tabular}{|c|c|c|c|c|}
\hline Série & Grupo & Modelo & $d_{b}(m m)$ & $t_{c h}(\mathrm{~mm})$ \\
\hline \multirow{6}{*}{ E2 } & \multirow{6}{*}{1} & E2P-T125-P190 & \multirow{6}{*}{19,0} & 12,5 \\
\hline & & E2P-T160-P190 & & 16,0 \\
\hline & & E2P-T190-P190 & & 19,0 \\
\hline & & E2P-T224-P190 & & 22,4 \\
\hline & & E2P-T250-P190 & & 25,0 \\
\hline & & E2P-T315-P190 & & 31,5 \\
\hline
\end{tabular}

O gabarito da chapa de topo para a série $\mathbf{E 1}$ foi fixado independentemente da variação do diâmetro dos parafusos dentro de cada grupo. Neste caso, para a série E1 a utilização dos parafusos de $19,0 \mathrm{~mm}$ não segue as recomendações para as distâncias mínimas entre os furos e as bordas da chapa de topo, enquanto que a utilização dos parafusos de 12,5 $\mathrm{mm}$ não é usual em termos de dimensionamento.

Esses modelos foram incluídos na análise apenas para simular a variação do diâmetro dos parafusos como um parâmetro isolado, sem modificar as distâncias entre centros de furos e centros de furos e bordas dentro da mesma série, o que significaria modificar o braço de alavanca dos parafusos com relação à mesa tracionada da viga e ao plano de simetria. 
Um outro fator a ser salientado refere-se às espessuras escolhidas para algumas chapas de topo, em especial nos modelos com chapas de 9,5, 12,5 e $\mathbf{3 1 , 5} \mathbf{m m}$. A combinação destas espessuras com os parafusos de $\mathbf{1 6 , 0}$ mm, por exemplo, também não são usuais em termos práticos. Esses modelos foram utilizados para representar casos extremos e, principalmente para os modelos com chapas mais finas, para simular o modo de falha 1 da "teoria $T$ Stub" (plastificação da chapa nas proximidades dos furos), que não foi possível de se observar com os protótipos experimentais.

Para facilitar a identificação dos modelos, a indicação da espessura da chapa de topo e do diâmetro dos parafusos é realizada, respectivamente, pelas letras "T" e "P", permitindo a identificação desses parâmetros diretamente na nomenclatura adotada para os modelos em geral. Como exemplo, o modelo E1P-T190P160 possui chapa de topo de $19,0 \mathrm{~mm}$ de espessura e parafusos com diâmetro de 16,0 mm. A letra "P" indica a aplicação da protensão inicial nos parafusos.

Avaliando-se, inicialmente, a influência da variação da espessura da chapa de topo, são realizadas a seguir observações preliminares sobre as relações de rigidez globais dentro da série E1, agrupando-se os modelos separadamente para os parafusos de 12,5, 16,0 e 19,0 mm.

Na figura 7.29 são apresentadas as curvas momento-rotação para os modelos do grupo 1 da série $\mathbf{E 1}$, com parafusos de $12,5 \mathrm{~mm}$. A rotação da ligação foi calculada considerando-se a relação entre a abertura média da chapa de topo na altura da mesa tracionada da viga e a distância entre os planos médios das mesas, supondo-se o centro de rotação no plano médio da mesa comprimida da viga, como descrito na análise dos resultados experimentais. A abertura média é a média das aberturas da chapa de topo na borda lateral e no plano de simetria.

Tomando-se como referência o momento de plastificação da seção transversal da viga, $\mathbf{M}_{\mathrm{p}}$, de aproximadamente $116 \mathrm{kNm}\left(\mathbf{f}_{\mathrm{y}}=250 \mathrm{Mpa}\right)$, é visível na figura 7.29 que a ligação, independentemente da espessura da chapa de topo, possui capacidade resistente limitada com relação à viga o que, em termos práticos, não é uma situação recomendada.

Apesar disso, mesmo com a capacidade resistente limitada dos parafusos, é interessante observar que o aumento da espessura da chapa de 
topo influencia de forma distinta a resistência e a ductilidade da ligação em função da interação entre a chapa de topo e os parafusos, fator já observado nos resultados experimentais obtidos para as ligações duplo "T".

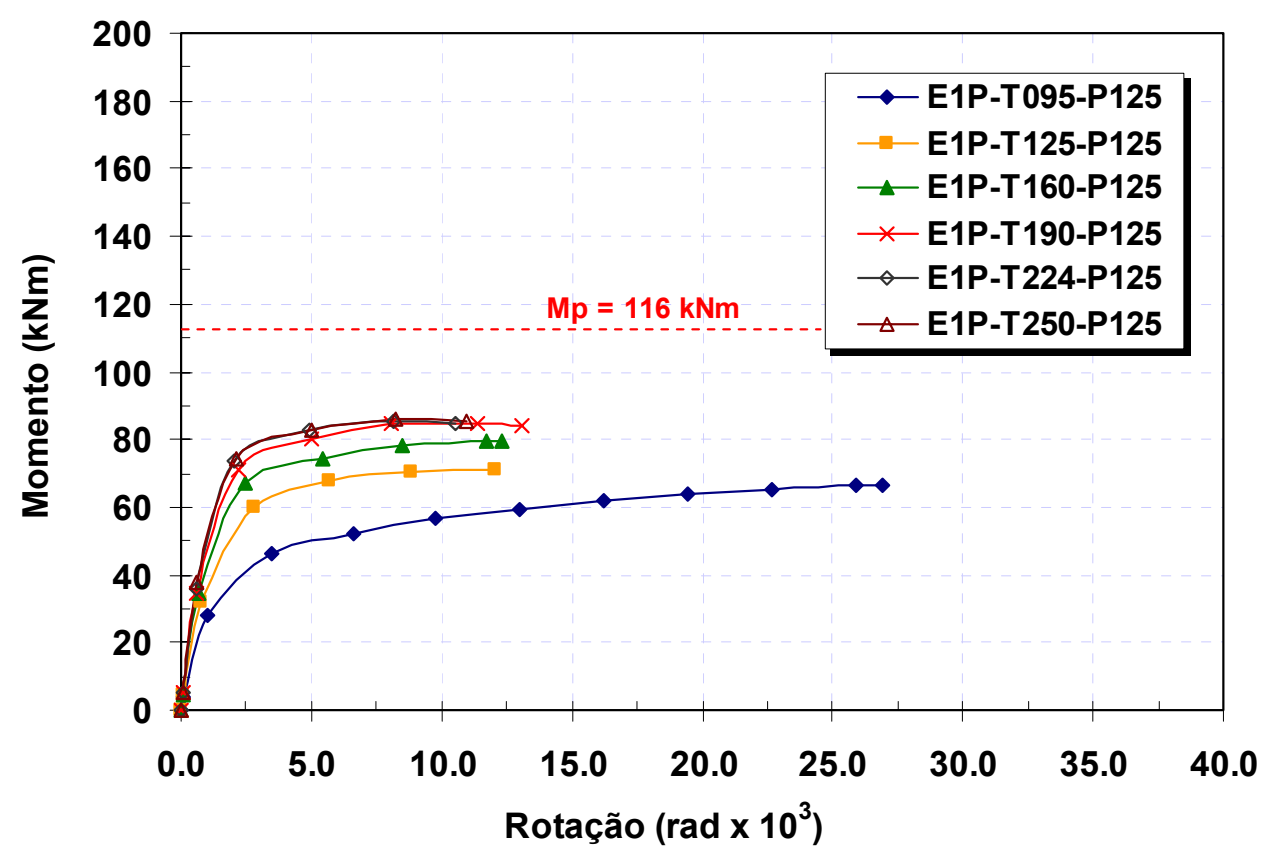

Figura 7.29 - Curvas momento-rotação para a série E1 - grupo 1 - variação da espessura da chapa de topo para parafusos de $12,5 \mathrm{~mm}$

Desconsiderando-se a limitação de resistência da ligação e comparando-se as curvas da figura 7.29, observa-se um aumento da resistência da ligação com o aumento da espessura da chapa de topo até um limite superior, igual para os modelos com chapas de 19,0, 22,4 e 25,0 mm.

A variação de ductilidade, no entanto, não é uniforme. Considerandose que as curvas momento-rotação são um indicativo da deformabilidade da chapa de topo, a figura 7.30 apresenta detalhes das deformações na região da ligação para alguns dos modelos da figura 7.29, pouco antes do colapso. Os deslocamentos foram ampliados em 2 vezes para melhor visualização.

Com as figuras 7.29 e 7.30 é possível identificar três regiões de variação para a ductilidade em função da contribuição da chapa de topo e dos parafusos para a deformabilidade da ligação.

Na primeira região, compreendida entre os modelos E1P-T095-P125 e E1P-T125-P125, o aumento da espessura da chapa de topo causa uma diminuição acentuada na ductilidade da ligação, o que é indicativo de uma 
mudança nas linhas de plastificação da chapa de topo e, fazendo-se uma analogia aos perfis "T", também indica uma modificação no modo de falha associado à chapa de topo.

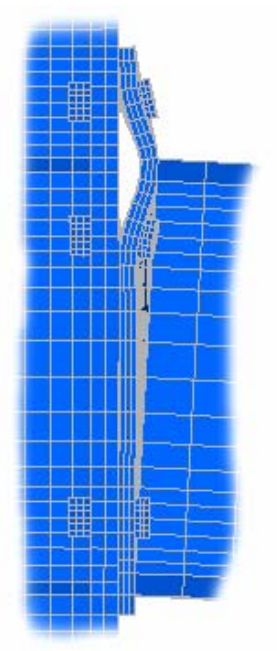

E1P-T095-P125

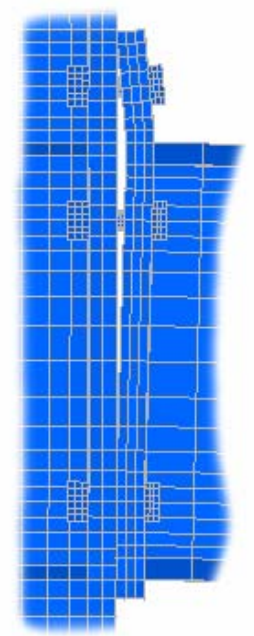

E1P-T160-P125

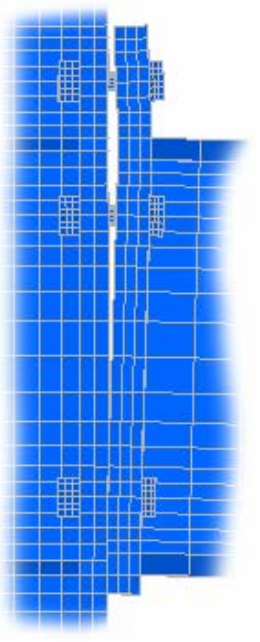

E1P-T190-P125

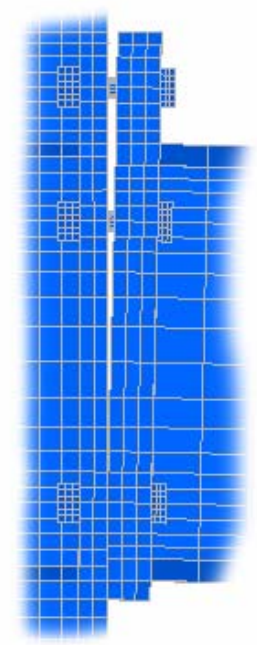

E1P-T250-P125

Figura 7.30 - Deformações na chapa de topo - série E1 - grupo 1 - vista externa

Discutindo-se com mais detalhes essa variação entre os dois modelos, a figura 7.31 ilustra as deformações na chapa de topo e a distribuição das tensões plásticas equivalentes (von Mises) para duas configurações: a primeira para a rotação máxima no modelo E1P-T125-P125 com rotação similar no modelo E1P-T095-P125 e a segunda para a rotação máxima no modelo E1P-T095-P125.

A chapa de topo de $12,5 \mathrm{~mm}$, na configuração de colapso para a rotação máxima de $\mathbf{0 , 0 1 2}$ rad, apresenta uma plastificação bem visível na região correspondente à face superior da mesa tracionada da viga. Para uma rotação similar, a chapa de $\mathbf{9 , 5} \mathbf{m m}$ apresenta indicações da formação de linhas de plastificação tanto na intersecção chapa/mesa quanto na linha dos furos. Para uma rotação de 0,027 rad, máxima para a chapa de 9,5 $\mathrm{mm}$, é possível observar uma rótula plástica bem definida na intersecção chapa/mesa.

Neste caso, confirma-se a hipótese de variação do modo de falha associado à chapa de topo que, segundo a "teoria T-Stub", passa do modo 1 na chapa de $9,5 \mathrm{~mm}$ para o modo 2 na chapa de $12,5 \mathrm{~mm}$, quando combinadas aos parafusos de $12,5 \mathrm{~mm}$. 

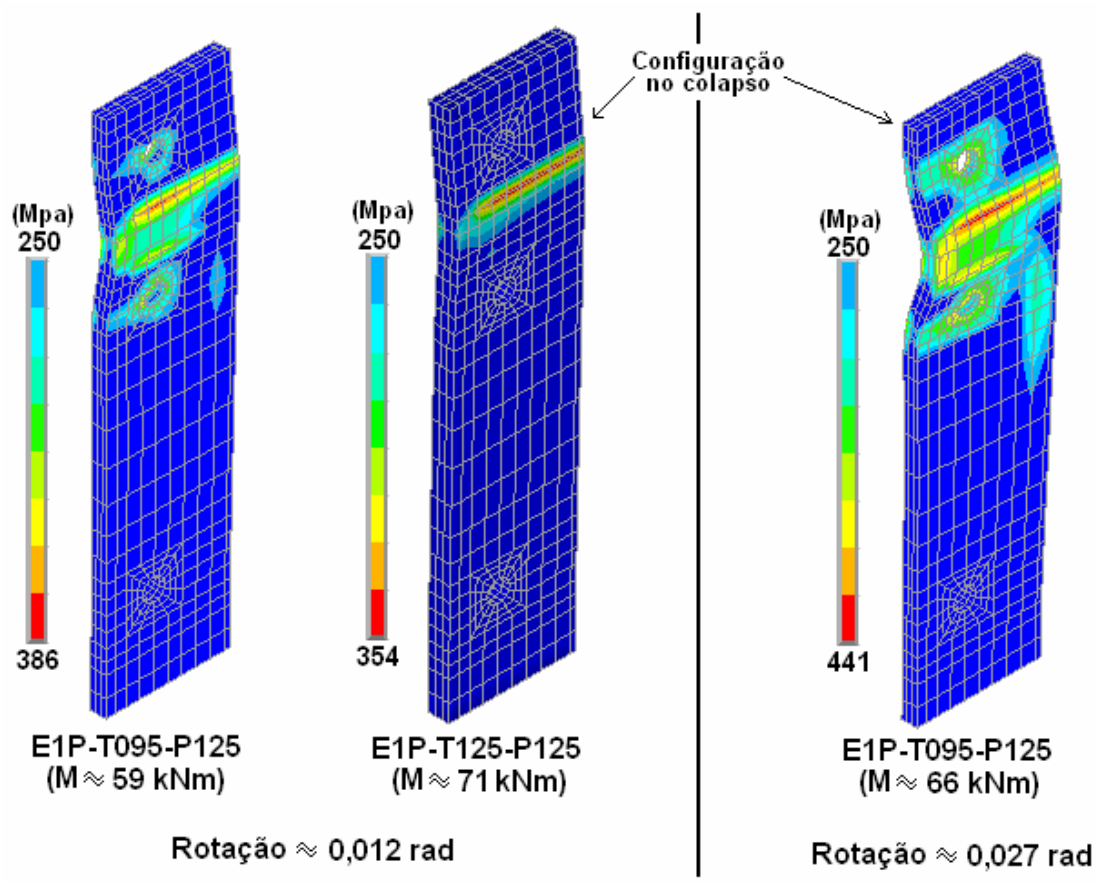

Figura 7.31 - Tensões plásticas equivalentes nas chapas de topo dos modelos E1P-T095-P125 e E1P-T125-P125 - vista externa

As conseqüências dessa variação para os parafusos tracionados podem ser observadas na figura 7.32, que apresenta as distribuições de deformações equivalentes totais para estes componentes nas mesmas rotações apresentadas na figura 7.31.

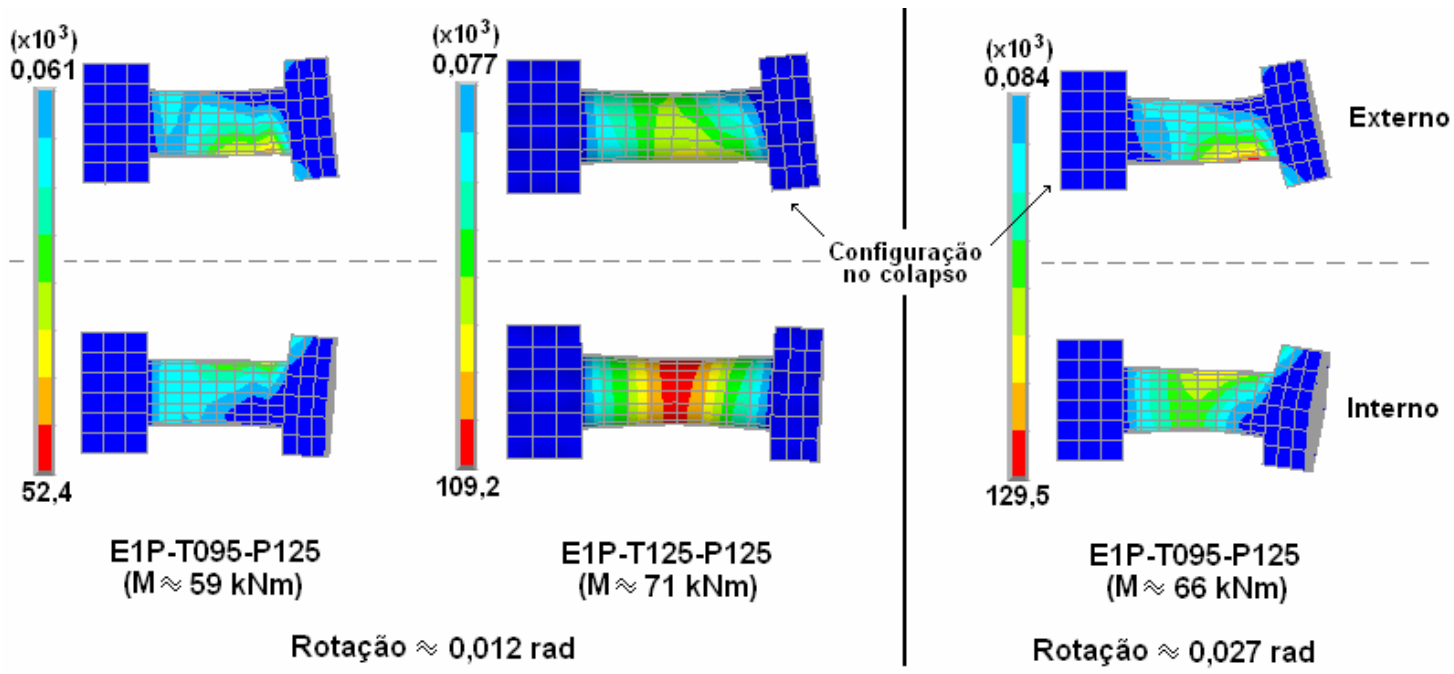

Figura 7.32 - Deformações equivalentes totais nos parafusos dos modelos E1P-T095-P125 e E1P-T125-P125 - vista externa

Para o modelo E1P-T095-P125, a plastificação acentuada da chapa de topo permite que as taxas de deformação nos parafusos sejam mais lentas, 
com uma queda prematura na rigidez rotacional da ligação. Além disso, a flexão nos parafusos do modelo E1P-T095-P125, principalmente junto à cabeça, é mais significativa devido à flexão da chapa de topo, havendo uma distribuição não uniforme de deformações ao longo do fuste.

Com o aumento da chapa de topo, as deformações - e tensões - se distribuem mais uniformemente, concentrando-se na região central do fuste, como pode ser observado para o parafuso interno do modelo E1P-T125-P125.

As forças de tração nos parafusos dos dois modelos em função do momento na ligação podem ser visualizadas no gráfico da figura 7.33, calculadas em função da área nominal do parafuso e das tensões longitudinais médias na seção transversal central do fuste.

Também é apresentada uma reta que representa a força teórica de tração, $\mathbf{F}^{*}$, por parafuso, calculada pela divisão da força total de tração transmitida pela mesa da viga pelo número de parafusos da região tracionada. A força de total de tração é calculada em função do momento aplicado na ligação, considerando-se um binário agindo nas mesas da viga. Para a força teórica $\mathbf{F}^{*}$ não se considera a existência das forças iniciais de protensão.

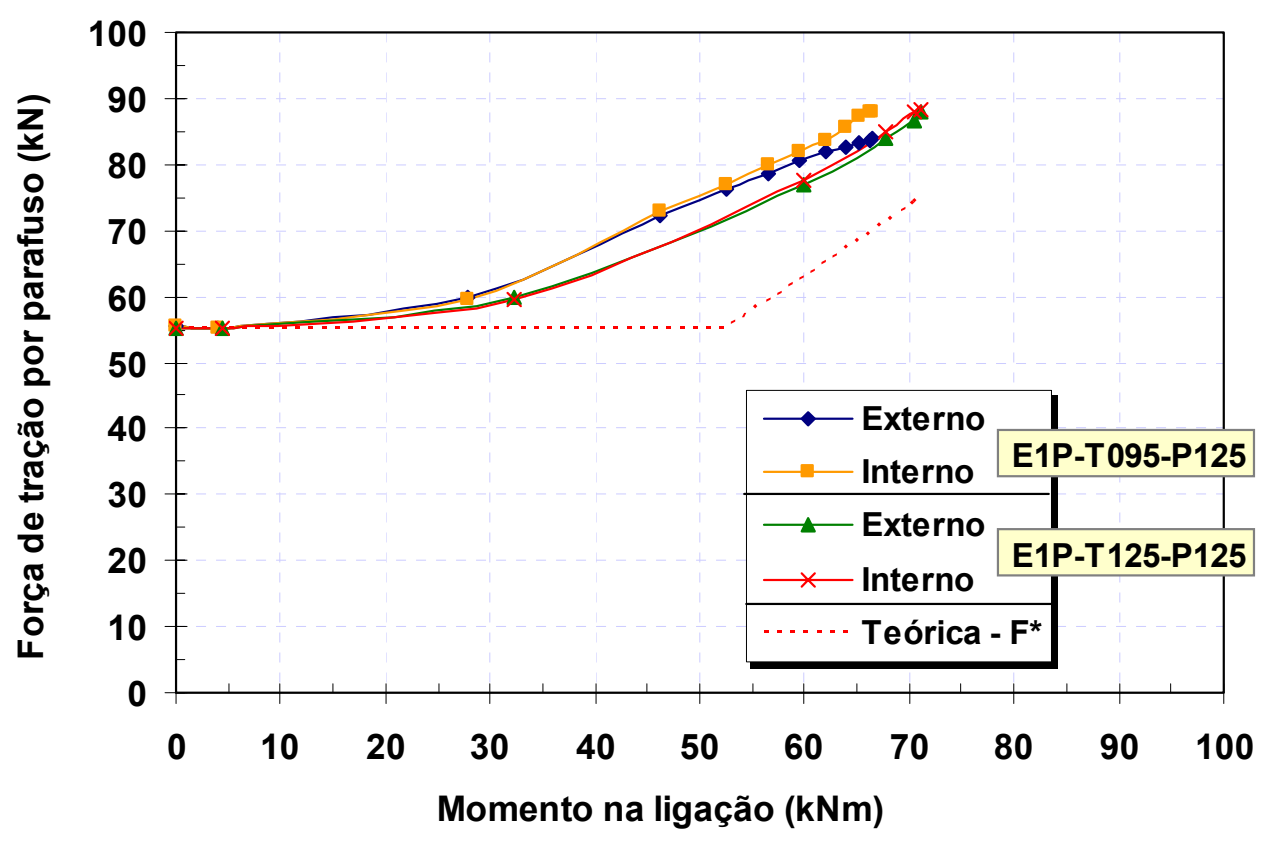

Figura 7.33 - Forças de tração nos parafusos dos modelos E1P-T095-125 e E1P-T125-P125 
Quando aplicado aos perfis "T", o modelo analítico do modo de falha 1 faz a hipótese de que as "forças de alavanca" são máximas para o mecanismo de flexão da mesa. Um aspecto interessante das curvas apresentadas na figura 7.33 é que, apesar de não haver variações significativas para o "efeito alavanca" nos dois modelos, há indicações de que essa hipótese pode ser considerada verdadeira.

No entanto, não é possível concluir se as forças de tração nos parafusos do modelo E1P-T095-P125 são maiores devido ao "efeito alavanca" ou à flexão acentuada do fuste nas proximidades da cabeça dos parafusos.

Convém ressaltar que o "efeito alavanca" ocorre nas duas ligações e seu valor pode ser estimado pela diferença entre a força de tração no parafuso e a força teórica $F^{*}$.

A mudança de comportamento da chapa de topo e dos parafusos, como foi observada acima, indica que ao modo de falha 1 pode-se associar a mínima resistência e a máxima ductilidade para o conjunto chapa de topo e parafusos.

Com o aumento sucessivo da espessura da chapa de topo, na segunda região observada nas curvas momento-rotação da figura 7.29, situada entre os modelos E1P-T125-P125 e E1P-T190-P125, o aumento de resistência é seguido por um crescimento suave na ductilidade da ligação.

Fazendo-se, novamente, uma comparação entre os modelos, a figura 7.34 apresenta as distribuições de tensões plásticas equivalentes nas chapas de topo dos modelos E1P-T160-P125 e E1P-T190-P125, correspondente à configuração no colapso.

As linhas de plastificação observadas na figura 7.34 indicam que as deformações na chapa de topo, para esses modelos, se concentram na intersecção chapa/mesa, mantendo a configuração da chapa no modelo E1P. T125-P125.

As deformações na ligação, apresentadas na figura 7.30, também indicam que, para o modelo E1P-T190-P125, as "forças de alavanca" nos parafusos deixam de existir, já que a chapa de topo perde contato com a mesa do pilar. 
De fato, esse comportamento pode ser observado na figura 7.35, onde se faz uma comparação entre as forças de tração nos parafusos para os modelos com chapas de $12,5,16,0$ e $19,0 \mathrm{~mm}$.
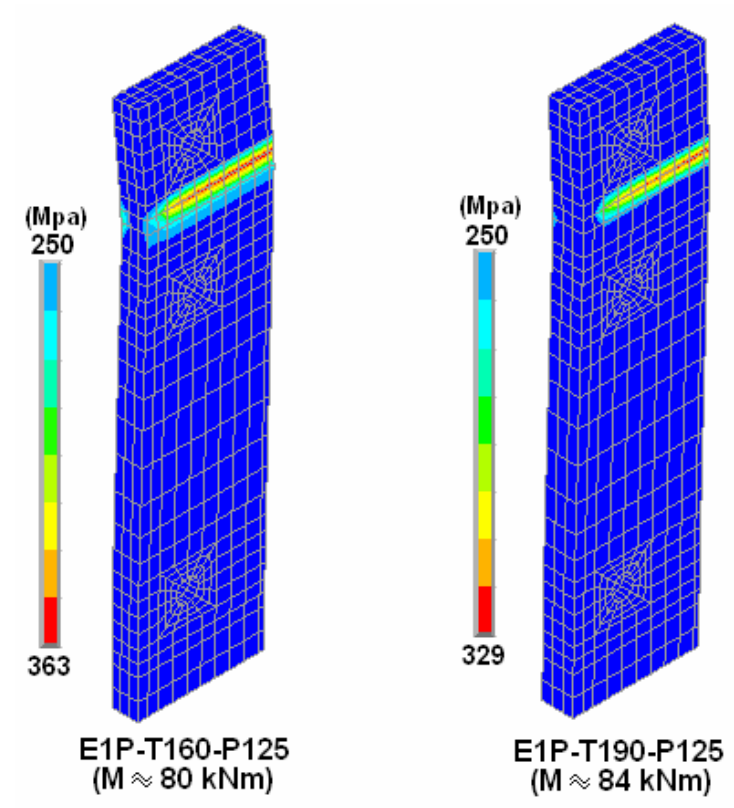

Figura 7.34 - Tensões plásticas equivalentes nas chapas de topo dos modelos E1P-T160-P125 e E1P-T190-P125 - vista externa

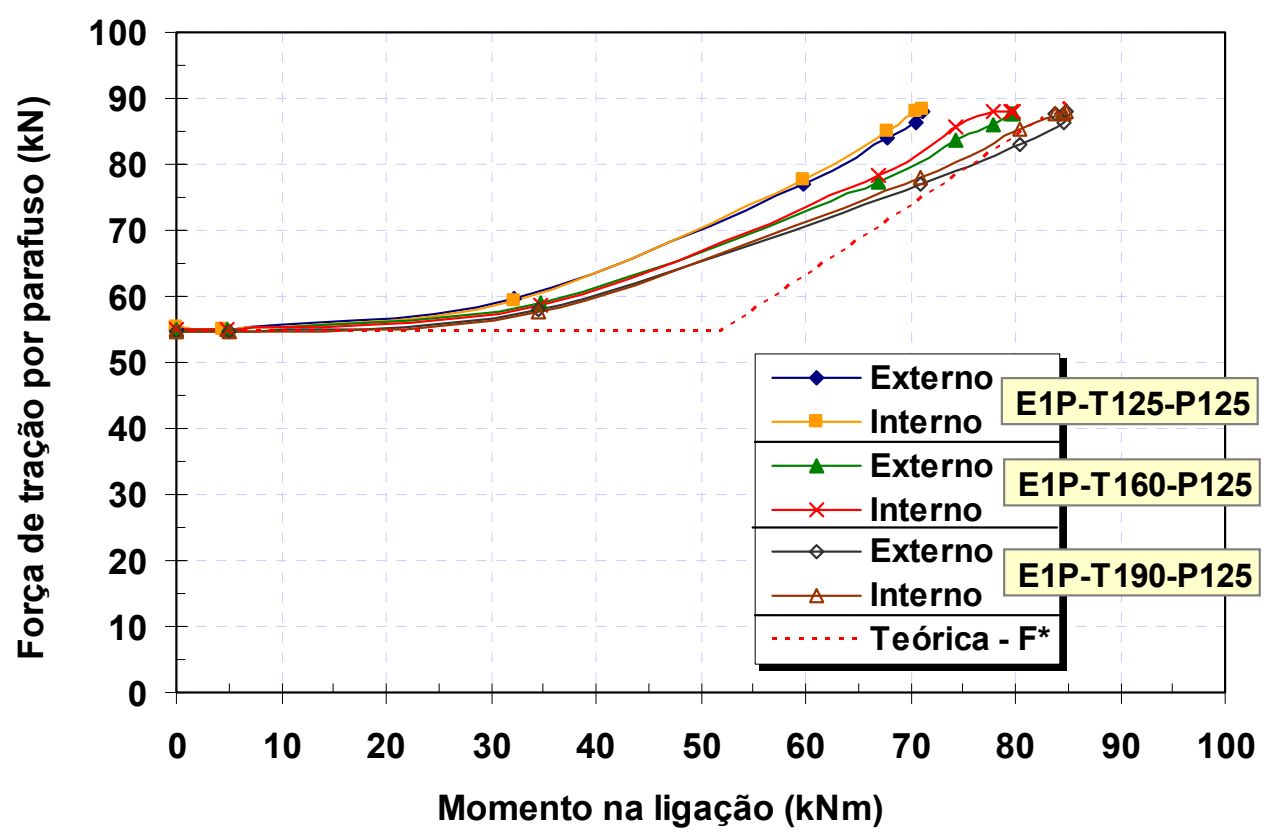

Figura 7.35 - Forças de tração nos parafusos dos modelos E1P-T125-125, E1P-T160-P125 e E1P-T190-P125

$\mathrm{Na}$ figura 7.35 é possível se observar a diminuição do "efeito alavanca", com um aumento quase proporcional do momento último e um 
aumento na ductilidade da ligação, desta vez sem a influência significativa da deformabilidade da chapa de topo mas sim do aumento da capacidade de deformação dos parafusos.

É interessante ressaltar, mais uma vez, que a distribuição das forças de alavanca é praticamente uniforme entre os parafusos da região tracionada.

Finalmente, para os modelos restantes, com chapas de topo de 22,4 e $\mathbf{2 5 , 0} \mathbf{~ m m}$, mantém a resistência que é função apenas da capacidade resistente à tração do parafuso, com uma diminuição da deformabilidade da ligação. Para este último caso, a flexão nas chapas de topo dos modelos E1P-T224-P125 e E1P-T250-P125 é reduzida.

$\mathrm{Na}$ figura 7.30 é possível observar que os parafusos externos, na extensão da chapa de topo, são mais solicitados que os internos, reduzindo a ductilidade da ligação devido ao aumento do alongamento dos parafusos externos, com a manutenção da capacidade resistente.

Para ilustrar o afirmado acima apresenta-se, na figura 7.36 , as deformações totais equivalentes nos parafusos dos modelos E1P-T190-P125 e E1P-T250-P125, para o momento último. Os níveis de deformação nos parafusos de ambos os modelos indicam a variação de ductilidade, bem como estão de acordo com as deformações da chapa de topo apresentadas na figura 7.30.

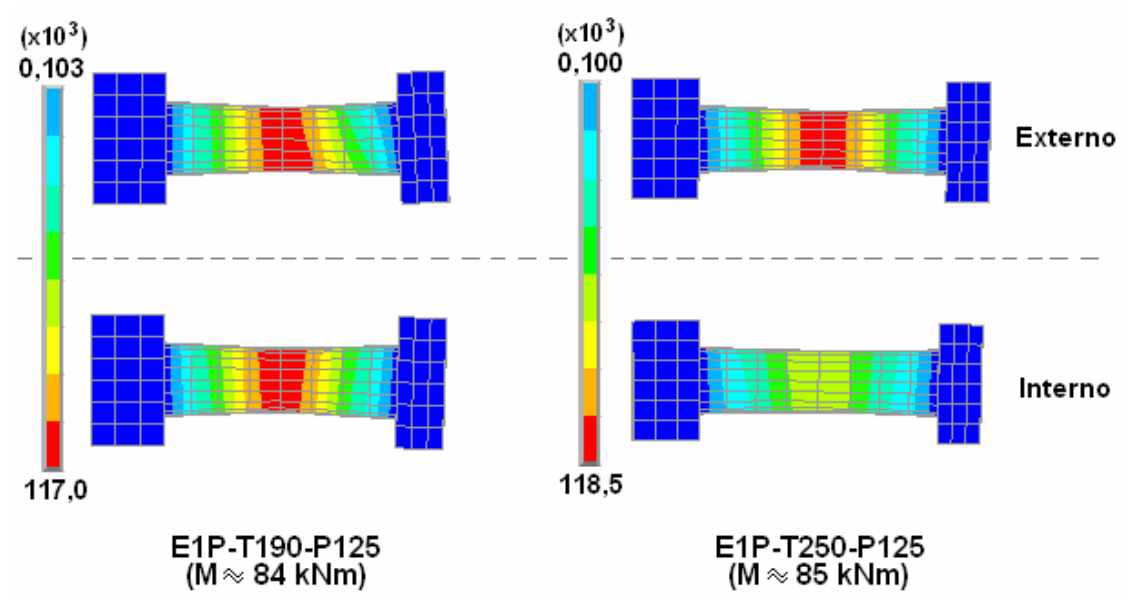

Figura 7.36 - Deformações equivalentes totais nos parafusos dos modelos E1P-T190-P125 e E1P-T250-P125 - vista externa 
Ainda dentro da série E1 e para as mesmas variações da chapa de topo, as figuras 7.37 e 7.38 apresentam, respectivamente, as curvas momentorotação para os grupos com parafusos de 16,0 e $19,0 \mathrm{~mm}$.

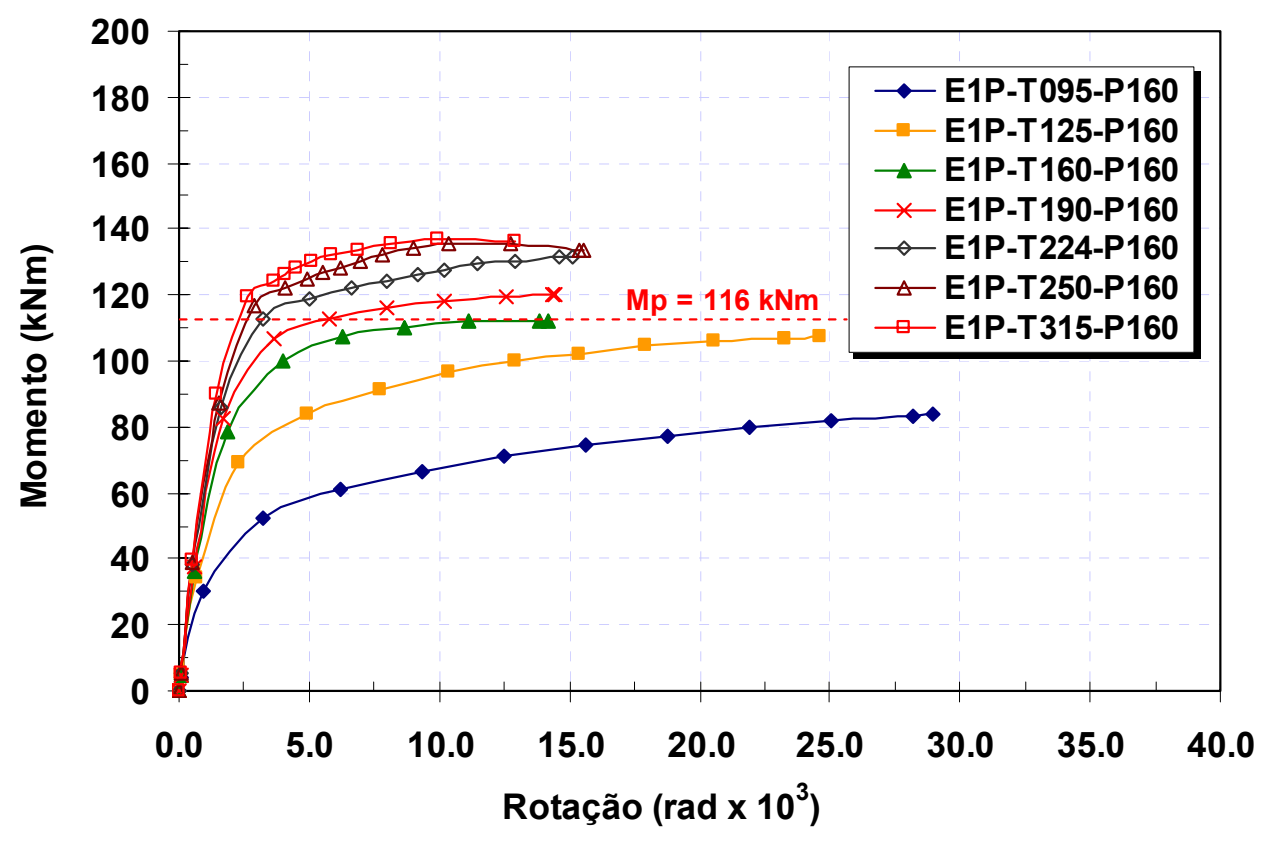

Figura 7.37 - Curvas momento-rotação para a série E1 - grupo 2 - variação da espessura da chapa de topo para parafusos de $16,0 \mathrm{~mm}$

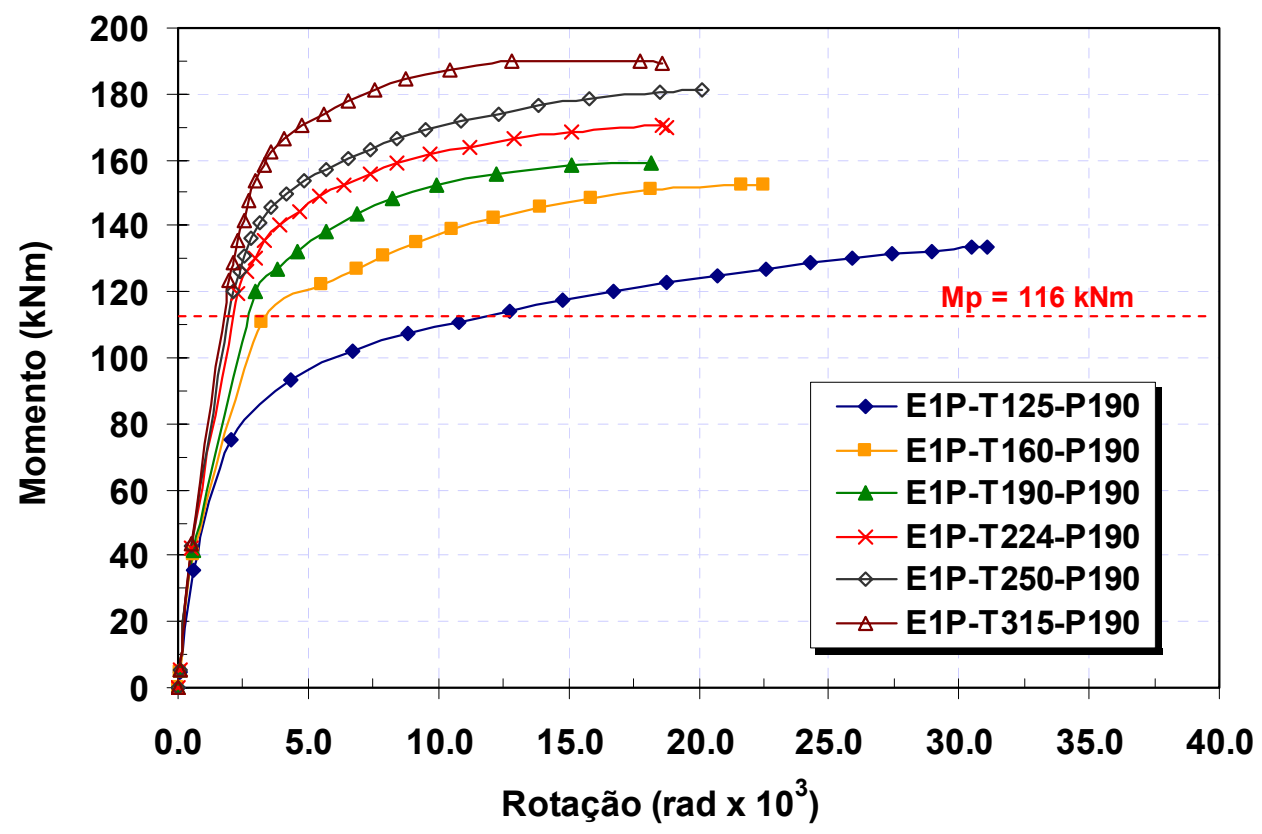

Figura 7.38 - Curvas momento-rotação para a série E1 - grupo 3 - variação da espessura da chapa de topo para parafusos de $19,0 \mathrm{~mm}$ 
Nas figuras 7.37 e 7.38 é importante observar que as variações de resistência e de ductilidade dentro de cada grupo segue o mesmo padrão, apenas com a mudança da configuração que representa o limite entre os modos de falha 1 e 2, cuja ductilidade é mínima.

Coincidentemente para estes grupos, esse limite ocorreu sempre quando a espessura da chapa de topo é igual ao diâmetro do parafuso.

Um aspecto interessante na comparação entre os modelos é que as variações nas curvas momento-rotação são diretamente relacionadas aos padrões de plastificação da chapa e, havendo padrões para essas curvas há também padrões para as linhas de plastificação.

O mesmo ocorre para a série E2, cujas curvas momento-rotação estão apresentadas na figura 7.39.

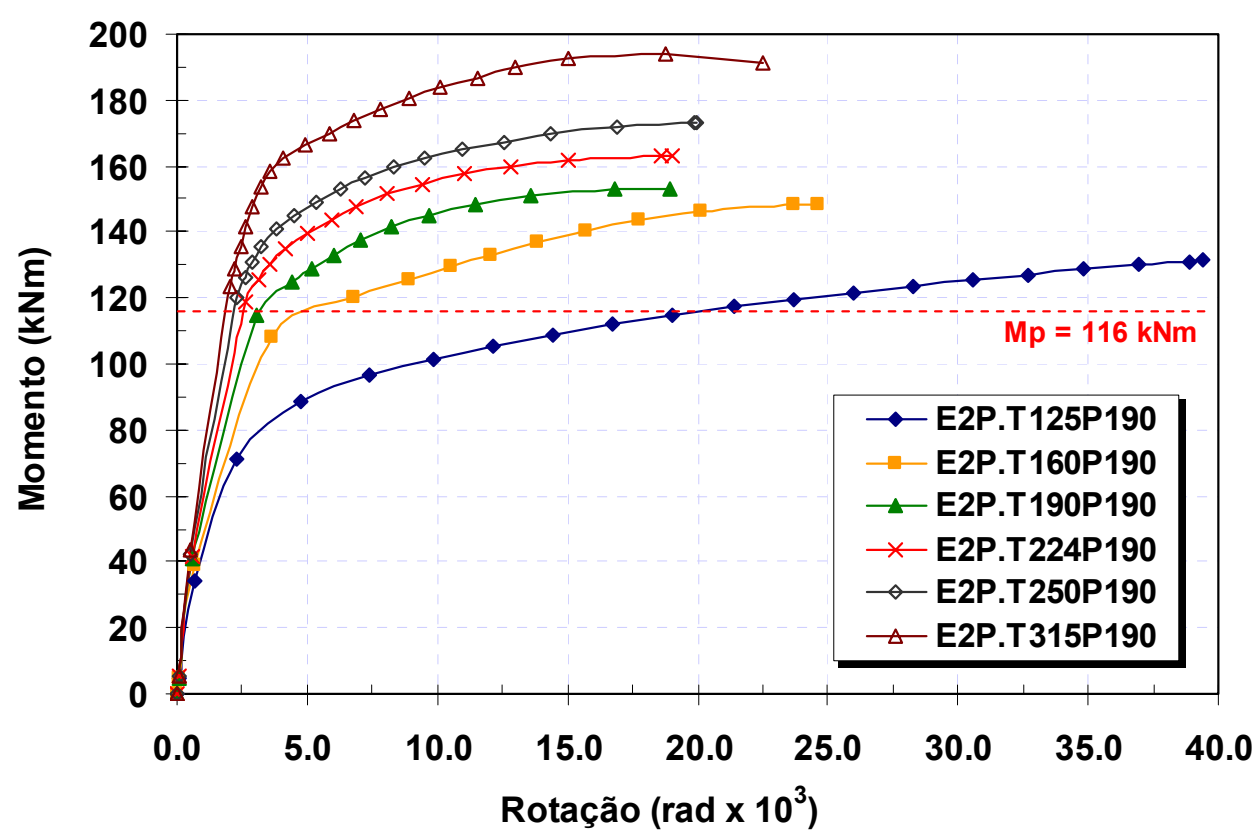

Figura 7.39 - Curvas momento-rotação para a série E2 - grupo 1 - variação da espessura da chapa de topo para parafusos de $19,0 \mathrm{~mm}$

A variação para os parafusos é praticamente conseqüência das variações observadas para a chapa de topo, com um aumento de resistência e de ductilidade proporcional ao aumento do diâmetro, observado nas figuras 7.40 e 7.41 , respectivamente para os modelos com chapas de 12,5 e $19,0 \mathbf{m m}$. 


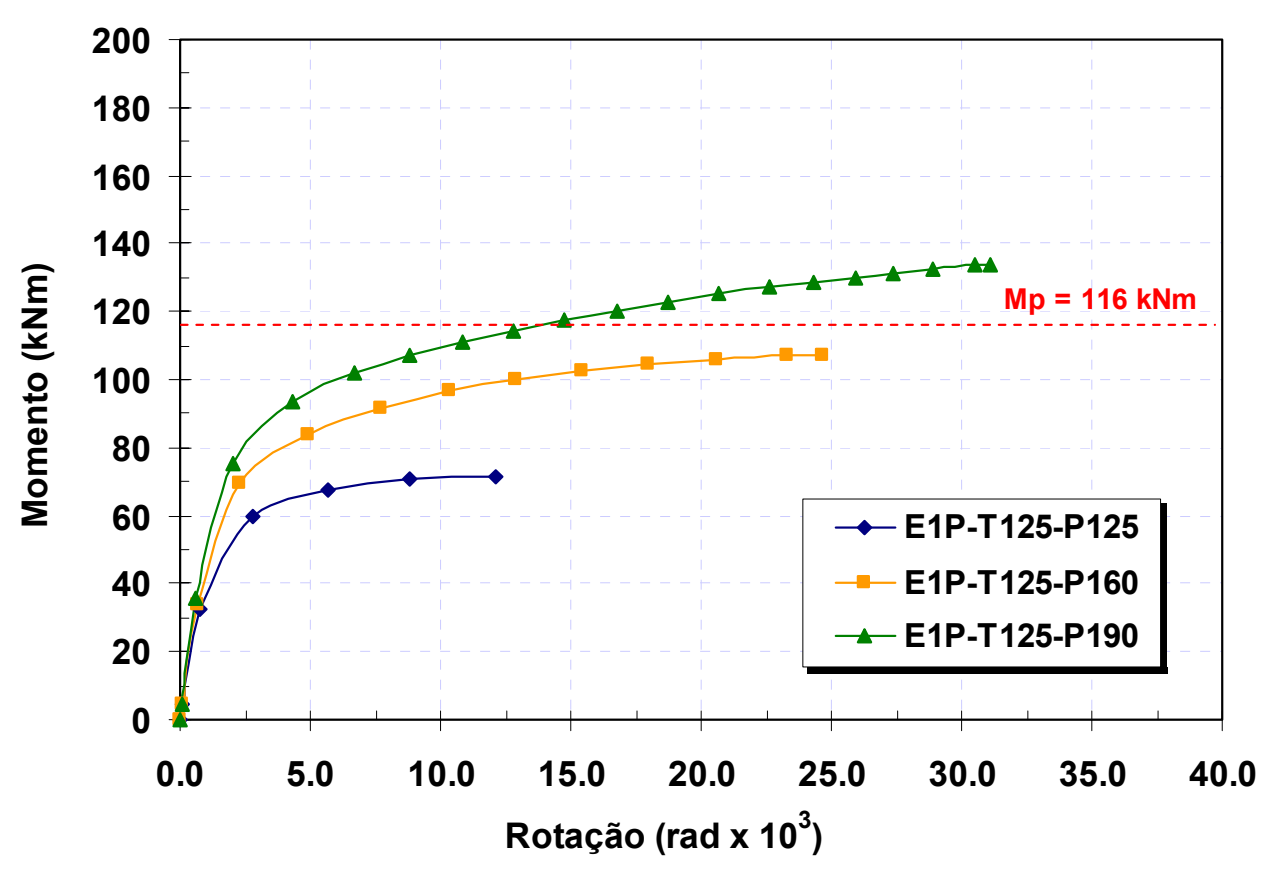

Figura 7.40 - Curvas momento-rotação para a série E1 - variação do diâmetro dos parafusos para a chapa de topo de $12,5 \mathrm{~mm}$

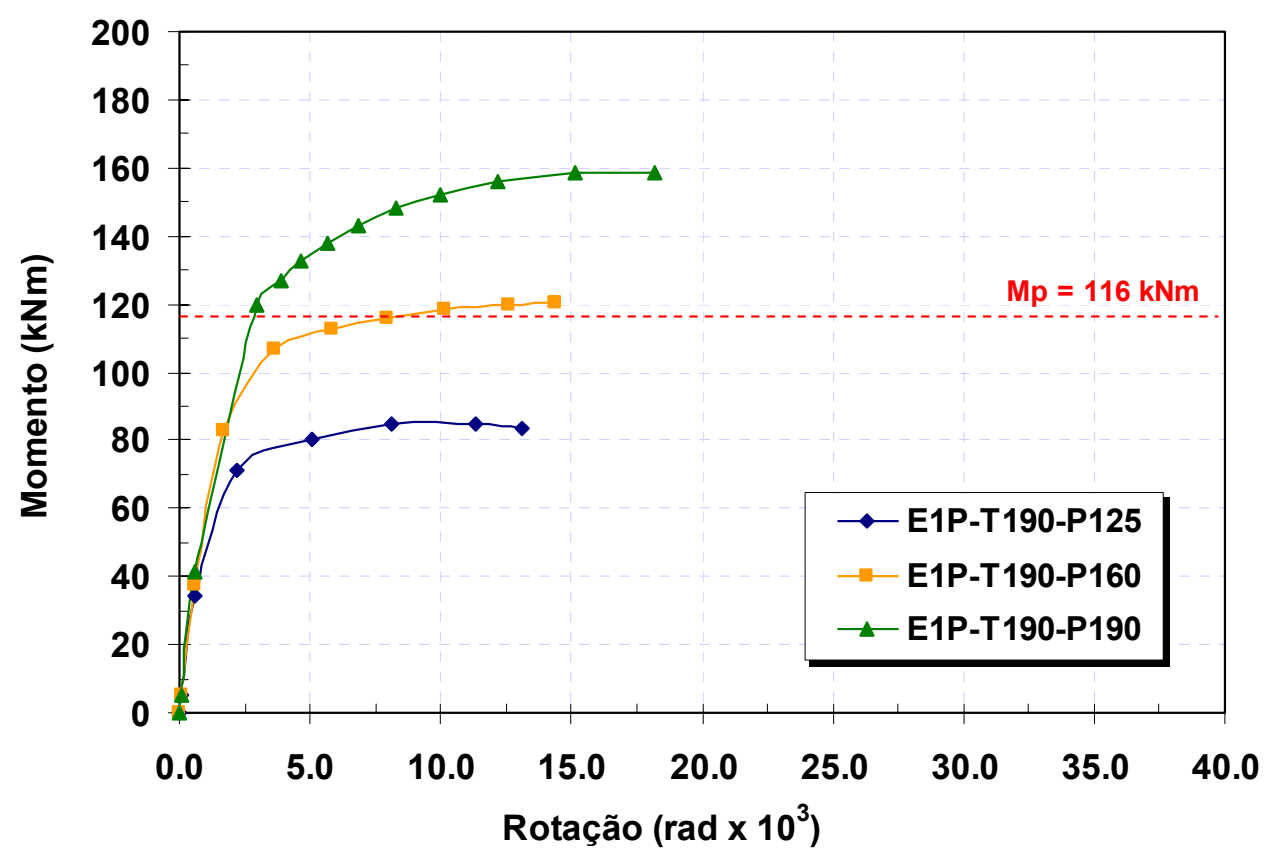

Figura 7.41 - Curvas momento-rotação para a série E1 - variação do diâmetro dos parafusos para a chapa de topo de $19,0 \mathrm{~mm}$

\subsubsection{Variação da distância entre furos e mesa da viga}

Essa variável foi incluída para a avaliação da variação do braço de alavanca do parafuso com relação à mesa tracionada da viga. 
Para a geometria da chapa de topo, foi variada a distância entre o centro dos furos e a face da mesa tracionada da viga $\left(\mathbf{d}_{z, p}\right)$, modificando também a altura total $\left(\boldsymbol{h}_{\mathbf{p}}\right)$ da chapa de topo, conforme esquematizado na figura 7.42. Os modelos desta série estão listados na tabela 7.9.

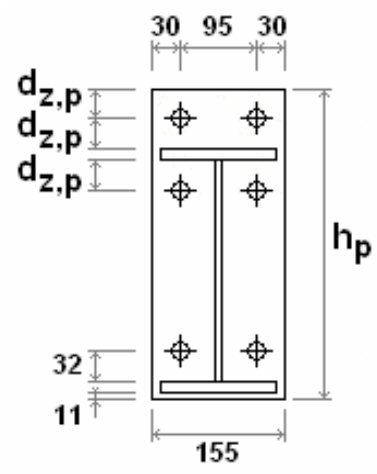

Série E3

Figura 7.42 - Dimensões das chapas de topo para as séries E3

Tabela 7.9 - Modelos numéricos para a série E3

\begin{tabular}{|c|c|c|c|c|c|}
\hline Série & Grupo & Modelo & $d_{z, p}(m m)$ & $d_{b}(m m)$ & $t_{c h}(m m)$ \\
\hline \multirow{8}{*}{ E3 } & \multirow{4}{*}{1} & E31P-T125-P160 & \multirow{4}{*}{40,0} & \multirow{4}{*}{16,0} & 12,5 \\
\hline & & E31P-T160-P160 & & & 16,0 \\
\hline & & E31P-T190-P160 & & & 19,0 \\
\hline & & E31P-T224-P160 & & & 22,4 \\
\hline & \multirow{4}{*}{2} & E32P-T125-P160 & \multirow{4}{*}{48,0} & \multirow{4}{*}{16,0} & 12,5 \\
\hline & & E32P-T160-P160 & & & 16,0 \\
\hline & & E32P-T190-P160 & & & 19,0 \\
\hline & & E32P-T224-P160 & & & 22,4 \\
\hline
\end{tabular}

De maneira geral, não há variações nos padrões de plastificação para essa série que, devido ao aumento do braço de alavanca dos parafusos, se concentra na intersecção chapa/mesa.

Assim, o que se observa é uma diminuição da resistência e um aumento da ductilidade com o aumento da distância $\mathbf{d}_{\mathbf{z}, \mathbf{p}}$, comparando-se as curvas momento-rotação entre os modelos correspondentes das séries E1 e os grupos 1 e 2 da série E3, respectivamente nas figuras 7.43 e 7.44. 


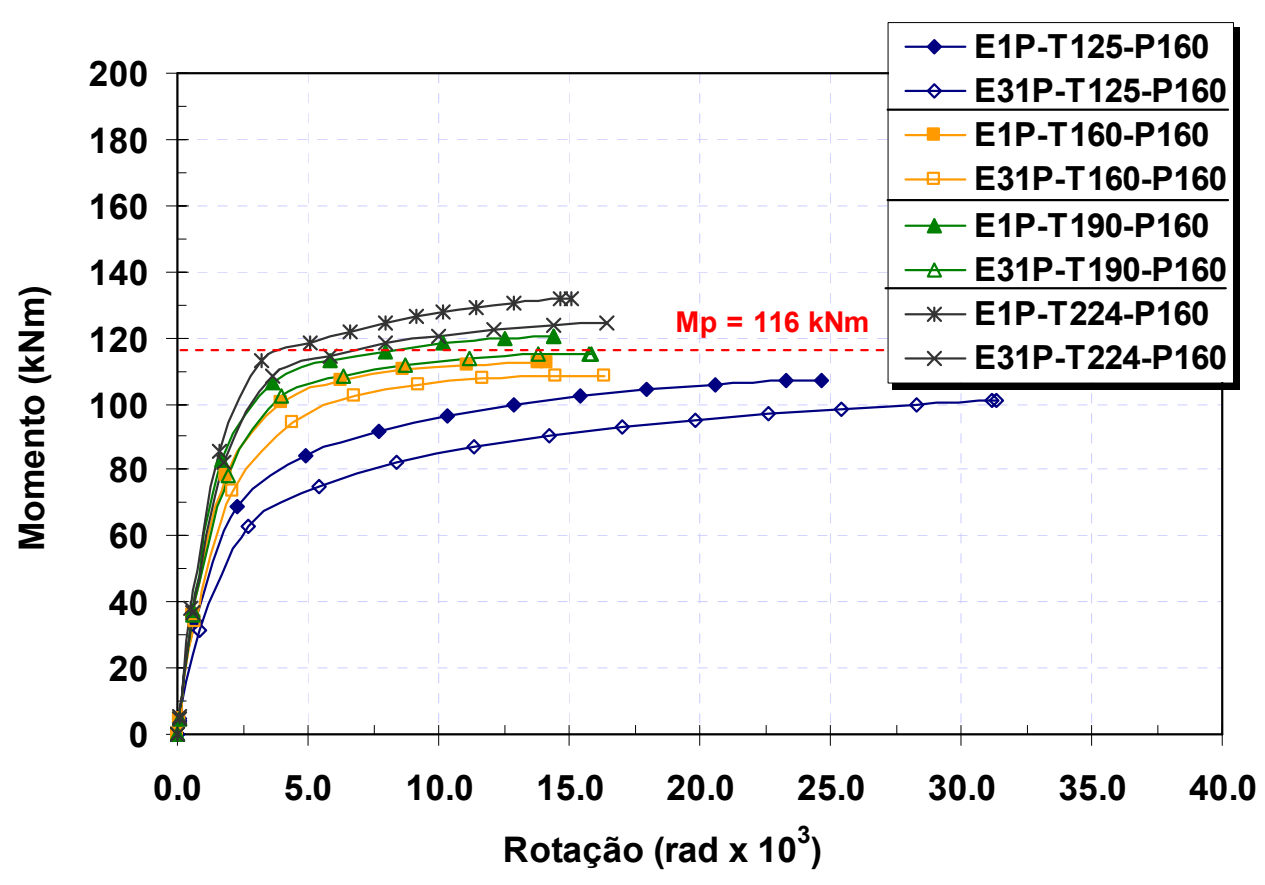

Figura 7.43 - Curvas momento-rotação para a série E1 e grupo 1 da série E3

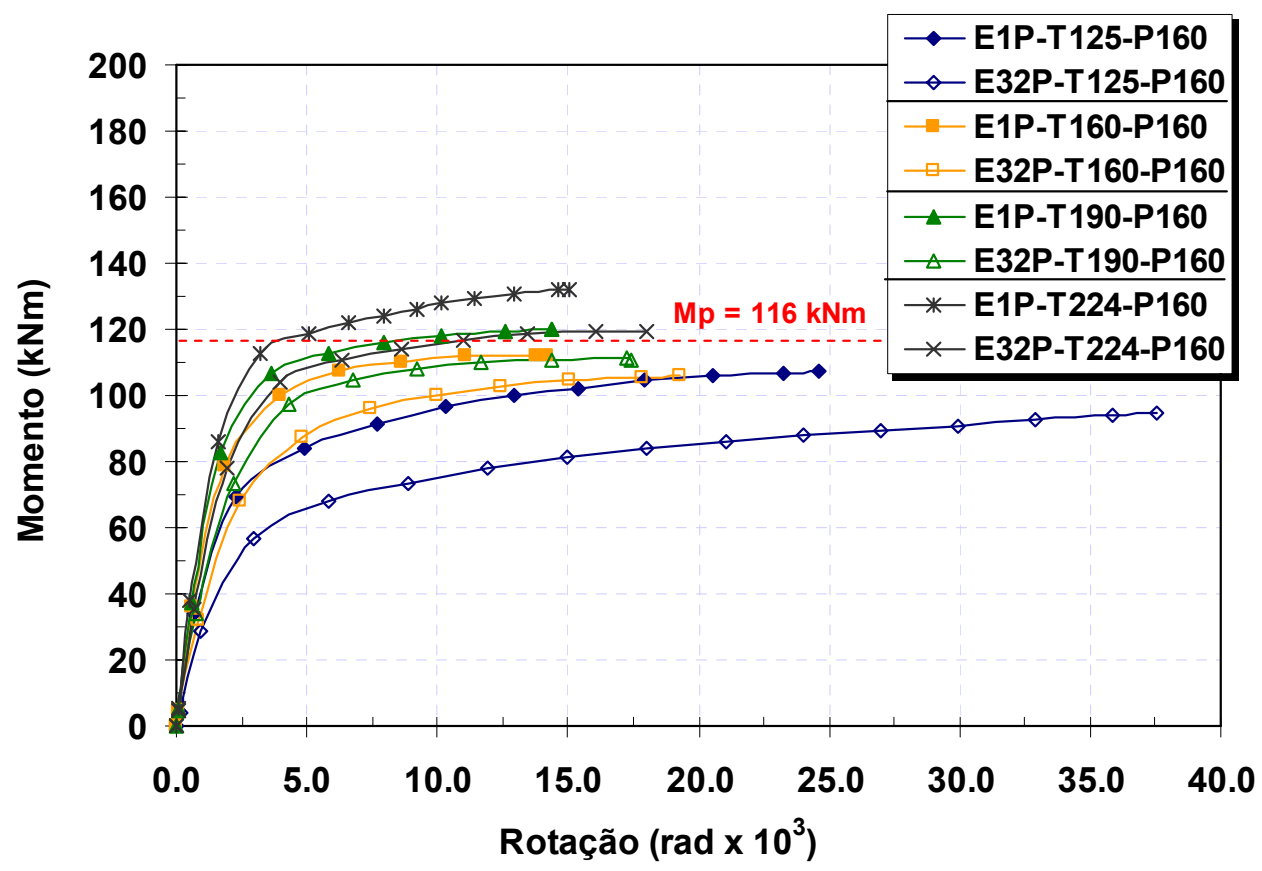

Figura 7.44 - Curvas momento-rotação para a série E1 e grupo 2 da série E3

\subsection{CONSIDERAÇÕES GERAIS}

A análise apresentada neste capítulo foi realizada com o objetivo de investigar as configurações de plastificação da chapa de topo que são 
utilizadas nos modelos analíticos do Eurocode 3 (1993) para a determinação da capacidade resistente da chapa de topo em combinação com os parafusos.

Os modelos analíticos que são utilizados para a verificação destes dois componentes, principalmente com relação à analogia com os modos de falha de perfis "T", têm uma base conceitual interessante, mas em diferentes níveis, conduzem a valores teóricos muito abaixo do obtido para as ligações analisadas.

Esse aspecto tem como causa a consideração de padrões de plastificação também simplificados para a chapa de topo e que, em muitos casos, não simulam satisfatoriamente os mecanismos observados na chapa de topo, conduzindo a comprimentos equivalentes errôneos para os perfis "T".

No entanto, foi possível determinar que a variação das linhas de plastificação segue alguns padrões com a variação do conjunto chapa de topo/parafusos e, com a utilização da modelagem numérica, indica a possibilidade de estudos mais específicos para quantificação destes padrões, com o objetivo de aprimorar os métodos de cálculo existentes. 


\section{Capítulo}

\section{CONCLUSÕES}

A proposta inicial deste trabalho teve como principal objetivo a análise do comportamento de ligações parafusadas viga-pilar com chapa de topo estendida, do ponto de vista da observação específica do comportamento da chapa de topo e dos parafusos na determinação da capacidade resistente destas ligações.

As comparações com a metodologia proposta pelo Eurocode 3 (1993), desta maneira, foram feitas apenas para as verificações nestes dois componentes. O pilar utilizado nas análises, por suas características geométricas e devido ao enrijecimento entre suas mesas, não representa um ponto de colapso para essas ligações.

A metodologia empregada para este estudo, além do programa experimental, utilizou a modelagem numérica como principal ferramenta para a análise dessas ligações.

Como comentado ao longo deste trabalho, os modelos numéricos têm a capacidade de permitir análises mais detalhadas com relação a diversos dados que não podem ser coletados experimentalmente, ou pela inacessibilidade ou pelo alto custo da instrumentação, e com o aperfeiçoamento da modelagem tridimensional tornaram-se uma ferramenta importante para complementar a análise experimental.

Assim, o desenvolvimento dos modelos numéricos teve parte importante como objetivo deste trabalho, já que foi possível estabelecer uma metodologia de modelagem numérica para o estudo das ligações com chapa de topo e que também pode ser estendida para o estudo de outras tipologias de ligações parafusadas, como por exemplo, as ligações com chapa de topo não estendida, ligações com cantoneiras, ligações com perfis " $T$ ", entre outras. 
É claro que, dentro das limitações da modelagem, os resultados numéricos devem ser utilizados com critério já que geralmente reproduzem modelos idealizados das ligações reais, ou seja, sem considerar imperfeições geométricas. Além disso, utilizam relações uniaxiais tensão-deformação para simular os materiais, notadamente uma simplificação.

No entanto, cabe ressaltar que determinadas simplificações podem ser utilizadas uma vez determinados os objetivos da modelagem.

Considerando-se esses aspectos, com relação à modelagem numérica podem-se fazer as seguintes conclusões:

i. a modelagem tridimensional mostrou-se uma excelente ferramenta para simular as ligações e deve ser utilizada para o estudo de comportamentos que são tridimensionais, uma vez que o tempo computacional já não é um fator limitante;

ii. com a metodologia de modelagem proposta neste trabalho foi possível generalizar satisfatoriamente a aplicação dos modelos numéricos para a realização de análises paramétricas. Não foram realizadas retro-análises que são necessárias quando o objetivo é a calibração dos resultados numéricos com resultados experimentais;

iii. as simplificações de geometria pela exclusão das soldas e a padronização do comportamento dos materiais mostraram-se adequadas, uma vez que a influência desses parâmetros sob a resposta dos modelos é uniforme e pode ser desprezada em análises comparativas entre resultados numéricos; $\mathrm{e}$

iv. a simulação dos parafusos como um único sólido tridimensional permitiu a inclusão das características geométricas da cabeça sextavada, da porca e do fuste cilíndrico na modelagem deste componente. A consideração do diâmetro nominal do parafuso foi adequada para simular o contato entre o fuste e o furo. Adaptações aplicadas no modelo constitutivo do material dos parafusos, com base nas especificações de tensão, foram utilizadas como artifício para fazer a equivalência entre a área bruta do fuste no modelo e a área efetiva dos parafusos e também para considerar a flexibilidade 
da rosca e das arruelas, não incluídas na modelagem. Estas adaptações permitiram uma excelente representação da capacidade resistente à tração e da ductilidade deste componente, cujo comportamento força-alongamento foi comparado aos resultados de caracterização obtidos em laboratório.

Com a aplicação da modelagem e com base nos resultados comparativos apresentados nos capítulos 6 e 7, conclui-se que os modelos numéricos são capazes de representar, satisfatoriamente, os mecanismos de transferência de esforços entre viga e pilar, os mecanismos de plastificação de cada componente e os estados limites últimos. A metodologia de modelagem proposta, por sua vez, pode ser aplicada de uma forma geral para o estudo das ligações parafusadas.

Os resultados numéricos foram utilizados, juntamente com os resultados experimentais, para a discussão do comportamento de ligações duplo "T" de diferentes tipologias e de ligações com chapa de topo estendida. A analogia entre essas ligações foi realizada com o objetivo de se analisar as linhas de plastificação nos perfis "T" e na chapa de topo para avaliar a metodologia proposta pelo Eurocode 3 (1993) para o dimensionamento da chapa de topo.

Com base nos resultados numéricos e experimentais e considerandose o comportamento observado para as ligações duplo "T", conclui-se que:

i. As ligação duplo "T", independentemente da tipologia, estão sujeitas à "forças de alavanca" significativas nos parafusos dependendo da geometria da mesa e dos parafusos, o que já era esperado. A magnitude das "forças de alavanca" variou entre $\mathbf{5 \%}$ e 65\% da força total aplicada aos protótipos;

ii. as variações de tipologia das ligações duplo "T" usuais (TSC) para se considerar a perpendicularidade entre as mesas (TSI) e o efeito do enrijecimento (TSIE) não modificam significativamente o comportamento global e os estados limites últimos observados nos protótipos, para as combinações ensaiadas; 
iii. nas observações dos resultados numéricos, as ligações duplo "T" usuais, com planos de tração coplanares sem enrijecimento (TSC), foram as que apresentaram maior "efeito alavanca" quando comparadas às tipologias TSI e TSIE. Esse resultado está de acordo com as observações experimentais, nas quais verificou-se maior capacidade resistente para os grupos TSI e TSIE, o que sugere a diminuição do "efeito alavanca" nesses grupos. A única exceção ocorreu para o modelo TSI-T095-P160, com chapa de 9,5 $\mathrm{mm}$ e parafusos de $16,0 \mathrm{~mm}$, não incluída no programa experimental, que apresentou capacidade resistente menor que o modelo TSC correspondente devido à flexão acentuada nas mesas. A configuração do grupo TSI é análoga a uma ligação com chapa de topo sem enrijecimento entre as mesas do pilar;

iv. como conseqüência da conclusão anterior, a menos do modelo TSI-T095-P160, a capacidade resistente das ligações duplo "T" depende fortemente da magnitude do "efeito alavanca" e não das variações de tipologia analisadas;

v. as linhas de plastificação nos grupos TSC, TSI e TSIE seguem padrões semelhantes, independentemente da posição relativa da alma. O modelo TSI-T095-P160 é novamente uma exceção, no qual foi observada uma linha de plastificação oblíqua passando pelo furo na mesa, que não ocorreu em nenhum outro modelo analisado. Salienta-se que a combinação entre a mesa de $\mathbf{9 , 5} \mathbf{~ m m}$ e os parafusos de $16,0 \mathrm{~mm}$ não é uma relação recomendada em termos práticos;

vi. os modos de falha identificados por Zoetemeijer \& deBack (1972) para os perfis "T" foram observados nas ligações duplo "T" e, de modo geral, as hipóteses utilizadas pelos autores para as linhas de plastificação nos perfis "T" foram verificadas nos modelos. No entanto, a determinação analítica da capacidade resistente pelo modo de falha 1 apresenta valores muito abaixo do observado experimental e numericamente. Isso ocorre porque nos modelos cuja plastificação da chapa segue o modo de falha 1, a distribuição das "forças de alavanca" nos perfis "T" não ocorre na borda da 
mesa e sim segundo um bulbo de pressão que se distribui do furo em direção à borda, por causa das forças iniciais de protensão;

vii. para o modo de falha 2, o comportamento dos perfis "T" depende da interação entre a mesa e os parafusos, ainda sofrendo a influência dos "efeitos de alavanca". No entanto, as variações de comportamento para o modo 2 são menores e a determinação analítica da capacidade resistente se aproxima dos valores experimentais, uma vez que há um equilíbrio maior entre a deformabilidade da mesa e dos parafusos; e

viii. o modo de falha 3 depende fundamentalmente da resistência à tração dos parafusos. Dessa forma, é o único modo de falha bem determinado, se aproximando dos resultados experimentais.

A partir da observação das linhas de plastificação nos perfis "T" e fazendo-se uma comparação com a plastificação da chapa de topo, pode-se indicar as seguintes conclusões:

i. as linhas de plastificação que ocorrem na chapa de topo, da mesma forma que para os perfis "T", seguem um padrão coerente com as indicações dos três modos de falha. No entanto, os mecanismos entre a chapa de topo e os parafusos não ocorrem de forma similar aos observados nas ligações duplo "T". Principalmente para o modo de falha 1, a flexão nos perfis "T" ocorre segundo uma direção preferencial, perpendicular à alma, enquanto que na chapa de topo observa-se uma dupla curvatura, o que modifica o padrão de plastificação;

ii. a variação da espessura da chapa de topo e do diâmetro dos parafusos modifica significativamente as linhas de plastificação na chapa de topo. O cálculo do comprimento equivalente do perfil "T" para a representação da capacidade resistente da chapa de topo não considera essas variações, apresentando configurações teóricas de plastificação que não foram observadas em nenhum dos modelos analisados. Neste caso, conclui-se que as linhas de plastificação propostas pelo Eurocode 3 (1993) não representam 
satisfatoriamente os mecanismos na chapa de topo, o que leva a valores conservadores da capacidade resistente da ligação;

iii. o comportamento global das ligações com chapa de topo, analisando-se as variações da deformabilidade da chapa com relação aos parafusos, apresentou variações diferentes quanto à resistência e ductilidade. Mantendo-se os parafusos com diâmetro constante, o aumento da espessura da chapa de topo causa um aumento de resistência até o limite de resistência à tração dos parafusos devido à eliminação do "efeito alavanca". No entanto, a ductilidade varia de forma irregular, sendo máxima para o modo de falha 1 e apresentando um limite mínimo entre os modos de falha 1 e 2;

iv. com as afirmações anteriores, conclui-se que o limite entre os modos de falha 1 e 2 representa o equilíbrio entre a deformabilidade da mesa e dos parafusos; e

v. o comportamento da chapa de topo segue padrões bem definidos para a variação da resistência e da ductilidade, apesar deste último não ser uniforme. Assim, mesmo com as variações da espessura da chapa e do diâmetro dos parafusos, é possível identificar em um determinado grupo de variação da chapa os limites entre os modos de falha 1,2 e 3.

A comparação das linhas de plastificação entre a chapa de topo e os perfis "T" mostraram que, apesar de seguirem os mesmos modos de falha, não são equivalentes quanto aos mecanismos de plastificação da chapa de topo.

Além disso, as linhas de plastificação propostas pelo Eurocode 3 (1993) representam padrões limitados de plastificação com configurações fixas em função da geometria da chapa de topo, o que não ocorre para essas ligações.

Das conclusões comentadas acima, destaca-se novamente que:

i. O dimensionamento da chapa de topo segundo a metodologia proposta pelo Eurocode 3 (1993) é conservador e não representa 
os mecanismos plásticos que ocorrem entre a chapa de topo e os parafusos;

ii. o comportamento de resistência e ductilidade da chapa de topo segue padrões com a identificação dos limites entre os modos de falha; e

iii. os modelos numéricos são capazes de representar de forma altamente satisfatória os mecanismos plásticos e os estados limites últimos das ligações parafusadas.

Com o exposto acima, conclui-se que uma metodologia mais racional para a determinação da capacidade resistente da chapa de topo deveria considerar as configurações de plastificação que ocorrem diretamente neste componente, como alternativa para a utilização dos perfis "T" equivalentes.

A análise destas configurações pode ser realizada com a utilização de modelos numéricos que, além de apresentarem correlações excelentes com o comportamento das ligações, representam uma ferramenta potencial para o desenvolvimento de análises paramétricas mais abrangentes, que certamente conduziriam ao desenvolvimento ou ao aprimoramento dos modelos analíticos existentes.

Considerando-se as limitações da análise proposta neste trabalho, os seguintes tópicos são sugeridos a fim de dar continuidade a esta linha de pesquisa:

i. a realização de análises paramétricas para a observação das linhas de plastificação na chapa de topo com a inclusão de variações no posicionamento dos furos, na largura da chapa de topo, na largura da viga, na altura da viga, nas forças de protensão e outras configurações de espessura da chapa de topo e diâmetro dos parafusos;

ii. a determinação, com base na análise paramétrica citada acima, de modelos analíticos, complexos ou simplificados, que representem diretamente a capacidade resistente da chapa de topo; 
iii. havendo o desenvolvimento de modelos analíticos, a incorporação destes modelos na determinação da rigidez das ligações, seguindo a filosofia do "método dos componentes";

iv. a inclusão do pilar na análise do comportamento global das ligações, com e sem a consideração do enrijecimento entre as mesas do pilar;

v. a incorporação de modelos tridimensionais em estruturas de pórtico para a avaliação da influência do comportamento das ligações no comportamento global das estruturas;

vi. a discussão da validade das relações momento-rotação obtidas experimental e numericamente, tanto para a chapa de topo como para a viga, quando aplicadas na análise estrutural; e

vii. a discussão do comportamento das ligações com chapa de topo com a consideração de carregamento e descarregamento.

Finalmente ressalta-se que, dentre as metodologias existentes para o dimensionamento das ligações, o "método dos componentes" talvez seja, atualmente, o modelo mais racional e o conceitualmente mais moderno. No entanto, ao dividir a ligação em componentes, surgem comportamentos complexos que não podem ser tratados isoladamente. Como conseqüência, surgem as simplificações.

Por isso, justifica-se toda pesquisa cujo objetivo seja a análise mais detalhada do comportamento destes componentes e de sua influência no comportamento das ligações. Conhecendo-se melhor esse comportamento e suas variações, viabiliza-se a representação mais realística das ligações na análise estrutural. 


\section{REFERÊNCIAS BIBLIOGRÁFICAS}

AGERSKOV, H. (1979). Discussion of "A fresh look at bolted end-plate behavior and design". AISC Engineering Journal, v.16, 2nd Quarter, p.54-55 / paper by KRISHNAMURTHY, N. (1978b). AISC Engineering Journal, v.15, n.2, 2nd Quarter.

AMERICAN INSTITUTE OF STEEL CONSTRUCTION (1980). Manual of steel construction. 8.ed. Chicago.

AMERICAN INSTITUTE OF STEEL CONSTRUCTION (1986). Manual of steel construction: load and resistance factor design. 1st ed., Chicago.

AMERICAN INSTITUTE OF STEEL CONSTRUCTION (1989). Manual of steel construction: allowable stress design. 9.ed. Chicago.

AMERICAN SOCIETY FOR TESTING AND MATERIALS (1997). ASTM E8M Standard Test Methods for Tension Testing of Metallic Materials. West Conshohocken.

AMERICAN SOCIETY FOR TESTING AND MATERIALS (1995). ASTM F 606 Standard Test Methods for Determining the Mechanical Properties of Externally and Internally Threaded Fasteners, Washers, and Rivets. West Conshohocken.

BAHAARI, M.R.; SHERBOURNE, A.N. (1994). Computer modeling of an extended end-plate bolted connection. Computers \& Structures, v.52, n.5, p.879-893.

BAHAARI, M.R.; SHERBOURNE, A.N. (1996a). Structural behavior of endplate connections to stiffened columns. Journal of Structural Division, v.122, n.8, p.926-935, August. 
BAHAARI, M.R.; SHERBOURNE, A.N. (1996b). 3D simulation of bolted connections to unstiffened columns - II. Extended endplate connections. Journal of Constructional Steel Research, v.40, n.3, p.189-223, October.

BAHAARI, M. R.; SHERBOURNE, A. N. (2000). Behaviour of eight-bolt large capacity endplate connections. Computer \& Structures, 77 315-325.

BJORHOVDE, R.; COLSON, A.; BROZZETTI, J (1990). Classification system for beam-to-column connections. Journal of Structural Engineering, 116(11), p.3059-3077.

BROWN, D.G. et al. (1996). A new industry standard for moment connections in steelwork. The Structural Engineer, v.74, n.20, p.335-342, October.

BROWN, N. D.; ANDERSON, D. (2001). Structural properties of composite major axis end plate connections. Journal of Constructional Steel Research, 57 327-349.

BURSI, O. S.; JASPART, J. P. (1997a). Benchmarks for finite element modelling of bolted steel connections. Journal of Constructional Steel Research. 43(1-3) 17-42.

BURSI, O. S.; JASPART, J. P. (1997b). Calibration of a finite element model for isolated bolted end-plate steel connections. Journal of Constructional Steel Research, v.44, n.3, p225-262.

BURSI, O. S.; JASPART, J. P. (1998). Basic issues in the finite element simulation of extended end plate connections. Computer \& Structures, 69 361-382.

CALADO, L.; CASTIGLIONI, C. A. (1996). Steel Beam-to-Column Connections Under Low-Cycle Fatigue Experimental and Numerical Research. Proceedings. of XI World Conference on Earthquake Engineering, Acapulco, Mexico, CD-ROM.

CARVAlHO, L. C. V.; ANDRADE, S. A. L.; VElLASCO, P. C. G. S. (1998). Experimental analysis of bolted semi-rigid steel connections. Journal of Constructional Steel Research, v.46(1-3), p328-240. 
CHEN, W.F.; PATEL, K. V. (1981). Static behavior of beam-to-column moment connections. Journal of Structural Division, v.107, n.ST9, p.1815-1838, September.

CHEN, W.F.; LUI, E.M. (1988a). Static flange moment connections. Journal of Constructional Steel Research, v.10, p.39-88.

CHISALA, M. L. (1999). Modelling M- $\phi$ curves for standard beam-to-column connections. Engineering Structures, 21 1066-1075.

DAVISON, J. B.; KIRBY, P. A.; NETHERCOT, D. A. (1987a). Rotational stiffness characteristics of steel beam-to-column connections. Journal of Constructional Steel Research, v.8, n.1, p.15-54.

DISSANAYAKE, U. I.; DAVISON, J. B.; BURGESS, I. W. (2000) Limit State Behaviour of Composite Frames. Semi-Rigid Connections, Ouro Preto, julho.

EUROCODE 3 (1992). Design of steel structures: Part 1.1 - General rules and rules for buildings.

EUROCODE 3 (1993). Design of steel structures: Part 1.1 - General rules and rules for buildings - Revised Annex J: Joints in building frames.

EUROPEAN COMMUNITY OF STEEL CONSTRUCTION (1997). Frame design including joint behaviour. v. 1 e 2, Liège, ECSC.

FAElla, C.; PIlUSO, V.; RIZZANO, G. (1997). A New Method do Design Extended End Plate Connections and Semirigid Braced Frames. Journal of Constructional Steel Research, 41 61-91.

FRANCE, J. E.; DAVISON, J. B.; KIRBY, P. A. (1999) Moment-Capacity and Rotational Stiffness of Endplate Connections to Concrete-Filled Tubular Columns with Flowdrilled Connectors. Journal of Constructional Steel Research, 50 35-48.

FRANCE, J. E.; DAVISON, J. B.; KIRBY, P. A. (1999) Strength and Rotational Stiffness of Simple Connections to Tubular Columns Using Flowdrill Connectors. Journal of Constructional Steel Research, 50 15-34. 
GOVERDHAM, A. V. (1984). A collection of experimental moment rotation curves and evaluation of predict equations for semi-rigid connections. Nashville. Master's Thesis - Vanderbilt University.

HUANG, J.S.; CHEN, W.F.; BEEDLE, L.S. (1973). Behavior and design of steel beam-to-column moment connections. Welding Research Council Bulletin, n.188, p.1-23, October.

JASPART, J. P.; STEENHUIS, M.; ANDERSON, D. (1997) Characterisation of the Joint Properties by Means of the Component Method. Proceedings of the Liege COST C1 conference of semi-rigid behaviour of civil engineering structural connections.

JONES, S. W.; KIRBY, P. A.; NETHERCOT, D. A. (1980). Effect of semi-rigid connections on steel column strength. Journal of Constructional Steel Research, v.1, n.1, p.38-46.

JONES, S. W.; KIRBY, P. A.; NETHERCOT, D. A. (1983). The analysis of frames with semi-rigid connections: a state of the art report. Journal of Constructional Steel Research, v.3, n.2, p.2-13.

KAMEI, C. M. (2001). Estado da arte das ligações metálicas viga-coluna com comportamento semi-rígido. Trabalho auxiliar para a Dissertação de Mestrado, UFES, Vitória.

KAMESHKI, E. S.; SAKA, M. P. (2001). Optimum design of nonlinear steel frames with semi-rigid connections using a genetic algorithm. Computer \& Structures. 79 1593-1604.

KATTNER, M.; CRISINEL, M. (2000). Finite element modelling of semi-rigid composite joints. Computer \& Structures, 78 341-353.

KIRBY, P. A.; DAVISON, J. B. (2000) Full Scale Testing for Semi-Rigid Response in Non-Sway Steel Frames. Semi-Rigid Connections. Ouro Preto, julho.

KIRBY, P. A.; DAVISON, J. B; CARR, J. F. (2000) A 'Simplified Approach' to the Design of Columns in Simple Construction. Semi-Rigid Connections. Ouro Preto, julho. 
KISHI, N.; CHEN, W. F. (1986). Data base of steel beam-to-column connections. West Lafayette, School of Civil Engineering, Purdue University. 2v. Structural Engineering Report n. CE-STR-86-26.

KISHI, N. (1994). Semi-rigid connections. In: CHEN, W. F.; TOMA, S., ed. Advanced analysis of steel frames. Boca Raton, CRC Press. Cap.3, p.91-137.

KISHI, N.; HASAN, R.; CHEN, W. F.; GOTO, Y (1997). Study of Eurocode 3 steel connection classification. Engineering Structures, v. 19, n. 9, p.772779

KRISHNAMURTHY, N. (1973a). Finite element analysis of splice-plate connections: a feasible study. Auburn, Alabama, Auburn University. Report n. CE-AISC-MBMA-1.

KRISHNAMURTHY, N. (1973b). Effects of plate thickness and pretensioning in typical bolted end-plate connections. Auburn, Alabama, Auburn University. Report n. CE-AISC-MBMA-2.

KRISHNAMURTHY, N. (1974a). Two-dimensional finite element analysis of steel end-plate connections: parametric considerations. Auburn, Alabama, Auburn University. Report n. CE-AISC-MBMA-3.

KRISHNAMURTHY, N. (1974b). Correlation between three-dimensional and two-dimensional finite element analysis of end-plate connections. Auburn, Alabama, Auburn University. Report n. CE-AISC-MBMA-4.

KRISHNAMURTHY, N. (1974c). Parameter study of steel end-plate connections by two-dimensional finite element analysis. Auburn, Alabama, Auburn University. Report n. CE-AISC-MBMA-5.

KRISHNAMURTHY, N. (1975a). Discussion of "High strength bolts subject to tension and prying". Journal of the Structural Division, v.101, n.ST1, p.335-337, January / paper by NAIR, R.S.; BIRKEMOE, P.C.; MUNSE, W.H. (1974). Journal of Structural Division, v.100, n.ST2, p.351-372, February. 
KRISHNAMURTHY, N. (1975b). Two-dimensional finite element analysis of extended and flush connections with multiple rows of bolts. Auburn, Alabama, Auburn University. Report n. CE-AISC-MBMA-6.

KRISHNAMURTHY, N. (1975c). Tests on bolted end-plate connections and comparisons with finite element analysis. Auburn, Alabama, Auburn University. Report n. CE-AISC-MBMA-7.

KRISHNAMURTHY, N. (1975d). Effects of reduction in bolt size and pretension on end-plate connection behavior. Auburn, Alabama, Auburn University. Report n. CE-AISC-MBMA-8.

KRISHNAMURTHY, N. (1975e). Auburn University research on end-plate connections: a summary. Auburn, Alabama, Auburn University. Report $\mathrm{n}$. CE-AISC-MBMA-9.

KRISHNAMURTHY, N. (1976). Design of end-plate connections. Vanderbilt, Tennessee, Vanderbilt University. Report n. CE-AISC-MBMA-10.

KRISHNAMURTHY, N.; GRADDY, D. (1976). Correlation between 2- and 3dimensional finite element analysis of steel bolted end-plate connections. Computers \& Structures, v.6, p.381-389.

KRISHNAMURTHY, N. (1977). Discussion of "High-strength bolted connections subject to prying". Journal of Structural Division, v.103, n.ST1, p.299-300, January / paper by NAIR, R.S.; BIRKEMOE, P.C.; MUNSE, W.H. (1974). Journal of Structural Division, v.100, n.ST2, p.351372 , February.

KRISHNAMURTHY, N. (1978a). Discussion of "Analysis of bolted connections subject to prying". Journal of the Structural Division, v.104, n.ST12, p.1928-1930, December / paper by AGERSKOV, H. (1977b). Journal of Structural Division, v.103, n.ST11, p.2145-2163, November.

KRISHNAMURTHY, N. (1978b). A fresh look at bolted end-plate behavior and design. AISC Engineering Journal, v.15, 2nd Quarter, p.39-49, April.

KRISHNAMURTHY, N. (1978c). Photoelastic and finite element investigation of steel bolted tee hangers. Vanderbilt, Tennessee, Vanderbilt University. Report n. CE-MBMA-1903-1. 
KRISHNAMURTHY, N. (1978d). Effects of bolt heads and welds in steel bolted tee-type connections. Vanderbilt, Tennessee, Vanderbilt University. Report n. CE-MBMA-1903-11.

KRISHNAMURTHY, N. (1978e). Analytical investigation of end-plate connection design. Vanderbilt, Tennessee, Vanderbilt University. Report n. CE-MBMA-1902-1.

KRISHNAMURTHY, N. (1979a). Experimental validation of end-plate connection design. Vanderbilt, Tennessee, Vanderbilt University. Report n. CE-AISC-37025-1.

KRISHNAMURTHY, N. (1979b). Experimental investigation of bolted stiffened tee-stubs. Vanderbilt, Tennessee, Vanderbilt University. Report n. CEMBMA-1902-2.

KRISHNAMURTHY, N. (1979c). Closure of "A fresh look at bolted end-plate behavior and design”. AISC Engineering Journal, v.16, 2nd Quarter, p.6064 / paper by KRISHNAMURTHY, N. (1978b). AISC Engineering Journal, v.15, 2nd Quarter, p.39-49, April.

KULAK, G. L.; FISHER, J. W. E STRUIK, J. H. A. (1987). Guide to Design Criteria for Bolted and Riveted Joints, 2nd ed. John Wiley \& Sons.

LIMA, L. R. O. de; VEllasco, P. C. G. da S.; ANDRADE, S. A. L. (1999). Bolted Semi-Rigid Connections in the Column's MinorA xis. Eurosteel, Second European Conference on Steel Structures, Praga.

LUI, E.M.; CHEN, W.F. (1986). Analysis and behavior of flexibly jointed frames. Engineering Structures, v.8, n.2, p.107-118.

MAGGI, Y. I. (2000). Análise numérica, via M.E.F., do comportamento de ligações parafusadas viga-coluna com chapa de topo. São Carlos. Dissertação (Mestrado). 195p. Escola de Engenharia de São Carlos, Universidade de São Paulo.

MAIOLA, C. H. (1999). Análise teórica e experimental de treliças metálicas especiais constituídas por barras com extremidades estampadas. São Carlos. Dissertação (Mestrado). 111p. Escola de Engenharia de São Carlos, Universidade de São Paulo. 
MANUAL brasileiro para cálculo de estruturas metálicas (1988). Brasília-DF, $\mathrm{MCl} / \mathrm{STI}$. v.3, tomo 2.

McGUIRE, W. (1979). Discussion of "A fresh look at bolted end-plate behavior and design". AISC Engineering Journal, v.16, 2nd Quarter, p.55-56 / paper by KRISHNAMURTHY, N. (1978b). AISC Engineering Journal, v.15, 2nd Quarter, p.39-49, April.

MCGUIRE, W. (1988). Introduction. In: CHEN, W. F., ed. Steel beam-tocolumn building connections. London, Elsevier. p. 1-35.

MELLO, W. L.; REQUeNA, J. A. V. (2000) Análise de Pórticos Metálicos Planos com Conexões Semi-Rígidas Considerando a Não Linearidade Física e Geométrica. XXIX Jornadas Sudamericanas de Ingenieria Structural, Punta del Este, Uruguai.

MISTAKIDIS, E. S.; BANIOTOPOULOS, C. C.; BISBOS, C. D.; PANAGIOTOPOULOS, P. D. (1998) Steel T-Stub Connections Under Static Loading: an Effective 2-D Numerical Model. Journal of Constructional Steel Research, vol. 44, n. 1-2, pp 51-67.

MOFID, M.; ASL, M. G.; McCABE, S. L. (2001). On the analytical model of beam-to-column semi-rigid connections, using plate theory. Thin-Walled Structures, 39 307-325.

MOORE, D. B.; NETHERCOT, D. A.; KIRBY, P. A. (1993) Testing Steel Frames at Full Scale. The Structural Engineer, 71, n. 23 e 24, dezembro, pp 418427.

MUNSE, W.H.; PETERSEN, K.S.; CHESSON JR., E. (1959b). Behavior of riveted and bolted beam-to-column connections. Journal of Structural Division, v.85, n.ST3, p.29-50, March.

NAIR, R.S.; BIRKEMOE, P.C.; MUNSE, W.H. (1974). High-strength bolts subject to tension and prying. Journal of Structural Division, v.100, n.ST2, p.351-372, February.

NBR-8800 (1986). Dimensionamento e Construção de Estruturas de Aço em Edifícios. Associação Brasileira de Normas Técnicas. Rio de Janeiro. 
NETHERCOT, D. A. (1985). Utilization of experimentally obtained connection data in assessing the performance of steel frames. In: CHEN, W. F., ed. Connection flexibility and steel frames (Proceedings of session sponsored by Structural Division, Detroit, October). New York, ASCE. p.13-37.

NETHERCOT, D. A.; LI, T. Q.; CHOO, B. S (1995). Required rotations and moment redistribution for composite and continuous beams. Journal of Constructional Steel Research, 35(2), p.121-163.

NETHERCOT, D. A.; LI, T. Q.; AHMED, B (1998). Unified classification system for beam-to-column connections. Journal of Constructional Steel Research, 45(1), p.39-65.

NEVES, L. A. C.; CRUZ, P. J. S.; HENRIQUES, A. A. R. (2001). Reliability analysis of steel connection components bases on FEM. Engineering Failure Analysis, 8 29-48.

PILUSO, V.; FAELLA, C.; RIZZANO, G. (2001a). Ultimate Behavior of Bolted T-Stubs. I: Theoretical Model. Journal of Structural Engineering, vol. 127, no. 6 , Junho, p686-693.

PILUSO, V.; FAELLA, C.; RIZZANO, G. (2001b). Ultimate Behavior of Bolted T-Stubs. II: Model Validation. Journal of Structural Engineering, vol. 127, no. 6, Junho, p694-704.

PRELORENTZOU, P. A. (1991). Um estudo sobre ligações viga-coluna em estruturas de aço. São Carlos. 221p. Dissertação (Mestrado) - Escola de Engenharia de São Carlos, Universidade de São Paulo.

PUCINOTTI, R. (2001). Top-and-seat and web angle connections: prediction via mechanical model. Journal of Constructional Steel Research, 57661 694.

QUEIROZ, G. (1992). Estudo do comportamento e sistematização do projeto de ligações rígidas entre perfis I com almas coplanares. Belo Horizonte. 159p. Dissertação (Mestrado) - Escola de Engenharia, Universidade Federal de Minas Gerais. 
QUEIROZ, G. (1995). Análise experimental de ligações soldadas. Belo Horizonte. 285p. Tese (Doutorado) - Escola de Engenharia, Universidade Federal de Minas Gerais.

QUEIROZ, G.; MATA, L. A. C.; ALVES, V. C. G. (2000) Análise NuméricoExperimental de uma Ligação Mista com Cantoneiras na Alma e na Mesa Inferior. XXIX Jornadas Sudamericanas de Ingenieria Structural, Punta del Este, Uruguai.

RIBEIRO, L. F. L. (1998). Estudo do Comportamento Estrutural de Ligações Parafusadas Viga-coluna com Chapa de Topo: Análise TeóricoExperimental. São Carlos. 524p. Tese (Doutorado) - Escola de Engenharia de São Carlos, Universidade de São Paulo.

RODRIGUES, F. C. (1991). Previsão do comportamento de pórticos planos metálicos com ligações semi-rígidas. $13^{\circ}$. Seminário de Doutoramento, COPPE/UFRJ, Rio de Janeiro.

ROMANO, V. P. (2001). Dimensionamento de Ligações Viga-Coluna com Chapa de Topo: Modelo do Eurocode 3. Ouro Preto. Dissertação (Mestrado) - Escola de Minas, Universidade Federal de Ouro Preto.

ROMSTAD, K.M.; SUBRAMANIAN, C.V. (1970). Analysis of frames with partial connection rigidity. Journal of Structural Division, v.96, n.ST11, p.22832300, November.

SEKULOVIC, M.; SALATIC, R. (2001). Nonlinear analysis of frames with flexible connections. Computer \& Structures, 79 1097-1107.

SHI, Y. J.; CHAN, S. L.; WONG, Y. L. (1998) Modelling for Moment-Rotation Characteristics for End-Plate Connections. Journal of Structural Engineering, vol. 122, n. 11, pp 1300-1306.

SILVA, P. P. Jr.; LORIGGIO, D. D. (2000) Análise Elasto-Plástica de Pórticos Planos com Conexões Semi-Rígidas. XXIX Jornadas Sudamericanas de Ingenieria Structural, Punta del Este, Uruguai.

SILVA, L. S.; COELHO, A. G. (2001). A ductility model for steel connections. Journal of Constructional Steel Research, 57 45-70. 


\section{STEEL CONSTRUCTION INSTITUTE / BRITISH CONSTRUCTIONAL} STEELWORK ASSOCIATION (1996). Joints in steel construction: moment connections. London, SCl/BCSA.

SWANSON, J. A. (1999). Characterization of the Strength, Stiffness, and Ductility Behavior of T-Stub Connections. Ph.D. Dissertation, Georgia Institute of Technology.

TARPY, T.S.; CARDINAL, J.W. (1981). Behavior of semi-rigid beam-to-column end plate connections. In: HOWLETT, J.H.; JENKINS, W.M.; STAINSBY, R., ed. Joints in structural steelwork. London, Pentech Press. .2.3-2.25.

WITTEVEEN, J. et al. (1982). Welded and bolted beam-to-column connections. Journal of Structural Division, v.108, n.ST2, p.433-455, February.

ZOETEMEIJER, P.; BACK, J. de. (1972). High strength bolted beam to column connections. The computation of bolts, t-stub flanges and column flanges. Report 6-72-13, Delft University of Technology, Stevin Laboratory.

ZOETEMEIJER, P. (1974). A design method for the tension side of statically loaded, bolted beam-to-column connections. Heron, Volume 20, n.1. 